\title{
MATERIALES HÍBRIDOS ORGÁNICOS-INORGÁNICOS BASADOS EN DISILANOS COMO UNIDADES ESTRUCTURALES
}

TESIS DOCTORAL

\author{
Presentada por: \\ MARÍA TERESA GARCÍA FERNÁNDEZ \\ Dirigida por: \\ Dr. URBANO MANUEL DÍAZ MORALES
}

VALENCIA, 2012 

MATERIALES HÍBRIDOS ORGÁNICOS-INORGÁNICOS BASADOS EN DISILANOS COMO UNIDADES ESTRUCTURALES

\author{
MEMORIA \\ Presentada por: \\ MARÍA TERESA GARCÍA FERNÁNDEZ
}

Dirigida por:

Dr. URBANO MANUEL DÍAZ MORALES

Para optar al título de:

DOCTOR EN CIENCIAS QUIIMICAS

UNIVERSITAT POLITÈCNICA DE VALÈNCIA

DEPARTAMENTO DE QUÍMICA

INSTITUTO UNIVERSITARIO MIXTO DE TECNOLOGÍA QUÍMICA (UPV-CSIC)

VALENCIA, 2012 



\section{Agradecimientos}

Después de cinco años de trabajo son muchos los momentos y experiencias compartidas con mucha gente, algunos han aparecido por el camino y otros han estado siempre ahí, pero todos han contribuido en gran medida al desarrollo de esta Tesis. Por fin ha llegado el momento de agradecerles a todos ellos su ayuda, apoyo y comprensión, sin los cuales no habría sido posible la realización de este trabajo.

En primer lugar quisiera agradecer al Profesor Avelino Corma el ofrecerme la oportunidad de formarme en el Instituto de Tecnología Química.

A la profesora Amparo Mifsud, la primera persona que conocí del centro y me dio una vuelta por él intentando convencerme de que realizara la tesis, por preocuparse y ser accesible para realizar cualquier trámite o duda.

Y sobre todo a mi director de Tesis, Dr. Urbano Díaz, por todo lo que me ha enseñado en estos años, por su paciencia y comprensión, por haber estado pendiente de todo en todo momento, por estar siempre dispuesto a ayudarme, por su dedicación, por ser un gran jefe y mejor persona.

A todo el personal de administración, incluyendo a la actual gerente del centro, Mónica, por todos y cada uno de los trámites que he tenido que realizar.

A todos mis compañeros del instituto, empezando por la planta baja, incluyendo a la primera al completo, y muy especialmente a los del segundo piso, en el que he desarrollado mi trabajo, sin olvidarme de los de la tercera donde he pasado éstos últimos meses. Agradecer su compañía y ayuda, tanto a los que aún permanecen en el centro como los que en algún momento formaron parte de él y dejaron tan buen recuerdo. Mención especial para mis compis de laboratorio, por las mil y una anécdotas, el buen rollo, las risas constantes, la ayuda prestada y nuestras comiditas sanas en el Cabanyal.

Y por supuesto al grupo de I@s Xung@s con los que he compartido todo durante estos cinco años: las alegrías, las penas, los agobios, los nervios, las celebraciones varias...Mil gracias por estar siempre ahí, tanto en lo académico y profesional como en lo 
personal. Por tantos buenos ratos vividos: comidas, barbacoas, squash y carreras, viajes por el mundo, pero sobre todo las incalculables horas en el laboratorio.

Muchísimas gracias a les xiques $i$ xics del Puig/Puçol (para que nadie se enfade) por tantos y tan buenos momentos compartidos durante estos años: cervecitas, cumpleaños, escapadas, carreras y eventos varios, por estar a mi lado en todo momento, por haberme hecho desconectar y animarme en los momentos difíciles, en resumen: por ser tan buenos amigos.

A Marisol y Victor, los mejores castelloneros del mundo, por ser tan buenos anfitriones y cuidarnos tanto cada vez que os hemos visitado. Por haber mantenido la amistad durante tantos años y con mayor intensidad en estos últimos tiempos.

Por último, y no por ello menos importante, quisiera agradecer a toda mi familia el respaldo, comprensión pero sobre todo la confianza depositada en mí en todo aquello que he llevado a cabo. Por estar incondicionalmente animándome y apoyándome. 
A mis padres.

A Ángel. 



\section{ÍNDICE}

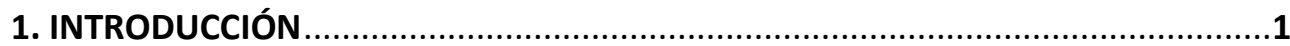

1.1. Materiales híbridos: Concepto general .................................................... 4

1.2. Tipos de unidades estructurales …........................................................ 8

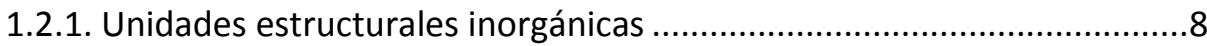

1.2.2. Unidades estructurales orgánicas ......................................................11

1.2.3. Unidades estructurales orgánicas-inorgánicas: Disilanos ......................14

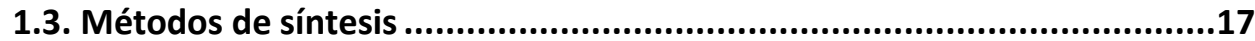

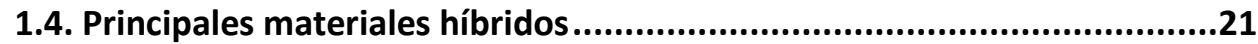

1.4.1. Materiales basados en redes estructurales metal-orgánicas (MOFs)...23

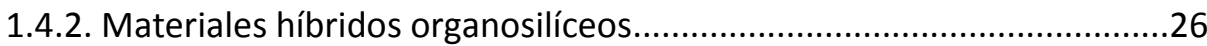

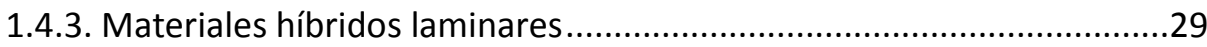

1.5. Aplicaciones de los materiales híbridos ...............................................32

Referencias bibliográficas .............................................................................36

2. OBJETIVOS

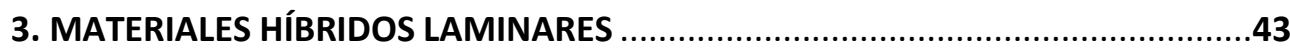

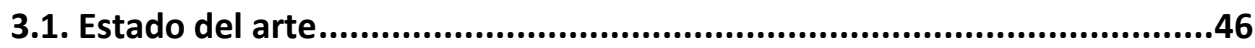

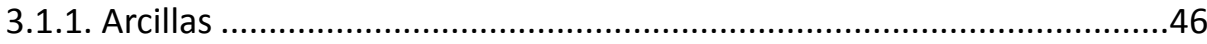

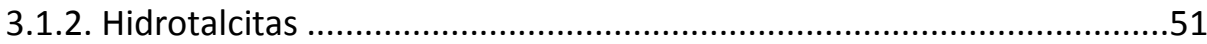

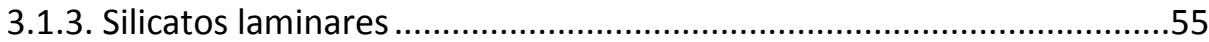

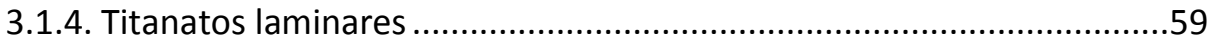

3.1.5. Materiales laminares de naturaleza zeolítica........................................61

3.1.6. Otros precursores laminares ...............................................................68 
3.2. Objetivos.

3.3. Materiales híbridos pilareados derivados de silicatos laminares .73

3.3.1. Magadiita como precursor laminar ...................................................73

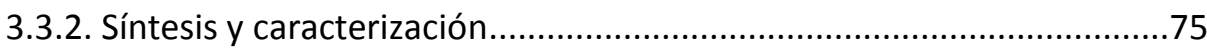

3.3.3. Materiales híbridos laminares con centros ácidos. Actividad catalítica

3.3.4. Materiales híbridos laminares con centros básicos. Actividad catalítica

3.4. Materiales híbrido pilareados de naturaleza zeolítica con topología tipo

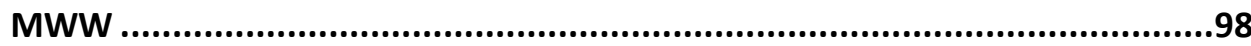

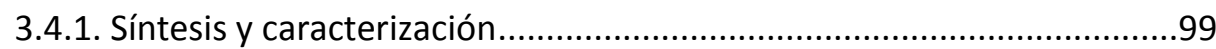

3.4.2. Incorporación de grupos funcionales. Generación de materiales

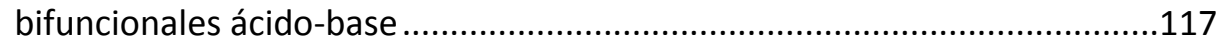

3.4.3. Estudios teóricos estructurales ........................................................120

3.4.4. Actividad catalítica: Reacciones en cascada ......................................123

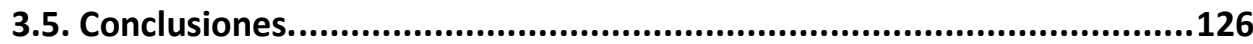

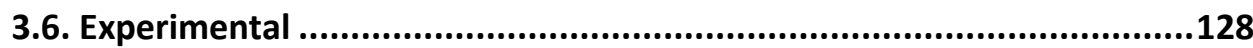

3.6.1. Materiales híbridos pilareados derivados de silicatos laminares........128

3.6.2. Materiales híbridos pilareados derivados de precursores zeolíticos laminares

3.6.3. Determinación de centros activos. Valoraciones ácido-base de los

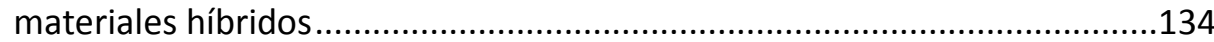

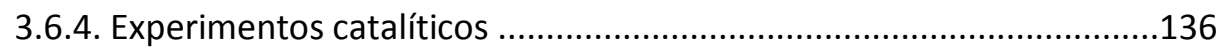

Referencias bibliográficas ....................................................................137

\section{MATERIALES HÍBRIDOS MESOPOROSOS: PROCESOS SOL-GEL EN MEDIO} FLUORURO

4.1. Estado del arte. 
4.1.1. Métodos Sol-Gel: Materiales mesoporosos sin organización estructural

4.1.2. Materiales mesoporosos con orden laminar

4.1.3. Métodos Micelares: Organosílicas Periódicas Mesoporosas (PMOs) 152

4.1.4. Métodos Hidrotermales: Organozeolitas (OZs). 159

4.2. Objetivos. 164

4.3. Materiales híbridos mesoporosos obtenidos a través de métodos sol-gel en medio fluoruro 166

4.3.1. Síntesis y caracterización. 166

4.3.2. Variables del método de síntesis en medio fluoruro 179

4.3.2.1. Influencia del tipo de disilano 180

4.3.2.2. Influencia de la relación disilano/ $\mathrm{SiO}_{2}$..... 183

4.3.2.3. Influencia de la relación $\mathrm{SiO}_{2} / \mathrm{NH}_{4} \mathrm{~F}$ 188

4.3.2.4. Influencia del disolvente 191

4.3.2.5. Influencia de la cantidad de grupos disulfuro. Conversión a grupos sulfónicos. .193

4.3.3. Actividad catalítica 196

4.4. Conclusiones. 198

4.5. Experimental 200

4.5.1. Síntesis de materiales híbridos porosos a través de métodos sol-gel en medio fluoruro 200

4.5.2. Experimentos catalíticos 201

Referencias bibliográficas 203

\section{MATERIALES HÍBRIDOS MESOPOROSOS DERIVADOS DE SILANOS POLIÉDRICOS (POSS) 201}

5.1. Estado del arte.........................................................................210

5.2. Objetivos .216 
5.3. Materiales híbridos mesoporosos basados en POSS .............................217

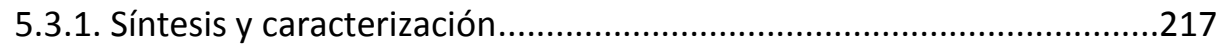

5.3.2. Incorporación de grupos funcionales básicos ...................................237

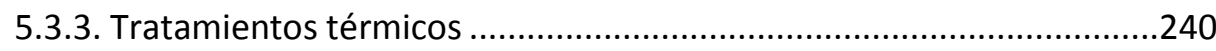

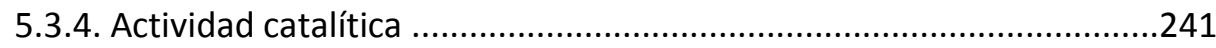

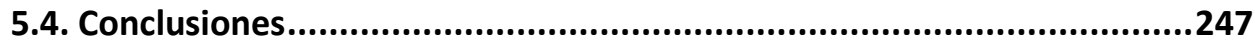

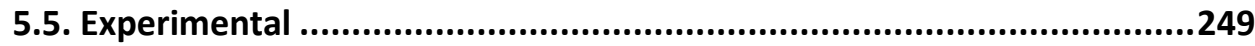

5.5.1. Síntesis de materiales mesoporosos derivados de POSS ....................249

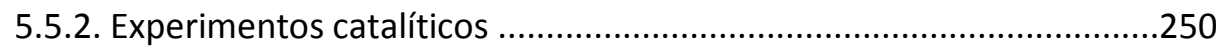

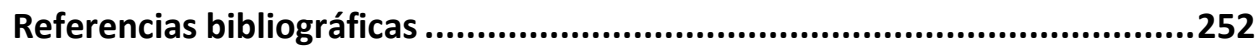

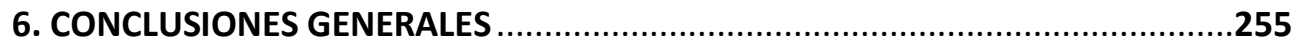

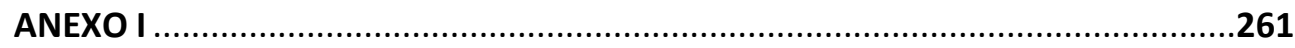

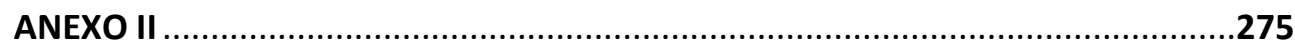

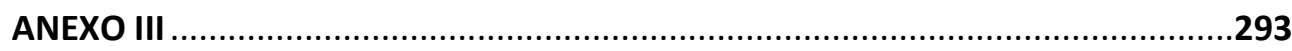

RESUMEN-RESUM-ABSTRACT 


\section{Capítulo 1}

\section{INTRODUCCIÓN}
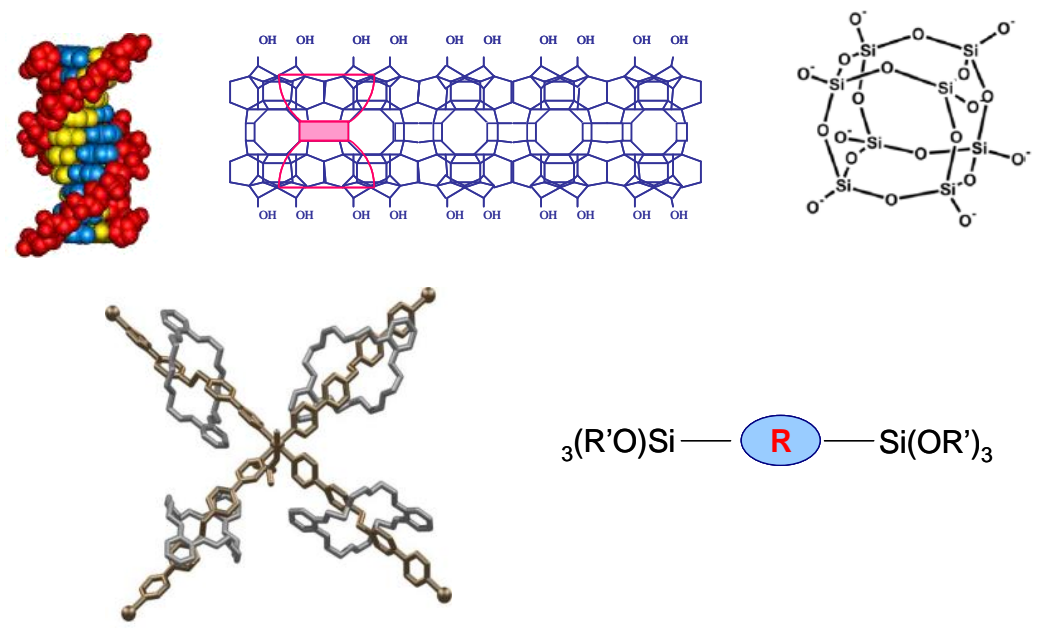

${ }_{3}\left(\mathrm{R}^{\prime} \mathrm{O}\right) \mathrm{Si}-\mathrm{R}-\mathrm{Si}\left(\mathrm{OR}^{\prime}\right)_{3}$ 

La investigación y el descubrimiento de nuevos materiales híbridos orgánicosinorgánicos es una de las temáticas más atractivas y emergentes dentro de la ciencia de materiales en los últimos años. La razón de esta tendencia viene dada por la existencia en estos sólidos de la adecuada combinación entre los diferentes componentes que constituyen su entramado estructural, conjugándose las propiedades que cada uno de ellos exhibe de manera individual e, incluso, mejorándolas. La óptima unión de unidades estructurales funcionales de naturaleza físico-química variada permitiría la preparación de materiales originales con propiedades características y, en algunos casos, únicas, con múltiples aplicaciones.

A lo largo del desarrollo de esta Tesis se realizará un estudio que pretende mostrar la importancia que tienen los materiales híbridos en diferentes áreas tecnológicas como la catálisis, reflejando que se trata de un campo de investigación en plena expansión. Además, se pondrá de manifiesto la relevancia que tienen tanto los métodos de síntesis como el tipo de unidades estructurales empleadas para la obtención de nuevas familias de materiales porosos orgánicos-inorgánicos que contienen diferentes funciones activas constituyendo su red cristalina. La utilización de fragmentos moleculares con una doble misión, estructural y funcional, abre la posibilidad de diseñar materiales multiactivos con propiedades altamente específicas que puedan llevar a cabo procesos reactivos más complejos en una sola etapa.

Con este fin, este trabajo está dividido, principalmente, en tres capítulos de resultados donde se estudiarán nuevas familias de materiales híbridos con características laminares, micro- y/o mesoporosas con aplicaciones catalíticas, obtenidos a través del ensamblaje de láminas inorgánicas, siloxanos puente orgánicos-inorgánicos (disilanos) y silanos poliédricos. 


\subsection{Materiales híbridos: Concepto general}

El término material híbrido es muy amplio y engloba a un elevado número de sólidos, tan diferentes entre sí como polímeros de coordinación de alta cristalinidad o compuestos amorfos obtenidos a través de procesos sol-gel. En su sentido más general, un material híbrido se define como aquel que incluye en su composición al menos dos tipos de fracciones o unidades de diferente naturaleza, siendo, normalmente, una orgánica y otra inorgánica, las cuales se combinan a escala nanométrica ${ }^{[1]}$.

En la última década ha aumentado considerablemente la demanda de materiales con propiedades físico-químicas específicas, hecho que ha motivado a los investigadores a dirigir sus esfuerzos hacia el diseño de sólidos nanoestructurados híbridos. En este sentido, se han preparado materiales multicomponente formados por óxidos inorgánicos, moléculas orgánicas, complejos metálicos 0 , incluso, polímeros ${ }^{[2]}$. Dichos materiales son empleados en un amplio número de aplicaciones que pueden ir desde las más convencionales como catálisis $^{[3]}$, adsorción ${ }^{[4]}$ o separación ${ }^{[5]}$ hasta las más nanotecnológicas al ser empleados en microelectrónica ${ }^{[6]}$, fotoluminiscencia ${ }^{[7]}$, óptica no lineal ${ }^{[8]}$ y como sensores.

En los sólidos orgánicos-inorgánicos se combinan las ventajas de los materiales inorgánicos, como son su elevada estabilidad mecánica, térmica y estructural, sin perder las características de las moléculas orgánicas, es decir, flexibilidad y funcionalidad. Todo ello, hace que la preparación de nuevos sólidos híbridos sea una de las prioridades en el campo de la nanociencia debido a que son múltiples las combinaciones que se pueden establecer entre fragmentos orgánicos diferentes, con una o varias funcionalidades activas en cada uno de ellos, pudiendose diseñar, a priori, materiales estructurados con propiedades y aplicaciones específicas.

Una definición más detallada de los materiales híbridos se puede realizar atendiendo a la naturaleza química de las interacciones que se establecen entre los fragmentos orgánicos e inorgánicos que conforman su estructura ${ }^{[9]}$. Así, se denominan materiales híbridos de Clase $I$ a aquellos en los que la conexión entre las diferentes unidades estructurales se realiza a través de uniones débiles, tales como enlaces de Van 
der Waals, enlaces por puente de hidrógeno o interacciones electrostáticas. Por otra parte, existen los materiales híbridos de Clase II en los que se produce una interacción fuerte entre los diferentes componentes estructurales, siendo este tipo de sólidos los que se pretenden obtener a lo largo de este estudio ${ }^{[10]}$.

Es cierto que, en ocasiones, no es fácil apreciar la fortaleza real de las interacciones químicas que se establecen, ni su efectividad en el mantenimiento del esqueleto estructural de los materiales (Figura 1.1.). Por ejemplo, existen sólidos basados en conexiones por puente de hidrógeno que presentan una estabilidad mayor que muchos complejos de coordinación. No obstante, en general, se consideran híbridos de Clase II aquellos que se estructuran a través de enlaces, preferentemente, covalentes entre las unidades estructurales que les confieren una estabilidad, prácticamente, irreversible. No obstante, la interacción por medio de enlaces de coordinación, como es el caso de la unión de clústeres metálicos con ligandos orgánicos bidentados, también conduce a la formación de sólidos de elevada estabilidad que se pueden incluir dentro de los materiales híbridos de Clase II (Tabla 1.1.).

Tradicionalmente, los materiales híbridos de Clase I han sido los más estudiados debido a sus simples metodologías de preparación. Sería el caso de moléculas orgánicas ocluidas en el seno de matrices inorgánicas como la sílice, la combinación de partículas metálicas con polímeros orgánicos, así como la mezcla de dos o más redes poliméricas interpenetradas entre sí (Figura 1.2.). Una importante familia de materiales de Clase I, muy estudiada en el campo de los catalizadores, sería aquella basada en la preparación e inclusión in situ de moléculas orgánicas (organocatalizadores) en el interior de cavidades microporosas presentes en silicatos o zeolitas (ship-in-a-bottle $)^{[11]}$. 


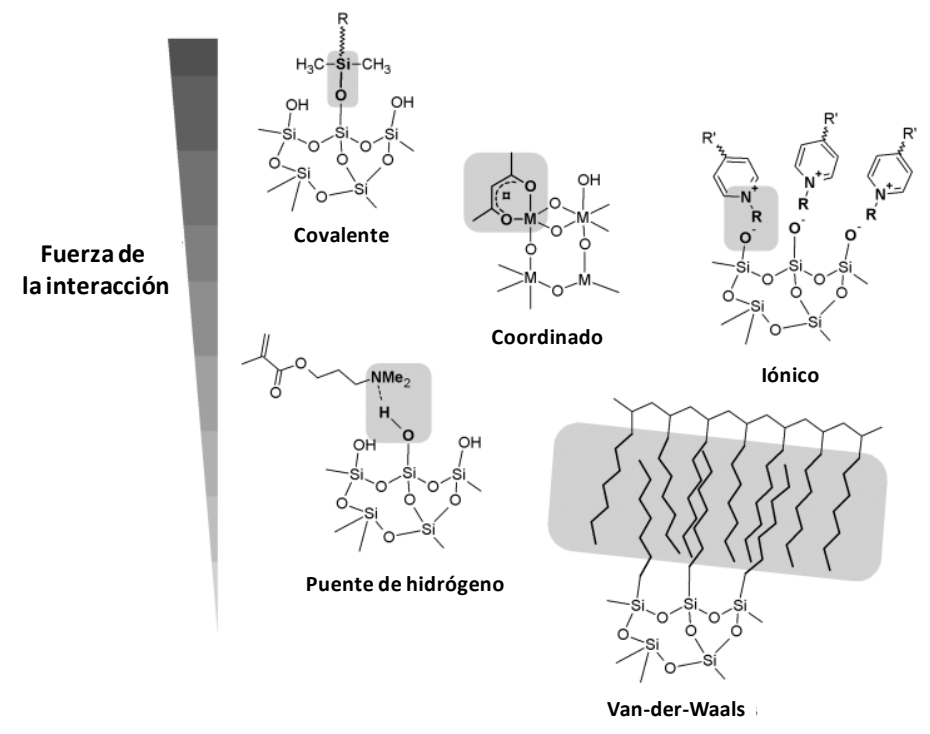

Figura 1.1. Interacciones presentes en materiales híbridos relacionadas con su fuerza relativa.

Tabla 1.1. Diferentes tipos de interacciones químicas y sus respectivas fuerzas.

\begin{tabular}{cccc}
\hline Interacción & Fuerza $\left(\mathbf{k J ~ m o l}^{-\mathbf{1}}\right)$ & Rango & Carácter \\
\hline Van-der-Waals & 50 & Corto & $\begin{array}{c}\text { No selectivo. } \\
\text { No direccional }\end{array}$ \\
Puente Hidrógeno & $5-65$ & Corto & Selectivo. Direccional \\
Coordinación & $50-200$ & Corto & Direccional \\
lónico & $50-250^{\mathrm{a}}$ & Largo & No selectivo \\
Covalente & 350 & Corto & Irreversible \\
\hline
\end{tabular}

${ }^{\mathrm{a}}$ : En función del tipo de solvente. Datos para un medio orgánico.

Por otra parte, sólidos híbridos de Clase II serían aquellos constituidos por unidades estructurales, orgánicas e inorgánicas, que se unen covalentemente o por enlaces de coordinación para generar materiales estructurados. Dentro de este grupo se encuentran, por ejemplo, aquellos sólidos formados por clusters metálicos conectados a polímeros orgánicos, redes poliméricas orgánicas e inorgánicas unidas entre sí o láminas 
inorgánicas separadas por pilares orgánicos insertados en la región interlaminar (Figura 1.2.).

Con frecuencia se suelen utilizar indistintamente los términos materiales híbridos y nanocomposites, no estando clara la frontera entre ambos tipos de compuestos. En general, se puede afirmar que el concepto global de materiales híbridos, atendiendo a aquellos sólidos formados por más de dos componentes, engloba también al de los nanocomposites, siendo este último concepto normalmente aplicado a los materiales en los que, al menos uno de sus componentes está basado en unidades estructurales discretas dentro del rango nanométrico (por ejemplo nanopartículas metálicas o nanotubos de carbono) embebidas en una matriz polimérica. El término materiales híbridos, aunque es un concepto más general, se suele usar más asiduamente cuando las unidades o fragmentos estructurales inorgánicos se forman in situ durante el proceso de síntesis, a través, en la mayoría de casos, de procesos sol-gel ${ }^{[9]}$.

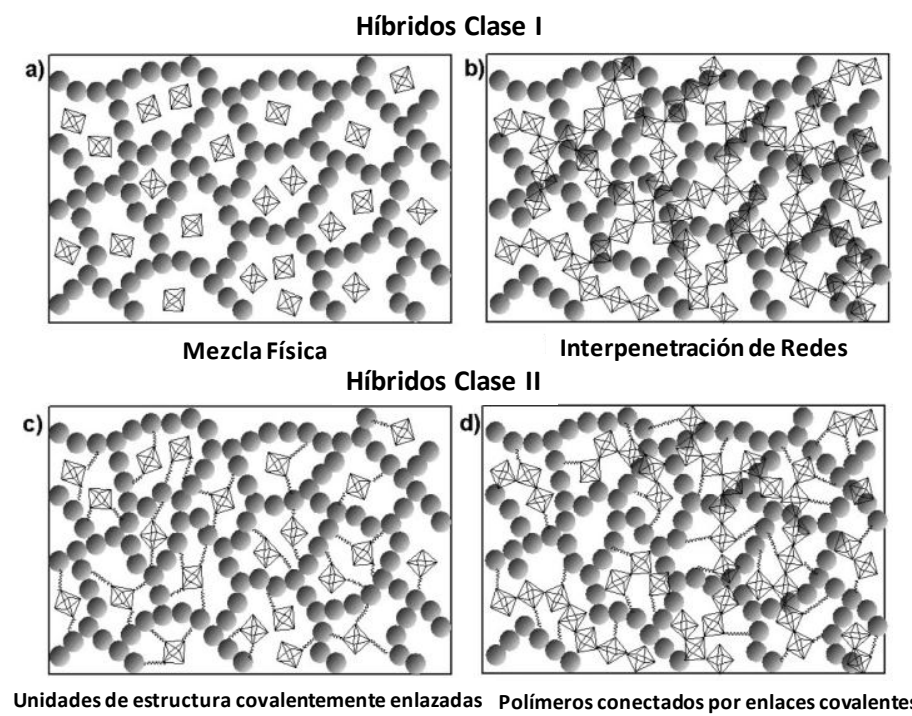

Figura 1.2. Diferentes tipos de materiales híbridos. 


\subsection{Tipos de unidades estructurales}

Para la preparación de materiales híbridos es necesaria la combinación adecuada de unidades estructurales de naturaleza orgánica e inorgánica, existiendo la posibilidad de emplear precursores en los que ya se encuentran conectados, previamente al proceso de síntesis, dichos fragmentos.

\subsubsection{Unidades estructurales inorgánicas}

La obtención de sólidos orgánicos-inorgánicos, tanto de Clase I como de Clase II, está fundamentada en la incorporación en la red cristalina de, normalmente, uno de estos tres tipos de unidades de estructura de naturaleza inorgánica: silanos y sus derivados, especies metálicas, entre las que se incluyen nanopartículas, y láminas inorgánicas (Figura 1.3.).

a)<smiles>[2H][Si](O)(O)O</smiles><smiles>[2H][Si]([2H])(O)O</smiles>

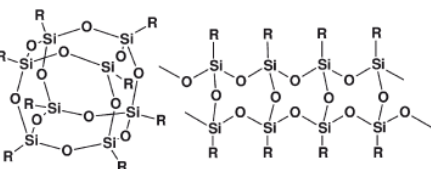

Sílice

b)

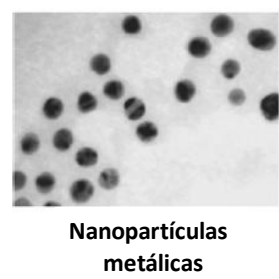

Silsesquioxanos
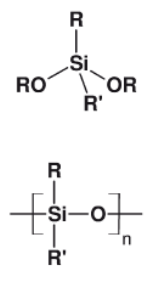

Oligo- / poli-siloxanos

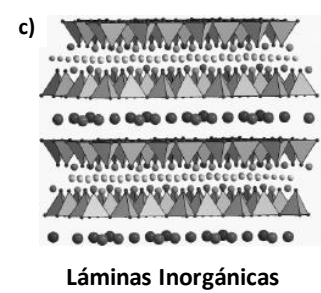

Figura 1.3. Unidades estructurales inorgánicas: (a) Silanos y derivados, (b) nanopartículas metálicas y (c) precursor laminar.

\section{Silanos y sus derivados}

La mayor parte de híbridos de Clase II organosilíceos, conocidos en la bibliografía, están basados en unidades tetraédricas de silicio, $\mathrm{SiO}_{4}$, obtenidos a partir de un proceso 
de hidrólisis ácida o básica, partiendo de sílice o tetraalcoxisilanos (Figura 1.4.). Los derivados tipo siloxano generados son los más habituales para obtener materiales híbridos estables por su facilidad para reaccionar in situ, bien entre sí o bien con otras unidades estructurales, a través de procesos de condensación sol-gel ${ }^{[12]}$.

Las unidades que se denominan esferosilicatos serían otros derivados silíceos, ampliamente usados en procesos de ensamblaje molecular en los que intervienen diferentes fragmentos estructurales. La obtención de siloxanos poliédricos, derivados de estos esferosilicatos, con funcionalidades diversas en los vértices de cada unidad poliédrica ha permitido la generación tanto de materiales híbridos mesoporosos organizados como dendrímeros compactos sin porosidad asociada (Figura 1.5.) ${ }^{[13]}$.

\section{Catálisis ácida}

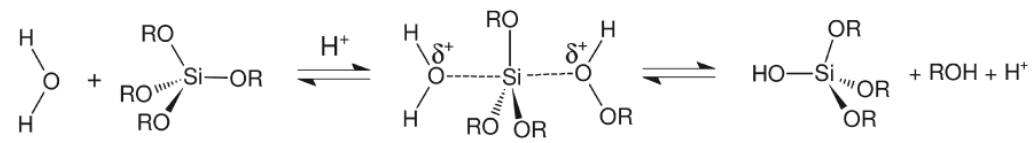

Catálisis básica

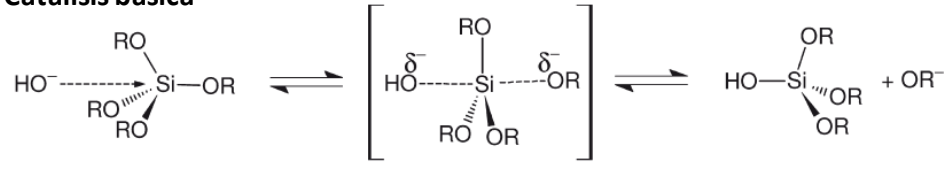

Figura 1.4. Unidades de siloxanos, precursoras de materiales híbridos organosilíceos basados en tetraedros $\mathrm{SiO}_{4}$, obtenidas a través de hidrólisis ácida o básica.

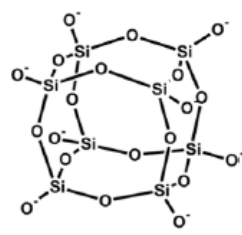

Esferosilicatos

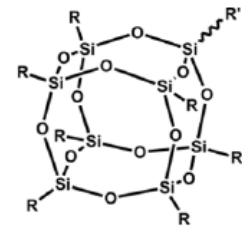

Siloxanos Poliédricos (POSS)

Figura 1.5. Esferosilicatos y siloxanos poliédricos derivados como unidades inorgánicas de estructura. 


\section{Especies metálicas}

Dentro de este grupo destacan los clusters metálicos que se forman directamente durante el proceso de síntesis, los cuales intervienen como nodos de estructura para la formación de materiales híbridos basados en redes cristalinas metal-orgánicas (metalorganic frameworks, MOFs). Este tipo de nodos estructurales también se integran en la formación de polímeros de coordinación que se incluyen, a su vez, en diferentes tipos de nanocomposites (Figura 1.6.) ${ }^{[14]}$.

Por otra parte, las nanopartículas metálicas se han utilizado frecuentemente, generadas in situ durante el proceso de preparación o incorporadas a través de procesos post-síntesis, para la obtención de materiales orgánicos-inorgánicos. Para ello, normalmente, se han soportado de forma directa en el seno de matrices porosas poliméricas, por medio de métodos de impregnación, deposición y/o precipitación ${ }^{[15]}$. Otra posibilidad implicaría la funcionalización de las nanopartículas metálicas con grupos orgánicos superficiales que facilitarían su integración en redes híbridas porosas, actuando como eslabones estructurales (Figura 1.6.) ${ }^{[16]}$.

a)

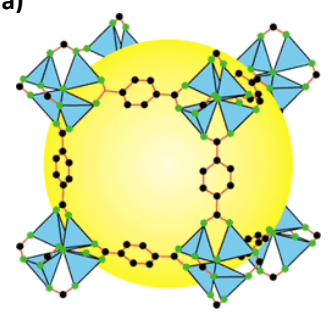

Red Metal-Orgánica b)

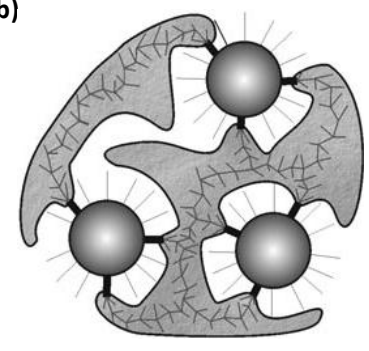

Nanopartículas Metálicas

Figura 1.6. Especies metálicas como unidades estructurales inorgánicas: (a) clusters metálicos (en azul) y (b) nanopartículas metálicas como componentes estructurales de materiales híbridos.

\section{Láminas inorgánicas}

Un elevado número de materiales híbridos obtenidos por ensamblaje directo de unidades estructurales, previamente sintetizadas, tienen como punto de partida el empleo de precursores laminares ordenados, ya sea de naturaleza silícea, zeolítica o basados en óxidos metálicos (hidrotalcitas), principalmente. La versatilidad mostrada por 
los materiales laminares, así como su capacidad de hidratación y de intercambio iónico, ha sido aprovechada para preparar tanto híbridos más simples de Clase I, a través, por ejemplo, de la estabilización por puentes de hidrógeno de policationes orgánicos en el espacio interlaminar, como otros más sofisticados de Clase II, siendo un ejemplo de este último grupo los silicatos pilareados con polímeros orgánicos insertados covalentemente entre las láminas inorgánicas (Figura 1.7.) ${ }^{[17]}$.
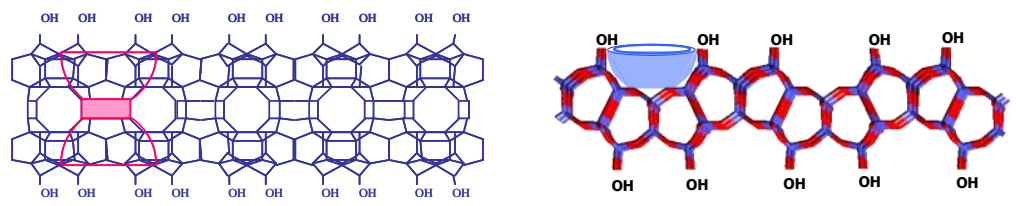

Figura 1.7. Ejemplos de láminas inorgánicas de naturaleza zeolítica.

\subsubsection{Unidades estructurales orgánicas}

La preparación más simple de materiales híbridos viene dada por la incorporación de pequeñas moléculas orgánicas en las cavidades de matrices inorgánicas porosas. No obstante, se han empleado moléculas más complejas, tales como oligómeros, polímeros o, incluso, enzimas como componentes de materiales híbridos. Entre las principales unidades estructurales de naturaleza orgánica se encuentran moléculas de reducidas dimensiones, macromoléculas y otro tipo de unidades discretas que se detallarán a continuación.

\section{Moléculas orgánicas de dimensiones reducidas}

En la modificación de redes cristalinas inorgánicas por simples moléculas orgánicas reside el origen de los denominados materiales híbridos ${ }^{[18]}$. En general, la inclusión de dichos compuestos orgánicos en el interior de cavidades o canales porosos, a través de fenómenos de adsorción o por interacciones electrostáticas, ha sido útil para la generación de materiales orgánicos-inorgánicos de Clase I. En estos casos, la polaridad de la molécula orgánica que se pretende introducir será determinante para llevar a cabo con efectividad este proceso, dependiendo del grado de hidrofobicidad exhibida por la matriz inorgánica con la que interactúa. Por otra parte, la posibilidad de alterar la composición de las moléculas orgánicas con grupos siloxano facilitaría su integración, a través de procesos 
de hidrólisis y condensación, en el entramado estructural inorgánico, obteniéndose, en estos casos, materiales híbridos más estables de Clase II (Figura 1.8.).<smiles>C=C(C)C(=O)O</smiles><smiles>C=C(C)C(N)=O</smiles>

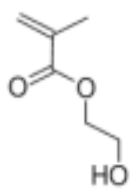<smiles>C=C(C)C(=O)OCCN</smiles>
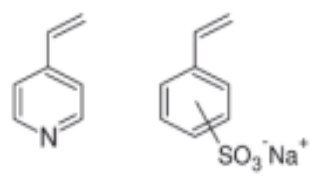

Figura 1.8. Ejemplos de moléculas orgánicas de reducidas dimensiones que interaccionan de manera óptima con matrices inorgánicas hidrófilas.

\section{Macromoléculas}

Dentro de este grupo se encuentran compuestos muy variados tales como oligómeros, polímeros, así como otros tipos de macromoléculas de origen biológico, como las enzimas, las cuales presentan solubilidades muy diferentes en comparación con los monómeros por los que están constituidos. Esta particularidad hace que, en ocasiones, sea difícil introducir estos compuestos en el seno de matrices inorgánicas de una forma controlada y homogénea. Recientemente, se han empleado surfactantes tipo bloque polímerico (block copolymers), conformados por segmentos hidrofílicos e hidrofóbicos, que facilitan el ensamblaje iónico de especies orgánicas e inorgánicas de diferente naturaleza para la obtención de materiales híbridos de elevada estabilidad, aún si en ellos no intervienen enlaces covalentes para conectar las distintas unidades estructurales (Figura 1.9. $)^{[19]}$.

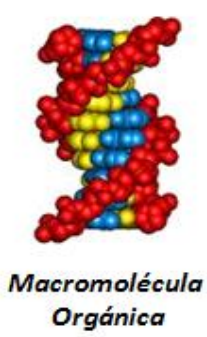

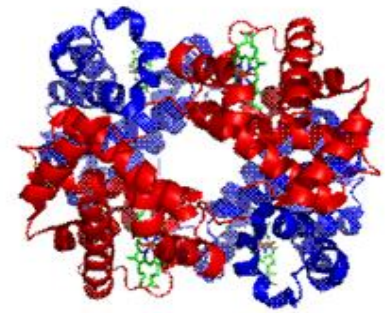

Enzima

Figura 1.9. Representación artística de macromoléculas y enzimas como ejemplos de unidades estructurales orgánicas que intervienen en la formación de materiales híbridos. 


\section{Unidades discretas de naturaleza orgánica}

Algunas unidades discretas orgánicas, tales como nanotubos de carbono, fullerenos o láminas de grafito, se han empleado recientemente para la generación de materiales híbridos tras la interacción adecuada con compuestos o matrices inorgánicas $^{[20]}$.

La incorporación de especies metálicas depositadas en las paredes internas de los nanotubos de carbono o de las unidades de fullereno ha sido descrita para la obtención de materiales híbridos de Clase I con aplicaciones, sobre todo, en nanotecnología. Además, la posibilidad de anclar covalentemente complejos organometálicos en sus paredes, aprovechando el elevado número de grupos carbonilos y carboxílicos que presentan en su superficie, abre la posibilidad de obtener híbridos de Clase II por ensamblaje directo de diferentes unidades estructurales. No obstante, se han descrito pocos ejemplos de este tipo de sólidos orgánicos-inorgánicos, cuyo componente mayoritario es de naturaleza orgánica, siendo todavía un campo por explorar (Figura 1.10.).

En el caso de las láminas grafíticas, el elevado número de centros activos presentes en su superficie, unido a la versatilidad propia asociada a los precursores laminares, las convierte en unidades estructurales idóneas para la obtención de materiales híbridos con múltiples aplicaciones gracias a que exhiben una elevada conductividad. En los últimos años, se han obtenido materiales híbridos por interacción electrostática o covalente, tanto de especies metálicas (nanopartículas) como de complejos organometálicos con láminas de grafito, los cuales se han empleado dentro del área de los sensores o de la óptica no lineal (Figura 1.10.) ${ }^{[21]}$. 


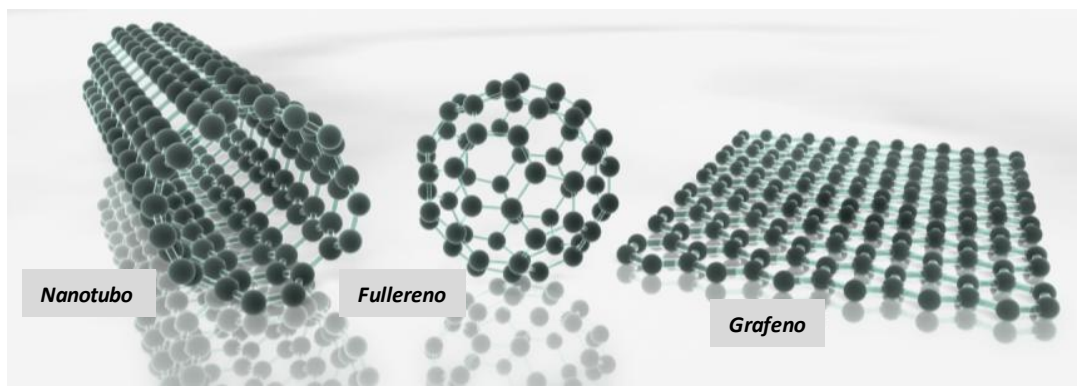

Figura 1.10. Unidades discretas de estructura de naturaleza orgánica: Nanotubos de carbono, fullerenos y láminas grafíticas.

\subsubsection{Unidades estructurales orgánicas-inorgánicas: Disilanos}

Un tercer tipo de unidades estructurales, empleadas para la generación de materiales híbridos, serían aquellas en las que diferentes segmentos orgánicos e inorgánicos se encuentran previamente enlazados, a través de interacciones covalentes, constituyendo el monómero de partida. La utilización de este tipo de precursores en el proceso de síntesis facilita la preparación de materiales híbridos estables y homogéneos, ya que la interacción entre fragmentos orgánicos e inorgánicos se traslada directamente desde el monómero inicial hacia el sólido finalmente obtenido. Este hecho evita la separación entre las diferentes fases que componen el material, integrándose de manera efectiva en su red estructural $^{[22]}$.

Cuando se han descrito las principales unidades estructurales orgánicas e inorgánicas, ya se ha avanzado, en cierta forma, esta posibilidad a través de la modificación de los precursores de partida, ya sea previamente o bien in situ durante el mismo proceso de síntesis. Es el caso de los complejos organometálicos basados en la interacción existente entre clusters metálicos y espaciadores orgánicos multidentados, los cuales son empleados para la formación de polímeros de coordinación o estructuras metal-orgánicas tipo MOF. Del mismo modo, se ha planteado la posibilidad de preparar monómeros organosilíceos a través de la modificación de silanos con compuestos orgánicos para generar mono o disilanos que, posteriormente, son empleados en procesos 
sol-gel o de auto-ensamblaje molecular directo para la obtención de una gran variedad de materiales híbridos (Figura 1.11.).

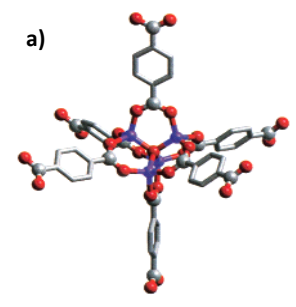

Complejo Organometálico

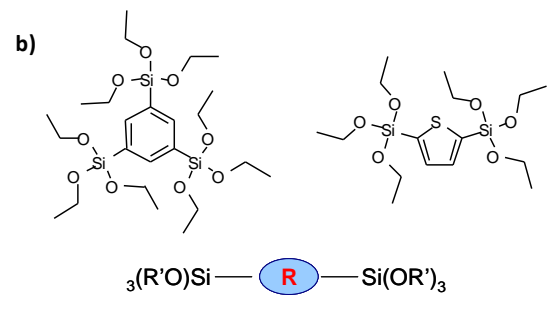

Disilanos

Figura 1.11. Ejemplos de unidades estructurales orgánicas-inorgánicas: (a) Complejo organometálico y (b) Disilanos.

Dentro de los silanos obtenidos por su interacción con moléculas orgánicas, se puede distinguir entre los monosilanos que actúan como modificadores de la red estructural silícea en la que se incorporan, introduciendo, en ocasiones, funcionalidades adicionales (funcionalizadores), y los disilanos (también denominados silsesquioxanos tipo puente) en los que los fragmentos orgánicos entran a formar parte real del entramado estructural, integrados en sus paredes cristalinas en lugar de estar colgando de la superficie de las mismas hacia las cavidades o canales porosos (Figura 1.12.). Este tipo de precursores orgánicos-inorgánicos suponen una alternativa a los monosilanos convencionales empleados en la síntesis de materiales híbridos organosilíceos ${ }^{[23]}$.

En concreto, los disilanos poseen la fórmula general $\left(\mathrm{R}^{\prime} \mathrm{O}\right)_{3}-\mathrm{Si}-\mathrm{R}-\mathrm{Si}-(\mathrm{OR})_{3}$, donde $\mathrm{R}$ es la funcionalidad orgánica presente a modo de puente, la cual contiene los centros activos, correspondiendo $\mathrm{R}^{\prime}$ a los grupos metilo o etilo. El término silsesquioxano para este tipo de monómeros hace referencia al promedio estequiométrico de valor 1.5, equivalente a un átomo y medio de oxígeno por cada átomo de silicio presente en una molécula de disilano, debido a que en cada enlace siloxano intervienen dos átomos de silicio de monómeros diferentes (...- ${ }^{-1.5} \mathrm{O}-\mathrm{Si}-\mathrm{R}-\mathrm{Si}_{-} \mathrm{O}_{\left.1.5^{-} \ldots\right)}$. 


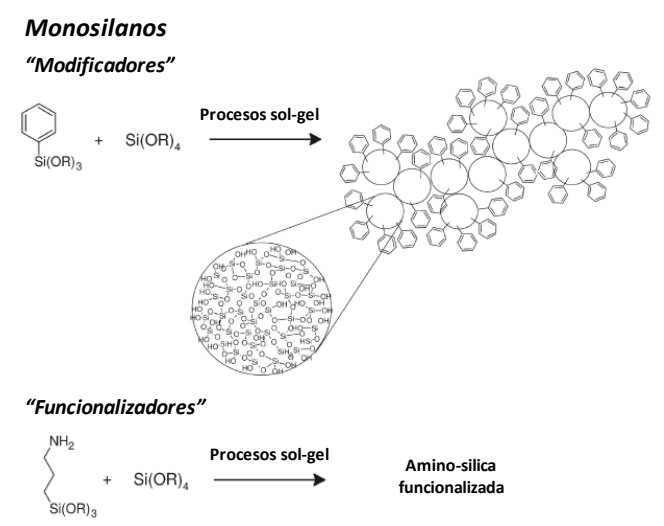

Disilanos ("bridged silsesquioxanes")

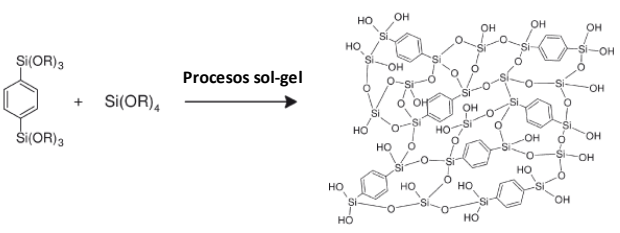

Figura 1.12. Silanos modificados, mono y disilanos, como unidades estructurales que intervienen en procesos de síntesis sol-gel para la obtención de materiales híbridos.

En general, es preferible el empleo de disilanos con grupos alcóxido terminales altamente reactivos. Estos grupos, tras un proceso de hidrólisis, se transforman en silanoles, siendo esta etapa varios órdenes de magnitud más lenta que en los precursores con grupos clorosilano, también empleados en la síntesis de materiales híbridos. Este hecho facilita que haya una mejor estructuración y una distribución más homogénea, entre los diferentes fragmentos orgánicos e inorgánicos, durante los procesos sol-gel en los que normalmente intervienen.

En la actualidad existe un número relativamente alto de disilanos comerciales que pueden ser empleados como unidades de estructuración (Figura 1.13.), siendo a priori posible preparar monómeros de este tipo con una gran variedad de fragmentos orgánicos que contengan, a su vez, diversas funcionalidades. Entre las rutas de síntesis más habituales para la preparación de disilanos, se encuentran la sililación de haluros aromáticos, la hidrosililación de dienos o, directamente, el tratamiento de organotrialcoxisilanos con grupos amino o alquil-isocianato ${ }^{[24]}$. 


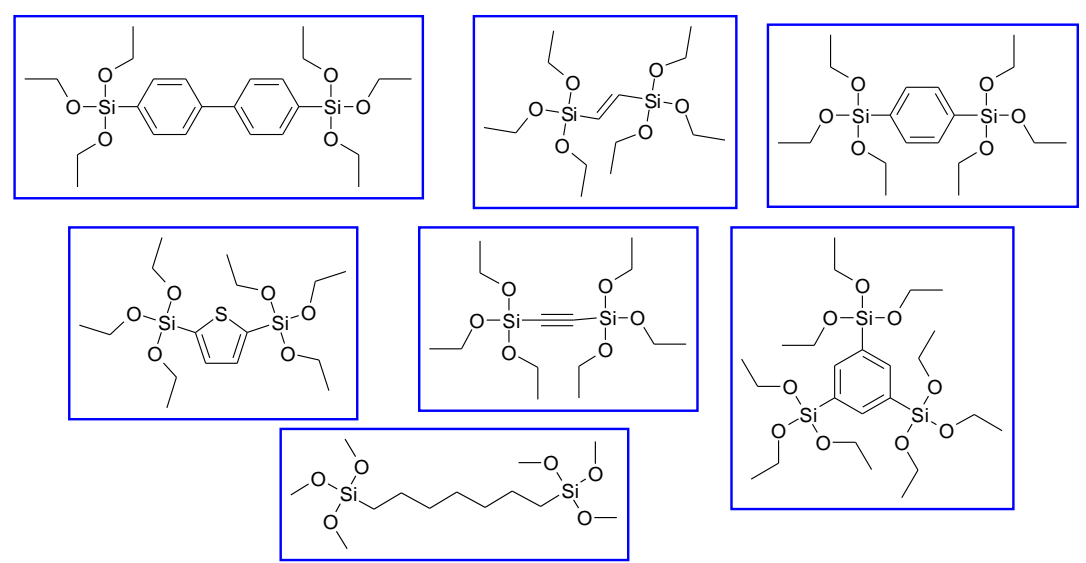

Figura 1.13. Algunos de los principales disilanos, empleados en la bibliografía, para la preparación de materiales híbridos organosilíceos.

La naturaleza de dichos segmentos orgánicos, incluidos en los silsesquioxanos, influirá sobre el posterior proceso de estructuración sol-gel, así como sobre las propiedades finales de los materiales híbridos orgánicos-inorgánicos sintetizados. Es el caso de los disilanos que contienen grupos orgánicos rígidos a modo de puente, tales como fenileno o acetileno, los cuales generalmente conducen a la formación de xerogeles y aerogeles porosos. En cambio, la presencia de fragmentos orgánicos flexibles favorece la generación de geles cuya porosidad colapsa por completo durante la etapa de secado ${ }^{[25]}$.

Otro ejemplo de la influencia que tienen las características de las unidades orgánicas, presentes en los disilanos, sobre los materiales finales viene dada por el hecho de que la integración en la estructura de espaciadores orgánicos con mayores longitudes moleculares tiende a favorecer la preparación de sólidos híbridos con cavidades porosas de diámetro más elevado ${ }^{[26],[24]}$.

\subsection{Métodos de síntesis}

La preparación de materiales híbridos puede llevarse a cabo, utilizando las unidades estructurales antes consideradas, a través de diferentes métodos de síntesis que implican desde una simple mezcla física de reactivos hasta métodos más sofisticados para 
obtener materiales híbridos a escala nanométrica, favoreciéndose de este modo la conexión homogénea entre los diferentes segmentos orgánicos e inorgánicos, con el objetivo de preparar sólidos en los que no se detecte separación de fases y, por lo tanto, en los que no existan problemas interfaciales.

Durante la revisión de las principales unidades estructurales ya se ha puesto de manifiesto que tanto el ensamblaje directo, así como la generación in situ de las mismas son los dos métodos más efectivos para la obtención de materiales híbridos orgánicosinorgánicos de Clase ${ }^{[1,27]}$.

\section{Ensamblaje directo}

En este caso, la preparación de materiales híbridos se lleva a cabo por la unión directa entre diferentes unidades estructurales formadas previamente. Este tipo de síntesis permite realizar un diseño a priori bastante acertado del material final que se va a obtener, en el cual las propiedades morfológicas y físico-químicas de los monómeros iniciales se mantienen prácticamente invariables. Ejemplos representativos de sólidos orgánicos-inorgánicos obtenidos por esta vía serían tanto nanopartículas o nanoclústeres metálicos que poseen grupos orgánicos anclados en su superficie, como materiales laminares, de naturaleza inorgánica, que presentan organosilanos funcionalizados anclados en su superficie externa (Figura 1.14.) ${ }^{[28]}$.

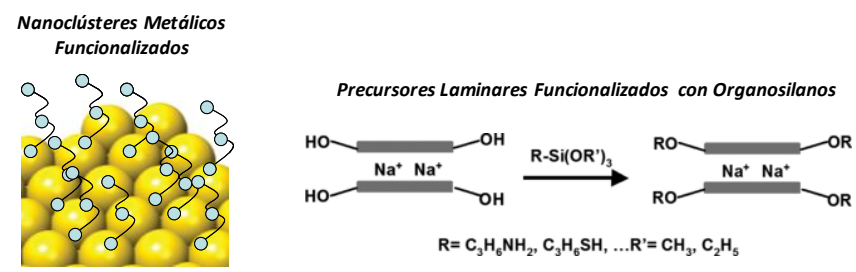

Figura 1.14. Materiales híbridos obtenidos por ensamblaje directo de unidades estructurales. 


\section{Formación in situ de unidades de estructura}

Mediante este método se preparan materiales híbridos a través de la generación in situ de una o varias de las unidades estructurales que intervienen durante el proceso de preparación, las cuales acaban integrándose en el entramado estructural de los sólidos de los que forman parte. La generación tanto de especies organometálicas como de unidades inorgánicas silíceas, son los casos más relevantes de formación in situ de eslabones estructurales en el proceso de síntesis, siendo, en concreto, los obtenidos a través de procesos sol-gel los que más serán tratados durante el desarrollo de esta Tesis. En general, los materiales obtenidos por este método in situ exhiben unas propiedades que se diferencian sustancialmente de las presentadas por los precursores originales a partir de los cuales han sido obtenidos, siendo determinantes las condiciones de síntesis empleadas para su obtención, las cuales influyen sobre sus propiedades finales.

Como ya se ha comentado, los procesos sol-gel han sido empleados habitualmente para la obtención de materiales híbridos por la formación in situ de derivados inorgánicos de naturaleza silícea que actúan como unidades de estructura. La utilización de precursores tipo disilano, en este tipo de método de síntesis, facilita la efectiva incorporación de fragmentos orgánicos formando parte de redes estructurales tridimensionales con elevada accesibilidad, ya que los enlaces $\mathrm{Si}-\mathrm{C}$ se suelen preservar, en su mayoría, durante las etapas de hidrólisis y condensación, en fase acuosa, que se llevan a cabo en estos procesos de síntesis ${ }^{[29]}$.

Normalmente, cuando se usan precursores organosilíceos tipo $\mathrm{R}_{1-n} \mathrm{SiX}$ ( $n=1-4$, $\mathrm{X}=\mathrm{OR}$ 'o halógeno), los grupos $\mathrm{Si}-\mathrm{X}$ son modificables durante la hidrólisis, formando silanoles $(\mathrm{Si}-\mathrm{OH})$ inestables que condensan entre sí para generar grupos $\mathrm{Si}-\mathrm{O}-\mathrm{Si}$. En las primeras etapas de este proceso se forman oligómeros, polímeros e, incluso, compuestos cíclicos en forma de coloides que constituyen el denominado sol. Después de esto, aparecen partículas sólidas que se ensamblan entre sí para formar el gel. Este mecanismo está catalizado por ácidos o por bases que influyen en la velocidad del proceso de condensación (Figura 1.15.) [30] $^{[3}$ 

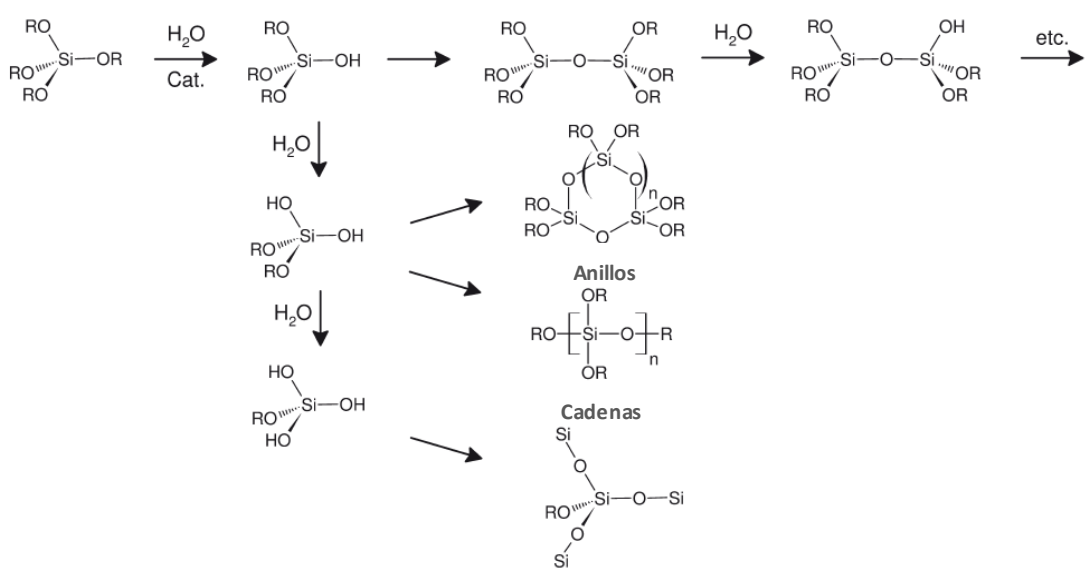

Figura 1.15. Etapas principales de un proceso sol-gel iniciado a partir de tetraalcoxisilanos.

El pH es otro parámetro importante en los procesos sol-gel, siendo, en general, la velocidad de la síntesis más lenta a pHs entre 2.5 y 4.5 , es decir, en el punto isoeléctrico de la sílice, incrementándose la velocidad al modificar el $\mathrm{pH}$ del medio. Sin embargo, el pH no sólo juega un papel importante en el mecanismo del proceso sol-gel sino también en la morfología final de los sólidos. Así, materiales obtenidos en medio ácido favorecen la formación de un gran número de partículas individuales en los primeros instantes que se aglomeran en pequeños clústeres en etapas sucesivas. Por el contrario, cuando la síntesis se lleva a cabo en medio básico, ya desde el inicio se observa un proceso de ensamblaje entre las diferentes partículas silíceas formadas en el sol. Este hecho implica importantes diferencias texturales y morfológicas en los materiales híbridos finalmente obtenidos. Los catalizadores habitualmente empleados son $\mathrm{HCl}, \mathrm{NaOH}$ o $\mathrm{NH}_{4} \mathrm{OH}$, aunque también pueden ser empleados procesos en medio fluoruro, los cuales permiten realizar la hidrólisis y condensación a pHs cercanos a la neutralidad, a temperaturas relativamente bajas y en tiempos extremadamente cortos.

Es importante destacar, la necesidad de realizar una etapa final de secado o envejecimiento del gel, con el fin de lograr que la condensación de las diferentes especies silíceas generadas sea prácticamente total, favoreciendo tanto la eliminación del disolvente ocluido (agua y/o alcohol) como la finalización de la etapa de polimerización entre todos los grupos silanoles presentes en el entramado estructural ${ }^{[31]}$. 
En resumen, la optimización de todos los parámetros de síntesis que intervienen en un proceso sol-gel $(\mathrm{pH}$, disolvente, tiempo de gelificación, catalizador ácido o básico, etc.) influye enormemente sobre los materiales híbridos formados, siendo necesario encontrar las condiciones más adecuadas que permitan una distribución homogénea y sin separaciones interfaciales entre los diferentes segmentos, orgánicos e inorgánicos, que conforman los materiales preparados.

La presencia, durante los procesos sol-gel, de moléculas orgánicas o surfactantes que actúan como agentes directores de estructura (ADEs), en las condiciones de síntesis adecuadas, permite alcanzar una organización supramolecular, generando estructuras ordenadas bi y tridimensionales con canales y cavidades porosas. Ejemplos de materiales híbridos obtenidos a través de esta metodología serían las organosílicas periódicas mesoporosas $(\mathrm{PMOs})^{[32]}$ o los materiales organozeolíticos $(\mathrm{OZs})^{[33]}$. En ambos casos, se emplean disilanos como precursores organosilíceos.

Por otra parte, existen algunos casos, en los que se pueden preparar sólidos híbridos por la formación in situ, durante el proceso de síntesis, de unidades estructurales de naturaleza orgánica, en lugar de inorgánica como eran los derivados silíceos vistos anteriormente. Un ejemplo de este caso sería la polimerización de monómeros orgánicos, bien sobre la superficie de nanopartículas de óxidos metálicos, bien insertados en la región interlaminar de diferentes precursores laminares inorgánicos ${ }^{[34]}$. Por último, sería posible la obtención de materiales híbridos cristalinos y de elevado volumen poroso por la formación in situ de ambos tipos de unidades estructurales, orgánicas e inorgánicas, durante el proceso de síntesis. El caso de algunos materiales metal-orgánicos, MOFs, o polímeros de coordinación serían los más representativos dentro de este grupo, donde tanto clústeres o nodos metálicos como complejos organometálicos que actúan como eslabones estructurales se forman directamente en el mismo proceso de preparación ${ }^{[35]}$.

\subsection{Principales materiales híbridos}

A lo largo de esta introducción, se han identificado dos tipos principales de unidades estructurales que permiten la incorporación de fragmentos orgánicos insertados 
en la red estructural de los materiales en los que entran a formar parte, enlazados con otros segmentos inorgánicos de manera estable y homogénea. Se trata de los complejos organometálicos y las moléculas de disilano (silsesquioxanos tipo puente), los cuales pueden formarse bien durante el proceso de síntesis, como es el caso de los complejos, bien previamente, como es el caso de los disilanos. El empleo de este tipo de precursores permite la preparación de dos tipos de familias de materiales híbridos de Clase II como son los sólidos metal-orgánicos, MOFs, y los híbridos organosíliceos partiendo de complejos organometálicos y disilanos, respectivamente. Es significativo destacar que en ambos tipo de materiales, durante el proceso de síntesis, se forman in situ algunos de los precursores (complejos organometálicos o tetraedros de silicio) que actúan como eslabones estructurales.

Por otra parte, es importante resaltar que existe un numeroso grupo de materiales orgánicos-inorgánicos que se obtienen a partir de precursores laminares inorgánicos, previamente sintetizados, por la intercalación o auto-ensamblaje directo de silanos modificados que se sitúan y estabilizan en la región interlaminar.

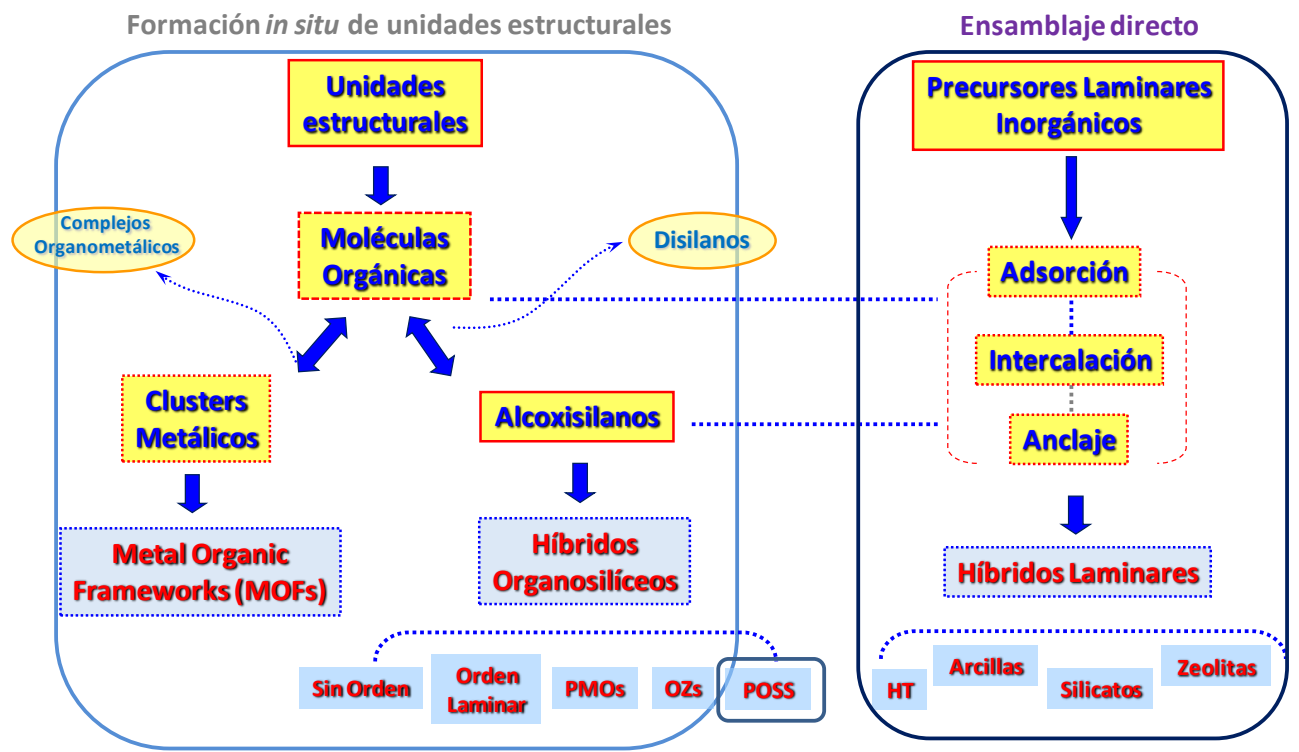

Figura 1.16. Clasificación de los materiales híbridos orgánicos-inorgánicos de Clase II más representativos en función de las unidades estructurales que los constituyen y del mecanismo de síntesis utilizado para su preparación. 
En la Figura 1.16. se muestra un esquema general de las principales familias de materiales híbridos de Clase II existentes y los sólidos que de ellas se derivan, clasificados en función del tipo de unidades estructurales que intervienen y de la metodología de síntesis empleada.

\subsubsection{Materiales basados en redes estructurales metal-orgánicas (MOFs)}

Los materiales denominados MOFs son sólidos porosos cristalinos, constituidos por redes tridimensionales basadas en clústeres metálicos (nodos) conectados a través de ligandos orgánicos bi o multidentados (espaciadores) ${ }^{[36]}$. La distribución ordenada de estas unidades estructurales conduce a la formación de sistemas de canales y cavidades a escala nanométrica, similar a los que se encuentran en los materiales zeolíticos. La elección adecuada de las subunidades y precursores estructurales empleados, así como la forma en la cual se conectan conduce a modificaciones sustanciales de la estructura porosa de los diferentes MOFs que pueden formarse (Figura 1.17.a) ${ }^{[37]}$.

Las unidades estructurales básicas de los MOFs, es decir, nodos inorgánicos y espaciadores orgánicos, se caracterizan tanto por el número como por la orientación de los grupos funcionales que contienen, los cuales son susceptibles de interaccionar con otras unidades de estructura. En concreto, los nodos, generalmente, están basados en metales de transición o clústeres metálicos polinucleares con diferentes índices de coordinación y geometrías. Por otra parte, los espaciadores suelen ser ligandos orgánicos bi o multidentados que facilitan la interacción, a través de enlaces fuertes de coordinación, con los nodos metálicos (Figura 1.17.b).

a)

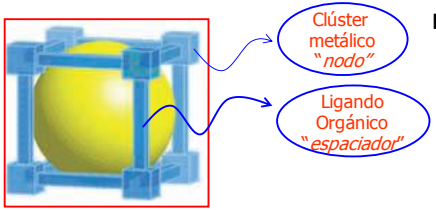

b)

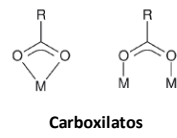

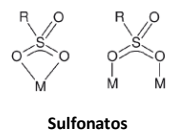

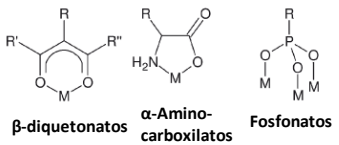

Figura 1.17. (a) Representación esquemática de la estructura básica de una red cristalina metalorgánica tipo MOF; (b) Ligandos orgánicos bi y multidentados que pueden coordinarse con diferentes especies o clústeres metálicos. 
Por medio de este tipo de interacciones es posible formar estructuras porosas mono, bi o tridimensionales, teniendo en cuenta los diferentes tipos de coordinación que ofrecen los clústeres metálicos, unido a la posibilidad de diseñar espaciadores orgánicos con múltiples funcionalidades y disposiciones espaciales. En el caso más sencillo, metales de transición, actuando como nodos o conectores, reaccionan con ligandos orgánicos, a modo de espaciadores o puentes, para formar polímeros lineales mono-dimensionales. Esta enorme versatilidad ha permitido preparar más de 13000 tipos de redes cristalinas basadas en la interacción coordinativa entre especies metálicas y ligandos orgánicos ${ }^{[38]}$.

En general, la baja densidad estructural de este tipo de sólidos metal-orgánicos hace que presenten diámetros de poro elevados (>30 ̊̊) y superficies específicas accesibles, siendo habitual encontrar materiales tipo MOFs con áreas y volúmenes de poro libre superiores a los $1000 \mathrm{~m}^{2} \mathrm{~g}^{-1}$ y $0.7 \mathrm{~cm}^{3} \mathrm{~g}^{-1}$, respectivamente. Estas características hacen que a priori presenten una gran capacidad de adsorción, siendo empleados para

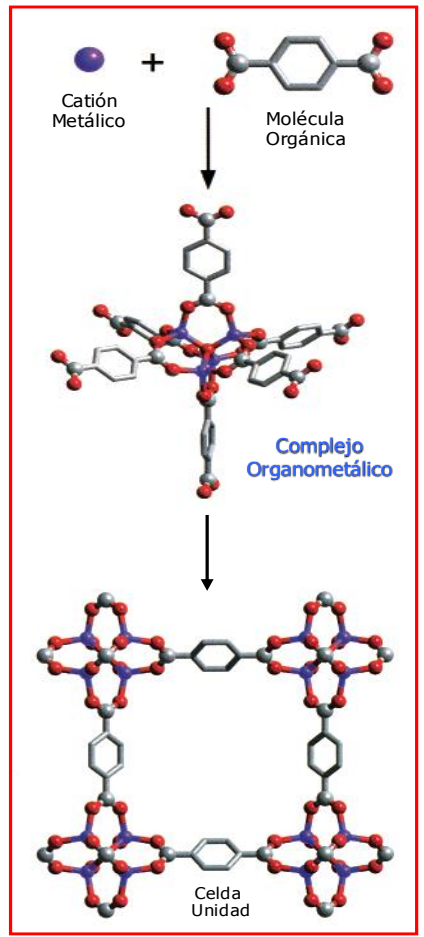

Figura 1.18. Proceso de formación de MOFs. almacenar gases tales como hidrógeno, metano $0 \mathrm{CO}_{2}$. Además, la presencia de especies metálicas y ligandos orgánicos con diferentes grupos funcionales en su composición, les confiere propiedades interesantes para ser empleados como catalizadores o en procesos más tecnológicos relacionados con fenómenos ópticos, fotoluminiscentes, electrónicos o magnéticos. No obstante, su baja estabilidad hidrotérmica hace que, en cierto modo, sus potenciales aplicaciones se vean limitadas en gran medida.

Como ya se ha comentado anteriormente, en el caso de los MOFs, durante el proceso de síntesis se generan in situ nodos estructurales metálicos que forman, de manera inmediata, complejos organometálicos al reaccionar con los correspondientes espaciadores orgánicos, constituyendo las unidades 
básicas de estructura de las redes metal-orgánicas (Figura 1.18.). Normalmente, el autoensamblaje de las diferentes unidades estructurales se realiza a través de un proceso solvotermal, empleando disolventes polares (EtOH o derivados de la formamida, entre otros), temperaturas superiores a $\operatorname{los} 100^{\circ} \mathrm{C}$ y bases fuertes para llevar a cabo la desprotonación de los grupos carboxílicos, los cuales están, en general, presentes en los ligandos orgánicos que actúan como espaciadores en la mayoría de MOFs, facilitando así su interacción coordinativa con los clústeres metálicos. Aunque de elevada estabilidad, los enlaces de coordinación metal-ligando formados son altamente lábiles, pudiendo ser modificados en determinadas condiciones, para con posterioridad reordenarse nuevamente para formar la red cristalina inicial, la cual es la más favorable termodinámicamente ${ }^{[39]}$.

El material más representativo de los sólidos metal-orgánicos es el MOF-5, el cual está constituido por clústeres de zinc, conformados por cuatro tetraedros $\mathrm{ZnO}_{4}$, que reaccionan con moléculas del tipo bencenodicarboxilato para generar complejos organometálicos que actúan como las unidades básicas de estructura. El ensamblaje de dichas unidades, a través de un proceso solvotermal, facilita la formación de una estructura cúbica tridimensional, cuyos vértices son los clústeres polinucleares octaédricos, siendo sus aristas los anillos aromáticos. Dado que sus unidades estructurales son rígidas, su porosidad y estabilidad son muy elevadas. La versatilidad de este tipo de materiales queda plenamente confirmada por el elevado número de estructuras tipo MOF-5 que pueden ser generadas por el empleo de diferentes ligandos orgánicos con distintos esqueletos aromáticos, los cuales interaccionan con clústeres polinucleares de zinc (Figura 1.19.) ${ }^{[40]}$. 


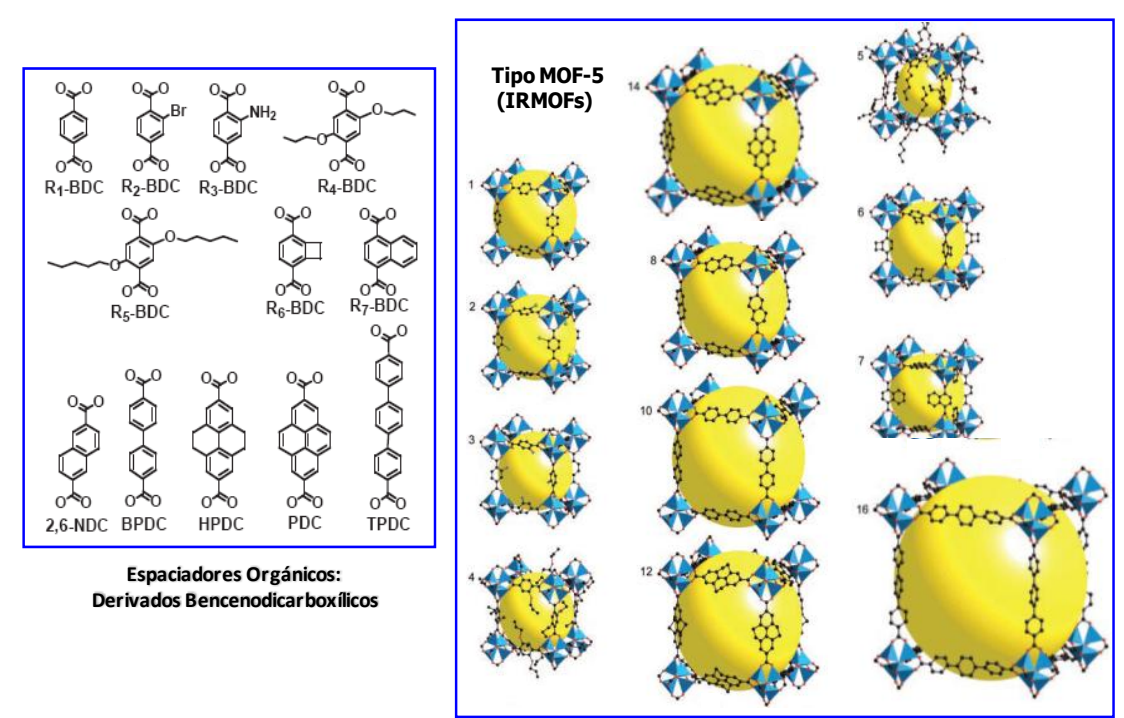

Figura 1.19. Estructuras metal-orgánicas de la familia del MOF-5 obtenidas por el empleo de diferentes tipos de moléculas bencenodicarboxilato como espaciadores orgánicos.

\subsubsection{Materiales híbridos organosilíceos}

La utilización de moléculas de silanos, modificados previamente por fragmentos orgánicos, ha servido con frecuencia para obtener sólidos híbridos de variada organización estructural, con funcionalidades y propiedades texturales específicas (Figura 1.20.). Dentro de esta metodología, el empleo de disilanos (silsesquioxanos puente) ha sido fundamental para lograr incorporar fragmentos orgánicos que se insertan en las paredes de los materiales formados, cumpliendo una doble misión, tanto de tipo estructural como de centro activo. Este hecho ha supuesto un avance significativo respecto al empleo de monosilanos convencionales, ya que se pasa de realizar procesos químicos que son llevados a cabo en los canales porosos de los materiales a otros en los que es el propio entramado estructural el que está implicado de forma activa. Además, la inserción estructural de unidades orgánicas en la red cristalina permite incorporar un mayor número de funciones activas distribuidas homogéneamente comparado con el empleo de monosilanos anclados, sin llegar a bloquear de ningún modo los canales y las cavidades internas de los sólidos obtenidos ${ }^{[41]}$. 


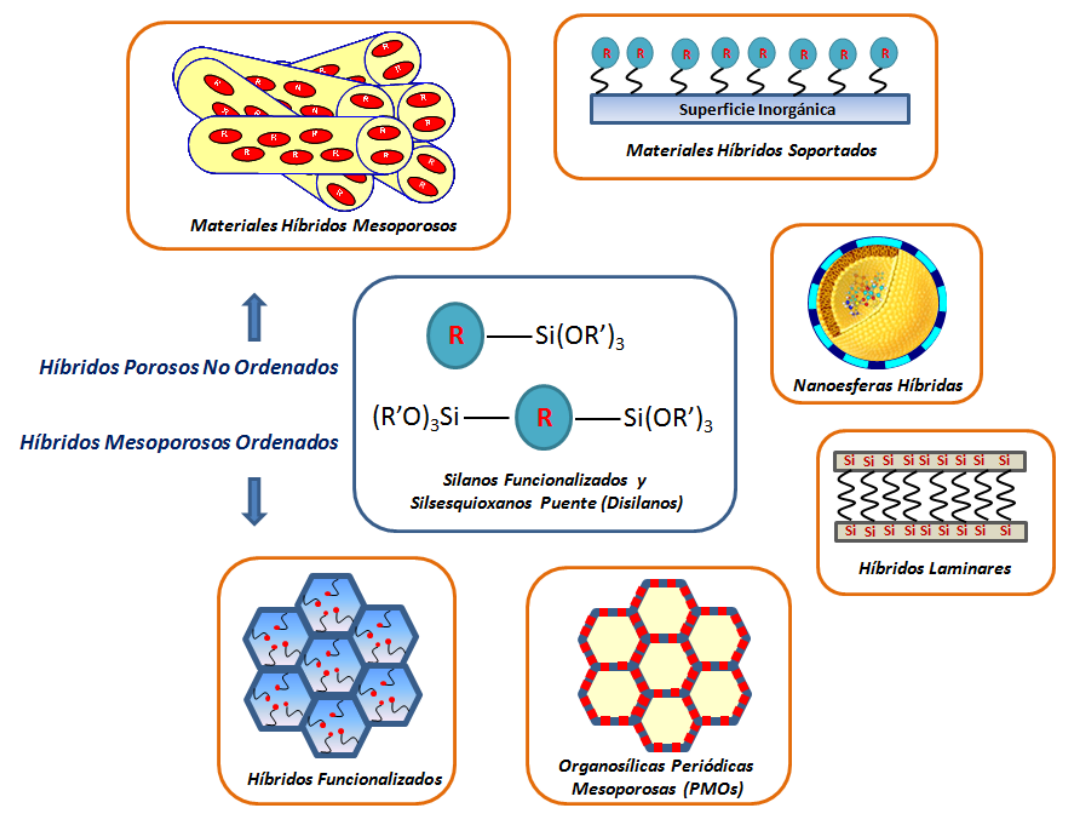

Figura 1.20. Materiales organosilíceos obtenidos a partir de silanos y disilanos funcionalizados.

Tal y como se ha mostrado en la Figura 1.16., los materiales híbridos organosilíceos que presentan fragmentos orgánicos insertados en su entramado estructural están basados en unidades estructurales denominadas disilanos, los cuales, como se ha visto anteriormente, son el resultado de la asociación previa entre moléculas orgánicas y alcoxisilanos. Dependiendo de las condiciones de síntesis y de los precursores empleados, se generan una gran variedad de sólidos orgánicos-inorgánicos que presentan diferentes propiedades.

En concreto, los procesos sol-gel, en medio ácido o básico y en ausencia de agentes directores de estructura, suelen ser empleados para generar híbridos orgánicosinorgánicos que carecen de orden a largo alcance y que contienen un elevado contenido de grupos orgánicos como parte integrante de la red sólida ${ }^{[42]}$. Basados en esta misma metodología, se obtienen materiales porosos con orden laminar en los que los silanos funcionalizados se asocian para formar materiales laminares, en ellos las partes inorgánicas del silano polimerizan para formar láminas silíceas unidas a través de fragmentos orgánicos que se sitúan entre las mismas. Otro tipo de fases laminares se 
forman debido a las interacciones electrostáticas que se establecen entre los segmentos orgánicos en función tanto de la longitud como de las propiedades hidrófobas-hidrófilas del puente orgánico presente en las moléculas de disilano ${ }^{[43]}$.

Por otra parte, de entre todos los materiales orgánicos-inorgánicos obtenidos a partir de disilanos, los más relevantes y estudiados en la bibliografía han sido las organosílicas periódicas mesoporosas (periodic mesoporous organosilicas, PMOs). En este caso, se emplean métodos de síntesis por ensamblaje molecular realizados en una sola etapa, en el que se forman tetraedros de silicio como unidades estructurales inorgánicas, in situ, durante el proceso de preparación, lográndose que los fragmentos orgánicos, provenientes de los disilanos, estén formando parte de las paredes del material. En el año 1999, tres grupos de investigación obtuvieron estos materiales de manera independiente (Inagaki $y$ col. ${ }^{[44]}$, Ozin $y$ col. ${ }^{[45]}$, Stein $y$ col. ${ }^{[46]}$ ), siendo ampliamente estudiadas las variables y parámetros que intervienen durante su preparación a través de rutas micelares, tales como tipo de hidrólisis (ácida o básica), clase de surfactante empleado (catiónico, aniónico o neutro), combinación de monosilanos junto a disilanos o incorporación isomórfica de átomos metálicos ( $\mathrm{Al}, \mathrm{Ti}, \mathrm{Fe}$ o $\mathrm{Zr}$ ). En su mayoría, los materiales PMOs han sido empleados en procesos catalíticos ${ }^{[32]}$.

Partiendo de la misma idea que en los PMOs, se emplearon disilanos, en condiciones de síntesis hidrotermales y en presencia de moléculas de ADE adecuadas, para obtener materiales orgánicos-inorgánicos en tres dimensiones que exhiben una organización y estructura de naturaleza zeolítica. Estas organozeolitas (OZs) combinan las características texturales y morfológicas propias de los materiales zeolíticos convencionales, junto con las propiedades hidrófobas-hidrófilas y funcionalidades provenientes de los segmentos orgánicos insertados ${ }^{[47]}$.

Por último, debido a su interés como potenciales unidades estructurales inorgánicas para la obtención de materiales híbridos, destaca el papel recientemente desempeñado por determinados silanos poliédricos (polyhedral oligomeric silsesquioxanes, POSS), los cuales se han empleado para preparar, por ensamblaje directo, redes de dendrímeros no porosos ${ }^{[48]}$, así como materiales mesoporosos ordenados de 
elevada estabilidad ${ }^{[49]}$. La posibilidad de incorporar funciones orgánicas adicionales en los vértices de las poliedros silíceos abre el camino para preparar nuevas familias de materiales híbridos cristalinos ${ }^{[50]}$.

En los Capítulos 4 y 5 de esta memoria, relacionados con la preparación de materiales orgánicos-inorgánicos mesoporosos, se realizará una revisión más detallada de los híbridos organosilíceos que se han tratado de manera resumida en esta parte inicial.

\subsubsection{Materiales híbridos laminares}

Un elevado número de materiales híbridos son obtenidos a partir de precursores laminares inorgánicos de diferente naturaleza. En general, los sólidos que presentan una organización laminar son bidimensionales, estando constituidos por átomos ligados fuertemente entre ellos en dos direcciones del espacio dando lugar a láminas, las cuales, a su vez, interaccionan débil y perpendicularmente entre sí. La región existente entre las láminas, en la que se establecen dichas interacciones débiles, recibe el nombre de espacio interlaminar ${ }^{[51]}$, siendo la zona donde se adsorben, anclan o intercalan diferentes compuestos orgánicos u organosilíceos para generar materiales híbridos, por los general, de elevada accesibilidad (Figura 1.21.) ${ }^{[52]}$.

Las características de los materiales orgánicos-inorgánicos obtenidos dependen tanto de las características físico-químicas de las láminas que constituyen el precursor inicial, así como de la facilidad que tienen dichos precursores para modificar su espaciado interlaminar y alojar especies orgánicas estabilizadas. Así, en el caso de que las láminas sean eléctricamente neutras, como ocurre por ejemplo en el grafito, las láminas adyacentes están interconectadas a través de enlaces débiles de tipo Van der Waals. En esta clase de precursores laminares, se pueden incorporar moléculas orgánicas neutras entre las láminas dando lugar a materiales híbridos de Clase I, los cuales están estabilizados por la reacción de transferencia electrónica que se establece entre la lámina inorgánica y la molécula orgánica huésped ${ }^{[53]}$. 


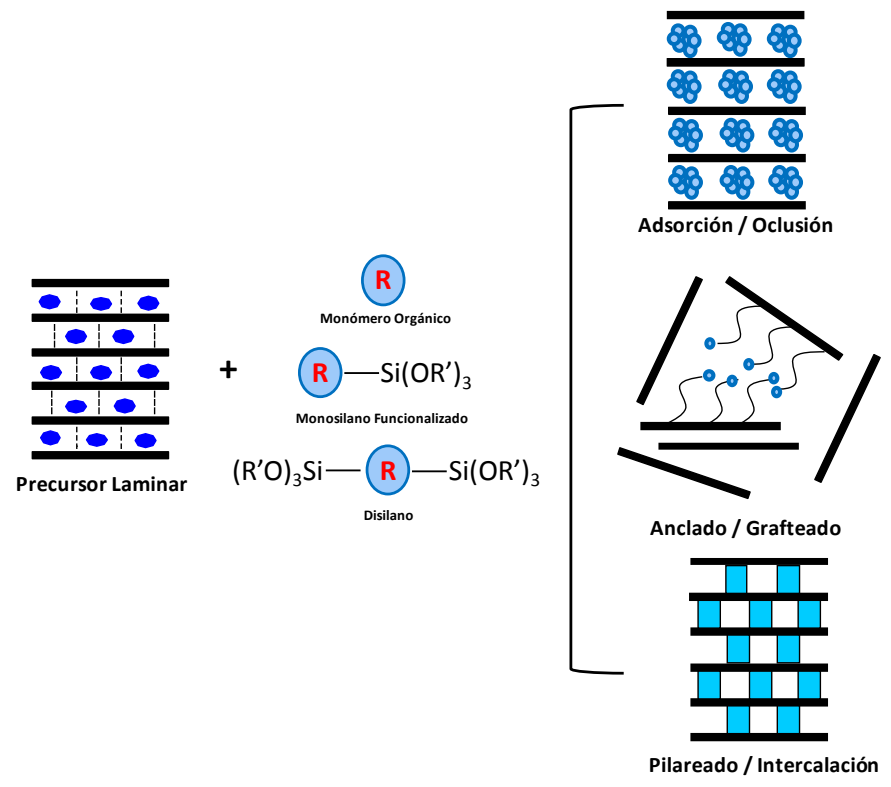

Figura 1.21. Principales tipos de materiales híbridos orgánicos-inorgánicos con organización laminar.

En otras ocasiones los sólidos están conformados por láminas que poseen una carga eléctrica como consecuencia de las sustituciones isomórficas llevadas a cabo en su red cristalina que, finalmente, queda constituida por varios átomos que presentan diferente carga. Este es el caso de las arcillas, los hidróxidos dobles laminares y una gran mayoría de silicatos y precursores zeolíticos laminares. En estos precursores laminares, para que la estructura alcance un balance neutro de carga, se disponen iones de carga opuesta en el espacio interlaminar, los cuales suelen estar solvatados por moléculas polares, generalmente agua, actuando como iones de compensación. Cuando se eliminan las moléculas de solvatación a elevadas temperaturas se produce el colapso del espacio interlaminar, especialmente si los iones compensadores de carga son pequeños. En cambio si estos iones son relativamente grandes pueden actuar a modo de pilares y evitar así el colapso del espacio interlaminar. De este modo se han logrado generar materiales híbridos por la presencia de iones poliméricos que se insertan entre las láminas de precursores tales como arcillas o hidróxidos dobles laminares (hidrotalcitas), principalmente, utilizados en la formación de composites ${ }^{[54]}$. 
Siguiendo con este concepto y aprovechando la versatilidad ofrecida por los precursores laminares, se consiguieron obtener materiales pilareados por la inserción covalente de especies silíceas, tetraalcoxisilanos, en la región interlaminar a través de la interacción que se produce con los silanoles presentes en la superficie de las láminas. Este método ha sido empleado con éxito especialmente en silicatos y precursores zeolíticos laminares, para generar materiales de elevada estabilidad hidrotérmica y alta accesibilidad debida a las nuevas galerías generadas entre los pilares y las láminas ${ }^{[55]}$.

Este tipo de sólidos pilareados se pueden considerar como compuestos de intercalación que presentan tres importantes requisitos:

- Las especies interlaminares han de ser lo suficientemente robustas para facilitar la expansión vertical de las láminas y evitar su colapso durante el proceso de calcinación.

- $\quad$ Los pilares generados han de estar espaciados y suficientemente separados para facilitar el acceso de las moléculas al espacio interlaminar.

- Las láminas han de ser rígidas para mantener la adecuada separación entre los pilares.

Estas características se cumplen cuando se insertan moléculas de disilano, a modo de pilar, por ensamblaje directo con las láminas inorgánicas del precursor, obteniéndose, en este caso, materiales híbridos orgánicos-inorgánicos de Clase II que no sólo poseen las características propias de los materiales pilareados, sino que también exhiben la funcionalidad aportada por los grupos orgánicos incorporados y estabilizados entre las láminas. En la bibliografía, existen sólo algunos casos de este tipo de materiales orgánicos-inorgánicos obtenidos a partir de silicatos laminares, por ejemplo utilizando ilerita como precursor ${ }^{[56]}$. Por lo tanto, teniendo en cuenta que se trata de un campo, dentro de los sólidos híbridos, poco estudiado, será considerado en detalle a lo largo del Capítulo 3 de esta memoria de Tesis.

Por otra parte, también es posible obtener materiales híbridos laminares a través del anclaje de monosilanos funcionalizados orgánicamente, en la superficie de las láminas 
inorgánicas. Existen numerosos métodos descritos que han sido empleados para conseguir anclar diferentes grupos orgánicos a las superficies silíceas, sobre todo en silicatos y precursores zeolíticos, a través de la formación de enlaces covalentes, para generar, en algunos casos, catalizadores de elevada actividad ${ }^{[57]}$.

\subsection{Aplicaciones de los materiales híbridos}

La combinación de diferentes componentes orgánicos e inorgánicos en un mismo material ha permitido la obtención de sólidos híbridos con propiedades y características específicas, con potenciales aplicaciones tanto en catálisis, adsorción o separación, como en procesos más nanotecnológicos relacionados con la transferencia electrónica, la fotoluminiscencia o en el campo de los sensores ${ }^{[58]}$. No obstante, es en el área de la catálisis donde los materiales híbridos orgánicos-inorgánicos han sido empleados con mayor frecuencia debido a la posibilidad de heterogeneizar funciones activas ${ }^{[59]}$. En general, se han buscado catalizadores sólidos para realizar todo tipo de reacciones, ya que permiten su recuperación y reciclado del medio de reacción. No obstante, los catalizadores heterogéneos están ciertamente limitados en la naturaleza de sus centros activos y, por lo tanto, en el campo de las reacciones que llevan a cabo. En cambio los catalizadores orgánicos solubles, organocatalizadores, pueden llevar a cabo una mayor variedad de reacciones que los tradicionales catalizadores sólidos, aunque poseen el inconveniente de su incapacidad para ser reciclados. La solución pasaría por emplear catalizadores sólidos, fácilmente recuperables tras el proceso de reacción, en los cuales se encuentren incorporados uno o varios fragmentos orgánicos activos.

Tradicionalmente, el diseño de materiales orgánicos-inorgánicos consistía en la simple incorporación de moléculas orgánicas en el interior de matrices inorgánicas, con el fin de desarrollar catalizadores heterogéneos. Aunque las interacciones que se establecen entre los componentes orgánicos e inorgánicos son débiles, se consiguieron preparar catalizadores sólidos en los que la funcionalidad aportada por las moléculas orgánicas es convenientemente aprovechada, permaneciendo activa durante un largo periodo de tiempo. Algunos ejemplos representativos de este tipo de catalizadores son los formados 
por moléculas orgánicas ocluidas o preparados in situ (ship-in-a-bottle) en el interior de las cavidades de silicatos microporosos o zeolitas ${ }^{[60]}$. Con este método se lograron superar algunos de los problemas más importantes vinculados a los catalizadores homogéneos, como son la separación de los productos de reacción o la recuperación y la reutilización del catalizador, es decir, etapas que, por lo general, se realizan de forma sencilla cuando se emplean catalizadores sólidos (Figura 1.22.).

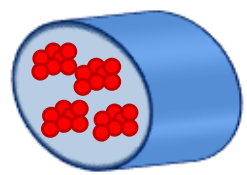

Oclusión (Ship-in-a-bottle)

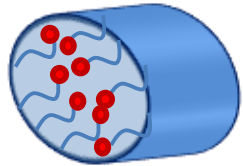

Anclaje

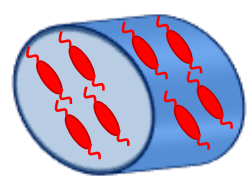

Inserción estructural

Figura 1.22. Materiales orgánicos-inorgánicos con diferentes modos de incorporar organocatalizadores.

Sin embargo, aunque las funciones orgánicas exhiben una mayor estabilidad, cuando se encuentran ocluidas en el seno de redes inorgánicas, es posible apreciar que dichas interacciones químicas débiles entre ambos tipos de componentes tienden a favorecer la separación en dos fases independientes que actúan de forma separada, sin que pueda apreciarse un efecto catalítico cooperativo entre el huésped orgánico y la matriz inorgánica que lo aloja. Otras limitaciones importantes que presentan este tipo de materiales son la lixiviación (leaching), la desactivación y la fácil desorción de los organocatalizadores presentes, así como el bloqueo parcial del volumen poroso libre del soporte inorgánico, lo cual hace disminuir su eficiencia en los procesos catalíticos en los que intervienen ${ }^{[61]}$.

Como se ha visto a lo largo de esta introducción, en los últimos años se han llevado a cabo importantes avances en el desarrollo de nuevos materiales híbridos basados en interacciones químicas fuertes entre fragmentos de diferente naturaleza, los cuales se encuentran integrando la red estructural a escala nanométrica de los sólidos en los que entran a formar parte, a través, principalmente, de enlaces covalentes o de coordinación. En estos materiales, las unidades orgánicas e inorgánicas se alternan entre 
sí, generando la estructura final de los materiales híbridos de Clase II. Siguiendo esta metodología, se evitan los obstáculos anteriormente descritos, generando materiales con diferentes funcionalidades orgánicas activas, separadas entre sí, estabilizadas e integradas en el entramado estructural ${ }^{[44,62]}$. Los problemas convencionales asociados a los materiales híbridos que contienen moléculas orgánicas adsorbidas o alojadas se consiguen minimizar, debido a que dichos fragmentos orgánicos, y con ellos los centros activos que contienen, se encuentran distribuidos homogéneamente y en gran cantidad a lo largo de los canales porosos de los materiales, sin que se produzca un bloqueo de su volumen libre, permitiendo, por lo tanto, un mayor aprovechamiento tanto de su porosidad como de su actividad. Este hecho está en claro contraste con lo que ocurre en los materiales orgánicos-inorgánicos en los que las funciones activas no forman parte integrante de las paredes sino que penden de ellas hacia la cavidad porosa o se ocluyen en el espacio interno libre (Figura 1.22. $)^{[45-46]}$. En definitiva, estas características presentes en los híbridos de Clase II, conllevan que el desarrollo de la reacción se traslade desde las cavidades o canales para tener lugar en la propia red estructural de los catalizadores ${ }^{[63]}$.

A través de la elección adecuada de los monómeros empleados como precursores, formados por unidades orgánicas e inorgánicas previamente conectadas, tales como los silsesquioxanos puente (disilanos) anteriormente citados, es posible obtener sólidos híbridos cuyo entramado estructural está conformado por ambos componentes lo que les confiere propiedades únicas, no sólo por las funciones propias de sus componentes individuales, sino por el efecto cooperativo y las nuevas propiedades interfaciales generadas que consiguen mejorar la actividad final de los catalizadores obtenidos $^{[64]}$. La combinación de diferentes tipos de fragmentos orgánicos, cada uno de ellos conteniendo, a su vez, una o varias funciones activas, abre la posibilidad de preparar catalizadores sólidos orgánicos-inorgánicos multifuncionales capaces de llevar acabo procesos consecutivos, tándem o en cascada, siendo este un campo de investigación en franca expansión en los últimos años y que, en parte, será abordado a lo largo del estudio presentado en esta memoria de Tesis Doctoral (Figura 1.23.) ${ }^{[65]}$. 


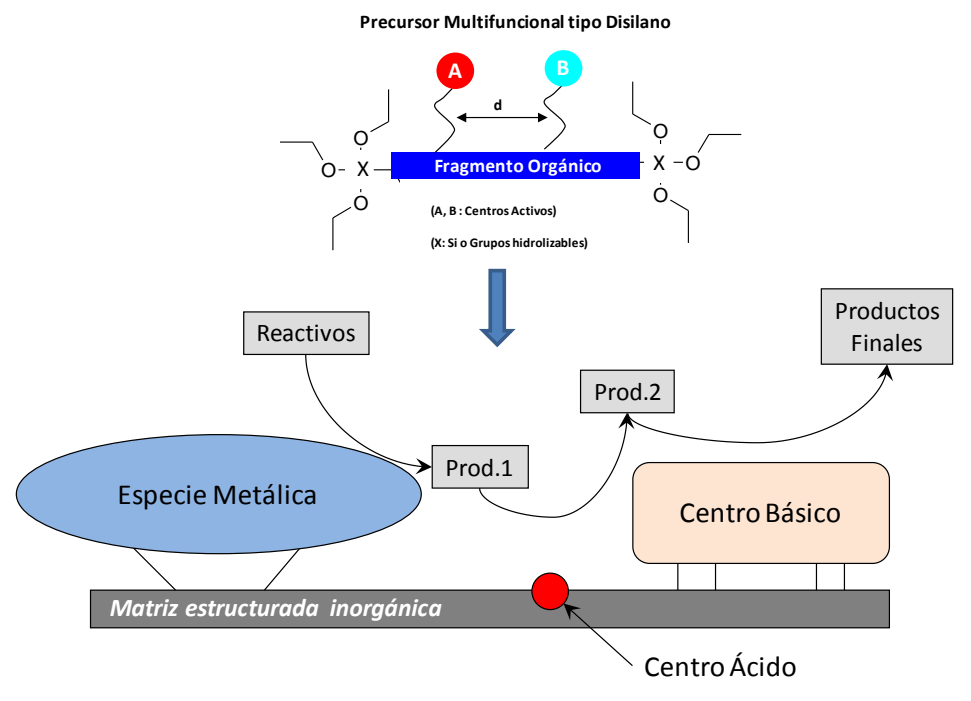

Figura 1.23. Representación esquemática de un catalizador híbrido multifuncional preparado a partir de un precursor tipo disilano que contiene varios centros activos. 


\section{Referencias bibliográficas}

[1] G. Kickelbick, Hybrid Materials. Synthesis, characterization and applications. Ed. G. Kickelbick. pp. 1-48. Weinheim, German. Wiley-VCH, 2007.

[2] a)G. Ferey, Chemical Society Reviews 2008, 37, 191; b)P. Van Der Voort, C. Vercaemst, D. Schaubroeck, F. Verpoort, Physical Chemistry Chemical Physics 2008, 10, 347; c)S. Fujita, S. Inagaki, Chemistry of Materials 2008, 20, 891.

[3] M. P. Kapoor, A. K. Sinha, S. Seelan, S. Inagaki, S. Tsubota, H. Yoshida, M. Haruta, Chemical Communications 2002, 2902.

[4] D. J. Collins, H.-C. Zhou, Journal of Materials Chemistry 2007, 17, 3154.

[5] O. Dag, C. Yoshina-Ishii, T. Asefa, M. J. MacLachlan, H. Grondey, N. Coombs, G. A. Ozin, Advanced Functional Materials 2001, 11, 213.

[6] K. J. Shea, D. A. Loy, Chemistry of Materials 2001, 13, 3306.

[7] B. V. Harbuzaru, A. Corma, F. Rey, P. Atienzar, J. L. Jordá, H. García, D. Ananias, L. D. Carlos, J. Rocha, Angewandte Chemie International Edition 2008, 47, 1080.

[8] H. Jiang, A. K. Kakkar, Journal of the American Chemical Society 1999, 121, 3657.

[9] C. Sanchez, F. Ribot, New J. Chem. 1994, 18, 1007.

[10] C. Sanchez, B. Julian, P. Belleville, M. Popall, Journal of Materials Chemistry 2005, 15, 3559.

[11] A. Corma, H. Garcia, European Journal of Inorganic Chemistry 2004, 2004, 1143.

[12] C. J. Blinker, G. W. Scherrer, The physics and chemistry of sol-gel processing. Sol-Gel Science. Ed. C. J. Blinker. San Diego, USA. Academic Press, 1990.

[13] P. A. Agaskar, Inorganic Chemistry 1991, 30, 2707. 4606.

[15] H. G.J, Journal of Catalysis 1985, 96, 292.

[16] G. Budroni, A. Corma, Angewandte Chemie International Edition 2006, 45, 3328.

[17] T. J. Pinnavaia, Science 1983, 220, 365.

[18] A. P. Wight, M. E. Davis, Chemical Reviews 2002, 102, 3589.

[19] L. A. Levine, M. E. Williams, Current Opinion in Chemical Biology 2009, 13, 669.

[20] A. Hirsch, Angewandte Chemie International Edition 2002, 41, 1853.

[21] S. Yang, X. Feng, L. Wang, K. Tang, J. Maier, K. Müllen, Angewandte Chemie International Edition 2010, 49, 4795. 
[22] D. A. Loy, K. J. Shea, Chemical Reviews 1995, 95, 1431.

[23] K. J. Shea, D. A. Loy, Accounts of Chemical Research 2001, 34, 707.

[24] K. J. Shea, D. A. Loy, O. Webster, Journal of the American Chemical Society 1992, 114, 6700.

[25] R. J. P. Corriu, Angewandte Chemie International Edition 2000, 39, 1376.

[26] K. J. Shea, G. J. Stoddard, D. M. Shavelle, F. Wakui, R. M. Choate, Macromolecules 1990, 23, 4497.

[27] C. Sanchez, G. J. d. A. A. Soler-Illia, F. Ribot, T. Lalot, C. R. Mayer, V. Cabuil, Chemistry of Materials 2001, 13, 3061.

[28] D. Mochizuki, S. Kowata, K. Kuroda, Chemistry of Materials 2006, 18, 5223.

[29] R. J. P. Corriu, A. Mehdi, C. Reye, Journal of Materials Chemistry 2005, 15, 4285.

[30] E. Lindner, M. Kemmler, H. A. Mayer, P. Wegner, Journal of the American Chemical Society 1994, 116, 348.

[31] F. Ben, B. Boury, R. J. P. Corriu, V. Le Strat, Chemistry of Materials 2000, $12,3249$.

[32] F. Hoffmann, M. Cornelius, J. Morell, M. Fröba, Angewandte Chemie International Edition 2006, 45, 3216.

[33] K. Yamamoto, Y. Sakata, Y. Nohara, Y. Takahashi, T. Tatsumi, Science 2003, 300, 470.

[34] R. A. Vaia, R. K. Teukolsky, E. P. Giannelis, Chemistry of Materials 1994, 6, 1017.

[35] J. Lee, O. K. Farha, J. Roberts, K. A. Scheidt, S. T. Nguyen, J. T. Hupp, Chemical Society Reviews 2009, 38, 1450.

[36] a)M. Eddaoudi, D. B. Moler, H. Li, B. Chen, T. M. Reineke, M. O'Keeffe, O. M. Yaghi, Accounts of Chemical Research 2001, 34, 319; b)S. L. James, Chemical Society Reviews 2003, 32, 276.

[37] L.-G. Qiu, T. Xu, Z.-Q. Li, W. Wang, Y. Wu, X. Jiang, X.-Y. Tian, L.-D. Zhang, Angewandte Chemie International Edition 2008, 47, 9487.

[38] S. Natarajan, P. Mahata, Chemical Society Reviews 2009, 38, 2304.

[39] F. Millange, C. Serre, J. Marrot, N. Gardant, F. Pelle, G. Ferey, Journal of Materials Chemistry 2004, 14, 642.

[40] O. M. Yaghi, M. O'Keeffe, N. W. Ockwig, H. K. Chae, M. Eddaoudi, J. Kim, Nature 2003, 423, 705.

[41] M. J. MacLachlan, T. Asefa, G. A. Ozin, Chemistry - A European Journal 2000, 6, 2507.

[42] A. Mehdi, C. Reye, R. Corriu, Chemical Society Reviews 2011, 40, 563.

[43] I. Karatchevtseva, D. J. Cassidy, M. Wong Chi Man, D. R. G. Mitchell, J. V. Hanna, C. Carcel, C. Bied, J. J. E. Moreau, J. R. Bartlett, Advanced Functional Materials 2007, 17, 3926. 
[44] S. Inagaki, S. Guan, Y. Fukushima, T. Ohsuna, O. Terasaki, Journal of the American Chemical Society 1999, 121, 9611.

[45] T. Asefa, M. J. MacLachlan, N. Coombs, G. A. Ozin, Nature 1999, 402, 867.

[46] B. J. Melde, B. T. Holland, C. F. Blanford, A. Stein, Chemistry of Materials 1999, 11, 3302.

[47] K. Yamamoto, Y. Nohara, Y. Domon, Y. Takahashi, Y. Sakata, J. Plévert, T. Tatsumi, Chemistry of Materials 2005, 17, 3913.

[48] X. Zhang, K. J. Haxton, L. Ropartz, D. J. Cole-Hamilton, R. E. Morris, Journal of the Chemical Society, Dalton Transactions 2001, 3261.

[49] L. Zhang, H. C. L. Abbenhuis, Q. Yang, Y.-M. Wang, P. C. M. M. Magusin, B. Mezari, R. A. van Santen, C. Li, Angewandte Chemie International Edition 2007, 46, 5003.

[50] L. C.J, C. D. Andrews, R. E. Morris, in Studies in Surface Science and Catalysis, Vol. Volume 154, Part A (Eds.: I. M. C. E. van Steen, L. H. Callanan), Elsevier, 2004, pp. 133.

[51] T. J. Pinnavaia, Adv. Chem. Ser. 1995, 245, 283.

[52] H. Van Olphen, Cay colloid chemistry. New York, USA. John Wiley and Sons. 1963.

[53] N. I. Kovtyukhova, P. J. Ollivier, B. R. Martin, T. E. Mallouk, S. A. Chizhik, E. V. Buzaneva, A. D. Gorchinskiy, Chemistry of Materials 1999, 11, 771.

[54] Z. Liu, R. Ma, M. Osada, N. Iyi, Y. Ebina, K. Takada, T. Sasaki, Journal of the American Chemical Society 2006, 128, 4872.

[55] Y. J. He, G. S. Nivarthy, F. Eder, K. Seshan, J. A. Lercher, Microporous and Mesoporous Materials 1998, 25, 207.

[56] R. Ishii, Y. Shinohara, Journal of Materials Chemistry 2005, 15, 551.

[57] J. H. Clark, D. J. Macquarrie, Chemical Communications 1998, 853.

[58] M. P. Kapoor, S. Inagaki, Bulletin of the Chemical Society of Japan 2006, 79, 1463.

[59] A. Corma, Cat. Rev. 2004, 46, 369.

[60] a)A. Corma, H. Garcia, Topics in Catalysis 2008, 48, 8; b)E. Ruiz-Hitzky, J. M. Rojo, Nature 1980, 287, 28.

[61] G. Alberti, E. Giontella, S. Murcia-Mascarós, Inorganic Chemistry 1997, 36, 2844.

[62] M. Boronat, M. J. Climent, A. Corma, S. Iborra, R. Montón, M. J. Sabater, Chemistry - A European Journal 2010, 16, 1221.

[63] S. Inagaki, S. Guan, T. Ohsuna, O. Terasaki, Nature 2002, 416, 304.

[64] a)U. Diaz, T. Garcia, A. Velty, A. Corma, Journal of Materials Chemistry 2009, 19, 5970; b)R. J. P. Corriu, A. Mehdi, C. Reyé, C. Thieuleux, Chemistry of Materials 2003, 16, 159.

[65] M. J. Climent, A. Corma, S. Iborra, Chemical Reviews 2010, 111, 1072. 


\section{Capítulo 2}

OBJETIVOS 

A lo largo de la introducción, se ha mostrado como la utilización de disilanos (bridged silsesquioxanes) parece idónea para la preparación de materiales híbridos en los que se desee incorporar segmentos orgánicos formando parte de su entramado estructural. La presencia en dichas moléculas, $\left(\mathrm{R}^{\prime} \mathrm{O}\right)_{3} \mathrm{SiRSi}\left(\mathrm{OR}^{\prime}\right)_{3}$, de puentes orgánicos ya enlazados covalentemente con grupos siloxano, altamente reactivos, los convierte en precursores óptimos para trasladar la interacción entre unidades orgánicas e inorgánicas hasta la estructura final de los materiales en los que entran a formar parte. Es por ello que a lo largo de esta Tesis se pretende preparar diferentes tipos de materiales híbridos orgánicos-inorgánicos de Clase II a partir de disilanos específicos que actuarán como precursores en diferentes procesos de síntesis. En concreto, serán empleadas distintas metodologías para la generación de nuevas familias de sólidos de naturaleza híbrida, estudiándose tanto procesos de ensamblaje directo de unidades de estructura previamente obtenidas, como métodos directos de síntesis en los que algunos de los eslabones estructurales se forman in situ durante el proceso de preparación.

Teniendo en cuenta estas premisas previas, los objetivos principales que se pretenden conseguir en el estudio aquí presentado son los siguientes:

- Preparación de materiales híbridos laminares a través de procesos de pilarización. Para ello se emplearán precursores conocidos, tales como silicatos y precursores zeolíticos laminares, compuestos por láminas inorgánicas individuales entre las cuales se prentende intercalar, a modo de pilar, disilanos específicos. Con este método, se podrían obtener materiales de elevada accesibilidad (micro y/o mesoporosos) en los que se conjugasen los centros activos presentes en las láminas inorgánicas con los grupos funcionales incluidos en los fragmentos orgánicos situados y estabilizados en el espacio interlaminar.

- Preparación de materiales mesoporosos orgánicos-inorgánicos a través de procesos sol-gel en medio fluoruro, utilizando disilanos como precursores organosilíceos. Con ello, se pretende indagar en una ruta de síntesis poco explorada hasta el momento, 
para la generación de materiales híbridos en los que no se emplean ADEs en condiciones suaves de síntesis ( $\mathrm{pHs}$ cercanos a la neutralidad y temperaturas próximas a la ambiente). La utilización de disilanos con fragmentos orgánicos que contienen diferentes tipos de grupos funcionales, permitiría obtener materiales híbridos de elevada superficie y con centros activos específicos.

- Preparación de materiales mesoporosos orgánicos-inorgánicos ordenados, a través de procesos micelares por el ensamblaje directo de disilanos con siloxanos poliédricos (POSS). En este caso, la combinación de dos tipos de unidades de estructura, previamente formadas, las cuales ya han sido empleadas con éxito de manera independiente para la obtención de materiales organizados, podría ser explorada para la preparación de materiales mesoporosos homogéneos y de elevada estabilidad, con la presencia de grupos orgánicos funcionales insertados en su entramado estructural.

- Por último, se pretende mostrar la aplicabilidad de los materiales híbridos obtenidos al evaluar su actividad catalítica en diferentes procesos de reacción.

En definitiva, estos objetivos individuales se podrían englobar en uno mayor que se resumiría en la obtención de nuevas familias de materiales híbridos funcionales con distintos tipos de estructuración a partir del empleo de disilanos específicos. Todo ello, con el fin de ampliar y avanzar en el conocimiento de un área en plena expansión como es la de los sólidos orgánicos-inorgánicos (Figura 1.16., Capítulo 1). 


\section{Capítulo 3}

\section{MATERIALES HÍBRIDOS}

\section{LAMINARES}

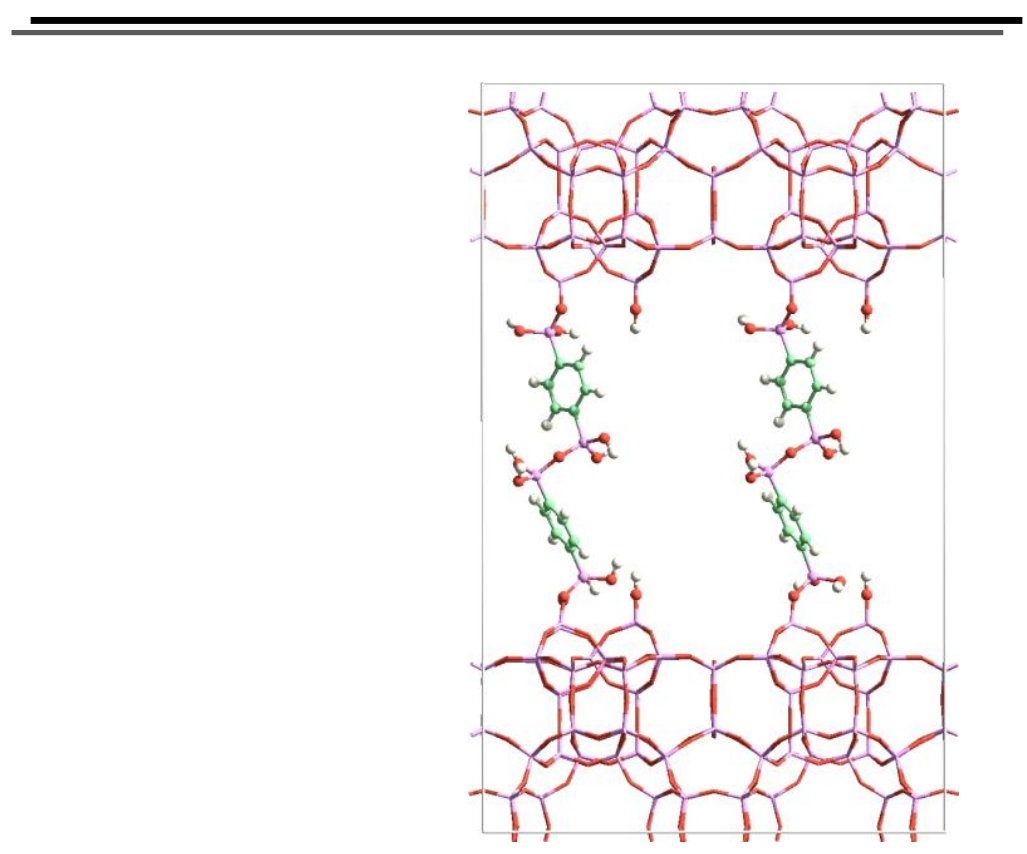



La preparación de materiales híbridos a partir de precursores laminares inorgánicos es una posibilidad viable que surge de la versatilidad que ofrecen este tipo de sólidos compuestos por láminas ordenadas. Tal y como se mostrará en la parte introductoria siguiente, la capacidad que tienen dichos precursores laminares para modificar su espaciado basal por medio de procesos de intercambio, hinchamiento, intercalación o exfoliación, los convierte en candidatos idóneos para ser la base de nuevos materiales híbridos multifuncionales. Las posibilidades que a priori poseen para alojar covalentemente en su espacio interlaminar moléculas de disilano a modo de pilares estructurales, permitiría tanto la apertura de galerías micro o mesoporosas adicionales situadas entre las láminas inorgánicas, así como la incorporación de funciones activas presentes en los propios fragmentos orgánicos intercalados. Todo ello, tendría como consecuencia la obtención de sólidos orgánicos-inorgánicos de alta accesibilidad, con un sistema poroso jerarquizado, conteniendo, al mismo tiempo varios centros activos distribuidos homogéneamente y estabilizados, presentes tanto en las láminas inorgánicas, inicialmente empleadas, como en los pilares orgánicos posteriormente introducidos.

A lo largo de este capítulo, serán obtenidos diferentes tipos de materiales híbridos laminares, utilizando silicatos y precursores zeolíticos laminares como punto de partida, junto a diferentes disilanos con funcionalidades diversas, con el objetivo final de preparar nuevos sólidos orgánicos-inorgánicos estables de Clase II que podrían ser empleados como catalizadores multifuncionales para llevar a cabo reacciones consecutivas o en cascada. 


\subsection{Estado del arte}

Durante el presente apartado introductorio se van a considerar diferentes precursores inorgánicos con la característica común, en todos ellos, de presentar una organización laminar. En función de la naturaleza y las propiedades de dichos precursores, se ilustrará como se obtienen, a partir de ellos, destacados materiales híbridos laminares descritos en la bibliografía.

\subsubsection{Arcillas}

Las arcillas ocupan un lugar preferente dentro de la familia de los precursores laminares, debido a su versatilidad para estabilizar en su espaciado interlaminar diferentes compuestos a través de procesos de intercalación, habiendo por ello recibido mucha atención desde hace décadas. En general, las arcillas se definen ${ }^{[1]}$, desde un punto de vista químico, como silicatos de aluminio/magnesio hidratados, pudiendo incluir en su composición otros elementos como hierro, calcio, sodio o potasio, conservando su organización laminar. Estructuralmente, los materiales arcillosos están formados por láminas individuales unidas entre sí, estando cada lámina constituida por la asociación de capas continuas formadas por tetraedros de $\mathrm{SiO}_{4} \mathrm{u}$ octaedros de $\mathrm{AlO}_{6} / \mathrm{MgO}_{6}$ (Figura 3.1.).

$$
\text { Tetraedro } \mathrm{SiO}_{4} \quad \text { Octaedro } \mathrm{AlO}_{6} / \mathrm{MgO}_{6}
$$

Unidades

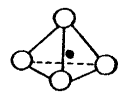

Capas

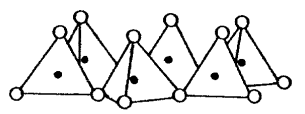

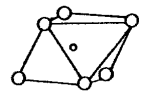

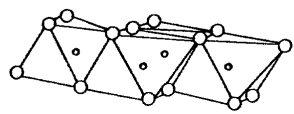

Figura 3.1. Unidades estructurales de las arcillas.

Las arcillas se pueden clasificar en grupos o familias dependiendo de las diferentes asociaciones que se establecen entre las capas tetraédricas y octaédricas, dando lugar a diferentes tipos de láminas que caracterizan a cada mineral. Por ejemplo, las arcillas del grupo de las esmectitas (montmorillonita, nontronita, beidelita, saponita, etc.) son las más conocidas y presentan una lámina de tipo 2:1, formada por dos capas 
tetraédricas y una central octaédrica, unidas entre sí a través de átomos de oxígeno comunes a ambas (Figura 3.2.).

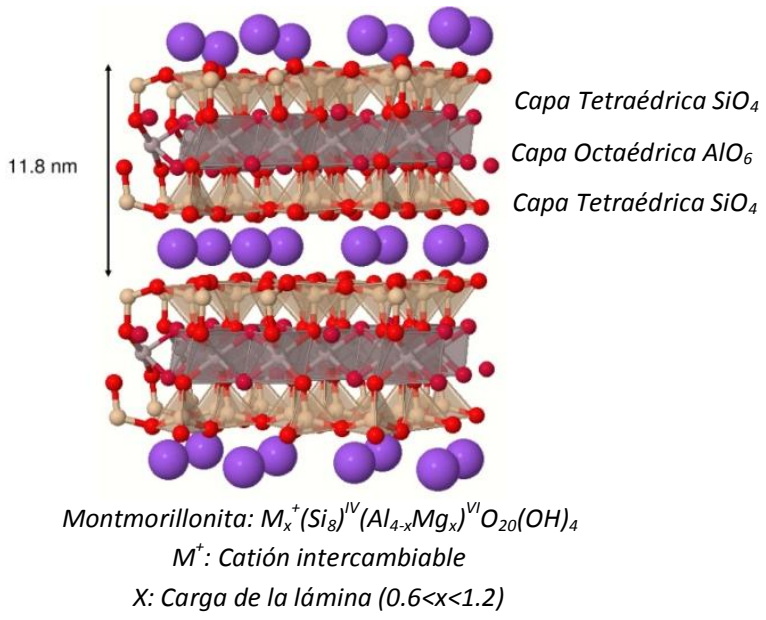

Figura 3.2. Estructura tipo 2:1, correspondiente a la montmorillonita, arcilla perteneciente al grupo de las esmectitas.

Las láminas se extienden a lo largo de los ejes $a$ y $b$, apilándose de forma ordenada perpendicularmente el eje $c$, las cuales se caracterizan por poseer una deficiencia de carga positiva ${ }^{[2]}$ que es compensada por cationes intercambiables, normalmente sodio, situados en el espacio interlaminar. Dichos cationes son fácilmente hidratados en ambientes húmedos, provocando un aumento en el espaciado basal con respecto a una arcilla anhidra. Debido al hinchamiento interlaminar producido ${ }^{[3]}$, es posible obtener arcillas con diferentes espaciados entre sus láminas, dependiendo este efecto de la propia naturaleza de los cationes intercambiados ${ }^{[4]}$, la cantidad de agua presente y la existencia de otras especies polares en el medio ${ }^{[5]}$.

Se ha constatado que las arcillas son materiales que presentan problemas de accesibilidad cuando son empleadas como catalizadores en reacciones en las que intervienen moléculas de gran tamaño, pero debido a su facilidad de hinchamiento se pueden obtener materiales pilareados que exhiben una mayor separación entre las láminas, representando este hecho una gran ventaja al permitir que tanto la superficie 
interlaminar como los centros activos presentes en dicha región estén disponibles para las moléculas de reactantes de elevado volumen.

Por otra parte, el proceso de pilarización de las arcillas, consiste en un proceso de intercambio iónico en el que los cationes interlaminares son sustituidos por otros de gran tamaño que mantienen separadas las láminas de manera permanente (Figura 3.3.), actuando a modo de pilares. Dichos pilares poseen, además, grupos funcionales que dotan a las arcillas de propiedades catalíticas adicionales a las intrínsecas a cada lámina $\operatorname{arcillosa}^{[6]}$.

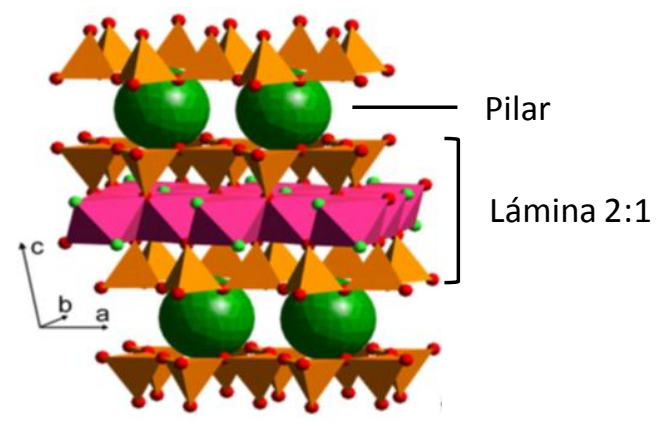

Figura 3.3. Estructura pilareada de una arcilla tipo 2:1.

En este caso, los agentes pilareantes más empleados son cationes organometálicos y polihidroxicationes ya que son fáciles de obtener y permiten un control adecuado sobre sus condiciones de preparación. Los más utilizados han sido diferentes óxidos de zirconio ${ }^{[7]}$, cromo $^{[8]}$, hierro ${ }^{[9]}$, titanio $^{[10]}$, silicio ${ }^{[11]}$ y aluminio (ión de Keggin, $\left.\mathrm{Al}_{13}\right)^{[12]}$ (Figura 3.4.). Tras el proceso de pilarización es posible obtener materiales arcillosos con una distancia interlaminar comprendida entre 1.8 y $2.8 \mathrm{~nm}$ con superficies específicas BET comprendidas entre 200 y $500 \mathrm{~m}^{2} \mathrm{~g}^{-1}$, presentando una elevada estabilidad térmica ${ }^{[13]}$, así como una apreciable acidez Brönsted y Lewis. 


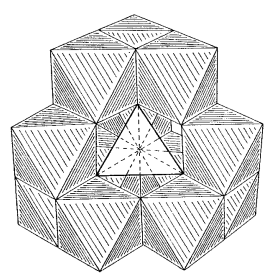

Ión de Keggin $\left[\mathrm{Al}_{13} \mathrm{O}_{4}(\mathrm{OH})_{24} \cdot 12 \mathrm{H}_{2} \mathrm{O}\right]^{+7}$

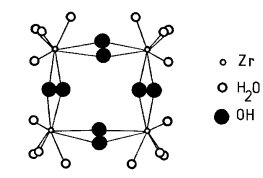

Ión Circonilo $\left[\left(\mathrm{Zr}(\mathrm{OH})_{2} \cdot 4 \mathrm{H}_{2} \mathrm{O}\right)_{4}\right]^{8+}$

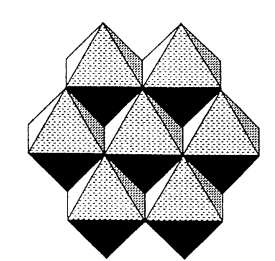

Polímero de Óxido de Titanio $\mathrm{TiO}_{x}(\mathrm{OH})_{2 x}(x=0,1,2)$

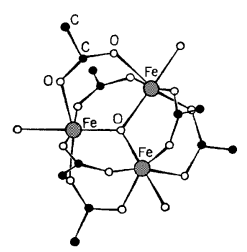

Ión Acetato de Hierro $\left[\mathrm{Fe}_{3} \mathrm{O}\left(\mathrm{OCOCH}_{3}\right)_{6} .3 \mathrm{H}_{2} \mathrm{O}\right]^{+}$

Figura 3.4. Diferentes agentes pilareantes empleados con arcillas como precursores inorgánicos.

Tanto los procesos de hinchamiento como pilarización, antes descritos, se han empleado para generar materiales híbridos que presentan interesantes aplicaciones catalíticas y nanotecnológicas ${ }^{[14]}$. Para ello, se han seguido varias rutas para modificar las arcillas como son la adsorción de polímeros orgánicos, el intercambio con cationes orgánicos, la fijación de aniones orgánicos principalmente en los bordes o defectos de las láminas de las arcillas, el anclaje de moléculas orgánicas en la superficie laminar y los procesos de polimerización in situ llevados a cabo en la región interlaminar ${ }^{[15]}$.

Dentro de este grupo de materiales híbridos, cabe destacar la generación de catalizadores enantioselectivos por la intercalación en el espacio interlaminar de la montmorillonita de diferentes tipos de aminoácidos, como sería el caso del derivado catiónico de la prolina (Figura 3.5a), empleándose con éxito en reacciones de aldolización entre aldehídos y cetonas. Incluso, se obtuvieron mejores resultados con este tipo de catalizadores cuando, además del derivado de la prolina, se intercalaron en el espacio interlaminar alquilamonios de cadena larga. En este caso, se aumentaba el espaciado basal entre las láminas de montmorillonita, aumentando la accesibilidad hacia el 
organocatalizador intercalado, favoreciéndose de este modo el proceso catalítico (Figura 3.5.b) ${ }^{[16]}$.

(a)

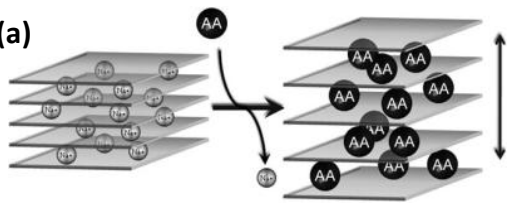

(b)

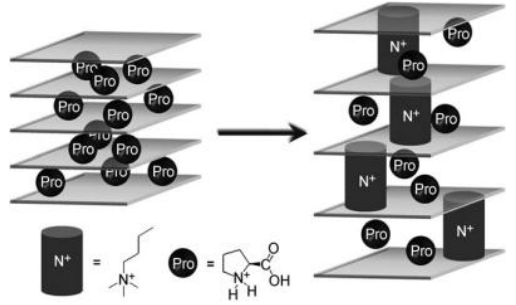

Figura 3.5. Intercalación de derivados de la prolina en la montmorillonita: (a) intercambio directo por $\mathrm{Na}^{+}$, (b) incorporación adicional de moléculas de alquilamonio en el espacio interlaminar (según referencia [16]).

Es importante destacar la preparación de nanocomposites orgánicos a partir de arcillas que exhiben una elevada estabilidad mecánica y térmica por la intercalación directa de polímeros en el espacio interlaminar. Otra ruta de síntesis para generar este tipo de materiales híbridos, sería la realización de procesos de polimerización in situ tras la intercalación de monómeros orgánicos entre las láminas de arcillas (Figura 3.6.) ${ }^{[14,17]}$. Los sólidos derivados de la montmorillonita generados con este método se han empleado con éxito como aditivos del nylon, aumentado su resistencia ${ }^{[18]}$.

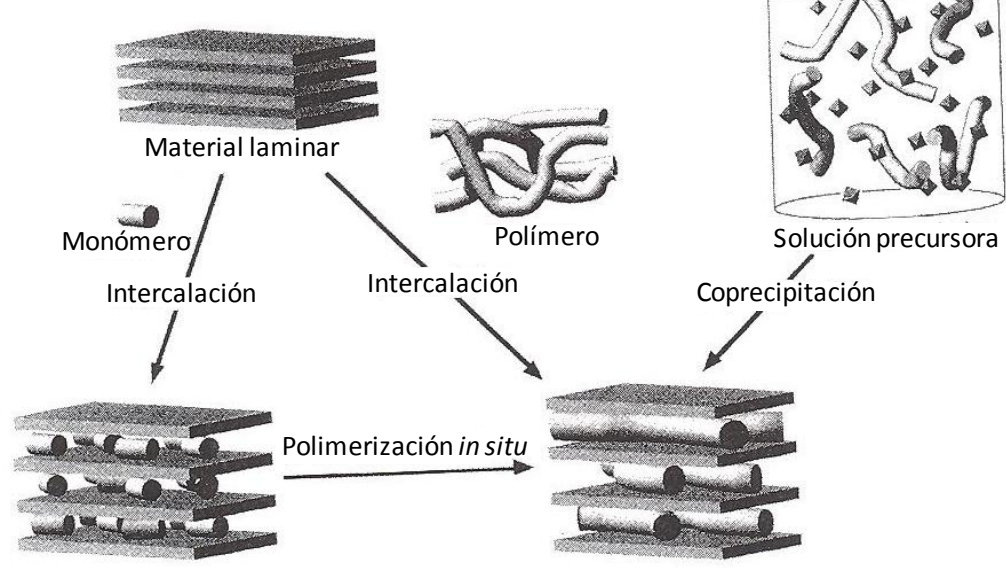

Figura 3.6. Representación esquemática del método de síntesis seguido para la obtención de nanocomposites poliméricos a partir de arcillas (referencias [14] y [17]). 


\subsubsection{Hidrotalcitas}

Las hidrotalcitas, también conocidas como hidróxidos dobles laminares (LDHs) ${ }^{[19]}$ o arcillas aniónicas, son minerales sintéticos que poseen estructuras similares a las arcillas, estando formadas por láminas individuales de polihidroxicationes bidimensionales que exhiben una deficiencia de carga negativa a nivel estructural, la cual es compensada por la presencia de aniones hidratados intercambiables situados en su espacio interlaminar (Figura 3.7.). En general, poseen una composición que viene dada por la fórmula:

$$
\left[\mathrm{M}_{1-\mathrm{x}}^{\prime \prime} \mathrm{M}_{\mathrm{x}}^{\prime \prime \prime}(\mathrm{OH})_{2}\right]\left[\mathrm{A}^{\mathrm{n}}\right]_{\mathrm{x} / \mathrm{n}} \cdot \mathrm{zH}_{2} \mathrm{O}
$$

donde $A^{n-}$ es una anión de carga negativa $n y, M^{\prime \prime}$ y $M^{\prime \prime \prime}$ son metales di y trivalentes respectivamente.

Las láminas de estos materiales están compuestas por cationes divalentes, generalmente $\mathrm{Mg}^{2+}$, coordinados octaédricamente a seis grupos $\mathrm{OH}$. Dichas unidades octaédricas comparten vértices con otros tres octaedros contiguos formando una lámina bidimensional que se extiende a lo largo de los ejes $a$ y $b$. Los iones divalentes se pueden sustituir isomórficamente por metales trivalentes $\left(\mathrm{Fe}^{3+}, \mathrm{Al}^{3+}\right.$, etc.), generándose un exceso de carga positiva que ha de ser compensada por aniones $\left(\mathrm{CO}_{3}{ }^{2-}, \mathrm{Cl}^{-}, \mathrm{OH}^{-}, \mathrm{NO}^{3-}\right.$, etc. $)$ que se sitúan en el espacio interlaminar. Dependiendo de la naturaleza tanto de los cationes $M^{\prime \prime}$ y $M^{\prime \prime \prime}$ como del anión $A^{n-}$, introducido en el espacio interlaminar, surgen un gran número de composiciones posibles para obtener materiales con estructura tipo hidrotalcita pero con propiedades diferentes ${ }^{[20],[21]}$.

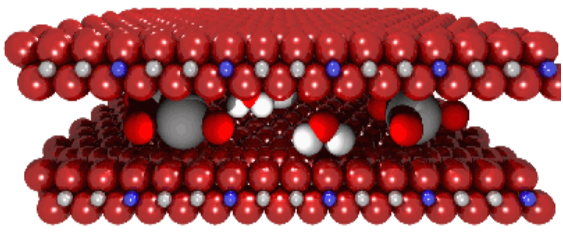

Red Tipo Hidrotalcita

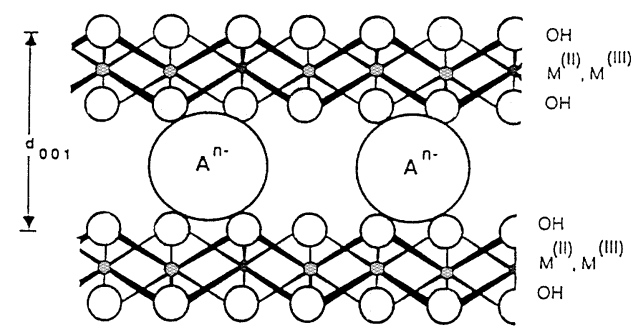

Esquema de la Red de Hidrotalcita

Figura 3.7. Estructura de un hidróxido doble laminar. 
Comparada con la elevada capacidad de intercambio iónico que presentan las acillas, este proceso en los hidróxidos dobles laminares es mucho más difícil debido al gran número de cargas presentes en la superficie de las láminas que hace que los materiales, una vez compensados por la intercalación de aniones interlaminares, sean muy estables y difíciles de modificar. Si a este hecho se suma la elevada selectividad que poseen hacia los aniones carbonato, hace más complicado que las hidrotalcitas sufran fenómenos de hinchamiento, pilarización, exfoliación o hibridación con moléculas o monómeros orgánicos.

No obstante, con el fin de preparar hidrotalcitas de elevada accesibilidad y con funcionalidades adicionales, se han utilizado los aniones polioxometalatos (POMs) con elevada carga como efectivos agentes de pilarización ${ }^{[22]}$. A diferencia de las arcillas, el proceso de pilarización por intercambio directo es complicado debido a que el hidróxido doble laminar es básico y los aniones POMs son ácidos, teniendo lugar reacciones de hidrólisis asociadas que originan materiales con una baja ordenación o que poseen varias fases cristalinas debido a la degradación parcial de las láminas bidimensionales. Por ello, se hace necesaria una etapa previa de hinchamiento para conseguir separar las láminas antes del proceso de pilarización. En dicha etapa se realiza un intercambio o solvatación con grandes aniones orgánicos (p-toluensulfonato, tereftalato, glicerol) para obtener un material pre-expandido y facilitar así la etapa posterior de pilarización. En concreto, algunos de los POMs más comunes utilizados son iones Keggin del tipo $\alpha-\left[\mathrm{xM}_{12} \mathrm{O}_{40}\right]^{\mathrm{n}-}$ con $n \geq 6^{[23]}$, complejos de ftalocianina como el tetrasulfonato de cobalto II ([CoPcTs $\left.{ }^{4-}\right)^{[24]}$, decavanadatos $\left(\left[\mathrm{V}_{10} \mathrm{O}_{28}\right]^{6-}\right)^{[25]}$ o molidabtos $\left(\left[\mathrm{Mo}_{7} \mathrm{O}_{24}\right]^{6-}\right)$ (Figura 3.8.).

En concreto, los hidróxidos dobles laminares pilareados poseen espaciados basales que varían entre 1.2 y $2.3 \mathrm{~nm}$ con áreas superficiales entre 30 y $160 \mathrm{~m}^{2} / \mathrm{g}$, siendo su baja estabilidad térmica el mayor inconveniente que presentan ${ }^{[26]}$ ya que descomponen por debajo de $250^{\circ} \mathrm{C}$, generando óxidos mixtos amorfos. Además, los materiales pilareados presentan la desventaja de que una vez perdida la estructura laminar al ser sometidos a altas temperaturas, no es posible reconstruirla por simple rehidratación (efecto memoria), algo que sí ocurre en los hidróxidos dobles laminares que no están pilareados $^{[27]}$. 


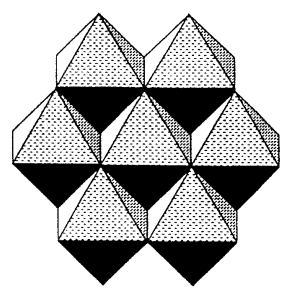

Anión Decavanadato $\left[\mathrm{V}_{10} \mathrm{O}_{28}\right]^{6-}$

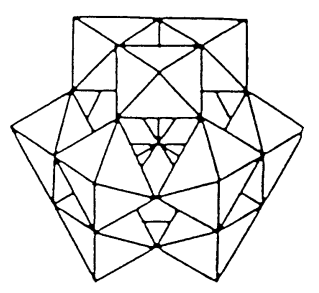

Ión de Keggin $\alpha-\left[X M_{12} O_{40}\right]^{n-}$

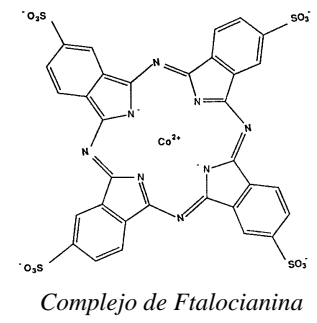

$[\mathrm{CoPcTs}]^{4-}$

Figura 3.8. Agentes de pilarización más comunes empleados con hidrotalcitas como precursores laminares.

Los procesos de hinchamiento y pilarización, aplicados con hidróxidos dobles laminares, también se han empleado para preparar materiales híbridos de elevada accesibilidad por la intercalación de diferentes aniones orgánicos, monómeros o polímeros en el espacio interlaminar ${ }^{[28]}$. Es el caso de los sólidos obtenidos por la pilarización de hidrotalcitas con aniones del tipo dodecilbencenosulfato ${ }^{[29]}$, tartrato o succinato $^{[30]}$, los cuales son empleados en procesos de adsorción para la eliminación de residuos orgánicos.

Del mismo modo, se han introducido con éxito aniones poliméricos, tales como poli(oxietilensulfato) o poli(sodio-estireno-sulfonato) para generar sólidos tipo composite o films que son utilizados como estabilizadores de redes poliméricas mejorando sus propiedades mecánicas y térmicas o, incluso, con aplicaciones nanotecnológicas al aprovechar sus interesantes propiedades magnético-ópticas (Figura 3.9. $)^{[31]}$. En estos ejemplos, es frecuente que sea necesaria una etapa de pre-hinchamiento, produciéndose una deslaminación parcial de los materiales tras el proceso de intercalación. 


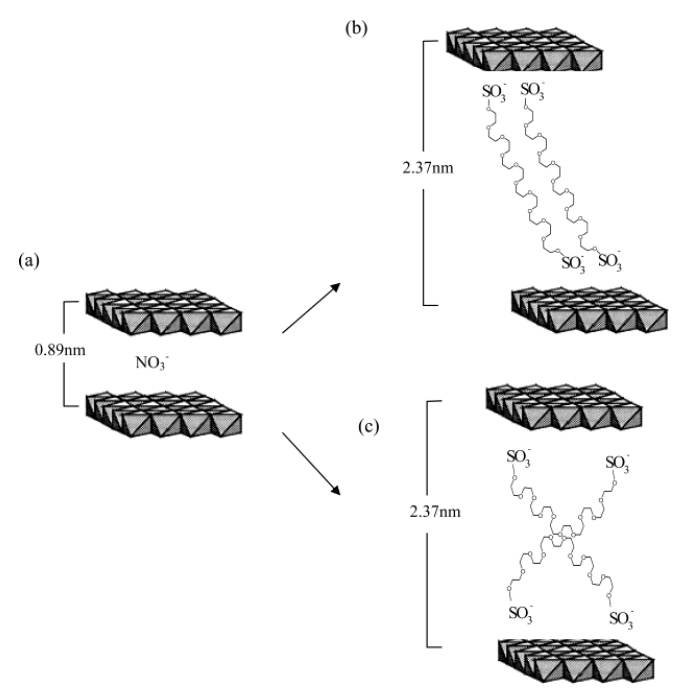

Figura 3.9. Ilustración esquemática de materiales híbridos preparados a partir de hidrotalcitas $\mathrm{Mg} / \mathrm{Al}$ con nitratos intercambiables (a), por la intercalación de aniones poli(oxietilensulfato) en forma de monocapa (b) o bicapa (c) en la región interlaminar (siguiendo referencia [31b]).

Dentro del campo de la catálisis, se han sintetizado materiales orgánicosinorgánicos, como potenciales catalizadores, por la intercalación y estabilización tanto de aminoácidos (glicina, fenilalanina o histidina) como de porfirinas (Figura 3.10.) ${ }^{[32]}$. En ambos casos, los materiales finales fueron deslaminados posteriormente al formar suspensiones coloidales, empleando formamida como disolvente.

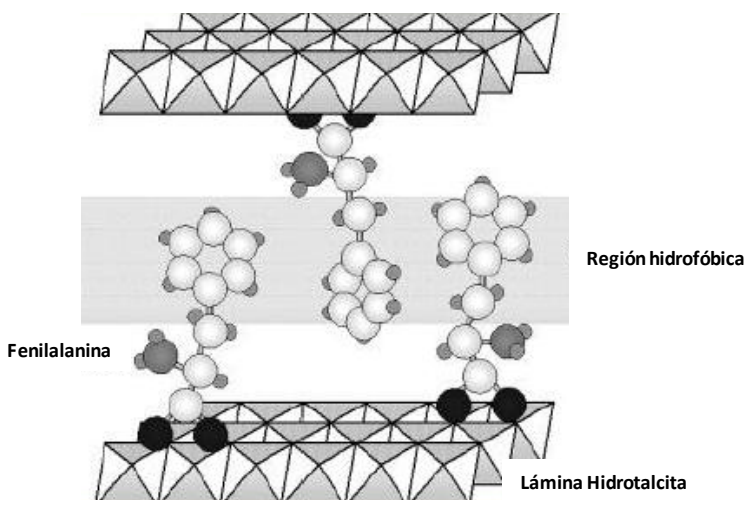

Figura 3.10. Esquema del material híbrido basado en la intercalación de fenilalanina entre láminas ordenadas de hidróxidos dobles laminares (siguiendo referencia [32a]). 


\subsubsection{Silicatos laminares}

La familia de los silicatos laminares es conocida desde hace varias décadas, estando basados en sales de ácidos silícicos que poseen una estructura laminar ${ }^{[33]}$. Normalmente, los iones de sodio hidratado, situados en el espacio interlaminar, favorecen los procesos de intercambio catiónico que tienden a incrementar la accesibilidad de estos materiales laminares hacia moléculas voluminosas de reactantes. La mayoría de estos silicatos existe en la naturaleza, así Eugster ${ }^{[34]}$, en 1967, fue el primero en descubrir la Magadiita y Kenyaita en los lechos del Lago Magadi en Kenya, aunque ya había sido sintetizada en forma sódica en el laboratorio varios años antes por MCulloch, en $1952^{[35]}$.

Los ácidos silícicos laminares poseen una estructura formada por capas de tetraedros de óxido de silicio condensadas unas sobre otras, sin presentar capas octaédricas como ocurre en las arcillas. Existen multitud de ácidos silícicos laminares ${ }^{[36]}$, entre los más conocidos se encuentran la Makatita, Illerita, Magadiita, Kenyaita, Neokita, Okenita, Dehayelita, Mcdonalita o Rhodesita. No obstante, únicamente se han estudiado en profundidad cinco ácidos silícicos naturales ${ }^{[37],[38]}$, cuyas composiciones se detallan en la Tabla 3.1.

Tabla 3.1. Composición de los cinco ácidos silícicos naturales más conocidos en la actualidad.

\begin{tabular}{cc}
\hline Silicato & Fórmula $^{[39]}$ \\
\hline Makatita & $\mathrm{Na}_{2} \mathrm{O} \cdot 4 \mathrm{SiO}_{2} \cdot 5 \mathrm{H}_{2} \mathrm{O}$ \\
Kanemita & $\mathrm{Na}_{2} \mathrm{O} \cdot 4 \mathrm{SiO}_{2} \cdot 7 \mathrm{H}_{2} \mathrm{O}$ \\
Illerita & $\mathrm{Na}_{2} \mathrm{O} \cdot 8 \mathrm{SiO}_{2} \cdot 9 \mathrm{H}_{2} \mathrm{O}$ \\
Magadiita & $\mathrm{Na}_{2} \mathrm{O} \cdot 14 \mathrm{SiO}_{2} \cdot 10 \mathrm{H}_{2} \mathrm{O}$ \\
Kenyaita & $\mathrm{Na}_{2} \mathrm{O} \cdot 22 \mathrm{SiO}_{2} \cdot 10 \mathrm{H}_{2} \mathrm{O}$ \\
\hline
\end{tabular}

Estos ácidos silícicos naturales también pueden ser obtenidos artificialmente mediante síntesis hidrotermal. Además, otros muchos se han preparado a escala de laboratorio, sin que se encuentren físicamente en la naturaleza ${ }^{[37 a, 37 c, 40]}$, tales como la Silanita ${ }^{[41]}$, Octosilicato ${ }^{[42]}$ (forma sintética de la Illerita natural) y el material Eu-19 ${ }^{[43]}$. 
Por otra parte, la síntesis hidrotermal de estos materiales, bien sean los naturales obtenidos artificialmente o los puramente sintéticos, se lleva a cabo en medio alcalino con el sistema ternario $\mathrm{Na}_{2} \mathrm{O} / \mathrm{SiO}_{2} / \mathrm{H}_{2} \mathrm{O}^{[44]}$. Por ejemplo, en la Figura 3.11. se muestra la disposición laminar de la Magadiita, Kenyaita e Illerita hidratada.

(a)

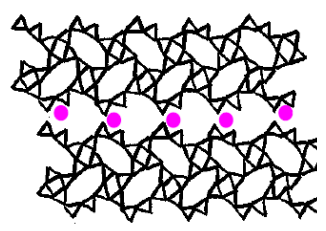

(b)

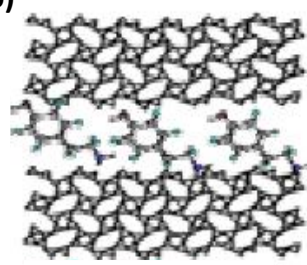

(c)

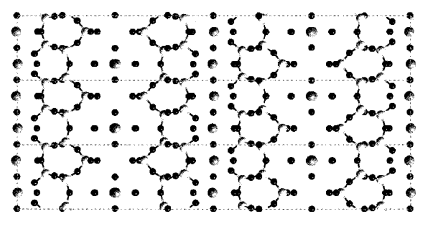

Figura 3.11. Estructuras de diferentes silicatos laminares: (a) Magadiita, (b) Kenyaita e (c) Illerita.

En general, los silicatos laminares presentan la particularidad de que pueden ser transformados fácilmente en su forma ácida por intercambio del sodio interlaminar por protones, siendo este hecho un paso necesario para la obtención de grupos silanoles en la superficie de las láminas. La presencia de estos grupos Si-OH es determinante para llevar a cabo el hinchamiento de estos precursores laminares, facilitado por la transferencia del protón de los silanoles superficiales a las moléculas de amina que actúan como agentes hinchantes. La posterior intercalación de diferentes tipos de policationes que actúan como pilares, genera la formación de materiales pilareados de elevada accesibilidad y altamente uniformes (Figura 3.12.) ${ }^{[45]}$.

Los silicatos laminares pilareados así preparados poseen poros que, de manera general, varían desde 2.1 hasta $3.6 \mathrm{~nm}$, exhibiendo áreas superficiales de hasta $1150 \mathrm{~m}^{2} \mathrm{~g}$ ${ }^{1[46]}$. Estos materiales pueden ser pilareados con especies que contienen aluminio o bien se pueden sustituir átomos de silicio por aluminio en el interior de la red de las láminas, introduciendo funcionalidades adicionales en los mismos ${ }^{[47]}$. 


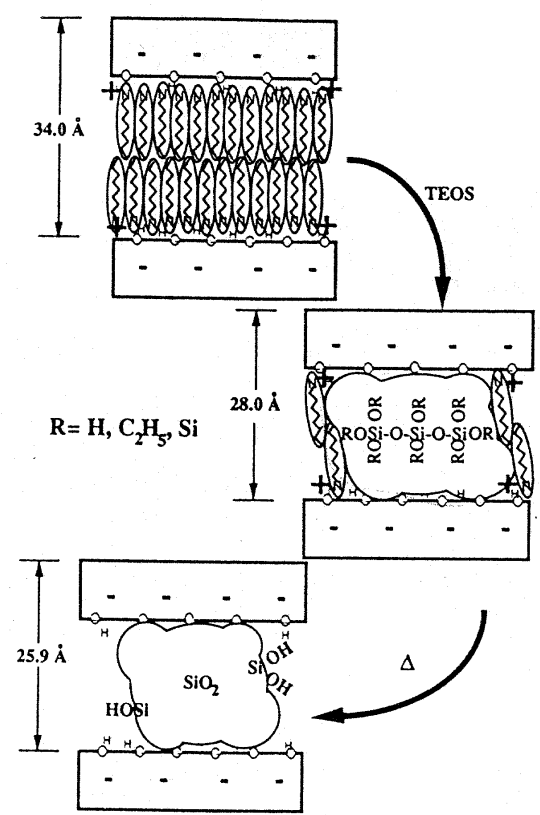

Figura 3.12. Esquema del proceso de pilarización empleando TEOS como agente de intercalación y silicatos laminares previamente hinchados.

Partiendo de estos conocimientos previos relacionados con el hinchamiento y la pilarización de los silicatos laminares, Rojo y col. ${ }^{[48]}$, en 1980, utilizaron Magadiita como precursor para generar materiales laminares híbridos al intercalar alquilmonosilanos con ayuda de disolventes polares como DMSO (Figura 3.13.). Este avance sirvió como punto de partida para generar nuevas redes orgánicas-inorgánicas bi o tridimensionales a partir de ácidos silícicos por sililación directa de las láminas inorgánicas del precursor con monosilanos específicos, preferentemente del tipo $\mathrm{ROSiCl}_{3}$. La posterior hidrólisis y condensación de los grupos cloruro terminales, sirvieron para generar silicatos con nuevas cavidades generadas entre láminas silíceas (Figura 3.14.) ${ }^{[49]}$.

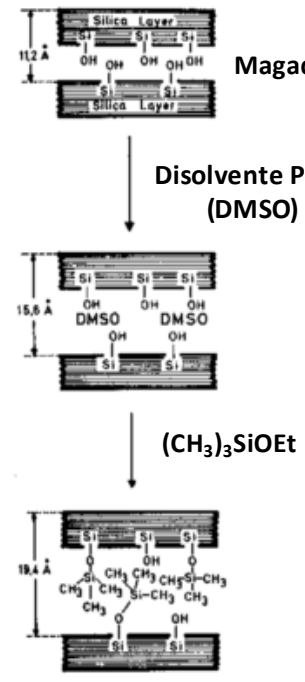

Figura 3.13. Anclaje de alquilmonosilanos en la Magadiita (siguiendo referencia [48]). 


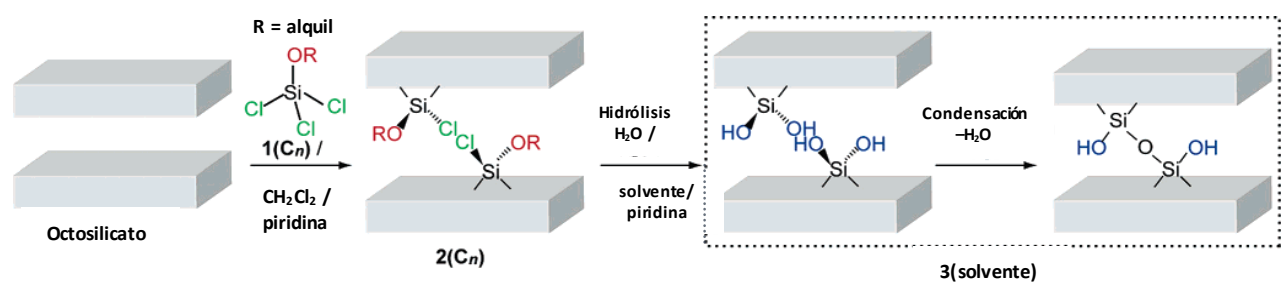

Figura 3.14. Generación de nuevas redes estructurales por el anclaje, hidrólisis y polimerización sucesivas de monosilanos partiendo de silicatos laminares como precursores (siguiendo referencia [49]).

(a)

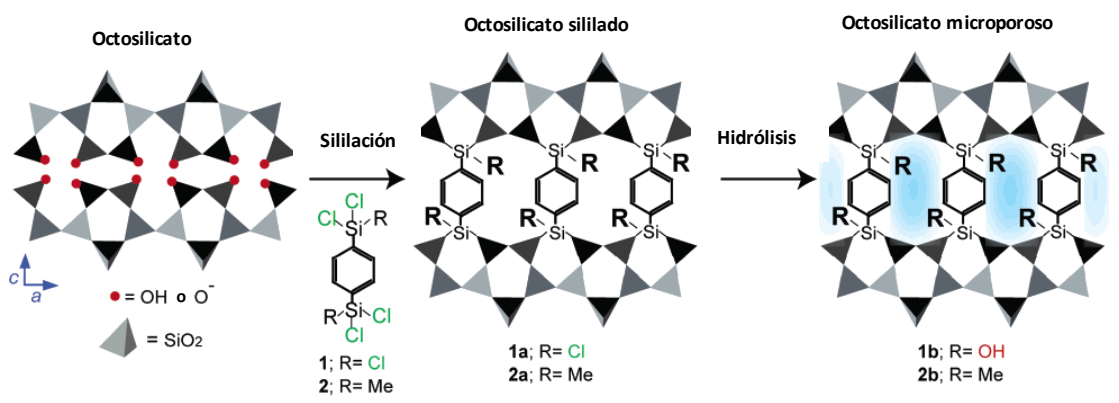

(b)
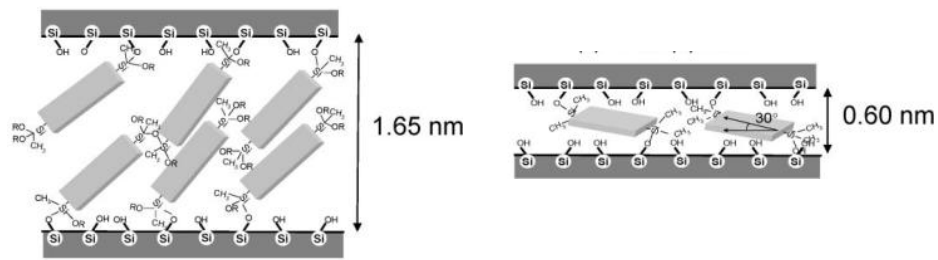

Figura 3.15. Materiales híbridos pilareados por inserción covalente de disilanos que contienen grupos arílicos a modo de puentes orgánicos utilizando como precursores: (a) Octosilicatos e (b) llerita (siguiendo referencias [50a] y [50b]).

Recientemente, en la literatura se ha descrito que en silicatos laminares, tales como llerita o distintos tipos de octosilicatos, se ha conseguido intercalar disilanos que presentan grupos fenilo o bifenilo a modo de puente orgánico, generando materiales híbridos pilareados. Sin embargo, las potenciales aplicaciones de estos materiales son reducidas, hasta el momento, ya que únicamente se han logrado intercalar grupos arílicos en el espacio interlaminar sin ninguna funcionalidad añadida. Además, exhiben una disposición irregular de los pilares orgánicos introducidos que se traduce en una 
distribución de la porosidad poco homogénea, acentuada por la polimerización observada entre disilanos que tiende a bloquear la región existente entre las láminas inorgánicas. Estos sólidos híbridos pilareados presentan una elevada contribución microporosa con áreas BET que oscilan en torno a $500 \mathrm{~m}^{2} \mathrm{~g}^{-1}$ (Figura 3.15.) ${ }^{[50]}$. A lo largo de este capítulo, se estudiará más en profundidad este tipo de materiales para conocer mejor sus propiedades, así como sus posibles aplicaciones catalíticas, buscando mejorar sus características texturales y físico-químicas.

\subsubsection{Titanatos laminares}

La obtención de nuevos titanatos estructurados es un campo en plena expansión en los últimos años debido a las interesantes aplicaciones catalíticas, sobre todo en procesos de epoxidación, que han mostrado diferentes materiales cristalinos que contienen titanio en su composición ${ }^{[51]}$. En este sentido, la preparación de titanosilicatos tridimensionales con una alta contribución porosa, tales como los materiales ETS-4 ${ }^{[52]} \mathrm{y}$ ETS-10 ${ }^{[53]}$, ha servido para conocer mejor el efecto que tiene, a nivel catalítico, la presencia de titanio en la red estructural de materiales organizados.

Dentro de esta familia de titanosilicatos, se han obtenido recientemente nuevos titanatos laminares que por su elevada capacidad de intercambio podrían ser susceptibles de ser modificados para generar materiales expandidos, pilareados o, incluso, deslaminados ${ }^{[54]}$. En función de su composición, se pueden encontrar titanatos laminares alcalinos $\left(\mathrm{K}_{2} \mathrm{Ti}_{4} \mathrm{O}_{9} \text {, JDF-L1: } \mathrm{Na}_{4} \mathrm{Ti}_{2} \mathrm{Si}_{8} \mathrm{O}_{22} \cdot 4 \mathrm{H}_{2} \mathrm{O}\right)^{[55]}$ o metal sustituidos $\left(\mathrm{K}_{0.8} \mathrm{Fe}_{0.8} \mathrm{Ti}_{1.2} \mathrm{O}_{4}\right)^{[56]}$. En especial, el material JDF-L1, también denominado AM-1 o NTS ${ }^{[57]}$, ha recibido más atención debido a que en su estructura, los átomos de titanio (IV) se encuentran pentacoordinados formando unidades piramidales de base cuadrada $\mathrm{TiO}_{5}$, estando cada uno de los vértices de esta base enlazados a su vez con tetraedros de sílice, $\mathrm{SiO}_{4}$, conformando de este modo láminas continuas individuales separadas por iones $\mathrm{Na}^{+}$hidratados situados en la región interlaminar (Figura 3.16. ${ }^{[58]}$. Esta posición estructural del titanio es ciertamente novedosa ya que, en general, la gran mayoría de titanosilicatos están constituidos por unidades tetraédricas y octaédricas de $\mathrm{SiO}_{4}$ y $\mathrm{TiO}_{6}$, respectivamente. 

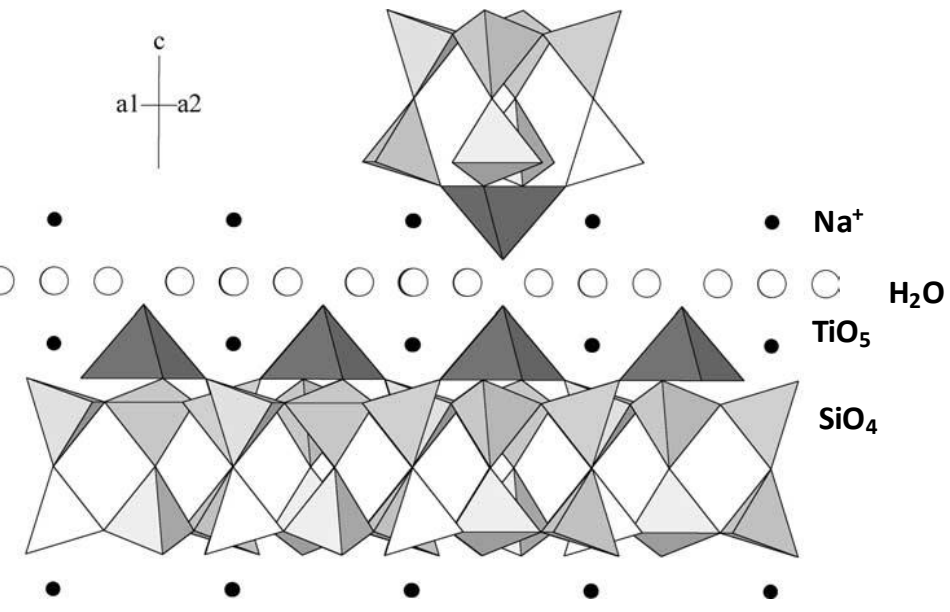

Figura 3.16. Estructura del titanato laminar JDF-L1 (siguiendo referencia [55a]).

En el caso del material JDF-L1, dada la elevada carga interlaminar que posee, hace muy difícil que el proceso de pilarización sea realizado de forma directa. Es por ello que, al igual que ocurre con los silicatos laminares, es necesaria una etapa previa de hinchamiento por intercalación de alquilaminas de cadena larga, obteniéndose materiales con espaciados basales de hasta $2.9 \mathrm{~nm}$. Posteriormente, se lleva a cabo el proceso de pilarización de manera más efectiva. Los agentes pilareantes utilizados que han dado resultados positivos han sido $\operatorname{TEOS}^{[59]}$ y octilsilano ${ }^{[60]}$, obteniéndose materiales laminares pilareados, en este último caso orgánicos-inorgánicos, con áreas superficiales de hasta 470 $\mathrm{m}^{2} \mathrm{~g}^{-1}$. Cabe destacar que con este precursor se han realizado los procesos de hinchamiento y pilarización simultáneamente, sin que sea necesario el aislamiento previo del material pre-expandido (Figura 3.17.), lo que indicaría que esta misma metodología podría ser aplicada con otras familias de precursores laminares.

Las posibles aplicaciones de los materiales híbridos derivados de los titanatos laminares por intercalación de compuestos orgánicos en el espacio interlaminar está todavía por determinar, teniendo en cuenta que la configuración especial del titanio pentacoordinado en su estructura podría tener cierta influencia en su comportamiento catalítico. Además, estudios recientes relacionados con la utilización de materiales exfoliados derivados del precursor JDF-L1, denominados UZAR-S1 ${ }^{[61]}$, como componentes 
de membranas mixtas abre el campo de utilización de estos materiales en áreas nanotecnológicas.

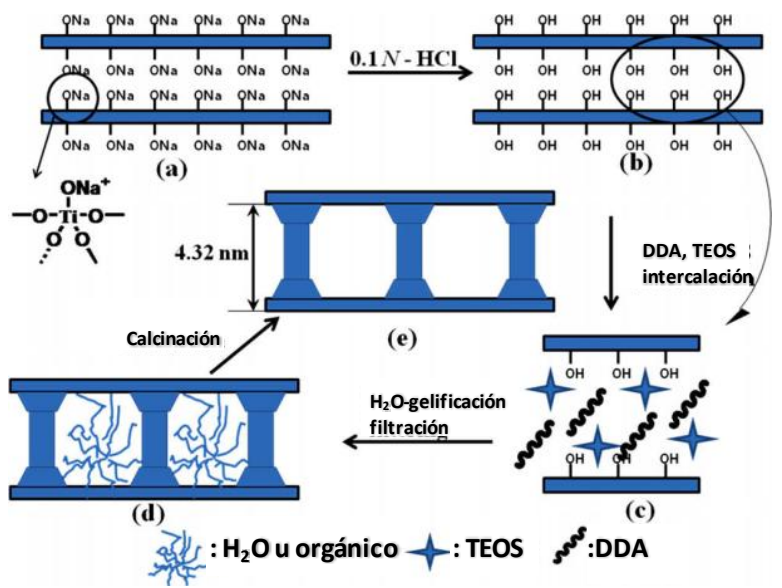

Figura 3.17. Hinchamiento y pilareado simultáneo de dodecilamina (DDA) y octilsilano, respectivamente, en el espacio interlaminar del titanato JDF-L1 (siguiendo referencia [60]).

\subsubsection{Materiales laminares de naturaleza zeolítica}

Las zeolitas son una familia de silicoaluminatos naturales que exhiben propiedades particulares como el intercambio de iones y la desorción reversible del agua. Esta última propiedad es la que dio origen al nombre genérico de zeolita, el cual deriva de los términos griegos, zeo: que hierve, y lithos: piedra ${ }^{[62]}$.

La estructura de estos materiales, tanto naturales como sintéticos, consiste en una red cristalina formada por la combinación tridimensional de tetraedros, $\mathrm{TO}_{4}$, unidos entre sí a través de átomos de oxígeno comunes, generando un entramado de canales y cavidades de dimensiones moleculares que le confieren porosidad y una elevada superficie específica. En la mayoría de zeolitas, T representa a los átomos de silicio y aluminio. Teniendo en cuenta que el aluminio es trivalente, los tetraedros $\mathrm{TO}_{4}$ inducen cargas negativas en la estructura que son neutralizadas por cationes de compensación intercambiables. Estos cationes junto con las moléculas de agua de hidratación se encuentran ocupando el espacio intracristalino de los materiales zeolíticos. La fórmula química por celda unidad se puede expresar como ${ }^{[63]}$ : 


$$
\mathrm{M}_{x / n}\left[\left(\mathrm{AlO}_{2}\right)_{x}\left(\mathrm{SiO}_{2}\right)_{y}\right] \cdot m \mathrm{H}_{2} \mathrm{O}
$$

donde $M$ es un catión intercambiable de valencia $n, m$ el número de moléculas de agua y la suma de $x$ e $y$ indica el número de tetraedros por celda unidad.

La accesibilidad de las moléculas de reactivos al espacio intracristalino está limitado por el diámetro de los poros que forman los tetraedros, es decir, que solamente podrán entrar o salir del espacio interno microporoso aquellas moléculas de dimensiones inferiores a un cierto valor crítico, el cual varia de una zeolita a otra ${ }^{[64]}$. Este parámetro hace que las zeolitas sean consideradas como verdaderos tamices moleculares, introduciendo la variable de la selectividad de forma en los procesos reactivos en los que intervienen como catalizadores.

Dentro de la amplia familia de las zeolitas se encuentran algunas cuya estructura final se obtiene por calcinación de un material intermedio al que se denomina precursor $z_{\text {zeolítico laminar }}^{[65]}$. Éstos poseen estructuras muy parecidas a las de otros materiales laminares ya estudiados en apartados anteriores, consistentes en láminas individuales separadas entre sí por cationes y moléculas de solvatación, convirtiéndolos en atractivos candidatos para llevar a cabo procesos de hinchamiento, pilarización o deslaminación, pudiendo dar lugar a materiales con poros de mayor tamaño y de elevada accesibilidad. Cuando estos precursores recién sintetizados son sometidos a un proceso de calcinación, se produce la unión de las láminas, a través de la hidrólisis y condensación de los silanoles superficiales, formando así la estructura tridimensional convencional de las zeolitas ${ }^{[66]}$.

Hasta el momento, no han sido muchos los precursores zeolíticos laminares descritos en la bibliografía, siendo los más estudiados los que están constituidos por láminas individuales tipo $\mathrm{MWW}^{[67]}$, ferrieríticas $(\mathrm{PREFER})^{[68]}$ y tipo CAS (Nu6(1)) ${ }^{[69]}$, los cuales dan lugar a las zeolitas tridimensionales $\mathrm{MCM}-22^{[70]}$, Ferrierita ${ }^{[71]}$ y Nu6(2) ${ }^{[72]}$, también denominada NSI, respectivamente (denominaciones adoptadas de los códigos IZA, International Zeolite Association) ${ }^{[73]}$. 
En dichos precursores las láminas individuales están estabilizadas por interacciones de Van der Waals o puente de hidrógeno en el plano perpendicular al del ordenamiento de las láminas (Figura 3.18.). Estas uniones de tipo iónico, junto a la presencia de cationes hidratados intercambiables, localizados en el espacio interlaminar, facilitan la inserción de agentes de hinchamiento y/o intercalación entre las láminas para generar sólidos pilareados de naturaleza zeolítica que poseen cavidades mesoporosas. Además, tras el proceso de hinchamiento, es posible llevar a cabo un proceso de exfoliación controlado, por medio de agentes físicos (agitación o ultrasonidos) o químicos (solvatación), para obtener zeolitas deslaminadas que se caracterizan por presentar una elevada superficie externa, sin perder las características y propiedades intrínsecas de los materiales zeolíticos convencionales. En la Figura 3.19. se esquematizan los procesos de pilarización y deslaminación llevados a cabo, por ejemplo a partir de un precursor zeolítico tipo MWW para obtener los materiales denominados MCM-36 e ITQ-2, respectivamente. Se han llevado a cabo procesos similares con los precursores PREFER y Nu6(1) para obtener, en ambos casos, nuevos sólidos pilareados y deslaminados de elevada accesibilidad.

(a)

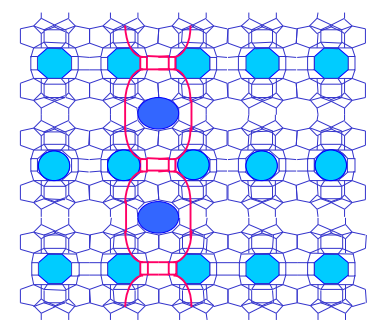

(b)

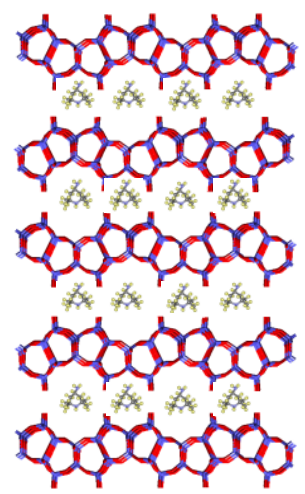

(c)

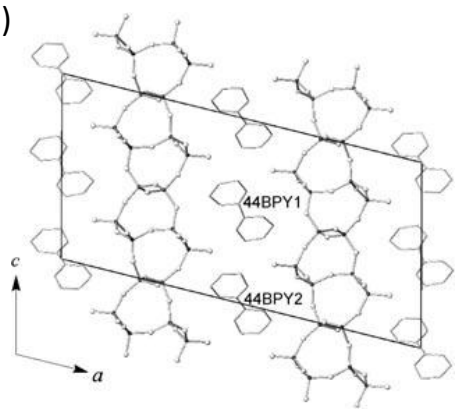

Figura 3.18. Esquema de los precursores zeolíticos laminares tipo (a) MWW, (b) PREFER y (c) Nu6(1). 


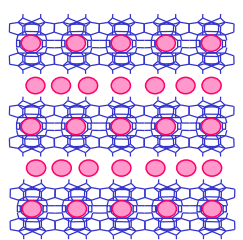

$\operatorname{MCM-22(P)~}$
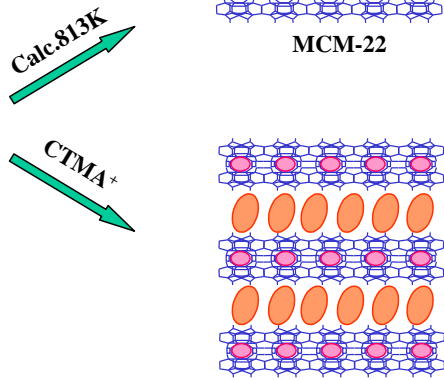

MCM-22 HINCHADA

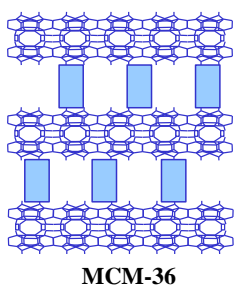

MCM-36
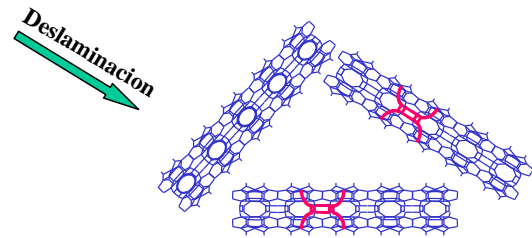

ITQ-2

Figura 3.19. Procesos de hinchamiento, pilarización y deslaminación del precursor zeolítico MWW para la obtención de los materiales MCM-36 e ITQ-2.

La versatilidad demostrada por los precursores laminares para generar materiales híbridos se ha puesto de manifiesto, sobre todo, a partir del precursor laminar conformado por láminas individuales tipo MWW. Dicho precursor está formado por láminas de $2.5 \mathrm{~nm}$ de espesor que contienen en su interior un canal sinosuidal delimitado por anillos de 10 miembros (10MR). Cada lámina posee en su superficie una gran cantidad de grupos silanoles (Si-OH), los cuales durante el proceso de calcinación condensan con los grupos silanoles de las láminas adyacentes dando lugar a la estructura tridimensional, con la consiguiente eliminación de las moléculas que actúan como agentes directores de estructura que se sitúan en el espacio interlaminar. Cuando se unen las láminas entre sí se forma un segundo sistema de poros constituido por supercavidades delimitadas por anillos de 12 miembros (12 MR), debido a que en la superficie de cada lámina se encuentra la mitad de cada supercavidad. En la Figura 3.20. se muestra el esquema de la estructura del precursor laminar tipo $\mathrm{MWW}^{[67]}$. 


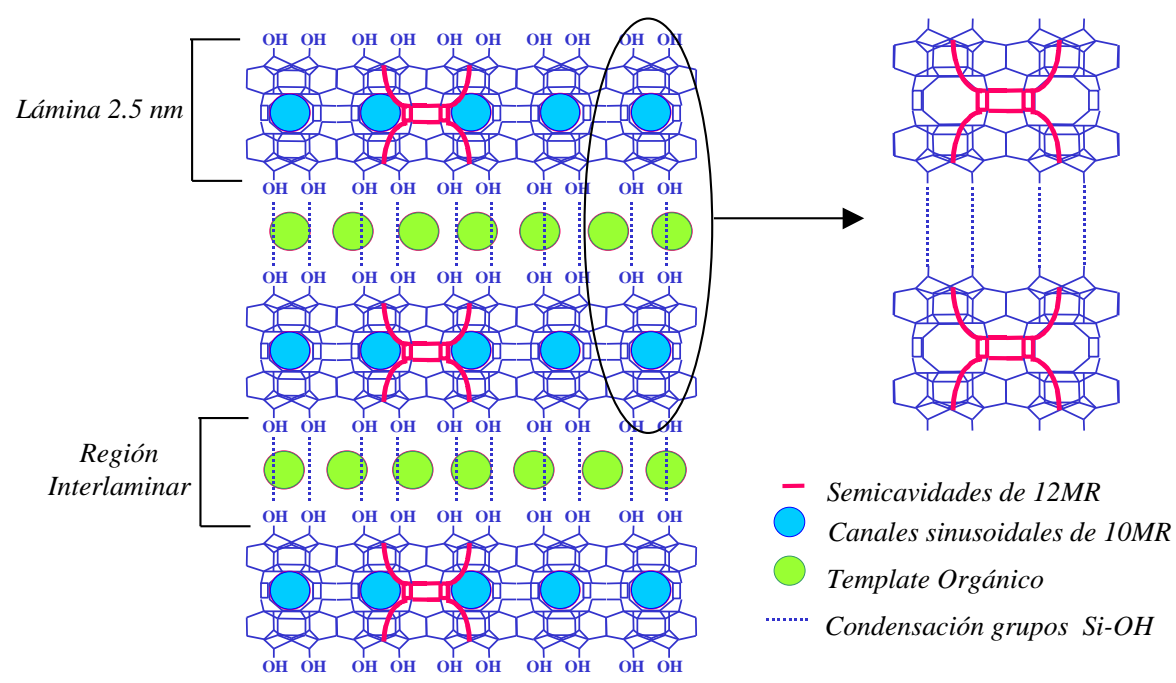

Figura 3.20. Esquema del precursor laminar tipo MWW.

En concreto, partiendo de los conocimientos previos adquiridos para la pilarización de este precursor laminar, Tatsumi y col. han generado materiales híbridos orgánicos-inorgánicos por la intercalación directa, entre las láminas tipo MWW, de agentes sililantes tales como dialquilsilanos $\left[\mathrm{SiMe}_{2} \mathrm{Cl}_{2} \circ \mathrm{Si}(\mathrm{OEt})_{2} \mathrm{Me}_{2}\right]$, los cuales reaccionan con los grupos silanoles superficiales. Esta metodología ha permitido la obtención de materiales zeolíticos expandidos, denominados IEZ, basados en láminas tipo MWW separadas por pequeños pilares constituidos por un solo átomo de silicio. Este hecho ha generado una nueva familia de zeolitas tridimensionales MWW que contienen un canal microporoso adicional delimitado por anillos de 12 miembros (12MR) localizado entre las láminas inorgánicas (Figura 3.21. ${ }^{[74]}$. Estos materiales presentan una mayor superficie específica y volumen de poro que la estructura original, preservándose la naturaleza ácida debida al alumino tetraédrico presente en las láminas individuales. Normalmente, la síntesis es llevada a cabo en fase vapor, lo que evita la desaluminización parcial del material $^{[75]}$. La mayor accesibilidad de las zeolitas IEZ-MWW ha permitido la adsorción de moléculas de mayor tamaño como ciclohexano, exhibiendo una alta actividad catalítica en la acilación de anisol con anhídrido acético. Esta misma ruta de síntesis ha sido empleada para preparar zeolitas expandidas IEZ partiendo de precursores zeolíticos laminares 
constituidos por láminas de naturaleza ferrierítica o con presencia, en las mismas, de titanio en posiciones tetraédricas (Ti-MWW) ${ }^{[76]}$.

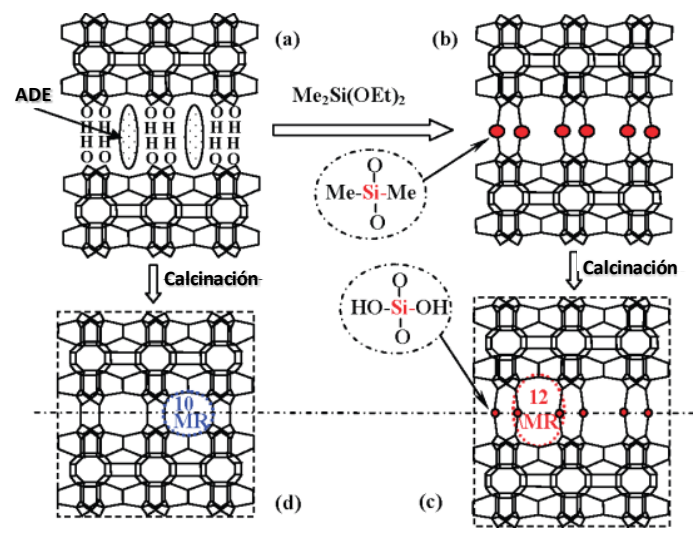

Figura 3.21. Proceso de síntesis para obtener zeolitas expandidas (IEZ) por tratamiento del precursor laminar MWW con dialquilsilanos (siguiendo referencia [74]).

Por otra parte, el material deslaminado ITQ-2, derivado del precursor MWW, ha sido empleado para preparar materiales híbridos funcionales, aprovechando el elevado número de silanoles superficiales accesibles presentes en la superficie de cada lámina. En detalle, la zeolita ITQ-2 está formada por láminas individuales de $2.5 \mathrm{~nm}$ de espesor que dan lugar a un material con una elevada superficie externa $\left(\geq 700 \mathrm{~m}^{2} \mathrm{~g}^{-1}\right)$. Las láminas están constituidas por una distribución hexagonal de "copas" que se encuentran en ambos lados de las láminas MWW. Estas copas están delimitadas por anillos de 12MR y se encuentran conectadas con las copas de la otra cara de la lámina a través de un doble anillo de 6MR que las une por su base. Además, un sistema de canales sinusoidales de 10MR discurre alrededor de las copas por el interior las láminas $\mathrm{MWW}^{[77]}$. En la Figura 3.22. se presenta un esquema de la estructura del material ITQ-2. 


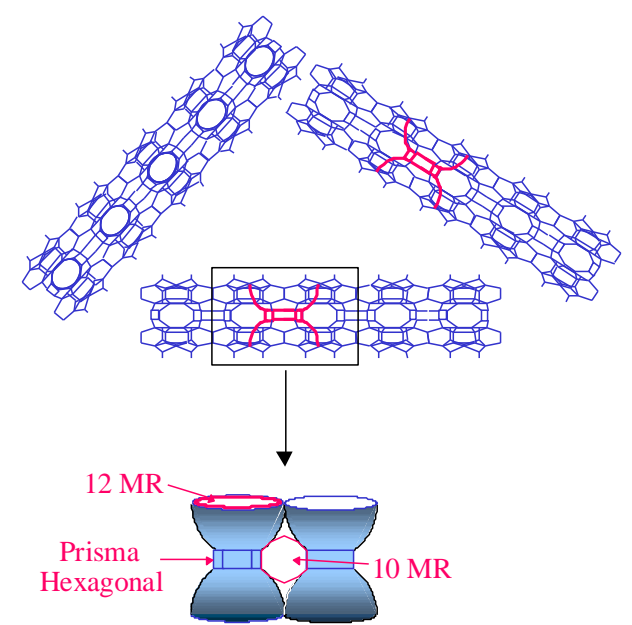

Figura 3.22. Representación de la estructura de la zeolita deslaminada ITQ-2.

La especial morfología del material deslaminado ITQ-2 lo convierte en idóneo para incorporar covalentemente sobre su superficie una gran variedad de organocatalizadores, los cuales quedarán estabilizados, aislados entre sí, distribuidos homogéneamente y totalmente accesibles hacia las moléculas de reactivos. Es el caso de los catalizadores híbridos obtenidos por el anclaje de moléculas de titanoceno, Ti-ITQ-2, que se han empleado con éxito en procesos de epoxidación de olefinas, usando hidroperóxidos orgánicos como agentes de oxidación (Figura 3.23. ${ }^{[78]}$.

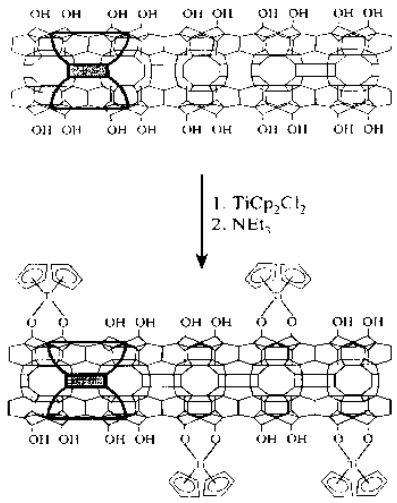

Además, la selectividad a epóxido de dichos materiales pudo ser, incluso, mejorada modificando las propiedades de adsorción de la zeolita Ti-ITQ-2 por medio de tratamientos de sililación, siendo dicho catalizador reutilizado durante tres ciclos consecutivos, manteniendo prácticamente la conversión inicial.

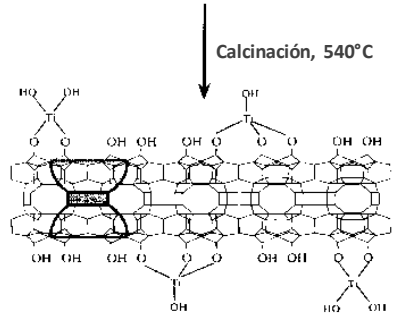

Figura 3.23. Zeolita Ti-ITQ-2 obtenida por hibridación de la superficie de las láminas MWW con grupos titanoceno. 
Siguiendo esta metodología se estabilizaron una gran variedad de organocatalizadores sobre las láminas que componen la zeolita ITQ-2, tales como complejos metálicos de $\mathrm{Cr}$, $\mathrm{Ni}$ o $\mathrm{Pd}$ tipo Salen para llevar a cabo procesos enantioselectivos de apertura de epóxidos ${ }^{[79]}$, bases de Schiff con Ni o Pd efectivas en la reacción de $\mathrm{Heck}^{[80]}$, especies organometálicas de $\mathrm{Au}$ basadas en carbenos para realizar procesos de hidrogenación selectiva de alquenos e iminas y reacciones tipo Suzuki ${ }^{[81]}$, metaloporfirinas para la electro-reducción catalítica de oxígeno ${ }^{[82]}$ o, incluso, complejos enzimáticos derivados de la $\beta$-galactosidasa o penicilina $\mathrm{G}$ acilasa ${ }^{[83]}$.

No sólo se han preparado materiales híbridos derivados del precursor tipo MWW con fines catalíticos, ya que ha sido posible encapsular en las semicavidades presentes en las láminas que componen la zeolita deslaminada ITQ-2, especies fotoluminiscentes, tales como complejos derivados de quinolatos o pirenos, generando sólidos orgánicosinorgánicos con posibles aplicaciones dentro de áreas nanotecnológicas al poder actuar como sensores $^{[84]}$.

\subsubsection{Otros precursores laminares}

Existen otras familias de compuestos que presentan una estructura laminar, destacando entre ellos el grafito, fosfatos $(\alpha-\mathrm{ZrP})^{[85]}$, sulfuros $\left(\mathrm{MoS}_{2}, \mathrm{FeS}_{2}\right)$, óxidos metálicos $\left(\mathrm{V}_{2} \mathrm{O}_{5}\right)$, hidróxidos $\left[\mathrm{MoO}_{3}\left(\mathrm{OH}_{2}\right), \mathrm{WO}_{3}\left(\mathrm{OH}_{2}\right)\right]$, hidroxiacetatos $\left[\mathrm{Ni}_{1}\right.$. $\left.{ }_{x} \mathrm{Zn}_{2 x}(\mathrm{OH})_{2}\left(\mathrm{CH}_{3} \mathrm{COO}\right)_{2 x}\right]^{[86]}$, arseniatos $\left(\mathrm{KNiAsO}_{4}, \mathrm{NaNiAsO}_{4}\right)$, vanadatos $\left(\mathrm{KV}_{3} \mathrm{O}_{8}\right)$, molibdatos $\left(\mathrm{Ag}_{6} \mathrm{Mo}_{10} \mathrm{O}_{33}\right)$, perovskitas ${ }^{[87]}$, manganatos $\left(\mathrm{Na}_{4} \mathrm{Mn}_{10} \mathrm{O}_{27} . x \mathrm{H}_{2} \mathrm{O}\right)$, cloruros $\left(\mathrm{ReCl}_{3}\right)$, oxicloruros $(\mathrm{FeOCl})$ o cianuros $\left[\mathrm{Ni}(\mathrm{CN})_{2}\right]^{[88]}$. En todos ellos sería, en principio, posible llevar a cabo procesos de hinchamiento e intercalación de diferentes compuestos, tales como monómeros, polianiones o, incluso, complejos metálicos que actuasen como efectivos organocatalizadores heterogeneizados en el seno de una matriz inorgánica. Por lo tanto, la posibilidad de preparar materiales híbridos, orgánicos-inorgánicos, a partir de estos precursores laminares parece, a priori, una posibilidad viable ${ }^{[89]}$.

En concreto, en la bibliografía, existen ejemplos de materiales híbridos obtenidos a partir de fosfatos laminares de zirconio $(\alpha-Z r P)$, en los que se intercalan covalentemente 
moléculas de difosfonatos $\left(\mathrm{O}_{3} \mathrm{P}-\mathrm{R}-\mathrm{PO}_{3}\right)$ entre dos láminas adyacentes a modo de puente, evitando así el colapso de la región interlaminar. La posterior funcionalización de los pilares de difosfonatos con grupos sulfónicos, $-\mathrm{SO}_{3} \mathrm{H}$, ha permitido la generación de interesantes catalizadores ácidos ${ }^{[90]}$.

Dentro del grupo de los molibdatos laminares destacan la obtención de nuevas familias de híbridos orgánicos-inorgánicos bidimensionales preparados a través de la reacción de $\mathrm{Na}_{2} \mathrm{MoO}_{4}$ con monómeros del tipo alquildiestaño. En este caso, en función del $\mathrm{pH}$ empleado durante la síntesis, se obtuvieron sólidos compuestos por láminas ordenadas, estando cada una de ellas constituida por unidades estructurales de oxoaniones $\mathrm{MoO}_{4}{ }^{2-}$ y tetrámeros $\left[\left(\mathrm{Me}_{2} \mathrm{Sn}\right)_{4}\right]^{2+}$. La presencia de estaño (IV), estabilizado en el entramado estructural de las láminas, abre la posibilidad de emplear estos materiales híbridos como catalizadores en reacciones de epoxidación de olefinas (Figura 3.24.) ${ }^{[1]}$.

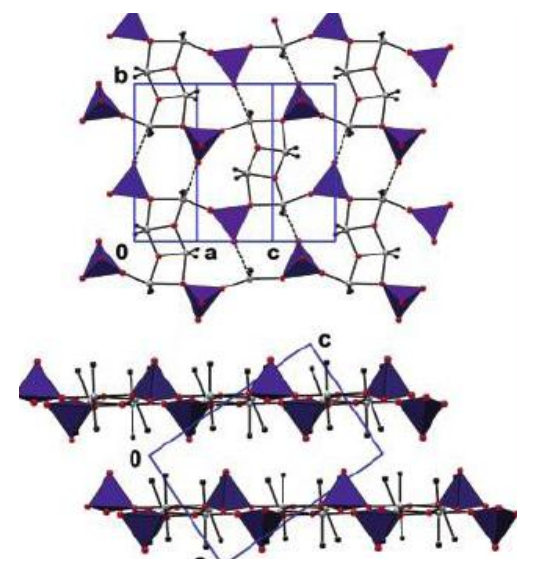

Figura 3.24. Representación del material híbrido compuesto por láminas constituidas por oxoaniones de Mo y tetrámeros de Sn (siguiendo referencia [91]).

Recientemente, se han estado realizando interesantes avances tomando como punto de partida óxido de grafito laminar para obtener materiales híbridos multifuncionales con posibles aplicaciones catalíticas. Hasta el momento, el grafito había sido empleado, normalmente, para preparar films o composites por intercalación en su espacio interlaminar de policationes, polímeros o, incluso, moléculas fotoactivas con el fin de emplearlos como componentes de pilas de combustibles o en el campo de los 
sensores ${ }^{[92]}$. Sin embargo, en los últimos años, se han preparado materiales orgánicosinorgánicos con potencial actividad catalítica, cuyo entramado estructural está constituido, tras un proceso de reducción, por nanopartículas de platino soportadas sobre grafeno que se dispersan y estabilizan en una red polimérica de Nafión que actúa como matriz porosa (Figura 3.25.) (93] $^{[3}$

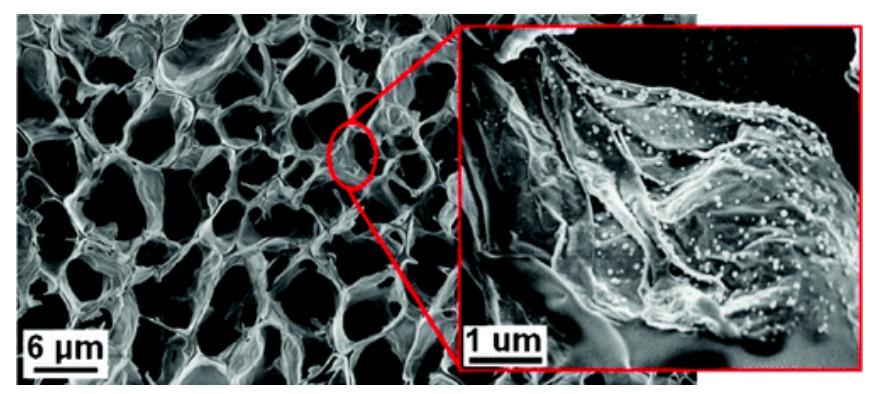

Figura 3.25. Imagen de microscopía electrónica de barrido (SEM) del material híbrido constituido por láminas de grafeno con nanopartículas de Pt soportadas incluidas en una matriz polimérica y porosa de Nafión (siguiendo la referencia [93]).

En definitiva, a lo largo de esta introducción, se han revisado los principales precursores laminares que se encuentran en la bibliografía, mostrándose cómo, a partir de ellos, se alojan y estabilizan distintos tipos de compuestos y moléculas en su espacio interlaminar, aprovechando tanto su versatilidad y elevada accesibilidad como su capacidad de intercambio iónico. Aunque se han descrito diferentes sólidos orgánicosinorgánicos que conservan un ordenamiento laminar, se trata de un campo todavía en franca expansión, en el que se tratará de profundizar y avanzar con el estudio de nuevas familias de materiales laminares híbridos que, a continuación, se mostrarán. 


\subsection{Objetivos}

Después de la revisión realizada, donde se ha comprobado la idoneidad de los precursores laminares para generar sólidos orgánicos-inorgánicos, se han seleccionado los silicatos laminares y los precursores zeolíticos laminares, como punto de partida, para preparar nuevas familias de materiales híbridos pilareados (Clase II) con potenciales aplicaciones catalíticas. Esta elección no ha sido arbitraria ya que ambos tipos de precursores laminares exhiben una elevada estabilidad hidrotermal, pueden contener funciones activas en sus propias láminas inorgánicas y, además, son susceptibles de ser modificados en procesos post-síntesis para obtener materiales de elevada accesibilidad. Por otra parte, en el caso de los silicatos laminares son pocos los ejemplos que se han descrito de sólidos orgánicos-inorgánicos obtenidos por intercalación ordenada, a modo de pilares, de fragmentos orgánicos en su espacio interlaminar, obteniéndose, en la mayoría de casos, materiales con baja regularidad estructural y escasa accesibilidad. En el caso de los precursores zeolíticos laminares, únicamente se han obtenido sólidos pilareados por intercalación de policationes inorgánicos derivados normalmente de TEOS. Es por ello, que la preparación de sólidos pilareados orgánicos-inorgánicos, partiendo de ambos tipos de precursores laminares es una opción, a priori, viable y poco explorada que trataremos de abordar a continuación.

Como moléculas de intercalación se utilizarán disilanos, $\left(\mathrm{R}^{\prime} \mathrm{O}\right)_{3} \mathrm{SiRSi}\left(\mathrm{OR}^{\prime}\right)_{3}$, los cuales, gracias a sus grupos alcóxidos terminales podrían actuar como agentes de pilarización efectivos al reaccionar con los silanoles externos presentes en las láminas inorgánicas del precursor empleado. Además, la efectividad de los disilanos ha quedado probada al emplearse con éxito en la preparación de diferentes materiales híbridos al actuar como unidades estructurales que entran a formar parte de diferentes tipos de redes cristalinas. 
Teniendo en cuenta estas consideraciones previas, los objetivos principales de este capítulo son los siguientes:

- Síntesis y caracterización de nuevas familias de materiales laminares orgánicosinorgánicos a través de procesos de pilarización. Para ello, se utilizarán, como punto de partida, silicatos (magadiita) y precursores zeolíticos laminares (tipo MWW), empleando disilanos como agentes de pilarización.

- Se realizará un estudio pormenorizado de las condiciones de preparación óptimas para sintetizar dichos materiales laminares híbridos, considerando las etapas de hinchamiento, pilarización y extracción.

- Se insertarán, a modo de pilares en el espacio interlaminar, diferentes fragmentos orgánicos estabilizados, tales como anillos aromáticos y grupos diamino, disulfuro y etileno, generando materiales híbridos ordenados, accesibles y funcionales.

- Se estudiará la posible combinación de varias funcionalidades presentes tanto en las láminas inorgánicas como en los pilares orgánicos para la generación de materiales multifuncionales.

- Se evaluará la actividad catalítica de los materiales orgánicos-inorgánicos obtenidos. En el caso de aquellos que contengan más de una funcionalidad, se determinará su actividad en procesos catalíticos consecutivos o en "cascada". 


\subsection{Materiales híbridos pilareados derivados de silicatos laminares}

\subsubsection{Magadiita como precursor laminar}

En este caso, el precursor laminar empleado para la obtención de materiales híbridos pilareados es el derivado del ácido silícico en forma sódica denominado magadiita $\left(\mathrm{Na}_{2} \mathrm{Si}_{14} \mathrm{O}_{29} \cdot 9 \mathrm{H}_{2} \mathrm{O}\right)^{[94]}$. La magadiita posee una estructura bidimensional en la que los enlaces covalentes se establecen únicamente en dos dimensiones (plano $a b$ ) que definen cada una de las láminas individuales. La estructura final viene dada por la acumulación vertical de láminas, una sobre otra, perpendicularmente al eje $c$. Las interacciones que se producen a lo largo de la dirección c son más débiles que los enlaces establecidos en el plano $a b$. Estos enlaces débiles mantienen unidas las láminas mediante interacciones de Van der Waals, interacciones electrostáticas o puentes de hidrogeno. Se trata, por lo tanto, de un silicato con estructura multicapa estando conformadas sus láminas por anillos de 5 y 6 miembros, mostrando una simetría $C_{2 h}$. Al encontrarse este material en forma sódica, están favorecidos los procesos de intercambio catiónico, los cuales pueden incrementar la accesibilidad de estos materiales hacia moléculas voluminosas de reactantes, en función de los compuestos intercalados entre las láminas de silicato.

En general, los ácidos silícicos laminares, entre ellos la magadiita, están formados por capas de tetraedros condensadas, sin poseer capas octaédricas características de las arcillas. Aunque la estructura de la magadiita no es conocida con exactitud, debido a la dificultad de obtener cristales lo suficientemente grandes para su análisis por difracción de rayos $\mathrm{X}$ de monocristal, la corriente más extendida es que sus láminas están conformadas a su vez por la asociación de dos láminas individuales de makatita, siendo esta la monocapa constituida por tetraedros de silicio que es la unidad estructural básica de la mayoría de ácidos silícicos laminares ${ }^{[43,95]}$. No obstante, otros estudios reflejan que la magadiita puede estar formada por diferentes tipos de asociación entre las láminas de makatita $^{[39-40,96]}$ (ver Figura 3.26.). 


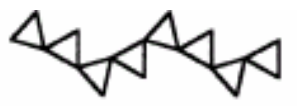

(a)

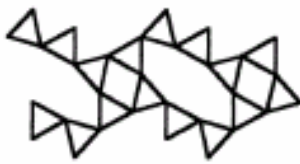

(b)
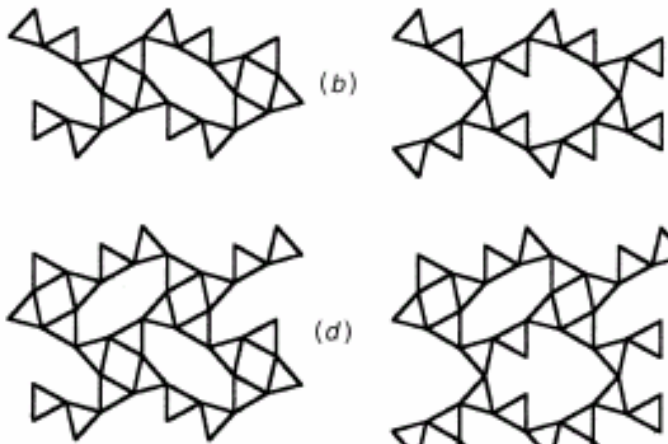

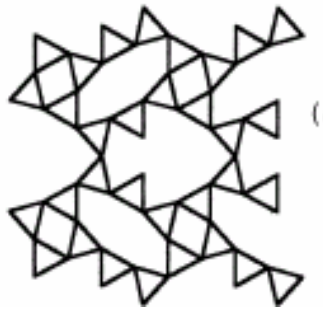

Figura 3.26. La posible condensación de láminas de makatita para formar láminas de silicato de mayor espesor: (a) Lámina de makatita, proyectada a lo largo del eje $a$, (b) Dos láminas de makatita condensadas para formar una doble lámina constituida por anillos de 4 y 8 miembros (4MR y $8 \mathrm{MR}$ ), (c) Dos láminas de makatita condensadas para dar lugar a una doble lámina formada por anillos de 10 miembros (10MR).

Estructura de la magadiita

propuesta por Schwieger y col. ${ }^{[40]}$, basada en tres láminas de makatita condensadas según el modelo propuesto en (b) y, (e) Estructura propuesta para la magadiita según Nesbitt ${ }^{\text {[95c] }}$ que consiste en 4 láminas de makatita condensadas según el modelo propuesto en (b) y (c).

En la Figura 3.27. se muestra el difractograma de rayos $X$ de la magadiita recién sintetizada en este trabajo, empleada como precursor para la obtención de materiales híbridos pilareados, siendo coincidente con el encontrado en la bibliografía.

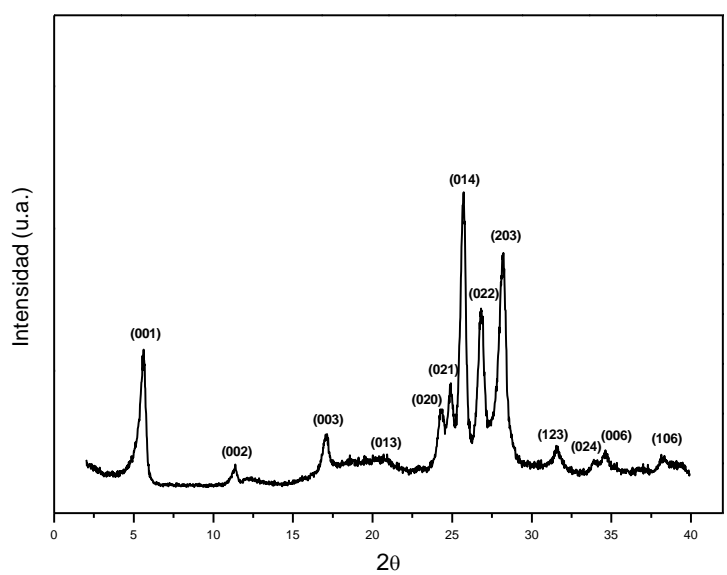

Figura 3.27. Difractograma de rayos $X$ de la Na-magadiita recién sintetizada con la asignación de cada una de sus reflexiones ( $h k l)$. 
En la Tabla 3.2. se muestran los espaciados en los que aparecen cada una de las bandas de reflexión de la muestra aquí sintetizada, los cuales coinciden con los que se describen en la bibliografía ${ }^{[97]}$.

Tabla 3.2. Comparación de bandas de difracción de rayos $X$ entre la magadiita descrita en la bibliografía y la sintetizada en este trabajo.

\begin{tabular}{ccccc}
\hline Índices $(\boldsymbol{h k l})$ & $\mathbf{d}_{\text {teórica }}(\AA)^{\mathbf{a}}$ & $\mathbf{d}_{\text {obs }}(\AA)$ & $\mathbf{I}_{\text {rel. teórica }}{ }^{\mathbf{b}}$ & $\mathbf{I}_{\text {rel. experim. }}$ \\
\hline $\mathbf{0 0 1}$ & 15.58 & 15.70 & 100 & 100 \\
$\mathbf{0 0 2}$ & 7.79 & 7.76 & 9 & 9 \\
$\mathbf{0 0 3}$ & 5.19 & 5.19 & 18 & 34 \\
$\mathbf{0 1 3}$ & 4.22 & 4.25 & 3 & 19 \\
$\mathbf{0 2 0}$ & 3.62 & 3.66 & 13 & 53 \\
$\mathbf{0 2 1}$ & 3.53 & 3.57 & 19 & 75 \\
$\mathbf{0 1 4}$ & 3.43 & 3.46 & 75 & 100 \\
$\mathbf{0 2 2}$ & 3.28 & 3.31 & 40 & 100 \\
$\mathbf{2 0 3}$ & 3.13 & 3.16 & 60 & 100 \\
$\mathbf{1 2 3}$ & 2.81 & 2.82 & - & 25 \\
$\mathbf{0 2 4}$ & 2.65 & 2.64 & - & 13 \\
$\mathbf{0 0 6}$ & 2.59 & 2.59 & 11 & 22 \\
$\mathbf{1 0 6}$ & 2.35 & 2.35 & 12 & 13 \\
\hline
\end{tabular}

${ }^{a}$ : Espaciado para cada banda de difracción; ${ }^{b}$ Intensidad relativa de las bandas de difracción.

\subsubsection{Síntesis y caracterización}

\section{Sintesis}

Los materiales híbridos pilareados derivados de la magadiita, denominados MAGDISILANO, se preparan siguiendo el procedimiento experimental descrito en el apartado 3.6., en el que aparece detallada la síntesis, como referencia, de un material híbrido laminar empleando bis(trietoxisililpropil)disulfuro (BTES) como agente de pilarización. En la Figura 3.28. se muestra el esquema propuesto para la síntesis de estos materiales híbridos pilareados. 
El silicato laminar magadiita está formado por láminas ordenadas de naturaleza silícea, perpendiculares al eje $c$, que contienen átomos de silicio con oxígenos terminales en la superficie de cada lámina, compensados por cationes sodio fácilmente intercambiables y por moléculas de agentes directores de estructura , trans-4aminociclohexanol, presentes en el espacio interlaminar. Cuando tiene lugar un tratamiento ácido en el precursor Na-magadiita (Na-MAG), se produce el intercambio de los iones alcalinos $\mathrm{Na}^{+}$por $\mathrm{H}^{+}$, obteniéndose así la magadiita en forma ácida (H-MAG), lo cual facilitará el posterior proceso de hinchamiento. De este modo, al hinchar el precursor en las condiciones adecuadas con moléculas de n-hexilamina, se produce la separación de las láminas de silicato, pasando a estar las moléculas de agente hinchante protonado en el espacio interlaminar unidas a éstas a través de interacciones débiles de tipo Van der Waals (MAG-HEX).

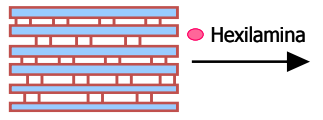

MAG-H

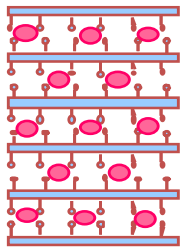

MAG-HEX

- Hexilamina

Disilano

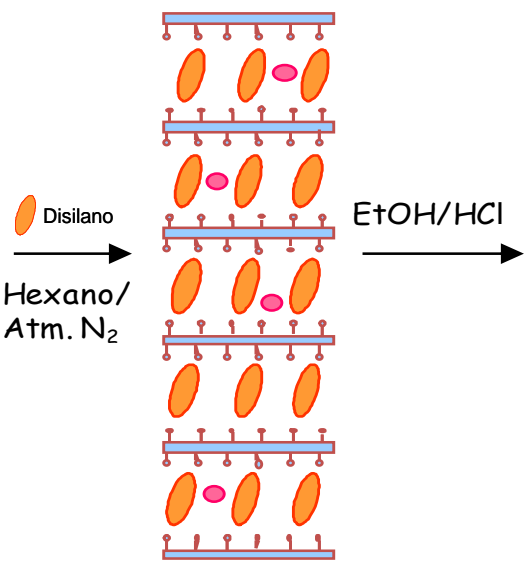

MAG-HEX-DISILANO
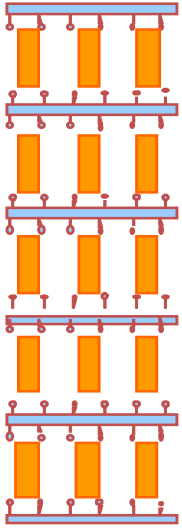

MAG-DISILANO

Figura 3.28. Esquema general de preparación de los materiales híbridos pilareados obtenidos a partir de la magadiita como precursor laminar.

La mayor distancia entre las láminas facilitará la entrada en la región interlaminar de moléculas de disilano, cuando se lleve a cabo el proceso de pilarización, en presencia de hexano, sustituyendo parcial o totalmente a las moléculas de n-hexilamina (MAG-HEXDISILANO). En este etapa, se producirá la interacción de tipo covalente entre los grupos alcóxido terminales de los disilanos y los silanoles (-SiOH) presentes en la superficie de las 
láminas inorgánicas, permitiendo así la intercalación estable de los fragmentos orgánicos a modo de pilar entre las láminas. Por último, tras el proceso de extracción ácida, que sirve para la eliminación de toda la materia orgánica presente en el espacio interlaminar y que no está unida covalentemente a las láminas silícicas, como son las moléculas de agente hinchante y las moléculas de disilano en exceso que no han reaccionado con los silanoles superficiales, se obtiene, finalmente, un material orgánico-inorgánico pilareado (MAGDISILANO). Este material está compuesto por láminas ordenadas de tipo magadiita perpendiculares al eje $c$ de $9.5 \AA$ de espesor cada una, unidas covalentemente a fragmentos orgánicos, situados en el espacio interlaminar, a modo de pilares, generándose de este modo nuevas galerías porosas que discurren entre las láminas inorgánicas y los pilares orgánicos. La altura de dichas galerías y la accesibilidad alcanzada dependerá del tipo de disilano finalmente intercalado.

Una representación artística de los materiales híbridos orgánicos-inorgánicos obtenidos, según la metodología propuesta, se representa en la Figura 3.29., donde se observa la distribución homogénea, que se pretende alcanzar, entre los puentes orgánicos situados en el espacio interlaminar. En esta misma figura también se muestra la estructura de los disilanos empleados como agentes de pilarización en el presente estudio, bis(trietoxisililpropil)disulfuro (BTES), bis(trimetoxisililpropil)etilendiamino (BTMN) y bis(trietoxisilil)etileno (BTEEthy), los cuales han conseguido intercalarse en el espacio interlaminar, acompañados de una tabla con la comparativa entre su longitud molecular y el espaciado basal, observado a través de DRX, de los sólidos pilareados obtenidos. 
(a)

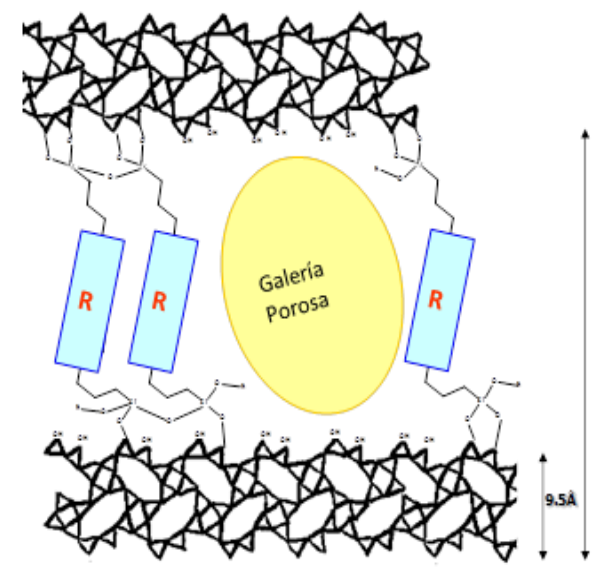

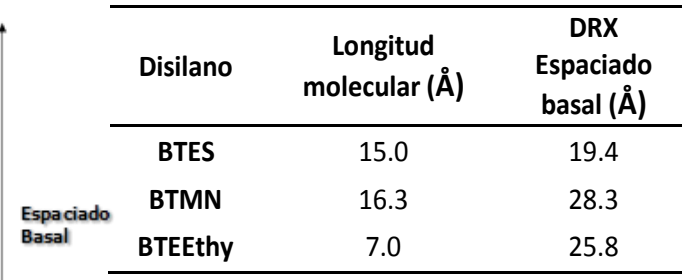

BTES: Bis(trietoxisililpropil)disulfuro

BTMN: Bis(trimetoxisililpropil)etilendiamino

BTEEthy: Bis(trietoxisilil)etileno

(b)
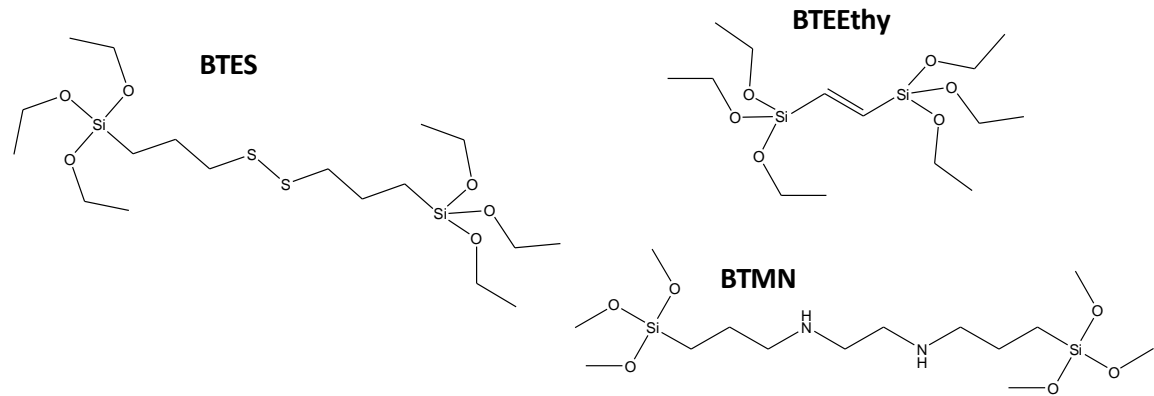

Figura 3.29. (a) Representación esquemática de los materiales laminares híbridos preparados, utilizando diferentes disilanos como agentes de pilarización. Se incluye la comparación entre las longitudes moleculares de cada uno de los disilanos empleados con el espaciado basal observado por DRX. (b) Disilanos empleados como agentes de pilarización.

A continuación, se realizará un estudio de caracterización en el que se analizarán las sucesivas etapas del proceso de pilarización. Igualmente se estudiarán las propiedades de los diferentes materiales híbridos que se han obtenido. 


\section{Caracterización}

\section{Difracción de Rayos X}

En la Figura 3.30. se comparan los difractogramas de rayos $\mathrm{X}$ de los materiales obtenidos tras las sucesivas etapas de intercambio protónico, hinchamiento, pilarización y extracción ácida realizadas, partiendo de la magadiita como precursor y llegando hasta el material final MAG-BTES. El ordenamiento laminar de los diferentes materiales obtenidos a partir de la magadiita puede seguirse a través del primer pico de difracción asignado a la reflexión (001), la cual nos indica que la láminas silíceas se ordenan perpendicularmente al eje $c$, así como el espacio interlaminar existente entre ellas. El silicato laminar inicial posee un espaciado basal de $15.7 \AA$, que corresponde a la separación existente entre la base de dos láminas de silicato adyacentes, el cual disminuye hasta $12.4 \AA$ cuando tiene lugar el proceso de intercambio catiónico, ya que los cationes $\mathrm{Na}^{+}$presentes entre las láminas son sustituidos por $\mathrm{H}^{+}$mucho menos voluminosos disminuyendo el espaciado basal, $d$, entre las láminas del silicato.

El siguiente paso consiste en el hinchamiento con moléculas de $\mathrm{N}$-hexilamina de forma que el espaciado basal vuelve a aumentar hasta $14.7 \AA$, estando este hecho de acuerdo con la entrada de moléculas de hexilamina entre las láminas inorgánicas cuya longitud molecular es de $6.4 \AA$ A. Una vez hinchado el material se produce la pilarización con el disilano que contiene grupos disulfuro, BTES, observándose en el difractograma un espaciado de $25.3 \AA$, lo que indica que el disilano se ha intercalado en el espacio interlaminar debido a la separación existente entre las láminas.

Por último, se lleva a cabo la extracción ácida del material pilareado con el fin de eliminar las moléculas de agente hinchante (hexilamina), obteniéndose en este caso un espaciado basal de $\left.19.4 \AA \mathrm{d}_{(001)}\right)$, pudiéndose distinguir incluso una banda de difracción que corresponde a un segundo orden $\left(d_{(002)}=9.7 \AA\right)$ que muestra la elevada homogeneidad alcanzada tras el proceso de pilarización. Teniendo en cuenta que el espesor de las láminas de magadiita es aproximadamente de $9.5 \AA$, el espaciado basal finalmente obtenido (19.4 ̊̊) muestra la presencia, en el espacio interlaminar, de fragmentos individuales propildisulfuro provenientes del disilano BTES, dispuestos 
perpendicularmente a las láminas de magadiita. No obstante, considerando que la longitud de las moléculas de BTES es de $15 \AA$, lo más probable es que los pilares orgánicos estén ligeramente inclinados entre las láminas de magadiita.

La conservación de la banda de difracción (020) situada a $24^{\circ}(2 \theta)$, en cada uno de los difractogramas de los materiales que se obtienen durante el proceso de intercalación del disilano, muestra que la estructura de las láminas de magadiita se mantiene inalterada por el proceso de pilarización, ya que esta banda corresponde a la reflexión en la dirección cristalográfica $b$ de cada lámina sin que intervenga, en este caso, el componente $c$ indicativo del orden interlaminar, siendo éste último el que se modifica sustancialmente durante los procesos de hinchamiento y pilarización.

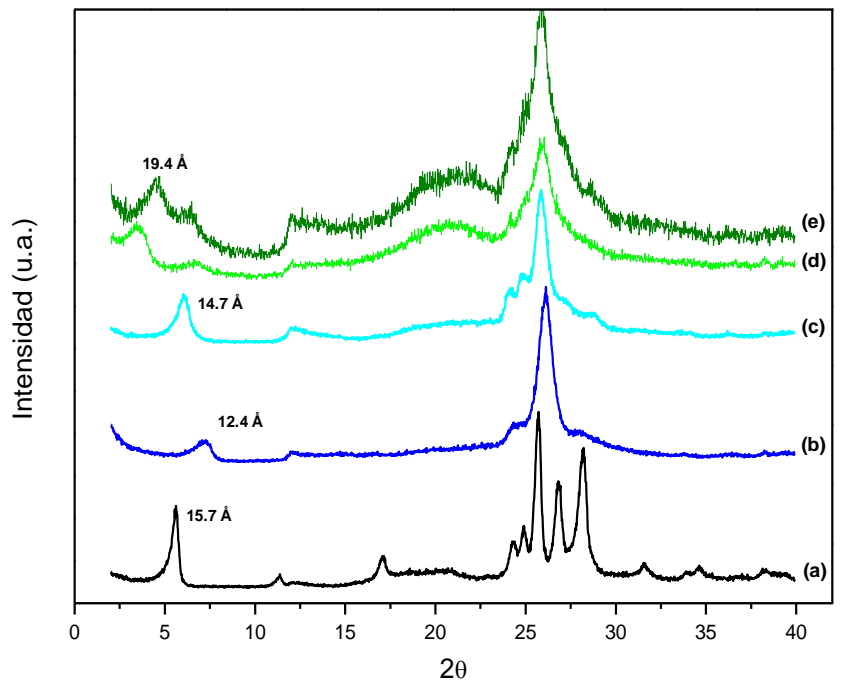

Figura 3.30. Difractogramas de rayos $X$ de: (a) Na-magadiita, (b) H-magadiita, (c) magadiita hinchada con n-hexilamina y (d) muestra pilareada con BTES antes y (e) después del proceso de extracción ácida (MAG-BTES).

Los materiales híbridos pilareados obtenidos utilizando los disilanos BTMN (MAGBTMN) y BTEEthy (MAG-BTEEthy) exhiben unos espaciados basales de $28.3 \AA$ y $25.8 \AA$, respectivamente, tras la intercalación de los correspondientes disilanos. En el caso del material MAG-BTMN, se puede afirmar que las moléculas de disilano están dispuestas perpendicularmente a las láminas inorgánicas del precursor, al tener en cuenta tanto el espesor de las láminas de magadiita (9.5 ̊̊) como la longitud molecular del BTMN (16.3 $)$. 
Para el material híbrido pilareado con BTEEthy, el mayor espaciado basal obtenido, teniendo en cuenta que la longitud molecular de este disilano es de $7.0 \AA$, indicaría que probablemente son dímeros formados por dos moléculas de BTEEthy los que actúan a modo de pilar situándose entre las láminas de magadiita (Figura 3.31.).

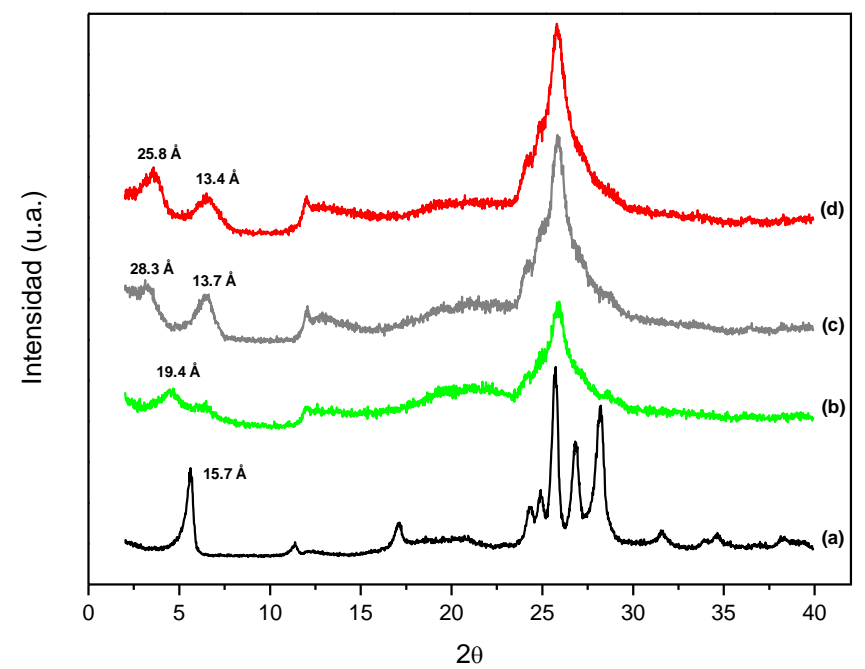

Figura 3.31. Difractogramas de rayos $X$ de: (a) Na-magadiita, (b) MAG-BTES, (c) MAG-BTMN y (d) MAG-BTEEthy. Los difractogramas de los materiales híbridos pilareados corresponden a los sólidos obtenidos tras el proceso de extracción ácida.

\section{Análisis Elemental}

El contenido orgánico presente en los materiales hinchados $\mathrm{y}$, posteriormente pilareados, empleando diferentes disilanos, se muestra en la Tabla 3.3. En ella se pueden observar los datos que confirman la integridad de los fragmentos orgánicos intercalados, puesto que las relaciones molares $\mathrm{C} / \mathrm{S}$ y $\mathrm{C} / \mathrm{N}$ son de 3.1 y 4.7 para las muestras extraídas MAG-BTES y MAG-BTMN, respectivamente, coincidiendo prácticamente con el valor teórico esperado para las moléculas de los disilanos puros, $(C / S)_{B T E S}=3,(C / N)_{B T M N}=4$. Estos datos también confirman que tras el proceso de extracción ácida, la mayoría de las moléculas de hexilamina han sido eliminadas, ya que el contenido en nitrógeno $(\% \mathrm{~N})$ para las muestras pilareadas con BTES y BTEEthy es prácticamente nulo, hecho que demuestra la alta efectividad del proceso de extracción. 
A partir de los datos obtenidos por análisis elemental (Tabla 3.3.), se puede también observar que las moléculas de hexilamina, las cuales son usadas como agentes hinchantes, están presentes, al menos parcialmente, en las muestras antes del proceso de extracción ácida junto con las moléculas de agentes pilareantes BTES o BTEEthy ya que el contenido en carbono $(\% \mathrm{C})$ y la relación $\mathrm{C} / \mathrm{N}$ aumentan con respecto a las muestras extraídas finales. Por el contrario, en el caso de la pilarización con el disilano BTMN, una gran parte de las moléculas de hexilamina son eliminadas durante el proceso de pilarización, produciéndose, en realidad, un intercambio de moléculas de agentes hinchantes por disilanos con grupos diamino. Esta hipótesis se confirma por el hecho de que tanto el contenido en carbono $(\% \mathrm{C}$ ) como la relación $\mathrm{C} / \mathrm{N}$ de las muestras antes (MAGHEX-BTMN) y después de la extracción ácida (MAG-BTMN) se mantiene en valores similares y coincidentes con la casi única presencia de moléculas de BTMN, no detectándose, por lo tanto, la presencia de hexilamina tras el proceso de pilarización.

Tabla 3.3. Incorporación de grupos orgánicos en el espacio interlaminar de la magadiita estimada por análisis elemental.

\begin{tabular}{cccccccc}
\hline Muestra & \%C & \%N & \%S & \%Org. & $\mathbf{C / N}$ & $\mathbf{C} / \mathbf{S}$ & $\left(\mathbf{S i}_{\text {func }} / \mathbf{S i}_{\text {total }}\right)^{\mathbf{a}}$ \\
\hline Magadiita & 6.8 & 1.2 & 0 & 8.0 & 6.6 & - & - \\
MAG-HEX-BTES & 19.4 & 1.5 & 11.1 & 32.0 & 15.1 & 4.7 & - \\
MAG-BTES & 14.0 & 0.1 & 12.2 & 26.3 & - & 3.1 & 0.23 \\
MAG-HEX-BTMN & 12.7 & 3.1 & 0 & 15.8 & 4.4 & - & - \\
MAG-BTMN & 10.6 & 2.6 & 0 & 13.2 & 4.8 & - & 0.11 \\
MAG-HEX-BTEEthy & 11.0 & 1.5 & 0 & 12.5 & 8.6 & - & - \\
MAG-BTEEthy & 4.7 & 0.1 & 0 & 4.8 & - & - & 0.12 \\
\hline
\end{tabular}

${ }^{a}$ : Fracción de átomos de silicio del material híbrido enlazados a fragmentos orgánicos. Valor estimado a partir de análisis elemental.

Además, teniendo en cuenta los datos mostrados en la Tabla 3.3., se puede calcular que el número de átomos de silicio, presentes en los sólidos pilareados, enlazados a fragmentos orgánicos-inorgánicos provenientes de los disilanos es de un 23\% para las muestras pilareadas con grupos disulfuro y en torno a un 11-12 \% para los materiales con fragmentos diamino y etileno situados en el espacio interlaminar. 


\section{Análisis Termogravimétrico}

En la Figura 3.32. se muestran las curvas termogravimétricas y sus respectivas derivadas de las muestras Na-magadiita (Na-MAG), magadiita hinchada con hexilamina (MAG-HEX) y del material híbrido con grupos disulfuro antes (MAG-HEX-BTES) y después de la etapa de extracción ácida (MAG-BTES). En las curvas mostradas se han señalado las principales pérdidas de peso en función del intervalo de temperaturas en las que se producen: I $\equiv(100-250)^{\circ} \mathrm{C}, \mathrm{II} \equiv(250-450)^{\circ} \mathrm{C}$ y III $\equiv(450-650)^{\circ} \mathrm{C}$. Además, en todas ellas, se observa una primera pérdida de peso asignada al agua de hidratación detectada a temperaturas inferiores a $100^{\circ} \mathrm{C}$. Igualmente, en todos los casos, la pérdida de peso III se debe a la generación de agua de deshidroxilación surgida, fundamentalmente, tras la interacción de los grupos silanoles superficiales entre láminas contiguas, una vez la materia orgánica ha sido eliminada a altas temperaturas, produciéndose el colapso interlaminar.

En el caso de la muestra hinchada con hexilamina, MAG-HXA (Figura 4.6.b), se observa que las moléculas de agentes hinchantes se pueden asociar tanto a las pérdidas de peso I como II. Este hecho indicaría que existe hexilamina menos retenida entre las láminas de magadiita, probablemente por su carácter no iónico (I), además de otras moléculas protonadas que interaccionan electrostáticamente con las láminas inorgánicas, estando por ello más retenidas (II).

Al llevarse a cabo el proceso de pilarización, MAG-HEX-BTES (Figura 4.6.c), se observa un fuerte incremento de peso en el intervalo II debido a la presencia de los fragmentos orgánicos propildisulfuro provenientes de las moléculas de disilano BTES usados como agentes de pilarización, permaneciendo las pérdidas de peso I y III prácticamente invariables. Por último, tras el proceso de extracción ácida, MAG-BTES (Figura 4.6.d), la pérdida de peso I ha desaparecido por completo e, incluso, se observa una pequeña disminución de la pérdida II, lo cual corrobora que las moléculas de hexilamina, usadas como agentes hinchantes, situadas en los rangos de temperatura I y II (Figura 4.6.b), han sido efectivamente eliminadas. 
Es importante resaltar que la curva termogravimétrica para el material híbrido MAG-BTES (Figura 4.6.d) permite identificar que en la muestra pilareada finalmente extraída, la estabilidad de los fragmentos orgánicos propildisulfuro se sitúa en torno a los $350^{\circ} \mathrm{C}-450^{\circ} \mathrm{C}$ (intervalo II). Además, los resultados obtenidos a través del análisis termogravimétrico coinciden con el contenido orgánico obtenido a partir de los datos de análisis elemental (Tabla 3.3.), lo que confirma de nuevo la presencia de unidades orgánicas en estos materiales.

(a)

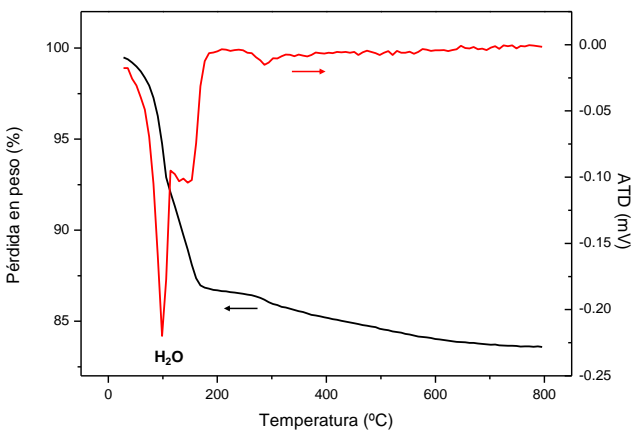

(c)

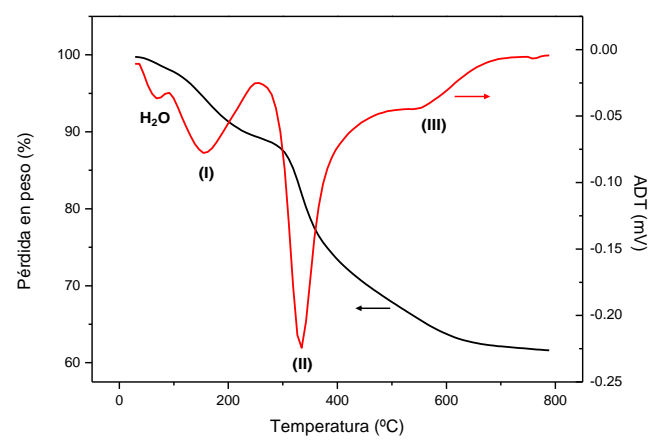

(b)

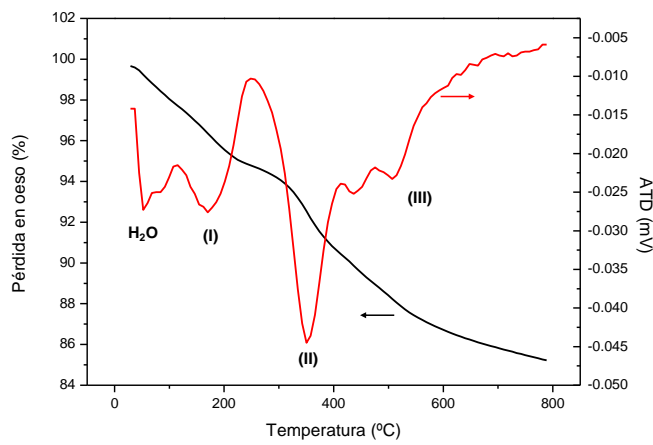

(d)

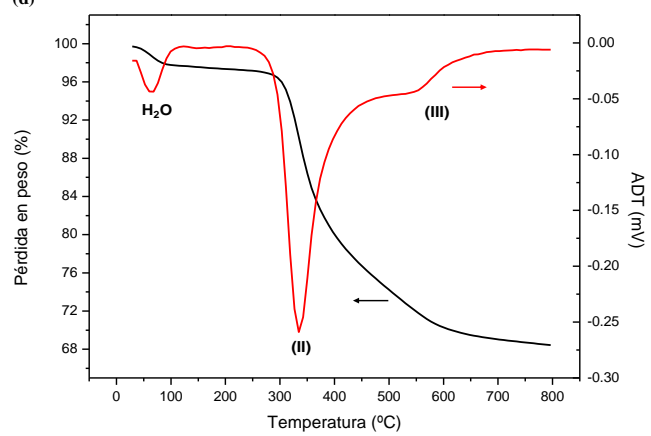

Figura 3.32. Curvas termogravimétricas (ATG) y sus correspondientes derivadas (ATD) de: (a) NaMAG, (b) MAG-HEX, (c) MAG-HEX-BTES y (d) MAG-BTES.

En la Figura 3.33. se muestran las curvas termogravimétricas y sus derivadas para los materiales MAG-BTMN y MAG-BTEEthy después del proceso de extracción ácida. En ellas, al igual que para las muestras MAG-BTES, es posible observar la eliminación de las moléculas de hexilamina después del proceso de extracción ácida, lo cual se confirma por la ausencia de materia orgánica en el intervalo I. La curva termogravimétrica para el 
material híbrido MAG-BTMN permite identificar que a partir de $250^{\circ} \mathrm{C}$ comienzan a descomponerse los grupos etilendiamino presentes en el espacio interlaminar, mientras que para el material MAG-BTEEthy es a partir de los $350^{\circ} \mathrm{C}$ cuando se observa la descomposición de los grupos etileno insertados como pilares orgánicos. Como era de esperar, en ambos casos, al tratarse de los materiales finales ya extraídos, se observan pérdidas de peso asociadas al agua de hidratación, a los fragmentos orgánicos del disilano correspondiente (II) y las atribuidas al agua de deshidroxilación generada a altas temperaturas (III).

(a)

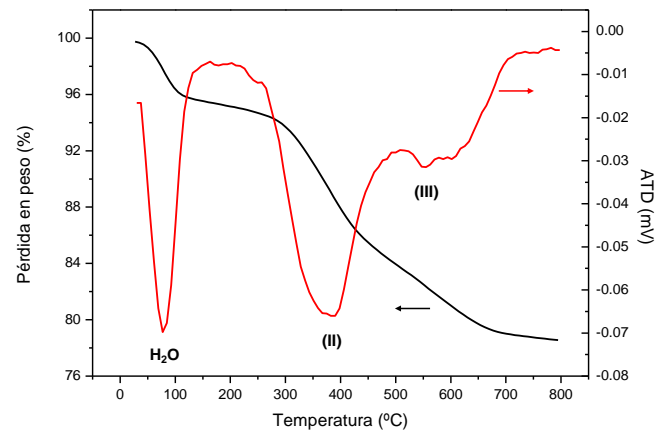

(b)

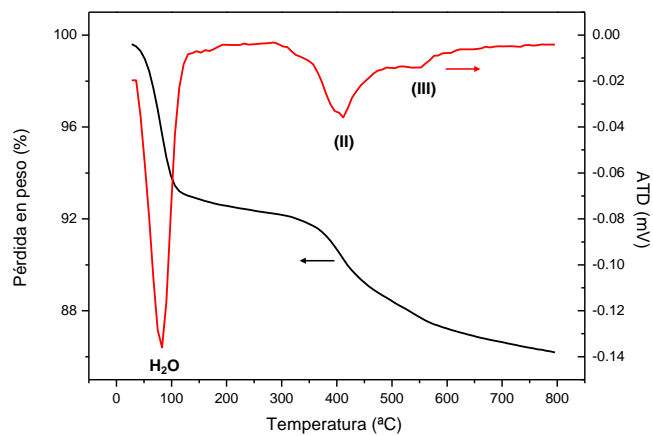

Figura 3.33. Curvas termogravimétricas (ATG) y sus correspondientes derivadas (ATD) de los materiales extraídos: (a) MAG-BTMN y (b) MAG-BTEEthy.

\section{Espectroscopía Infrarroja}

A través de la espectroscopía infrarroja es posible confirmar, no sólo la presencia, sino también la integridad de los fragmentos orgánicos presentes en el espacio interlaminar del precursor inorgánico tipo magadiita (Figura 3.34.). En el caso de la muestra que contiene unidades propildisulfuro entre las láminas (MAG-BTES), se observan bandas de vibración stretching $(v)$ de débil intensidad situadas entre $2700-2780 \mathrm{~cm}^{-1}$ asociadas a la presencia de especies disulfuro. Igualmente, se aprecian con claridad otras bandas de elevada intensidad situadas en torno a $2860 \mathrm{~cm}^{-1}$ debidas a vibraciones stretching asimétricas $(v)$ de los grupos del tipo $(\mathrm{S}-) \mathrm{CH}_{2}$ presentes en los pilares interlaminares. 
En el caso de los materiales laminares híbridos que contienen grupos etilendiamino a modo de pilar (MAG-BTMN), se aprecia una banda a $1650 \mathrm{~cm}^{-1}$ asignada a la vibración de bending $(\delta)$ de los grupos $\mathrm{NH}$ insertados entre las láminas, los cuales presentan otra banda característica, en este caso debida a la vibración stretching (v), centrada alrededor de $3420 \mathrm{~cm}^{-1}$. En el espectro característico de estas muestras, también se observan, en el intervalo entre $2870-2960 \mathrm{~cm}^{-1}$, diferentes bandas que podrían ser atribuidas a vibraciones stretching $(v)$ de las especies insertadas del tipo $(\mathrm{N}-) \mathrm{CH}_{2}$.

La presencia de grupos etileno en los materiales MAG-BTEEthy también se identifica por medio de la espectroscopía infrarroja, observándose una banda alrededor de $1670 \mathrm{~cm}^{-1}$ asignada a la vibración ( $v$ ) de los enlaces $C=C$ incluidos en el fragmento orgánico situado en el espacio interlaminar. Las bandas presentes en el intervalo comprendido entre 2930 y $2975 \mathrm{~cm}^{-1}$ se deberían a las vibraciones de los grupos $=\mathrm{CH}_{2}$.

No es descartable que en el intervalo comprendido entre $2900-3000 \mathrm{~cm}^{-1}$ se puedan observar algunas bandas de vibración correspondientes a moléculas de hexilamina residual empleada como agente hinchante durante el proceso de pilarización.

Es importante remarcar que, en todos los casos, se observan las bandas características de la red del silicato $\left(\sim 1900 \mathrm{~cm}^{-1}\right)$, lo cual indica que la estructura de las láminas de magadiita se mantiene tras el proceso de hibridación por la incorporación de especies orgánicas en el espacio interlaminar. Además, en los espectros se observan diferentes bandas en la zona de hidroxilos $\left(3300-3900 \mathrm{~cm}^{-1}\right)$, sobre todo centradas en torno a $3700-3750 \mathrm{~cm}^{-1}$, asignadas a los silanoles externos ( $\mathrm{Si}-\mathrm{OH}$ ) que están presentes en la superficie de las láminas tras el proceso de intercalación con los respectivos disilanos.

En definitiva, el estudio de los espectros de infrarrojo obtenidos para los materiales híbridos laminares ha servido para verificar que, efectivamente, diferentes grupos orgánicos provenientes de los disilanos empleados como agentes de pilarización están presentes en los sólidos obtenidos conservando su integridad y naturaleza química. 


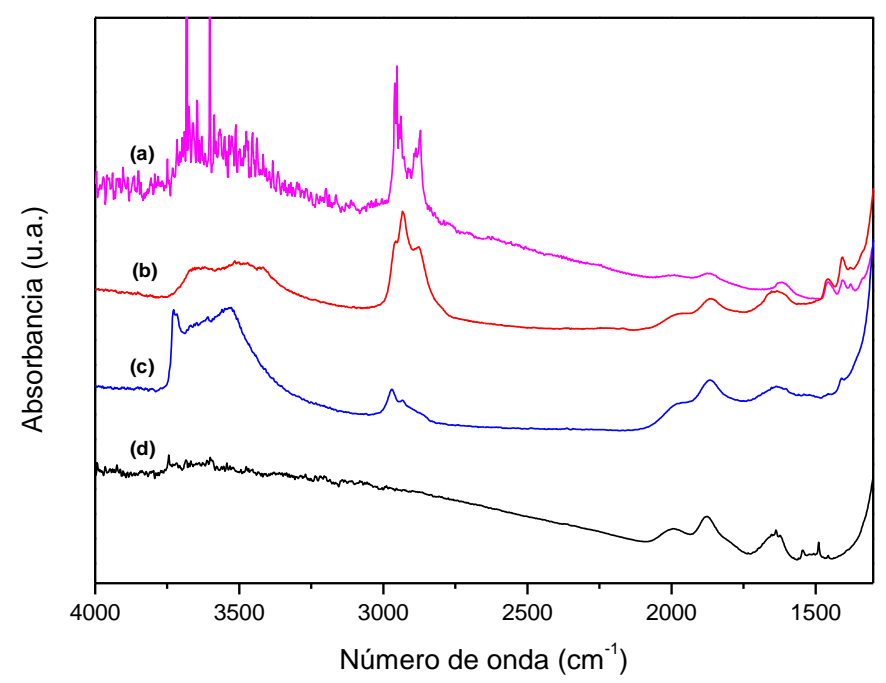

Figura 3.34. Espectros de infrarrojo obtenidos a $300^{\circ} \mathrm{C}$ y vacío de las muestras híbridas laminares derivadas de la magadiita: (a) MAG-BTES, (b) MAG-BTMN, (c) MAG-BTEEthy y (d) Na-MAG.

\section{Resonancia Magnética Nuclear}

En la Figura 3.35. se muestran los espectros de $\mathrm{RMN}$ de ${ }^{13} \mathrm{C}$ de los materiales híbridos MAG-BTES, MAG-BTMN y MAG-BTEEthy obtenidos después del proceso de extracción ácida, en los que se observa una banda alrededor de 12 ppm, en el caso de que los grupos intercalados sean disulfuro y etilendiamino, asignada a especies orgánicas en las que átomos de carbono están directamente enlazados a átomos de silicio. En el caso de los grupos etileno esta banda se sitúa a 145 ppm, debido a la diferente naturaleza de los átomos de carbono que, en este caso, al tratarse de un doble enlace poseen una hibridación $\mathrm{sp}^{2}$. Este hecho confirma la existencia de fragmentos orgánicos intactos, durante el proceso de pilarización, con respecto a su composición en el disilano de partida. Además, es posible asignar unívocamente el resto de átomos de carbono presentes en los agentes de intercalación, corroborando la integridad total de dichos fragmentos orgánicos (Figura 3.35.). 


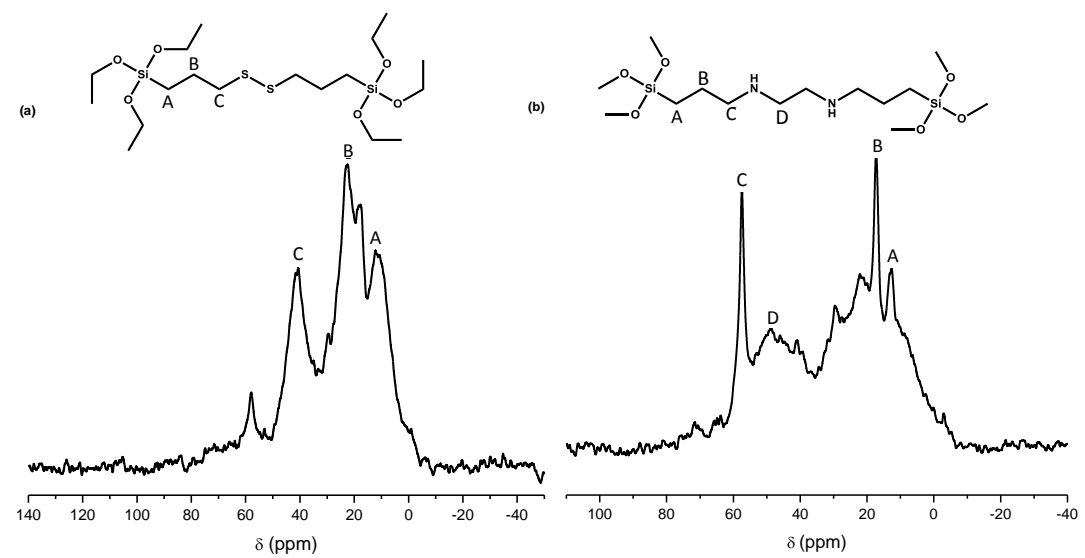

(c)

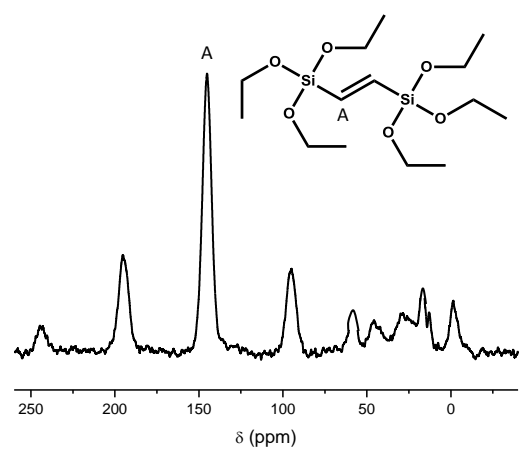

Figura 3.35. Espectros de RMN CP/MAS de ${ }^{13} \mathrm{C}$ de los diferentes materiales híbridos laminares, mostrando la asignación de las bandas a los átomos de carbono contenidos en los sólidos: (a) MAGBTES, (b) MAG-BTMN y (c) MAG-BTEEthy.

No obstante, es a través del RMN de ${ }^{29} \mathrm{Si}$ donde se corrobora que no sólo los fragmentos orgánicos permanecen intactos, sino que se incorporan covalentemente enlazados a las láminas inorgánicas de magadiita, situándose en el espacio interlaminar (Figura 3.36.). Prueba de ello son las bandas que muestra el espectro del material MAGBTES, comprendidas entre -60 y -80 ppm, asignadas a especies de silicio de tipo T, correspondientes a grupos Si-C.

En el caso de los disilanos puros (monómeros), la banda asignada a los átomos de silicio se sitúa en torno a -40 ppm. Sin embargo, cuando estos grupos orgánicos se incorporan actuando como pilares de los materiales híbridos sintetizados, la señal correspondiente a los átomos de silicio enlazados a especies orgánicas cambia a 
desplazamientos $(\delta)$ más bajos (-60 ppm - -80 ppm), lo que confirma su integración covalente en la estructura de los materiales híbridos obtenidos. Además, es posible incluso distinguir, en los espectros de $\mathrm{RMN}$ de ${ }^{29} \mathrm{Si}$, los desplazamientos químicos característicos de los átomos tipo $\mathrm{T}^{3}\left[\mathrm{C}-\mathrm{Si}(\mathrm{OSi})_{3}\right], \mathrm{T}^{2}\left[\mathrm{C}-\mathrm{Si}(\mathrm{OH})(\mathrm{OSi})_{2}\right]$ y $\mathrm{T}^{1}\left[\mathrm{C}-\mathrm{Si}(\mathrm{OH})_{2}(\mathrm{OSi})\right]$. Igualmente, también se observan las bandas convencionales situadas entre -100 y -110 ppm asignadas a los átomos de silicio $\mathrm{Q}^{3}\left[\mathrm{Si}(\mathrm{OH})(\mathrm{OSi})_{3}\right]$ y $\mathrm{Q}^{4}\left[\mathrm{Si}(\mathrm{OSi})_{4}\right]$, debidas a las unidades de tetraédricas $\left[\mathrm{SiO}_{4}\right]$ y a los silanoles superficiales que componen las láminas inorgánicas de magadiita.

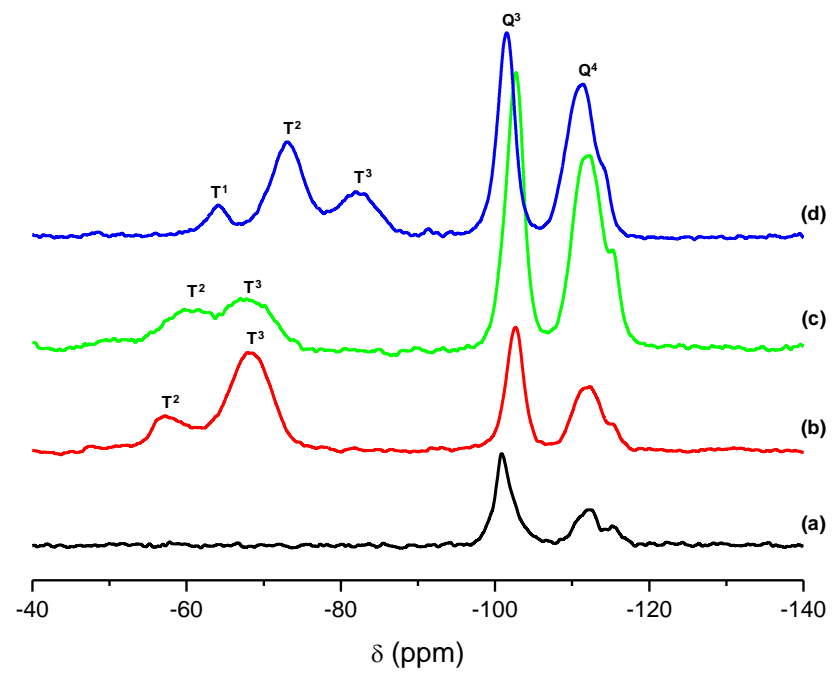

Figura 3.36. Espectros de RMN BD/MAS de ${ }^{29} \mathrm{Si}$ de los diferentes materiales híbridos laminares, mostrando la asignación de átomos de silicio T y Q: (a) Magadiita, (b) MAG-BTES, (c) MAG-BTMN y (d) MAG-BTEEthy.

\section{Análisis Textural}

Las isotermas de adsorción de nitrógeno de los materiales híbridos extraídos, Figura 3.37., son de tipo $\left.\right|^{[98]}$, lo que indica que los sólidos pilareados obtenidos son de naturaleza, esencialmente, microporosa. No obstante, es posible observar diferencias entre las distintas muestras en función del disilano empleado en el proceso de pilarización. 


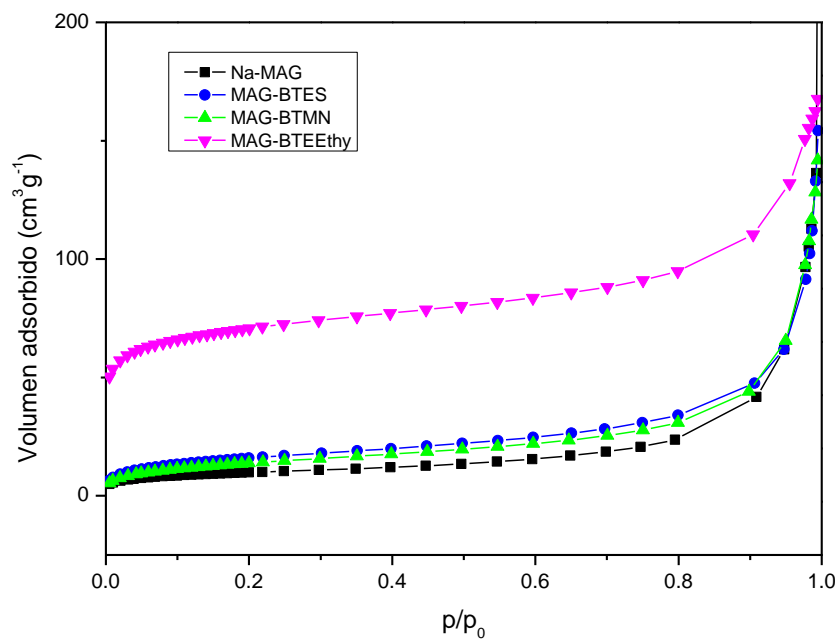

Figura 3.37. Isotermas de adsorción de nitrógeno de los diferentes materiales híbridos laminares derivados de la magadiita.

Si se comparan los resultados de superficie específica y volumen poroso obtenidos (Tabla 3.4.) con los que muestra una magadiita convencional, se puede observar que, en general, el proceso de pilarización con disilanos conlleva la generación de galerías microporosas en la región interlaminar, formadas entre las láminas inorgánicas y los pilares orgánicos intercalados, aumentando la accesibilidad del ácido silícico de partida. Este hecho se traduce en un aumento tanto en la superficie total BET como en el volumen total de los materiales híbridos. Los resultados obtenidos reflejan que, aproximadamente, el $75 \%$ de la superficie total corresponde a canales y cavidades microporosas generadas tras el proceso de pilarización. La elevada contribución microporosa se puede atribuir, probablemente, al gran número de grupos silanoles presentes en la superficie de las láminas de magadiita (relación $Q^{3} / Q^{4} \sim 0.5$ ), lo que contribuiría a la intercalación covalente de una elevada concentración de pilares orgánicos próximos entre sí, facilitando la generación de galerías microporosas. Por el contrario, en el caso de precursores zeolíticos laminares (tipo PREFER o MWW), el número de silanoles superficiales presentes en los precursores se reducen a la mitad en comparación con los ácidos silícicos (relación $Q^{3} / Q^{4} \sim 0.25$ ), lo que facilitaría que un menor número de pilares se 
inserten en el espacio interlaminar, estando más separados entre sí. Todo ello podría favorecer la generación, en este caso, de galerías mesoporosas en los materiales pilareados de naturaleza zeolítica. Este hecho será considerado, con más detalle, posteriormente, cuando el precursor laminar MWW sea sometido a procesos de pilarización con disilanos (sección 3.4.).

Tabla 3.4. Propiedades texturales de los materiales híbridos pilareados derivados de la magadiita.

\begin{tabular}{cccccc}
\hline Muestra & $\begin{array}{c}\mathrm{S}_{\mathrm{BET}} \\
\left(\mathbf{m}^{2} \mathbf{g}^{-1}\right)\end{array}$ & $\begin{array}{c}\mathrm{S}_{\mathrm{MIC}} \\
\left(\mathbf{m}^{2} \mathbf{g}^{-1}\right)\end{array}$ & $\begin{array}{c}\mathrm{S}_{\mathrm{EXT}}{ }^{\mathrm{a}} \\
\left(\mathbf{m}^{2} \mathbf{g}^{-1}\right)\end{array}$ & $\begin{array}{c}\mathrm{V}_{\mathrm{TOT}} \\
\left(\mathrm{cm}^{3} \mathbf{g}^{-1}\right)\end{array}$ & $\begin{array}{c}\mathrm{V}_{\text {MIC }} \\
\left(\mathbf{c m}^{3} \mathbf{g}^{-1}\right)\end{array}$ \\
\hline Magadiita & 35.5 & 0.5 & 35.0 & 0.198 & 0 \\
MAG-BTES & 96.8 & 81.3 & 15.5 & 0.237 & 0.057 \\
MAG-BTMN & 51.1 & 41.8 & 9.3 & 0.219 & 0.024 \\
MAG-BTEEthy & 238.3 & 180.0 & 58.3 & 0.259 & 0.086 \\
\hline
\end{tabular}

${ }^{a}: S_{\mathrm{EXT}}=\left(\mathrm{S}_{\mathrm{BET}}-\mathrm{S}_{\mathrm{MIC}}\right)$

\section{Microscopia Electrónica de Transmisión}

La morfología laminar de los precursores silícicos tipo magadiita, así como de los materiales híbridos obtenidos, tras sucesivos procesos de pilarización empleando disilanos, se estudió a través de microscopia electrónica de transmisión, TEM (Figura 3.38.). En el precursor laminar, Na-Magadiita, se aprecia una organización típicamente laminar, observándose diferentes capas silíceas apiladas que constituyen cada uno de los cristales individuales (Figura 3.38.a). Después del proceso de intercalación, los materiales finalmente extraídos, MAG-DISILANO, presentan una morfología diferente respecto al precursor de partida. En concreto, se distinguen cristales de tamaños más reducidos y con aspecto algodonoso que conservan la ordenación laminar del precursor inicial, observándose capas silíceas adyacentes apiladas entre sí. (Figura 3.38.b, c, d), siendo esta morfología también apreciada en materiales laminares con cierto grado de desorden, tales como las zeolitas deslaminadas ITQ-2 e ITQ- $6^{[99]}$. 
Es importante destacar que, a partir del espesor de los cristales observados, es posible determinar que el número de láminas silícicas que se apilan por bloques en los sólidos pilareados está comprendido entre 15 y 40, considerando que el grosor de cada lámina de magadiita es de $9.5 \AA$ A . En el caso específico del material MAG-BTMN (Figura 3.38.c) es posible incluso apreciar el espaciado entre dos láminas contiguas separadas por fragmentos propiletilendiamino provenientes del disilano BTMN, siendo el valor de separación interlaminar estimado de $\sim 26.8 \AA ̊$, el cual se aproxima al determinado a través de DRX (28.3 $\AA$, ver Figuras 3.29. y 3.31.). Estos resultados confirman la efectividad del proceso de pilarización llevado a cabo para la preparación final de materiales orgánicosinorgánicos laminares derivados de la magadiita.
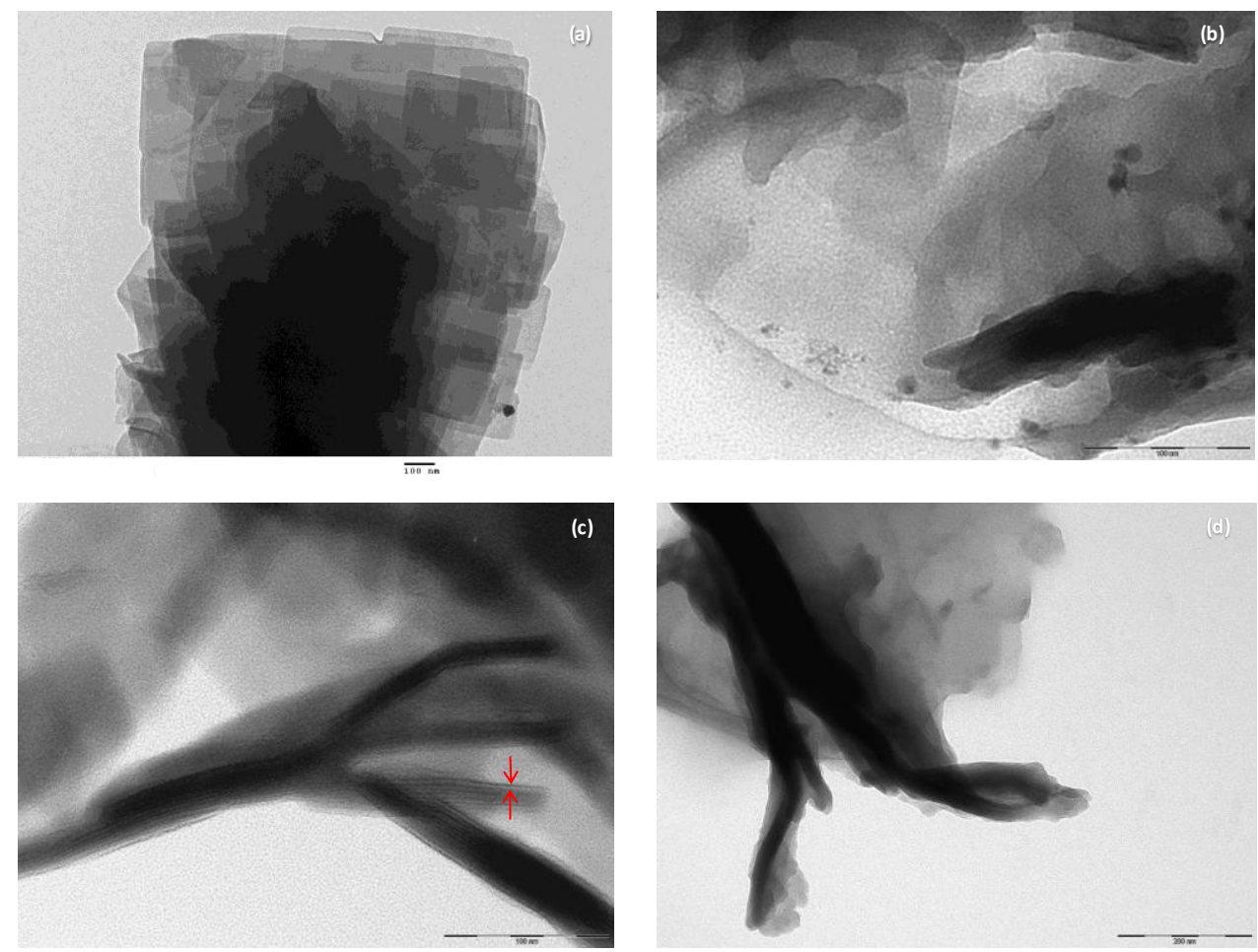

Figura 3.38. Fotografías de microscopía electrónica de transmisión para las muestras: (a) Na-MAG, (b) MAG-BTES, (c) MAG-BTMN y (d) MAG-BTEEthy. Escala de referencia para las fotografías (a), (b) y (c) $100 \mathrm{~nm}$ y (d) $200 \mathrm{~nm}$. 


\subsubsection{Materiales híbridos laminares con centros ácidos. Actividad catalítica}

En el caso particular del material híbrido sintetizado usando el disilano BTES como agente de pilarización, se han reducido los fragmentos disulfuro (S-S) hasta obtener grupos tiol (-SH), empleando para ello el compuesto tris(2-carboxietil)fosfina, $\mathrm{P}\left(\mathrm{CH}_{2} \mathrm{CH}_{2} \mathrm{COOH}\right)_{3}$, como agente reductor. Posteriormente, tras un tratamiento final de

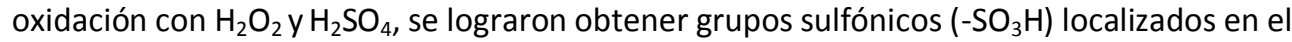
espacio interlaminar (ver parte experimental en la sección 3.6. y Figura 3.39.). En la Figura 3.40. se presentan los espectros de RMN de ${ }^{13} \mathrm{C}$ obtenidos para dicha muestra tras los dos pasos sucesivos de reducción-oxidación llevados a cabo, observándose una disminución en la intensidad de la banda centrada a 40 ppm correspondiente a los grupos disulfuro, así como la aparición de una nueva banda a 26 ppm debida a los grupos tiol, que aparecen tras el primer paso de reducción. Después del segundo paso de oxidación, se aprecia una señal adicional a 50 ppm, la cual es característica de los grupos sulfónicos. Estos resultados confirman la efectividad del proceso llevado a cabo para la obtención de un material con centros ácidos en su estructura (MAG- $\left.\mathrm{SO}_{3} \mathrm{H}\right)$.

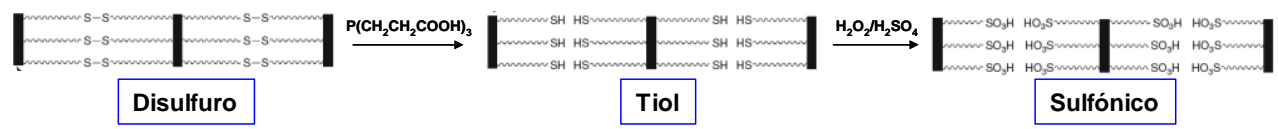

Figura 3.39. Transformación de los grupos disulfuro, presentes en el espacio interlaminar de la magadiita pilareada, en fragmentos tiol y sulfónico tras sucesivos procesos de reducción y oxidación.

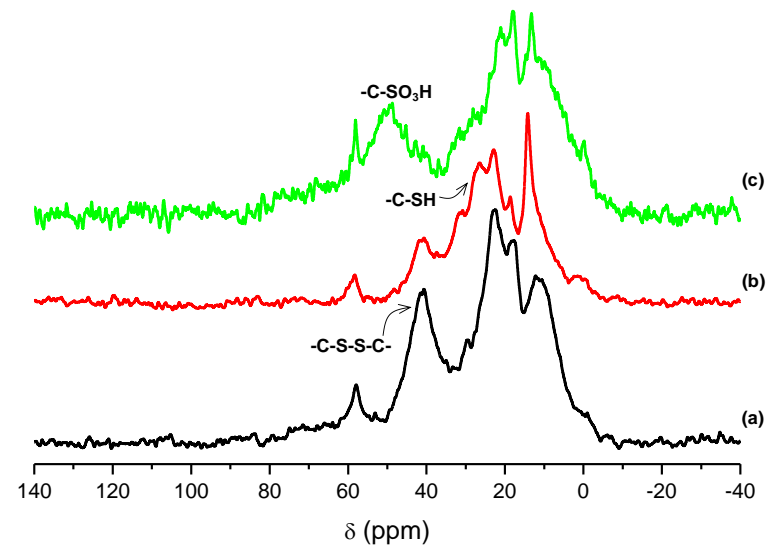

Figura 3.40. Espectros de RMN BD/MAS de ${ }^{13} \mathrm{C}$ de la muestra híbrida MAG-BTES (a), tratada con $\mathrm{P}\left(\mathrm{CH}_{2} \mathrm{CH}_{2} \mathrm{COOH}\right)_{3}$ como agente reductor (b) y, tras un proceso de oxidación con $\mathrm{H}_{2} \mathrm{O}_{2}$ y $\mathrm{H}_{2} \mathrm{SO}_{4}$ (c). 
Esta muestra de magadiita con grupos sulfónicos, se utilizó para realizar una valoración ácido-base que reveló que este material híbrido posee aproximadamente 1.0 $\mathrm{mmol} \mathrm{H}^{+}$por gramo de muestra, siendo este valor comparable al de otros materiales micro y mesoporosos descritos en el estado del arte (Tabla 3.5.), los cuales presentan este tipo de centros bien insertados en su entramado estructural o bien colgando hacia el interior de sus cavidades porosas, siendo normalmente empleados como catalizadores ácidos en diferentes procesos de reacción ${ }^{[100]}$.

Tabla 3.5. Sólidos de referencia descritos en la bibliografía con centros ácidos presentes en su estructura. Comparación entre la cantidad de centros ácidos accesibles estimados a través de valoraciones ácido-base.

\begin{tabular}{|c|c|c|c|c|c|}
\hline Material & Características & Síntesis & Disilano & $\begin{array}{l}\text { Centros } \\
\text { ácidos }\end{array}$ & $\begin{array}{c}\mathrm{mmol} \\
\mathrm{H}^{+} \mathrm{g}^{-1}\end{array}$ \\
\hline SBA-1 & $\begin{array}{c}\text { Material } \\
\text { mesoporoso }\end{array}$ & Condensación & - & $-\mathrm{SO}_{3} \mathrm{H}$ & 0.32 \\
\hline H-ZSM5 & $\begin{array}{c}\text { Zeolita } \\
\text { microporosa }\end{array}$ & Hidrotermal & - & $\mathrm{H}^{+}$ & 0.39 \\
\hline $\mathrm{H}_{2} \mathrm{SO}_{4}$ & Soportado sílice & Impregnación & - & $\mathrm{H}^{+}$ & 0.50 \\
\hline Nafión & Polímero ácido & - & - & $\mathrm{H}^{+}$ & 0.80 \\
\hline $\mathrm{PMO}^{\mathrm{a}}$ & $\begin{array}{c}\text { Hibrido } \\
\text { mesoporoso }\end{array}$ & Anclaje & BTEE $^{\text {b }}$ & $-\mathrm{SO}_{3} \mathrm{H}$ & 0.80 \\
\hline PMO & $\begin{array}{c}\text { Híbrido } \\
\text { mesoporoso }\end{array}$ & Condensación & BTEE & $-\mathrm{SO}_{3} \mathrm{H}$ & 0.90 \\
\hline PMO & $\begin{array}{c}\text { Híbrido } \\
\text { mesoporoso }\end{array}$ & Anclaje & BTEB $^{\mathrm{C}}$ & $-\mathrm{SO}_{3} \mathrm{H}$ & 0.90 \\
\hline PMO & $\begin{array}{c}\text { Híbrido } \\
\text { mesoporoso }\end{array}$ & Condensación & BTEB & $-\mathrm{SO}_{3} \mathrm{H}$ & 0.97 \\
\hline PMO & $\begin{array}{c}\text { Híbrido } \\
\text { mesoporoso }\end{array}$ & Condensación & BTEBifenil $^{d}$ & $-\mathrm{SO}_{3} \mathrm{H}$ & 0.99 \\
\hline MAG-BTES & $\begin{array}{l}\text { Muestra } \\
\text { estudiada }\end{array}$ & Pilarización & BTES $^{e}$ & $-\mathrm{SO}_{3} \mathrm{H}$ & 1.00 \\
\hline FSM & $\begin{array}{c}\text { Material } \\
\text { mesoporoso }\end{array}$ & Anclaje & - & $-\mathrm{SO}_{3} \mathrm{H}$ & 1.11 \\
\hline SBA-15 & $\begin{array}{c}\text { Material } \\
\text { mesoporoso }\end{array}$ & Condensación & - & $-\mathrm{SO}_{3} \mathrm{H}$ & 1.26 \\
\hline SBA-15 & $\begin{array}{c}\text { Material } \\
\text { mesoporoso }\end{array}$ & Condensación & - & Aril- $\mathrm{SO}_{3} \mathrm{H}$ & 1.34 \\
\hline PMO & $\begin{array}{c}\text { Híbrido } \\
\text { Mesoporoso }\end{array}$ & Condensación & BTEE & Aril- $\mathrm{SO}_{3} \mathrm{H}$ & 1.38 \\
\hline HY & $\begin{array}{c}\text { Zeolita } \\
\text { microporosa }\end{array}$ & Hidrotermal & - & $\mathrm{H}^{+}$ & 1.90 \\
\hline Amberlyst-15 & Resina ácida & - & - & $\mathrm{H}^{+}$ & 4.65 \\
\hline
\end{tabular}


Para comprobar la actividad catalítica del material híbrido laminar $\mathrm{MAG}-\mathrm{SO}_{3} \mathrm{H}$, el cual contiene grupos sulfónicos accesibles en el espacio interlaminar, se empleó como catalizador ácido en la reacción de esterificación entre el citronelol y el ácido acético para la obtención del acetato de citronelol como producto principal (Esquema 3.1.). EI citronelol es un monoterpeno natural que se encuentra en aceites de rosa o geranio, siendo el acetato de citronelol ampliamente usado en perfumería al estar presente en fragancias florales, tales como en colonias de geranio, lavanda, lirio, rosa y cítricos ${ }^{[101]}$. En concreto, al emplear el material MAG- $\mathrm{SO}_{3} \mathrm{H}$ como catalizador ácido en dicha reacción de esterificación, se obtuvo un rendimiento a acetato de citronelol del $42 \%$ después de 4 horas de reacción (Figura 3.41.). Este prometedor resultado confirma la potencialidad de los materiales pilareados que contienen centros ácidos insertados entre las láminas inorgánicas de magadiita para actuar como catalizadores efectivos en diferentes procesos de reacción.

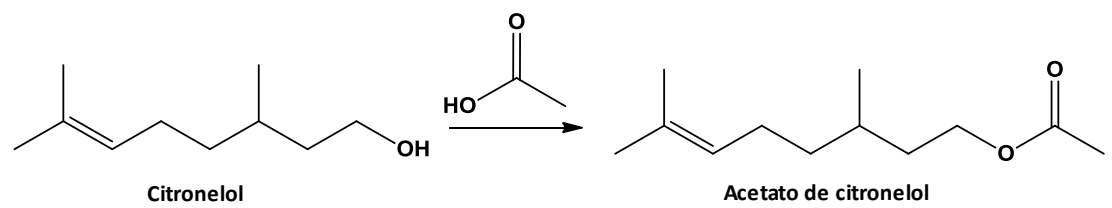

Esquema 3.1. Esterificación entre el citronelol y el ácido acético.

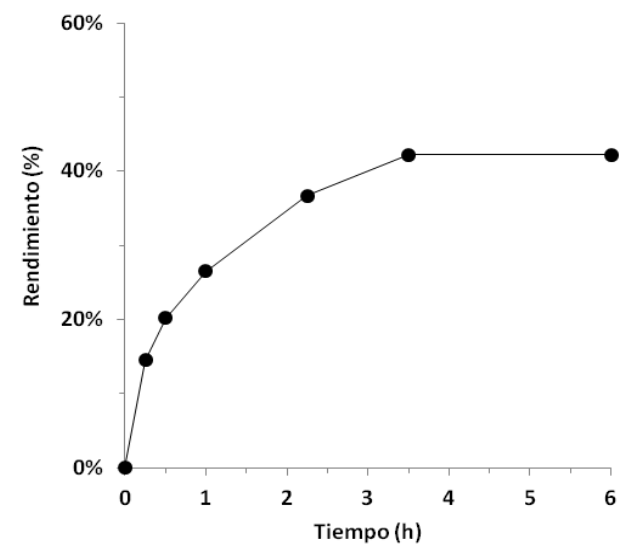

Figura 3.41. Rendimiento a acetato de citronelol frente al tiempo cuando la reacción se llevó a cabo en presencia del catalizador $\mathrm{MAG}-\mathrm{SO}_{3} \mathrm{H}$. Condiciones de reacción: $3.9 \mathrm{mmol}$ citronelol, $2.3 \mathrm{mmol}$ ácido acético, $30 \mathrm{mg}$ de catalizador o $0.56 \% \mathrm{~mol}, 100^{\circ} \mathrm{C}$, sin disolvente. 


\subsubsection{Materiales híbridos laminares con centros básicos. Actividad catalítica}

En el caso del material híbrido sintetizado empleando el disilano que contiene grupos etilendiamino (MAG-BTMN) como agente de pilarización, se procedió a valorar el número de centros básicos (-NH) que posee a través de análisis elemental y cuáles de ellos son realmente accesibles a través de una valoración ácido-base. Los resultados obtenidos confirman que la totalidad de grupos amino incorporados en la región interlaminar son accesibles, conteniendo los materiales pilareados finales $\sim 2.0 \mathrm{mmol}$ de grupos amino ($\mathrm{NH})$ por gramo de muestra.

Con el objetivo de confirmar la actividad catalítica de este tipo de sólidos, los materiales pilareados que poseen centros básicos en su estructura, fueron empleados como catalizadores en la reacción de Knoevenagel entre benzaldehído y cianoacetato de etilo (Esquema 3.2.). En general, la condensación de Knoevenagel entre compuestos carbonílicos y grupos metilénicos activados es de utilidad para producir derivados olefínicos de gran interés, al poder ser empleados como aditivos en alimentación, cosmética o en productos farmacológicos ${ }^{[102]}$.
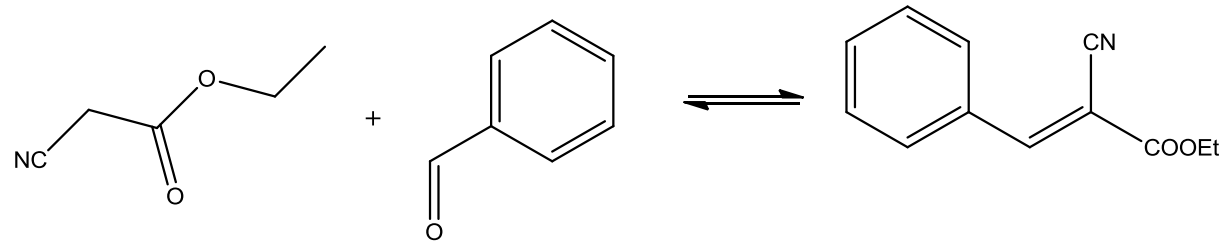

Esquema 3.2. Condensación de Knoevenagel entre benzaldehído y cianoacetato de etilo.

En la Figura 3.42. se muestran los resultados obtenidos, observándose que, a temperatura ambiente (ver condiciones experimentales de reacción en la sección 3.6.), se obtiene un rendimiento del $87 \%$ al producto de condensación tras 24 horas de reacción, con una selectividad del $100 \%$.

Si estos resultados se comparan con aquellos obtenidos al emplear una sílice amorfa mesoporosa como catalizador, la cual contiene igualmente grupos diamino en su estructura (HYB-BTMN), se observa que se obtienen rendimientos mayores a tiempos más 96 
cortos, aunque tras 24 horas los resultados se equiparan para ambos catalizadores. La razón podría deberse a los problemas de difusión de reactivos y productos presentes en el catalizador pilareado, asociados, sobre todo, a su reducida porosidad, los cuales son minimizados en el caso de la sílice mesoporosa (Tabla 3.6.). En definitiva, se puede concluir afirmando que los materiales híbridos laminares, MAG-BTMN, pilareados con fragmentos orgánicos, los cuales contienen grupos diamino activos y accesibles, podrían ser empleados con éxito en procesos de catálisis básica.

Tabla 3.6. Propiedades texturales y análisis elemental de los catalizadores orgánicos-inorgánicos que contienen grupos diamino.

\begin{tabular}{cccccc}
\hline Muestra & $\mathrm{S}_{\mathrm{BET}}\left(\mathrm{m}^{2} \mathbf{g}^{-1}\right)$ & $\mathrm{S}_{\mathrm{EXT}}\left(\mathbf{m}^{2} \mathbf{g}^{-1}\right)$ & $\mathbf{V}_{\text {Total }}\left(\mathrm{cm}^{3} \mathbf{g}^{-1}\right)$ & $\mathbf{\% N}^{\mathrm{a}}$ & $\mathbf{m m o l ~ N ~}^{-\mathbf{1 b}}$ \\
\hline MAG-BTMN & 51 & 9 & 0.22 & 2.6 & 1.9 \\
HYB-BTMN & 313 & 313 & 0.24 & 4.1 & 2.9 \\
\hline
\end{tabular}

${ }^{a}$ : Contenido en nitrógeno determinado por análisis elemental; ${ }^{b}$ : Contenido en grupos amino determinado por valoraciones ácido-base.

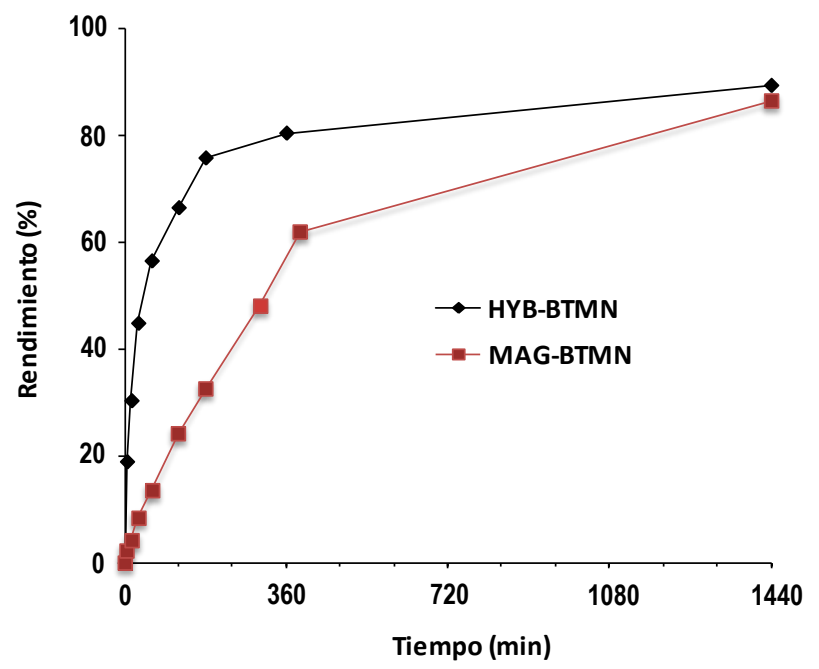

Figura 3.42. Resultados de actividad catalítica del material híbrido pilareado MAG-BTMN y el sólido basado en sílice mesoporosa HYB-BTMN para llevar a cabo la reacción de condensación de Knoevenagel entre benzaldehído y cianoacetato de etilo. Condiciones de reacción: benzaldehído (1.9 $\mathrm{mmol}$ ) y cianoacetato de etilo $(1.7 \mathrm{mmol})$, atmósfera inerte $\left(\mathrm{N}_{2}\right), 298 \mathrm{~K}$ y $7 \% \mathrm{~mol}$ de $\mathrm{N}$. 


\subsection{Materiales híbridos pilareados de naturaleza zeolítica con topología tipo} MWW

En el apartado anterior se han estudiado diferentes materiales laminares híbridos cuya parte inorgánica está basada en silicatos laminares tales como la magadiita. No obstante, estos materiales muestran con frecuencia una distribución porosa irregular con una accesibilidad reducida. Estas desventajas unidas a la escasa cristalinidad mostrada por los silicatos laminares puede ser un serio inconveniente para la potencial aplicación de los materiales híbridos como catalizadores. Una alternativa viable para superar estos problemas podría venir del uso de precursores zeolíticos laminares, los cuales exhiben una elevada cristalinidad y orden a corto alcance, actuando como unidades inorgánicas de estructura. Su empleo serviría para preparar materiales híbridos laminares homogéneos de elevada accesibilidad, a través de la interacción covalente con moléculas de disilano que se sitúan a modo de pilares entre las láminas inorgánicas. Las características zeolíticas de estos precursores laminares facilitarían la preparación de materiales híbridos con alta estabilidad mecánica y térmica, combinada con una elevada accesibilidad debido a la presencia de especies orgánicas en el espacio interlaminar, generando nuevos canales y cavidades en dicha región.

Un buen candidato para llevar a cabo esta propuesta, sería el precursor zeolítico laminar de la zeolita MCM-22 ${ }^{[103]}$, cuyas láminas presentan una estructura tipo MWW. La versatilidad de este precursor ha sido claramente demostrada, ya que a partir de él se han obtenido bien materiales pilareados puramente silíceos como la zeolita MCM-36 ${ }^{[104]}$, o bien deslaminados como la zeolita ITQ $-2^{[77 a]}$. Incluso recientemente, Tatsumi y col. han introducido entre láminas tipo MWW pilares compuestos por un solo átomo de silicio para obtener un nuevo tipo de zeolitas expandidas denominadas $\mathrm{IEZ}^{[74]}$, tal y como ha sido mostrado previamente en la introducción. Además, estudios relacionados con el anclaje de titanoceno sobre láminas de naturaleza $\mathrm{MWW}^{[78]}$ o la encapsulación de compuestos fotoluminiscentes en el interior de las copas externas de las láminas de la zeolita ITQ-2 ${ }^{\text {[84a] }}$, muestran la capacidad del precursor laminar tipo MWW para generar materiales híbridos. 
En este caso, se pretende preparar un material híbrido zeolítico con propiedades laminares partiendo del precursor laminar MWW por intercalación de disilanos específicos que se sitúan en el espacio interlaminar, siendo la primera vez que se obtiene este tipo de materiales híbridos pilareados empleando láminas zeolíticas y disilanos como unidades estructurales. La posterior funcionalización de los pilares orgánicos introducidos, junto con los centros activos presentes en las láminas inorgánicas tipo MWW, permitirían la obtención de materiales híbridos multifuncionales con sistemas porosos definidos aptos para llevar a cabo reacciones catalíticas consecutivas o en cascada en un solo paso.

\subsubsection{Síntesis y caracterización}

\section{Sintesis}

El material híbrido denominado MWW-BTEB, así como el precursor zeolítico a partir del que se obtiene, se sintetizan siguiendo el procedimiento descrito en el apartado 3.6.2. La preparación del material híbrido orgánico-inorgánico, MWW-BTEB, a partir del precursor zeolítico laminar, MWW-P, y moléculas de silsesquioxano con grupos arílicos tipo puente, se llevó a cabo después del hinchamiento e intercalación del precursor laminar con moléculas de alquilamonio de cadena larga (CTMA) y el disilano 1,4bis(trietoxisilil)benceno (BTEB), respectivamente. Tras un proceso de extracción ácida, para la eliminación de las moléculas empleadas como agentes hinchantes, se obtuvo finalmente el material orgánico-inorgánico pilareado. En estos sólidos híbridos, los espaciadores orgánicos están covalentemente enlazados a las láminas zeolíticas por reacción de los grupos alcóxido terminales, procedentes de los disilanos, con los grupos silanol $(\mathrm{Si}-\mathrm{OH})$ presentes en la superficie de las láminas inorgánicas MWW (ver Figura 3.43.).

Como se puede observar en el esquema mostrado, los materiales zeolíticos de naturaleza MWW, poseen una estructura basada en láminas ordenadas que surgen a partir de su correspondiente precursor zeolítico (MWW-P). En esta familia de zeolitas, se obtiene la topología 3D MWW cuando las láminas se unen entre sí tras, por ejemplo, un proceso de calcinación para eliminar las moléculas orgánicas de template situadas en el 
espacio interlaminar (MWW-P-CAL). La estructura final de los materiales tipo MWW ya condensados presenta dos sistemas independientes de poros: uno formado por cavidades de $12 \mathrm{MR}(18 \times 7 \AA$ ) conectadas por ventanas de 10MR, y otro definido por un sistema de canales sinusoidales de $10 \mathrm{MR}$, presentes en el interior de cada lámina. Este tipo de estructura microporosa resulta inaccesible a moléculas de elevadas dimensiones moleculares. Por ello, mediante la intercalación de moléculas orgánicas en el espacio interlaminar, a modo de pilar, se pretende tanto aumentar su accesibilidad como introducir nuevas funcionalidades en los materiales, como más adelante será mostrado en detalle.

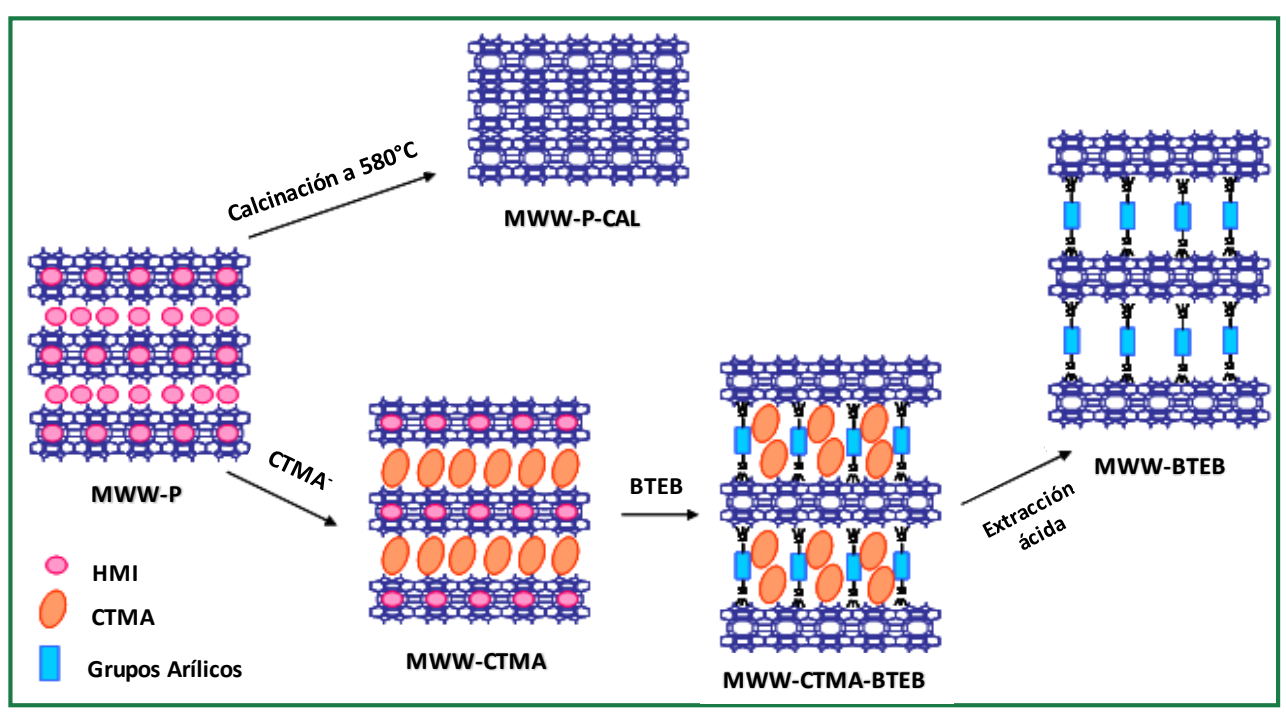

Figura 3.43. Esquema de preparación de los materiales híbridos pilareados, MWW-BTEB, obtenidos a partir del precursor zeolítico MWW-P.

\section{Caracterización}

\section{Difracción de Rayos X}

La efectiva intercalación de los grupos silil-arilo en el espacio interlaminar del precursor zeolítico de los materiales tipo MWW, se puede confirmar a través de difracción de rayos $X$ (Figura 3.44.). En esta figura se aprecia como el precursor laminar presenta las bandas características de los materiales tipo MWW a $27.1 \AA$ y $13.6 \AA$, asignadas a las 
reflexiones de primer y segundo orden, (001) y (002), lo que confirma que las láminas inorgánicas están ordenadas perpendicularmente al eje c. Teniendo en cuenta que el espesor de cada una de las láminas tipo MWW es de $25 \AA$, la presencia en la región interlaminar de moléculas de agua y del agente director de estructura (hexametilenimina, HMI) hace que para la primera reflexión se observe un espaciado basal de aproximadamente $27 \AA$ A. Después del proceso de hinchamiento, el espaciado basal aumenta a $36.0 \AA ̊$ debido a la incorporación de moléculas de CTMA en el espacio interlaminar (MWW-CTMA). A continuación, cuando tiene lugar el proceso de intercalación con moléculas del disilano BTEB, el espaciado basal vuelve a aumentar hasta 40.1 Å en el material híbrido final (MWW-BTEB).

Si se considera el espesor de las láminas de las zeolitas tipo MWW (25 ̊̊), el espacio ocupado por el grupo orgánico intercalado, proveniente del disilano, es de $15.1 \AA$, estando este valor próximo a la longitud de dos moléculas de BTEB que han condensado entre sí, las cuales deben actuar como pilares (Figura 3.45.). Este hecho confirma que los disilanos de partida, conteniendo en realidad dos grupos silil-benceno condensados (dímeros), se intercalaron satisfactoriamente en el espacio interlaminar, perpendicularmente a las láminas del precursor.

El espectro de difracción de rayos $X$ del material híbrido antes del proceso de extracción ácida (MWW-CTMA-BTEB) muestra dos picos a $44.5 \AA$ y $37.0 \AA$, lo que indica que el espacio interlaminar no es uniforme, en esta etapa, debido a la presencia de moléculas de CTMA y BTEB, simultáneamente, que impiden que la separación entre las láminas sea homogénea. Cuando se eliminan las moléculas de CTMA tras el proceso de extracción ácida (MWW-BTEB), se observa la aparición de una sola banda de difracción a bajo ángulo (40.1 ̊̊) de elevada intensidad, que indica la obtención de un material zeolítico laminar con una separación interlaminar constante debido a la intercalación de fragmentos arílicos, distribuidos homogéneamente entre las láminas tipo MWW. Este fenómeno se explica por la condensación que se produce entre los silanoles externos y los grupos alcóxido terminales de las moléculas de BTEB empleadas como agentes de pilarización. 
Es importante remarcar que en todos los difractogramas es posible observar, invariablemente, la banda (100) situada a $12.1 \AA$, confirmando este hecho que se preserva la integridad estructural de cada lámina tipo MWW durante los procesos de hinchamiento, intercalación y extracción ácida, ya que dicha reflexión no se ve afectada por las modificaciones llevadas a cabo en el ordenamiento laminar.

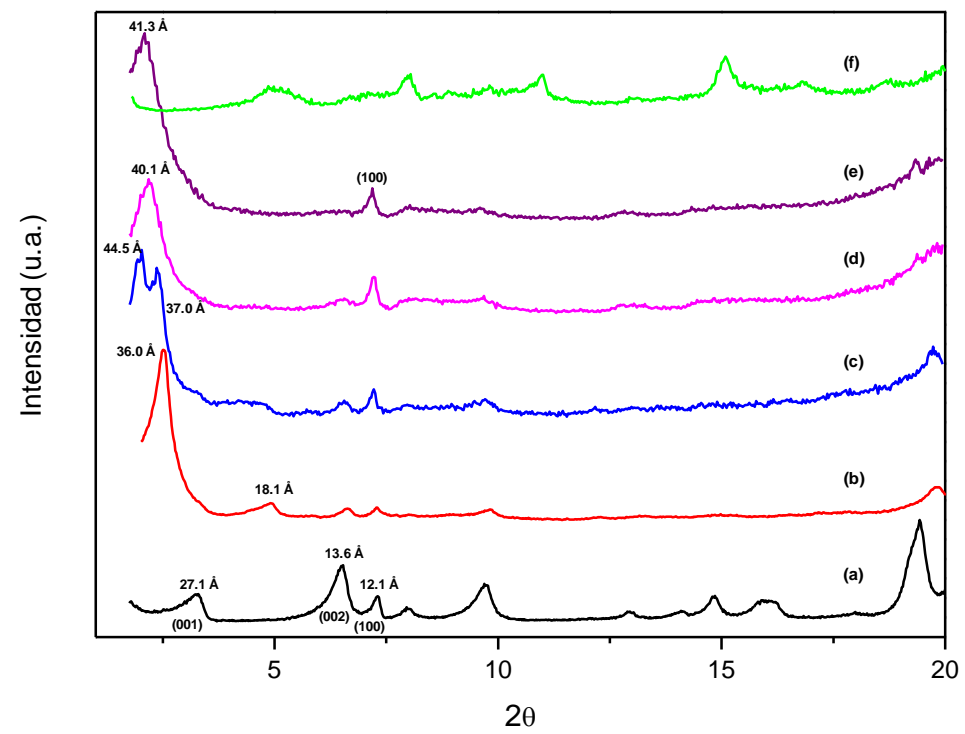

Figura 3.44. Difractogramas de rayos $X$ de: (a) MWW-P, (b) MWW-CTMA, (c) MWW-CTMA-BTEB, (d) MWW-BTEB, (e) MWW-BTEB-NH 2 y (f) MWW-BTEB-CAL.

(a)

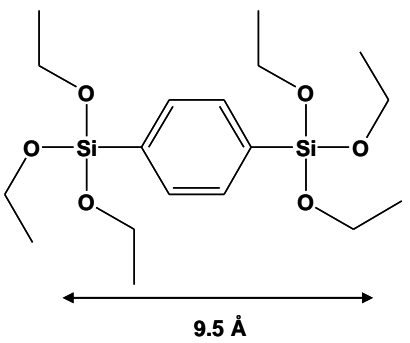

(b)<smiles>[H][R](O)(O)c1ccc([Si](O[2H])(O[2H])O[Si](O[2H])(O[2H])c2ccc([Si](O[2H])(O[2H])O[2H])cc2)cc1</smiles>

Figura 3.45. Moléculas de silsesquioxano y dímeros formados a partir de su condensación: (a) 1,4bis(trietoxisilil)benceno (BTEB) y (b) agente pilareante arílico derivado del BTEB. 


\section{Análisis Elemental}

La incorporación de fragmentos orgánicos en el espacio interlaminar también fue seguida por análisis elemental $(\mathrm{C}, \mathrm{H}, \mathrm{N})$. El contenido orgánico presente en los materiales hinchados y finalmente pilareados con BTEB se muestra en la Tabla 3.7. En ella se pueden observar los datos obtenidos para cada muestra que indican la presencia de los agentes de hinchamiento y pilarización en el espacio interlaminar del precursor zeolítico.

Tabla 3.7. Contenido de grupos orgánicos en el espacio interlaminar del precursor de tipo MWW estimado por análisis elemental. Contenido en aluminio estimado por análisis químico.

\begin{tabular}{ccccccc}
\hline Muestra & \%C & \%N & \%H & C/N & $\begin{array}{c}\text { \%Contenido Orgánico } \\
\text { (AE) }\end{array}$ & Si/Al $^{a}$ \\
\hline MWW-P & 9.6 & 1.7 & 2.1 & 6.6 & 13.4 & 47 \\
MWW-CTMA & 20.1 & 1.7 & 4.1 & 14.2 & 25.9 & 52 \\
MWW-CTMA-BTEB & 26.3 & 1.5 & 4.2 & 20.5 & 32.0 & 51 \\
MWW-BTEB & 12.2 & 0.2 & 2.2 & 71.2 & 14.6 & 55 \\
MWW-BTEB-NH & 7.4 & 1.3 & 2.1 & 6.7 & 10.8 & 81 \\
MWW-BTEB-CAL $^{b}$ & 1.8 & 0.2 & 0.9 & 12.6 & 2.9 & 59 \\
\hline
\end{tabular}

${ }^{a} \mathrm{AE}:$ Análisis Elemental. ${ }^{b}$ Análisis Químico.

En el caso de la muestra correspondiente al precursor laminar, MWW-P, la relación molar $\mathrm{C} / \mathrm{N}$ experimental es de 6.6, estando este valor próximo al calculado teóricamente para el agente director de estructura, hexametilenimina (HMI), empleado en la síntesis, el cual posee una relación molar $(C / N)=6.0$. Después del hinchamiento, la muestra resultante (MWW-CTMA) posee un porcentaje en carbono mayor que la anterior, $20.1 \%$, lo que corrobora que las moléculas de CTMA están presentes en el espacio interlaminar. Cuando tiene lugar el proceso de intercalación con el disilano BTEB, el porcentaje en carbono vuelve a aumentar, $26.3 \%$, debido a la presencia de grupos arilo entre las láminas del precursor MWW-P junto con moléculas de CTMA (MWW-CTMABTEB).

El análisis de la muestra extraída refleja una disminución considerable tanto en el contenido en $\mathrm{C}(12.2 \%)$ como en el de $\mathrm{N}(0.2 \%)$, indicando que la práctica totalidad de las moléculas de agente hinchante han sido eliminadas durante la extracción ácida (MWWBTEB). Si se tiene en cuenta el contenido en carbono de la muestra intercalada, se puede 
concluir por análisis elemental que, aproximadamente, el $10 \%$ en peso del material híbrido laminar corresponde a los grupos arílicos incorporados.

\section{Análisis Termogravimétrico}

La estabilidad hidrotermal y la posible incorporación de los grupos arilo en el espacio interlaminar de los precursores zeolíticos tipo MWW se estudiaron también a través de análisis termogravimétrico (ATG) y termodiferencial (ATD) para las diferentes muestras obtenidas durante el proceso de pilarización (Figura 3.46.). En el caso del precursor zeolítico (MWW-P), se observaron dos importantes pérdidas de peso (nombradas como II y III en la Figura 3.46.a), correspondientes a la presencia de moléculas de $A D E$, en este caso $H M I$, ocluidas en el interior de las super-cavidades delimitadas por canales sinusoidales de 12 y de 10 miembros, las cuales se descomponen en los intervalos comprendidos entre $300-400^{\circ} \mathrm{C}$ y $400-500^{\circ} \mathrm{C}$, respectivamente. Por otra parte, se observó una pérdida de peso adicional (nombrada como IV), cuando el precursor inorgánico fue calcinado a $500-600^{\circ} \mathrm{C}$, siendo atribuida al agua generada por la deshidroxilación que tiene lugar cuando las láminas individuales de MWW se unen entre sí por condensación de los grupos silanoles de su superficie. Además, a temperaturas inferiores a $300^{\circ} \mathrm{C}$, se detectaron tanto las pérdidas debidas al agua de hidratación como una pequeña cantidad de moléculas de $\mathrm{HMI}$, las cuales probablemente no estén ocluidas en el interior de las cavidades zeolíticas.

Cuando se llevó a cabo la etapa de hinchamiento, se pudo observar claramente la presencia de moléculas de CTMA (11.4 \% en peso, ver Tabla 3.8.), las cuales se eliminaron a $200-300^{\circ} \mathrm{C}$ (pérdida de peso nombrada como I en la Figura 3.46.b), confirmando que los agentes de hinchamiento se introdujeron de forma efectiva en el precursor laminar. En el material hinchado, las pérdidas de peso debidas a la presencia de moléculas de ADE (II y III) y el agua de deshidroxilación (IV) son similares a las observadas en el precursor de partida (MWW-P).

Después del proceso de pilarización con moléculas de BTEB, es posible observar, en la Figura 3.46.c, un importante aumento en la pérdida de peso IV (10.4 \% en peso), sin 
observar modificaciones reseñables en las otras contribuciones orgánicas (I, II y III). Esta modificación en el intervalo IV sería debida a la inserción de grupos arílicos en el espacio interlaminar, los cuales exhiben una estabilidad térmica entre $500-600^{\circ} \mathrm{C}$. Por lo tanto, en la muestra pilareada, no es posible considerar el agua de deshidroxilación como único responsable de la pérdida de peso IV, siendo ésta debida a la efectiva inserción de pilares arílicos en el espacio interlaminar que provocan un incremento apreciable en este intervalo. Además, en los híbridos pilareados, el contenido orgánico asignado a los grupos arílicos a partir del ATG es similar al estimado por análisis elemental, siendo en ambos casos de aproximadamente un $10 \%$ en peso (Tabla 3.8.).

Cuando se llevó a cabo el proceso de extracción ácida (Figura 3.46.d), la muestra MWW-BTEB presentó un fuerte descenso en las pérdidas de peso I y II. Esto se debe a que han sido prácticamente eliminadas todas la moléculas de agente hinchante (CTMA) y de ADE (HMI) insertadas en el interior de las super-cavidades de 12 miembros por el tratamiento ácido. Sin embargo, la muestra extraída sigue conteniendo algunas moléculas de HMI residual (pérdida de peso III, $3.0 \%$ ), las cuales pueden estar localizadas, probablemente, en el interior de los canales de 10 miembros, no siendo fáciles de eliminar por completo. Es importante remarcar que la gran mayoría del contenido orgánico procedente de los grupos arílicos (pérdida de peso IV, $9.2 \%$ ), se conserva después del proceso de extracción ácida.

Por otra parte, cuando la muestra pilareada es calcinada a $400^{\circ} \mathrm{C}$ (Figura 3.46.f) se aprecia que los pilares orgánicos son eliminados parcialmente, viéndose la pérdida de peso IV drásticamente reducida (2.5 \% en peso). Esto confirma que los grupos arílicos insertados entre las láminas tipo MWW a modo de pilares se descomponen significativamente cuando se someten a temperaturas superiores a $400^{\circ} \mathrm{C}$ durante el proceso de calcinación. 

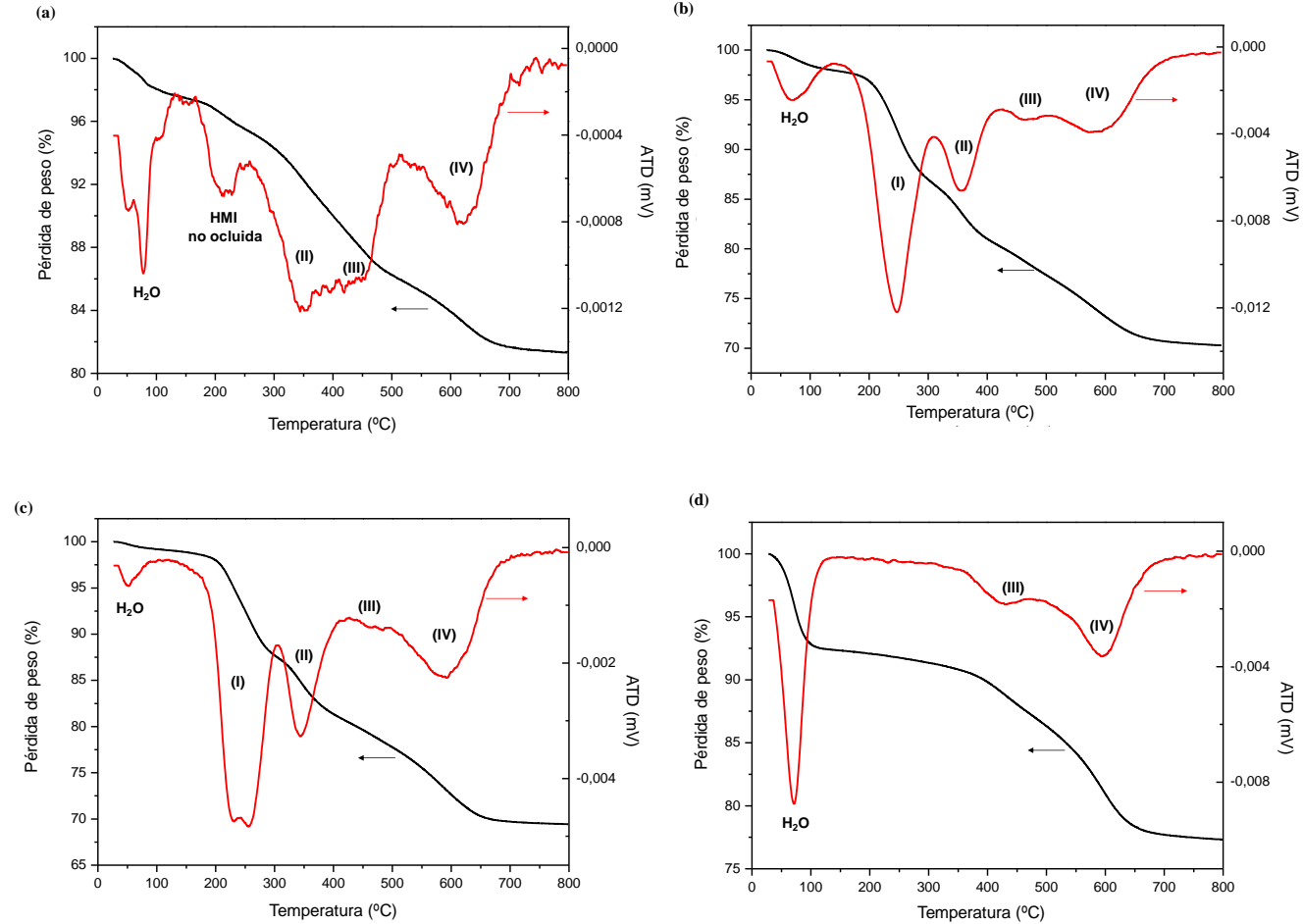

(e)
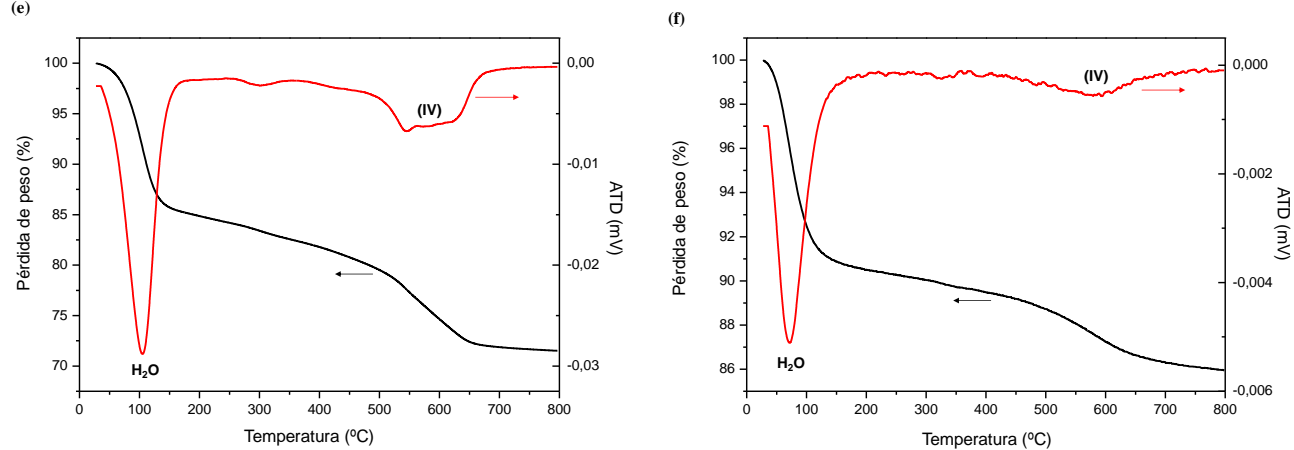

Figura 3.46. Curvas termogravimétricas (ATG) y sus correspondientes derivadas (ATD) de las muestras: (a) MWW-P, (b) MWW-CTMA, (c) MWW-CTMA-BTEB, (d) MWW-BTEB, (e) MWW-BTEB$\mathrm{NH}_{2}$ y (f) MWW-BTEB-CAL. 
Tabla 3.8. Contenido orgánico en los materiales híbridos de tipo MWW estimado por análisis elemental y termogravimétrico.

\begin{tabular}{|c|c|c|c|c|c|c|}
\hline \multirow[b]{2}{*}{ Muestra } & \multirow{2}{*}{$\begin{array}{l}\text { \%Cont. } \\
\text { Org. } \\
\text { (AE) }\end{array}$} & \multirow{2}{*}{$\begin{array}{l}\text { \%Cont. } \\
\text { Org. } \\
\text { (ATG) }^{b}\end{array}$} & \multicolumn{4}{|c|}{ \%Pérdidas de peso (ATG) ${ }^{b}$} \\
\hline & & & $\begin{array}{c}\text { (I) CTMA } \\
(200-300)^{\circ} \mathrm{C}\end{array}$ & $\begin{array}{c}\text { (II) HMI } \\
(12 \mathrm{MR}) \\
(300-400)^{\circ} \mathrm{C} \\
\end{array}$ & $\begin{array}{c}\text { (III) HMI } \\
(10 \mathrm{MR}) \\
(400-500)^{\circ} \mathrm{C} \\
\end{array}$ & $\begin{array}{l}\text { (IV) } \mathrm{H}_{2} \mathrm{O} \text { des. } \\
\text { o Pilar Org. } \\
(500-600)^{\circ} \mathrm{C}\end{array}$ \\
\hline MWW-P & 13.4 & 15.2 & - & 5.1 & 5.4 & 4.7 \\
\hline MWW-CTMA & 25.9 & 27.5 & 11.4 & 5.5 & 6.3 & 4.3 \\
\hline MWW-CTMA-BTEB & 32.0 & 34.2 & 11.9 & 5.4 & 6.5 & 10.4 \\
\hline MWW-BTEB & 14.6 & 15.1 & 1.5 & 1.4 & 3.0 & 9.2 \\
\hline MWW-BTEB-NH 2 & 10.8 & 14.4 & 1.1 & 1.3 & 2.0 & 10.0 \\
\hline MWW-BTEB-CAL & 2.9 & 3.9 & 0.2 & 0.5 & 0.7 & 2.5 \\
\hline
\end{tabular}

${ }^{a}$ AE: Análisis elemental. ${ }^{b}$ ATG: Análisis termogravimétrico. ${ }^{c} \mathrm{H}_{2} \mathrm{O}$ des.: Agua de deshidroxilación.

\section{Espectroscopia Infrarroja}

Es posible confirmar por espectroscopia infrarroja, la presencia e integridad de los grupos arílicos en el espacio interlaminar del material híbrido MWW-BTEB (Figura 3.47.b). En este espectro se observan bandas situadas a aproximadamente 1400, 1600, 3020 y $3060 \mathrm{~cm}^{-1}$ que no aparecen en el precursor MWW calcinado, asociadas a los modos de vibración stretching asimétricos del enlace Si-benceno, indicando la presencia de grupos aromáticos procedentes del disilano BTEB. Además, se observan bandas a 2860 y $2980 \mathrm{~cm}^{-1}$ que pueden deberse tanto a la presencia de grupos arílicos como a fragmentos hidrocarbonados residuales procedentes del agente hinchante (CTMA) o del agente director de estructura (HMI) que permanecen después de la extracción ácida. El pico asignado a los grupos silanoles, $3730 \mathrm{~cm}^{-1}$, presentes en el precursor zeolítico calcinado, se desplaza parcialmente $\mathrm{a} \sim 3500 \mathrm{~cm}^{-1}$ cuando se incorporan los grupos arílicos al material zeolítico, debiéndose este hecho a la proximidad entre los silanoles de la superficie de las láminas y los grupos silil-arilo intercalados. Por otra parte, la banda adicional presente en torno a $3620 \mathrm{~cm}^{-1}$, se debe a la interacción de las moléculas de agua con los silanoles de la superficie laminar ${ }^{[105]}$. 


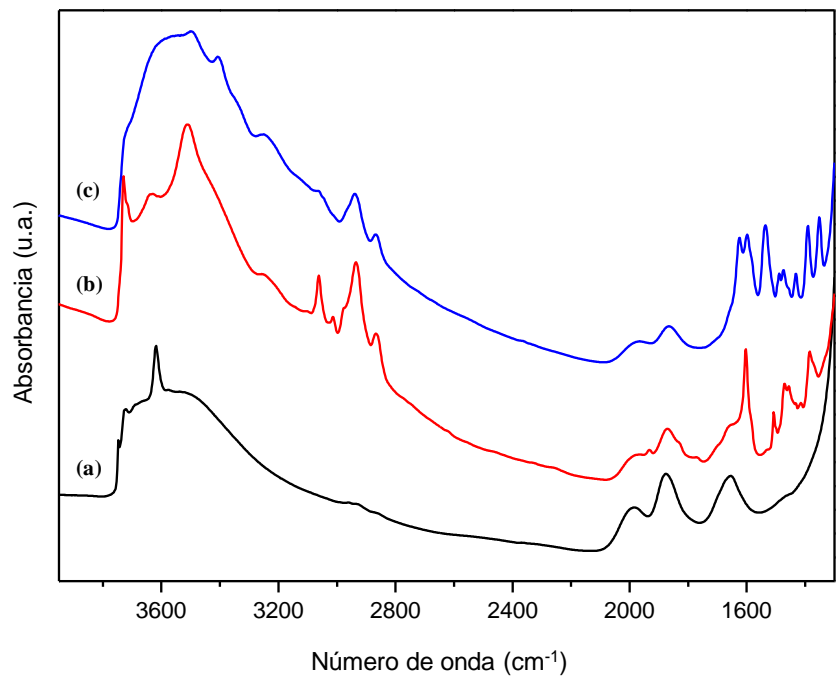

Figura 3.47. Espectros de infrarrojo obtenidos a $300^{\circ} \mathrm{C}$ y vacío de las muestras híbridas laminares derivadas del precursor MWW-P: (a) MWW-P-CAL, (b) MWW-BTEB y (c) MWW-BTEB-NH 2 .

\section{Resonancia Magnética Nuclear}

En la Figura 3.48. se muestran los espectros de $\mathrm{RMN}$ de ${ }^{13} \mathrm{C}$ para cada una de las muestras obtenidas en los distintos pasos del proceso de síntesis del material híbrido pilareado, a partir de los cuales se puede confirmar la efectividad del proceso de intercalación así como la integridad de los grupos orgánicos introducidos en el espacio interlaminar del precursor MWW-P. En el caso de los materiales MWW-P, MWW-CTMA y MWW-BTEB, se observan las bandas asignadas a los átomos de carbono correspondientes a la moléculas del ADE (HMI), del agente hinchante (CTMA) y del disilano (BTEB), respectivamente. En la muestra MWW-BTEB se distingue además la señal debida a los átomos de carbono directamente enlazados al átomo de silicio (enlace Si-C). Todo ello corrobora el hecho de que los fragmentos arílicos tipo puente permanecen intactos con respecto al disilano de partida. Por otra parte, la marcada reducción en la intensidad de las bandas asociadas a las moléculas de agente hinchante en el material MWW-BTEB confirma la efectividad del proceso de extracción ácida (Figura 3.48.c). 


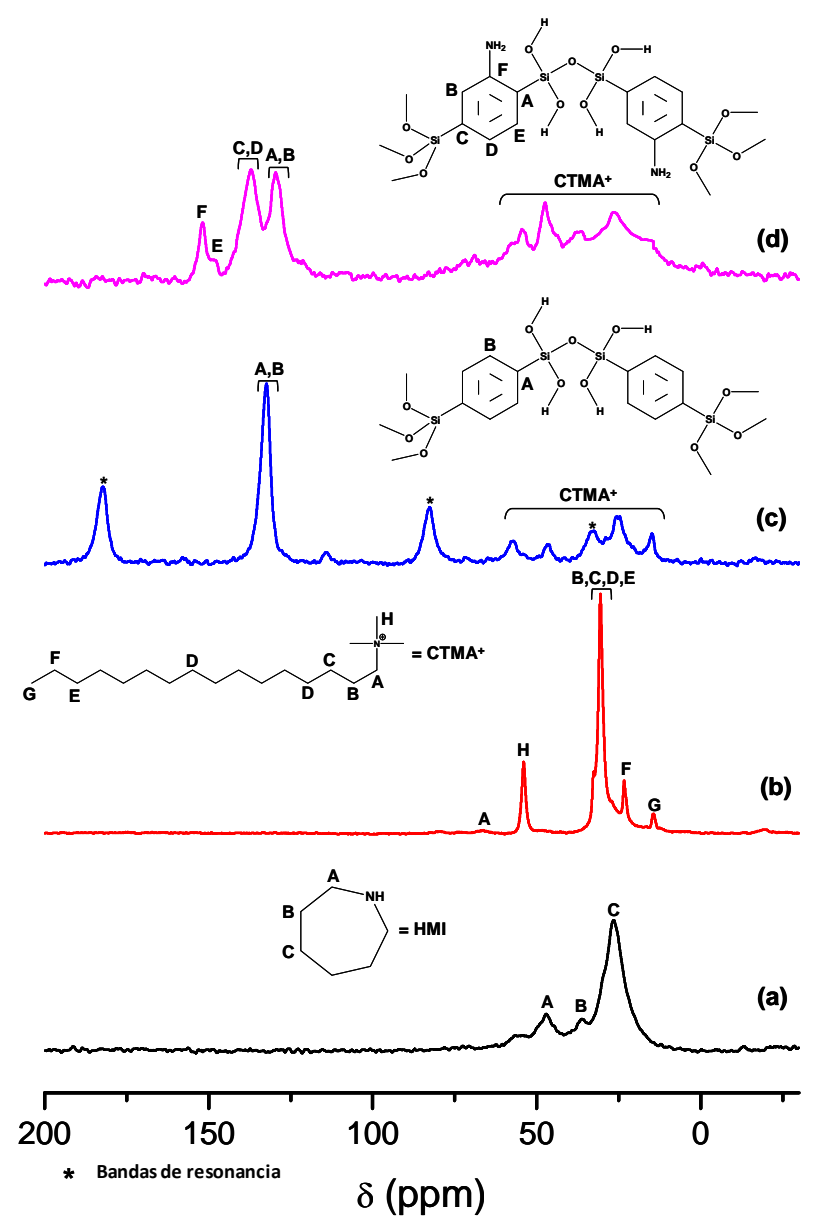

Figura 3.48. Espectros de RMN CP/MAS de ${ }^{13} \mathrm{C}$ de los diferentes materiales zeolíticos laminares híbridos tipo MWW, mostrando la asignación de las bandas a los átomos de carbono contenidos en los sólidos: (a) MWW-P, (b) MWW-CTMA, (c) MWW-BTEB y (d) MWW-BTEB-NH ${ }_{2}$.

Además de confirmar por RMN de ${ }^{13} \mathrm{C}$ que las unidades orgánicas permanecen íntegras durante el proceso de pilarización, es posible corroborar que los grupos arílicos han sido covalentemente incorporados en el espacio interlaminar, a modo de pilares orgánicos, a través de la espectroscopia RMN de ${ }^{29} \mathrm{Si}$ (Figura 3.49.). El espectro del precursor zeolítico, MWW-P, muestra señales a $-95,-100$ y en el intervalo $-110--120$ ppm correspondientes a bandas del tipo $\mathrm{Q}^{2}\left[\mathrm{Si}(\mathrm{OH})_{2}(\mathrm{OSi})_{2}\right], \mathrm{Q}^{3}\left[\mathrm{Si}(\mathrm{OH})(\mathrm{OSi})_{3}\right]$ y $\mathrm{Q}^{4}\left[\mathrm{Si}(\mathrm{OSi})_{4}\right]$ respectivamente, observándose también una banda a -105 ppm correspondiente a 
especies del tipo $\mathrm{Si}(\mathrm{OSi})_{3}(\mathrm{OAl})$. Cuando tiene lugar el proceso de pilarización, en el espectro de la muestra MWW-BTEB (Figura 3.49.b), se observan bandas en el rango comprendido entre -60 y -80 ppm asignadas a átomos de Si de tipo T, debido a los enlaces Si-C procedentes de las moléculas de disilano intercaladas covalentemente entre las láminas del precursor. En concreto, es posible observar tres bandas que se asignan a especies de tipo $\mathrm{T}^{1}\left[\mathrm{C}-\mathrm{Si}(\mathrm{OH})_{2}(\mathrm{OSi})\right], \mathrm{T}^{2}\left[\mathrm{C}-\mathrm{Si}(\mathrm{OH})(\mathrm{OSi})_{2}\right]$ y $\mathrm{T}^{3}\left[\mathrm{C}-\mathrm{Si}(\mathrm{OSi})_{3}\right]$. La existencia de bandas $\mathrm{T}^{1}$ y $\mathrm{T}^{2}$ en las muestras pilareadas indicaría que durante la hidrólisis y condensación entre los grupos silanoles presentes en la superficie de las láminas del precursor MWW-P y las moléculas derivadas del disilano BTEB, no todos los grupos alcóxido terminales de los agentes pilareantes participan en el proceso, permaneciendo algunos sin reaccionar. Estos átomos de silicio $\left(T^{1} y \mathrm{~T}^{2}\right)$ también podrían asignarse a grupos $\mathrm{Si}-\mathrm{OH}$ presentes en los pilares interlaminares generados durante la condensación de dos moléculas de BTEB (Figura 3.45.b). La variación en las intensidades observadas para las bandas $Q^{4}$, cuando se comparan los espectros de los materiales MWW-P y MWW-BTEB, se atribuye a la generación de nuevos átomos de tipo $Q^{4}$ en el material híbrido después del proceso de intercalación a partir de grupos silanoles superficiales de tipo $Q^{3}$, presentes previamente en el precursor zeolítico laminar.

Otra confirmación de la incorporación efectiva de los fragmentos orgánicos proviene de la comparación entre el espectro de RMN de ${ }^{29} \mathrm{Si}$ del disilano BTEB puro (Figura 3.49.d) con el del material final pilareado MWW-BTEB. En el caso del disilano, se observa un único pico característico de los átomos de silicio centrado a -59 ppm. Sin embargo, después de la incorporación de los grupos arílicos entre las láminas del precursor, la señal asignada a los átomos de silicio enlazados a carbono se desplaza a valores comprendidos entre -60 y -80 ppm, siendo este hecho una prueba inequívoca de la intercalación de los grupos arílicos. 


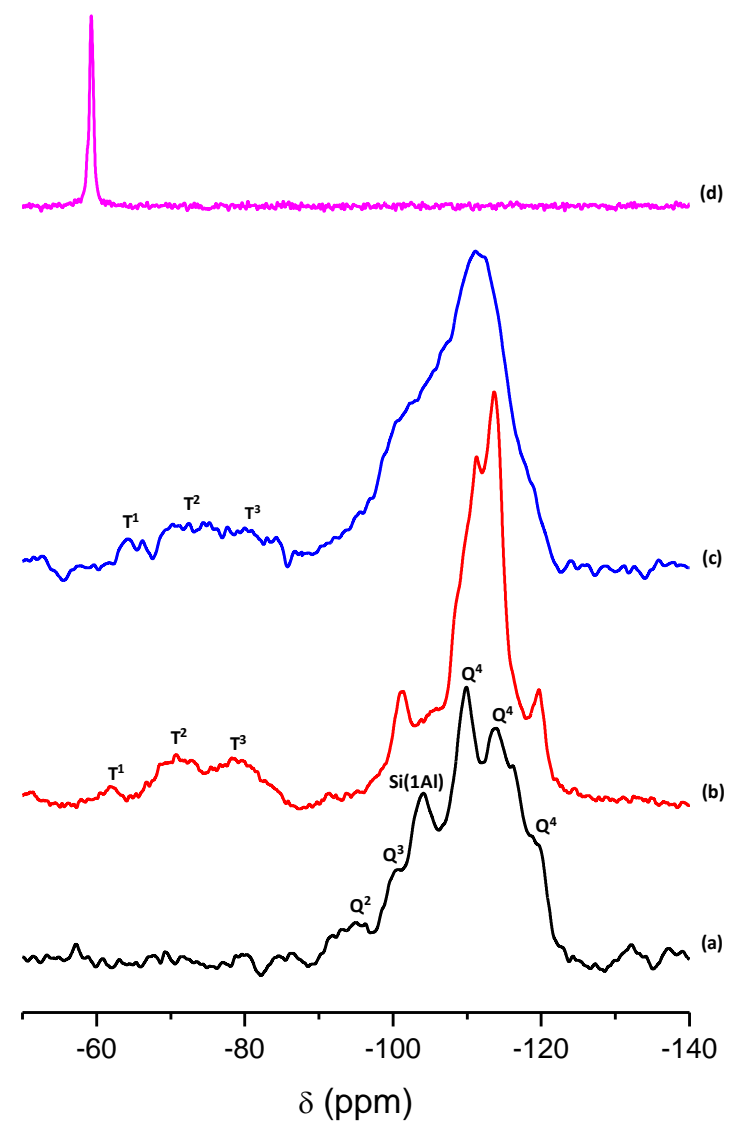

Figura 3.49. Espectros de RMN BD/MAS de ${ }^{29} \mathrm{Si}$ de los diferentes materiales zeolíticos laminares híbridos, mostrando la asignación de átomos de silicio de tipo T y Q: (a) MWW-P, (b) MWW-BTEB, (c) MWW-BTEB- $\mathrm{NH}_{2}$ y (d) 1,4-bis(trietoxisilil)benceno puro (BTEB).

Por otra parte, las relaciones integradas $\left(Q^{2}+Q^{3}\right) / Q$ obtenidas para el precursor zeolítico, MWW-P, y para el material pilareado, MWW-BTEB, pueden ser útiles para corroborar que los grupos alcóxido terminales de los silsesquioxanos se han hidrolizado y condensado con los silanoles externos de la superficie de las láminas tipo MWW. Para el precursor zeolítico, MWW-P, dicha relación es de 0.41 , decreciendo a 0.25 después del proceso de pilarización. Este resultado muestra que aproximadamente un $60 \%$ de los grupos silanoles iniciales están involucrados en la inserción covalente de los grupos disilano entre las láminas inorgánicas. Además, la integración de la señales T y $Q$ presentes en los espectros de RMN de ${ }^{29}$ Si permite calcular la relación $T /(Q+T)$ y dar una estimación 
del número de átomos de silicio funcionalizados en los materiales híbridos pilareados. Los valores obtenidos muestran que aproximadamente el $21 \%$ de los átomos de silicio están funcionalizados por especies arílicas en el material final MWW-BTEB, siendo este valor próximo al calculado por análisis elemental.

La presencia de aluminio en la estructura de los materiales híbridos se confirmó claramente a través del análisis de $\mathrm{RMN}$ de ${ }^{27} \mathrm{Al}$. En la Figura 3.50. se muestran los espectros para las muestras híbridas con grupos silil-arilo intercalados que exhiben únicamente una banda centrada a -56 ppm, la cual se pude asignar a la presencia de aluminio tetraédrico. La banda centrada a 0 ppm, asignado al aluminio extrarred, no se observa en los materiales estudiados. La presencia de $\mathrm{Al}^{\mathrm{IV}}$ en las láminas inorgánicas de los materiales híbridos confirma, por lo tanto, la presencia de grupos hidroxilo puente $y$, consecuentemente, la existencia de centros ácidos de tipo Brönsted característicos de los materiales zeolíticos.

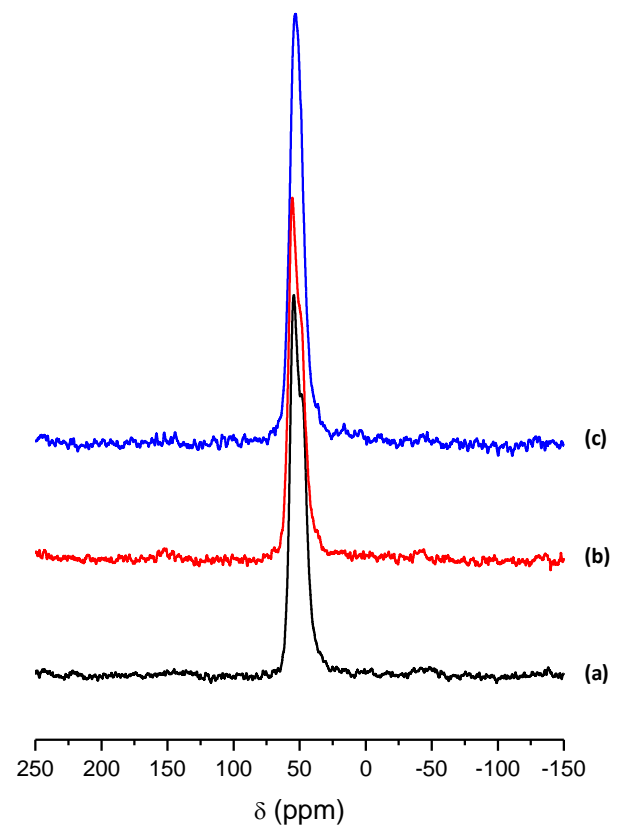

Figura 3.50. Espectros de RMN BD/MAS de ${ }^{27} \mathrm{Al}$ de los diferentes materiales zeolíticos híbridos: (a) MWW-P, (b) MWW-BTEB Y (c) MWW-BTEB-NH 2 . 


\section{Análisis Textural}

En la Tabla 3.9. se muestran las propiedades texturales de los diferentes materiales híbridos estimadas a partir de las isotermas de adsorción de nitrógeno. Los resultados confirman que la introducción de grupos silil-arilo en el espacio interlaminar implica modificaciones importantes en la superficie y porosidad de los materiales resultantes. Así, la superficie BET del precursor calcinado (MWW-P-CAL) es de $408 \mathrm{~m}^{2} \mathrm{~g}^{-1}$, mientras que cuando se lleva a cabo el proceso de intercalación (MWW-BTEB) la superficie BET aumenta hasta $539 \mathrm{~m}^{2} \mathrm{~g}^{-1}$, siendo un $70 \%$ debida a la contribución de la superficie externa (meso y macroporosa). El volumen BJH obtenido también muestra un aumento de la superficie mesoporosa en el material híbrido después del proceso de pilarización (0.234 $\left.\mathrm{cm}^{3} \mathrm{~g}^{-1}\right)$. Cuando la extracción del agente hinchante se lleva a cabo mediante calcinación (MWW-BTEB-CAL), los grupos arílicos se descomponen parcialmente favoreciendo el colapso entre las láminas tipo MWW. Cuando esto ocurre, el área superficial y el volumen de poro son similares a los obtenidos para los materiales microporosos MWW calcinados (MWW-P-CAL).

Tabla 3.9. Propiedades texturales de los materiales híbridos orgánicos-inorgánicos con topología MWW.

\begin{tabular}{ccccccc}
\hline Muestra & $\begin{array}{c}\mathrm{S}_{\mathrm{BET}} \\
\left(\mathbf{m}^{2} \mathbf{g}^{-1}\right)\end{array}$ & $\begin{array}{c}\mathrm{S}_{\mathrm{MIC}} \\
\left(\mathbf{m}^{2} \mathbf{g}^{-1}\right)\end{array}$ & $\begin{array}{c}\mathrm{S}_{\mathrm{EXT}}^{\mathrm{a}} \\
\left(\mathbf{m}^{2} \mathbf{g}^{-1}\right)\end{array}$ & $\begin{array}{c}\mathrm{V}_{\mathrm{TOT}} \\
\left(\mathrm{cm}^{3} \mathbf{g}^{-1}\right)\end{array}$ & $\begin{array}{c}\mathrm{V}_{\mathrm{MIC}} \\
\left(\mathbf{c m}^{3} \mathbf{g}^{-1}\right)\end{array}$ & $\begin{array}{c}\mathrm{V}_{\mathrm{BJH}} \\
\left(\mathbf{c m}^{3} \mathbf{g}^{-1}\right)\end{array}$ \\
\hline MWW-P-CAL & 408 & 325 & 83 & 0.512 & 0.170 & 0.078 \\
MWW-BTEB & 539 & 151 & 388 & 0.640 & 0.070 & 0.234 \\
MWW-BTEB-NH & 556 & 112 & 444 & 0.685 & 0.054 & 0.267 \\
MWW-BTEB-CAL & 386 & 315 & 71 & 0.413 & 0.150 & 0.080 \\
\hline
\end{tabular}

${ }^{a} \mathrm{~S}_{\mathrm{EXT}}=\left(\mathrm{S}_{\mathrm{BET}}-\mathrm{S}_{\mathrm{MIC}}\right)$

La isoterma de adsorción de $\mathrm{N}_{2}$ del precursor zeolítico calcinado es de tipo I, característica de los materiales microporosos sin contribución mesoporosa (Figura 3.51.). Por contra, la muestra pilareada MWW-BTEB presenta una isoterma con un punto de inflexión desplazado hacia mayores presiones relativas $\left(p / p_{0}\right)$, indicando que la contribución mesoporosa y el diámetro de poro (54 Å) son más grandes que en el caso de los materiales sin pilarear. De hecho, la isoterma de la muestra MWW-BTEB exhibe un aumento en la adsorción a $p / p_{0}$ entre 0.3 y 0.4 , que corresponde a un sólido con 
contribución mesoporosa, no observando este hecho en el caso del precursor MWW calcinado (Figura 3.51.).

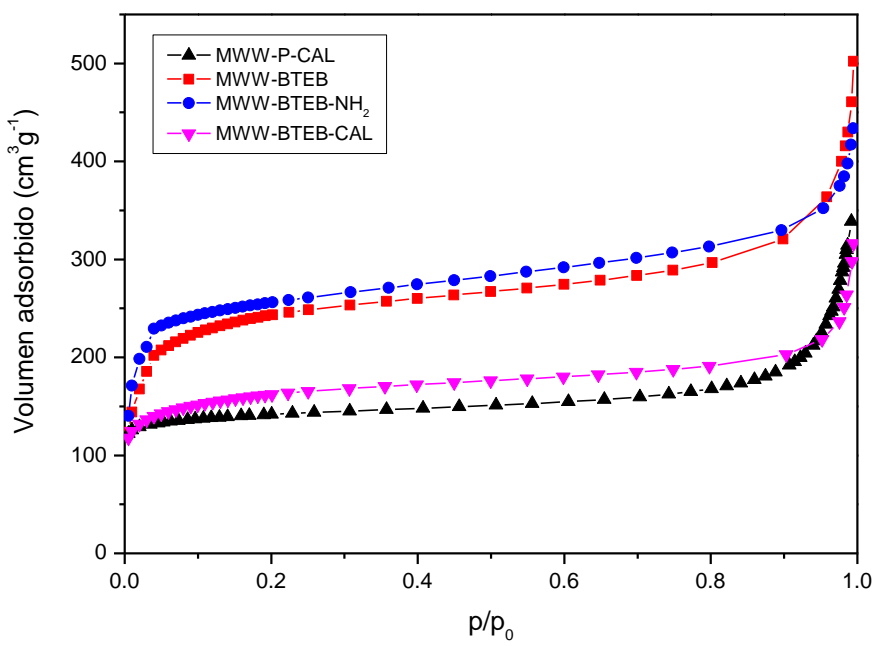

Figura 3.51. Isotermas de adsorción de nitrógeno de los diferentes materiales híbridos de tipo MWW.

A partir de las isotermas de adsorción de Ar, Figura 3.52., se comprueba que todas las muestras de la familia MWW tienen un sistema de poros que se satura a presiones relativas próximas a $5 \times 10^{-6}$. Además, se observa un segundo punto de inflexión en la isoterma del precursor zeolítico calcinado localizado a presiones relativas en torno a $5 \times 10^{-3}$, el cual no se observa para el material híbrido pilareado MWW-BTEB. La primera inflexión corresponde a los microporos delimitados por anillos de diez miembros (10MR), mientras que el segundo se debe al sistema de poros delimitados por anillos de doce miembros (12 MR), siendo

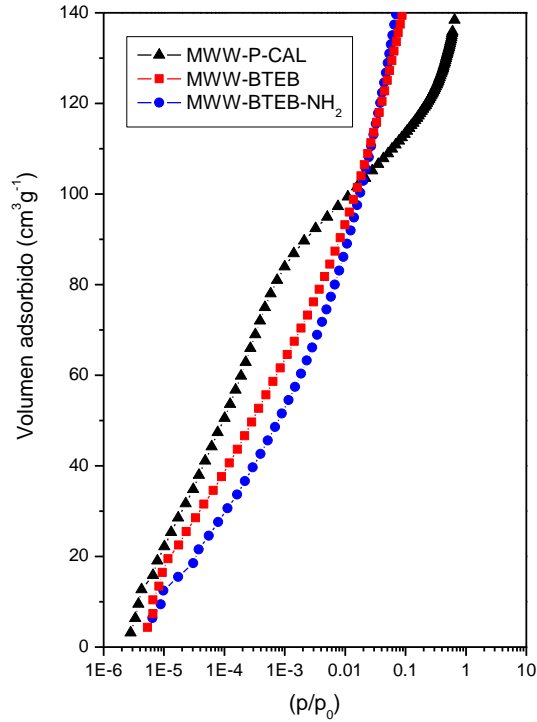

Figura 3.52. Isotermas de adsorción de Argon para materiales con topología MWW. 
posible concluir que las supercajas de $12 \mathrm{MR}$ formadas en la zeolita 3D MWW, tras el colapso laminar, no existen en el material híbrido pilareado. Esto es debido a que las láminas no se conectan directamente entre sí, después del proceso de pilarización, siendo, por lo tanto, imposible la formación de estas grandes supercavidades en la región interlaminar.

Otra confirmación de la elevada accesibilidad alcanzada en los materiales híbridos pilareados proviene del estudio de la distribución del diámetro de poro BJH, Figura 3.53., donde se observa que la muestra pilareada MWW-BTEB presenta una distribución centrada en torno a 40-50 $\AA$, asociada a la mesoporosidad creada entre las láminas debido a la presencia de los grupos silil-arilo. Por el contrario, el precursor calcinado no posee contribución mesoporosa.

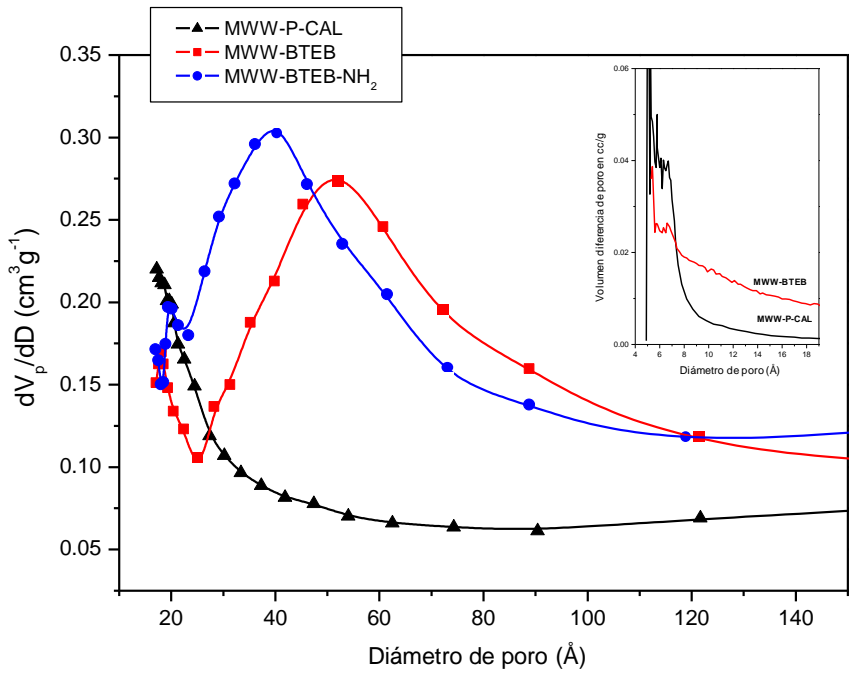

Figura 3.53. Distribución de poro BJH de diferentes materiales zeolíticos laminares híbridos con topología MWW. En la gráfica insertada se muestra la distribución de poro, calculada a través del método Horvath-Kawazoe, de los materiales MWW-P-CAL y MWW-BTEB.

Por otro lado, los materiales zeolíticos MWW presentan la particularidad de que los canales sinusoidales de 10 MR están presentes en el interior de las láminas que los componen, siendo posible observar esa microporosidad característica también en las sólidos híbridos pilareados a partir de las distribuciones de tamaño de poro estimadas a través del método de Horvath-Kawazoe (Figura 3.53.). Este hecho confirma que la 
pilarización con grupos arilo no modifica la estructura interna de las láminas individuales, exhibiendo el material híbrido final un sistema microporoso (láminas zeolíticas) mesoporoso (galerías interlaminares) estructurado jerárquicamente.

\section{Microscopía Electrónica de Transmisión}

La microscopía electrónica de transmisión (TEM) se ha empleado para confirmar la morfología laminar tanto de los precursores zeolíticos tipo MWW, como la de los materiales híbridos pilareados generados después de la intercalación con moléculas del disilano BTEB (Figura 3.54.). El precursor inicial, MWW-P, se trata de un material altamente cristalino, observándose que presenta una distribución ordenada de las láminas que constituyen cada cristal (Figura 3.54.a). Más específicamente, los cristales presentan un grosor que oscila entre 150 y 200 nm, correspondiendo a la presencia de, aproximadamente, 60-80 láminas individuales tipo MWW, las cuales están perpendicularmente empaquetadas y orientadas respecto al eje $c$ (Figura 3.54.b).

Después del proceso de intercalación, la morfología de los materiales híbridos pilareados, MWW-BTEB, se ha modificado sustancialmente (Figura 3.54.c). En este caso, los sólidos presentan una distribución laminar con un menor orden comparado con el precursor MWW-P, estando conformados los cristales por un reducido número de láminas apiladas tipo MWW, entre 5 y 8, como se puede observar en la Figura 3.54.d. En la ampliación de esta fotografía, es posible apreciar incluso el espacio interlaminar entre dos láminas contiguas, siendo el valor medido de separación de 38-40 A, aproximadamente, el cual está en consonancia con la distancia basal estimada a través de DRX para los materiales híbridos pilareados (Figura 3.44.). Este hecho corrobora que existen pilares orgánicos de $\sim 15 \AA$, constituidos por dos grupos arílicos condensados (Figura 3.45.), efectivamente intercalados en el espacio zeolítico interlaminar. 

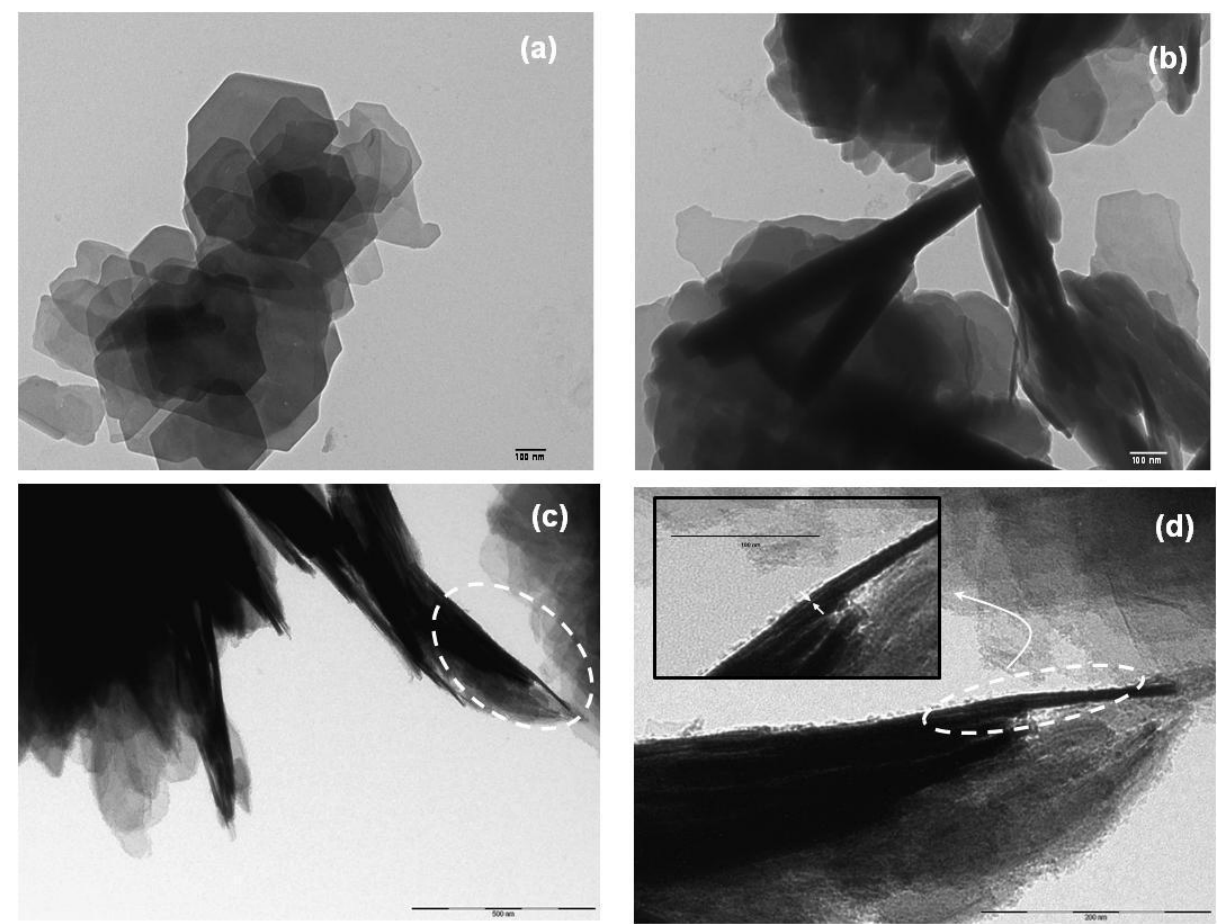

Figura 3.54. Fotografías de microscopía electrónica de transmisión para las muestras: (a) y (b) MWW-P, (c) y (d) MWW-BTEB. Escala de referencia para las fotografías (a) y (b) $100 \mathrm{~nm}$, (c) $500 \mathrm{~nm}$ y (d) $200 \mathrm{~nm}$.

\subsubsection{Incorporación de grupos funcionales. Generación de materiales bifuncionales ácido-base}

Con el fin de obtener sólidos híbridos bifuncionales tipo MWW, los materiales MWW-BTEB sintetizados en el apartado anterior se sometieron a un proceso post-síntesis de aminación. De este modo, se incorporaron centros básicos adicionales a dichos materiales, lo que unido a los centros ácidos tipo Brönsted que poseen en su estructura las láminas zeolíticas, debido a la presencia de átomos de Al tetracoordinado, los convertiría en sólidos bifuncionales ácido-base. Los centros básicos (- $\left.\mathrm{NH}_{2}\right)$ entran a formar parte de los fragmentos orgánicos situados a modo de pilar, al estar enlazados directamente al anillo aromático, mientras que los centros ácidos están localizados en las láminas inorgánicas que forman parte del entramado de naturaleza zeolítica proveniente del precursor laminar. Los materiales bifuncionales obtenidos podrían actuar como 
catalizadores para llevar a cabo reacciones tipo cascada en un solo paso como se mostrará más adelante.

\section{Caracterización}

\section{Difracción de Rayos X}

Cuando se llevó a cabo el proceso post-síntesis para incorporar grupos amino a los fragmentos arílicos (MWW-BTEB- $\mathrm{NH}_{2}$ ), el espectro de difracción de rayos $\mathrm{X}$ obtenido para esta muestra (Figura 3.44.e.) es similar al obtenido después del proceso de extracción ácida (MWW-BTEB), mostrando que el proceso de aminación no conlleva una modificación significativa del material híbrido de naturaleza zeolítica. En este espectro también se confirma la existencia de la banda de reflexión (100) debida a las láminas individuales tipo MWW que permanecen intactas tras el proceso de aminación.

\section{Análisis Elemental}

La incorporación de grupos amino, durante el proceso post-síntesis, se confirmó por análisis elemental (Tabla 3.7.). De hecho, el contenido en nitrógeno aumenta hasta un 1.3 \% en peso tras la etapa de aminación, siendo la relación molar $\mathrm{C} / \mathrm{N}$ experimental de 6.7. Este resultado indica que algunos grupos arílicos interlaminares pueden ser funcionalizados con al menos un grupo amino. El proceso de tratamiento ácido usado para llevar a cabo la etapa de aminación fue el responsable de la parcial desaluminización de los sólidos ya que la relación molar Si/Al experimental aumenta hasta 80 en el material final MWW-BTEB- $\mathrm{NH}_{2}$.

\section{Análisis Termogravimétrico}

La muestra obtenida después del proceso de aminación (MWW-BTEB- $\mathrm{NH}_{2}$ ) exhibe unas curvas ATG y ATD (Figura 3.46.e) y unas pérdidas de peso (Tabla 3.8.) similares a la muestra pilareada (MWW-BTEB), mostrando que la incorporación de grupos amino en las unidades silil-arilo interlaminares no implica alteraciones importantes en los materiales híbridos pilareados finalmente obtenidos. 


\section{Espectroscopia Infrarroja}

El espectro infrarrojo del material MWW-BTEB- $\mathrm{NH}_{2}$ (Figura 3.47.c) muestra bandas adicionales a 1540 y $1630 \mathrm{~cm}^{-1}$ asignadas a los modos de vibración bending $\delta$ $\left(\mathrm{NH}_{2}\right)$, junto con otra banda a $3400 \mathrm{~cm}^{-1}$ debida a los modos de vibración de stretching v$\left(\mathrm{NH}_{2}\right)$, confirmando que los grupos amino están efectivamente incorporados a las especies arílicas. La presencia de bandas asignadas a grupos benceno, en el espectro de IR de la muestra MWW-BTEB- $\mathrm{NH}_{2}$, indica que la integridad de las especies arílicas se preserva durante el proceso ácido de aminación. En conclusión, la espectroscopia IR verifica inequívocamente la presencia de especies aril-amino en el interior de los materiales híbridos de tipo zeolítico.

\section{Resonancia Magnética Nuclear}

La post-funcionalización de los fragmentos derivados de benceno con grupos amino se confirmó por RMN de ${ }^{13} \mathrm{C}$ (Figura 3.48.d) ya que la banda asignada a los carbonos aromáticos está dividida en tres señales, asociándose el pico a 150 ppm a la unión covalente de los grupos amino a los anillos aromáticos ${ }^{[106]}$. Además, el post-tratamiento de aminación no implica una modificación sustancial de los fragmentos orgánicos insertados en el espacio interlaminar ya que a través de los espectros de RMN de ${ }^{29} \mathrm{Si}$ (Figura 3.49.) se aprecian las mismas especies de tipo T observadas en el material laminar antes de esta etapa (MWW-BTEB). Por otra parte, en la muestra aminada, el aluminio contenido en el sólido sigue ocupando posiciones tetraédricas, conservando los centros ácidos tipo Brönsted localizados en las láminas zeolíticas (Figura 3.50.).

\section{Análisis Textural}

El material híbrido preparado después del proceso de aminación (MWW-BTEB$\mathrm{NH}_{2}$ ), exhibe un área superficial y un volumen de poro similar al material pilareado extraído (MWW-BTEB), indicando que la incorporación de los grupos amino en el interior de los grupos arílicos no ha modificado sustancialmente el sistema mesoporoso adicional generado tras el proceso de pilarización (Tabla 3.9. y Figura 3.51.). A partir de los datos de la distribución del diámetro de poro (BJH), se observa que la muestra MWW-BTEB- $\mathrm{NH}_{2}$ presenta una distribución centrada entre 40-50 ̊̊ asociada a la mesoporosidad generada 
entre las láminas debida a la presencia de los grupos silil-arilo interlaminares, tal y como ocurría en el material MWW-BTEB antes del tratamiento post-síntesis de aminación (Figura 3.53.).

\subsubsection{Estudios teóricos estructurales}

Teniendo en cuenta la estructura de las láminas MWW, así como la cantidad y localización de los grupos silanoles presentes en su superficie, ambos conocidos en el estado del arte ${ }^{[107]}$, se realizó una modelización teórica del material MWW-BTEB para así conocer situación, estructuración y cantidad de moléculas derivadas del disilano BTEB presentes en el material híbrido pilareado.

Según este estudio, cada molécula de agente pilareante une dos láminas MWW, a través de la condensación con dos grupos $\mathrm{Si}-\mathrm{OH}$ opuestos localizados en dos láminas adyacentes del precursor MWW-P. Dentro de la simetría hexagonal exhibida por el precursor zeolítico tipo MWW, cada silanol está rodeado por otros tres grupos $\mathrm{Si}-\mathrm{OH}$, estando separados entre sí por $8.2 \AA$. Aunque las moléculas derivadas del BTEB son voluminosas, esta distancia entre silanoles es suficiente para permitir la localización de varios pilares arílicos incluidos en la misma celda unidad, como se muestra en la Figura 3.55., teniendo en cuenta los resultados de minimización de energía del entramado estructural calculados por métodos computacionales.

Además, la posible relación $\mathrm{OH}_{\text {sustituidos }} / \mathrm{OH}_{\text {totales }}$ se extiende en el intervalo comprendido entre 0 y 1 , lo que significa que teóricamente cualquier número entre 0 y 8 moléculas derivadas del BTEB podrían estar presentes en el modelo establecido. Todo ello, permite llegar a la conclusión, teniendo en cuenta el contenido orgánico y el peso relativo de las moléculas de BTEB comparado con el total del sistema, de que el número de moléculas que actúan como pilares finalmente incorporadas es 5 , siendo el contenido orgánico en este caso próximo a 10 \% (Tabla 3.10.), el cual es bastante aproximado al obtenido a través del análisis elemental (Tabla 3.7.) y del análisis termogravimétrico (Tabla 3.8. y Figura 3.46.) para el sólido MWW-BTEB. 

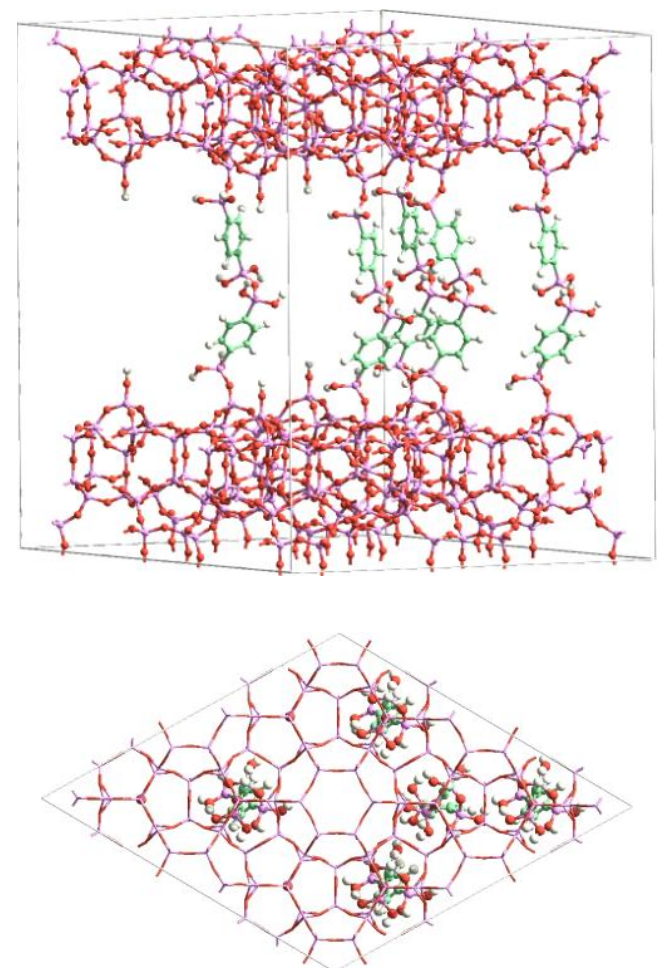

Figura 3.55. Modelo teórico del material híbrido MWW-BTEB donde 5/8 de los grupos silanoles han reaccionado con el pilar arílico interlaminar.

Tabla 3.10. Relación entre el número de moléculas derivadas del disilano BTEB y el contenido orgánico en el material MWW-BTEB.

\begin{tabular}{cc}
\hline $\begin{array}{c}\text { No moléculas } \\
\text { derivadas de BTEB }\end{array}$ & $\begin{array}{c}\text { \% Contenido } \\
\text { orgánico }\end{array}$ \\
\hline 1 & 2.3 \\
2 & 4.6 \\
3 & 6.7 \\
4 & 8.7 \\
5 & 10.7 \\
6 & 12.5 \\
\hline
\end{tabular}


La minimización de la correspondiente celda unidad para 5 moléculas de agentes de pilarización insertadas, proporciona una geometría compatible con la de los enlaces químicos y ángulos esperados, próximos a sus valores de equilibrio, lo cual significa que el sistema es razonablemente estable. El parámetro " $c$ " optimizado encontrado para este sistema es de $39.8 \AA$ (Figura 3.56.), el cual está de acuerdo con la determinación experimental obtenida a través de DRX que mostraba un espaciado basal de $40.1 \AA$ (Figura 3.44.).

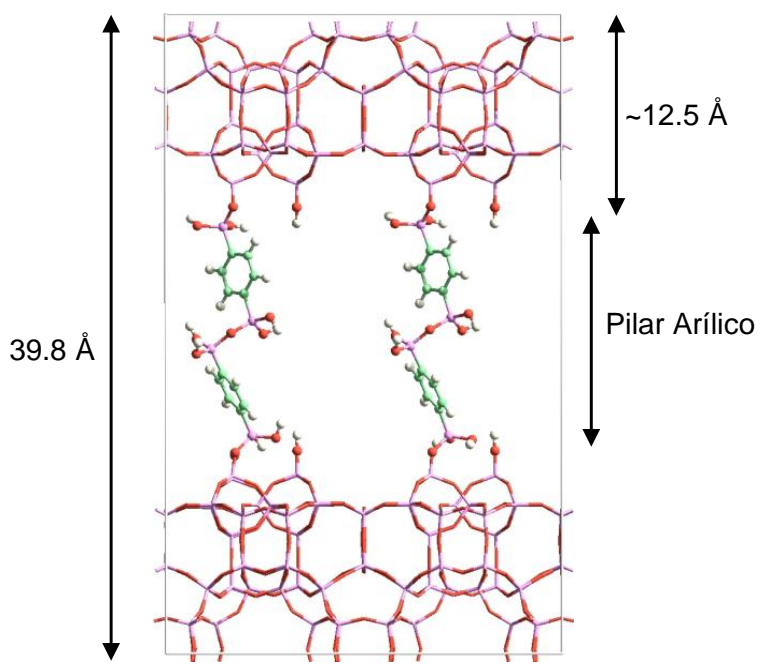

Figura 3.56. Clúster representativo del material híbrido pilareado MWW-BTEB.

Los cálculos teóricos, por lo tanto, confirman que las hipótesis hechas en base a los resultados de caracterización son consistentes con la obtención de un material híbrido orgánico-inorgánico bien estructurado, donde láminas zeolíticas conteniendo canales microporosos están incluidas en la estructura inorgánica. Por su parte, el componente orgánico está localizado entre las láminas formando pilares espaciados regularmente, generando un sistema mesoporoso bidimensional. 


\subsubsection{Actividad catalítica: Reacciones en cascada}

La actividad catalítica del material híbrido bifuncional (MWW-BTEB-NH ${ }_{2}$ ) se ha estudiado en una reacción que consta de dos etapas realizada en un solo paso, la cual requiere tanto centros ácidos como básicos para llevarse a cabo. Este proceso servirá para poner de manifiesto las posibilidades catalíticas del sólido laminar orgánico-inorgánico aquí sintetizado. En concreto, la reacción en cascada estudiada comprende la hidrólisis de un acetal seguida de una condensación de Knoevenagel ${ }^{[108]}$, es decir, el dimetilacetalbenzaldehído se hidroliza para producir benzaldehído, como producto intermedio, el cual reacciona con malononitrilo para dar bencilidenmalononitrilo como producto final (Figura 3.57.).

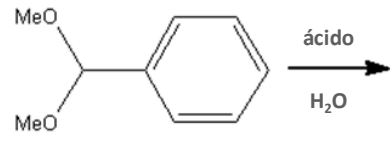

(1)

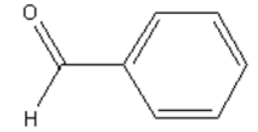

(2)

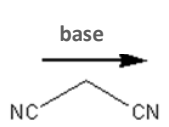

(3)

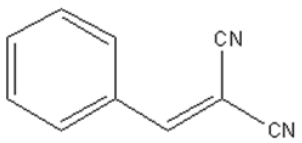

(4)

Figura 3.57. Reacción en cascada consistente en dos etapas: Hidrólisis acetal - Condensación de Knoevenagel.

La reacción que tiene lugar en la primera etapa requiere la presencia de centros ácidos, los cuales son aportados por las láminas MWW del aluminosilicato, mientras que la etapa de condensación involucra a los centros básicos, es decir, a los grupos amino presentes en los anillos aromáticos que se encuentran formando la galería mesoporosa en el espacio interlaminar. Los resultados muestran que la reacción tándem se llevó a cabo satisfactoriamente, dando el producto final (4) con un rendimiento del $96 \%$ después de 7.2 horas de reacción, con una selectividad del 99\% (Tabla 3.11.). En la Figura 3.58. se observa la conversión de dimetilacetal inicial (1) y la formación del benzaldehído (2) como intermedio, el cual reacciona inmediatamente a través de una condensación de Knoevenagel en presencia de malononitrilo (3) para dar el producto (4).

Cuando el proceso catalítico, el cual tiene lugar de forma consecutiva, es llevado a cabo por el material MWW-BTEB, que no posee grupos amino enlazados a los fragmentos orgánicos de tipo arílico (Tabla 3.11.), se produce la hidrólisis ácida del acetal, con una conversión del $51 \%$, pero el producto de condensación se obtiene con un 
rendimiento de tan solo un $11 \%$. Este hecho confirma inequívocamente que la contribución de los centros ácidos, presentes en las láminas inorgánicas para llevar a cabo la condensación de Knoevenagel, es muy pequeña, observándose que este paso es realizado por los centros básicos que actúan como catalizadores de la reacción, localizados en el espacio interlaminar del material híbrido MWW-BTEB- $\mathrm{NH}_{2}$. Adicionalmente, se llevó a cabo un blanco de reacción, mostrándose que bajo estas condiciones, en ausencia de catalizador, la reacción de condensación en estudio no tiene lugar, puesto que se obtiene un rendimiento de tan solo el $3 \%$ al producto final, transcurridas 7.2 horas (Tabla 3.11.).

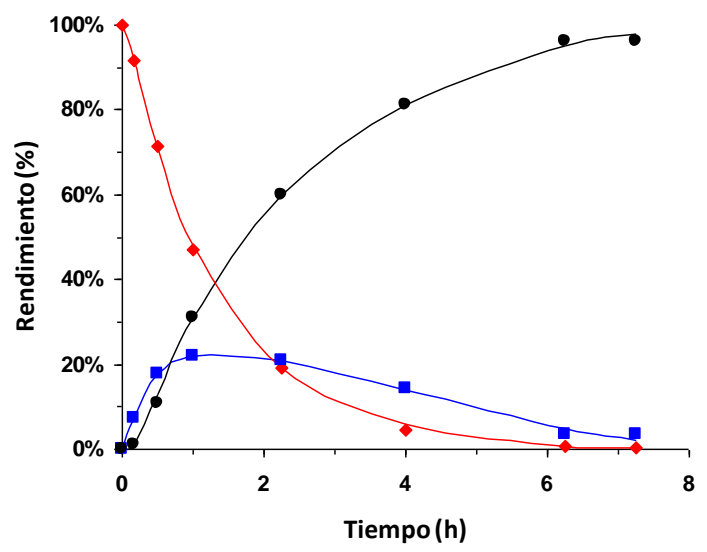

Figura 3.58. Resultados de la actividad catalítica del material híbrido bifuncional (MWW-BTEB-NH para la reacción hidrólisis-aldol en cascada. Se representa rendimiento frente a tiempo de reacción

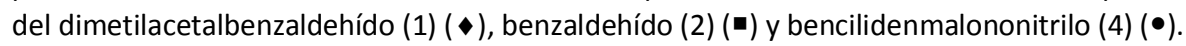

Tabla 3.11. Resultados catalíticos de la reacción en cascada: Hidrólisis acetal - Condensación de Knoevenagel.

\begin{tabular}{|c|c|c|c|}
\hline Catalizador $^{a}$ & $\begin{array}{c}\text { Conversión } \\
\text { de } 1(\%)\end{array}$ & $\begin{array}{c}\text { Rendimiento } \\
\text { de } 2(\%)\end{array}$ & $\begin{array}{c}\text { Rendimiento } \\
\text { de } 4(\%)\end{array}$ \\
\hline MWW-BTEB- $\mathrm{NH}_{2}$ & 99 & 3 & 96 \\
\hline MWW-BTEB & 51 & 40 & 11 \\
\hline Blanco $^{b}$ & - & 97 & 3 \\
\hline
\end{tabular}

${ }^{a}$ Reacción en cascada en un solo paso: dimetilacetalbenzaldehído (5.45 mmol), malononitrilo (5.24 $\left.\mathrm{mmol}\right), 30 \mu \mathrm{L}$ $\mathrm{H}_{2} \mathrm{O}$, acetonitrilo $(2 \mathrm{~mL}$ ) y $50 \mathrm{mg}$ de catalizador híbrido, durante 7.25 horas a $355 \mathrm{~K}$.

${ }^{b}$ Condensación de Knoevenagel, experimento blanco (sin catalizador): benzaldehído (5.45 mmol), malononitrilo (5.24 mmol) y $30 \mu \mathrm{L}$ de $\mathrm{H}_{2} \mathrm{O}$, acetonitrilo $(2 \mathrm{~mL})$, durante 7.25 horas a $355 \mathrm{~K}$. 
Además, se estudió la desactivación y la reutilización del catalizador híbrido a través de su empleo después de cada ciclo catalítico. La Figura 3.59. muestra la conversión a bencilidenmalononitrilo (4) después de cuatro reutilizaciones consecutivas del catalizador. Se observa que el catalizador mantiene su actividad inicial, indicando que los materiales zeolíticos híbridos bifuncionales pueden ser interesantes catalizadores heterogéneos, estables, activos y reutilizables. Por lo tanto, este sistema catalítico que combina microporos y mesoporos ordenados de forma jerárquica, conteniendo diferentes centros activos, podría ser utilizado como catalizador altamente efectivo para llevar a cabo diferentes procesos consecutivos o en cascada.

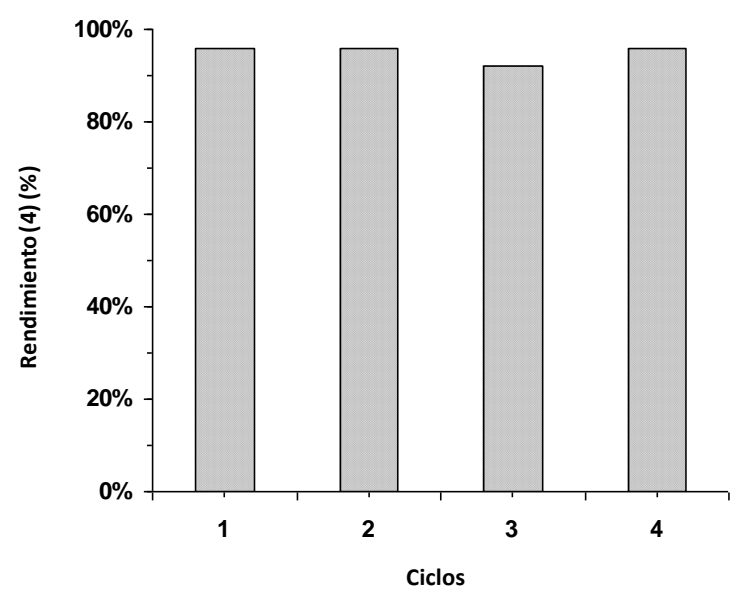

Figura 3.59. Resultados de rendimiento a bencilidenmalononitrilo (4) cuando el catalizador bifuncional MWW-BTEB- $\mathrm{NH}_{2}$ se usa durante cuatro ciclos de reacción consecutivos. 


\subsection{Conclusiones}

- Se han obtenido nuevas familias de materiales híbridos laminares (Clase II) por la interacción covalente entre láminas inorgánicas, provenientes de precursores silíceos o zeolíticos, y moléculas de disilano que se sitúan en el espacio interlaminar a modo de pilar o puente estructural de naturaleza orgánica.

- Se han incorporado unidades orgánicas, tales como disulfuro, diamino o etileno como pilares entre las láminas del silicato laminar magadiita. Este proceso de síntesis ha sido estudiado y optimizado, controlándose en detalle cada una de las diferentes etapas que se siguen para su preparación: síntesis del precursor laminar, hinchamiento, pilarización y extracción ácida. Los resultados obtenidos confirman que los fragmentos orgánicos se insertan y estabilizan en la región interlaminar, llegándose a incorporar hasta un $26 \%$ en peso de unidades disulfuro en los materiales híbridos pilareados, situándose la estabilidad hidrotermal de dichas unidades orgánicas en torno a los $400^{\circ} \mathrm{C}$. Por otra parte, diferentes técnicas espectroscópicas corroboran no solo la presencia, sino también la integridad e interacción covalente de los diferentes fragmentos orgánicos e inorgánicos enlazados entre sí que conforman la estructura laminar de los sólidos obtenidos.

- La presencia de pilares orgánicos genera cavidades microporosas adicionales en el espacio interlaminar de la magadiita, aumentando la accesibilidad hacia los centros activos intercalados. En el caso de la inserción de grupos etileno se llega a multiplicar por siete la superficie específica obtenida al compararla con la exhibida por silicatos laminares convencionales.

- La efectiva intercalación de fragmentos orgánicos, estabilizados y distribuidos homogéneamente en el espacio interlaminar proporciona interesantes propiedades ácidas (grupos sulfónicos), básicas (grupos amino) o con capacidad para ser químicamente modificados (grupos etileno) que convierten a estos materiales híbridos en potenciales catalizadores para un elevado número de procesos de reacción. En concreto, los materiales con grupos sulfónicos y diamino muestran una elevada actividad para llevar a cabo reacciones tales como esterificaciones o procesos de condensación, respectivamente. 
- Considerando los resultados obtenidos con silicatos laminares, se consiguieron preparar, por primera vez, nuevos materiales laminares orgánicos-inorgánicos de naturaleza zeolítica a partir de precursores laminares MWW pilareados con moléculas de disilano (BTEB) que contienen anillos aromáticos, los cuales se intercalan y estabilizan covalentemente en el espacio interlaminar (MWW-BTEB).

- Los estudios de caracterización realizados confirman la estructura laminar del material híbrido pilareado, en el cual se llega a incorporar hasta un $10 \%$ en peso de unidades arílicas en el espacio interlaminar, lo que corresponde a la presencia de 5 moléculas del dímero derivado de BTEB incorporadas entre láminas MWW por celda unidad.

- El material MWW-BTEB contiene un sistema jerárquico de poros, debido a la presencia de canales microporosos en las láminas zeolíticas MWW que se combinan con nuevas galerías mesoporosas generadas en la región interlaminar tras el proceso de pilarización, las cuales presentan un diámetro de poro centrado en torno a 40-50 Å. Los sólidos híbridos obtenidos presentan una accesibilidad mayor que las correspondientes zeolitas MWW tridimensionales, aumentando su superficie externa hasta cinco veces respecto a la exhibida por una zeolita MWW convencional.

- Las zeolitas híbridas laminares son estables hidrotermalmente hasta $400^{\circ} \mathrm{C}$, pudiéndose incorporar centros básicos adicionales en los pilares arílicos a través de procesos post-síntesis de aminación. Por lo tanto, los materiales bifuncionales MWW, finalmente obtenidos, combinan la presencia de centros ácidos Brönsted, localizados en los microporos de las láminas inorgánicas debido al aluminio tetraédrico que contienen, con centros básicos presentes en las galerías mesoporosas interlaminares.

- Los materiales pilareados bifuncionales de naturaleza MWW muestran interesantes propiedades catalíticas para llevar a cabo reacciones en cascada en un solo paso, como es el caso del proceso combinado o tándem que implica la desprotección de un acetal por centros ácidos, seguida de una reacción de condensación catalizada por centros básicos. 


\subsection{Experimental}

\subsubsection{Materiales híbridos pilareados derivados de silicatos laminares}

El precursor laminar empleado para la obtención de este tipo de materiales pilareados es el derivado del ácido silícico en forma sódica denominado Magadiita.

El método desarrollado para la obtención de magadiita en forma pura sílice consiste en el empleo de trans-4-aminociclohexanol que actúa como agente director de estructura ( $A D E$ ) en presencia de una fuente silícea, $\mathrm{NaOH}$ y $\mathrm{H}_{2} \mathrm{O}$ milliQ.

En concreto, los ADEs empleados para la síntesis de magadiita son moléculas orgánicas pertenecientes a la familia de los amino-alcoholes. En la Figura 3.60. se muestra la molécula de trans-4-aminociclohexanol, observándose los grupos funcionales amino y alcohol en los extremos separados por un anillo hidrocarbonado de seis átomos de carbono.

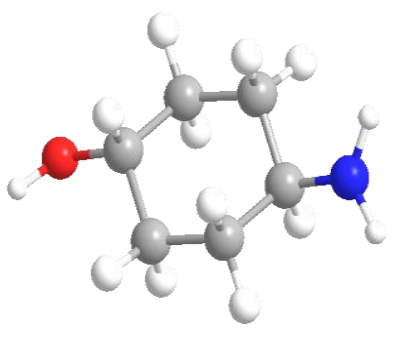

Figura 3.60. Molécula de trans-4-aminociclohexanol, empleada para la cristalización del ácido silícico Magadiita.

\section{Síntesis del precursor laminar Magadiita}

La Na-Magadiita es sintetizada a través de un proceso hidrotermal, empleando autoclaves de acero inoxidable con agitación constante a $150^{\circ} \mathrm{C}$ durante 72 horas. La composición molar del gel de síntesis es la siguiente:

$$
\text { [1 } \left.\mathrm{SiO}_{2}: 0.2 \mathrm{NaOH}: 0.5 \mathrm{ADE}: 15 \mathrm{H}_{2} \mathrm{O}\right]
$$

En primer lugar, se prepara una disolución básica formada por $1.33 \mathrm{~g}$ de $\mathrm{NaOH}$ (99.9\%, Scharlau) y $29.98 \mathrm{~g}$ de $\mathrm{H}_{2} \mathrm{O}$ MilliQ, a la que se adiciona sucesivamente y con agitación constante $9.58 \mathrm{~g}$ de trans-4-aminociclohexanol (97\%, Acros ) y $25.00 \mathrm{~g}$ de sílice 128 
(LUDOX AS-40, Aldrich). La mezcla formada se agita a temperatura ambiente durante 2 horas aproximadamente, hasta obtener un gel homogéneo con un pH alrededor de 12.5 . Este gel se introduce en fundas de teflón que se ajustan en autoclaves de acero inoxidable, los cuales se mantienen a $150^{\circ} \mathrm{C}$ en agitación durante tres días. Al finalizar este periodo, los autoclaves son enfriados en agua, y el producto resultante es filtrado y lavado con agua destilada hasta que el pH del agua de lavado sea neutro. Por último, el sólido es secado a $100^{\circ} \mathrm{C}$ durante 12 horas.

Posteriormente, una vez obtenido el precursor laminar magadiita, éste es utilizado para formar materiales híbridos pilareados por la inserción interlaminar de diferentes disilanos. En concreto, se empleó bis(trietoxisililpropil)disulfuro (BTES, 90\%, $A B C R$ ), bis(3-trimetoxisililpropil)etilendiamina (BTMN, 95\%, $A B C R$ ) o bis(trietoxisilil)etileno (BTEEthy, 95\%, ABCR) como agente de pilarización para la obtención de los materiales orgánicos-inorgánicos pilareados denominados MAG-BTES, MAG-BTMN o MAG-BTEEthy, respectivamente. A continuación, se describirá en detalle la preparación del material híbrido MAG-BTES, siendo el proceso de síntesis de los materiales MAG-BTMN y MAGBTEEthy idéntico al que a continuación se describe, utilizando, en cada caso, un disilano diferente.

\section{MAG-BTES}

El material híbrido laminar MAG-BTES se obtiene a partir del precursor laminar magadiita. Su preparación consta de tres etapas:

(i) Intercambio catiónico

(ii) Hinchamiento y pilarización

(iii) Extracción ácida

El proceso de intercambio en la magadiita consiste en la sustitución de los cationes $\mathrm{Na}^{+}$presentes entre las láminas por $\mathrm{H}^{+}$. Para ello se emplean $1.5 \mathrm{~g}$ de $\mathrm{Na}-$ Magadiita que se disuelven en $20 \mathrm{~mL}$ de agua MilliQ. Por otro lado, se prepara una disolución acuosa de $\mathrm{HCl} 0.1 \mathrm{M}$, empezándose a añadir gota a gota y con agitación 
constante la disolución ácida sobre la disolución acuosa de magadiita hasta conseguir un $\mathrm{pH}$ de 2. La disolución resultante se deja en agitación durante 48 horas a temperatura ambiente, controlando periódicamente su pH. Transcurrido ese tiempo se filtra y se lava con agua destilada hasta alcanzar un pH neutro en las aguas de lavado. Por último se seca a $60^{\circ} \mathrm{C}$ durante 12 horas, obteniéndose así el ácido silícico H-Magadiita.

La pilarización se efectúa preparando una disolución del material laminar, HMagadiita, antes descrito, con n-hexilamina. Para ello se pesan $0.4 \mathrm{~g}$ de sólido que se disuelven en $11.47 \mathrm{~g}$ de $\mathrm{n}$-hexilamina (98\%, Fluka). La solución se mantiene en agitación contante durante 2 días a temperatura ambiente. Transcurrido ese período de hinchamiento, se añade a la suspensión inicial $1 \mathrm{~mL}$ de disilano, en este caso, bis(trietoxisililpropil)disulfuro (BTES), disuelto en $20 \mathrm{~mL}$ de $\mathrm{n}$-hexano (96\%, Scharlau), manteniéndose la agitación durante 7 días más. Finalizado este proceso, el sólido blanco es separado de la suspensión por centrifugación y secado a $60^{\circ} \mathrm{C}$ durante 12 horas.

Por último, el sólido es sometido a un proceso de extracción ácida, con el fin de eliminar las moléculas de agente hinchante previamente utilizadas ( $\mathrm{n}$-hexilamina). Para ello el material es suspendido en $20 \mathrm{~mL}$ de una disolución de $\mathrm{HCl} 1 \mathrm{M}$ en etanol, calentándose a $70^{\circ} \mathrm{C}$ durante 16 horas con agitación continua. El producto es recuperado por filtración y secado a $60^{\circ} \mathrm{C}$. El proceso de extracción ácida se repite una vez más.

Una vez obtenido el material híbrido laminar MAG-BTES, es posible generar centros ácidos en el pilar orgánico intercalado entre las láminas de silicato a través de un tratamiento post-síntesis que a continuación se detalla, para obtener el material denominado $\mathrm{MAG}-\mathrm{SO}_{3} \mathrm{H}$.

\section{$\mathrm{MAG}-\mathrm{SO}_{3} \mathrm{H}$}

El material híbrido $\mathrm{MAG}-\mathrm{SO}_{3} \mathrm{H}$ se obtiene a partir del material laminar pilareado MAG-BTES. Su preparación consta de dos etapas:

(i) Reducción de grupos disulfuro a tiol

(ii) Oxidación de grupos tiol a sulfónico 
La etapa de reducción de grupos disulfuro (S-S) tiene lugar disolviendo $1 \mathrm{~g}$ de MAG-BTES en $400 \mathrm{~mL}$ de agua MilliQ, a los que se añaden $0.6 \mathrm{~g}$ de agente reductor, en este caso tris(2-carboxietil)fosfina, $\mathrm{P}\left(\mathrm{CH}_{2} \mathrm{CH}_{2} \mathrm{COOH}\right)_{3}$ (99\%, Strem Chemicals), .La mezcla resultante se mantiene en agitación a temperatura ambiente durante 24 horas. En este paso se obtienen grupos tiol (-SH) a partir de los disulfuro (S-S) iniciales.

El proceso de oxidación se lleva a cabo disolviendo $0.90 \mathrm{~g}$ de MAG-SH en 36 g de $\mathrm{H}_{2} \mathrm{O}_{2}\left(30 \%\right.$, Fluka) y calentando la mezcla a $70^{\circ} \mathrm{C}$ con agitación constante durante 24 horas. Transcurrido ese tiempo se recupera el sólido por filtración, lavándolo primero con etanol y después con agua destilada, siendo secado a continuación a $60^{\circ} \mathrm{C}$. Un vez seco, el producto se disuelve en $68 \mathrm{~g}$ de una disolución acuosa de $\mathrm{H}_{2} \mathrm{SO}_{4} 0.1 \mathrm{M}$ y se mantiene en agitación a $70^{\circ} \mathrm{C}$ durante otras 24 horas. Pasado este periodo se filtra la suspensión y se lava con abundante agua destilada. En este paso se consiguen obtener grupos sulfónicos ($\mathrm{SO}_{3} \mathrm{H}$ ) a partir de los tioles (-SH) obtenidos en la etapa anterior.

\subsubsection{Materiales híbridos pilareados derivados de precursores zeolíticos laminares}

En este caso el precursor laminar empleado para obtener materiales híbridos pilareados es la MCM-22 (P), aquí denominado MWW-P, compuesta por láminas ordenadas de naturaleza MWW.

\section{Síntesis del precursor laminar MWW-P}

El precursor laminar de la zeolita MCM-22 fue preparado disolviendo $0.12 \mathrm{~g}$ de $\mathrm{NaAlO}_{2}\left(37 \% \mathrm{Na}_{2} \mathrm{O}, 56 \% \mathrm{Al}_{2} \mathrm{O}_{3}\right.$, Carlo Erba) en una disolución básica formada por $0.41 \mathrm{~g}$ de $\mathrm{NaOH}$ y $53.87 \mathrm{~g}$ de agua MilliQ, a la que se añaden a continuación y de forma sucesiva $3.30 \mathrm{~g}$ de hexametilenimina (HMI, 99\%, Aldrich) (Figura 3.61.) y $4.0 \mathrm{~g}$ de $\mathrm{SiO}_{2}$ (Aerosil 200, Degussa). La mezcla fue agitada vigorosamente durante 1 hora a temperatura ambiente, produciendo un gel con una relación atómica Si/Al de 50 (correspondiente a una relación molar $\mathrm{SiO}_{2} / \mathrm{Al}_{2} \mathrm{O}_{3}$ de 100) y un $\mathrm{pH}$ próximo a 12. La cristalización del precursor laminar fue llevada a cabo a $150^{\circ} \mathrm{C}$ y agitación durante 7 días en autoclaves de acero inoxidable con 
una funda interna de teflón. Tras este periodo, el producto cristalino es filtrado y lavado con agua destilada hasta un $\mathrm{pH}$ menor a 9. Finalmente el sólido es secado a $60^{\circ} \mathrm{C}$ durante 12 horas.

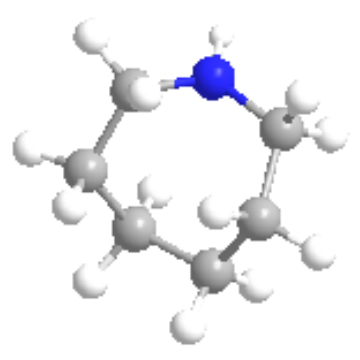

Figura 3.61. Molécula de hexametilenimina, empleada para la cristalización del precursor zeolítico laminar MWW-P.

A continuación, el precursor zeolítico obtenido se utiliza como punto de partida para la preparación de un material laminar compuesto por láminas inorgánicas MWW con grupos arílicos intercalados covalentemente entre ellas a modo de pilar, denominado MWW-BTEB.

\section{MWW-BTEB}

El material híbrido laminar MWW-BTEB se obtiene a partir del precursor laminar MCM-22 (P). Su preparación consta de tres etapas:

(i) Hinchamiento (MWW-CTMA)

(ii) Pilarización (MWW-CTMA-BTEB)

(iii) Extracción ácida (MWW-BTEB)

El proceso de hinchamiento se realiza preparando previamente una suspensión acuosa (20\% en peso de sólido) formada por $1 \mathrm{~g}$ de precursor MWW-P y $4 \mathrm{~g}$ de agua MilliQ que se mezcla con $20 \mathrm{~g}$ de una solución de cetiltrimetilamonio $(\mathrm{CTMA})^{+} \mathrm{OH}^{-} / \mathrm{Br}^{-}(25 \%$ en peso) y con $6 \mathrm{~g}$ de otra solución de tetrapropilamonio (TPA) ${ }^{+} \mathrm{OH}^{-} / \mathrm{Br}^{-}$(40\% en peso), siendo el intercambio de $\mathrm{Br}^{-}$por $\mathrm{OH}^{-}$del 50\% en el CTMA y del 70\% en el TPA, empleando resina Amberlite IRN-78 (Supelco) para dichos intercambios. La relación en peso de esta mezcla 
es CTMA (4) : TPA (1.2) : MWW-P (1). La suspensión formada, con un pH alrededor de 12.5 , se mantiene a reflujo y agitación vigorosa durante 16 horas a $80^{\circ} \mathrm{C}$, consiguiéndose el hinchamiento del precursor laminar, el cual es lavado y recuperado por sucesivas centrifugaciones de $12000 \mathrm{rpm}$ y 20 minutos cada una, secándose, finalmente a $60{ }^{\circ} \mathrm{C}$ durante 12 horas.

La pilarización se efectúa añadiéndo $0.5 \mathrm{~g}$ del precursor hinchado, con agitación vigorosa, a una disolución formada por $0.5 \mathrm{~g}$ de disilano BTEB (96\%, Aldrich) en $50 \mathrm{~mL}$ de 1,4-dioxano anhidro (99.8\%, Aldrich), manteniendo la agitación a $80^{\circ} \mathrm{C}$ durante 48 horas en atmósfera de nitrógeno. El material pilareado se recupera por filtración de la suspensión anterior, lavando primero con dioxano y después con etanol. Por último, el producto obtenido es secado a temperatura ambiente durante 5 días.

Finalmente, el material pilareado es sometido a un proceso de extracción ácida realizado en dos etapas consecutivas, para conseguir eliminar las moléculas de CTMA usadas como agentes hinchantes. Primero, $1 \mathrm{~g}$ del material híbrido es suspendido en 50 $\mathrm{mL}$ de una disolución acuosa de $\mathrm{H}_{2} \mathrm{SO}_{4} 0.05 \mathrm{M}$ en etanol, el cual se calienta a reflujo durante 1 hora a $70{ }^{\circ} \mathrm{C}$. El sólido obtenido, tras filtración y lavado con etanol, es secado a $60{ }^{\circ} \mathrm{C}$ durante 8 horas. El polvo blanco resultante se suspende en $50 \mathrm{~mL}$ de $\mathrm{HCl} 0.15 \mathrm{M}$ etanol/n-heptano $(1 / 1, v / v)$ durante 16 horas a $90^{\circ} \mathrm{C}$. El producto final se recupera por filtración, lavando con una mezcla etanol/n-heptano $(1 / 1, v / v) y$, posteriormente, es secado a $60^{\circ} \mathrm{C}$ durante 12 horas.

El sólido MWW-BTEB, además, se somete a un proceso post-síntesis de aminación, con el fin de generar un material híbrido bifuncional con centros básicos incorporados en su estructura (MWW-BTEB-NH

\section{MWW-BTEB-NH}

Para incorporar grupos amino a los pilares orgánicos presentes en el espacio interlaminar del material pilareado MWW-BTEB, se lleva a cabo un proceso post-síntesis en dos etapas: 
(i) Nitración (MWW-BTEB-NO

(ii) Reducción (MWW-BTEB- $\mathrm{NH}_{2}$ )

La etapa de nitración del grupo arílico se realiza añadiendo lentamente a $0.5 \mathrm{~g}$ del material híbrido MWW-BTEB una mezcla ácida preparada previamente, consistente en $15.2 \mathrm{~g}$ de $\mathrm{H}_{2} \mathrm{SO}_{4}$ (95-98\%, Aldrich) y $3.47 \mathrm{~g}$ de $\mathrm{HNO}_{3}$ (65\%, Panreac), manteniendo la suspensión formada tres días en agitación a temperatura ambiente. Pasado ese tiempo, se añaden $300 \mathrm{~mL}$ de agua destilada fría y la solución formada se agita durante 4 horas más a temperatura ambiente. El sólido amarillo pálido obtenido se recupera por filtración y se lava con abundante agua destilada. Finalmente, se seca a $60^{\circ} \mathrm{C}$ durante 8 horas. De esta forma se obtiene un producto que posee grupos nitro unidos al anillo aromático interlaminar (MWW-BTEB-NO 2$)$.

La reducción de grupos nitro a amino se lleva a cabo disolviendo el sólido obtenido en la etapa anterior en una disolución formada por $15 \mathrm{~mL}$ de $\mathrm{HCl}$ (37\%, Aldrich) y $1.59 \mathrm{~g}$ de $\mathrm{SnCl}_{2}$ (98\%, Aldrich), preparada con anterioridad, manteniendose la agitación durante tres días a temperatura ambiente. Después de esta etapa, se añadieron $300 \mathrm{~mL}$ de agua destilada a la disolución dejándose 4 horas más en agitación. El sólido amarillomarrón obtenido se filtra y se lava, primero con unos $100 \mathrm{~mL}$ de agua destilada, a continuación con $100 \mathrm{~mL}$ de etanol y por último con $10 \mathrm{~mL}$ de isopropilamina (99.5\%, Aldrich) Finalmente, el producto con grupos amino se seca a $60^{\circ} \mathrm{C}$ durante 8 horas (MWWBTEB- $\mathrm{NH}_{2}$ ).

\subsubsection{Determinación de centros activos. Valoraciones ácido-base de los materiales híbridos}

Para la determinación tanto de la acidez, presencia de grupos sulfónicos $\left(-\mathrm{SO}_{3} \mathrm{H}\right)$, como de la basicidad, presencia de grupos amino $\left(-\mathrm{NH}_{2}\right)$, de los diferentes materiales sintetizados se realizaron valoraciones ácido-base, de forma que se complementaba la información aportada por los resultados obtenidos mediante análisis elemental. A través de estas valoraciones es posible conocer la cantidad de centros realmente accesibles y 
disponibles para actuar durante los procesos de reacción. Los procedimientos seguidos para estas valoraciones se describen a continuación.

\section{Valoración de centros ácidos}

Para la determinación del número de centros ácidos presentes en los materiales híbridos sintetizados se realizó un tratamiento previo de las muestras. Primero se pesaron $0.3 \mathrm{~g}$ del sólido que se disolvieron en $50 \mathrm{~mL}$ de $\mathrm{NaCl} 2 \mathrm{M}$ y se mantuvieron en agitación constante durante 24 horas a temperatura ambiente. Transcurrido ese tiempo se filtró el sólido y se recuperó la disolución que se valoró potenciométricamente frente a una disolución de $\mathrm{NaOH} 0.1 \mathrm{M}$. Los valores de $\mathrm{pH}$ obtenidos para cada uno de los volúmenes de hidróxido sódico añadidos de forma sucesiva se representaron gráficamente obteniéndose una curva, en la que su punto de inflexión nos proporciona el volumen de equivalencia. Este volumen nos permite calcular el número de centros ácidos que son realmente accesibles.

\section{Valoración de centros básicos}

Para la determinación del número de centros básicos presentes en los materiales híbridos sintetizados también se realizó un tratamiento previo de las muestras. Primero se pesaron $0.3 \mathrm{~g}$ del sólido que se disolvieron en $30 \mathrm{~mL}$ de $\mathrm{HCl} 2 \times 10^{-2} \mathrm{M}$ y se mantuvieron en agitación constante durante 2 horas a temperatura ambiente. Transcurrido ese tiempo se filtró el sólido y se recuperó la disolución que se valoró potenciométricamente frente a una disolución de $\mathrm{NaOH} 0.1 \mathrm{M}$. Los valores de $\mathrm{pH}$ obtenidos para cada uno de los volúmenes de sosa añadidos de manera sucesiva se representaron gráficamente obteniéndose una curva, en la que su punto de inflexión nos proporciona el volumen de equivalencia. Este volumen nos permite calcular el número de centros básicos que son realmente accesibles. 


\subsubsection{Experimentos catalíticos}

Las condiciones de reacción para la esterificación realizada con el material híbrido MAG-SO ${ }_{3} \mathrm{H}$ son: $3.9 \mathrm{mmol}$ citronelol, $2.3 \mathrm{mmol}$ ácido acético, $30 \mathrm{mg}$ de catalizador o 0.56 $\% \mathrm{~mol}, 100^{\circ} \mathrm{C}$ en ausencia de disolvente.

Para llevar a cabo la reacción de condensación de Knoevenagel entre benzaldehído y cianoacetato de etilo, empleando como catalizador el material híbrido laminar MAG-BTMN, las condiciones de reacción son: $1.9 \mathrm{mmol}$ de benzaldehído y 1.7 mmol de cianoacetato de etilo en atmósfera inerte $\left(\mathrm{N}_{2}\right)$ a $298 \mathrm{~K}$ y $7 \% \mathrm{~mol}$ de $\mathrm{N}$.

Las condiciones de reacción para llevar a cabo la reacción en cascada Hidrólisis acetal - Condensación de Knoevenagel son las siguientes:

a) Reacción cascada en un solo paso: $5.45 \mathrm{mmol}$ de dimetilacetalbenzaldehído, 5.24 mmol de malononitrilo, $30 \mu \mathrm{L}$ de $\mathrm{H}_{2} \mathrm{O}$ (33\% moles) y $50 \mathrm{mg}$ del catalizador híbrido laminar (MWW-BTEB-NH 2 ), $2 \mathrm{~mL}$ de acetonitrilo como disolvente, durante 7.25 horas de reacción a $355 \mathrm{~K}$.

b) Condensación de Knoevenagel (experimento sin catalizador): $5.45 \mathrm{mmol}$ de benzaldehído, $5.24 \mathrm{mmol}$ de malononitrilo, $30 \mu \mathrm{L}$ de $\mathrm{H}_{2} \mathrm{O}$ (33\% moles), $2 \mathrm{~mL}$ de acetonitrilo como disolvente, durante 7.25 horas de reacción a $355 \mathrm{~K}$.

En todos los casos, las muestras se tomaron periódicamente durante el transcurso de la reacción y se analizaron por CG equipado con una columna HP-5 (30 m x $0.25 \times 0.25 \mu \mathrm{m})$ y un detector FID. 


\section{Referencias bibliográficas}

[1] T. J. Pinnavaia, Adv. Chem. Ser. 1995, 245, 283.

[2] M. C.J.B, Catalysis Today 1988, 2, 199.

[3] M. Chorom, P. Rengasamy, Clays and Clay Minerals 1996, 44, 783.

[4] K. Tamura, H. Nakazawa, Clays and Clay Minerals 1996, 44, 501.

[5] O.-Y. Kwon, S.-Y. Jeong, J.-K. Suh, B.-H. Ryu, J.-M. Lee, Journal of Colloid and Interface Science 1996, 177, 677.

[6] M. L. Occelli, R. M. Tindwa, Clays and Clay Minerals 1983, 31, 22.

[7] B. G.J.J, Catalysis Today 1988, 2, 233.

[8] S. M. Bradley, R. A. Kydd, Journal of Catalysis 1993, 141, 239.

[9] S. Yamanaka, M. Hattori, Catalysis Today 1988, 2, 261.

[10] H. L. D. Castillo, P. Grange, Applied Catalysis A: General 1993, 103, 23.

[11] a)T. Endo, M. M. Mortland, T. J. Pinnavaia, Clays and Clay Minerals 1980, 28, 105; b)G. Fetter, D. Tichit, P. Massiani, R. Dutarte, F. Figuera, 12응 Simposio Iberoamericano de Catálisis 1990, 448, 457.

[12] a)T. J. Pinnavaia, Chemical Reactions in Organic and Inorganic Constrianed Systems, Ed. R. Setton 1986, 151; b)S. J, Catalysis Today 1988, 2, 219.

[13] A. V. Coelho, G. Poncelet, Applied Catalysis 1991, 77, 303.

[14] L. B. de Paiva, A. R. Morales, F. R. Valenzuela Díaz, Applied Clay Science 2008, 42, 8 .

[15] F. Bergaya, G. Lagaly, Applied Clay Science 2001, 19, 1.

[16] V. Srivastava, K. Gaubert, M. Pucheault, M. Vaultier, ChemCatChem 2009, 1,94 .

[17] M. Ogawa, K. Kuroda, Bulletin of the Chemical Society of Japan 1997, 70, 2593.

[18] A. Usuki, Y. Kojima, M. Kawasumi, A. Okada, Y. Fukushima, T. Kurauchi, O. Kamigaito, J. Mater. Res. 1993, 8, 1179.

[19] F. Rey García, Tesis Doctoral, Universidad Autónoma de Madrid, Facultad de Ciencia

1992.

[20] M. Chibwe, J. B. Valim, W. Jones, Multifunctional Mesoporous Inorganic Solids 1993, 191.

[21] F. Cavani, F. Trifirò, A. Vaccari, Catalysis Today 1991, 11, 173.

[22] G. Lagaly, K. Beneke, Colloid \& Polymer Science 1991, 269, 1198.

[23] T. Kwon, T. J. Pinnavaia, Journal of Molecular Catalysis, 74, 23.

[24] V. I. Iliev, A. I. Ileva, L. D. Dimitrov, Applied Catalysis A: General 1995, 126, 333.

[25] J. Twu, P. K. Dutta, Journal of Catalysis 1990, 124, 503.

[26] T. Tatsumi, K. Yamamoto, H. Tajima, H.-o. Tominaga, Chemistry Letters 1992, 21, 815. 
[27] T. Kwon, T. J. Pinnavaia, Journal of Molecular Catalysis 1992, 74, 23.

[28] a)M. Elena Pérez-Bernal, R. Ruano-Casero, T. J. Pinnavaia, Catalysis Letters 1991, 11, 55; b)K. Kuma, W. Paplawsky, B. Gedulin, G. Arrhenius, Origins of Life and Evolution of Biospheres 1989, 19, 573.

[29] J. T. Rajamathi, N. Ravishankar, M. Rajamathi, Solid State Sciences 2005, 7, 195.

[30] J. Pisson, C. Taviot-Guého, Y. Israëli, F. Leroux, P. Munsch, J. P. Itié, V. Briois, N. Morel-Desrosiers, J. P. Besse, The Journal of Physical Chemistry $B$ 2003, 107, 9243.

[31] a)S. O'Leary, D. O'Hare, G. Seeley, Chemical Communications 2002, 1506; b)Q. Z. Yang, D. J. Sun, C. G. Zhang, X. J. Wang, W. A. Zhao, Langmuir 2003, 19, 5570; c)Z. Liu, R. Ma, M. Osada, N. Iyi, Y. Ebina, K. Takada, T. Sasaki, Journal of the American Chemical Society 2006, 128, 4872.

[32] a)T. Hibino, Chemistry of Materials 2004, 16

J. L. Bourdelande, J. Hernando, I. Jirka, E. Káfuňková, F. Kovanda, P. Kubát, J. Mosinger, D. M. Wagnerová, Chemistry of Materials 2007, 19, 3822.

J. S. Dailey, T. J. Pinnavaia, Chemistry of Materials 1992, 4, 855.

H. B. Eugster, Science 1967, 157, 1177.

L. McCulloch, Journal of the American Chemical Society 1952, 74, 2453.

U. Brenn, H. Ernst, D. Freude, R. Herrmann, R. Jähnig, H. G. Karge, J. Kärger, T. König, B. Mädler, U. T. Pingel, D. Prochnow, W. Schwieger, Microporous and Mesoporous Materials 2000, 40, 43.

[37] a)R. A. Fletcher, D. M. Bibby, Clays and Clay Minerals 1987, 35, 318; b)K. Beneke, G. Lagaly, American Mineral 1983, 68, 818; c)J. W. Greig, Am J Sci 1927, s5-13, 1; d)K. Beneke, G. Lagaly, American Mineral 1977, 62, 763.

[38] J. C. Vartulo, a. e. al, U.S. Patent 5236681.

[39] K.-H. Bergk, W. Schwieger, M. Posch, Chem Techonol. 1987, 39, 459.

[40] a)K.-H. Bergk, J. Jurkschat, W. Schwieger, Acta Hydrochim Hydrobiol 1986, 14, 5; b)W. Schwieger, P. Werner, K. H. Bergk, Colloid \& Polymer Science 1991, 269, 1071.

[41] G. Lagaly, K. Beneke, A. Weiss, Zaturforch Teil B 1973, 28, 234.

[42] K. Beneke, P. Thiesen, G. Lagaly, Inorganic Chemistry 1995, 34, 900.

[43] J. M. Garces, S. C. Rocke, C. E. Crowder, D. L. Hasha, Clays and Clay Minerals 1988, 36, 409.

[44] A. J. Blake, K. R. Franlin, B. M. Lowe, Dalton Transactions 1988, 2513.

[45] K. Kosuge, A. Tsunashima, Journal of the Chemical Society, Chemical Communications 1995, 2427.

[46] M. E. Landis, B. A. Aufdembrink, P. Chu, I. D. Johnson, G. W. Kirker, M. K. Rubin, Journal of the American Chemical Society 1991, 113, 3189. 
[47] S. Inagaki, Y. Yamada, Y. Fukushima, in Studies in Surface Science and Catalysis, Vol. Volume 105 (Eds.: S.-K. I. Hakze Chon, U. Young Sun), Elsevier, 1997, pp. 109.

[48] E. Ruiz-Hitzky, J. M. Rojo, Nature 1980, 287, 28.

[49] D. Mochizuki, A. Shimojima, T. Imagawa, K. Kuroda, Journal of the American Chemical Society 2005, 127, 7183.

[50] a)R. Ishii, T. Ikeda, T. Itoh, T. Ebina, T. Yokoyama, T. Hanaoka, F. Mizukami, Journal of Materials Chemistry 2006, 16, 4035; b)D. Mochizuki, S. Kowata, K. Kuroda, Chemistry of Materials 2006, 18, 5223.

[51] a)T. Blasco, M. A. Camblor, A. Corma, J. Perez-Pariente, Journal of the American Chemical Society 1993, 115, 11806; b)S. Bordiga, S. Coluccia, C. Lamberti, L. Marchese, A. Zecchina, F. Boscherini, F. Buffa, F. Genoni, G. Leofanti, The Journal of Physical Chemistry 1994, 98, 4125.

[52] D. M. Chapman, A. L. Roe, Zeolites 1990, 10, 730.

[53] M. W. Anderson, O. Terasaki, T. Ohsuna, A. Philippou, S. P. MacKay, A. Ferreira, J. Rocha, S. Lidin, Nature 1994, 367, 347.

[54] F. Kooli, T. Sasaki, M. Watanabe, Chemical Communications 1999, 211.

[55] a)W. Hou, Q. Yan, X. Fu, Journal of the Chemical Society, Chemical Communications 1994, 1371; b)M. A. Roberts, G. Sankar, J. M. Thomas, R. H. Jones, H. Du, J. Chen, W. Pang, R. Xu, Nature 1996, 381, 401.

[56] J. N. Kondo, S. Shibata, Y. Ebina, K. Domen, A. Tanaka, The Journal of Physical Chemistry 1995, 99, 16043.

[57] a)Z. Lin, J. Rocha, P. Brandão, A. Ferreira, A. P. Esculcas, J. D. Pedrosa de Jesus, A. Philippou, M. W. Anderson, The Journal of Physical Chemistry $B$ 1997, 101, 7114; b)M. Veltri, D. Vuono, P. De Luca, J. Nagy, A. Nastro, Journal of Thermal Analysis and Calorimetry 2006, 84, 247.

[58] a)H. Du, M. Fang, J. Chen, W. Pang, Journal of Materials Chemistry 1996, 6, 1827; b)S. Ferdov, V. Kostov-Kytin, O. Petrov, Chemical Communications 2002, 1786; c)C. Rubio, C. Casado, S. Uriel, C. Téllez, J. Coronas, Materials Letters 2009, 63, 113.

[59] a)M. Machida, X. W. Ma, H. Taniguchi, J.-i. Yabunaka, T. Kijima, Journal of Molecular Catalysis A: Chemical 2000, 155, 131; b)K.-W. Park, J. H. Jung, J. D. Kim, S.-K. Kim, O.-Y. Kwon, Microporous and Mesoporous Materials 2009, 118, 100.

[60] P. Kyeong-Won, Microporous and Mesoporous Materials 2010, 127, 142.

[61] C. Rubio, C. Casado, P. Gorgojo, F. Etayo, S. Uriel, C. Téllez, J. Coronas, European Journal of Inorganic Chemistry 2010, 2010, 159.

[62] D. Breck, Ed. Wiley 1974.

[63] D. Breck, Zeolite Molecular Sieves. Structure, Chemistry and Use; Ed. J. Wiley 1974. 
[64] A. Corma, C. Corell, J. Pérez-Pariente, J. M. Guil, R. Guil-López, S. Nicolopoulos, J. G. Calbet, M. Vallet-Regi, Zeolites 1996, 16, 7.

[65] a)W. J. Roth, D. L. Dorset, G. J. Kennedy, Microporous and Mesoporous Materials 2011, 142, 168; b)W. J. Roth, D. L. Dorset, Microporous and Mesoporous Materials 2011, 142, 32; c)W. J. Roth, J. Cejka, Catalysis Science \& Technology 2011, 1, 43.

[66] R. Ravishankar, P. N. Joshi, S. S. Tamhankar, S. Sivasanker, V. P. Shiralkar, Adsorption Science and Technology 1998, 16, 607.

[67] M. E. Leonowicz, J. A. Lawton, S. L. Lawton, M. K. Rubin, Science 1994, 264, 1910.

[68] L. Schreyeck, P. Caullet, J.-C. Mougenel, J.-L. Guth, B. Marler, Journal of the Chemical Society, Chemical Communications 1995, 2187.

[69] A. Corma, V. Fornes, U. Diaz, Chemical Communications 2001, 2642.

[70] A. Corma, C. Corell, J. Pérez-Pariente, Zeolites 1995, 15, 2.

[71] L. Schreyeck, P. Caullet, J. C. Mougenel, J. L. Guth, B. Marler, Microporous Materials 1996, 6, 259.

[72] S. Zanardi, A. Alberti, G. Cruciani, A. Corma, V. Fornés, M. Brunelli, Angewandte Chemie International Edition 2004, 43, 4933.

[73] C. Baerlocher, W. M. Meier, O. D.H., Atlas of Zeolite Framework Types, Elsevier 2001.

[74] P. Wu, J. Ruan, L. Wang, L. Wu, Y. Wang, Y. Liu, W. Fan, M. He, O. Terasaki, T. Tatsumi, Journal of the American Chemical Society 2008, 130, 8178.

[75] S. Inagaki, T. Tatsumi, Chemical Communications 2009, 2583.

[76] L. Wang, Y. Wang, Y. Liu, H. Wu, X. Li, M. He, P. Wu, Journal of Materials Chemistry 2009, 19, 8594.

[77] a)A. Corma, V. Fornes, S. B. Pergher, M. T. L. M, J. G. Buglass, Nature 1998, 396, 353; b)A. Corma, U. Diaz, V. Fornés, J. M. Guil, J. Martinez-Triguero, E. J. Creyghton, Journal of Catalysis 2000, 191, 218.

[78] A. Corma, U. Diaz, V. Fornes, J. L. Jorda, M. Domine, F. Rey, Chemical Communications 1999, 779.

[79] a)C. Baleizao, B. Gigante, M. J. Sabater, H. Garcia, A. Corma, Applied Catalysis A: General 2002, 228, 279; b)V. Ayala, A. Corma, M. Iglesias, J. A. Rincón, F. Sánchez, Journal of Catalysis 2004, 224, 170.

[80] C. González-Arellano, A. Corma, M. Iglesias, F. Sánchez, Advanced Synthesis \& Catalysis 2004, 346, 1758.

[81] A. Corma, E. Gutiérrez-Puebla, M. Iglesias, A. Monge, S. Pérez-Ferreras, F. Sánchez, Advanced Synthesis \& Catalysis 2006, 348, 1899.

[82] a)A. Fuerte, A. Corma, M. Iglesias, E. Morales, F. Sánchez, Catalysis Letters 2005, 101, 99; b)A. Fuerte, A. Corma, M. Iglesias, E. Morales, F. Sánchez, Journal of Molecular Catalysis A: Chemical 2006, 246, 109.

[83] A. Corma, V. Fornes, F. Rey, Advanced Materials 2002, 14, 71. 
[84] a)A. Corma, U. Díaz, B. Ferrer, V. Fornés, M. S. Galletero, H. García, Chemistry of Materials 2004, 16, 1170; b)A. Corma, M. S. Galletero, H. Garcia, E. Palomares, F. Rey, Chemical Communications 2002, 1100.

[85] G. Alberti, U. Costantino, C. Dionigi, S. Murcia-Mascarós, R. Vivani, Supramol. Chem. 1995, 6, 29.

[86] R. Rojas, C. Barriga, M. Angeles Ulibarri, P. Malet, V. Rives, Journal of Materials Chemistry 2002, 12, 1071.

[87] K.-i. Shimizu, S. Itoh, T. Hatamachi, Y. Kitayama, T. Kodama, Journal of Materials Chemistry 2006, 16, 773.

[88] L. G, Solid State lonics 1986, 22, 43.

[89] M. S. Whittingham, A. J. Jacobson, Intercalation Chemistry, Academic Press 1982.

[90] a)M. B. Dines, P. C. Griffith, Polyhedron 1983, 2, 607; b)G. Alberti, U. Constantino, F. Marmottini, R. Vivani, P. Zappelli, Pillared Layered Structures - Current Trends and Applications, Ed., I.V. Mitchell 1990, 119.

[91] S. Reinoso, M. H. Dickman, M. Reicke, U. Kortz, Inorganic Chemistry 2006, 45, 9014.

[92] N. I. Kovtyukhova, P. J. Ollivier, B. R. Martin, T. E. Mallouk, S. A. Chizhik, E. V. Buzaneva, A. D. Gorchinskiy, Chemistry of Materials 1999, 11, 771.

[93] L. Estevez, A. Kelarakis, Q. Gong, E. H. Da'as, E. P. Giannelis, Journal of the American Chemical Society 2011, 133, 6122.

[94] U. Brenn, W. Schwieger, K. Wuttig, Colloid \& Polymer Science 1999, 277, 394.

[95] a)A. Bradt, W. Schwieger, K.-H. Bergk, Crystal Research and Technology 1988, 23, 1201; b)Y. Huang, Jiang, Z., Schwieger, W., Can, J., J. Chem. In press; c)G. J. Nesbitt, University of Durham 1986.

[96] G. Lagaly, K. Beneke, A. Weiss, American Mineral 1975, 60, 642.

[97] G. W. Brindley, The American Mineralogist 1969, 54, 1583.

[98] S. J. Gregg, K. S. W. Sing, Adsorption, Surface Area and Pororosity 1982.

[99] A. Corma, V. Fornés, J. M. Guil, S. Pergher, T. L. M. Maesen, J. G. Buglass, Microporous and Mesoporous Materials 2000, 38, 301.

[100] a)J. A. Melero, R. van Grieken, G. Morales, Chemical Reviews 2006, 106, 3790; b)F. Hoffmann, M. Cornelius, J. Morell, M. Fröba, Angewandte Chemie International Edition 2006, 45, 3216.

[101] a)W. G. Taylor, C. E. Schreck, Journal of Pharmaceutical Sciences 1985, 74, 534; b)K. Scherlach, D. Boettger, N. Remme, C. Hertweck, Natural Product Reports 2010, 27, 869.

[102] a)F. S. Proust, U. D. Beaucaire, G. R. Dyrkarcz, W. M. Koppes, R. E. Kuznicki, T. A. Marlewski, J. A. Pienkowski, J. M. Puda, J. Org. Chem 1973, 38, 1512; b)G. Jones, Org. React. 1967, 15, 204; c)J. Guyot, A. Kergomard, Tetrahedron 1983, 39, 1167. 
[103] M. E. Leonowicz, J. Lawton, S. L. Lawton, M. K. Rubin, Science 1994, 264, 1910.

[104] a)W. J. Roth, C. T. Kresge, J. C. Vartuli, M. E. Leonowicz, A. S. Fung, S. B. McCullen, Studies in Surface Science and Catalysis 1995, 94; b)Y. J. He, G. S. Nivarthy, F. Eder, K. Seshan, J. A. Lercher, Microporous and Mesoporous Materials 1998, 25, 207.

[105] J. Sauer, P. Ugliengo, E. Garrone, V. R. Saunders, Chemical Reviews 1994, 94, 2095.

[106] E. Prescth, T. Clerc, J. Seibl, W. Simon, Structural Elucidation of Organic Compounds Using Spectroscopic Methods 1976.

[107] M. A. Camblor, C. Corell, A. Corma, M.-J. Díaz-Cabañas, S. Nicolopoulos, J. M. González-Calbet, M. Vallet-Regí, Chemistry of Materials 1996, 8, 2415.

[108] a)E. L. Margelefsky, R. K. Zeidan, V. Dufaud, M. E. Davis, Journal of the American Chemical Society 2007, 129, 13691; b)J. D. Bass, A. Katz, Chemistry of Materials 2006, 18, 1611; c)A. Katz, M. E. Davis, Nature 2000, 403, 286. 


\section{Capítulo 4}

\section{MATERIALES HÍBRIDOS}

\section{MESOPOROSOS:}

\section{PROCESOS SOL-GEL EN}

\section{MEDIO FLUORURO}

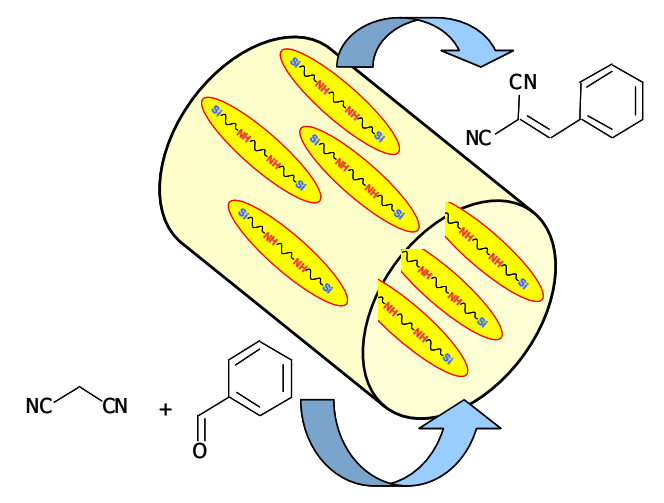



En el capítulo anterior se ha mostrado la posibilidad de preparar materiales híbridos multifuncionales de Clase II, a partir de precursores laminares inorgánicos y disilanos actuando como agentes de pilarización. Sin embargo, ha sido dentro de los materiales mesoporosos donde se ha obtenido un mayor número de sólidos híbridos a partir de precursores organosilíceos, empleando procesos sol-gel como rutas de síntesis basadas en el ensamblaje molecular que utilizan, con frecuencia, surfactantes como agentes directores de estructura. En un principio, este tipo de materiales fueron preparados por medio de la incorporación de monosilanos funcionalizados que quedan colgando de las paredes de los sólidos mesoporosos, ya sea a través de procesos postsíntesis de anclaje o de condensación directa ${ }^{[1]}$. Con posterioridad, se logró un importante avance, a finales de los años noventa, con la preparación de nuevas familias de organosílicas periódicas mesoporosas (PMOs) con el empleo de disilanos, $\left(\mathrm{R}^{\prime} \mathrm{O}\right)_{3} \mathrm{SiRSi}\left(\mathrm{OR}^{\prime}\right)_{3}$, como precursores orgánicos-inorgánicos usando métodos micelares ${ }^{[2]}$. Incluso, se han realizado intentos por preparar sólidos microporosos de naturaleza zeolítica a partir de dichos disilanos sin demasiado éxito, utilizando procesos de síntesis hidrotermal ${ }^{[3]}$. Por todo ello, la utilización de disilanos altamente específicos que permitan la obtención de nuevas familias de materiales híbridos mesoporosos que contengan centros activos accesibles y estables, así como la exploración de nuevas rutas de síntesis, en los que dichos disilanos intervengan, son aspectos de elevado interés en este campo y que serán abordados a lo largo de este capítulo. 


\subsection{Estado del arte}

La utilización de disilanos durante la preparación de materiales híbridos ha servido, sobre todo en la última década, para la generación de sólidos con diferente nivel de estructuración y jerarquía porosa (micro o mesoporosa). Dichos materiales tienen en común que su estructura está constituida por segmentos orgánicos e inorgánicos alternados homogéneamente entre sí. A lo largo de esta parte introductoria se mostrarán los principales materiales híbridos porosos de Clase II obtenidos, normalmente, a través de procesos sol-gel, empleando disilanos como precursores orgánicos-inorgánicos, en los que sus unidades estructurales silíceas se forman in situ durante el proceso de síntesis.

\subsubsection{Métodos Sol-Gel: Materiales mesoporosos sin organización estructural}

Desde la década de los ochenta, se han preparado un elevado número de materiales híbridos con un nivel bajo de estructuración, a través del anclaje de monosilanos funcionalizados sobre diferentes tipos de soportes, tales como sílice, alúmina u óxidos metálicos de alta superficie. Dentro de esta tarea han destacado los estudios realizados por los grupos de Katz, Davis e Igasawa, los cuales han preparado catalizadores multifuncionales por la incorporación de centros activos ácidos, básicos, redox o quirales que cohabitan sobre el mismo soporte sólido (Figura 4.1.). Además, se ha observado la existencia de interesantes efectos cooperativos entre los diferentes centros activos o, incluso, entre los centros activos y los silanoles presentes en la superficie, en el caso de que se haya empleado sílice como soporte, que incrementan la actividad y eficiencia catalítica de los materiales obtenidos (Figura 4.2.). No obstante, la distribución poco homogénea de los centros activos, la separación existente entre las fases orgánica e inorgánica, así como la completa ausencia de selectividad de forma en los materiales soportados, limita enormemente su aplicación en el campo de la catálisis ${ }^{[4]}$.

Como alternativa, tal y como se ha mostrado en el Capítulo 1 de esta Tesis, la utilización de disilanos que intervienen en rutas de síntesis sol-gel ha permitido preparar materiales híbridos sin ordenamiento estructural que incorporan funciones orgánicas en su entramado. Los procesos sol-gel consisten en reacciones de hidrólisis y policondensación, las cuales involucran a pequeñas moléculas que actúan como 
precursores para formar redes porosas tridimensionales mediante la pérdida de sus sustituyentes. Específicamente, los procesos sol-gel basados en silicio han sido los más estudiados en la bibliografía, siendo predominantes en la formación de materiales híbridos debido a la facilidad para incorporar grupos orgánicos a través del empleo de silanos modificados orgánicamente, tales como los disilanos, $\left(\mathrm{R}^{\prime} \mathrm{O}\right)_{3} \mathrm{SiRSi}\left(\mathrm{OR}^{\prime}\right)_{3}{ }^{[5]}$.
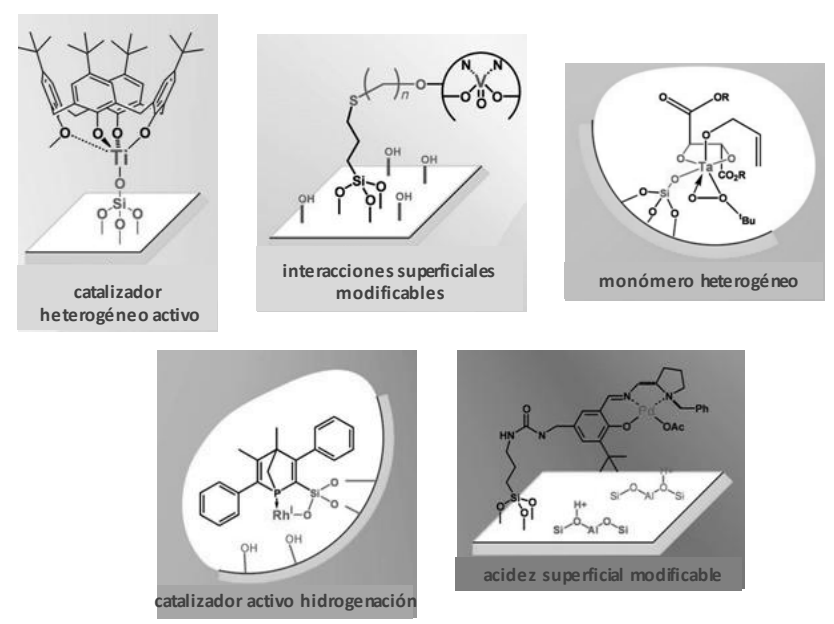

Figura 4.1. Ejemplos de catalizadores híbridos obtenidos por el anclaje de monosilanos funcionalizados sobre soportes de alta superficie.

A)

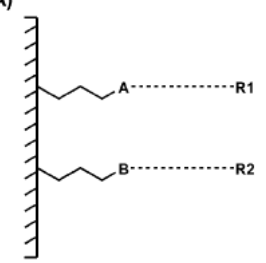

c)

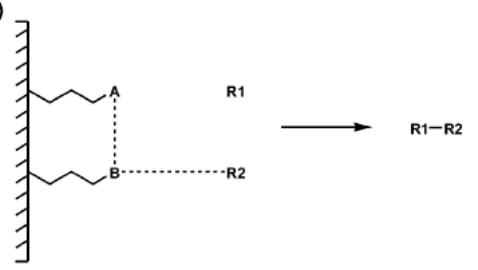

B)

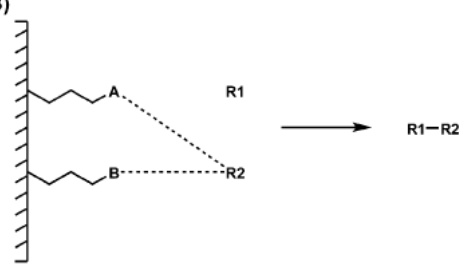

D)

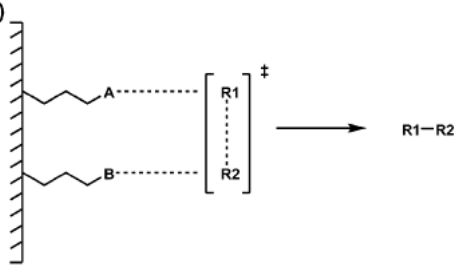

Figura 4.2. Diferentes ejemplos de modos cooperativos establecidos entre centros activos, A y B, anclados en la superficie de un soporte que catalizan los reactantes, R1 y R2. 
En este tipo de procesos, los enlaces Si-C permanecen estables frente a los procesos de hidrólisis que tienen lugar en medio acuoso, generalmente utilizado, siendo posible incorporar una gran variedad de grupos orgánicos presentes en los disilanos iniciales. De forma general, los precursores orgánicos-inorgánicos empleados presentan enlaces alcóxido terminales $-\mathrm{Si}\left(\mathrm{OR}^{\prime}\right)_{3}$, los cuales intervienen durante las reacciones de hidrólisis, dando lugar a grupos silanoles altamente reactivos, $\mathrm{Si}-\mathrm{OH}$, que condensan entre sí para dar grupos Si-O-Si que conforman la red estructural de los materiales. Este proceso es catalizado por ácidos, bases o iones fluoruro, involucrando diferentes mecanismos de reacción en función del catalizador empleado. Además, el pH con el que se trabaja tiene un efecto importante sobre la cinética, en concreto sobre la gelificación provocada en el proceso de síntesis ${ }^{[6]}$.

Algunas de las principales ventajas de esta ruta de síntesis son la preparación de materiales porosos estables y bien definidos, en ausencia de sofisticadas moléculas orgánicas o surfactantes utilizados como agentes directores de estructura (ADEs), alcanzando una elevada homogeneidad en cuanto a la distribución de fragmentos orgánicos e inorgánicos. Estos materiales pese a no exhibir orden estructural presentan, en algunos casos, una elevada accesibilidad ${ }^{[7]}$. Generalmente, se usan $\mathrm{HCl}, \mathrm{NaOH} \circ \mathrm{NH}_{4} \mathrm{OH}$ como catalizadores del proceso, pero también pueden ser empleados iones fluoruros ( $\mathrm{NaF}$ - $\mathrm{NH}_{4} \mathrm{~F}$ ), para los cuales las velocidades de reacción son mucho más rápidas por la generación de especies intermedias, penta- y hexa-fluorosilicatos, altamente reactivas. No obstante, los procesos sol-gel en medio fluoruro no han sido muy estudiados, hasta el momento, para la preparación de materiales híbridos porosos, siendo considerados con mayor atención a lo largo del presente capítulo.

La naturaleza de los disilanos empleados influye enormemente sobre las características finales de los materiales orgánicos-inorgánicos sin organización estructural obtenidos a través de procesos de policondensación sol-gel. Así, en el caso de que el disilano empleado como precursor presente un puente orgánico rígido, como sería el caso de anillos aromáticos, el proceso sol-gel llevado a cabo conduce a la formación de materiales híbridos con una superficie específica elevada, incluso superior a $900 \mathrm{~m}^{2} \mathrm{~g}^{-1}$. Por el contrario, cuando el puente orgánico es más flexible, como es el caso de largas cadenas 148 
hidrocarbonadas, los sólidos obtenidos no presentan porosidad debido al colapsamiento producido durante el proceso de condensación. Ambas situaciones han sido ampliamente exploradas en procesos sol-gel cuya etapa de hidrólisis se realiza en condiciones ácidas o básicas (Figura 4.3.) ${ }^{[8]}$.
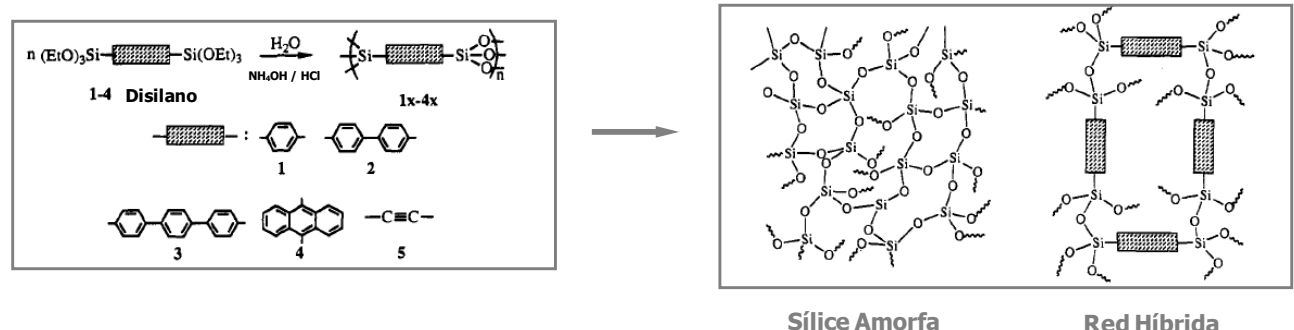

Figura 4.3. Esquema de preparación de materiales híbridos no ordenados a través de procesos solgel, partiendo de disilanos con fragmentos orgánicos rígidos.

\subsubsection{Materiales porosos con orden laminar}

Existe otro tipo de materiales híbridos orgánicos-inorgánicos con organización laminar que se forman a partir del ensamblaje molecular de precursores organosiliceos, disilanos, que poseen largas cadenas hidrocarbonadas a modo de puente, a través de procesos sol-gel ${ }^{[9]}$. Este proceso de ensamblaje está basado en las interacciones lipofílicas de tipo Van der Waals o por puente de hidrógeno que se establecen entre las cadenas alquílicas presentes en las moléculas de silsesquioxano. Aunque no ha sido muy estudiado hasta el momento, la existencia de grupos orgánicos funcionales en dichas cadenas permitiría obtener materiales híbridos laminares con centros activos incluidos en su entramado estructural que les permitiría actuar como catalizadores.

Siguiendo esta metodología, Alauzun y col. ${ }^{[9]}$ encontraron diferencias importantes en cuanto a la organización estructural de los materiales obtenidos al emplear disilanos de distinta naturaleza. Así, cuando los disilanos utilizados como precursores poseían cadenas, a modo de puente, con menos de 10 unidades metilénicas $\left(-\mathrm{CH}_{2}-\right)$, el auto-ensamblaje molecular no tenía lugar ya que tras el proceso de policondensación se obtenían materiales orgánicos-inorgánicos sin orden a largo alcance. En cambio, cuando la longitud de las cadenas oscilaba entre 10 y 20 unidades $-\mathrm{CH}_{2^{-}}$, se obtienen materiales que siguen 
un ordenamiento laminar. Por otra parte, cuando la cadena hidrocarbonada tipo puente poseía más de 20 unidades $-\mathrm{CH}_{2^{-}}$, las interacciones hidrofóbicas entre las cadenas alquílicas no permitían la organización laminar, obteniéndose materiales con una simetría hexagonal en el caso específico de que el número de dichas unidades fuese igual a 30, ya que el disilano actúa a modo de surfactante, sobre todo al trabajar en medios acuosos. La explicación a este hecho radica en que las largas cadenas hidrofóbicas se agrupan entre sí en el centro de una micela, facilitando una mayor proximidad entre los grupos silanoles localizados en la parte externa (hidrofílica), los cuales condensan para generar una fase hexagonal típica de materiales mesoporosos tipo M41S (Figura 4.4.).

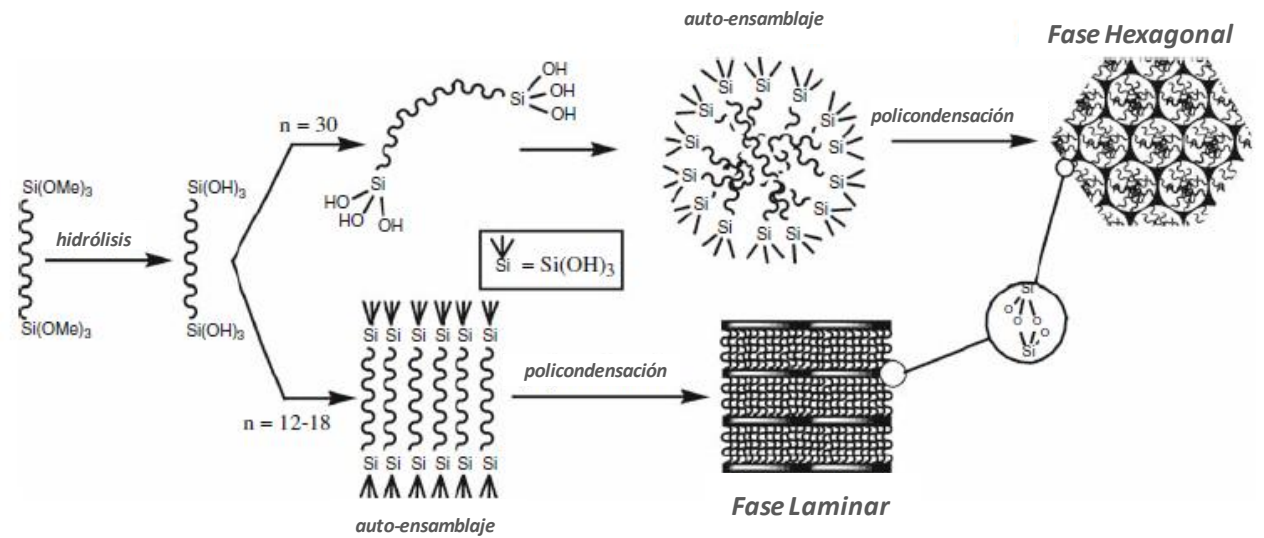

Figura 4.4. Auto-ensamblaje molecular de disilanos que poseen cadenas alquílicas a modo de puente debido a las interacciones hidrofóbicas que se establecen entre ellas.

Siguiendo con esta aproximación, Moreau y col. prepararon una nueva familia de materiales híbridos laminares, a través de procesos sol-gel en medio ácido o básico, debido al ensamblaje molecular de disilanos que contienen grupos ureido-fenilo a modo de puente. Las interacciones electrostáticas por puente de hidrógeno que se establecen de una manera estable y regular entre dichos fragmentos orgánicos, unido a la polimerización de los grupos terminales siloxano, facilita la generación de estructuras orgánicas-inorgánicas que siguen un ordenamiento laminar, las cuales se han empleado con éxito para formar films o, incluso, fibras helicoidales con potenciales aplicaciones como conductores o en el campo de los sensores (Figura 4.5. $)^{[10]}$. Dentro de esta línea, se han empleado disilanos que contienen ciclos con carbonos quirales como puente orgánico 150 
para preparar materiales híbridos laminares con posibles aplicaciones en catálisis asimétrica (Figura 4.6.) ${ }^{[11]}$.

(a)

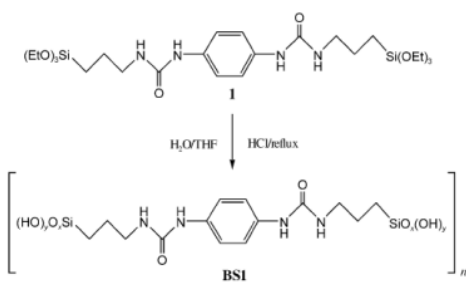

(b)

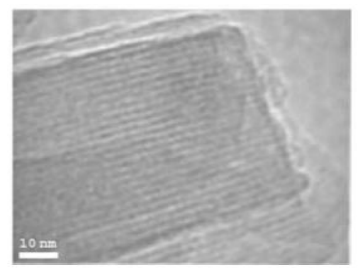

(c)

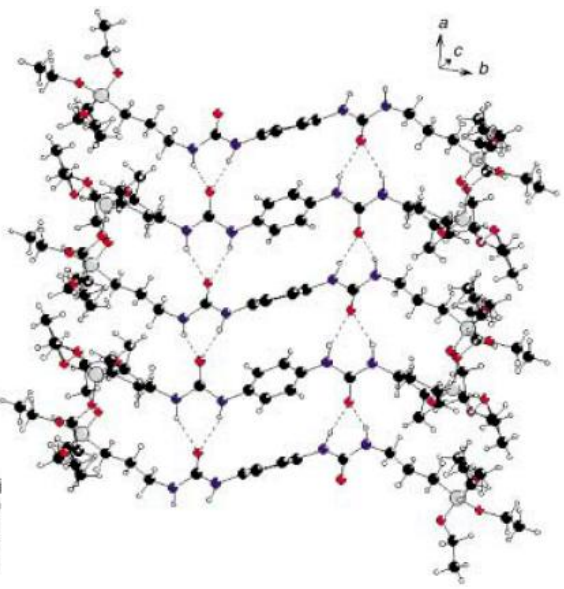

Figura 4.5. Material híbrido laminar formado por la interacción electrostática entre grupos ureidofenilo presentes en las moléculas de silsesquioxano empleadas como precursores: (a) disilano con grupos ureido-fenilo tipo puente, (b) micrografía TEM del material laminar y (c) esquema de la estructura laminar.

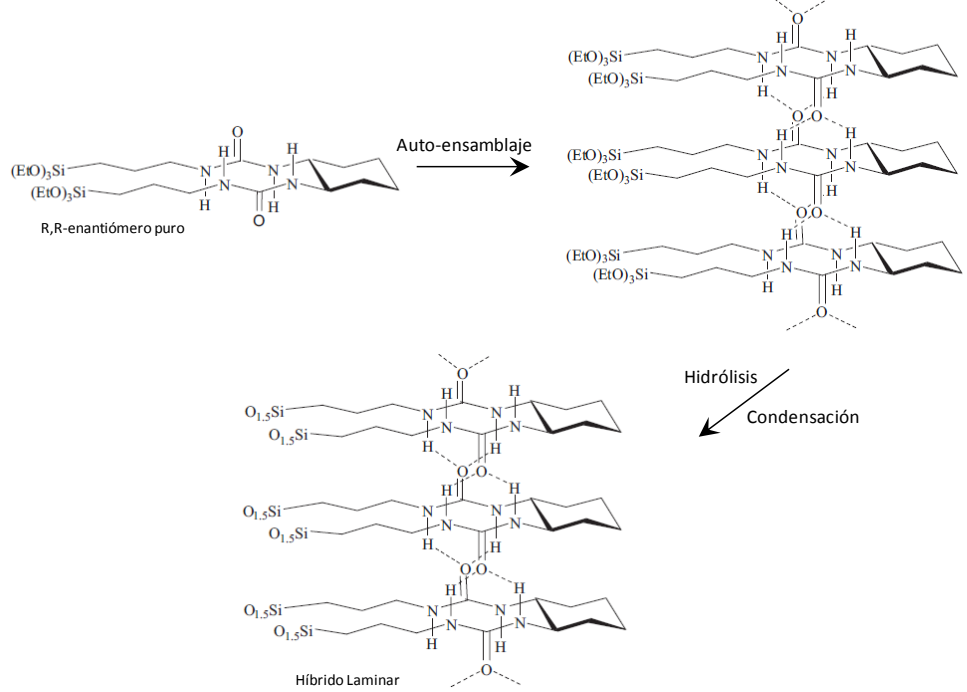

Figura 4.6. Ensamblaje molecular siguiendo un ordenamiento laminar de disilanos que contienen grupos ureido-quirales a modo de puente. 
Por otra parte, Bellussi y col. han preparado recientemente interesantes aluminosilicatos orgánicos-inorgánicos, denominados ECS (Eni Carbon Silicate) con organización laminar, empleando relaciones Si/Al próximas a 1, en medio alcalino y en ausencia de agentes directores de estructura, gracias a la intervención de disilanos que contienen grupos aromáticos a modo de puente que interaccionan electrostáticamente entre sí. Estas condiciones de síntesis favorecen la formación de láminas inorgánicas enlazadas a través de anillos aromáticos, las cuales están constituidas por tetraedros de $\left[\mathrm{AlO}_{4}\right]$ y $\left[\mathrm{SiO}_{3} \mathrm{C}\right]$. Estudios de resolución estructural por difracción de rayos $\mathrm{X}$ revelaron que en estos materiales existen un doble sistema de poros: intralaminar, constituido por canales delimitados por pequeños anillos de 6 miembros (6 MR), e interlaminar, debido a las cavidades que se generan entre las láminas inorgánicas y los grupos aromáticos que las separan. Estas características hacen que, en algunos casos, se obtengan materiales híbridos laminares con una superficie específica y un volumen de poro próximos a 350 $\mathrm{m}^{2} \mathrm{~g}^{-1}$ y $0.70 \mathrm{~cm}^{3} \mathrm{~g}^{-1}$ (Figura 4.7.) ${ }^{[12]}$.
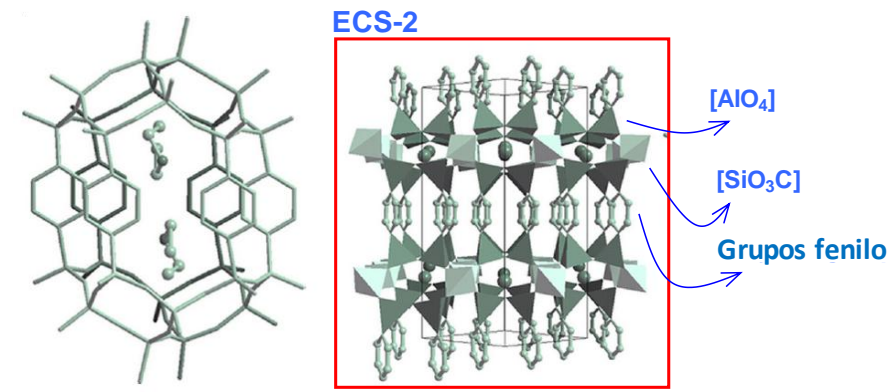

Figura 4.7. Aluminosilicato laminar orgánico-inorgánico denominado ECS-2.

\subsubsection{Métodos Micelares: Organosílicas periódicas mesoporosas (PMOs)}

El descubrimiento de una nueva familia de materiales ordenados mesoporosos, M41S, por investigadores de Mobil Oil Company en el año 1992, a través de la combinación de procesos sol-gel en fase acuosa, empleando surfactantes líquidos que se disponían en forma de micelas, sirvió para abrir una nueva área dentro del campo de la ciencia de los materiales ${ }^{[13]}$. Estos sólidos se caracterizan por presentar elevadas áreas superficiales debido al sistema ordenado de poros que poseen, con diámetros 
comprendidos entre 2 y $15 \mathrm{~nm}$, cuyas paredes están constituidas por sílice sin orden cristalino a corto alcance. Para su preparación se siguen rutas micelares de síntesis en las que son empleadas moléculas de surfactantes que actúan a modo de ADEs, las cuales facilitan la formación de la matriz porosa. El material más representativo dentro de esta familia es la MCM-41 que posee una disposición hexagonal de poros, perteneciente al grupo espacial $p 6 \mathrm{~mm}$. La eliminación del template orgánico a través de procesos de calcinación o de extracción ácida, mediante el uso de disolventes polares, permite obtener los materiales mesoporosos finales.

La incorporación y estabilización de organocatalizadores en el seno de matrices mesoporosas ha sido un objetivo primordial en los últimos años con el fin de obtener catalizadores heterogéneos altamente específicos y de elevada eficiencia. En la Figura 4.8. se muestran los tres métodos principales empleados para generar materiales híbridos orgánicos-inorgánicos mesoporosos. En concreto, estas tres vías consisten en el anclaje o grafting de monosilanos que contienen la funcionalidad a introducir a través de etapas post-síntesis; procesos de co-condensación basados en la reacción simultánea, durante la ruta micelar, entre especies inorgánicas de naturaleza silícea y monosilanos funcionalizados por especies orgánicas y, por último, el uso de precursores orgánicos bisililados, disilanos, a través de métodos de síntesis directa en presencia de surfactantes, generándose organosílicas periódicas mesoporosas (PMOs), en las que los grupos orgánicos introducidos están formando parte de las red estructural de los materiales ${ }^{[2]}$.

Tradicionalmente, la funcionalización de materiales mesoporosos inorgánicos se ha realizado utilizando monosilanos con grupos orgánicos específicos, consiguiéndose sólidos híbridos que poseen grupos activos colgando de las paredes de la matriz inorgánica hacia las cavidades o canales. Estos materiales fueron ampliamente estudiados puesto que permitieron la introducción de funciones catalíticas solubles en las superficies silíceas de materiales mesoporosos convencionales, a través bien de procesos post-síntesis de anclaje o grafting o bien, directamente, por fenómenos de co-condensación. En el caso de los sólidos híbridos preparados por anclaje de monosilanos que reaccionan con los silanoles presentes en la superficie de las paredes silíceas, presentan la ventaja de que la mesoestructura, exhibida por el material de partida, se preserva, aunque el revestimiento 
orgánico introducido viene acompañado de una marcada disminución en la porosidad del material orgánico-inorgánico, llegándose a producir, en casos extremos, el bloqueo completo del sistema poroso ${ }^{[14]}$.

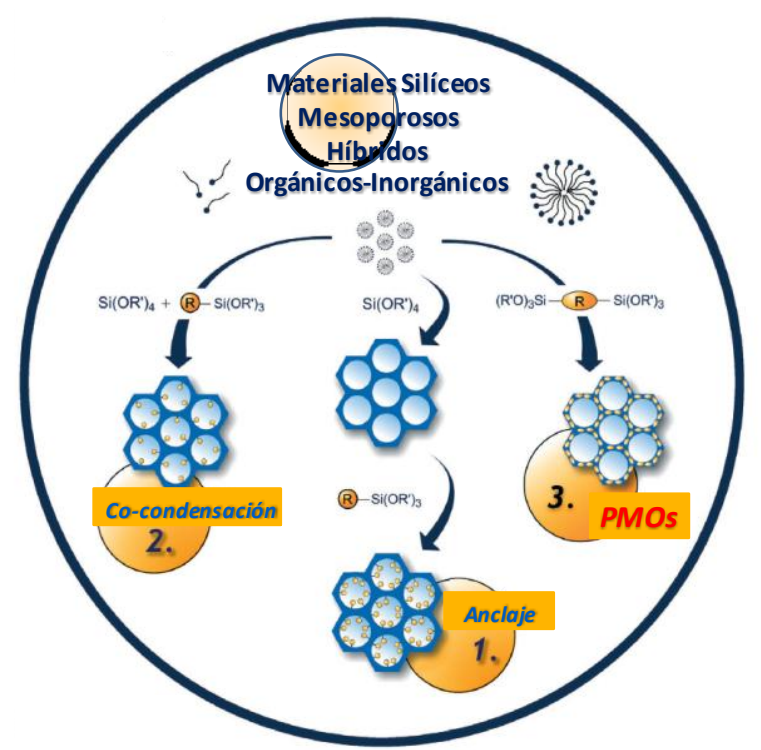

Figura 4.8. Métodos para la obtención de materiales híbridos mesoporosos a partir de silanos funcionalizados.

Como alternativa a la funcionalización post-síntesis, surge el método de cocondensación llevado a cabo a través de un proceso sol-gel en un solo paso por combinación de tetraalcoxisilanos (TMOS o TEOS, preferentemente) con trialcoxiorganosilanos, $\mathrm{RSi}\left(\mathrm{OR}^{\prime}\right)_{3}$, en presencia de agentes directores de estructura, dando lugar a materiales con segmentos orgánicos enlazados covalentemente en la superficie de las paredes que delimitan los canales porosos. Con este método las funciones orgánicas introducidas se distribuyen más homogéneamente en la superficie de las paredes comparado con el proceso de grafting post-síntesis. No obstante, presenta el inconveniente de que el orden mesoporoso disminuye con el aumento de la concentración de monosilanos presentes en el gel de síntesis. Siguiendo esta metodología, el contenido orgánico no sobrepasa el $20 \%$ en moles totales de silicio, favoreciéndose a elevadas concentraciones de $\operatorname{RSi}\left(\mathrm{OR}^{\prime}\right)_{3}$ las reacciones de polimerización exclusivamente entre moléculas de organosilanos. Además, al igual que ocurre en los sólidos híbridos 154 
obtenidos por anclaje, la co-condensación no evita el bloqueo parcial del volumen poroso libre presente en estos materiales en los que las unidades orgánicas penden desde las paredes silíceas hacia los canales mesoporosos ${ }^{[15]}$.

Estos inconvenientes serían superados, en su mayoría, con la obtención de una nueva familia de sólidos porosos cristalinos (no amorfos) en los que los fragmentos orgánicos e inorgánicos se alternan entre sí de manera estable y homogénea integrados en la red estructural de los materiales híbridos obtenidos. De este modo, en el año 1999, tres grupos de investigación simultáneamente, liderados por Inagaki ${ }^{[16]}, \mathrm{Ozin}^{[17]}$ y Stein ${ }^{[18]}$, sintetizaron un nuevo tipo de Organosílicas Periódicas Mesoporosas (PMOs) a partir de la hidrólisis y condensación de precursores organosiliceos silsesquioxano tipo puente, $\left(\mathrm{R}^{\prime} \mathrm{O}\right)_{3} \mathrm{SiRSi}\left(\mathrm{OR}^{\prime}\right)_{3}$, también denominados disilanos, los cuales son empleados como fuente de silicio. Siguiendo este procedimiento, en presencia de surfactantes, se consiguieron incorporar covalentemente fragmentos orgánicos directamente en el interior de la estructura de las paredes de los materiales mesoporosos, a diferencia de los materiales obtenidos por grafting o co-condensación con monosilanos cuyas unidades orgánicas colgaban de la superficie silícea ${ }^{[16-17]}$. En este caso las grupos orgánicos se incorporan en el entramado estructural a través de enlaces covalentes, estando distribuidos de forma homogénea en las paredes que delimitan el sistema poroso. En la Figura 4.9. se muestra la metodología general seguida para la síntesis de $\mathrm{PMOs}^{[2]}$, empleando para ello una ruta tradicional de auto-ensamblaje en presencia de surfactantes que actúan como agentes directores de estructura (ADEs). Los ADEs más frecuentemente utilizados son sales de alquiltrimetilamonio o alquilpiridina de cadena larga. Bajo determinadas condiciones de concentración, temperatura, tipo de disolvente, $\mathrm{pH}$ o tiempo y, en presencia de los precursores organosilíceos adecuados, los surfactantes se ensamblan en forma de micelas para formar una fase líquida cristalina en medio acuoso, en la cual tiene lugar la hidrólisis y condensación de dichos precursores (disilanos) para generar el material híbrido. Tras la eliminación del surfactante, los sólidos obtenidos exhiben un sistema de canales organizado con una distribución dentro del rango del mesoporo ${ }^{[19]}$. 


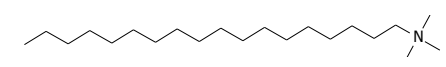

bromuro de octadeciltrimetilamonio (ODTMA)
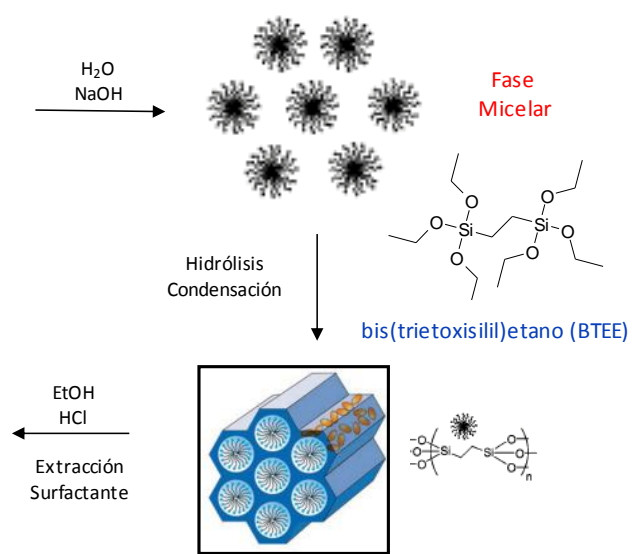

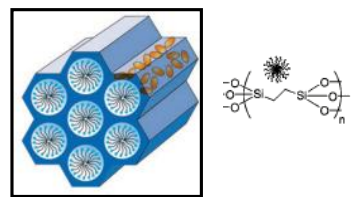

Composite Mesoscópico Ordenado

Figura 4.9. Proceso de auto-ensamblaje para la obtención de PMOs en presencia de surfactantes (ODTMA) y del disilano bis(trietoxisilil)etano (BTEE) como precursor organosilíceo.

Los PMOs se caracterizan por presentar una organización periódica de su sistema poroso, así como una estrecha distribución del diámetro de poro, tal y como ocurre con los materiales mesoporosos convencionales, presentando además las ventajas adicionales atribuidas a la distribución homogénea de fragmentos funcionales orgánicos insertados en su estructura sin que lleguen a bloquear sus canales mesoporosos libres. Por lo tanto, en estos materiales se conjugan las características de los sólidos silíceos mesoporosos junto con las propiedades aportadas por los segmentos orgánicos incorporados covalentemente en su red estructural. Además, presentan la particularidad de que sus propiedades físicoquímicas, tales como por ejemplo hidrofobia-hidrofilia, pueden ser modificadas a priori cambiando el grupo orgánico que actúa a modo de puente en el disilano de partida utilizado como precursor ${ }^{[20]}$. Entre los diferentes PMOs, destaca por su elevada cristalinidad aquel que ha sido obtenido empleando 1,4-bis(trietoxisilil)benceno (BTEB) como única fuente de silicio en presencia de octadeciltrimetilamonio (ODTMA) como surfactante, en medio básico. En este sólido se aprecia una doble periodicidad: a largo alcance, debida al sistema de canales mesoporosos que siguen una simetría hexagonal, y a corto alcance, fruto de la distribución laminar de los anillos aromáticos que conforman las paredes del material (Figura 4.10.) ${ }^{[21]}$. 


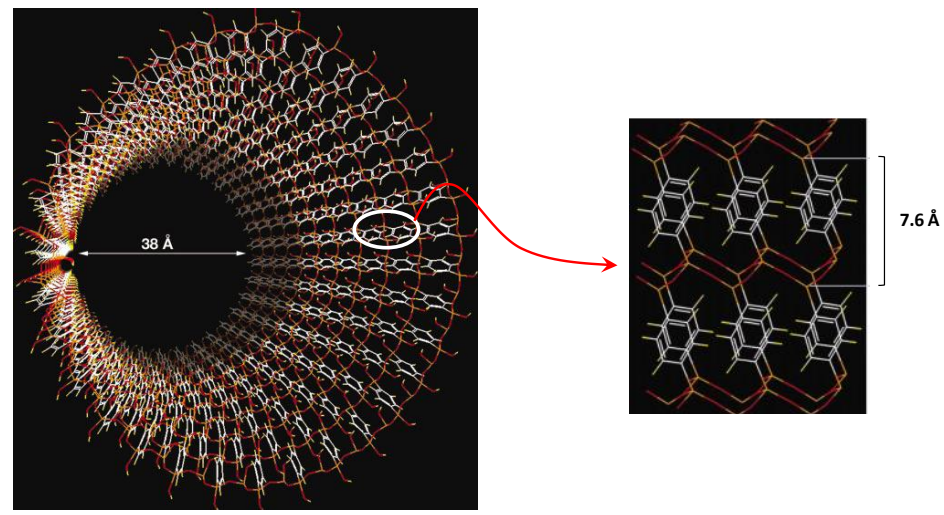

Figura 4.10. Modelo artístico de PMO con grupos arílicos formando su red estructural obtenido a partir del disilano BTEB. Los anillos bencénicos están alineados circularmente alrededor del canal mesoporoso. Las láminas organosilícicas están dispuestas sucesivamente a lo largo del eje del poro con una separación de $7.6 \AA$ entre las sucesivas láminas formadas por anillos bencénicos. Si naranja; $\mathrm{O}$ rojo; $\mathrm{C}$ blanco; $\mathrm{H}$ amarillo.

La incorporación de unidades orgánicas en la estructura de los materiales mesoporosos, los convierte en prometedores candidatos para muy diferentes campos de aplicación, tales como adsorción, cromatografía, almacenaje, electrónica, magnetismo o fotoluminiscencia ${ }^{[22]}$. Sin embargo, es en la catálisis donde han encontrado un mayor número de aplicaciones debido a la posibilidad de insertar diferentes tipos de grupos funcionales, organocatalizadores, con propiedades muy variadas, los cuales pasan a formar parte de materiales sólidos porosos con las ventajas que eso conlleva, en cuanto a su estabilidad y reutilización. Así, gracias a la capacidad de introducir diferentes centros activos como espaciadores orgánicos, a partir de disilanos específicos, se han podido incorporar funciones ácidas ${ }^{[23]}$, básicas ${ }^{[24]}$, redox ${ }^{[25]}$, especies quirales ${ }^{[26]}$ o incluso la combinación de varias de ellas, generándose, por lo tanto, catalizadores híbridos funcionales con organocatalizadores altamente específicos estabilizados en su estructura.

La posibilidad de introducir diferentes centros activos en la estructura de materiales mesoporosos, PMOs, permite preparar materiales multifuncionales que pueden ser empleados con éxito como catalizadores para llevar a cabo reacciones cascada o consecutivas. El desarrollo de este tipo de procesos está siendo muy estudiado en los últimos años, ya que implicaría el empleo de tan sólo un catalizador que interviene en 
todas las etapas de la reacción, sin que sea necesario aislar y recuperar especies intermedias con la consiguiente reducción de subproductos formados. Todo ello, supondría un aumento considerable en la eficiencia global del proceso reactivo ${ }^{[27]}$.

La generación de este tipo de materiales PMOs multifuncionales es llevada a cabo bien partiendo de dos o más disilanos que contienen cada uno de ellos diferentes grupos funcionales a modo de puente ${ }^{[28]}$, bien por combinación de disilanos con monosilanos específicos ${ }^{[29]} \mathrm{O}$, incluso, con la utilización de un único disilano en cuyo fragmento orgánico puente estén incluidos diferentes centros activos ${ }^{[30]}$.

Dentro de este grupo de sólidos que presentan varias funciones activas en su composición destaca el sintetizado por Corriu y col. a partir de disilanos que contienen grupos disulfuro y monosilanos con grupos amino terminales, los cuales se insertan, respectivamente, tanto en el interior de su entramado estructural como colgando de su superficie hacia las cavidades. Las posteriores etapas de reducción y oxidación de los grupos disulfuro estructurales permiten la obtención de una material híbrido mesoporoso bifuncional, el cual contiene grupos sulfónicos en las paredes y grupos amino en los canales porosos (Figura 4.11.), siendo este un buen ejemplo de un material mesoporoso en el que cohabitan simultáneamente centros ácidos y básicos que se encuentran perfectamente aislados y accesibles ${ }^{[31]}$.

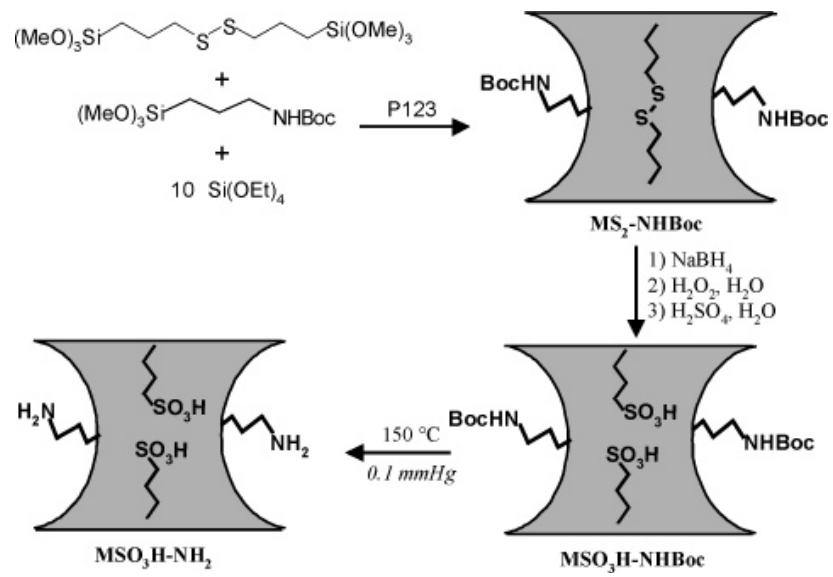

Figura 4.11. Ruta de síntesis seguida para la obtención de PMOs bifuncionales con grupos sulfónicos y amino presentes en su estructura. 
Este concepto ha sido desarrollado por Shylesh y col., empleando disilanos con anillos aromáticos (BTEB) y monosilanos con aminas primarias, para obtener PMOs bifuncionales tras un proceso de sulfonación de los grupos arílicos estructurales. Estos materiales híbridos fueron utilizados en procesos catalíticos consecutivos en los que en una primera etapa se lleva a cabo una hidrólisis ácida de un hemiacetal, catalizada por grupos sulfónicos, y en una segunda etapa se produce la reacción básica de Henry para formar nitro-derivados, catalizada por los grupos amino (Figura 4.12.) [32] $^{[3}$

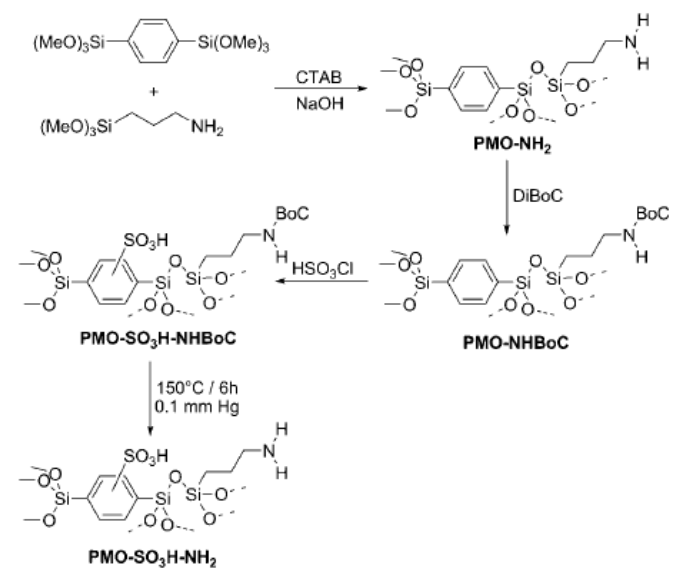

Figura 4.12. Ruta de síntesis para la obtención de PMOs bifuncionales con grupos aril-sulfónicos y amino cohabitando en su estructura.

Aunque en la bibliografía existen cada vez más ejemplos de organosílicas periódicas mesoporosas en las que se combinan, en su red estructural, diferentes centros activos, todavía son pocos los estudios que demuestran su efectividad como catalizadores para llevar a cabo reacciones en cascada, siendo, por lo tanto, un campo de investigación en plena expansión.

\subsubsection{Métodos Hidrotermales: Organozeolitas (OZs)}

Hasta el momento, tal y como se ha detallado en el apartado anterior, la aproximación más comúnmente empleada y con mayor éxito para preparar materiales híbridos ha sido la síntesis de materiales mesoporosos, PMOs, en los que se han 
introducido grupos orgánicos en sus paredes partiendo de organosilanos (disilanos) y con ayuda de surfactantes. No obstante, al igual que los materiales mesoporosos convencionales (tipo M41S), los PMOs presentan el principal inconveniente de que son sólidos moleculares con reducida cristalinidad, sobre todo a corto alcance, y con baja estabilidad hidrotérmica, lo cual limita enormemente su campo de aplicación en determinados procesos catalíticos. Es por ello que sería de gran interés la incorporación de segmentos orgánicos en la estructura de materiales altamente cristalinos, tridimensionales, con canales y cavidades porosas, como son las zeolitas, las cuales exhiben una elevada estabilidad hidrotérmica. De este modo, las presumibles futuras aplicaciones de estos nuevos OrganoZeotipos serían mucho más atractivas que, incluso, las obtenidas con las PMOs. En este sentido, en la bibliografía, se han descrito diferentes intentos para obtener nuevos materiales organozeolíticos, aunque se han encontrado serios inconvenientes para la efectiva incorporación de grupos orgánicos en la estructura típicamente inorgánica de las zeolitas.

Davis y col. fueron pioneros en este campo ya que lograron sintetizar tamices moleculares, con propiedades físico-químicas clásicas de zeolitas, en los que incorporaron diferentes grupos orgánicos, los cuales están realmente colgando de la superficie de sus paredes más que formando parte de ellas. Es decir, los segmentos orgánicos no se encuentran dentro de su entramado estructural si no que están anclados sobre el mismo. Los sólidos porosos así obtenidos, denominados OFMS (Organic Functionalized Molecular Sieves), apenas han encontrado aplicaciones para su uso, ya que la estabilidad de la parte orgánica es muy débil. Además, la presencia de los fragmentos orgánicos colgando de las paredes hace que el volumen poroso libre se reduzca considerablemente. Por todo ello, únicamente las zeolitas de poro grande, como la zeolita $Y$ o Beta, pudieron ser obtenidas con elevada cristalinidad ya que son las únicas que lograron albergar en sus poros, de elevadas dimensiones, una gran cantidad de unidades orgánicas que cuelgan desde sus paredes, sin modificar su estructura Debido a estas importantes limitaciones, estos materiales solamente han encontrado aplicación en algunos procesos de oxidación como catalizadores ácidos al introducir grupos toluensulfónicos. La metodología empleada seguía la síntesis estándar tipo hidrotermal, normalmente empleada para la preparación 
de zeolitas convencionales, trabajando en medio acuoso y en condiciones $\mathrm{OH}^{-}$o $\mathrm{F}^{-}$con ayuda de un agente director de estructura (template), incorporando como novedad, en el gel de síntesis, un alquiltrialcoxisilano $\left(\mathrm{RSi}\left(\mathrm{OR}^{\prime}\right)_{3}\right)$ que aportaba el grupo orgánico colgante a la matriz inorgánica (Figura 4.13.) ${ }^{[33]}$.

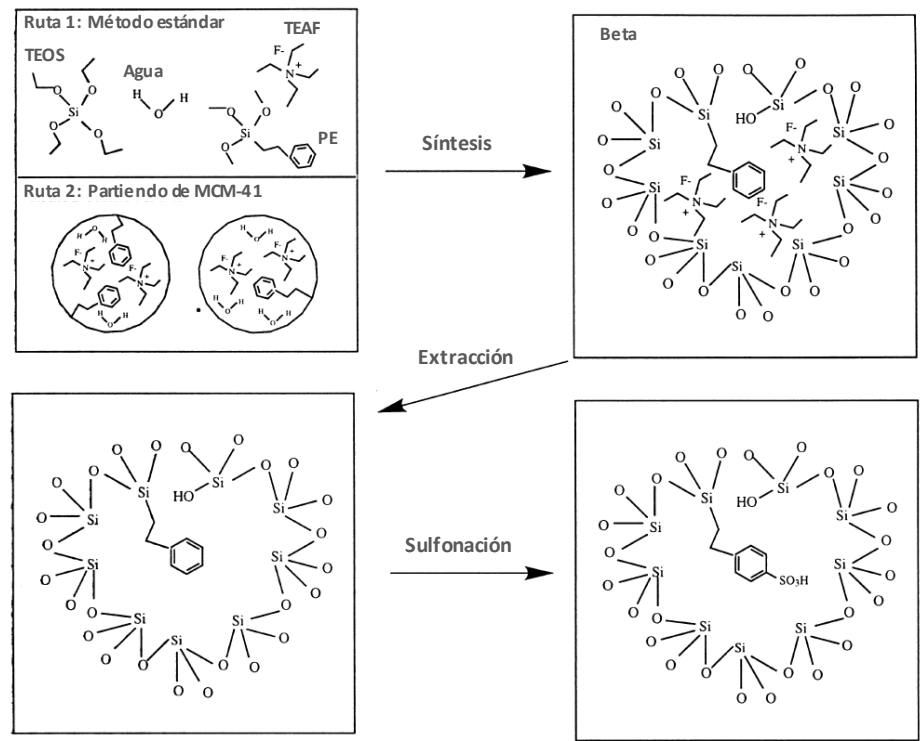

Figura 4.13. Preparación de materiales zeolíticos con topología Beta que presentan grupos arilsulfónicos colgando de la superficie de su red cristalina.

Con posterioridad a estos estudios, en el año 2003, Tatsumi y col. prepararon una nueva familia de OrganoZeolitas (OZ), también denominadas ZOL (Zeolite with Organic group as Lattice) en las que grupos orgánicos e inorgánicos estaban realmente formando la red estructural de materiales con características zeolíticas. Los resultados aportados reflejan que, efectivamente, se consiguieron introducir pequeños grupos orgánicos (normalmente metilénicos, $-\mathrm{CH}_{2}$-) en la estructura de zeolitas tipo MFI, LTA o SOD. En estos casos, el nivel de incorporación de grupos orgánicos insertados era ciertamente limitado, no llegando en ningún caso a introducir más del 3\% respecto al peso total del material final. Otro importante inconveniente de este tipo de materiales organozeolíticos es la facilidad que tienen las unidades $\equiv \mathrm{Si}-\mathrm{CH}_{2}-\mathrm{Si} \equiv$ en fraccionarse, para formar grupos terminales $\equiv \mathrm{Si}-\mathrm{CH}_{3}$, al ser susceptibles de sufrir sustituciones nucleofílicas de especies intermedias, como por ejemplo $\equiv \mathrm{Si}^{-} \mathrm{CH}_{2}^{-}$(Figura 4.14.). No obstante, la principal novedad 
en la preparación de estos materiales organozeolíticos fue la utilización de precursores silsesquioxano, disilanos, durante el proceso de síntesis, tales como bis(trietoxisilil)metano (BTESM), los cuales condensaban y polimerizaban con las unidades inorgánicas silíceas para formar su estructura ${ }^{[34]}$.

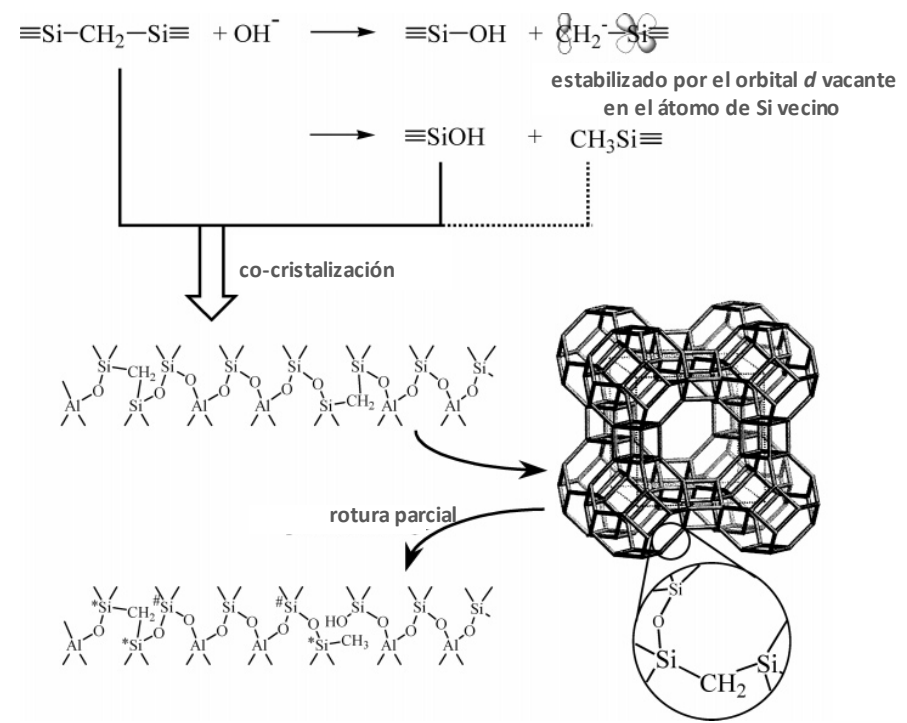

Figura 4.14. Esquema de cristalización de los materiales tipo ZOL.

Generalmente, la cristalización de los materiales tipo ZOL necesita tiempos de síntesis más prolongados que los necesarios para obtener sus respectivas isoestructuras inorgánicas, debido a que las etapas de hidrólisis y condensación de los grupos que contienen los fragmentos orgánicos retardan el proceso de formación. Este hecho, unido a que la introducción de segmentos orgánicos supone un fuerte obstáculo a los requerimientos estructurales mínimos para la formación de redes zeolíticas cristalinas, hace que sean limitados los casos en los que se han obtenido organozeolitas. En el caso concreto de los materiales ZOL que exhiben una topología MFI, se ha comprobado que la longitud del enlace Si-C es de $1.88 \AA$, la cual es más elevada que la del enlace convencional

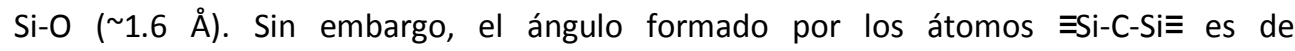
aproximadamente $109^{\circ}$, es decir, menor que el formado por el grupo $\equiv \mathrm{Si}-\mathrm{O}-\mathrm{Si} \equiv$, ya que este último puede oscilar, normalmente, entre $140-170^{\circ}$. Este menor ángulo compensa la 
mayor distancia entre los dos átomos de silicio contiguos, permitiendo la cristalización de este tipo de material zeolítico orgánico-inorgánico isoestructural con las zeolitas $\mathrm{MFI}^{[3,35]}$.

Durante los últimos años se han realizado esfuerzos para incorporar fragmentos orgánicos en otro tipo de estructuras zeolíticas y, sobre todo, en mayor proporción. En este sentido, Díaz y col. prepararon OZs isoestructurales con las zeolitas ITQ-21 y Beta, en las que insertaron, a nivel estructural, altos contenidos de grupos metilénicos y etilénicos en lugar de los grupos siloxano ( $\equiv \mathrm{Si}-\mathrm{O}-\mathrm{Si} \equiv$ ) presentes en la matriz inorgánica tridimensional ${ }^{[36]}$.

En definitiva, a lo largo de esta introducción se han mostrado los principales materiales porosos que pueden ser obtenidos de modo directo empleando silsesquioxanos tipo puente, disilanos, como agentes precursores, obteniéndose sólidos variados en cuanto a nivel de estructuración y porosidad alcanzadas. Buscando profundizar en este campo, en los siguientes apartados, se estudiará la posibilidad de obtener nuevas familias de materiales mesoporosos a partir de disilanos, explorando rutas de síntesis, hasta el momento, poco consideradas para la preparación de sólidos orgánicos-inorgánicos. 


\subsection{Objetivos}

Como se ha mostrado en la revisión del estado del arte, la familia de PMOs ha sido la más ampliamente estudiada en la preparación de materiales híbridos organosilíceos porosos a partir del empleo de disilanos como unidades precursoras. Normalmente, el método de síntesis empleado consiste en un proceso de ensamblaje molecular empleando surfactantes como ADEs, en un medio ácido o alcalino, siendo necesario, en la mayoría de casos, someter al gel de síntesis durante periodos prolongados de tiempo a temperaturas próximas a los $100^{\circ} \mathrm{C}$. Considerando estas condiciones y teniendo en cuenta la dificultad que conlleva la preparación de sofisticadas moléculas de ADEs, unido a los elevados costes asociados, surge la necesidad de preparar materiales híbridos mesoporosos en ausencia de surfactantes, como es el caso de los procesos solgel.

En estos procesos donde se produce la hidrólisis y polimerización, en medio ácido o básico, de los precursores organosilíceos (disilanos), se pueden generar sólidos de naturaleza porosa sin orden a largo alcance. No obstante, los materiales híbridos preparados hasta el momento, siguiendo esta ruta de preparación, no presentan, en su mayoría, una elevada accesibilidad tal y como hemos visto en la revisión bibliográfica previa. Por todo ello, sería conveniente investigar más en profundidad estos procesos de síntesis sol-gel en ausencia de ADEs y que, además, sean catalizados por iones fluoruro, lo cual permitiría realizar la preparación en condiciones más suaves, es decir, a temperaturas próximas a la ambiente y a pH neutro, con las ventajas que eso conllevaría asociadas a procesos químicos más sostenibles que los convencionalmente empleados ${ }^{[37]}$.

Por todo ello, siguiendo un método de síntesis basado en procesos sol-gel en medio fluoruro y en presencia de disilanos, se pretende obtener un nuevo tipo de materiales híbridos mesoporosos en cuyas paredes se encuentren insertados y estabilizados diferentes grupos funcionales accesibles, permitiendo que sean utilizados como catalizadores en diferentes procesos de reacción. 
En concreto, los objetivos principales de este capítulo son los siguientes:

- Preparación de materiales mesoporosos híbridos siguiendo un proceso sol-gel en medio fluoruro en ausencia de ADEs, a pHs neutros y con temperaturas próximas a la ambiente, estudiando las diferentes variables y parámetros que afectan a las propiedades de los sólidos sintetizados, siendo posible modularlas.

- Introducción de fragmentos orgánicos estructurales, tales como arilos, disulfuro, diamino, alquilos u olefínicos, los cuales se encontrarán estabilizados en los materiales mesoporosos. Será considerada la influencia de la flexibilidad o rigidez aportada por estas unidades estructurales sobre las propiedades texturales de los materiales híbridos preparados.

- Medida de la actividad catalítica de los sólidos obtenidos, confirmando que los grupos funcionales insertados conservan sus propiedades ácidas o básicas, pudiendo ser recuperados y reutilizados sin pérdida sustancial de su actividad inicial. 


\subsection{Materiales híbridos mesoporosos obtenidos a través de métodos sol-gel en medio fluoruro}

\subsubsection{Síntesis y caracterización}

\section{Síntesis}

Se prepararon diferentes tipos de materiales híbridos porosos orgánicosinorgánicos no ordenados a partir de una mezcla inicial de tetrametoxisilano (TMOS), como precursor silíceo, y cantidades apropiadas de disilano, $\left(\mathrm{R}^{\prime} \mathrm{O}\right)_{3} \mathrm{Si}-\mathrm{R}-\mathrm{Si}(\mathrm{OR})_{3}$, usando metanol como disolvente. Una vez disueltos los precursores, se añadió una disolución acuosa de $\mathrm{NH}_{4} \mathrm{~F}$, bajo agitación vigorosa. La mezcla final de reacción tiene la siguiente composición molar:

$$
1 \mathrm{SiO}_{2} \text { [(1-x) TMOS }+x \text { Disilano]: } 4 \mathrm{MeOH}: 4 \mathrm{H}_{2} \mathrm{O}: 3.13 \times 10^{-3} \mathrm{NH}_{4} \mathrm{~F}
$$

donde $x$ corresponde a los moles de sílice que son introducidos como disilano puro. La hidrólisis y condensación se llevó a cabo bajo agitación a temperatura ambiente hasta que tuvo lugar la gelificación rápidamente, en tan solo unos pocos segundos. Después, el gel se envejeció durante 24 horas a $36^{\circ} \mathrm{C}$, siendo finalmente secado a $150^{\circ} \mathrm{C}$ durante otras 24 horas. En los disilanos empleados, R corresponde a grupos orgánicos del tipo benceno, disulfuro, diamino, etano y etileno, siendo $R^{\prime}$ grupos etilo o metilo (Figura 4.15.). Los materiales híbridos preparados fueron nombrados como HYB-BTEB, HYB-BTES, HYBBTMN, HYB-BTEE, HYB-BTEEthy, en función del disilano empleado durante el proceso de síntesis. Los materiales considerados en esta sección 4.3.1., donde se estudia su síntesis y caracterización fueron obtenidos empleando el 33\% de los moles de silicio totales a partir del disilano $(x=0.33$, Disilano/TMOS=0.5) y fijándose la relación molar Si/F en 319. Con estas condiciones se obtuvieron materiales con una cantidad apreciable de fragmentos orgánicos insertados a nivel estructural, exhibiendo una elevada accesibilidad debido a la presencia de cavidades mesoporosas.

En secciones sucesivas de este capítulo, serán modificadas diferentes variables que intervienen en el proceso sol-gel como son la cantidad de disilano y de iones fluoruro introducidos en la síntesis, así como el tipo de disolvente, para determinar su influencia. 
En la Figura 4.16. se muestra una esquema del proceso de síntesis llevado a cabo para obtener este tipo de materiales híbridos.
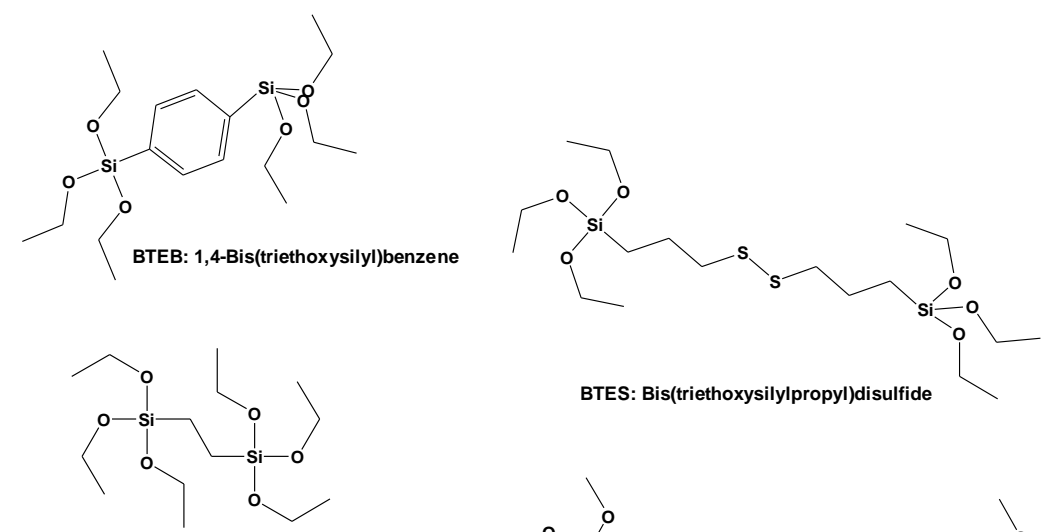

BTEE: Bis(triethoxysilyl)ethane
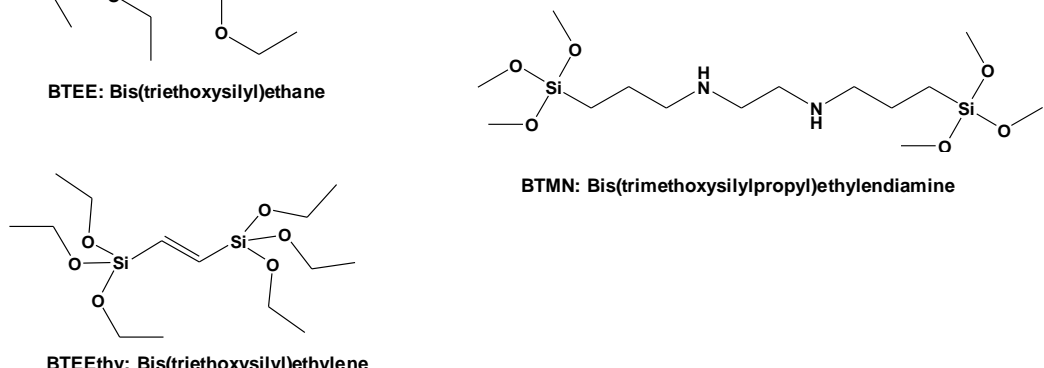

BTMN: Bis(trimethoxysilylpropyl)ethylendiamine

BTEEthy: Bis(triethoxysilyl)ethylene

Figura 4.15. Disilanos (bridged silsesquioxanes) usados como precursores orgánicos-inorgánicos para la preparación de materiales híbridos mesoporosos, con sus correspondientes abreviaturas.

$$
\begin{aligned}
& (\mathrm{RO})_{3} \mathrm{Si}-\mathrm{R}-\mathrm{Si}\left(\mathrm{OR}^{\prime}\right)_{3} \\
& \left(x \mathrm{~mol} \mathrm{SiO}_{2}\right) \\
& \stackrel{+}{\mathrm{Si}(\mathrm{OMe}})_{4} \\
& + \\
& \mathrm{NH}_{4} \mathrm{~F}, \mathrm{MeOH}, \mathrm{H}_{2} \mathrm{O}
\end{aligned}
$$

$1 \mathrm{SiO}_{2}\left[(1-x)\right.$ TMOS $+x$ Disilano : $4 \mathrm{MeOH}: 4 \mathrm{H}_{2} \mathrm{O}: y \mathrm{NH}_{4} \mathrm{~F}$
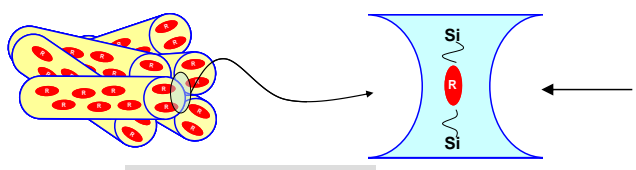

R: Fragmento Orgánico

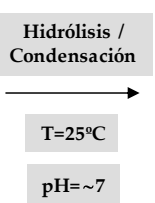

$\mathrm{pH}=\sim 7$

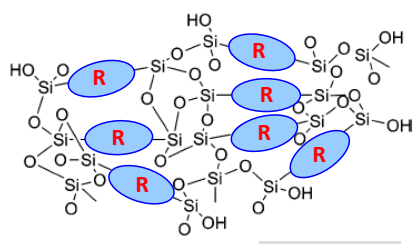

Gelificación

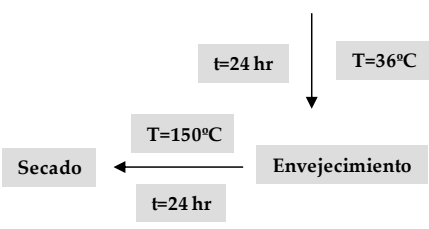

Figura 4.16. Procedimiento sol-gel empleado para obtener materiales híbridos no ordenados orgánicos-inorgánicos. 
Los procesos sol-gel conllevan la hidrólisis y condensación de las especies silíceas en medios acuosos (Esquema 4.1.a), en tiempos relativamente cortos, siendo incluso acelerado el proceso cuando se realiza en medio ácido o básico (Esquema 4.1.b). Otra alternativa viene dada por el hecho de emplear iones fluoruro como catalizador de este proceso sol-gel, tal y como se plantea en el estudio aquí presentado, observándose que en este caso la gelificación es extraordinariamente rápida, produciéndose en apenas unos pocos segundos. En este caso, la hidrólisis ocurre a través de un mecanismo de sustitución nucleofílica en el que aniones $\mathrm{F}^{-}$interaccionan directamente con los grupos $\left(\mathrm{OR}^{\prime}\right)_{3} \mathrm{Si}-\mathrm{R}-\mathrm{de}$ cada molécula de disilano. Este mecanismo implica la expansión transitoria del número de coordinación de los átomos de silicio desde cuatro hasta cinco o, incluso, seis (Esquema 4.1. c) ${ }^{[37-38]}$.

La efectividad de esta reacción de polimerización en presencia de iones $\mathrm{F}^{-}$se debe a su pequeño radio iónico frente al de los grupos hidroxilo que normalmente intervienen en el proceso de gelificación, lo cual hace que puedan desempeñar su función como catalizador del proceso sol-gel, incrementando al mismo tiempo el número de coordinación del silicio ${ }^{[39]}$. Estudios semiempíricos, a través de cálculos basados en orbitales moleculares, han demostrado que las especies aniónicas pentacoordinadas de silicio juegan un importante papel como intermedios en procesos de polimerización ${ }^{[40]}$. La reacción de desplazamiento en los átomos de silicio inducida por los iones $\mathrm{F}^{-}$estaría facilitada por su capacidad para formar estados de transición pentacoordinados, utilizando sus orbitales $d$ y, por lo tanto, generando especies silíceas altamente activas (electrofílicas) que reaccionan rápidamente, resultando en una aceleración considerable de la velocidad de polimerización, tal y como fue comprobado en los experimentos realizados para la obtención de materiales porosos híbridos. 
(a)

$$
-\mathrm{RSi}\left(\mathrm{OR}^{\prime}\right)_{3}+n \mathrm{H}_{2} \mathrm{O} \longrightarrow-\mathrm{RSi}\left(\mathrm{OR}^{\prime}\right)_{3-n}(\mathrm{OH})_{n}+n \mathrm{R}^{\prime} \mathrm{OH} \quad \text { Hidrólisis }
$$<smiles>[R6]O[Sn](C)(C)CC[Si](C)(C)O[Si](C)(C)[CH-][OH+]</smiles><smiles>C[13CH]([Si](C)(C)O[Si](C)(C)C)[Si](C)(C)O[Sn](C)(C)O</smiles>

Condensación

(b)

$$
\begin{array}{lll}
-\mathrm{RSi}\left(\mathrm{OR}^{\prime}\right)_{3}+\mathrm{H}_{3} \mathrm{O}^{+} \longrightarrow & -\mathrm{RSi}\left(\mathrm{OR}^{\prime}\right)_{2}(\mathrm{OH})+\mathrm{R}^{\prime} \mathrm{OH}+\mathrm{H}^{+} & \text {Hidrólisis Ácida } \\
-\mathrm{RSi}\left(\mathrm{OR}^{\prime}\right)_{3}+\mathrm{OH}^{-} \longrightarrow & -\mathrm{RSi}\left(\mathrm{OR}^{\prime}\right)_{2}(\mathrm{OH})+\mathrm{R}^{\prime} \mathrm{O}^{-} & \text {Hidrólisis Básica }
\end{array}
$$

(c)

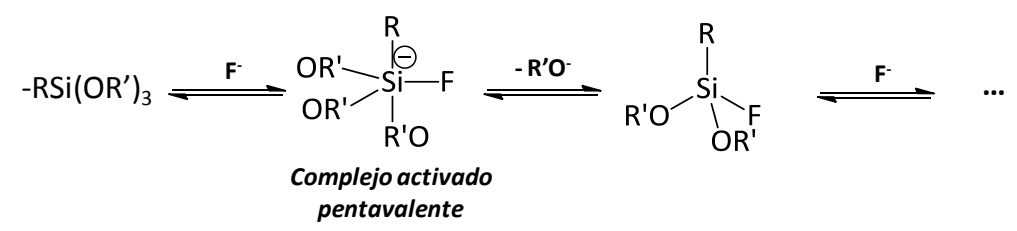

Esquema 4.1. (a) Proceso sol-gel: Etapas de hidrólisis y condensación; (b) hidrólisis ácida o básica; (c) sustitución nucleófila de grupos -OR' por iones F'.

\section{Caracterización}

Es importante destacar que a través de la difracción de rayos $X$ se constató la ausencia de orden a largo alcance de los materiales híbridos obtenidos, no observándose ninguna banda de difracción a bajos ángulos característica de materiales mesoporosos ordenados convencionales, tipo M41S o SBA-15. Este resultado es el esperado para materiales mesoporosos no ordenados obtenidos a través de procesos sol-gel, tal y como se refleja ampliamente en el estado del $\operatorname{arte}^{[41]}$.

\section{Análisis Elemental}

La presencia de fragmentos orgánicos en la matriz silícea de los materiales porosos se siguió por análisis elemental. El contenido en $\mathrm{C}, \mathrm{H}, \mathrm{N}$ y $\mathrm{S}$, y el porcentaje en peso calculado de especies orgánicas presentes en los sólidos se muestran en la Tabla 4.1. 
La presencia de carbono en los sólidos preparados es una clara indicación de la incorporación de unidades orgánicas dentro de la red de estos materiales, teniendo en cuenta que no se emplearon moléculas de ADEs durante el proceso de síntesis. Por lo tanto, los átomos de carbono sólo pueden provenir de los disilanos usados como precursores orgánicos-inorgánicos. Además, las relaciones molares $\mathrm{C} / \mathrm{S}$ y $\mathrm{C} / \mathrm{N}$ experimentales para las muestras HYB-BTES y HYB-BTMN son 3.3 y 4.4, respectivamente, estando estos valores cerca de las relaciones teóricas calculadas para los disilanos de partida ( $C / S=3$ para $B T E S$ y $C / N=4$ para $B T M N)$. Este resultado confirma que la integridad de los grupos disulfuro y diamino en los materiales porosos se mantiene después del proceso de síntesis, siendo posible extrapolar este supuesto a los otros disilanos ya que la metodología de síntesis seguida fue la misma. A partir de los resultados de análisis elemental es posible evaluar el contenido orgánico de los sólidos, el cual varía desde 10 \% para materiales con grupos etano y etileno hasta $30 \%$ en peso para sólidos con unidades disulfuro. Esta variación se puede explicar por los diferentes pesos moleculares de los disilanos usados durante el proceso de síntesis.

Tabla 4.1. Análisis elemental y termogravimétrico de las muestras híbridas.

\begin{tabular}{|c|c|c|c|c|c|c|c|c|c|}
\hline Muestra & $\% \mathbf{N}$ & $\% \mathrm{C}$ & $\% S$ & $C / N$ & $\mathrm{C} / \mathrm{S}$ & $\begin{array}{c}\text { \%Cont. } \\
\text { Org } \\
\text { (A.E.) }^{\text {a }}\end{array}$ & $\begin{array}{c}\text { \% Cont. } \\
\text { Org } \\
\text { (ATG) }^{\text {(AT }}\end{array}$ & $\begin{array}{c}\mathrm{Si}_{\text {func }} / \mathrm{Si}_{\text {total }} \\
(\mathrm{AE})^{\mathrm{a}}\end{array}$ & $\begin{array}{c}\mathrm{Si}_{\text {func }} / \mathrm{Si}_{\text {total }} \\
(\mathrm{RMN})^{\mathrm{c}}\end{array}$ \\
\hline HYB-BTEB & 0.0 & 16.1 & 0.0 & - & - & 18.9 & 20.1 & 0.33 & 0.33 \\
\hline HYB-BTES & 0.0 & 14.7 & 11.8 & - & 3.3 & 29.4 & 30.2 & 0.32 & 0.34 \\
\hline HYB-BTMN & 4.1 & 15.6 & 0.0 & 4.4 & - & 23.1 & 24.7 & 0.25 & 0.27 \\
\hline HYB-BTEE & 0.0 & 8.8 & 0.0 & - & - & 11.4 & 11.5 & 0.48 & 0.33 \\
\hline HYB-BTEEthy & 0.0 & 6.7 & 0.0 & - & - & 8.6 & 8.9 & 0.37 & 0.32 \\
\hline
\end{tabular}

${ }^{a}$ Contenido orgánico determinado por análisis elemental; ${ }^{b}$ Contenido orgánico determinado por análisis termogravimétrico; ${ }^{c}$ Átomos de silicio funcionalizados frente a silicio total a través de RMN.

\section{Análisis Termogravimétrico}

En la Figura 4.17. se muestran las pérdidas en peso (ATG), así como sus derivadas correspondientes (ATD) con la temperatura, detectadas en los híbridos sintetizados. Esto permite establecer, no solo la cantidad de fragmentos orgánicos incorporados en los sólidos, sino también su estabilidad hidrotérmica. 

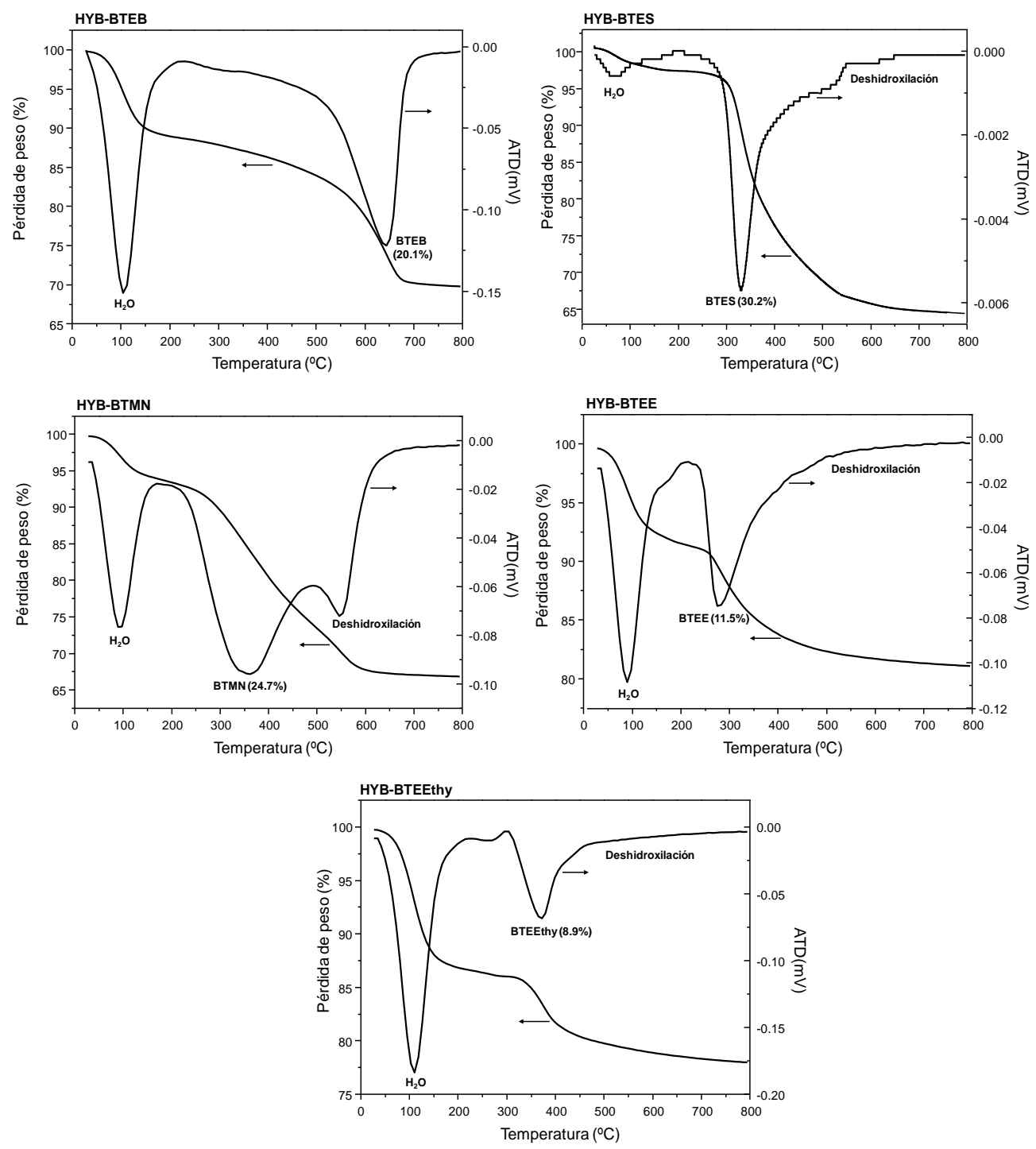

Figura 4.17. Curvas termogravimétricas (ATG) y sus correspondientes derivadas (ATD) de los materiales híbridos.

En todos los casos, después de la eliminación del agua de hidratación, es posible apreciar una pérdida de peso principal asignada a la presencia de unidades orgánicas procedentes de los disilanos. El contenido orgánico calculado a partir de las curvas termogravimétricas es similar a los resultados obtenidos por análisis elemental (ver Tabla 4.1.), confirmando la presencia de diferentes fragmentos orgánicos incorporados en los 
híbridos porosos. A partir de las curvas ATD (Figura 4.17.), es posible asignar una estabilidad hidrotermal diferente de las unidades orgánicas presentes en los diferentes materiales híbridos. Así, los grupos benceno son los más estables, descomponiéndose a temperaturas cercanas a los $640^{\circ} \mathrm{C}$. La estabilidad hidrotermal para las unidades disulfuro, etilendiamina y etileno es menor $(300-400)^{\circ} \mathrm{C}$, siendo todavía menor para los grupos etano $\left(270^{\circ} \mathrm{C}\right)$.

\section{Espectroscopia Raman}

La incorporación y la integridad de las diferentes especies orgánicas presentes en los materiales porosos también han sido confirmadas a través de la espectroscopía Raman (Figura 4.18.). En el caso del material HYB-BTEB, la banda asociada a la vibración stretching asimétrica $\mathrm{Si}-\mathrm{C}_{6} \mathrm{H}_{5}$ se observa a $1104 \mathrm{~cm}^{-1}$. Además, se aprecian otras dos bandas situadas a $1598 \mathrm{~cm}^{-1}(\mathrm{v})$ y $636 \mathrm{~cm}^{-1}(\delta)$ asignadas a las vibraciones stretching y bending del anillo aromático, respectivamente. La asignación de la banda a $783 \mathrm{~cm}^{-1}$, descrita en otros materiales híbridos obtenidos a partir de BTEB, es hasta ahora incierta ${ }^{[42]}$.

Los espectros Raman obtenidos para los otros materiales híbridos estudiados en este trabajo se muestran también en la Figura 4.18. Las unidades propildisulfuro del material HYB-BTES también se detectaron, pudiéndose observar vibraciones de tipo stretching asociadas a los enlaces S-S y S-C a 508 y $634 \mathrm{~cm}^{-1}$, respectivamente. Los materiales híbridos obtenidos a partir del disilano BTMN muestran dos bandas a 1453 y $1636 \mathrm{~cm}^{-1}$, características de las vibraciones $\delta-\left(\mathrm{N}^{+} \mathrm{H}\right)$ y $\delta-(\mathrm{NH})$, respectivamente, corroborando la presencia de grupos diamino en el sólido. En el caso del material HYBBTEE, la integridad de los grupos etano se verifica por la existencia de dos bandas (1273 y $\left.1411 \mathrm{~cm}^{-1}\right)$ correspondientes a las vibraciones $\delta-\left(\mathrm{SiCH}_{2}\right)$ y $\delta-\left(\mathrm{CH}_{2}\right)$. Por último, el espectro obtenido para el sólido HYB-BTEEthy muestra claramente la banda debida a grupos etileno situada a $1304 \mathrm{~cm}^{-1}$. Además, en los espectros de los materiales híbridos no ordenados que contienen grupos etano y etileno, se pueden ver las bandas correspondientes a los enlaces Si-O-Si y Si-OH $\left(493,790\right.$ y $\left.975-995 \mathrm{~cm}^{-1}\right)$, los cuales están presentes, en general, en los materiales cuyo entramado está conformado por una gran cantidad de sílice, como 
ocurre en estos sólidos (HYB-BTEE y HYB-BTEEthy) que son los que presentan un menor contenido en fragmentos orgánicos (Tabla 4.1.). En conclusión, la espectroscopia Raman verifica inequívocamente la existencia e integridad de las diferentes especies orgánicas en los materiales porosos estudiados, procedentes de los disilanos empleados como precursores organosiliceos.
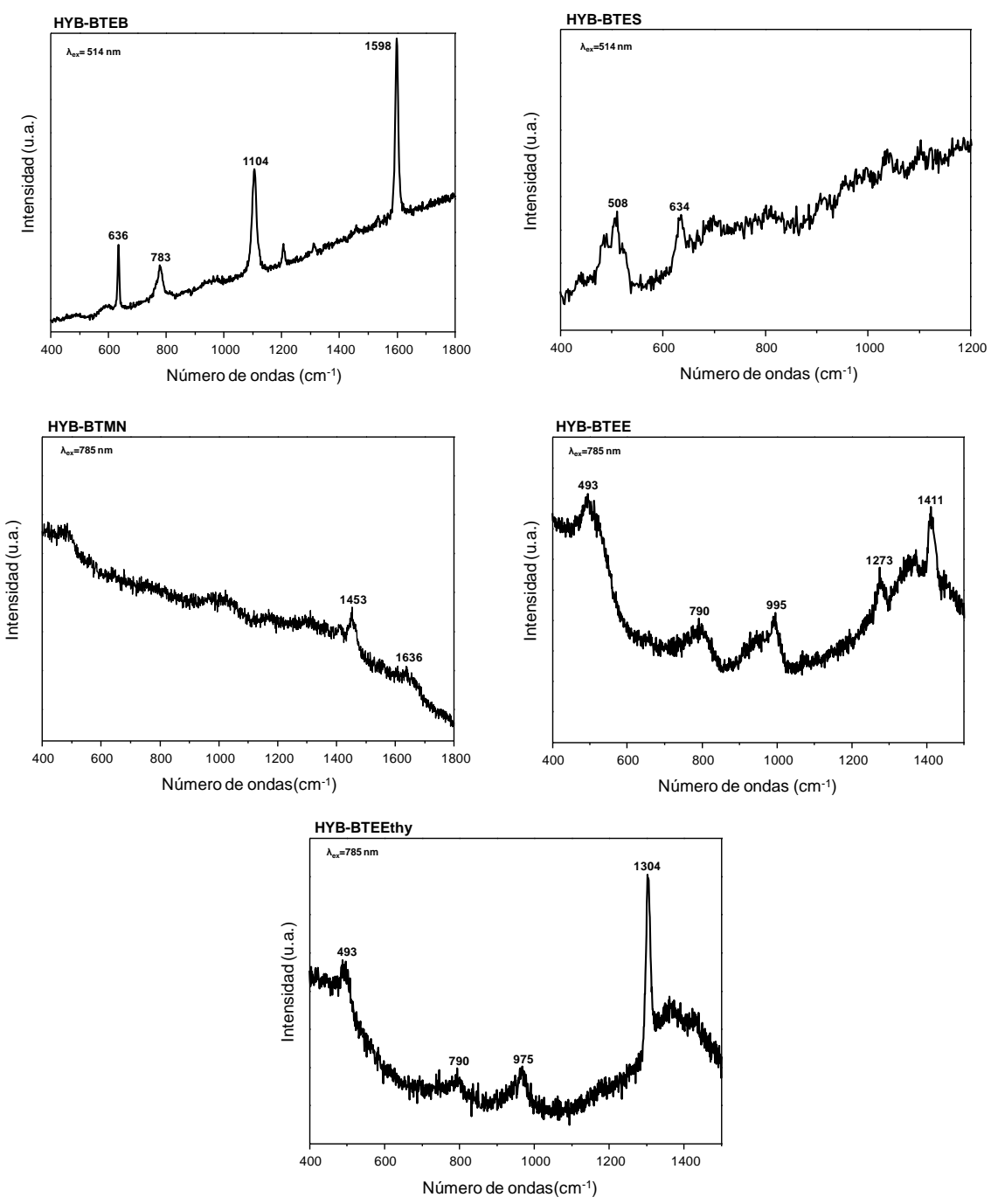

Figura 4.18. Espectros Raman de los materiales híbridos sintetizados con cada uno de los disilanos. 


\section{Resonancia Magnética Nuclear}

En la Figura 4.19. se muestran los espectros de $\mathrm{RMN}$ de ${ }^{13} \mathrm{C}$ de los materiales porosos orgánicos-inorgánicos sintetizados.

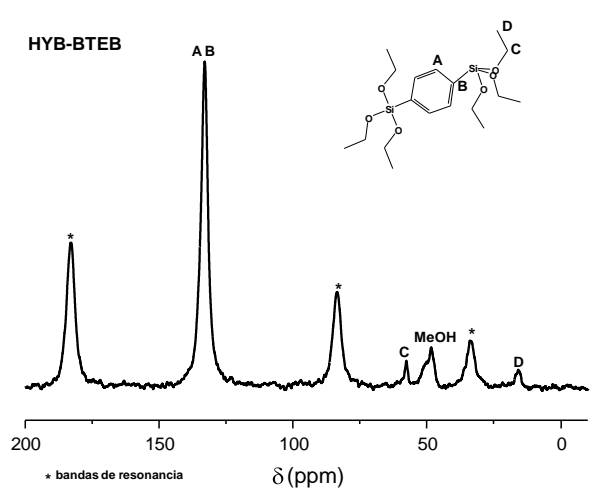

HYB-BTMN

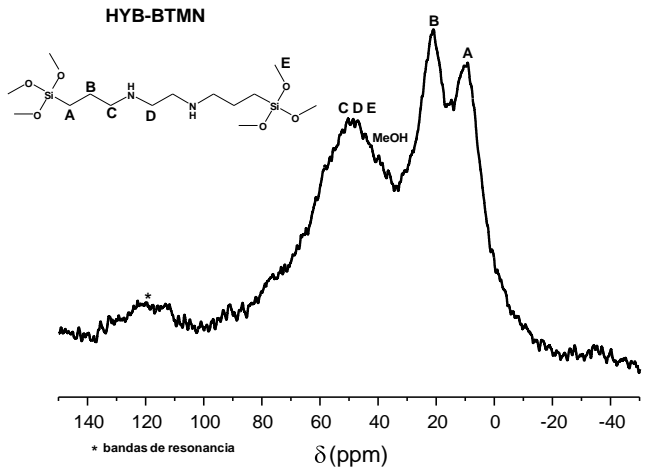

HYB-BTES

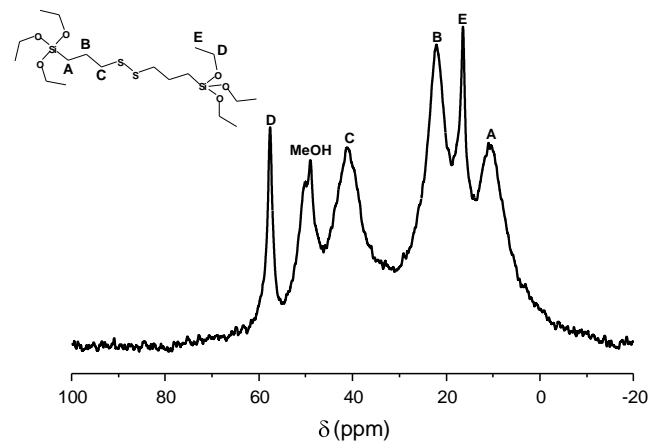

HYB-BTEE
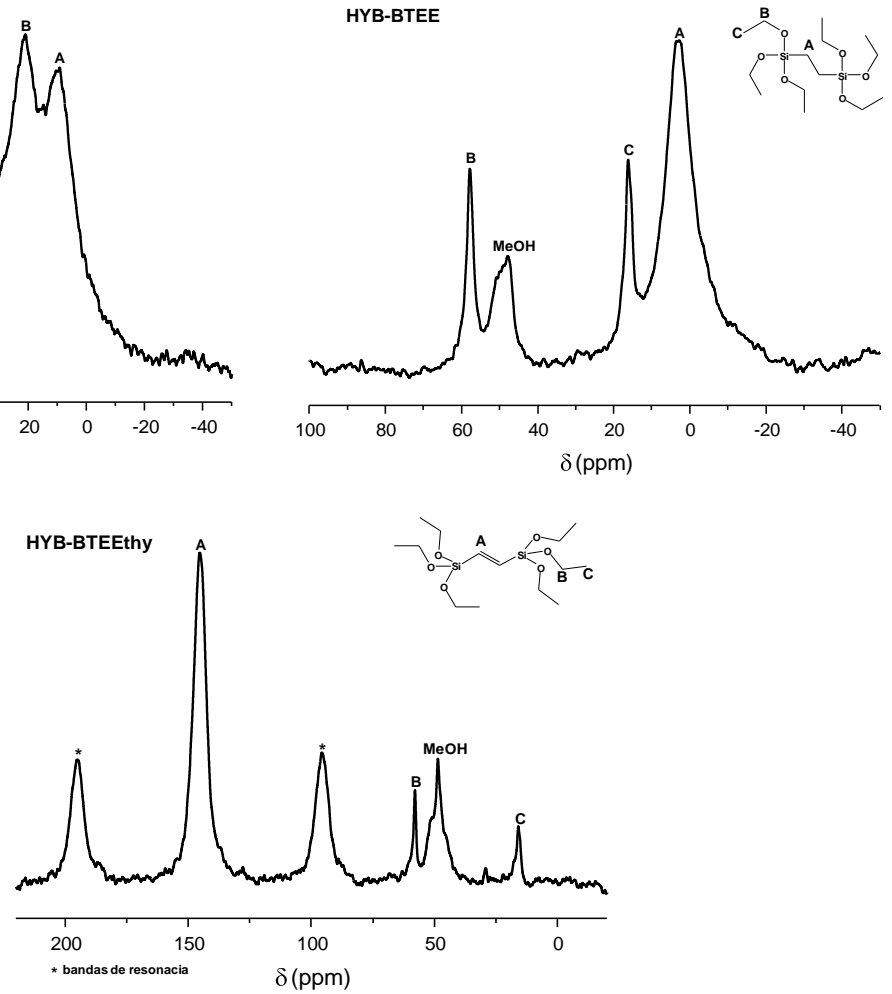

Figura 4.19. Espectros RMN CP/MAS de ${ }^{13} \mathrm{C}$ de los diferentes materiales híbridos y la asignación de las bandas a los átomos de carbono que forman parte de los fragmentos orgánicos. 
En todos los casos es posible confirmar la total integridad de las especies orgánicas después del proceso de síntesis ya que todos los átomos de carbono, incluyendo los enlazados directamente a los átomos de silicio, se pueden asignar inequívocamente en los respectivos espectros de $\mathrm{RMN}$ de ${ }^{13} \mathrm{C}$. En dichos espectros, cada banda ha sido asignada a los átomos de carbono presentes en los fragmentos orgánicos incluidos en los disilanos utilizados (ver la asignación efectuada en la Figura 4.19.). Este hecho corrobora que los unidades orgánicas permanecen intactas como en los precursores iniciales, indicando la efectiva incorporación de los segmentos orgánicos en los materiales sintetizados, siendo destacable que los átomos de carbono unidos a átomos de silicio se siguen conservando en los sólidos finales, tal y como estaban en los disilanos iniciales. En todos los casos es posible observar bandas asociadas a grupos alcóxido presentes en los disilanos de partida, indicando que la hidrólisis y condensación de todos los grupos terminales metóxido y etóxido de los disilanos no fue completa durante la ruta de síntesis catalizada por moléculas de $\mathrm{NH}_{4} \mathrm{~F}$. De este modo, se confirma que solo una fracción de los grupos alcóxido terminales participa en la formación de los materiales híbridos porosos. Todos los espectros de $\mathrm{RMN}$ de ${ }^{13} \mathrm{C}$ muestran la existencia de $\mathrm{MeOH}$ residual (banda centrada en 48 ppm), empleado como disolvente orgánico durante el proceso de síntesis, el cual permanece adsorbido parcialmente en las cavidades porosas de los materiales híbridos.

Además de confirmar por RMN de ${ }^{13} \mathrm{C}$ que los fragmentos orgánicos permanecen intactos, a través de RMN de ${ }^{29} \mathrm{Si}$ se puede afirmar que estos fragmentos se han incorporado a la red estructural de los materiales sintetizados, covalentemente enlazados a unidades silíceas. En la Figura 4.20. se muestran los espectros de RMN de ${ }^{29} \mathrm{Si}$ de los distintos sólidos orgánicos-inorgánicos preparados a partir de los diferentes disilanos. Todos los espectros muestran bandas características que van desde -60 a -80 ppm correspondientes a los átomos de silicio de tipo $\mathrm{T}$, los cuales confirman la presencia de fragmentos orgánicos e inorgánicos (enlaces $\mathrm{Si}-\mathrm{C}$ ) unidos covalentemente. Más específicamente, se puede observar de forma clara en el espectro tres bandas que se asignan a átomos de silicio de tipo $\mathrm{T}^{1}\left[\mathrm{C}-\mathrm{Si}(\mathrm{OH})_{2}(\mathrm{OSi})\right], \mathrm{T}^{2}\left[\mathrm{C}-\mathrm{Si}(\mathrm{OH})(\mathrm{OSi})_{2}\right]$ y $\mathrm{T}^{3}\left[\mathrm{C}-\mathrm{Si}(\mathrm{OSi})_{3}\right]$, las cuales están indicadas en la Figura 4.20. Este hecho confirma la presencia de especies silíceas con grupos benceno, disulfuro, etilendiamino, etano y etileno enlazadas a 
unidades tetraédricas de sílice $\left[\mathrm{SiO}_{4}\right]$ conformando la red estructural de los materiales porosos no ordenados. Por lo tanto, la existencia de bandas de tipo T demuestra que tienen lugar la hidrólisis y condensación de los silsesquioxanos de partida a través de los grupos alcóxido terminales presentes en cada uno de los espaciadores orgánicos.

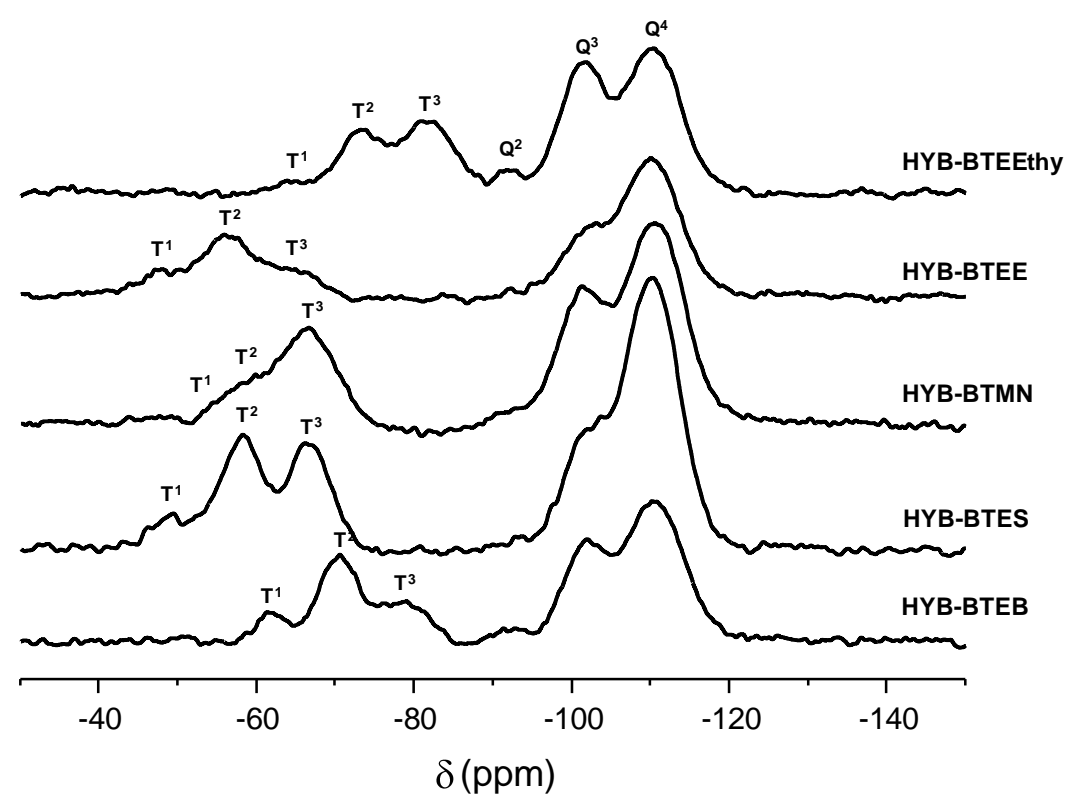

Figura 4.20. Espectros de RMN BD/MAS de ${ }^{29} \mathrm{Si}$ de los materiales híbridos y asignación de las bandas $T$ y $Q$ de los átomos de Si que los componen.

En todos los espectros de RMN de ${ }^{29} \mathrm{Si}$ se observan otras tres bandas centradas a 92, -100 y $-110 \mathrm{ppm}$ que se asignan a átomos de silicio de tipo $\mathrm{Q}^{2}\left[\mathrm{Si}(\mathrm{OH})_{2}(\mathrm{OSi})_{2}\right], \mathrm{Q}^{3}$ $\left[\mathrm{Si}(\mathrm{OH})(\mathrm{OSi})_{3}\right]$ y $\mathrm{Q}^{4}\left[\mathrm{Si}(\mathrm{OSi})_{4}\right]$, respectivamente. La existencia de átomos de silicio de tipo $\mathrm{Q}^{2}$ confirma el carácter no ordenado y con defectos de los híbridos porosos estudiados. Por otra parte, la presencia de átomos de silicio de tipo $\mathrm{T}^{1} \mathrm{y} \mathrm{T}^{2}$ revela que algunos grupos alcóxido terminales de los disilanos no han reaccionado durante el proceso de síntesis ${ }^{[43]}$.

Otra prueba de la efectiva incorporación de fragmentos orgánicos en la red estructural de los materiales preparados proviene directamente de los espectros de RMN de ${ }^{29} \mathrm{Si}$ de los disilanos de partida que mostrados en la Figura 4.21. Normalmente, los 
disilanos puros presentan un único pico característico de los átomos de silicio centrado entre -40 y -60 ppm, dependiendo del grupo orgánico que contengan. Cuando estos grupos orgánicos finalmente se incorporan en el entramado estructural de los materiales híbridos, la señal correspondiente a los átomos de silicio enlazados a especies orgánicas se desplaza a valores comprendidos entre -60 a -80 ppm (Figura 4.20.), lo que confirma su integración en los materiales porosos. En la Tabla 4.2., se muestra el desplazamiento en la posición de las bandas correspondientes a los átomos de silicio de tipo T en el espectro de $\mathrm{RMN}$, donde es posible ver una variación para las unidades Si-C cuando estas pasan de estar en los disilanos de partida, en estado puro, a cuando pasan a formar parte de la red estructural de los materiales.

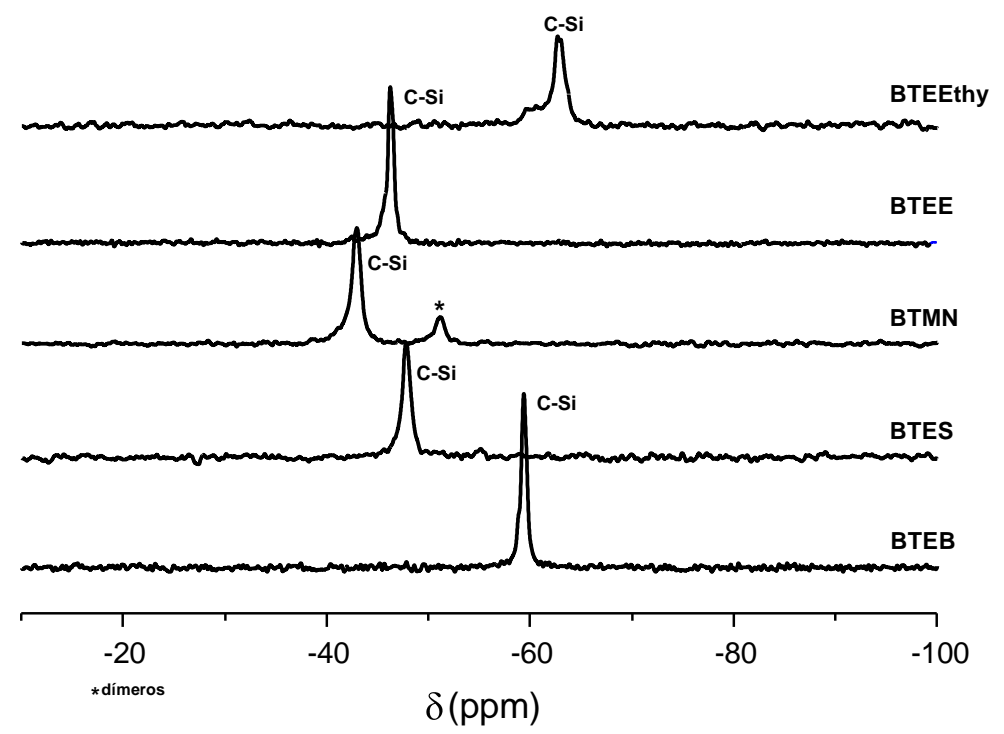

Figura 4.21. Espectros de RMN BD/MAS de ${ }^{29} \mathrm{Si}$ de los disilanos de partida usados en la síntesis de los materiales híbridos. 
Tabla 4.2. Desplazamientos $(\delta)$ de las bandas de los átomos de silicio de tipo $T$ a partir de los espectros de RMN BD/MAS de ${ }^{29} \mathrm{Si}$ de los materiales híbridos porosos y de los disilanos puros utilizados como precursores.

\begin{tabular}{|c|c|c|c|c|}
\hline Muestra & $\begin{array}{c}T^{1}(p p m) \\
C-S i(O H)_{2}(O S i)\end{array}$ & $\begin{array}{c}\mathrm{T}^{2}(\mathrm{ppm}) \\
\mathrm{C}-\mathrm{Si}(\mathrm{OH})(\mathrm{OSi})_{2}\end{array}$ & $\begin{array}{l}T^{3}(p p m) \\
C-S i(O S i)_{3}\end{array}$ & $\begin{array}{c}T_{(\mathrm{c}-\mathrm{Si})} \\
(\mathrm{ppm}) \\
\text { Disilano }\end{array}$ \\
\hline HYB-BTEB & -62.3 & -70.6 & -79.0 & -59.3 \\
\hline HYB-BTES & -50.1 & -58.2 & -66.3 & -47.7 \\
\hline HYB-BTMN & -54.7 & -60.5 & -66.7 & -42.9 \\
\hline HYB-BTEE & -48.3 & -55.9 & -65.3 & -46.3 \\
\hline HYB-BTEEthy & -64.8 & -73.5 & -81.7 & -62.6 \\
\hline
\end{tabular}

A partir de la integración de las seis señales (bandas $T$ y Q) presentes en los espectros de RMN de ${ }^{29} \mathrm{Si}$ es posible calcular la relación $\mathrm{T} /(\mathrm{Q}+\mathrm{T})$ y así evaluar el número de átomos de silicio funcionalizados en los materiales híbridos (ver relación $\mathrm{Si}_{\text {func }} / \mathrm{Si}_{\text {total }}$ en la Tabla 4.1). Los resultados muestran que aproximadamente entre $25-35 \%$ de los átomos de silicio en los sólidos están funcionalizados por grupos orgánicos, siendo este valor significativamente mayor que los reportados previamente para materiales mesoestructurados convencionales (MCM-41 y SBA-15), los cuales contiene, normalmente, un máximo de un $20 \%$ de átomos de silicio funcionalizados ${ }^{[44]}$. Igualmente, es posible evaluar el nivel de funcionalización a partir de los datos obtenidos por análisis elemental (Tabla 4.1), siendo la relación $\mathrm{Si}_{\text {func }} / \mathrm{Si}_{\text {total }}$ similar a la estimada por RMN, excepto para los sólidos HYB-BTEE y HYB-BTEEthy en los cuales la excesiva cantidad de $\mathrm{MeOH}$ adsorbido, utilizado durante la síntesis, puede alterar ligeramente los valores calculados a partir de los datos de análisis elemental.

Finalmente, los sólidos también fueron analizados a través de espectroscopia RMN de ${ }^{19} \mathrm{~F}$, comprobándose que no contienen fluoruro en su entramado estructural pese a la utilización de $\mathrm{NH}_{4} \mathrm{~F}$ durante el proceso de síntesis. 


\section{Propiedades Texturales}

Durante la preparación de los diferentes materiales porosos híbridos orgánicosinorgánicos, se comprobó que el tipo de disilano usado como precursor tiene una influencia muy importante tanto en las propiedades texturales finales como en la distribución del tamaño de poro de las cavidades y canales generados. En la Tabla 4.3. se presentan los valores de superficie específica BET y externa, así como el volumen total, microporoso y diámetro de poro estimados por el método $\mathrm{BJH}^{[45]}$ de los materiales híbridos resultantes, confirmándose que éstos son esencialmente mesoporosos con diámetros de poro que oscilan entre 20 y $80 \AA$. No obstante, en el apartado 4.3.2.1. se discutirán con más detalle cómo el tipo de disilano tiene una influencia decisiva sobre las propiedades texturales de los materiales híbridos preparados.

Tabla 4.3. Propiedades texturales de los materiales híbridos orgánicos-inorgánicos.

\begin{tabular}{cccccc}
\hline Muestra & $\begin{array}{c}\text { Superficie } \\
\text { BET } \\
\left(\mathbf{m}^{\mathbf{2}} \mathbf{g}^{-1}\right)\end{array}$ & $\begin{array}{c}\text { Superficie } \\
\text { Externa } \\
\left(\mathbf{m}^{\mathbf{2}} \mathbf{g}^{-1}\right)^{\mathbf{a}}\end{array}$ & $\begin{array}{c}\text { Volumen } \\
\text { Microporo } \\
\left(\mathbf{c m}^{\mathbf{3}} \mathbf{g}^{-1}\right)\end{array}$ & $\begin{array}{c}\text { Volumen } \\
\text { Total Poro } \\
\left(\mathbf{c m}^{\mathbf{3}} \mathbf{g}^{-1}\right)\end{array}$ & $\begin{array}{c}\text { Diámetro } \\
\text { Poro } \\
(\AA)\end{array}$ \\
\hline HYB-BTEB & 626.5 & 338.1 & 0.137 & 0.431 & $20-30$ \\
HYB-BTES & 567.0 & 567.0 & 0.000 & 1.436 & 65 \\
HYB-BTMN & 313.1 & 313.1 & 0.000 & 0.239 & 30 \\
HYB-BTEE & 563.3 & 453.4 & 0.048 & 0.530 & $20-80$ \\
HYB-BTEEthy & 713.3 & 519.9 & 0.090 & 0.452 & 20 \\
Pura Sílice & 668.0 & 547.4 & 0.053 & 0.473 & $20-30$ \\
\hline
\end{tabular}

${ }^{\mathrm{a}}$ A partir del t-plot, calculando $\mathrm{S}_{\mathrm{ext}}=\mathrm{S}_{\mathrm{BET}}-\mathrm{S}_{\text {micro; }}{ }^{\mathrm{b}}$ Calculado a través del método BJH.

\subsubsection{Variables del método de síntesis en medio fluoruro}

En la síntesis de este tipo de materiales híbridos orgánicos-inorgánicos no ordenados se han estudiado diversas variables con el fin de optimizar el proceso de preparación de los mismos, determinando la influencia de dichas variables en sus propiedades finales. 


\subsubsection{Influencia del tipo de disilano}

Se ha comprobado que el tipo de fragmento orgánico introducido en la red estructural tiene una influencia determinante sobre las propiedades texturales de los materiales híbridos sintetizados (Tabla 4.3.). Como se puede observar, la superficie BET fluctúa entre 300 y $700 \mathrm{~m}^{2} / \mathrm{g}$. En el caso de los materiales híbridos preparados a partir de BTES y BTMN, es posible apreciar una ausencia completa de microporosidad, exhibiendo una distribución de poro más estrecha centrada a $\sim 65 \AA$, en el caso de que se introduzcan grupos disulfuro en su estructura. Esto se puede deducir a partir de la observación de las isotermas de adsorción de $\mathrm{N}_{2}$ (Figura 4.22.) y la distribución del tamaño de poro BJH (Figura 4.23.).

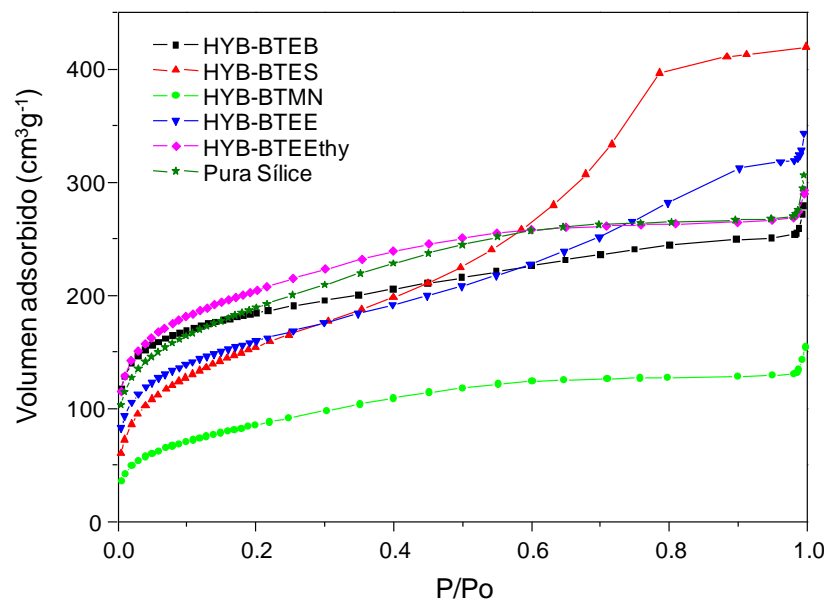

Figura 4.22. Isotermas de adsorción de nitrógeno de los híbridos no ordenados.

La muestra HYB-BTES presenta una isoterma con un marcado desplazamiento a altas presiones relativas en el punto de inflexión, indicando que el diámetro de poro es más grande que en los otros materiales. El acentuado cambio de pendiente observado en la isoterma de esta muestra indica que los sólidos híbridos no ordenados con unidades disulfuro en su estructura tienen una distribución de poro relativamente estrecha, la cual está próxima a la distribución de poro de los materiales silíceos mesoporosos convencionales obtenidos a través de autoensamblaje con ADEs como es el caso de la 
SBA-15 o $\mathrm{MSU}^{[46]}$, pero más ancha que las observadas para los sólidos M41S. Esto se puede apreciar en la Figura 4.24. donde se compara la distribución del tamaño de poro BJH para materiales mesoporosos convencionales como MCM-41, SBA-15 y MSU con los materiales híbridos que contienen grupos disulfuro en su estructura, HYB-BTES.

Por el contrario, los materiales híbridos sintetizados a partir de los disilanos BTEB, BTEE y BTEEthy muestran una reducción en su área externa comparada con la superficie $B E T$, junto con un aumento en el volumen de microporo (Tabla 4.3). En todas estas muestras se aprecia una disminución del diámetro de poro, si lo comparamos con el sólido HYB-BTES, presentándose en un amplio rango que va del microporo al pequeño mesoporo (20-25 Å) como se deduce de las curvas t-plot y de la distribución de tamaño de poro BJH (Figura 4.23.), siendo este comportamiento similar al observado para materiales puramente silíceos obtenidos en las mismas condiciones (Tabla 4.3). Este efecto se observa claramente en las isotermas de adsorción donde el punto de inflexión se desplaza a presiones relativas inferiores para los sólidos HYB-BTEB, HYB-BTEE y HYB-BTEEthy, como ocurre en los materiales puramente silíceos (Figura 4.23.).

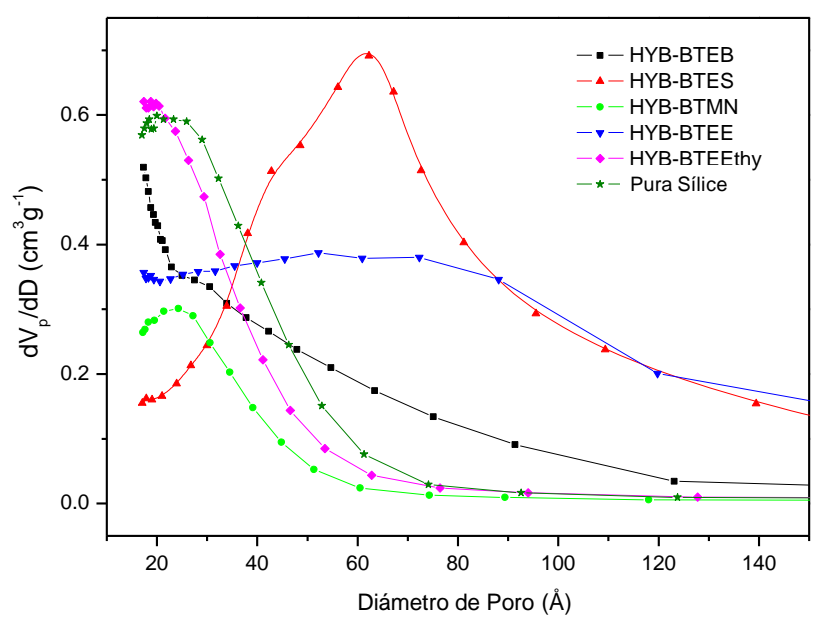

Figura 4.23. Distribución del diámetro de poro de los materiales híbridos calculado a partir del método $\mathrm{BJH}^{[45]}$. 


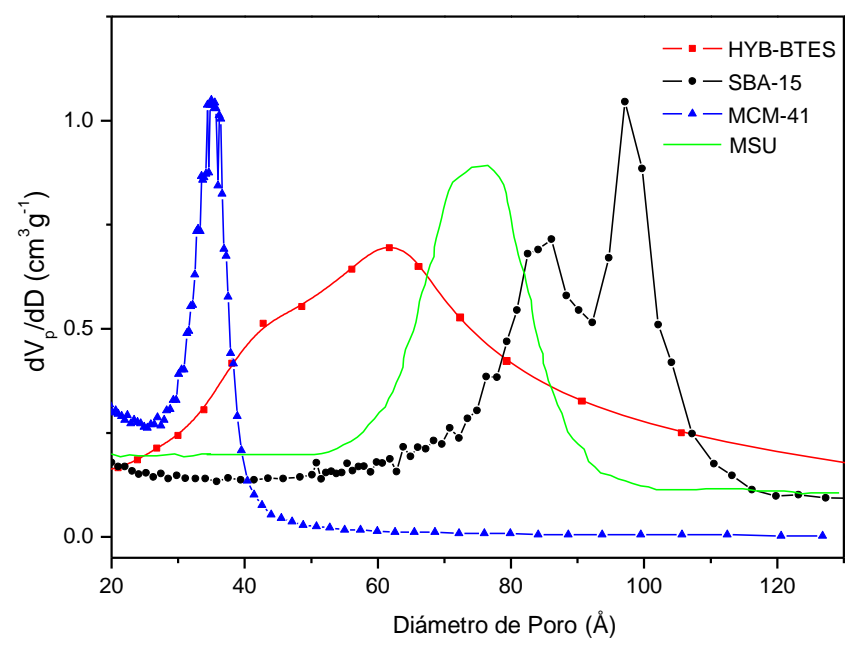

Figura 4.24. Distribución del diámetro de poro del material híbrido HYB-BTES y los materiales mesoporosos convencionales MCM-41, SBA-15 y MSU, calculado a partir del método BJH.

En el caso concreto de los materiales híbridos con grupos etano (HYB-BTEE), la distribución del diámetro de poro es muy amplia, alcanzando hasta $80 \AA$ como límite superior, debido, probablemente, a una peor homogeneidad y regularidad conseguida en los materiales híbridos al emplear este tipo de disilano (BTEE).

La variación en la porosidad de los diferentes sólidos preparados está marcadamente influenciada por el tipo y la naturaleza del grupo orgánico que se incorpora finalmente en la red estructural. La mayor o menor flexibilidad de los grupos orgánicos puede ser el motivo de las diferentes propiedades texturales observadas. El disilano BTES contiene el grupo orgánico más flexible, facilitando la formación de híbridos no ordenados cuyo entramado estructural es más abierto y accesible, presentando también una mayor contribución del volumen mesoporoso a la porosidad total. Por otro lado, la elevada rigidez exhibida por los disilanos que contienen grupos benceno, etano y etileno puede explicar la mayor contribución microporosa presente en los materiales híbridos sintetizados.

En el caso del material HYB-BTMN sus propiedades texturales, en general, son similares a las del material HYB-BTES, en el sentido de que no exhiben microporosidad. 
Este comportamiento se puede atribuir a que el disilano BTMN presenta una flexibilidad similar a la del precursor BTES. No obstante, la más que probable irregular distribución estructural entre fragmentos orgánicos, etilendiamino, e inorgánicos, unidades silíceas, contribuye a que la porosidad y la homogeneidad en los materiales HYB-BTMN sea menor que en el caso de los sólidos HYB-BTES.

\subsubsection{Influencia de la relación disilano/ $\mathrm{SiO}_{2}$}

Otra variable estudiada, durante los procesos sol-gel en medio fluoruo, fue la cantidad de disilano empleado en la síntesis, determinando su influencia sobre las propiedades texturales de los materiales mesoporosos obtenidos. Para ello, se realizaron diferentes síntesis en las que se fue modificando la cantidad de disilano respecto a la sílice total empleada. En concreto, este parámetro fue analizado usando dos tipos de precursores: BTEB y BTES. Con esta comparación, se pretende determinar si la mayor o menor presencia de fragmentos orgánicos en la estructura de los materiales influye sobre su porosidad en función de la rigidez o flexibilidad de las unidades estructurales finalmente utilizadas.

Los datos obtenidos a través de análisis elemental de las muestras (Tabla 4.4.) reflejan que el contenido orgánico $(\mathrm{C}, \mathrm{H}, \mathrm{N}$ y S) presente en las mismas es mayor conforme la cantidad de disilano empleado en la síntesis es más elevado, alcanzándose entre un 40 y $50 \%$ en peso de contenido orgánico cuando se emplean mayores proporciones de disilano. Además, en la mayoría de sólidos preparados con BTES, la relación $\mathrm{C} / \mathrm{S}$ se mantiene en torno a 3, lo que indicaría que los fragmentos orgánicos de tipo propildisulfuro se mantienen intactos como en el disilano de partida. Únicamente, en los casos que se emplea mayor cantidad de BTES, se obtienen relaciones C/S superiores a 3 debido, probablemente, tanto a la presencia de mayor número de grupos alcóxidos terminales que no se hidrolizan completamente en el proceso sol-gel, como a la presencia de metanol retenido en las cavidades porosas generadas, el cual es utilizado como disolvente en la preparación de los sólidos. Este último hecho también se corrobora a través de los espectros de RMN de los materiales con un mayor contenido en disilano (Figura 4.25.) 
donde se observan claramente las bandas asignadas a los carbonos de los grupos terminales etóxido. Aunque, tanto a través de los espectros de RMN de ${ }^{13} \mathrm{C}$ como de ${ }^{29} \mathrm{Si}$, es posible corroborar la integridad de los fragmentos orgánicos que están formando parte del entramado estructural de los materiales híbridos.
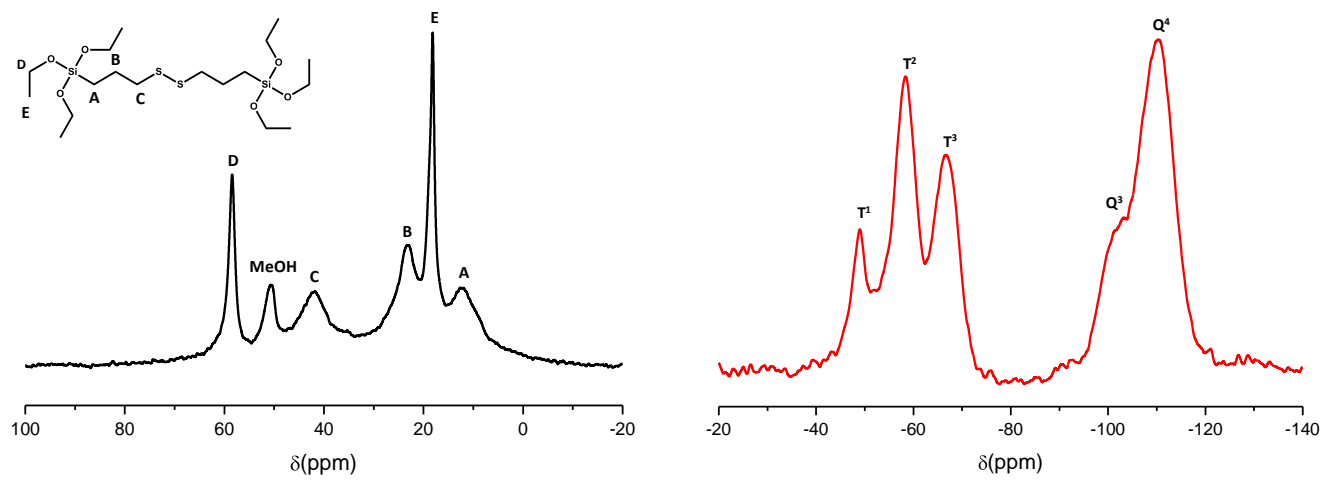

Figura 4.25. Espectros de RMN del material híbrido con una relación $B T E S / T M O S=1: C P / M A S$ de ${ }^{13} C$ (izquierda) y BD/MAS de ${ }^{29} \mathrm{Si}$ (derecha).

Tabla 4.4. Análisis elemental de las muestras obtenidas con los disilanos BTEB y BTES a partir de un gel de síntesis con una composición molar de $1 \mathrm{SiO}_{2}$ [(1-x) TMOS $+x$ Disilano]: $4 \mathrm{MeOH}$ : $4 \mathrm{H}_{2} \mathrm{O}$ : $3.13 \times 10^{-3} \mathrm{NH}_{4} \mathrm{~F}$.

\begin{tabular}{|c|c|c|c|c|c|c|c|}
\hline Disilano & Disilano/TMOS & $\% \mathrm{H}$ & $\% \mathbf{N}$ & $\% \mathrm{C}$ & $\% \mathrm{~S}$ & $\mathrm{C} / \mathrm{S}$ & $\begin{array}{c}\text { \%Contenido } \\
\text { Orgánico } \\
\end{array}$ \\
\hline \multirow{5}{*}{ BTEB } & 0.5 & 2.8 & 0.0 & 16.1 & 0.0 & - & 18.9 \\
\hline & 1 & 3.0 & 0.0 & 24.3 & 0.0 & - & 27.3 \\
\hline & & & & & & & \\
\hline & 1.5 & 3.8 & 0.0 & 28.4 & 0.0 & - & 32.2 \\
\hline & 2.0 & 4.2 & 0.0 & 32.8 & 0.0 & - & 37.0 \\
\hline \multirow{5}{*}{ BTES } & 0.5 & 2.9 & 0.0 & 14.7 & 11.8 & 3.3 & 29.4 \\
\hline & 1 & 3.9 & 0.0 & 18.6 & 17.3 & 2.9 & 39.8 \\
\hline & & & & & & & \\
\hline & 1.5 & 5.6 & 0.0 & 28.4 & 14.9 & 5.1 & 48.9 \\
\hline & 2.0 & 5.7 & 0.0 & 29.4 & 15.1 & 5.2 & 50.2 \\
\hline
\end{tabular}


Por otra parte, a partir de las isotermas de adsorción de nitrógeno, se observa que, en general, a mayor cantidad de disilano utilizado durante el proceso de síntesis (BTEB o BTES), la superficie específica y el volumen poroso disminuyen considerablemente (Figuras 4.26. y 4.27.). No obstante, cuando es empleado un disilano rígido (BTEB), se obtienen materiales con elevada porosidad hasta una relación molar Disilano/TMOS inferior a 2. Por el contrario, al emplear un precursor orgánico-inorgánico más flexible (BTES), únicamente se obtienen materiales de elevada accesibilidad con relaciones molares Disilano/TMOS inferiores a 0.5. Por encima de este valor la superficie y el volumen poroso son prácticamente nulos.

Estos resultados muestran la importancia de las unidades inorgánicas tipo Si-O-Si procedentes de las moléculas de TMOS, en el gel de síntesis, ya que facilitan la estructuración de los fragmentos orgánicos conformando la estructura de los sólidos, siendo necesarias para estabilizar y distanciar de una manera adecuada los fragmentos orgánicos alrededor de las cavidades mesoporosas que se van generando. En el caso de fragmentos rígidos, tales como los anillos aromáticos, se consiguen materiales mesoporosos mínimamente estructurados aún trabajando con elevadas cantidades de unidades orgánicas ${ }^{[21]}$. Sin embargo, cuando el proceso sol-gel es llevado a cabo en presencia de moléculas de disilano con unidades flexibles (grupos propildisulfuro), la estructuración en torno a los mesoporos se hace más complicada al emplear gran cantidad de moléculas de BTES, produciéndose con mayor facilidad el colapsamiento estructural debido al elevado grado de desorden alcanzado durante el proceso de polimerización. En estos últimos casos, parece evidente la necesidad de emplear mayor número de unidades inorgánicas $\mathrm{Si}-\mathrm{O}-\mathrm{Si}$, las cuales ayudan a insertar en las paredes del material fragmentos orgánicos de naturaleza más flexible. 

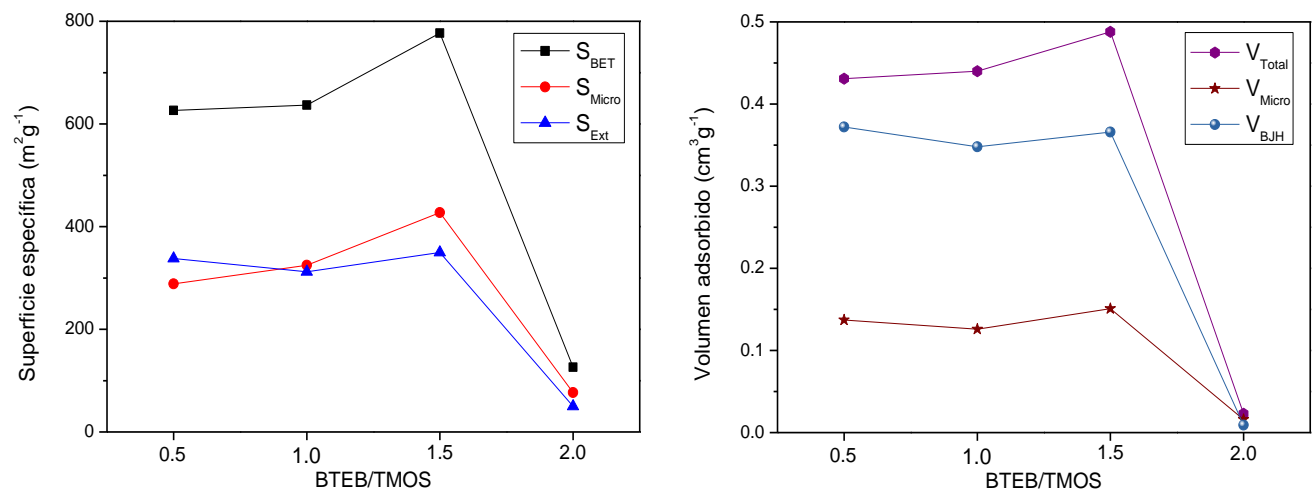

Figura 4.26. Superficie específica y volumen poroso de muestras híbridas preparadas con diferentes relaciones molares BTEB/TMOS.
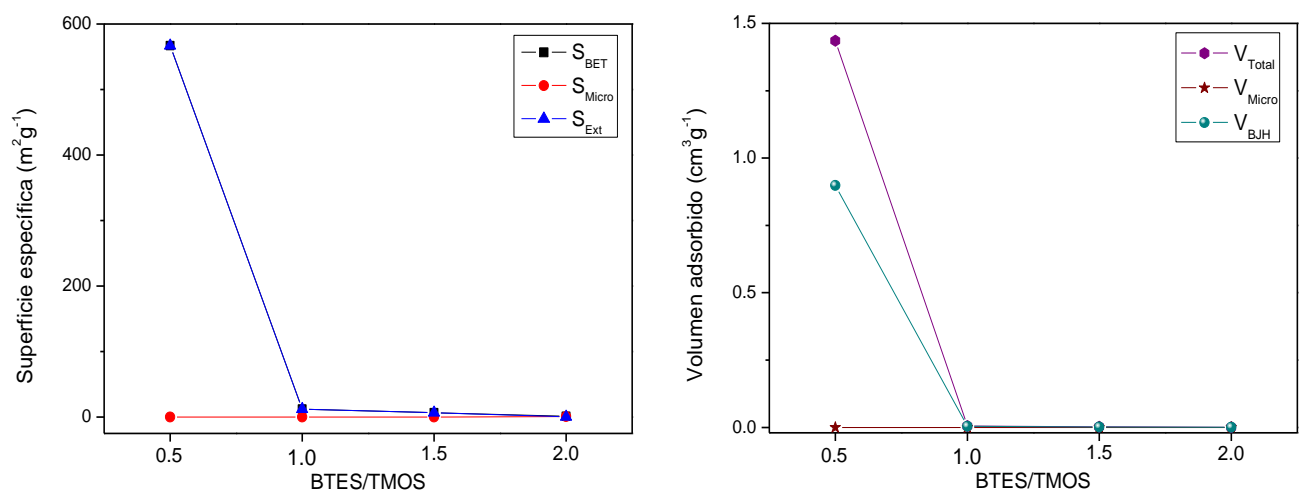

Figura 4.27. Superficie específica y volumen poroso de muestras híbridas preparadas con diferentes relaciones molares BTES/TMOS.

Con el fin de determinar con más detalle la influencia de la cantidad de unidades inorgánicas Si-O-Si insertadas finalmente en la estructura de los materiales híbridos sobre sus propiedades texturales, se prepararon diferentes sólidos con relaciones molares (BTES/TMOS) menores que 0.5. Los resultados obtenidos a partir de las isotermas de adsorción de $\mathrm{N}_{2}$ (Figura 4.28.) muestran que, dentro de unos márgenes estrechos, conforme la proporción de unidades inorgánicas es mayor en la conformación estructural, se observa un ligero aumento de la superficie total debido a un incremento del área microporosa que alcanza los $120 \mathrm{~m}^{2} \mathrm{~g}^{-1}$ en la muestra pura sílice, quedando la superficie 
externa prácticamente inalterada en torno a $550 \mathrm{~m}^{2} \mathrm{~g}^{-1}$ en todos los sólidos obtenidos con una relación (Disilano/TMOS) < 0.5. Esta tendencia corrobora que, en las proporciones adecuadas, la inserción de unidades orgánicas flexibles, tales como los grupos propildisulfuro, facilita la formación de materiales mesoporosos de elevada accesibilidad, anulándose por completo la contribución microporosa observada en los materiales preparados en ausencia de disilanos.

La distribución en el diámetro de poro está en consonancia con estos resultados ya que se pasa de obtener materiales con cavidades mesoporosas de $20 \AA$ de diámetro en los materiales únicamente estructurados con unidades $\mathrm{Si}-\mathrm{O}-\mathrm{Si}$, hasta otros con poros de aproximadamente $65 \AA ̊$ de diámetro cuando se insertan unidades flexibles propildisulfuro, generándose materiales de mayor accesibilidad. En el caso concreto del disilano BTES, tras el estudio realizado, parece que la relación molar BTES/TMOS de 0.5 es la idónea para obtener materiales completamente mesoporosos y con mayor diámetro de poro (Figura 4.28.).

En el caso de los materiales preparados partiendo de disilanos con fragmentos orgánicos más rígidos, por ejemplo anillos aromáticos a partir del disilano BTEB, sus propiedades texturales son más parecidas a los sólidos obtenidos sin disilanos, en el sentido de que se sigue apreciando una cierta contribución microporosa en su superficie específica total, estando conformados por cavidades mesoporosas de tamaño más reducido, alrededor de aproximadamente $20 \AA ̊$ (Tabla 4.3), tal y como ocurre en los sólidos puramente silíceos. Por lo tanto, se puede afirmar que la inserción de unidades orgánicas rígidas a nivel estructural supondría, en general, una menor alteración en el proceso de estructuración de los materiales mesoporosos, durante la síntesis sol-gel en medio fluoruro, si se compara con la introducción estructural de fragmentos orgánicos más flexibles. 


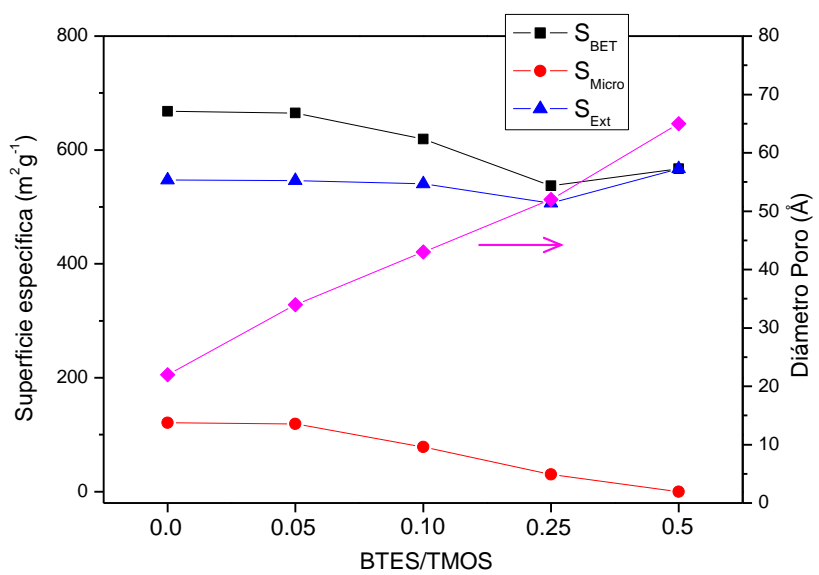

Figura 4.28. Superficie específica y volumen poroso de muestras híbridas preparadas con relaciones molares $($ BTES $/$ TMOS) $<0.5$.

\subsubsection{Influencia de la relación $\mathrm{SiO}_{2} / \mathrm{NH}_{4} \mathrm{~F}$}

Como se ha mostrado en las secciones anteriores, los iones fluoruro, en los procesos sol-gel aquí considerados, tienen un papel determinante sobre la etapa de gelificación de los sólidos, ocurriendo en tiempos extremadamente cortos. Con el fin de estimar mejor este efecto, se hicieron diferentes experimentos variando la concentración de iones fluoruro en el gel de síntesis, observando su influencia sobre las propiedades texturales de los materiales híbridos finalmente obtenidos. Para ello, al igual que en el apartado anterior, se prepararon diferentes materiales mesoporosos que contenían bien un fragmento orgánico rígido (obtenidos a partir del disilano BTEB) o bien flexible (obtenidos a partir del disilano BTES), fijando una relación molar Disilano/TMOS de 0.5 y modificando la concentración de iones $\mathrm{F}^{-}$desde una relación molar mínima Si/F $\mathrm{F}^{-}$de 5 hasta una máxima de 319. La simple observación del proceso de gelificación ya nos muestra con claridad que al aumentar la concentración de iones fluoruro, la hidrólisis y polimerización se produce en apenas unos pocos segundos. En concreto, en el caso de que la relación molar $\left(\mathrm{Si} / \mathrm{F}^{-}\right)$sea de 5 , el gel se forma tras 5 segundos de agitación a temperatura ambiente, mientras que al trabajar con una relación $\left(\mathrm{Si} / \mathrm{F}^{-}\right)$de 319 es necesario aproximadamente un minuto para que gelifique. Esta diferencia sería de esperar que 
tuviera un reflejo en el proceso de estructuración y, por lo tanto, en la porosidad de los materiales orgánicos-inorgánicos preparados.

En el caso de los materiales obtenidos usando el disilano rígido BTEB, los resultados obtenidos, a partir de las isotermas de adsorción de $\mathrm{N}_{2}$, muestran que a mayor concentración de iones $\mathrm{F}^{-}$la superficie mesoporosa de los sólidos formados aumenta apreciablemente, disminuyendo la contribución microporosa (Figura 4.29.). Esta tendencia ya ha sido constatada en la bibliografía y se podría explicar por la generación de geles de síntesis con una reducida concentración de núcleos que van creciendo hasta el consumo total de las especies organosilíceas presentes en el medio, ocurriendo esto preferentemente en procesos con una baja relación $\mathrm{Si} / \mathrm{F}^{-}$cuya gelificación es casi instantánea ${ }^{[47]}$. Es por ello que, en estas condiciones, se favorece la formación de pocas partículas pero de elevado diámetro, generándose entre ellas cavidades, principalmente, en el rango mesoporoso. Por el contrario, cuando la relación $\mathrm{Si} / \mathrm{F}^{-}$aumenta, se favorece la formación de un mayor número de núcleos organosilíceos de reducido tamaño que tienden a aglomerarse entre sí, obteniéndose materiales híbridos con menor superficie específica total, habiendo mayor contribución de cavidades en el rango microporoso (Figura 4.29.). En el Esquema 4.2. se muestran dos posibles estructuraciones de los materiales sintetizados a través de procesos sol-gel en función de la concentración de iones fluoruro presentes en el medio.
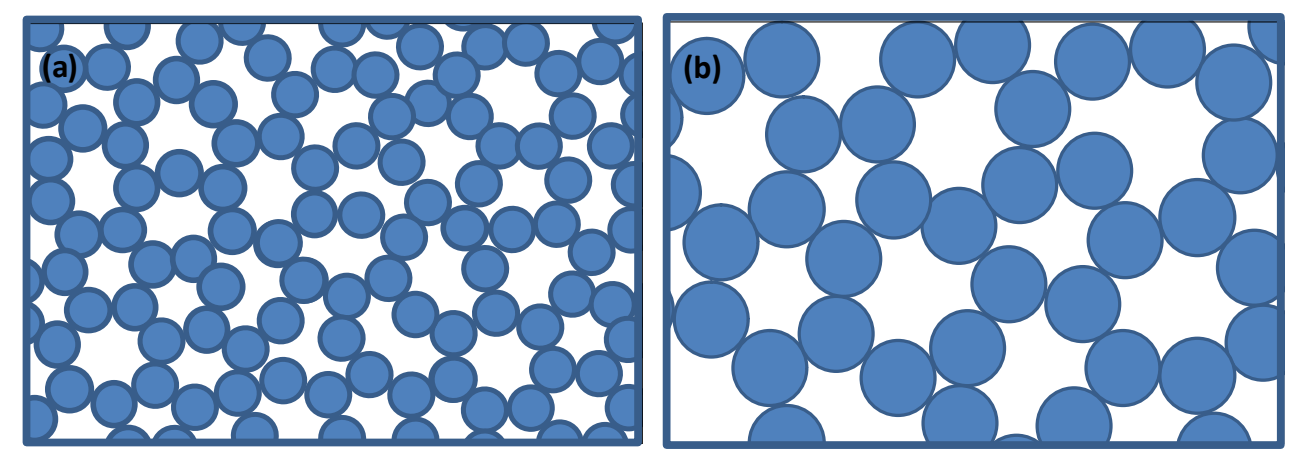

Esquema 4.2. Representación de diferentes materiales obtenidos a través de proceso sol-gel: (a) elevada relación $\mathrm{Si} / \mathrm{F}^{-}$favorece la formación de un mayor número de partículas pero de menor tamaño, generando cavidades microporosas; (b) baja relación $\mathrm{Si} / \mathrm{F}^{-}$favorece la generación de un menor número de partículas de mayor diámetro que dan lugar a cavidades mesoporosas. 
Por lo tanto, considerando los resultados obtenidos, en el caso de incorporar fragmentos orgánicos rígidos en la estructura de los materiales, convendría emplear altas concentraciones de iones $\mathrm{F}^{-}$para favorecer la generación de materiales de mayor accesibilidad, es decir, sólidos mesoporosos.
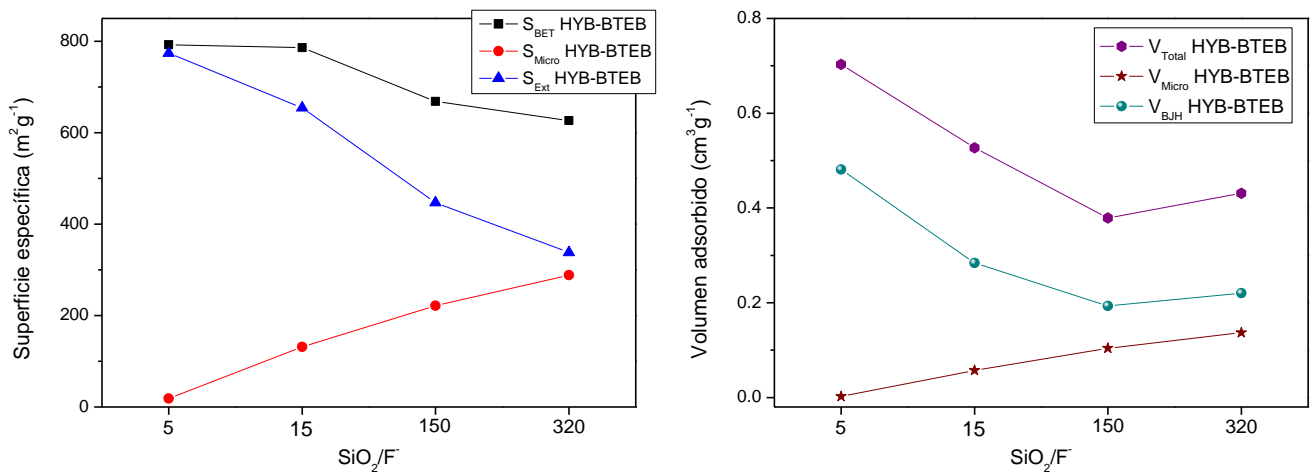

Figura 4.29. Superficie específica y volumen poroso de muestras híbridas preparadas con diferentes relaciones molares $\mathrm{Si} / \mathrm{F}^{-}$, manteniendo la relación $(\mathrm{BTEB} / \mathrm{TMOS})=0.5$.
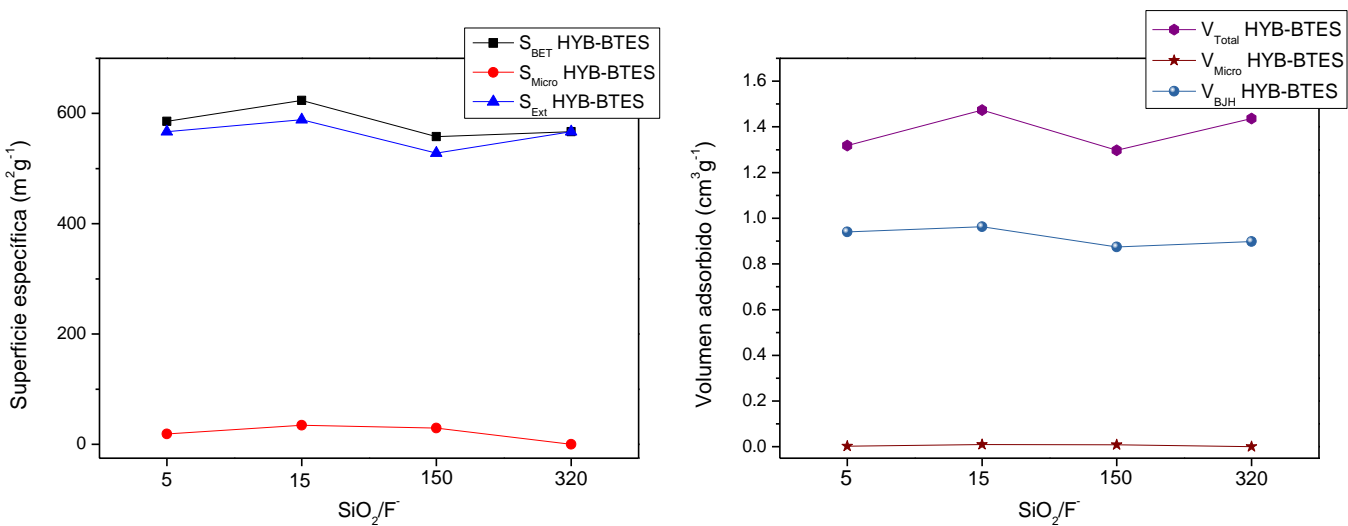

Figura 4.30. Superficie específica y volumen poroso de muestras híbridas preparadas con diferentes relaciones molares $\mathrm{Si} / \mathrm{F}^{-}$, manteniendo la relación $(\mathrm{BTES} / \mathrm{TMOS})=0.5$.

Por el contrario, en el caso de utilizar disilanos con unidades orgánicas más flexibles, como son los grupos propildisulfuro, las propiedades texturales se ven menos influenciadas por la concentración de iones fluoruro presentes en el medio de síntesis. En este caso, los materiales obtenidos son esencialmente mesoporosos con una contribución microporosa prácticamente nula, independientemente de la velocidad de hidrólisis y polimerización del proceso sol-gel. Por lo tanto, al emplear disilanos con puentes 
orgánicos de mayor flexibilidad estructural se deben de formar partículas organosilíceas de elevado diámetro, favoreciendo la generación de cavidades mesoporosas entre las mismas (Figura 4.30.).

\subsubsection{Influencia del disolvente}

Se realizaron distintos experimentos empleando disilanos rígidos (BTEB) o flexibles (BTES), como en los apartados anteriores, en presencia de diferentes disolventes orgánicos tales como metanol (normalmente empleado en este estudio), etanol o 2butanol, para observar la influencia de la polaridad del disolvente utilizado sobre las propiedades texturales de los materiales porosos orgánicos-inorgánicos preparados. Experimentalmente, se comprobó que en el caso de los disolventes más apolares (2butanol), el proceso de gelificación es mucho más lento, teniendo lugar a tiempos superiores a las 24 horas. Por el contrario, al emplear disolventes más polares (metanol o etanol), la hidrólisis y polimerización ocurre de manera casi instantánea, tal y como se ha mostrado a lo largo de este capítulo.

Analizando más en detalle los resultados, se observa como en los materiales en los que se han incorporado fragmentos orgánicos rígidos, tales como anillos bencénicos, las propiedades texturales sufren pocas alteraciones, tendiendo a obtenerse materiales con una superficie algo más reducida cuando se usan disolventes más apolares como el 2butanol. Este comportamiento también se observa para los materiales obtenidos sin emplear disilanos durante el proceso sol-gel, confirmándose de nuevo la similitud existente entre los sólidos puramente silíceos y aquellos que contienen unidades orgánicas rígidas en su estructura (Figura 4.31.).

Por otra parte, en los materiales en los que se pretende incorporar fragmentos flexibles propildisulfuro, la utilización en el medio de síntesis de disolventes apolares, como el 2-butanol, trae como consecuencia la obtención de materiales con una porosidad y accesibilidad muy reducidas (Figura 4.32.), no observándose grandes diferencias en el caso del empleo de disolventes polares. Este resultado muestra que al ralentizar enormemente la velocidad de gelificación, los disilanos más flexibles (BTES) no consiguen 
estructurarse con las unidades silíceas $\left[\mathrm{SiO}_{4}\right]$ en torno a cavidades mesoporosas de manera efectiva, favoreciendo materiales organosilíceos colapsados y sin porosidad. Esto podría explicarse por la mayor dificultad existente para que se produzca el ataque nucleofílico efectivo entre las moléculas de agua y los complejos intermedios fluorosilicato pentavalentes durante el proceso sol-gel (Esquema 4.1.), al emplear como disolventes alcoholes con una mayor cadena hidrocarbonada (2-butanol), siendo este efecto más acusado en el caso de intervenir disilanos de mayor flexibilidad estructural.
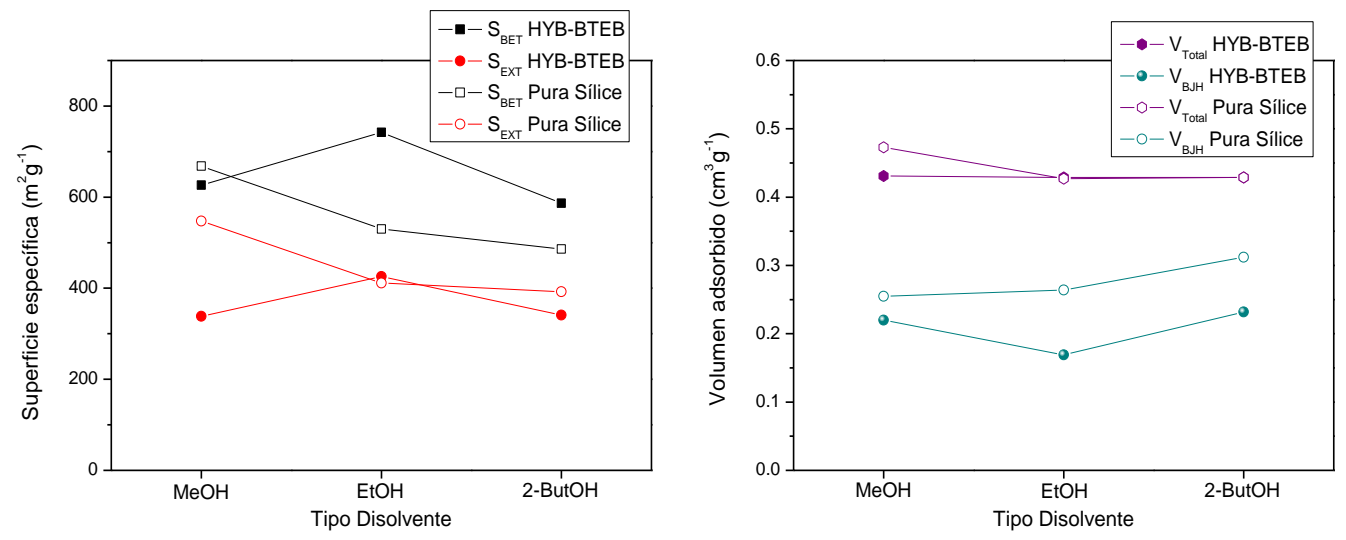

Figura 4.31. Superficie específica y volumen poroso de muestras híbridas obtenidas con diferentes disolventes. $($ Disilano/TMOS $)=0.5$ y $\left(\mathrm{Si} / \mathrm{F}^{-}\right)=319$.
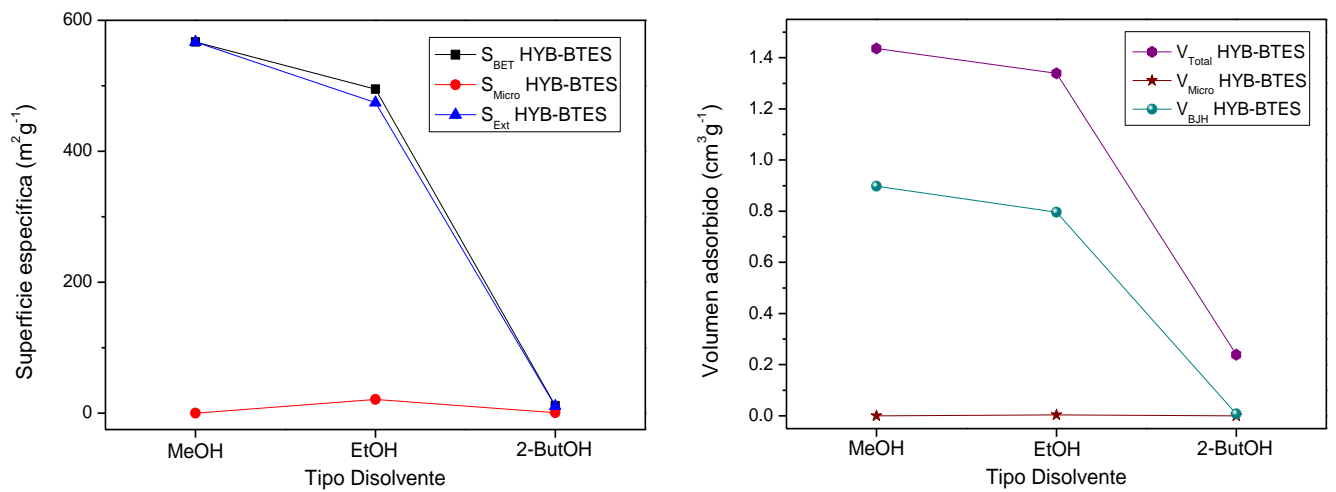

Figura 4.32. Superficie específica y volumen poroso de muestras híbridas preparadas con diferentes disolventes. $($ Disilano/TMOS $)=0.5$ y $\left(\mathrm{Si} / \mathrm{F}^{-}\right)=319$. 


\subsubsection{Influencia de la cantidad de grupos disulfuro. Conversión a grupos sulfónicos}

La obtención de materiales mesoporosos que contengan en su estructura grupos disulfuro, empleando el disilano BTES como precursor organosilíceo, implicaría la generación de sólidos híbridos con centros ácidos debido a la oxidación de dichas unidades disulfuro y su transformación en grupos sulfónicos a través de diferentes etapas post-síntesis, siendo de interés para su utilización como catalizadores ácidos (Figura 4.33. ${ }^{[48]}$. Teniendo en cuenta esta posibilidad, se llevó a cabo la oxidación de diferentes sólidos con cantidades crecientes de unidades disulfuro insertadas en su estructura, analizándose en cada caso el número de grupos sulfónicos convertidos y su accesibilidad, así como las propiedades texturales que presentan tras el proceso post-síntesis realizado (Tabla 4.5.). El procedimiento experimental empleado para llevar a cabo este tratamiento post-sintético se describe en detalle en la sección 4.5.

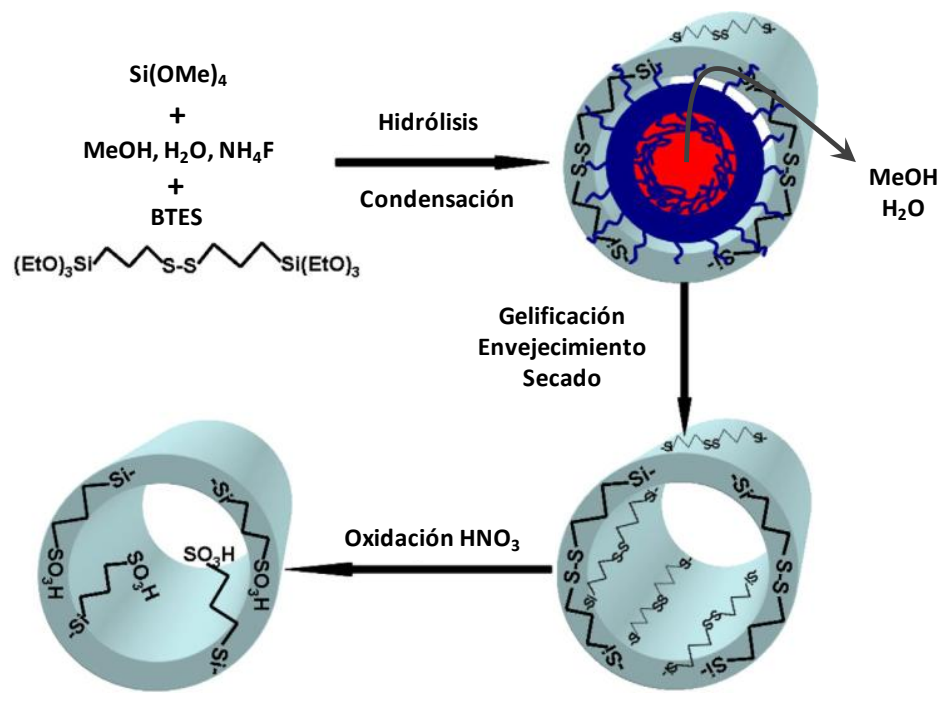

Figura 4.33. Proceso sol-gel y etapa post-síntesis de oxidación para obtener materiales mesoporosos híbridos con grupos sulfónicos.

Los resultados muestran que el proceso de oxidación de los grupos disulfuro a grupos sulfónicos ocurre de manera efectiva, como se puede corroborar a través del espectro de RMN de ${ }^{13} \mathrm{C}$ del material HYB-BTES antes y después de ser sometido a dicha 
oxidación (Figura 4.34.). En los espectros se observa el desplazamiento de la banda asignada a los átomos de carbono unidos a los grupos disulfuro desde 40.9 ppm hasta 53.8 ppm, confirmando claramente la generación de grupos sulfónicos tras el proceso de oxidación. La práctica ausencia de la señal asignada a las unidades -S-S- en el espectro de la muestra $\mathrm{HYB}-\mathrm{SO}_{3} \mathrm{H}$, corrobora la elevada efectividad del proceso post-síntesis para la obtención de grupos sulfónicos.

A través de los datos de análisis elemental se puede observar que, en todos los casos, se produce una pérdida apreciable del contenido en azufre en los materiales al llevar a cabo la etapa de oxidación. Este hecho se debe a las fuertes condiciones ácidas, en presencia de $\mathrm{HNO}_{3}$, que se emplean durante el proceso de oxidación que provoca la extracción parcial de las especies disulfuro y su consiguiente eliminación de las paredes del material. Considerando esta apreciación, se puede estimar que aproximadamente un $70 \%$ de los grupos disulfuro, insertados inicialmente, son transformados en grupos sulfónicos (Tabla 4.5., columnas 3 y 4 ).

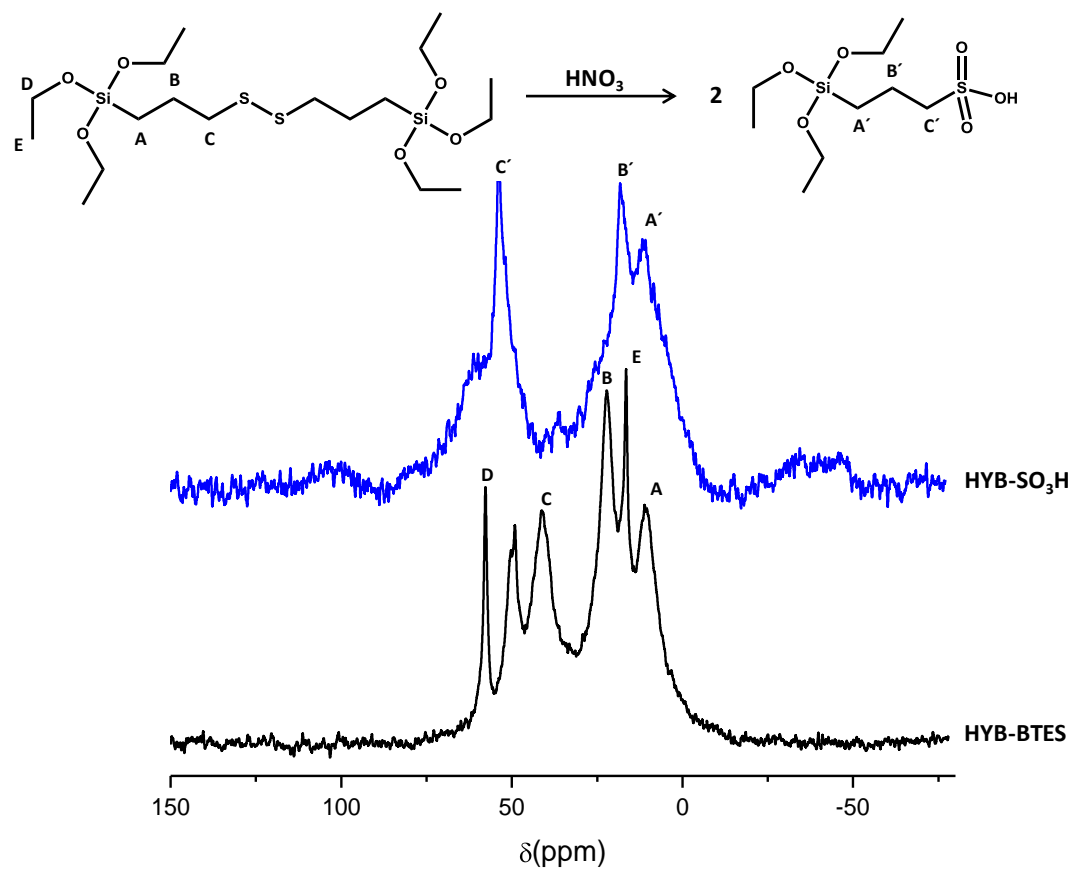

Figura 4.34. Espectros de RMN CP/MAS de ${ }^{13} \mathrm{C}$ del material híbrido con grupos disulfuro antes (HYBBTES) y después de ser sometido a la etapa de oxidación ( $\left.\mathrm{HYB}-\mathrm{SO}_{3} \mathrm{H}\right)$. 
Tabla 4.5. Contenido en grupos disulfuro y sulfónicos de diferentes materiales mesoporosos obtenidos a partir de BTES. Grado de accesibilidad a los centros ácidos y comparación con su superficie específica.

\begin{tabular}{|c|c|c|c|c|c|c|c|c|}
\hline \multirow{2}{*}{ BTES/TMOS } & \multirow{2}{*}{$\mathrm{Si} / \mathrm{F}^{-}$} & \multicolumn{2}{|c|}{$\% S^{a}$} & \multicolumn{2}{|c|}{$\mathrm{mmol} \mathrm{H}^{+} \mathrm{g}^{-1 \mathrm{~b}}$} & \multicolumn{2}{|c|}{$S_{\text {BET }}\left(m^{2} g^{-1}\right)^{c}$} & \multirow{2}{*}{$\begin{array}{c}\% A c c e s . \\
-\mathrm{SO}_{3} \mathrm{H}^{\mathrm{d}}\end{array}$} \\
\hline & & (S-S) & $\left(\mathrm{SO}_{3} \mathrm{H}\right)$ & Teor & Exp & (S-S) & $\left(\mathrm{SO}_{3} \mathrm{H}\right)$ & \\
\hline 0.05 & & 2.5 & 1.6 & 0.50 & 0.38 & 664.9 & 560.7 & 76.0 \\
\hline 0.10 & & 4.4 & 3.6 & 1.12 & 0.66 & 618.9 & 467.2 & 58.9 \\
\hline & 320 & & & & & & & \\
\hline 0.25 & & 8.2 & 5.7 & 1.78 & 0.77 & 537.0 & 292.7 & 43.3 \\
\hline 0.50 & & 11.8 & 8.3 & 2.59 & 0.45 & 567.0 & 225.4 & 17.4 \\
\hline
\end{tabular}

Por otra parte, la apertura de las unidades tipo disulfuro a través del proceso de oxidación trae como consecuencia una reducción apreciable de la superficie específica de los materiales, siendo esta tendencia más acusada cuando el contenido de grupos disulfuro en los materiales es más elevado (Tabla 4.5, columnas 7 y 8). Este comportamiento se explica por el colapsamiento que sufre el material tras la apertura de los grupos disulfuro a sulfónicos, constatándose de este modo el papel estructural que tienen los fragmentos orgánicos insertados, ya que su modificación lleva implícita la modificación y/o eliminación parcial de sus cavidades por el colapso parcial producido en su estructura porosa. Esta alteración en su estructura conlleva que una parte de los grupos sulfónicos generados queden bloqueados en el interior de la red organosilícea, siendo imposible detectarlos a través de valoraciones ácido-base convencionales. Obviamente, en el caso de sólidos con un elevado número de grupos disulfuro iniciales, tras el proceso de oxidación, el colapso estructural producido es mucho más pronunciado, siendo muy elevado el número de grupos sulfónicos que resultan inaccesibles. Este efecto se minimiza en el caso de materiales con un menor número de grupos disulfuro (Tabla 4.5., columnas $5,6$ y 9$)$ 


\subsubsection{Actividad catalítica}

El potencial de los materiales mesoporosos híbridos, preparados a través de procesos sol-gel en medio fluoruro, como catalizadores se confirmó al emplear los sólidos que contienen grupos etilendiamino en su estructura, HYB-BTMN, en procesos catalíticos que necesitan centros activos básicos para poderse llevar a cabo, como es el caso de la condensación de Knoevenagel. Este proceso está basado en la condensación de compuestos carbonílicos con grupos metilénicos activos con el fin de obtener alquenos derivados sustituidos. Estos compuestos son de interés en procesos de química fina para la generación de productos o intermedios de alto valor añadido en farmacología, perfumes o alimentación ${ }^{[49]}$. La condensación de Knoevenagel puede ser catalizada por centros básicos, siendo la cinética descrita para este proceso de primer orden con respecto al catalizador y cada uno de los reactantes ${ }^{[50]}$.

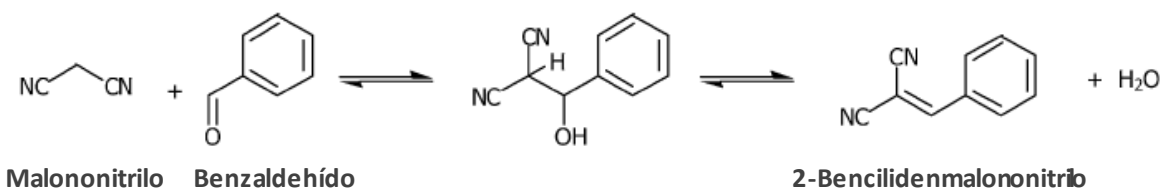

Esquema 4.3. Condensación de Knoevenagel entre benzaldehído y malononitrilo.

En este estudio se ha realizado la condensación de Knoevenagel entre el benzaldehído y el malononitrilo a temperatura ambiente (Esquema 4.3.), empleando el material HYB-BTMN que contiene grupos diamino como catalizador. Los resultados cinéticos (Figura 4.35.) muestran que en presencia de este material híbrido mesoporoso se obtiene un rendimiento del 95.4\% del producto de la reacción, 2-bencilidenmalononitrilo, tras 15 horas de reacción, siendo la selectividad a este compuesto del $100 \%$.

Con el fin de estudiar la desactivación y reutilización del catalizador, éste fue reciclado y reutilizado cinco veces. Para ello, el material fue filtrado después de cada ciclo catalítico, lavado con agua y acetonitrilo y, finalmente, secado 12 horas a $60^{\circ} \mathrm{C}$. En la Figura 4.35. se observa que el catalizador HYB-BTMN puede ser reutilizado durante cinco 
ciclos reactivos sucesivos sin que se aprecie prácticamente pérdida de actividad respecto a su primer uso, siendo el rendimiento aproximadamente el mismo en cada ciclo de reacción. Como se observa, se obtienen altos rendimientos al producto de reacción en todos los casos.

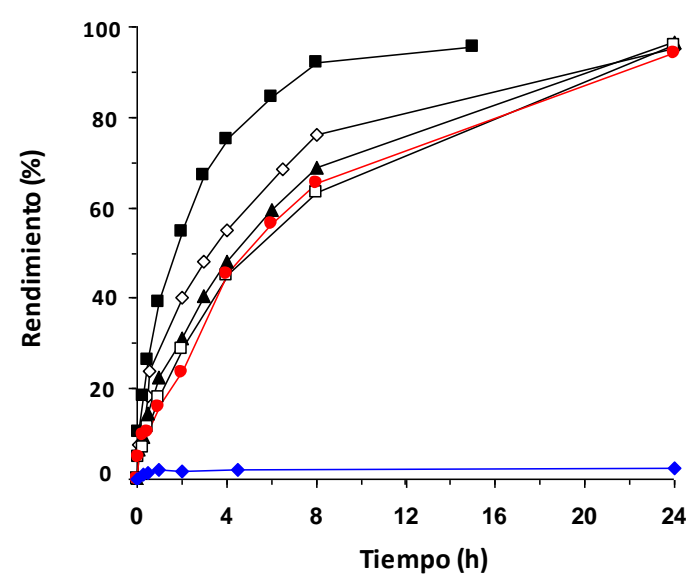

Figura 4.35. Resultados de la actividad catalítica del material híbrido HYB-BTMN en la reacción de Knoevenagel entre benzaldehído y malononitrilo; rendimiento de 2-bencilidenmalononitrilo para el primer ciclo $\square, 2^{\circ}$ ciclo $\diamond, 3^{\text {er }}$ ciclo $\boldsymbol{\Delta}, 4^{\circ}$ ciclo $\bullet$ y $5^{\circ}$ ciclo $\square$, Blanco $\bullet$. Condiciones de reacción: benzaldehído ( $51.9 \mathrm{mmol})$, malononitrilo $(48.5 \mathrm{mmol}), 6.5 \mathrm{~mL}$ de acetonitrilo, $298 \mathrm{~K}$, atmósfera de nitrógeno y $0.85 \% \mathrm{~mol}$ de $\mathrm{N}$ en el catalizador.

Por otra parte, la desactivación del catalizador, la cual se detecta a tiempos de reacción más prolongados, se podría deber, probablemente, a la adsorción sobre el catalizador de los propios compuestos orgánicos utilizados o producidos durante el proceso reactivo. Los resultados de análisis elemental $(\mathrm{C}, \mathrm{H}$ y $\mathrm{N}$ ) realizados sobre el catalizador después del primer ciclo de reacción, tras ser lavado y secado, muestran la presencia de aproximadamente un $5 \%$ en peso de compuestos orgánicos, provenientes de la reacción catalítica, los cuales permanecen adsorbidos sobre el mismo provocando su parcial desactivación. En cualquier caso, los resultados catalíticos reflejan que los materiales porosos orgánicos-inorgánicos aquí estudiados podrían ser empleados de manera satisfactoria como catalizadores heterogéneos en diferentes procesos reactivos. 


\subsection{Conclusiones}

- A lo largo de este capítulo se ha confirmado que las rutas de síntesis basadas en procesos sol-gel catalizados por iones fluoruro son válidas para preparar materiales mesoporosos orgánicos-inorgánicos, sin orden a largo alcance, en ausencia de agentes directores de estructura y en condiciones suaves de síntesis, es decir, a temperatura próxima a la ambiente y con pHs cercanos a la neutralidad.

- Se han conseguido preparar y caracterizar diferentes materiales híbridos mesoporosos que contienen, insertados covalentemente en su estructura, fragmentos orgánicos tales como arilos, disulfuro, diamino, etano y etileno, presentando características texturales y físico-químicas propias de materiales mesoporosos. Los sólidos sintetizados contienen entre un $10 \%$ y un $30 \%$ en peso de contenido orgánico insertado en su estructura, covalentemente enlazado a unidades tetraédricas de silicio $\left[\mathrm{SiO}_{4}\right]$, tal y como se ha confirmado a través de diferentes técnicas de caracterización (IR, Raman, RMN).

- En función de si el disilano empleado como precursor posee fragmentos orgánicos rígidos o flexibles, los materiales híbridos mesoporosos presentan alteraciones sustanciales en su porosidad. Así, en el caso de unidades orgánicas rígidas, tales como grupos bencénicos, los sólidos presentan una elevada contribución microporosa con diámetros de poro que oscilan alrededor de $30 \AA$. . Por el contrario, los materiales con unidades más flexibles a nivel estructural, tales como grupos propildisulfuro, presentan una superficie completamente mesoporosa, con ausencia de microporos, exhibiendo una mayor accesibilidad con diámetros de poro de aproximadamente 65 A.

- Se ha comprobado que existe un límite de incorporación de fragmentos orgánicos a nivel estructural, produciéndose por encima del mismo el colapsamiento de la estructura porosa de los materiales. En el caso de las unidades rígidas, se obtienen materiales porosos hasta prácticamente una relación molar (Disilano/TMOS) de aproximadamente 2.0. Sin embargo, cuando se han introducido unidades flexibles 
únicamente se obtienen materiales porosos cuando dicha relación molar es inferior a 0.5 .

- La cantidad de iones fluoruro que intervienen en el proceso sol-gel influyen enormemente no sólo en la velocidad de hidrólisis y polimerización, sino también en las propiedades texturales de los materiales híbridos obtenidos. Así, en el caso de los sólidos con unidades orgánicas rígidas en su estructura, se constata que a mayor concentración de iones $\mathrm{F}^{-}$la superficie mesoporosa de los sólidos aumenta apreciablemente, disminuyendo la contribución microporosa. En el caso de sólidos con unidades más flexibles en sus paredes, sus propiedades texturales se ven menos influenciadas por la cantidad de iones $\mathrm{F}^{-}$presentes en el medio de síntesis. Ambos fenómenos se explican por la influencia que tienen los iones $F^{-}$en el tamaño y cantidad de núcleos organosilíceos que se forman en el gel de síntesis.

- El empleo de disolventes más apolares trae consigo la generación de sólidos con porosidad más reducida, siendo este efecto más apreciable en los materiales híbridos que contienen unidades flexibles en su estructura. Este hecho está relacionado con la ralentización que se produce en el medio de síntesis al emplear disolventes menos polares que dificultan la etapa de gelificación.

- En general, las diferentes variables estudiadas muestran que los materiales híbridos que contienen unidades orgánicas rígidas presentan unas propiedades texturales y un comportamiento similares a los sólidos obtenidos sin disilanos, lo cual implica que, en estos casos, existe una menor alteración en el proceso de estructuración por la presencia de unidades orgánicas comparado con los materiales puramente silíceos.

- Es posible transformar la mayoría de grupos disulfuro ( 70\%) presentes en la estructura de los materiales mesoporosos en grupos sulfónicos tras un proceso postsíntesis de oxidación. Este proceso favorece la formación de materiales con gran número de centros ácidos de elevada fuerza. No obstante, cuando la cantidad de grupos disulfuro presente es muy elevada, su oxidación implica una alteración sustancial en la organización estructural de los materiales favoreciendo su colapsamiento. 
- La potencialidad de estos materiales como catalizadores queda demostrada por las altas conversiones y selectividades alcanzadas por los materiales con grupos diamino (HYB-BTMN), insertados en su estructura, en reacciones de condensación donde son necesarios centros básicos accesibles. Los diferentes reciclos muestran que los sólidos son estables, manteniendo su actividad catalítica tras sucesivas reutilizaciones.

\subsection{Experimental}

4.5.1. Síntesis de materiales híbridos porosos a través de métodos sol-gel en medio fluoruro

\section{HYB-Disilano}

Se han obtenido materiales híbridos porosos orgánicos-inorgánicos no ordenados a partir de una mezcla inicial de tetrametoxisilano (TMOS, 98\%, Aldrich) como precursor de silicio y cantidades apropiadas de disilano, $\left(\mathrm{R}^{\prime} \mathrm{O}\right)_{3} \mathrm{Si}-\mathrm{R}-\mathrm{Si}\left(\mathrm{OR}^{\prime}\right)_{3}$, usando metanol $(\mathrm{MeOH}$, 99.8\%, Scharlau) como disolvente. Los disilanos empleados fueron 1,4bis(trietoxisilil)benceno (BTEB, 96\%, Aldrich), bis(trietoxisililpropil)disulfuro (BTES, 90\%, $A B C R$ ), bis(3-trimetoxisililpropil)etilendiamina (BTMN, 95\%, $A B C R$ ), bis(trietoxisilil)etileno (BTEEthy, 97\%, ABCR) y bis(trietoxisilil)etano (BTEE, 95\%, ABCR). Una vez disueltos los precursores, se añadió una disolución acuosa de $\mathrm{NH}_{4} \mathrm{~F}$ (98\%, Aldrich) bajo agitación vigorosa. La mezcla final de síntesis tiene la siguiente composición molar:

$$
1 \mathrm{SiO}_{2}\left[(1-x) \text { TMOS + } x \text { Disilano]: } 4 \mathrm{MeOH}: 4 \mathrm{H}_{2} \mathrm{O}: 0.00313 \mathrm{NH}_{4} \mathrm{~F}\right.
$$

donde las relaciones Si/ $\mathrm{NH}_{4} \mathrm{~F}$ y Disilano/TMOS son 319 y 0.5, respectivamente. La hidrólisis y condenación se llevó a cabo bajo agitación a temperatura ambiente hasta que tuvo lugar la gelificación. Después, el gel se envejeció durante 24 horas a $36^{\circ} \mathrm{C}$ y, finalmente, fue sacado a $150^{\circ} \mathrm{C}$ durante otras 24 horas. En los disilanos, $\mathrm{R}$ corresponde a benceno, disulfuro, diamino, etano y etileno y $\mathrm{R}^{\prime}$ son grupos alquilo (etilo o metilo). Los materiales híbridos preparados fueron denotados como HYB-BTEB, HYB-BTES, HYB-BTMN, HYBBTEE, HYB-BTEEthy, en función del disilano utilizado en su preparación (Figura 4.15.). 


\section{$\mathrm{HYB}-\mathrm{SO}_{3} \mathrm{H}$}

El catalizador híbrido que posee grupos sulfónicos, $\mathrm{HYB}-\mathrm{SO}_{3} \mathrm{H}$, se ha obtenido a partir de la oxidación directa en un sólo paso del material mesoporoso con grupos disulfuros, HYB-BTES. En primer lugar se introduce $1 \mathrm{~g}$ de HYB-BTES en un matraz de fondo plano, al que se le incorpora un imán, a continuación, con agitación suave, se humedece el sólido con una disolución acuosa de $\mathrm{HNO}_{3}$ (20 \% en peso) añadida gota a gota, hasta obtener una mezcla homogénea. Seguidamente, se añaden $20 \mathrm{~g}$ de $\mathrm{HNO}_{3}$ concentrado, muy lentamente, en este paso se observa el desprendimiento de vapores, por ello se lleva a cabo este proceso en campana. La mezcla resultante de esta última adición se mantiene en agitación a temperatura ambiente durante 24 horas. Transcurrido ese tiempo, se añaden a la mezcla de reacción $20 \mathrm{~mL}$ de $\mathrm{H}_{2} \mathrm{O}$ milliQ, manteniendo la agitación durante varios minutos. Finalmente la mezcla es filtrada y lavada con abundante $\mathrm{H}_{2} \mathrm{O}$ destilada, hasta alcanzar un $\mathrm{pH}$ en las aguas de lavado igual a 7. El sólido final es secado a $60^{\circ} \mathrm{C}$ durante 12 horas.

El material seco una vez caracterizado mediante diferentes técnicas es sometido a una valoración ácido-base para estimar el porcentaje de centros ácidos $\left(-\mathrm{SO}_{3} \mathrm{H}\right)$ accesibles, estando este procedimiento descrito en la parte experimental 3.6.3.1 del Capítulo 3.

\subsubsection{Experimentos catalíticos}

La reacción de Knoevenagel se realizó como se detalla a continuación:

En un reactor de vidrio, bajo atmósfera de $\mathrm{N}_{2}$ y a $25^{\circ} \mathrm{C}$, se introdujo una mezcla de benzaldehído (51.9 mmol), malononitrilo $(48.5 \mathrm{mmol})$ y $6.5 \mathrm{~mL}$ de acetonitrilo, como disolvente, sometiéndose a agitación magnética. Entonces se añadió el catalizador híbrido con $0.85 \% \mathrm{~mol}$ de $\mathrm{N}$ con respecto a la suma de benzaldehído y malononitrilo. El avance de la reacción se siguió en el tiempo, tomando muestras a intervalos desde 0.1 hasta 24 horas. Los productos fueron analizados por cromatografía de gases (GC) y gases masas (GC-MS) utilizando una columna Equity-5 (30 $\mathrm{m} \times 0.25 \times 0.25 \mu \mathrm{m})$ y un detector tipo FID. 
En las pruebas realizadas para evaluar la reutilización del catalizador, éste fue filtrado y lavado con agua y acetonitrilo, después de su uso, y por último secado a $60^{\circ} \mathrm{C}$ durante 12 horas. El catalizador reciclado se usó en un nuevo ciclo catalítico, repitiendo el proceso durante sucesivos ciclos. 


\section{Referencias bibliográficas}

[1] E. A. Quadrelli, J. M. Basset, Coord. Chem. Rev. 2010, 254, 767.

[2] F. Hoffmann, M. Cornelius, J. Morell, M. Fröba, Angewandte Chemie International Edition 2006, 45, 3216.

[3] K. Yamamoto, T. Tatsumi, Chemistry of Materials 2007, 20, 972.

[4] a)J. M. Notestein, A. Katz, Chemistry - A European Journal 2006, 12, 3954; b)E. L. Margelefsky, R. K. Zeidan, M. E. Davis, Chemical Society Reviews 2008, 37, 1118; c)K. Motokura, M. Tada, Y. Iwasawa, Angewandte Chemie International Edition 2008, 47, 9230.

[5] G. Cerveau, R. J. P. Corriu, B. Dabiens, J. Le Bideau, Angewandte Chemie International Edition 2000, 39, 4533.

[6] K. J. Shea, D. A. Loy, O. Webster, Journal of the American Chemical Society 1992, 114, 6700 .

[7] a)U. Damrau, H. C. Marsmann, Journal of Non-Crystalline Solids 1994, 168, 42; b)N. K. Raman, T. L. Ward, C. J. Brinker, R. Sehgal, D. M. Smith, Z. Duan, M. Hampden-Smith, J. K. Bailey, T. J. Headley, Applied Catalysis A: General 1993, 96, 65.

[8] R. J. P. Corriu, A. Mehdi, C. Reyé, C. Thieuleux, Chemistry of Materials 2003, 16, 159.

[9] J. Alauzun, A. Mehdi, R. Mouawia, C. Reyé, R. Corriu, Journal of Sol-Gel Science and Technology 2008, 46, 383.

[10] a)J. J. E. Moreau, B. P. Pichon, M. Wong Chi Man, C. Bied, H. Pritzkow, J.-L. Bantignies, P. Dieudonné, J.-L. Sauvajol, Angewandte Chemie International Edition 2004, 43, 203; b)J. J. E. Moreau, L. Vellutini, M. Wong Chi Man, C. Bied, Journal of the American Chemical Society 2001, 123, 1509.

[11] I. Karatchevtseva, D. J. Cassidy, M. Wong Chi Man, D. R. G. Mitchell, J. V. Hanna, C. Carcel, C. Bied, J. J. E. Moreau, J. R. Bartlett, Advanced Functional Materials 2007, 17, 3926.

[12] G. Bellussi, A. Carati, E. Di Paola, R. Millini, W. O. N. Parker Jr, C. Rizzo, S. Zanardi, Microporous and Mesoporous Materials 2008, 113, 252.

[13] C. Kresge, M. Leonowicz, W. Roth, C. Vartuli, S. Beck, Nature 1992, 359, 710.

[14] S. Huh, H.-T. Chen, J. W. Wiench, M. Pruski, V. S. Y. Lin, Journal of the American Chemical Society 2004, 126, 1010. 
[15] C. González-Arellano, A. Corma, M. Iglesias, F. Sánchez, Advanced Synthesis \& Catalysis 2004, 346, 1758.

[16] S. Inagaki, S. Guan, Y. Fukushima, T. Ohsuna, O. Terasaki, Journal of the American Chemical Society 1999, 121, 9611.

[17] T. Asefa, M. J. MacLachlan, N. Coombs, G. A. Ozin, Nature 1999, 402, 867.

[18] B. J. Melde, B. T. Holland, C. F. Blanford, A. Stein, Chemistry of Materials 1999, 11, 3302.

[19] Q. Yang, M. P. Kapoor, S. Inagaki, Journal of the American Chemical Society 2002, 124, 9694.

[20] Q. Yang, J. Liu, J. Yang, M. P. Kapoor, S. Inagaki, C. Li, Journal of Catalysis 2004, 228, 265.

[21] S. Inagaki, S. Guan, T. Ohsuna, O. Terasaki, Nature 2002, 416, 304.

[22] A. Corma, Cat. Rev. 2004, 46, 369.

[23] M. P. Kapoor, Q. Yang, Y. Goto, S. Inagaki, Chemistry Letters 2003, 32, 914.

[24] M. C. Burleigh, M. A. Markowitz, M. S. Spector, B. P. Gaber, The Journal of Physical Chemistry B 2001, 105, 9935.

[25] A. Fukuoka, T. Higuchi, T. Ohtake, T. Oshio, J.-i. Kimura, Y. Sakamoto, N. Shimomura, S. Inagaki, M. Ichikawa, Chemistry of Materials 2005, 18, 337.

[26] C. Baleizao, B. Gigante, D. Das, M. Alvaro, H. Garcia, A. Corma, Chemical Communications 2003, 1860.

[27] T. Asefa, M. Kruk, M. J. MacLachlan, N. Coombs, H. Grondey, M. Jaroniec, G. A. Ozin, Journal of the American Chemical Society 2001, 123, 8520.

[28] J. Morell, M. Gungerich, G. Wolter, J. Jiao, M. Hunger, P. J. Klar, M. Froba, Journal of Materials Chemistry 2006, 16, 2809.

[29] O. Olkhovyk, S. Pikus, M. Jaroniec, Journal of Materials Chemistry 2005, 15, 1517.

[30] T. P. Nguyen, P. Hesemann, P. Gaveau, J. J. E. Moreau, Journal of Materials Chemistry 2009, 19, 4164.

[31] J. Alauzun, A. Mehdi, C. Reyé, R. J. P. Corriu, Journal of the American Chemical Society 2006, 128, 8718.

[32] S. Shylesh, A. Wagener, A. Seifert, S. Ernst, W. R. Thiel, Angewandte Chemie International Edition 2010, 49, 184. 
[33] a)C. W. Jones, K. Tsuji, M. E. Davis, Nature 1998, 393, 52; b)K. Tsuji, C. W. Jones, M. E. Davis, Microporous and Mesoporous Materials 1999, 29, 339; c)C. W. Jones, K. Tsuji, M. E. Davis, Microporous and Mesoporous Materials 1999, 33, 223; d)C. W. Jones, M. Tsapatsis, T. Okubo, M. E. Davis, Microporous and Mesoporous Materials 2001, 42, 21.

[34] a)K. Yamamoto, Y. Sakata, Y. Nohara, Y. Takahashi, T. Tatsumi, Science 2003, 300, 470; b)K. Yamamoto, Y. Takahashi, T. Tatsumi, in Studies in Surface Science and Catalysis, Vol. Volume 135 (Eds.: F. F. F. D. R. A. Galarneau, J. Vedrine), Elsevier, 2001, p. 299.

[35] K. Yamamoto, Y. Nohara, Y. Domon, Y. Takahashi, Y. Sakata, J. Plévert, T. Tatsumi, Chemistry of Materials 2005, 17, 3913.

[36] U. Díaz, J. A. Vidal-Moya, A. Corma, Microporous and Mesoporous Materials 2006, 93, 180.

[37] R. Winter, J. B. Chan, R. Frattini, J. Jonas, Journal of Non-Crystalline Solids 1988, 105, 214.

[38] E. J. A. Pope, J. D. Mackenzie, Journal of Non-Crystalline Solids 1986, 87, 185.

[39] S. Bracegirdle, E. A. Anderson, Chemical Communications 2010, 46, 3454.

[40] L. P. Davis, L. W. Burggraf, Mat. Res. Soc. Proc. 1986, 73, 529.

[41] E. Lindner, M. Kemmler, H. A. Mayer, P. Wegner, Journal of the American Chemical Society 1994, 116, 348.

[42] F. Hoffmann, M. Güngerich, P. J. Klar, M. Fröba, The Journal of Physical Chemistry C 2007, 111, 5648.

[43] E. Poli, E. Merino, U. Diaz, D. Brunel, A. Corma, Journal of Materials Chemistry 2011, 21, 8524.

[44] A. Corma, M. T. Navarro, F. Rey, Chemical Communications 1998, 1899.

[45] E. P. Barrett, L. G. Joyner, P. P. Halenda, Journal of the American Chemical Society 1951, 73, 373.

[46] S. S. Kim, A. Karkamkar, T. J. Pinnavaia, M. Kruk, M. Jaroniec, The Journal of Physical Chemistry B 2001, 105, 7663.

[47] a)E. M. Rabinovich, D. L. Wood, Mater. Res. Soc. Symp. Proc. 1986, 73, 251; b)D. M. Krol, E. M. Rabinovich, Journal of Non-Crystalline Solids 1986, 82,143 ; c)K. Nassau, E. M. Rabinovich, A. E. Miller, P. K. Gallagher, Journal of Non-Crystalline Solids 1986, 82, 78; d)D. L. Wood, E. M. Rabinovich, Journal of Non-Crystalline Solids 1986, 82, 171. 
[48] a)J. Liu, J. Yang, Q. Yang, G. Wang, Y. Li, Advanced Functional Materials 2005, 15, 1297; b)C. Li, J. Liu, L. Zhang, J. Yang, Q. Yang, Microporous and Mesoporous Materials 2008, 113, 333.

[49] a)I. Rodriguez, S. Iborra, F. Rey, A. Corma, Applied Catalysis A: General 2000, 194-195, 241; b)M. J. Climent, A. Corma, S. Iborra, K. Epping, A. Velty, Journal of Catalysis 2004, 225, 316.

[50] a)F. S. Proust, U. D. Beaucaire, G. R. Dyrkarcz, W. M. Koppes, R. E. Kuznicki, T. A. Marlewski, J. A. Pienkowski, J. M. Puda, J. Org. Chem 1973, 38, 1512; b)G. Jones, Org. React. 1967, 15, 204; c)J. Guyot, A. Kergomard, Tetrahedron 1983, 39, 1167. 


\section{Capítulo 5}

\section{MATERIALES HÍBRIDOS}

\section{MESOPOROSOS}

\section{DERIVADOS DE SILANOS}

\section{POLIÉDRICOS (POSS)}

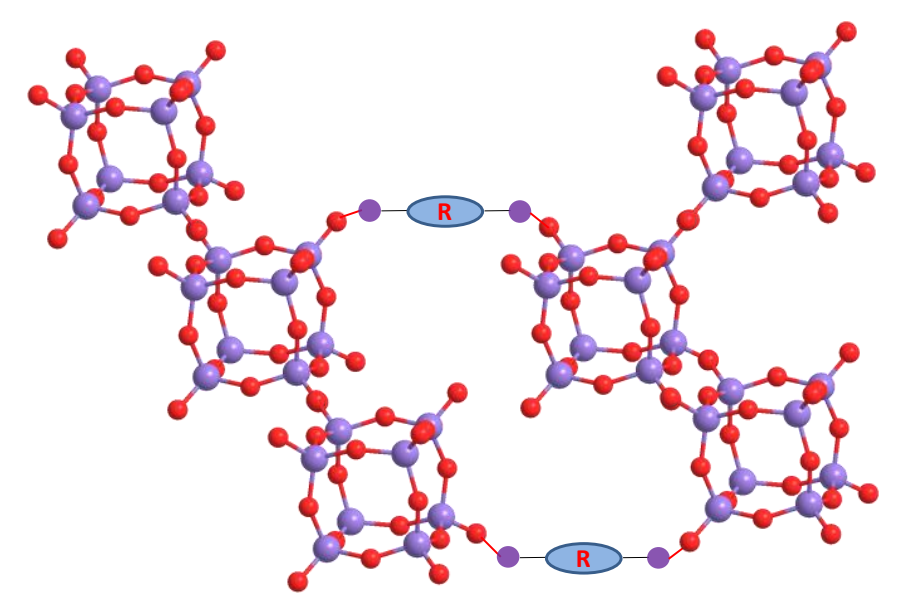



A lo largo del trabajo hasta aquí presentado, se ha mostrado cómo las moléculas de disilanos pueden ser empleadas de manera efectiva como unidades estructurales para la generación de materiales híbridos porosos. En un caso actuando como pilares que se insertan entre láminas silíceas para generar nuevas familias de sólidos laminares orgánicos-inorgánicos y, en un segundo caso, incorporados en las paredes de materiales mesoporosos obtenidos a través de procesos sol-gel. En ambas familias de sólidos, los fragmentos orgánicos e inorgánicos se encuentran covalentemente enlazados entre sí, sin que haya una separación entre las diferentes fases que los componen, presentando las propiedades físico-químicas tanto de las unidades orgánicas como de las inorgánicas.

La posibilidad de generar materiales híbridos de Clase II, como los hasta ahora estudiados, por la combinación directa de diferentes unidades de estructura que se ensamblan entre sí para formar el material final, ya se ha considerado durante la preparación de los sólidos híbridos pilareados, en los que disilanos y láminas silíceas actúan como unidades individuales de estructura. Sin embargo, en este caso, son necesarias etapas post-síntesis de hinchamiento y pilarización de precursores laminares previamente obtenidos. Algo que se pretende superar en el estudio que aquí se plantea, donde dos tipos de unidades estructurales, disilanos y silanos poliédricos (POSS), se ensamblarían de manera covalente, directamente durante el proceso de síntesis, con el objetivo de generar materiales híbridos funcionales de elevada accesibilidad que constituirían una nueva familia de sólidos estructurados de naturaleza mesoporosa. 


\subsection{Estado del arte: Silanos Poliédricos (POSS) y materiales derivados}

Dentro de la familia de los silsesquioxanos, además de los disilanos previamente considerados, destaca la presencia de especies oligoméricas poliédricas denominadas genéricamente POSS (Polyhedral Oligomeric Silsesquioxanes). La topología intrínseca de estas especies silíceas las convierte, a priori, en idóneas para generar materiales estructurados al emplearse como unidades básicas de estructura. En la Figura 5.1. se muestran algunos ejemplos de unidades tipo POSS, en las cuales se aprecia su geometría característica constituida por pequeñas cajas delimitadas, por ejemplo, por dobles anillos de cuatro miembros (D4R), $T_{8}$ - POSS, similares a las unidades secundarias de estructura presentes en el entramado de algunas zeolitas cristalinas descritas en la bibliografía ${ }^{[1]}$.
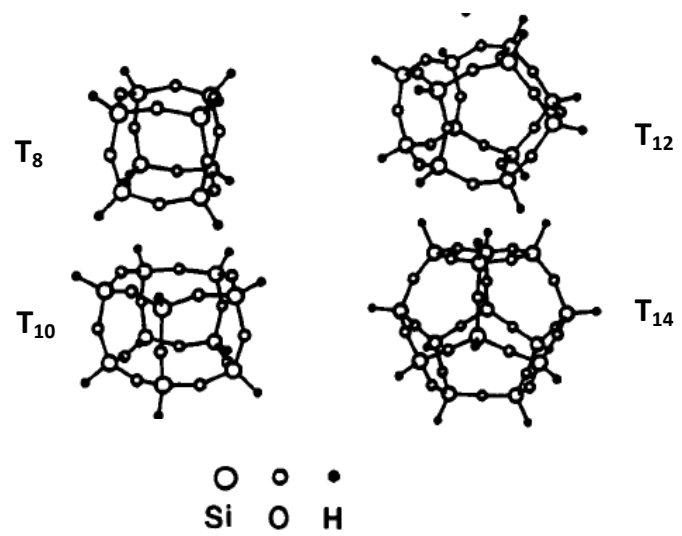

Si $0 \mathrm{H}$

Figura 5.1. Estructuras de diferentes unidades tipo POSS.

Este tipo de siloxanos poliédricos suele obtenerse utilizando trialcoxisilanos a través de procesos de hidrólisis (ácida o básica) y condensación, en presencia de disolventes no nuleofílicos. Alternativamente, también pueden emplearse rutas de síntesis en medio fluoruro, utilizando disolventes apróticos para la preparación de POSS con elevados rendimientos. Durante el proceso de obtención, es posible incorporar sustituyentes orgánicos 0 , incluso, especies metálicas en los vértices de estos siloxanos poliédricos (Figura 5.2.), generándose unidades orgánicas-inorgánicas que podrían ser integradas, como monómeros, en la formación de polímeros o nanocomposites ${ }^{[2]}$. 


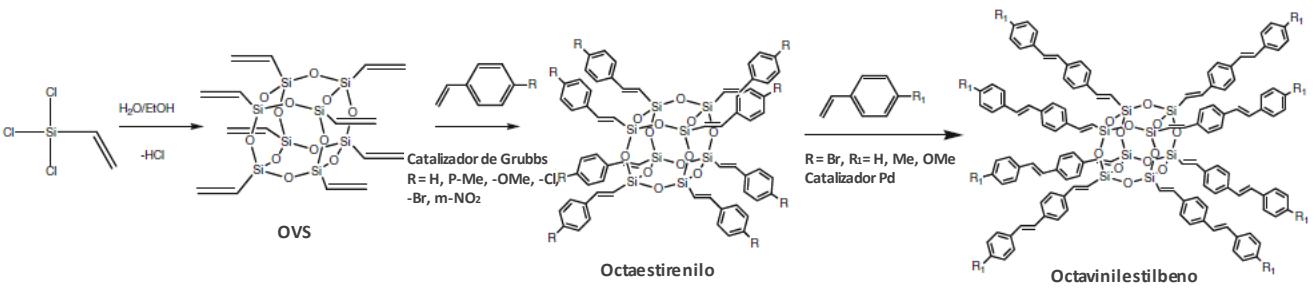

Figura 5.2. Ejemplo de preparación de unidades POSS funcionalizadas en sus vértices.

Por otra parte, existe la posibilidad de obtener POSS que no estén completamente condensados, siendo posible diferenciar los distintos vértices que se combinan en la misma unidad poliédrica, los cuales presentan grupos silanoles terminales altamente reactivos. A través de procesos post-síntesis de anclaje, se ha logrado introducir, en dichos vértices no condensados, diferentes tipos de monosilanos o complejos organometálicos, generándose POSS funcionalizados que presentan centros activos que cuelgan de las unidades poliédricas (Figura 5.3. $)^{[3]}$.

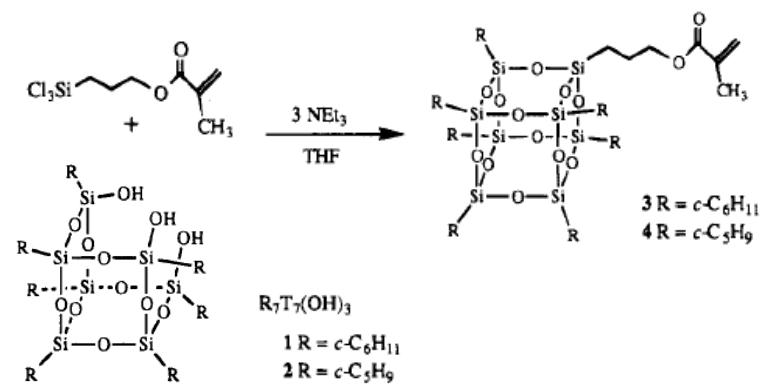

Figura 5.3. Ejemplo de POSS funcionalizado obtenido por un proceso de anclaje post-síntesis a través de los grupos $\mathrm{Si}-\mathrm{OH}$ presentes en los vértices no condensados del poliedro.

Tradicionalmente, la integración de siloxanos poliédricos (POSS) en la estructura de materiales organizados se ha llevado a cabo a través de procesos sol-gel, en condiciones ácidas o básicas. En estos casos, se obtienen sólidos poliméricos o dendrímeros, sin organización a largo alcance y, normalmente, con reducida porosidad. Es por ello que la aplicabilidad catalítica de estos materiales es escasa debido a que los centros activos presentes en los siloxanos poliédricos son, prácticamente, inaccesibles (Figura 5.4.) ${ }^{[4]}$. No obstante, algunos de estos polímeros no porosos, han sido funcionalizados con complejos de vanadio o molibdeno, los cuales se sitúan en los vértices 
de las unidades POSS, obteniéndose materiales que se han empleado con éxito como catalizadores en procesos como la metátesis de olefinas (Figura 5.5. ${ }^{[5]}$.
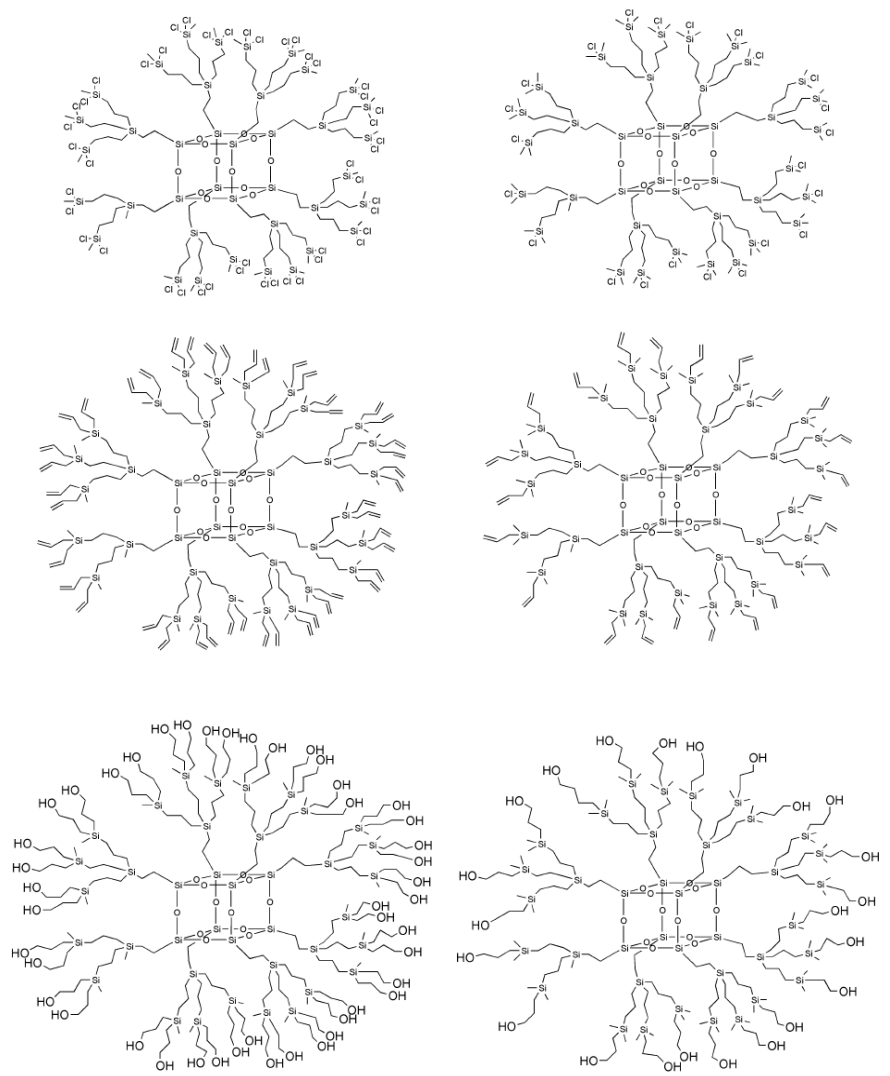

Figura 5.4. Diferentes dendrímeros orgánicos-inorgánicos obtenidos a partir de silsesquioxanos poliédricos (POSS).
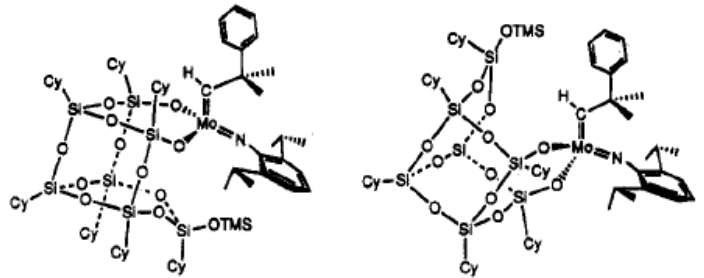

Figura 5.5. Isómeros de unidades Molibdeno-POSS que catalizan la metátesis de olefinas.

Por otra parte, Laine y col. han preparado unidades cúbicas poliédricas, $\mathrm{T}_{8}$ - POSS, funcionalizadas con grupos fenilamino localizados en sus vértices, los cuales también podrían emplearse como catalizadores básicos (Figura 5.6.) ${ }^{[6]}$. Siguiendo con esta línea, se 
han sintetizado potenciales catalizadores de oxidación por la formación de redes poliméricas basadas en unidades $T_{8}$ - POSS no condensadas que contienen grupos vinilo en los vértices de cada poliedro. Estas redes exhibían, además, cavidades dentro del rango del mesoporo, mostrando cierta flexibilidad estructural. Se realizaron diferentes tratamientos post-síntesis con el fin de anclar grupos titanoceno en los vértices en los que se localizan grupos silanoles accesibles (Figura 5.7.) ${ }^{[7]}$. Alternativamente, también se han introducido centros ácidos en siloxanos poliédricos, obteniéndose como derivados dendrímeros que contienen grupos carboxílicos en los vértices de las unidades POSS (Figura 5.8. $)^{[8]}$.

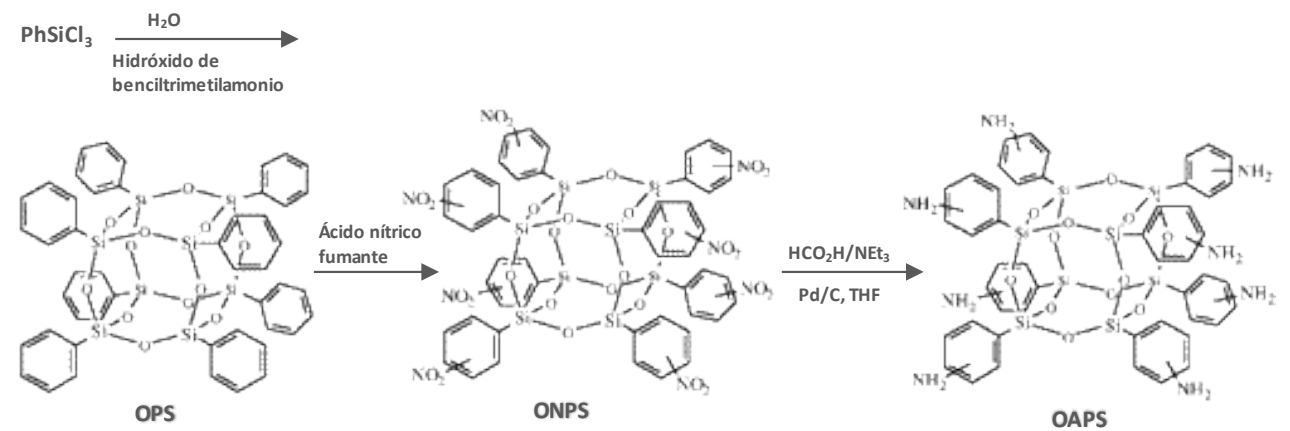

Figura 5.6. Representación de silsesquioxanos cúbicos $T_{8}$ POSS funcionalizados con grupos fenilamino.

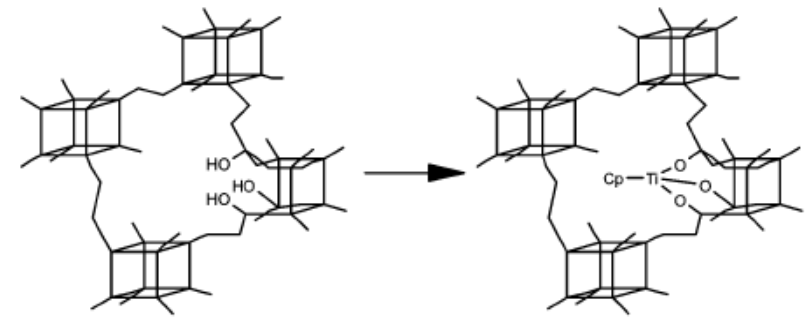

Figura 5.7. Incorporación de especies con titanio en redes poliméricas basadas en unidades $T_{8}$-POSS no condensadas con grupos silanoles en algunos de sus vértices.

Desde otra aproximación, se han obtenido interesantes materiales con aplicaciones catalíticas al soportar unidades POSS, previamente funcionalizadas, sobre sílices u óxidos metálicos de alta superficie. Considerando que los vértices de cada poliedro podrían contener diferentes fragmentos orgánicos, se podrían preparar catalizadores multifuncionales con dos o más centros activos concentrados alrededor de 
las unidades POSS, las cuales estarán, además, perfectamente estabilizadas y separadas entre sí a distancias moleculares controladas. En la Figura 5.9. se muestran diferentes ejemplos de este tipo de materiales híbridos que podrían ser el punto de partida de nuevos catalizadores multifuncionales ${ }^{[9]}$.
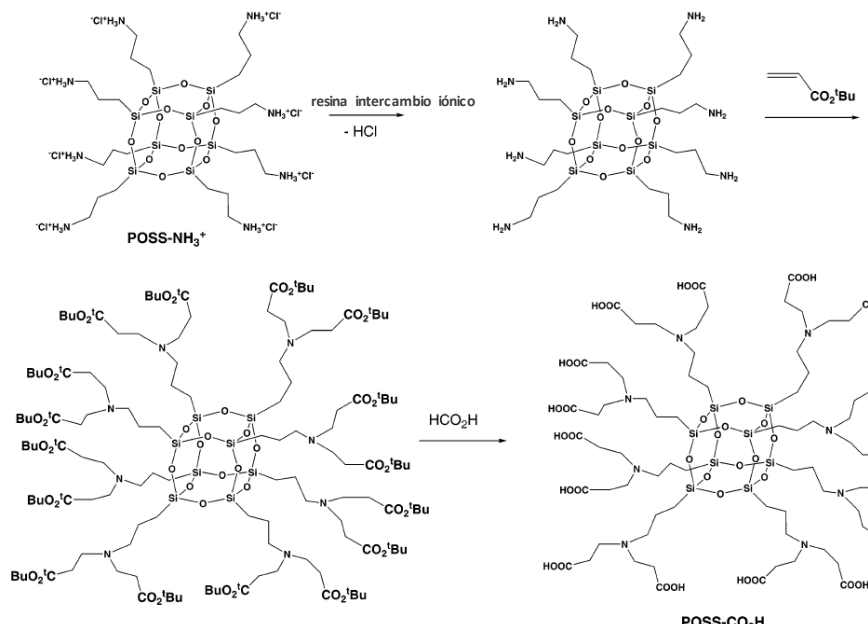

POSS- $\mathrm{CO}_{2} \mathrm{Bu}^{\mathrm{t}}$

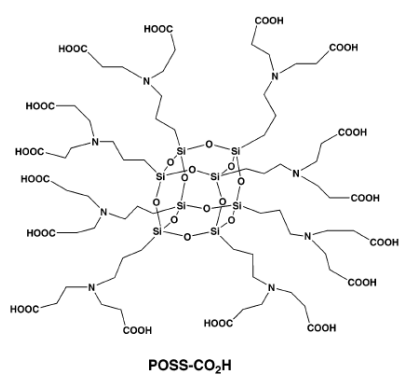

Figura 5.8. Preparación de oligosilsesquioxanos poliédricos (POSS) con grupos carboxílicos.
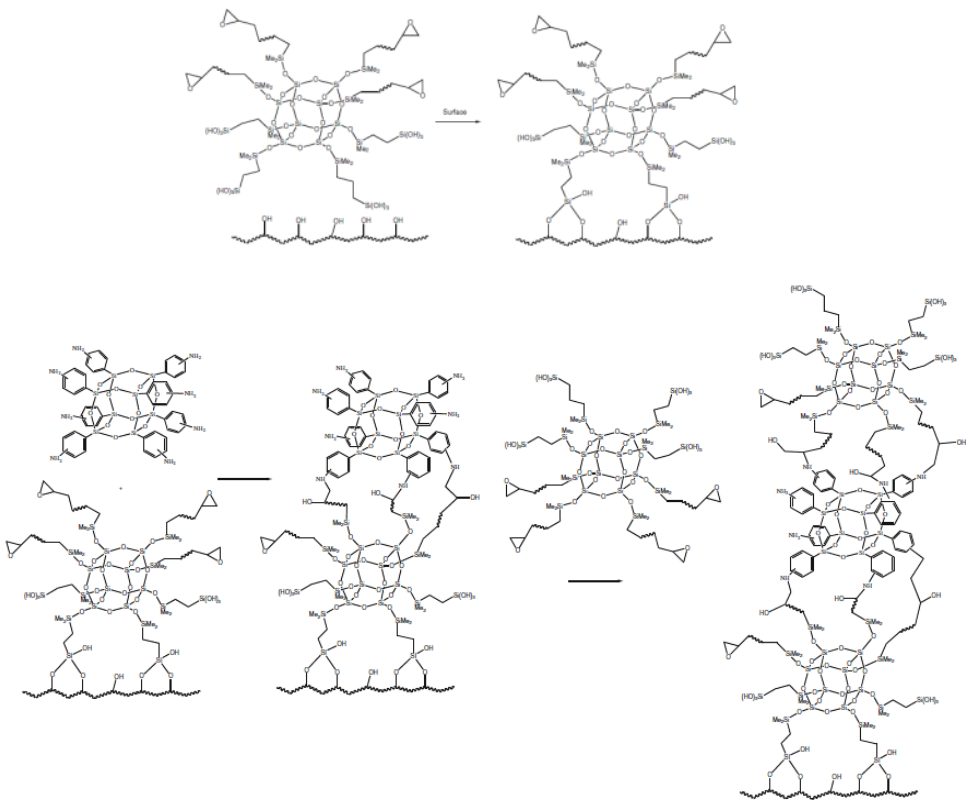

Figura 5.9. Diferentes ejemplos de siloxanos poliédricos funcionalizados soportados sobre sílice de alta superficie. 
Recientemente, los grupos liderados por Kuroda y van Santen han conseguido preparar materiales mesoporosos regulares y de elevada accesibilidad a partir de unidades $T_{8}$ - POSS previamente funcionalizadas con monosilanos o grupos vinilo en los vértices de los dobles anillos de cuatro miembros (D4R) que constituyen los siloxanos poliédricos. Para ello, siguieron rutas micelares de síntesis, empleando polímeros como surfactantes. La elevada área superficial ( $960 \mathrm{~m}^{2} \mathrm{~g}^{-1}$ ) junto con la alta estabilidad exhibida por los sólidos mesoporosos derivados de las unidades vinil- T $_{8}$ - POSS, los hace atractivos para ser empleados en diversos ámbitos nanotecnológicos o catalíticos (Figura 5.10.) ${ }^{[10]}$.

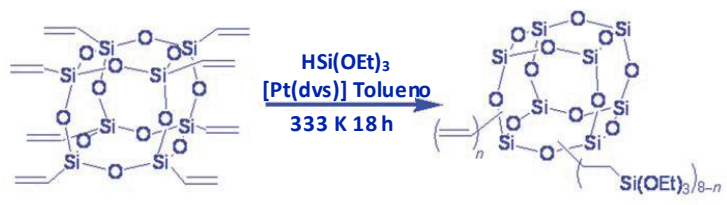

OVPOSS 1

OVPOSS-SILY 2

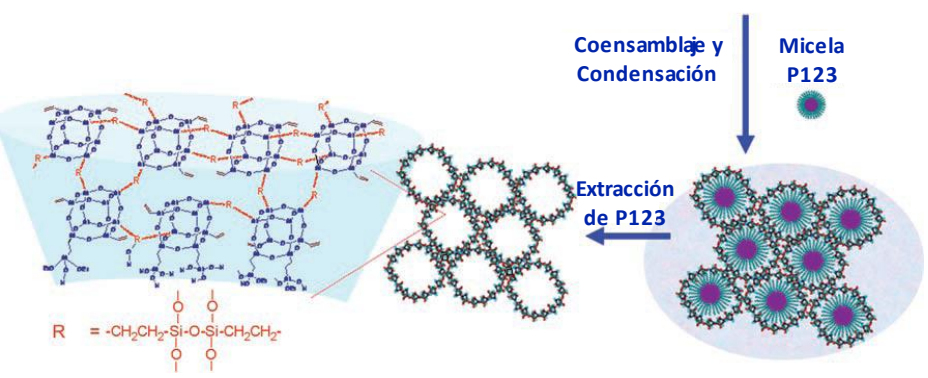

Figura 5.10. Materiales mesoporosos organizados preparados a partir de unidades vinil- $\mathrm{T}_{8}-\mathrm{POSS}$ siguiendo rutas micelares.

En definitiva, tras la revisión de los ejemplos aquí considerados queda claramente demostrada la capacidad que tienen las especies poliédricas tipo POSS para generar materiales porosos estructurados y estables, actuando como unidades básicas de estructura en las que, a su vez, se pueden introducir funciones activas adicionales que pasan a formar parte del entramado estructural de los sólidos obtenidos. Estas características convierten a las unidades POSS, a priori, en excelentes precursores para la obtención de materiales híbridos ordenados, funcionales y con elevada accesibilidad, cuyas posibilidades serán consideradas en los siguientes apartados de este capítulo. 


\subsection{Objetivos}

A lo largo de la revisión bibliográfica llevada a cabo, se ha constatado que los silanos poliédricos, denominados genéricamente POSS, pueden ser empleados con éxito como unidades estructurales para la obtención de materiales de tipo polimérico (dendrímeros) o, incluso, para formar sólidos con cavidades porosas. Teniendo en cuenta que las moléculas de disilanos, tal y como hemos comprobado en los anteriores capítulos de esta tesis, también pueden actuar como unidades válidas de estructura, se podría plantear la posibilidad de preparar materiales de elevada accesibilidad por ensamblaje directo de POSS y disilanos, en un solo paso, durante el proceso de preparación. La posibilidad de que los fragmentos orgánicos presentes en los disilanos, a modo de puente, posean diferentes grupos funcionales, abre la posibilidad de obtener una nueva familia de materiales híbridos constituidos, a nivel estructural, por unidades POSS y disilanos y que, además, contengan centros activos estabilizados en su red organosilícea.

En función de esto, los objetivos de este capítulo son los que a continuación se detallan:

- Síntesis y caracterización de materiales híbridos mesoporosos basados en dos clases de siloxanos tales como silanos poliédricos de tipo cúbico ( $T_{8}$ - POSS) y disilanos rígidos del tipo 1,4-bis(trietoxisilil)benceno (BTEB), los cuales actuarán simultáneamente como unidades estructurales. Para ello se seguirá un proceso micelar de ensamblaje molecular en presencia de surfactantes como agentes directores de estructura.

- Incorporación de grupos funcionales en los puentes orgánicos, provenientes de los disilanos, para generar materiales híbridos mesoporosos con centros activos accesibles y estabilizados en su entramado estructural.

- Medida de la actividad catalítica de los materiales mesoporosos conformados por unidades $T_{8}-$ POSS y BTEB en diferentes procesos reactivos. 


\subsection{Materiales híbridos mesoporosos basados en POSS}

\subsubsection{Síntesis y caracterización}

\section{Sintesis}

En este estudio se pretende obtener nuevos materiales híbridos mesoporosos a partir de la combinación de dos tipos de precursores silíceos, tales como silanos poliédricos de naturaleza cúbica ( $\mathrm{T}_{8}$ - POSS) y disilanos rígidos con grupos arílicos tipo puente, 1,4-bis(trietoxisilil)benceno (BTEB). Para que los monómeros de ambos compuestos actúen como unidades estructurales a escala nanométrica, se requiere una combinación covalente adecuada entre ellos que únicamente se consigue trabajando en un intervalo de relaciones molares adecuado, pudiéndose generar de esta forma, materiales homogéneos y altamente accesibles con simetría hexagonal y con una estrecha distribución del tamaño de poro. La presencia de silsesquioxanos poliédricos, a modo de pequeñas cajas de dobles anillos de cuatro miembros, conectadas con espaciadores orgánicos, ambos conformando las paredes de los sólidos, permitiría la preparación de materiales mesoporosos robustos y estables que podrían ser empleados en aplicaciones catalíticas.

Los materiales híbridos orgánicos-inorgánicos de tipo POSS se han preparado siguiendo el procedimiento descrito en la parte experimental de este capítulo (apartado 5.5.), consistente en un proceso micelar en medio ácido en presencia de moléculas de surfactante. En la Figura 5.11. se muestra un esquema de la ruta de síntesis empleada, así como una representación gráfica de la estructura de los materiales obtenidos. Dichos sólidos también fueron sometidos a etapas post-síntesis de aminación que permitieron incorporar centros básicos a los anillos arílicos, convirtiéndolos en potenciales catalizadores para llevar a cabo reacciones de condensación, lo cual será discutido más adelante (apartado 5.3.2.).

Tras diferentes estudios realizados, se observó que la mezcla óptima de reacción en el medio de síntesis debía tener la siguiente composición molar:

$$
1 \mathrm{SiO}_{2}\left[x\left(\mathrm{~T}_{8}-\mathrm{POSS}\right)+y(\mathrm{BTEB})\right]: 0.33 \mathrm{C}_{18} \mathrm{TMABr}: 9 \mathrm{HCl}: 133 \mathrm{H}_{2} \mathrm{O}
$$


En función de la relación molar, en moles de silicio, entre los monómeros orgánicos e inorgánicos usados durante el proceso de autoensamblaje, las muestras se designaron como HYB-xP-yB, siendo $x$ e $y$ el porcentaje de moles de sílice incorporados en el gel de partida provenientes de las moléculas de siloxano $\mathrm{T}_{8}-$ POSS y BTEB respectivamente, oscilando dichos valores entre 0 y 100.

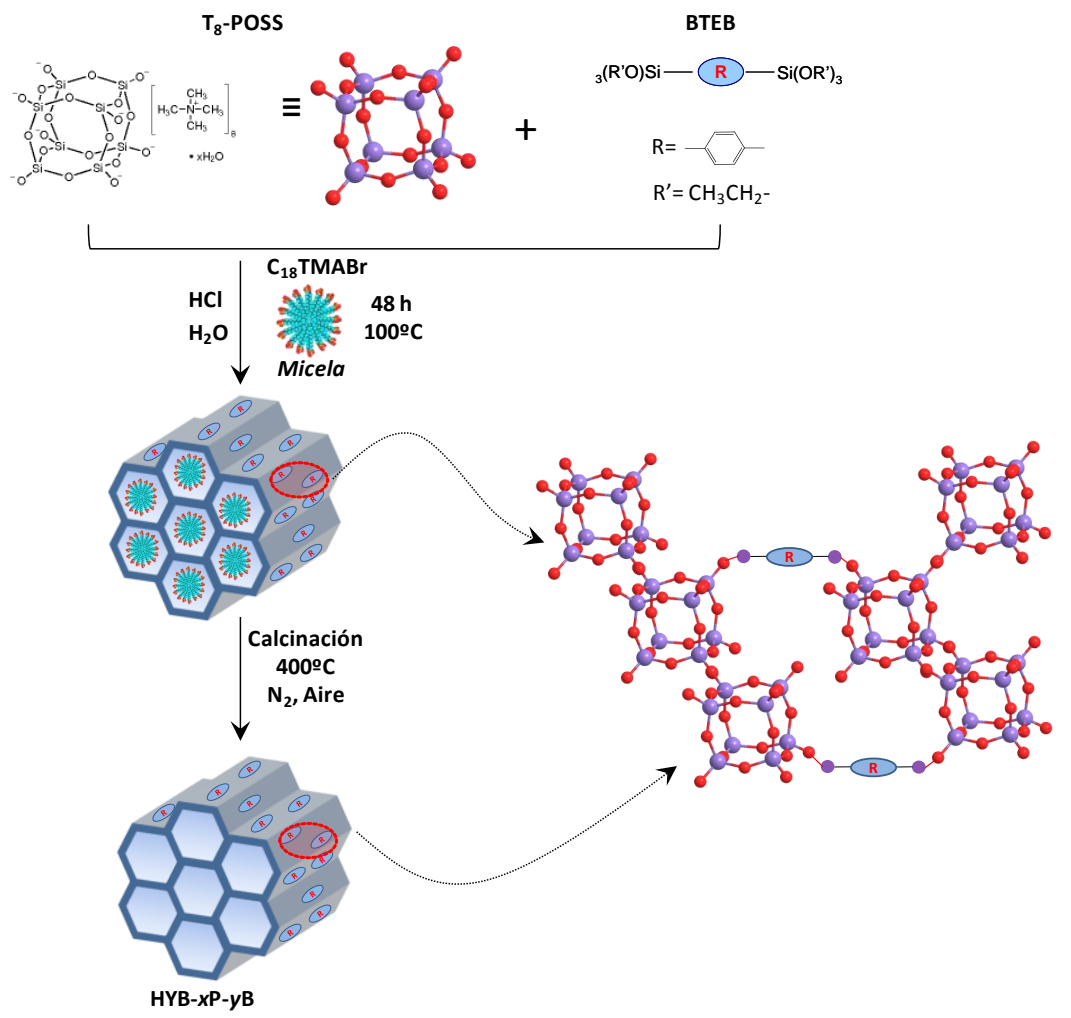

Figura 5.11. Esquema de la ruta de síntesis empleada para la obtención de los materiales híbridos mesoporosos y representación de la estructura orgánica-inorgánica formada por unidades de tipo $\mathrm{T}_{8}$ - POSS y arílicas procedentes de sus respectivos silsesquioxanos.

\section{Caracterización}

\section{Difracción de rayos $X$}

Los resultados obtenidos a partir de difracción de rayos $\mathrm{X}$ indican que la cantidad empleada de ambos silanos para la preparación de los materiales híbridos es decisiva para poder obtener sólidos mesoporosos homogéneos con orden a largo alcance, tal y como 
ocurre en los sólidos mesoporosos convencionales (Figura 5.12.). A partir de los difractogramas obtenidos, se observa como el material sintetizado únicamente a partir del siloxano $T_{8}$ - POSS (HYB-100P) no exhibe un orden estructural homogéneo, hecho que se puede comprobar debido a la baja intensidad y anchura de la banda de difracción que aparece a bajo ángulo, característica de los materiales mesoporosos (Figura 5.12.a). Por el contrario, cuando se incorpora a la síntesis el disilano BTEB en presencia de $\mathrm{T}_{8}-\mathrm{POSS}$, la homogeneidad alcanzada en los materiales aumenta considerablemente como puede deducirse de los espectros de difracción, en los cuales se llegan incluso a apreciar bandas de difracción asociadas a las reflexiones (110) y (200) para el material HYB-95P-5B presentes en sólidos mesoporosos que exhiben una topología hexagonal convencional tipo M41S (Figura 5.12.e) ${ }^{[11]}$.

Cuando se sintetizaron materiales que contenían un mayor número de unidades arílicas insertadas en su estructura (50\%, $75 \%$ y $100 \%$ del total de moles de silicio), tanto la regularidad estructural como la homogeneidad porosa alcanzada se redujo considerablemente como así lo confirman los espectros de difracción de rayos $\mathrm{X}$ a bajo ángulo (Figura 5.12.b, c, d).

Estos resultados permiten afirmar que las condiciones óptimas para preparar este tipo de materiales híbridos se consiguen al introducir una cantidad adecuada del disilano con grupos arílicos (BTEB) que oscile entre $5 \%$ y $25 \%$ del total de moles de silicio, los cuales se combinan con las unidades inorgánicas provenientes del siloxano $T_{8}$ - POSS. En estas condiciones es probable que los fragmentos arílicos rígidos integrantes del disilano BTEB, actúen como conectores estructurales de las unidades cúbicas POSS (Figura 5.11.), facilitando una estructuración óptima, así como una adecuada distribución de los fragmentos orgánicos-inorgánicos que conforman los materiales híbridos mesoporosos, exhibiendo la simetría característica del grupo espacial $p 6 \mathrm{~mm}$.

En este caso, se han empleado condiciones ácidas a través de una ruta micelar de síntesis, ya que ha resultado ser la más adecuada para preparar estos materiales en presencia sólo de $\mathrm{T}_{8}$ - POSS o combinado éste con BTEB. Es importante destacar que en la bibliografía están descritos materiales híbridos que exhiben una elevada cristalinidad, 
empleando únicamente BTEB como fuente de silicio, utilizando medios de síntesis también alcalinos ${ }^{[12]}$. Sin embargo, los experimentos llevados a cabo en este estudio en condiciones básicas no resultaron satisfactorios ${ }^{[13]}$, siendo imposible combinar de forma efectiva en un medio alcalino, los dos tipos de precursores empleados ( $T_{8}$ - POSS y BTEB) para generar materiales mesoporosos homogéneos y ordenados. Este hecho se podría deber al elevado número de cationes $\mathrm{TMA}^{+}$que se encuentran compensando la carga de los grupos siloxanos $T_{8}$ - POSS (ver parte experimental 5.5), los cuales tienden a formar las sales de amonio cuaternarias $\mathrm{TMACl}$, en presencia de $\mathrm{HCl}$, que exhiben una estabilidad mayor que en su forma hidróxido, $\mathrm{TMAOH}$, favorecidas, en principio, en medio alcalino. Por lo tanto, en medio ácido, se darían las condiciones más favorables para generar especies activas de siloxanos $\mathrm{T}_{8}$ - POSS aniónicos para llevar a cabo con efectividad los procesos de hidrólisis y polimerización asociados a la síntesis micelar.
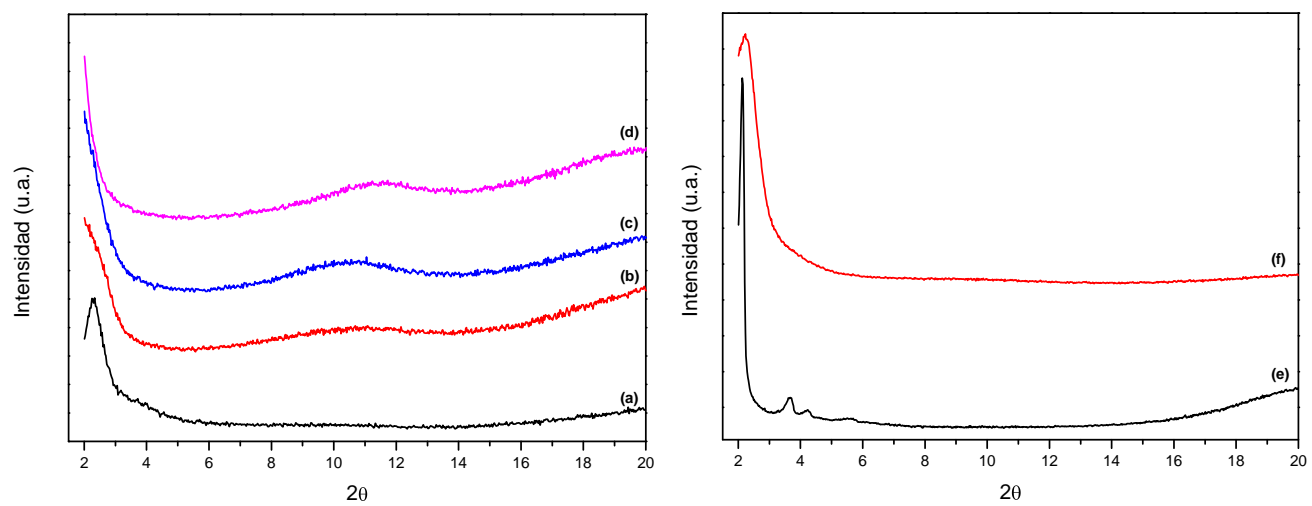

Figura 5.12. Difractogramas de rayos $X$ de los materiales mesoporosos recién sintetizados: (a) HYB100P, (b) HYB-50P-50B, (c) HYB-25P-75B, (d) HYB-100B, (e) HYB-95P-5B y (f) HYB-75P-25B.

Los difractogramas de rayos $\mathrm{X}$ obtenidos para las muestras calcinadas a $400^{\circ} \mathrm{C}$ (Figura 5.13.), exhiben bandas a bajo ángulo con una intensidad muy similar a la de los sólidos recién sintetizados cuando las cantidades añadidas del disilano BTEB oscilan entre $5 \%$ y $25 \%$ del total de moles de silicio, lo cual confirma que se mantiene el orden mesoporoso incluso después de la eliminación de las moléculas de surfactante empleadas como agentes directores de estructura (Figura 5.13.e, f). En el caso de las muestras preparadas con un alto contenido en el disilano BTEB en el proceso de síntesis, la etapa de 
calcinación mejora parcialmente el orden mesoporoso finalmente alcanzado, al comparar sus difractogramas con los de sus respectivas muestras recién sintetizadas, lo cual se deduce a través de la presencia de bandas anchas de difracción de baja intensidad (Figura 5.13.b, c, d).
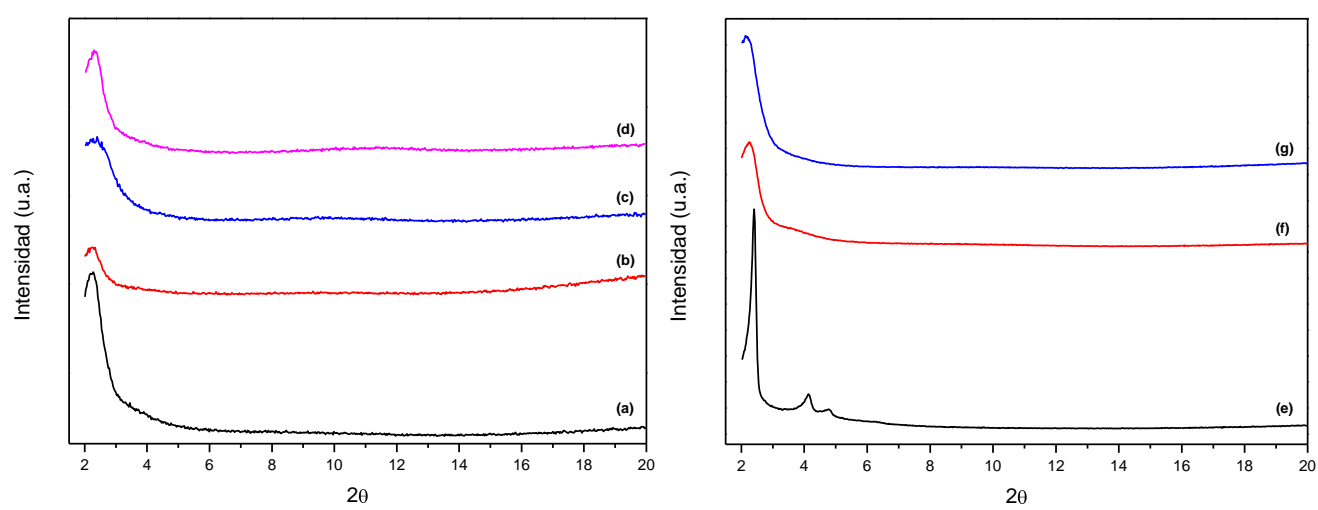

Figura 5.13. Difractogramas de rayos $X$ de los materiales mesoporosos calcinados: (a) HYB-100P, (b) HYB-50P-50B, (c) HYB-25P-75B, (d) HYB-100B, (e) HYB-95P-5B, (f) HYB-75P-25B y (g) HYB-75P-25B$\mathrm{NH}_{2}$.

\section{Análisis elemental}

En la Tabla 5.1. se muestran los resultados obtenidos a través del análisis elemental realizado para las muestras HYB-100P y HYB-75P-25B recién sintetizadas y tras someterlas a un proceso de calcinación. Dichos resultados indican que en el caso de las muestras sin calcinar, las moléculas de surfactante $\left(\mathrm{C}_{18} \mathrm{TMA}\right)$ están presentes en el interior de los canales, habiéndose incorporado durante la ruta micelar (Tabla 5.1., entrada 1), siendo la relación molar C/N experimental de 22.0, para la muestra HYB-100P, la cual es próxima al valor teórico esperado para las moléculas de $\mathrm{C}_{18} \mathrm{TMA}$ (relación molar teórica $\mathrm{C} / \mathrm{N}$ de 21.0).

Por otra parte, se ha podido confirmar que la práctica totalidad de los iones $\mathrm{TMA}^{+}$, los cuales actúan como contraiones para compensar a las unidades aniónicas $\mathrm{T}_{8}$ POSS (ver parte experimental, apartado 5.5.), no están presentes en el material híbrido final sintetizado, ya que la relación molar $\mathrm{C} / \mathrm{N}$ teórica para los iones $\mathrm{TMA}^{+}$es 4 , estando dicho valor alejado de la relación experimental obtenida $(\mathrm{C} / \mathrm{N}=22.0)$, siendo ésta 
prácticamente coincidente con la debida únicamente a la presencia de moléculas de surfactante.

Tabla 5.1. Contenido orgánico obtenido por análisis elemental y termogravimétrico para las muestras híbridas preparadas a partir de monómeros $\mathrm{T}_{8}$ - POSS y BTEB.

\begin{tabular}{|c|c|c|c|c|c|c|c|c|}
\hline \multirow[b]{2}{*}{ Muestra } & \multicolumn{5}{|c|}{ Análisis Elemental (AE) } & \multicolumn{3}{|c|}{$\begin{array}{l}\text { Análisis Termogravimétrico } \\
\text { (ATG) }\end{array}$} \\
\hline & $\% \mathrm{C}$ & $\% \mathrm{~N}$ & $\mathrm{C} / \mathrm{N}^{\mathrm{a}}$ & $\begin{array}{l}\text { \% Cont. } \\
\text { orgánico }\end{array}$ & $\begin{array}{c}1 \\
(200- \\
400)^{\circ} \mathrm{C}\end{array}$ & $\begin{array}{c}\text { II } \\
(500- \\
700)^{\circ} \mathrm{C}\end{array}$ & $\begin{array}{c}\% \text { Cont } \\
\text { orgánico }^{b}\end{array}$ & $\begin{array}{c}\text { mmol } \\
\text { frag. } \\
\text { arílicos } \\
\mathrm{g}^{-1} \mathrm{SiO}_{2}{ }^{\mathrm{C}} \\
\end{array}$ \\
\hline HYB-100P & 23.6 & 1.4 & 22.0 & 33.3 & 28.2 & 2.5 & 30.7 & - \\
\hline HYB-100P-CAL & 0.1 & 0 & - & 1.4 & 0 & 3.1 & 3.1 & - \\
\hline HYB-75P-25B & 30.7 & 1.0 & 35.8 & 38.3 & 20.5 & 15.2 & 35.7 & 3.28 \\
\hline HYB-75P-25B-CAL & 17.0 & 0 & - & 18.5 & 0 & 18.8 & 18.8 & 3.22 \\
\hline HYB-75P-25B-NH 2 & 13.0 & 2.5 & 6.1 & 17.6 & 0 & 15.5 & 15.5 & 2.55 \\
\hline
\end{tabular}

\footnotetext{
${ }^{a}$ Relación molar $\mathrm{C} / \mathrm{N}$ a partir de AE. ${ }^{b}$ Contenido orgánico a partir de ATG sin considerar el agua de hidratación. ${ }^{c}$ Determinado a partir de ATG por la pérdida de peso II, asignado a los fragmentos arílicos.
}

Cuando la etapa de síntesis tiene lugar en presencia de moléculas del disilano BTEB (HYB-75P-25B), se observa un aumento apreciable en el contenido orgánico, lo cual se debe a la incorporación de grupos aromáticos provenientes del disilano BTEB, en la estructura del material híbrido. Este hecho también se puede comprobar después del proceso de calcinación (HYB-75P-25B-CAL) debido a que el contenido en nitrógeno procedente del surfactante, $\mathrm{C}_{18} \mathrm{TMA}$, se reduce a cero, siendo apreciable solamente el contenido en carbono procedente de los fragmentos arílicos (Tabla 5.1., entrada 4). A través de este resultado también se puede corroborar la efectividad del método de calcinación empleado para la eliminación completa del contenido orgánico proveniente del surfactante, (Tabla 5.1., entradas 2 y 4), habiéndose detectado que alrededor de un $17 \%$ en peso del material híbrido final corresponde a fragmentos estructurales arílicos probablemente incorporados en el interior de la estructura de los materiales, enlazados covalentemente a unidades cúbicas $T_{8}$ - POSS. 


\section{Análisis Termogravimétrico}

En las Figuras 5.14. y 5.15. se muestran las curvas de las pérdidas en peso (ATG), así como sus correspondientes derivadas (ATD), de los sólidos sintetizados usando únicamente $T_{8}$ - POSS como fuente de silicio (HYB-100P) y en presencia del disilano BTEB (HYB-75P-25B), respectivamente. Los resultados permiten confirmar tanto la presencia de los diferentes grupos orgánicos incorporados (moléculas de surfactante, $\mathrm{C}_{18} \mathrm{TMA}$, y fragmentos arílicos) localizados en los materiales híbridos en estudio así como su estabilidad hidrotermal.
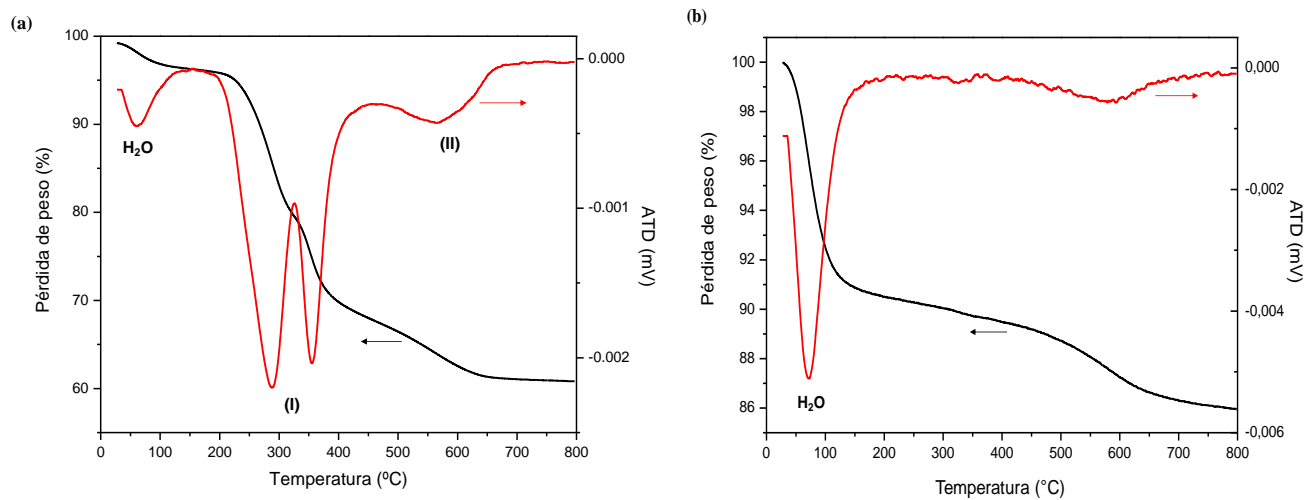

Figura 5.14. Curvas termogravimétricas (ATG) y sus correspondientes derivadas (ATD) de las muestras: (a) HYB-100P y (b) HYB-100P-CAL.

En concreto, en la muestra HYB-100P es posible observar una pérdida principal de peso entre $200^{\circ} \mathrm{C}$ y $400^{\circ} \mathrm{C}$, nombrada como I, la cual se atribuye a las moléculas de surfactante. El diferente nivel de estabilidad del agente director de estructura ( $\left.C_{18} T M A\right)$ en el interior de los canales permite distinguir entre dos tipos de moléculas de surfactante, pudiéndose observar en las curvas ATD la presencia de dos bandas para la pérdida en peso I (Figura 5.14.a). Además, entre $500^{\circ} \mathrm{C}$ y $700^{\circ} \mathrm{C}$, se observa una segunda pérdida en peso de alrededor de un 3\% (Tabla 5.1., entradas 1 y 2 ) en la muestra obtenida usando únicamente monómeros POSS, nombrada como II, correspondiente al agua de deshidroxilación, la cual se produce por la condensación de los grupos silanoles superficiales a altas temperaturas. Por otra parte, fue posible confirmar, a través de la curvas ATG y ATD de la muestra calcinada HYB-100P, la efectividad del proceso de 
calcinación a $400^{\circ} \mathrm{C}$ para eliminar completamente las moléculas de surfactante ocluidas (Figura 5.14.b) ya que tras este proceso no se observa la pérdida de peso I.

En el caso de la muestra formada por la combinación de monómeros de tipo POSS y BTEB (HYB-75P-25B), se constata la presencia de fragmentos arílicos debido a un marcado aumento en la pérdida de peso II (ver Tabla 5.1., entrada 3, y Figura 5.15.a) si se compara con la muestra sintetizada en ausencia de BTEB, pudiéndose estimar que aproximadamente el $16 \%$ del peso total de los materiales híbridos proviene de la presencia de fragmentos arílicos, deduciendo el agua de deshidroxilación formada a elevadas temperaturas. Es importante resaltar que el contenido orgánico procedente de los grupos arílicos es prácticamente el mismo que el obtenido a través de análisis elemental (Tabla 5.1.), siendo los fragmentos aromáticos hidrotermalmente estables por encima de los $600^{\circ} \mathrm{C}$. Este dato está en consonancia con la alta estabilidad observada en otras organosílicas periódicas mesoporosas descritas con anterioridad en la bibliografía que presentan unidades arílicas insertadas en su estructura ${ }^{[14]}$. Además, la pérdida en peso I, debida a la presencia de moléculas de surfactante, está localizada en el mismo rango de temperaturas que para la muestra HYB-100P, aunque la cantidad de moléculas de $\mathrm{C}_{18}$ TMA que finalmente se encuentran ocluidas en las muestras híbridas constituidas por unidades POSS y BTEB es menor ( 20\% en peso) que en ausencia del disilano puente (28\% en peso, ver Tabla 5.1., entradas 1 y 3).

Cuando se calcina la muestra HYB-75P-25B (Figura 5.15.b), la pérdida de peso I desaparece, lo cual confirma la completa eliminación de las moléculas de surfactante, mientras que la pérdida de peso II, asignada a los fragmentos arílicos, permanece invariable comparada con la misma muestra antes de su calcinación (19\% en peso, ver Tabla 5.1., entrada 4). Este resultado confirma que los fragmentos orgánicos de tipo fenilo son estables después de la eliminación de los agentes directores de estructura, cuando son sometidos a temperaturas superiores a los $400^{\circ} \mathrm{C}$. 
(a)

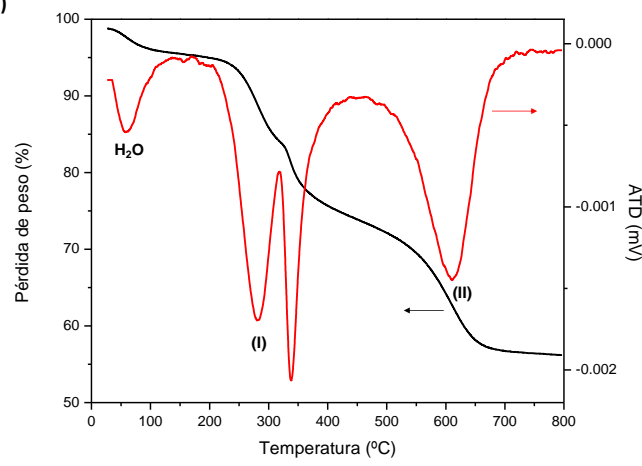

(b)

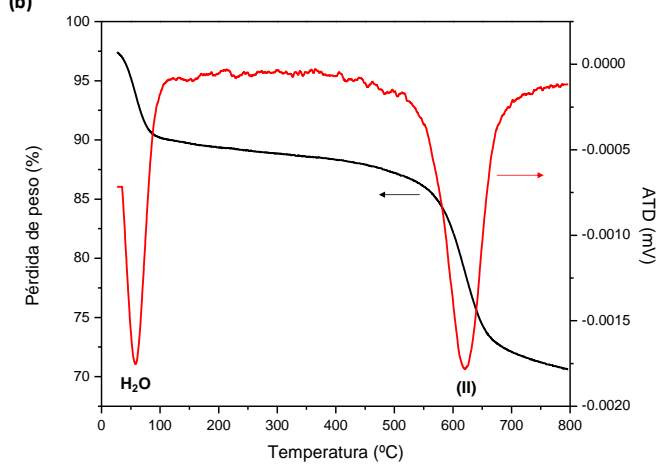

(c)

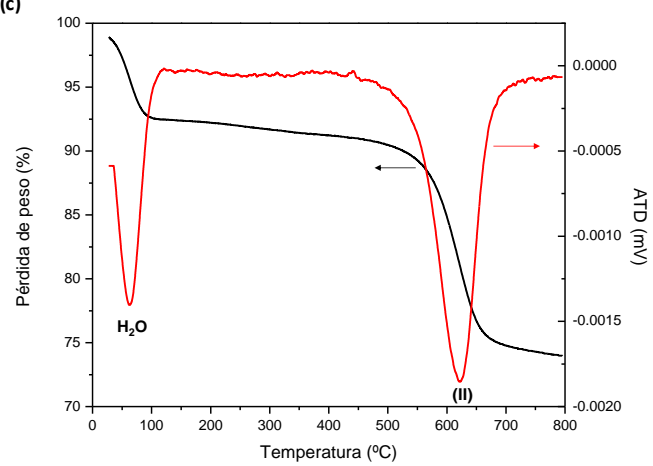

Figura 5.15. Curvas termogravimétricas (ATG) y sus correspondientes derivadas (ATD) de las muestras: (a) HYB-75P-25B, (b) HYB-75P-25B-CAL y (c) HYB-75P-25B-NH 2 .

\section{Espectroscopía infrarroja}

A partir de los datos obtenidos a través de espectroscopía IR es posible confirmar la presencia tanto de siloxanos cúbicos como de fragmentos arílicos que se encuentran conformando la estructura mesoporosa de los materiales híbridos sintetizados por la adecuada combinación de ambos tipos de precursores ( $T_{8}$ - POSS y BTEB).

En la Figura 5.16. se puede observar el espectro infrarrojo correspondiente al material híbrido HYB-75P-25B el cual exhibe, si se compara con el material obtenido sólo a partir del precursor $\mathrm{T}_{8}$ - POSS (HYB-100P), bandas adicionales a 1390, 1510, 1600, $\sim 3010$ y $\sim 3060 \mathrm{~cm}^{-1}$ asociadas a la vibraciones streching asimétricas de los enlaces siliciofenilo, lo cual indica la presencia de unidades arílicas en los materiales obtenidos (Figura 
5.16.b). Además, se detectaron fragmentos residuales hidrocarbonados procedentes de las moléculas de surfactante empleadas durante el proceso de auto-ensamblaje, las cuales permanecen después del proceso de calcinación, debido a la presencia de bandas de baja intensidad situadas a $\sim 2860$ y $\sim 2980 \mathrm{~cm}^{-1}$. La banda intensa apreciada a $\sim 3730 \mathrm{~cm}^{-1}$, característica de los grupos silanoles, la cual también está presente en los materiales mesoporosos convencionales, se observa igualmente en el material calcinado preparado exclusivamente a partir de unidades cúbicas del siloxano $\mathrm{T}_{8}$ - POSS, HYB-100P, (Figura 5.16.a), estando parcialmente desplazada a $\sim 3650 \mathrm{~cm}^{-1}$ cuando se incorporan los fragmentos arílicos en la red híbrida de los materiales (Figura 5.16.b). Este desplazamiento se debe, probablemente, a la proximidad espacial entre los $\mathrm{Si}-\mathrm{OH}$ superficiales y los grupos silil-aromáticos de la estructura ${ }^{[15]}$. En definitiva, estos resultados corroboran con claridad que los grupos arílicos están efectivamente presentes en los materiales híbridos mesoporosos.

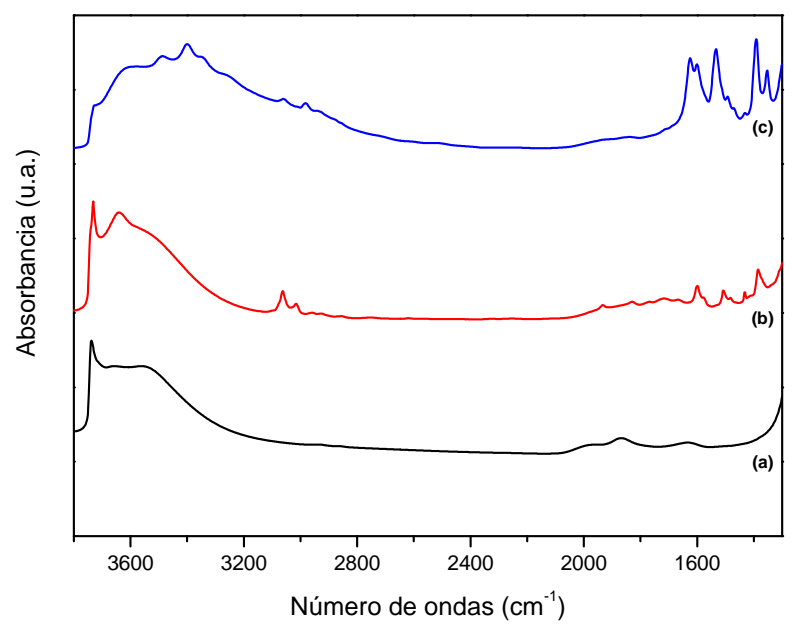

Figura 5.16. Espectros de infrarrojo de los materiales calcinados: (a) HYB-100P, (b) HYB-75P-25B y (c) HYB-75P-25B-NH . 
Por otra parte, a través de la espectroscopía infrarroja debe ser posible identificar y confirmar la presencia de unidades cúbicas que forman parte de la estructura mesoporosa, tanto en los sólidos que han sido sintetizados sólo a partir de los monómeros $\mathrm{T}_{8}$ - POSS como en los que, además, se han empleado moléculas del disilano BTEB (Figura 5.17.). En la bibliografía se ha descrito la asignación de bandas de vibración debidas a la presencia de dobles anillos de cuatro miembros (D4R) en el interior de las estructuras de diferentes materiales zeolíticos ${ }^{[16]}$, siendo aceptado que en el rango comprendido entre 550 y $600 \mathrm{~cm}^{-1}$ es posible detectar las bandas correspondientes a las vibraciones procedentes de las unidades $\mathrm{D}_{4} \mathrm{R}^{[17]}$. En concreto, modelos teóricos realizados con estructuras zeolíticas pura sílice estimaron que la frecuencia de vibración para estasunidades D4R debe de estar centrada a $581 \mathrm{~cm}^{-1[18]}$.

En el caso particular de los materiales mesoporosos sintetizados y estudiados en este capítulo, basados en monómeros cúbicos $\mathrm{T}_{8}$ - POSS, se observa que sus espectros muestran bandas de vibración alrededor de $580 \mathrm{~cm}^{-1}$, lo cual confirmaría la presencia de dobles anillos de cuatro provenientes de unidades cúbicas presentes en su estructura, incluso en presencia de anillos bencénicos (Figura 5.17.a). En este caso, el espectro de IR en la zona de red del material híbrido se ha comparado con los obtenidos para un material mesoporoso convencional tipo M41S y una zeolita A pura sílice (Figuras 5.17.c y 5.17.d, respectivamente). El primero, conformado por sílice amorfa, no presenta banda de infrarrojo vibracional debida a unidades D4R. En cambio, la zeolita A presenta una banda intensa centrada a $\sim 58 \mathrm{~cm}^{-1}$, como ocurre en los materiales mesoporosos híbridos estudiados, ya que esta estructura zeolítica está basada en unidades D4R con diferentes posiciones cristalográficas ${ }^{[19]}$. Todo ello corrobora de forma unívoca tanto la presencia como la preservación de las unidades cúbicas del siloxano $\mathrm{T}_{8}$ - POSS en los materiales híbridos obtenidos, las cuales son las principales unidades estructurales de la red porosa formada. 


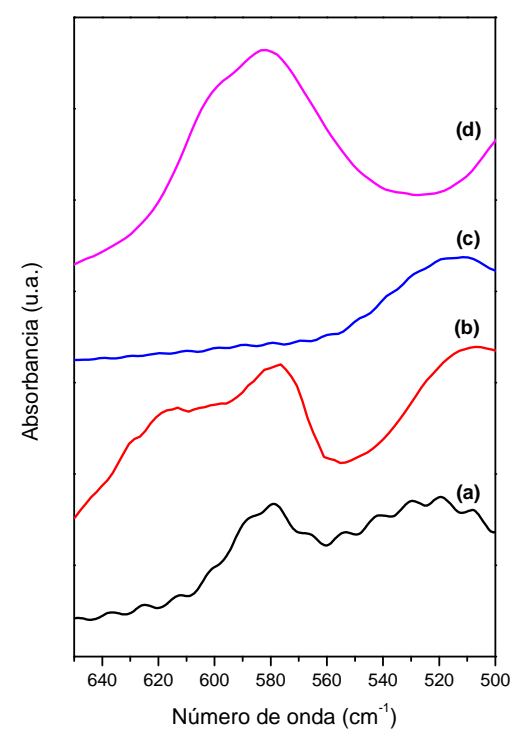

Figura 5.17. Espectros de infrarrojo en la zona de red para diferentes materiales porosos con un alto contenido silíceo: (a) HYB-75P-25B, (b) HYB-75P-25B-NH 2 , (c) MCM-41 y (d) zeolita A.

\section{Resonancia magnética nuclear}

A través de la espectroscopia de resonancia magnética nuclear es posible confirmar no sólo la presencia sino también la integridad de los fragmentos orgánicos que conforman la estructura de los materiales mesoporosos sintetizados, así como su interacción covalente con los siloxanos cúbicos $\mathrm{T}_{8}$ - POSS. En la Figura 5.18. se muestra el espectro de RMN CP/MAS de ${ }^{13} \mathrm{C}$ del material HYB-75P-25B recién sintetizado en el cual se puede observar la banda característica de los fragmentos aromáticos centrada a aproximadamente $133 \mathrm{ppm}$, demostrando su presencia en la red organosilícea (Figura 5.18.a). Además, es posible observar en dicho espectro otras bandas de elevada intensidad debidas a las moléculas de surfactante $\left(\mathrm{C}_{18} \mathrm{TMA}\right)$ empleado durante la síntesis de los materiales (ver esquema en la Figura 5.18.). Tras el proceso de calcinación, las bandas atribuidas a los agentes directores de estructura han desaparecido por completo, lo cual ratifica la efectividad del proceso de calcinación a elevadas temperaturas $\left(400^{\circ} \mathrm{C}\right)$, sin que ello suponga la destrucción de las unidades arílicas que han sido incorporadas en su estructura (Figura 5.18.b). 
Aunque a través de la espectroscopia de $\mathrm{RMN}$ de ${ }^{13} \mathrm{C}$ se puede confirmar tanto la presencia como la integridad de los fragmentos arílicos presentes en los materiales híbridos sintetizados, es a partir de la espectroscopia de RMN de ${ }^{29} \mathrm{Si}$ donde se puede comprobar la efectiva interacción covalente entre las diferentes unidades estructurales, $\mathrm{T}_{8}$ - POSS y BTEB, los cuales conforman la red de los sólidos obtenidos.

En la Figura 5.19. se muestra el espectro de RMN de ${ }^{29} \mathrm{Si}$ para el material HYB75P-25B, pudiéndose observar las bandas de tipo $Q$ convencionales, presentes en materiales mesoporosos estándar con un alto contenido silíceo, situadas alrededor de -95 a -110 ppm, atribuidas a los átomos de Si coordinados tetraédricamente, es decir, átomos de tipo $\mathrm{Q}^{4}\left[\mathrm{Si}(\mathrm{OSi})_{4}\right], \mathrm{Q}^{3}\left[\mathrm{Si}(\mathrm{OH})(\mathrm{OSi})_{3}\right]$ y $\mathrm{Q}^{2}\left[\mathrm{Si}(\mathrm{OH})_{2}(\mathrm{OSi})_{2}\right]$. Junto a las bandas $\mathrm{Q}$, se aprecian las de tipo $\mathrm{T}$ indicativas de la existencia de enlaces covalentes $\mathrm{Si}-\mathrm{C}$, los cuales provienen de la incorporación efectiva de las moléculas del precursor BTEB (Figura 5.19.a) en el seno de la matriz silícea. De hecho, es posible identificar, dentro de las especies de silicio de tipo $\mathrm{T}$, las bandas correspondientes a átomos de silicio $\mathrm{T}^{3}\left[\mathrm{SiC}(\mathrm{OSi})_{3}\right]$ y $\mathrm{T}^{2}$ $\left[\mathrm{SiC}(\mathrm{OH})(\mathrm{OSi})_{2}\right]$ a -78 y $-71 \mathrm{ppm}$, respectivamente. Igualmente, en la Figura 5.19., se comprueba la ausencia de átomos de silicio de tipo $\mathrm{T}^{1}\left[\mathrm{SiC}(\mathrm{OH})_{2}(\mathrm{OSi})\right]$ en el espectro correspondiente a la muestra HYB-75P-25B, lo que unido a la también ausencia de señales de carbono correspondientes a grupos etóxido terminales en el espectro de $\mathrm{RMN}$ de ${ }^{13} \mathrm{C}$ (Figura 5.18.a), permite confirmar que la práctica totalidad de los grupos alcóxido terminales procedentes de las moléculas del disilano BTEB están involucrados en el proceso de estructuración de los materiales mesoporosos híbridos. 

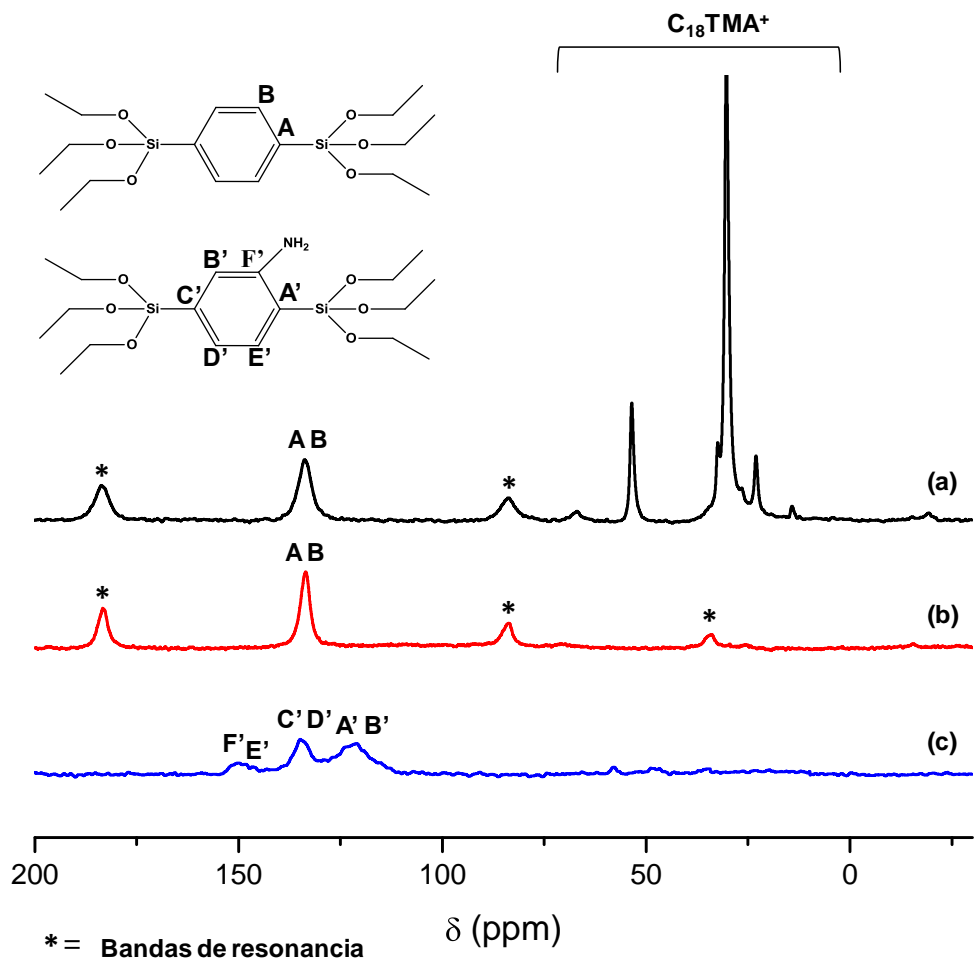

Figura 5.18. Espectros de RMN CP/MAS de ${ }^{13} \mathrm{C}$ de diferentes materiales híbridos mesoporosos estructurados a partir de siloxanos cúbicos $\mathrm{T}_{8}$-POSS unidos a través de fragmentos arílicos, mostrando la asignación de las bandas de los átomos de carbono contenidos en los sólidos: (a) HYB75P-25B, (b) HYB-75P-25B-CAL y (c) HYB-75P-25B- $\mathrm{NH}_{2}$.

Otra confirmación de la efectiva integración de los fragmentos arílicos en el interior de la estructura de los materiales híbridos sintetizados, proviene del marcado desplazamiento $(\delta)$ observado en las bandas de los átomos de silicio de tipo T cuando se comparan con las del espectro del disilano BTEB puro que actúa como precursor organosilíceo. En este caso, dicho disilano presenta una señal centrada en -59 ppm (Figura 5.19.e), siendo desplazada a un rango comprendido entre -60 a -80 ppm cuando el disilano está integrado covalentemente en el interior de la estructura mesoporosa (Figura 5.19.a $)^{[20]}$. 


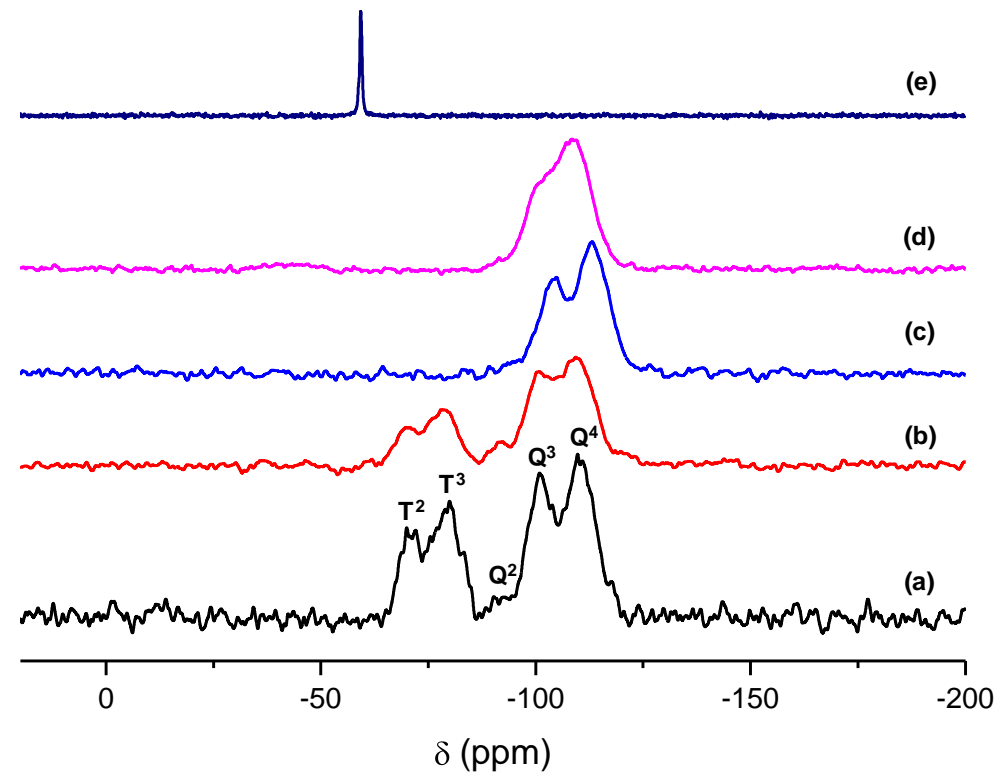

Figura 5.19. Espectros de RMN BD/MAS de ${ }^{29} \mathrm{Si}$ de diferentes materiales híbridos estructurados a partir de los siloxanos $\mathrm{T}_{8}$ - POSS y $\mathrm{BTEB}$, mostrando la asignación de átomos de silicio de tipo $\mathrm{T}$ y $\mathrm{Q}$ : (a) HYB-75P-25B-CAL, (b) HYB-75P-25B-NH 2 , (c) HYB-100P-CAL, (d) muestra convencional M41S y (e) 1,4-bis(trietoxisilil)benceno puro (BTEB).

Por otra parte, a partir de la integración de las bandas correspondientes a los átomos de silicio de tipo $\mathrm{T}$ del espectro de RMN de ${ }^{29} \mathrm{Si}$ de la muestra HYB-75P-25B y, además, considerando la relación $\mathrm{T} /(\mathrm{Q}+\mathrm{T})$, se pudo calcular que se habían incorporado $3.07 \mathrm{mmol}$ de grupos arílicos por cada gramo de $\mathrm{SiO}_{2}$, coincidiendo dicho valor con el estimado a partir de análisis termogravimétrico (3.22 $\mathrm{mmol} \mathrm{g}^{-1}$, ver Tabla 5.1.), lo que confirma la efectividad del proceso ya que prácticamente no ha habido ruptura de enlaces Si-C durante el proceso de síntesis.

A través de la espectroscopia de $\mathrm{RMN}$ de ${ }^{29} \mathrm{Si}$, también es posible obtener pruebas adicionales de la elevada cristalinidad que presentan los materiales mesoporosos estudiados basados en unidades cúbicas $\mathrm{T}_{8}$ - POSS de siloxano si se comparan con materiales silíceos M41S convencionales. En la Figura 5.19.c, se muestra el espectro de RMN de ${ }^{29}$ Si para la muestra HYB-100P, la cual fue preparada empleando únicamente 
monómeros de tipo $\mathrm{T}_{8}$ - POSS como fuente de silicio, donde se puede apreciar una elevada resolución e intensidad de las bandas correspondientes a los átomos de silicio de tipo Q, sobre todo cuando se compara con el espectro de materiales estándar de tipo M41S (Figura 5.19.d). Esta comparación demuestra que los materiales híbridos basados en monómeros cúbicos de tipo $\mathrm{T}_{8}$ - POSS, insertados en las paredes de los sólidos, exhiben una mayor cristalinidad y con ello, presumiblemente, mayor robustez que los materiales mesoporosos convencionales que no presentan orden a corto alcance.

\section{Propiedades texturales}

En la Figura 5.20. se muestran las isotermas de adsorción de nitrógeno de los diferentes materiales híbridos mesoporosos sintetizados con distintas relaciones molares POSS/BTEB. Además, en la Tabla 5.2. se indican los valores de las áreas superficiales específicas así como los volúmenes de poro calculados a partir de sus respectivas isotermas. Los resultados obtenidos muestran claramente que la cantidad de grupos arílicos, finalmente insertados en el interior de la estructura híbrida, influye decisivamente tanto en la superficie y volumen poroso como en la distribución del diámetro de poro exhibido por los sólidos preparados.

Más concretamente, los materiales preparados empleando entre un $5 \%$ y un $25 \%$ en moles de silicio a partir del disilano BTEB, es decir, las muestras nombradas como HYB95P-5B y HYB-75P-25B, respectivamente, exhiben una isoterma de tipo IV típica de materiales mesoporosos con una simetría hexagonal, tal y como se ha descrito para sólidos de tipo M41S (Figura 5.20., derecha) ${ }^{[21]}$, apreciando un fuerte desplazamiento en el punto de inflexión de las isotermas hacia elevados valores de presiones relativas $\left(p / p_{0}\right.$ ?0.3). Este efecto se observa, sobre todo, en la muestra HYB-95P-5B debido a la buena estructuración y la alta regularidad alcanzada cuando se incorpora la cantidad adecuada de unidades arílicas a modo de espaciadores orgánicos, conectándose de forma óptima con los monómeros cúbicos de tipo $\mathrm{T}_{8}$ - POSS para generar materiales porosos homogéneos. En este caso, la superficie BET es superior a $1100 \mathrm{~m}^{2} \mathrm{~g}^{-1}$, debiéndose en su totalidad a la contribución en el rango del mesoporo. Para la muestra HYB-75P-25B, la 
isoterma de adsorción de nitrógeno es similar a la de la muestra HYB-95P-5B, aunque en este caso se obtienen un área superficial y un volumen mesoporoso más bajos $\left(\mathrm{S}_{\mathrm{BET}} \sim 700\right.$ $\mathrm{m}^{2} \mathrm{~g}^{-1}$ ), lo cual puede deberse a una cierta pérdida de regularidad en la distribución mesoporosa. En ambos materiales, la distribución del tamaño de poro está centrada alrededor de $30 \AA$ (Figura 5.21.) en consonancia con los diámetros de poro observados por TEM (como veremos a continuación), estando este parámetro dentro del rango característico observado en los materiales estándar tipo M41S.
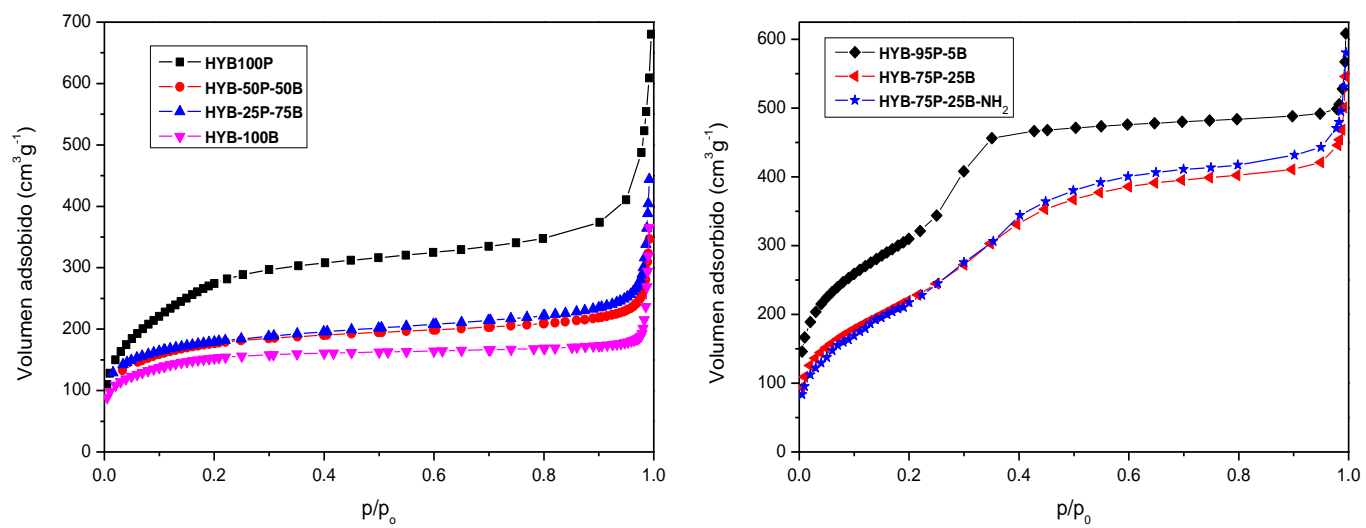

Figura 5.20. Isotermas de adsorción de nitrógeno de diferentes materiales híbridos basados en la combinación covalente entre siloxanos cúbicos, $\mathrm{T}_{8}-\mathrm{POSS}$, y arílicos, BTEB.

Los materiales mesoporosos sintetizados empleando únicamente POSS o los que combinan monómeros de siloxano $\mathrm{T}_{8}$ - POSS con altas cantidades del precursor BTEB (>25\% del total de los moles de silicio como BTEB), presentan isotermas de adsorción de nitrógeno diferentes a las de los materiales hexagonales convencionales (Figura 5.20., izquierda), estando más cercanas a las de los materiales porosos no ordenados, como se

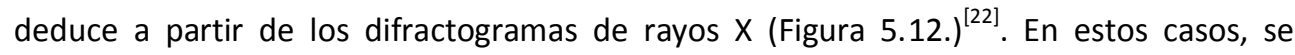
observa el desplazamiento del punto de inflexión en la isoterma de adsorción a presiones relativas más bajas $\left(\mathrm{p} / \mathrm{p}_{0}<0.2\right)$, lo cual indica la existencia de diámetros de poro más pequeños, probablemente, dentro del rango del microporo. El área superficial y el volumen de poro obtenidos para las muestras HYB-50P-50B y HYB-25P-75B (Tabla 5.2.) indican que estos sólidos presentan una contribución microporosa considerable, así como una amplia distribución del diámetro de poro (Figura 5.21.). La irregularidad y la 
estructuración no ordenada mostrada en estos sólidos están en consonancia con los resultados obtenidos previamente a partir de difracción de rayos $X$ (Figura 5.12.). En el caso de la muestra sintetizada empleando sólo cubos tipo POSS (HYB-100P), a pesar de presentar una isoterma característica de los materiales no ordenados, todavía se puede apreciar una ordenación mesoporosa con una distribución del tamaño de poro centrada en $\sim 25 \AA$ (Tabla 5.2.), mejorando, en cierta forma, la estructuración de los materiales mesoporosos cuando se incorpora una cantidad de fragmentos arílicos mayor a un 25\%, respecto a los moles totales de silicio.

Tabla 5.2. Propiedades texturales de los materiales híbridos orgánicos-inorgánicos calcinados.

\begin{tabular}{|c|c|c|c|c|c|c|c|}
\hline Muestra & $\begin{array}{c}\mathrm{S}_{\mathrm{BET}} \\
\left(\mathrm{m}^{2} \mathrm{~g}^{-1}\right)\end{array}$ & $\begin{array}{c}S_{\text {Micro }} \\
\left(\mathrm{m}^{2} \mathrm{~g}^{-1}\right)\end{array}$ & $\begin{array}{c}S_{E x t}^{a} \\
\left(m^{2} g^{-1}\right)\end{array}$ & $\begin{array}{c}\mathrm{V}_{\text {тот }} \\
\left(\mathrm{cm}^{3} \mathrm{~g}^{-1}\right)\end{array}$ & $\begin{array}{c}V_{\text {Micro }} \\
\left(\mathrm{cm}^{3} \mathrm{~g}^{-1}\right)\end{array}$ & $\begin{array}{c}V_{\mathrm{BJH}} \\
\left(\mathrm{cm}^{3} \mathrm{~g}^{-1}\right)\end{array}$ & $\begin{array}{r}d_{\mathrm{BJH}}{ }^{b} \\
(\AA)\end{array}$ \\
\hline HYB-100P & 832 & 0 & 832 & 0.845 & 0 & 0.505 & 25 \\
\hline HYB-95P-5B & 1149 & 0 & 1149 & 0.941 & 0 & 0.552 & 30 \\
\hline HYB-75P-25B & 721 & 0 & 721 & 0.785 & 0 & 0.344 & 30 \\
\hline HYB-50Р-50В & 584 & 201 & 383 & 0.536 & 0.106 & 0.103 & $m p^{c}$ \\
\hline HYB-25P-75B & 602 & 267 & 335 & 0.636 & 0.131 & 0.131 & $\mathrm{mp}$ \\
\hline HYB-100B & 514 & 193 & 321 & 0.564 & 0.100 & 0.045 & $\mathrm{mp}$ \\
\hline HYB-75P-25B-NH & 735 & 0 & 735 & 0.732 & 0 & 0.321 & 30 \\
\hline
\end{tabular}

${ }^{a} \mathrm{~S}_{\mathrm{Ext}}=\left(\mathrm{S}_{\mathrm{BET}}-\mathrm{S}_{\text {Micro }}\right)$ a partir del método t-plot;. ${ }^{b}$ Diámetro de poro BJH; ${ }^{c}$ Distribución del tamaño de poro en el rango de microporo.
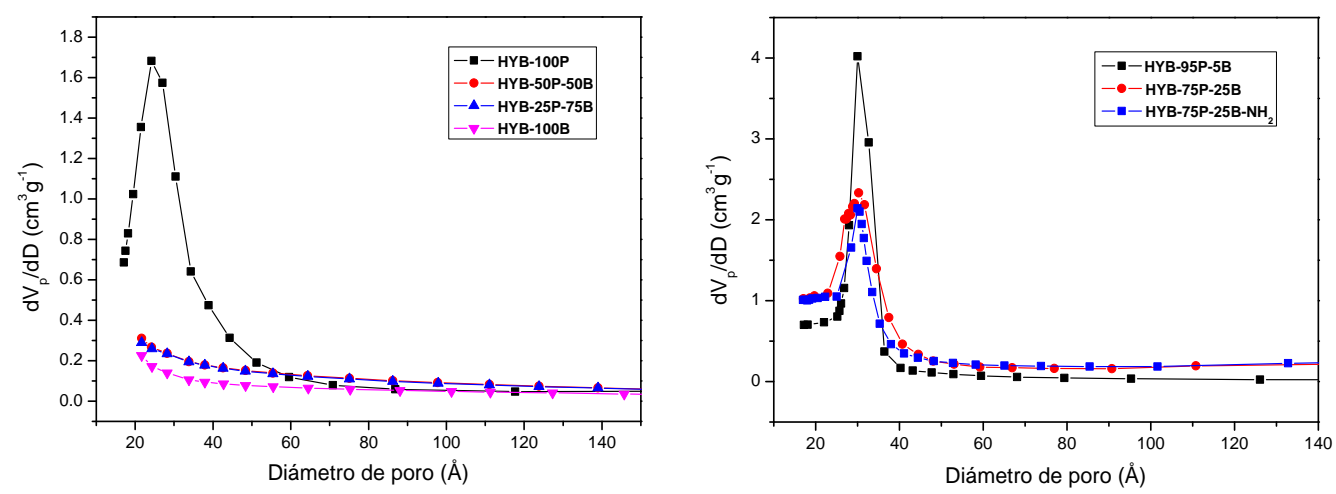

Figura 5.21. Distribución de poro BJH de materiales híbridos mesoporosos basados en interacciones covalentes entre siloxanos cúbicos y arílicos. 
Definitivamente, los resultados texturales obtenidos confirman que si la cantidad de unidades arílicas, finalmente incorporadas en el interior de las paredes de los materiales mesoporosos, es la adecuada, se obtiene una mejor estructuración y homogeneidad porosa debido a la existencia de una distribución óptima entre los fragmentos cúbicos de siloxano y las unidades arílicas que actúan como espaciadores orgánicos estructurales que estabilizan la red organosilícea.

\section{Microscopia electrónica de transmisión}

Las micrografías obtenidas, a partir de microscopia electrónica de transmisión (TEM) de los sólidos híbridos, confirman tanto los resultados observados a través de difracción de rayos $\mathrm{X}$ como los obtenidos a partir del análisis de sus propiedades texturales (Figura 5.22.). En concreto, se observa como las muestras sintetizadas empleando desde un 5\% hasta un $25 \%$ del total de moles de silicio como disilano BTEB (HYB-95P-5B y HYB-75P-25B), combinados con unidades de tipo $\mathrm{T}_{8}$ - POSS, exhiben una distribución ordenada y homogénea de canales porosos en el interior de grandes cristales, tal y como es característico de los materiales mesoporosos hexagonales tipo M41S, siendo el diámetro interno de estas cavidades de alrededor de $30 \AA ̊$ (Figuras 5.22.b, c).

Teniendo en cuenta tanto el algoritmo $a=2 d_{100} / \sqrt{ } 3$, válido para materiales mesoporosos convencionales con simetría hexagonal ${ }^{[23]}$, el valor del espaciado $(d)$ medido para la reflexión (100) a partir de los difractogramas de rayos $X$ (Figura 5.12.), así como el promedio del diámetro de poro estimado por TEM, es posible calcular que el espesor de las paredes de los materiales híbridos sintetizados es de aproximadamente $1.8 \mathrm{~nm}$. Este resultado permite estimar que, aproximadamente, cuatro monómeros cúbicos derivados del siloxano $\mathrm{T}_{8}$ - POSS, organizados a modo de estratos paralelos, están conformando las paredes de los sólidos mesoporosos (Figura 5.23.). 

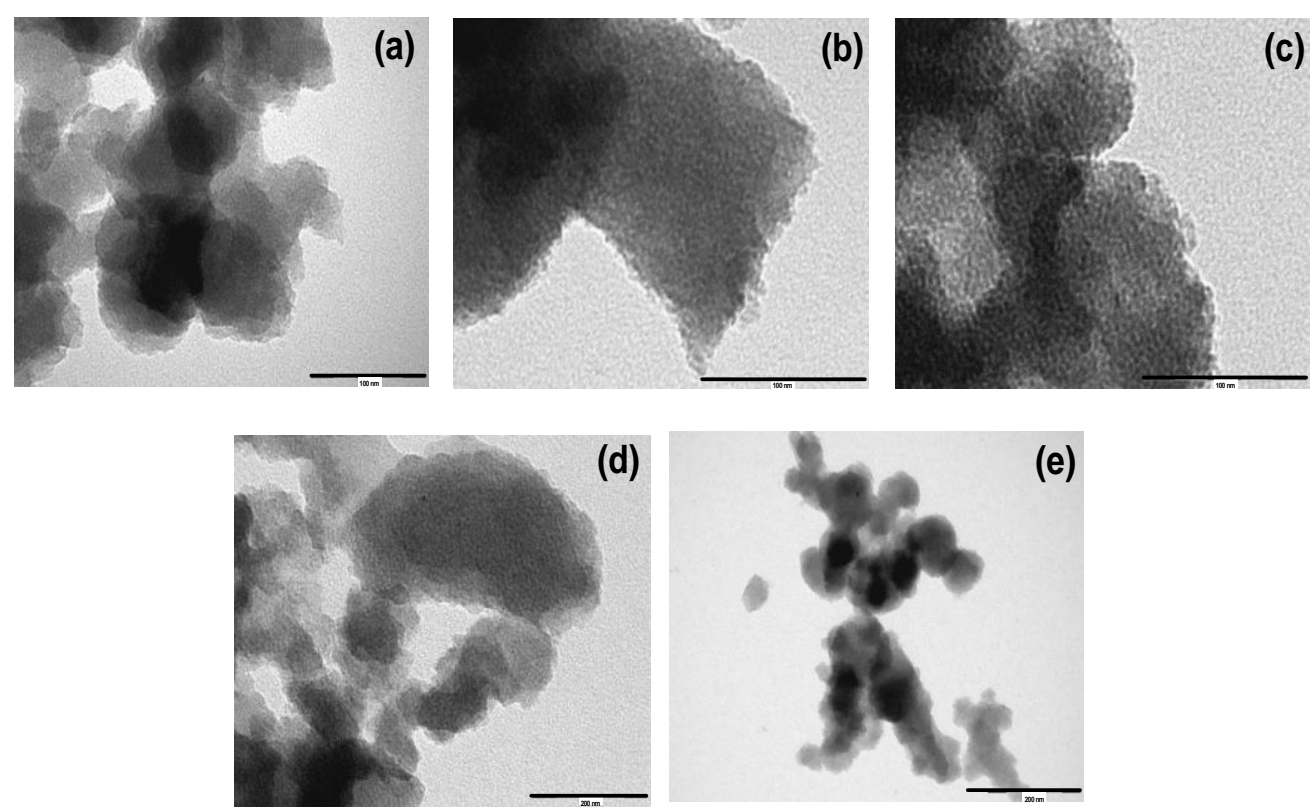

Figura 5.22. Micrografías obtenidas por TEM de las muestras (a) HYB-100P, (b) HYB-95P-5B, (c) HYB75P-25B, (d) HYB-50P-50B y (e) HYB-25P-75B. Escala de referencia para las fotografías (a), (b) y (c) $100 \mathrm{~nm}$ y, (d) y (e) $200 \mathrm{~nm}$.

Por otro lado, los materiales preparados en presencia de únicamente unidades cúbicas tipo POSS (HYB-100P) y, sobre todo, aquellos donde se combina unidades $T_{8}$ POSS con grandes cantidades de disilano BTEB ( $>25 \%$ del total de moles de silicio) exhiben, según la fotografías obtenidas por TEM, una distribución mesoporosa no homogénea con una organización estructural más pobre, como ya se ha deducido anteriormente a través de los difractogramas de rayos $\mathrm{X}$ y el análisis de sus propiedades texturales, siendo apreciable, en estos últimos casos, cierta contribución microporosa entre las pequeñas partículas organosilíceas que se forman (Figuras 5.22.a, d, e). 


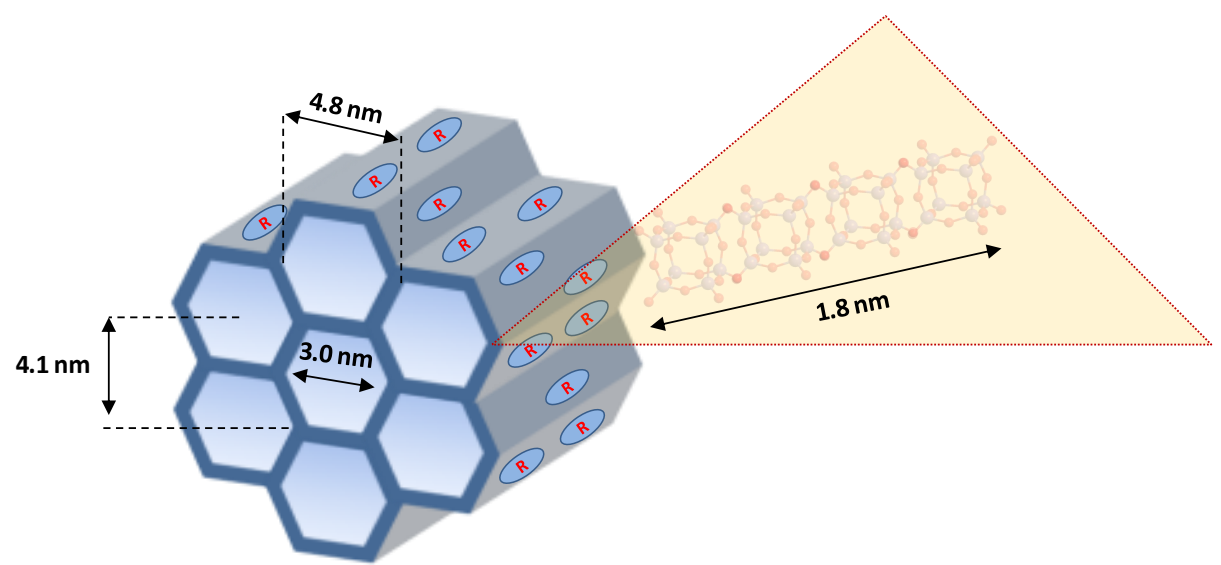

Figura 5.23. Modelo estructural de los materiales híbridos mesoporosos sintetizados a partir del siloxano cúbico $\mathrm{T}_{8}$ - POSS como fuente principal de silicio.

\subsubsection{Incorporación de grupos funcionales básicos}

Como en estudios precedentes, se procedió a realizar un proceso de aminación sobre los materiales mesoporosos híbridos, considerados en el apartado anterior, con el objetivo de generar sólidos con funcionalidades específicas que los conviertan en catalizadores activos y selectivos. Concretamente, se realizó una etapa post-síntesis para la incorporación de grupos nitro, $-\mathrm{NO}_{2}$, los cuales son inmediatamente reducidos para la obtención de unidades amino, $-\mathrm{NH}_{2}$, que están enlazadas covalentemente a los anillos aromáticos que, a su vez, se encuentran conformado la red estructural mesoporosa (ver sección experimental 5.5.). El material finalmente obtenido, HYB-75P-25B-NH , fue caracterizado a través de DRX, apreciándose que el difractograma obtenido (Figura 5.13.g) es prácticamente el mismo que para la muestra preparada antes del proceso de aminación (Figura 5.13.f), confirmándose que la incorporación de grupos amino en los anillos aromáticos tipo puente no altera la organización mesoporosa.

Por medio de los datos obtenidos a través de análisis elemental $(\mathrm{C}, \mathrm{H}, \mathrm{N})$ se confirma que el contenido en carbono disminuye ligeramente con respecto al valor obtenido para la muestra que no ha sido sometida al proceso de aminación, lo cual indica que se puede producir una parcial degradación en algunos de los fragmentos arílicos, presentes a nivel estructural, como consecuencia de las fuertes condiciones ácidas 
empleadas en el proceso post-síntesis (Tabla 5.1., entrada 5). Sin embargo, la presencia de nitrógeno (2.5\% $\mathrm{N}$ en peso) tras la incorporación de grupos amino, confirma la efectividad alcanzada en la introducción de centros básicos en el material, teniendo en cuenta que el contenido en nitrógeno, procedente de las moléculas de surfactante, había sido eliminado completamente en la muestra HYB-75P-25B calcinada (Tabla 5.1., entrada 4). En este caso, la relación molar $\mathrm{C} / \mathrm{N}$ se sitúa alrededor de 6 , lo cual corrobora que en la mayoría de los casos se ha incorporado un grupo amino por cada anillo bencénico.

A través del análisis termogravimétrico (ATG y ATD), se compueba como las curvas obtenidas para la muestra HYB-75P-25B-NH 2 (Figura 5.15.c) son similares a las del material previo calcinado, indicando que los fragmentos arílicos se conservan incluso después de la incorporación de los grupos amino. Únicamente se observa un ligero descenso en el contenido orgánico (15.5\% en peso, ver Tabla 5.1., entrada 5) en la pérdida II, debido, probablemente, a las fuertes condiciones ácidas empleadas durante dicho tratamiento, el cual podría causar la descomposición parcial de algunas unidades arilícas, como también se ha apreciado a partir de los resultados de análisis elemental.

Siguiendo con el estudio de caracterización efectuado a la muestra aminada (HYB-75P-25B- $\mathrm{NH}_{2}$ ), se observa que su espectro infrarrojo exhibe bandas adicionales de vibración situadas a 1350, 1540 y $\sim 1630 \mathrm{~cm}^{-1}$ correspondientes a los modos de vibración bending $\delta-\left(\mathrm{NH}_{2}\right)$, las cuales aparecen junto con las bandas características de los modos de vibración streching $\mathrm{v}-\left(\mathrm{NH}_{2}\right)$, situados entre 3350 y $3500 \mathrm{~cm}^{-1}$. La existencia de ambos modos confirma la efectiva incorporación de grupos amino covalentemente enlazados a los fragmentos arílicos (Figura 5.16.c). Es importante poner de manifiesto que la presencia de bandas asignadas a los grupos aromáticos en el espectro del material, tras el proceso de aminación, corrobora una vez más que las unidades arílicas se conservan durante este post-tratamiento. Además, a través del espectro de infrarrojo obtenido en la zona de red, también se observa la señal de vibración centrada a $\sim 50 \mathrm{~cm}^{-1}$ característica de las unidades tipo D4R (dobles anillos de cuatro miembros), corroborándose que los eslabones estructurales $\mathrm{T}_{8}$ - POSS se conservan después del proceso ácido de aminación, integrados en las paredes de los materiales preparados. Este hecho pondría de manifiesto la elevada 
estabilidad de la red híbrida mesoporosa conformada por unidades cúbicas de siloxano y fragmentos tipo puente de naturaleza arílica (Figura 5.17.b).

La incorporación de grupos amino se puede igualmente confirmar por medio de RMN de ${ }^{13} \mathrm{C}$, observándose, en el espectro de la muestra HYB-75P-25B- $\mathrm{NH}_{2}$, todas las bandas características de los átomos de carbono del anillo aromático enlazado covalentemente a uno o varios grupos amino $\left(-\mathrm{NH}_{2}\right)$. En concreto, se aprecia la banda centrada en $150 \mathrm{ppm}$ atribuida a los átomos de carbono de los fragmentos arílicos directamente unidos a los grupos amino (Figura 5.18.c). Después del tratamiento postsíntesis de aminación, las especies de tipo $\mathrm{Si}-\mathrm{C}$ se siguen conservando ya que las bandas de tipo $\mathrm{T}$, detectadas a través de la espectroscopía de $\mathrm{RMN}$ de ${ }^{29} \mathrm{Si}$, no sufren alteraciones con respecto a la muestra antes de ser sometida al tratamiento de aminación, lo cual confirma tanto la integridad como la estabilidad de las estructuras híbridas con grupos silil-amino incorporados. Sin embargo, el procedimiento ácido utilizado para llevar a cabo esta etapa post-síntesis conlleva probablemente una cierta pérdida de cristalinidad de los materiales orgánicos-inorgánicos mesoporosos, como se puede deducir de la baja resolución alcanzada en la bandas de silicio de tipo Q (Figura 5.19.b).

Por último, es importante resaltar que los sólidos híbridos obtenidos después del proceso de aminación mantienen las propiedades texturales propias de los materiales mesoporosos con estructura hexagonal, mostrando una isoterma de adsorción de nitrógeno, así como un área superficial y volumen poroso similares a los de los materiales mesoporos antes de dicho proceso post-síntesis (HYB-75P-25B) (Figura 5.20. derecha, Figura 5.21. y Tabla 5.2.), lo cual vuelve a reflejar la estabilidad de la estructura híbrida obtenida.

En definitiva, todos los resultados de caracterización arriba mostrados confirman que los grupos amino-arílicos están presentes en la estructura de los materiales híbridos mesoporosos, dotándolos con una funcionalidad adicional que podría hacerlos interesantes como catalizadores básicos en diferentes procesos de química fina. 


\subsubsection{Tratamientos térmicos}

Para comprobar la estabilidad de los materiales híbridos sintetizados se sometió la muestra HYB-75P-25B a un tratamiento térmico consistente en el calentamiento a $100^{\circ} \mathrm{C}$ de una suspensión del material en agua durante una semana, recuperándolo una vez transcurridas 24 horas, siendo entonces caracterizado y sometido de nuevo a dicho calentamiento durante otras 24 horas, así sucesivamente hasta completar una semana. Igualmente, se sometió a dicho tratamiento una muestra convencional de MCM-41 pura sílice, con el fin de demostrar que la presencia de unidades cúbicas, consistentes en dobles anillos de cuatro miembros, aporta rigidez al material y lo hace más estable frente a tratamientos hidrotermales.

En la Figura 5.24. se muestran los espectros de DRX de los sólidos sometidos a $100^{\circ} \mathrm{C}$ después de ser recuperados a distintos tiempos.
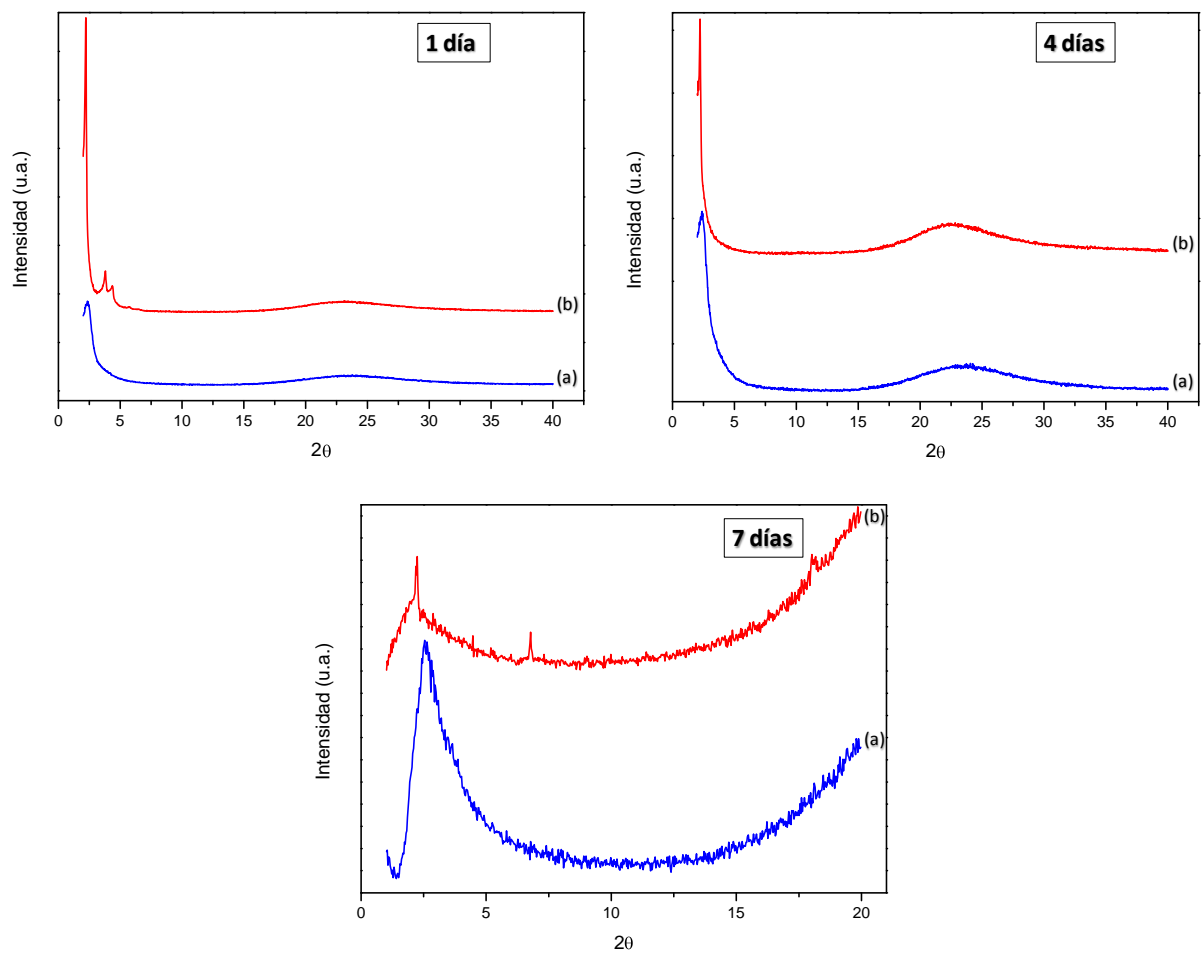

Figura 5.24. Difractogramas de rayos $X$ de los materiales mesoporosos calcinados sometidos a tratamiento térmico $\left(100^{\circ} \mathrm{C}\right.$ y agitación) a diferentes tiempos: (a) HYB-75P-25B y (b) MCM-41. 
A través de los espectros obtenidos por rayos $X$ es posible comprobar cómo la presencia de unidades estructurales cúbicas en el material híbrido lo hace más robusto. Transcurrido un día de tratamiento ambos materiales, tanto el sólido HYB-75P-25B como la MCM-41, conservan su orden, pudiéndose observar claramente sus bandas de difracción características a bajo ángulo. A medida que el tratamiento continúa se puede ver como la calidad de los espectros es mucho menor. Así, en el caso de la MCM-41, transcurridos 4 días, únicamente es posible observar la primera banda de difracción, con una menor intensidad comparado con el espectro realizado a la muestra tras un día de tratamiento, mientras que en el caso del material híbrido mesoporoso, HYB-75P-25B, se sigue observando la banda a bajo ángulo, con la misma intensidad que antes de ser sometido al tratamiento térmico. Por último, tras 7 días, se observa como en ambos casos se ha perdido parte del orden estructural, al presentar bandas de difracción muy poco intensas, siendo este hecho mucho más acusado en el caso de la MCM-41. En el caso del material HYB-75P-25B, se observa que todavía muestra la banda de difracción a bajo ángulo, con cierta intensidad, indicativo de la conservación de su orden a largo alcance.

Todo ello corrobora que la estructura de estos materiales híbridos, integrada por dobles anillos de cuatro miembros, procedentes de la condensación de unidades $\mathrm{T}_{8}-$ POSS unido a la ausencia de sílice amorfa en su entramado, los convierte en sólidos mucho más robustos y estables comparado con otros materiales mesoporosos convencionales tipo M41S.

\subsubsection{Actividad catalítica}

La condensación de Knoevenagel de compuestos carbonílicos que contienen grupos metilénicos altamente reactivos es una ruta de síntesis óptima para la preparación de derivados olefínicos, los cuales son de gran interés como productos finales o intermedios para la generación de sustancias de alto valor añadido en química fina (perfumes, productos farmacéuticos, polímeros) ${ }^{[24]}$. La cinética de la reacción de Knoevenagel ha sido ampliamente estudiada, determinándose que sigue una cinética de primer orden con respecto a cada reactante y al catalizador ${ }^{[25]}$. Además, este proceso se 
ha empleado como reacción test para determinar tanto el número como la fortaleza de los centros básicos presentes en el catalizador utilizado. De este modo, se ha llevado a cabo esta reacción de condensación entre el benzaldehído y sustratos con diferente pKa, es decir, con diferentes grupos metilénicos activados, como son el malononitrilo (pKa 7 ), cianoacetato de etilo (pKa $\approx$ ) y acetoacetato de etilo (pKa $\approx 11)$, en presencia del material híbrido conformado por unidades de tipo $\mathrm{T}_{8}$ - POSS y grupos amino-arilícos, HYB-75P-25B$\mathrm{NH}_{2}$ (Tabla 5.3.). El presente estudio, por lo tanto, sería de utilidad para evaluar tanto la fuerza como la efectividad de los centros básicos presentes en el catalizador híbrido. De los resultados cinéticos obtenidos se puede confirmar la presencia, la accesibilidad y la actividad de dichos centros básicos, consiguiéndose un $99 \%$ de rendimiento a bencilidenmalononitrilo y bencilidencianocinamato de etilo después de 10 y 3.5 horas de reacción, respectivamente, siendo la selectividad cercana al 100\% para ambos casos. Cuando se usa un sustrato con un mayor valor de pKa, como es el acetoacetato de etilo, se obtiene el producto, 2-bencilidenacetoacetato de etilo, después de 24 horas de reacción, con un rendimiento del 66\% (Tabla 5.3. y Figura 5.25.), indicando que los grupos amino introducidos en el material híbrido son capaces de catalizar reacciones que requieren centros básicos relativamente débiles.

Tabla 5.3. Resultados obtenidos para la reacción de condensación de Knoevenagel entre benzaldehído y diferentes sustratos con grupos metileno activados (con diferente $\mathrm{pKa}$ ), empleando el material híbrido mesoporoso HYB-75P-25B- $\mathrm{NH}_{2}$ como catalizador.

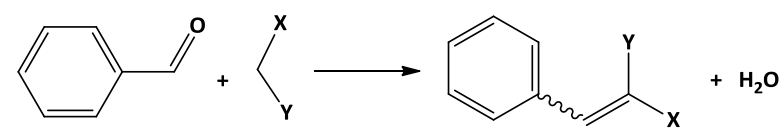

\begin{tabular}{cccccccc}
\hline Entrada & $\mathbf{X}$ & $\mathbf{Y}$ & $\mathbf{T}\left({ }^{\circ} \mathrm{C}\right)$ & $\mathbf{N ~ m o l}(\%)$ & $\mathbf{T}(\mathbf{h})$ & Rend. (\%) & Select. (\%) \\
\hline $\mathbf{1}$ & $\mathrm{CN}$ & $\mathrm{CN}$ & 30 & 2.1 & 10 & $99^{\mathrm{a}}$ & $>99$ \\
$\mathbf{2}$ & $\mathrm{CN}$ & $\mathrm{COOEt}$ & 60 & 3.4 & 3.5 & $99^{\mathrm{b}}$ & $>99$ \\
$\mathbf{3}$ & $\mathrm{COCH}_{3}$ & $\mathrm{COOEt}$ & 80 & 3.4 & 24 & $66^{\mathrm{c}}$ & 92.5 \\
\hline
\end{tabular}

Condiciones de reacción: las pruebas catalíticas fueron realizadas en un matraz cónico cerrado bajo atmósfera de nitrógeno y agitación magnética.

${ }^{a}$ Relación molar benzaldehído ( $\left.4.8 \mathrm{mmol}\right) /$ malononitrilo $(3.3 \mathrm{mmol})=1.45,1 \mathrm{~mL}$ de acetronitrilo como disolvente.

${ }^{\mathrm{b}}$ Relación molar benzaldehído (3 mmol)/cianoacetato de etilo $(2.1 \mathrm{mmol})=1.42,1 \mathrm{~mL}$ de etanol como disolvente.

'Relación molar benzaldehído (3 mmol)/acetoacetato de etilo $(2.1 \mathrm{mmol})=1.42,1 \mathrm{~mL}$ de etanol como disolvente. 


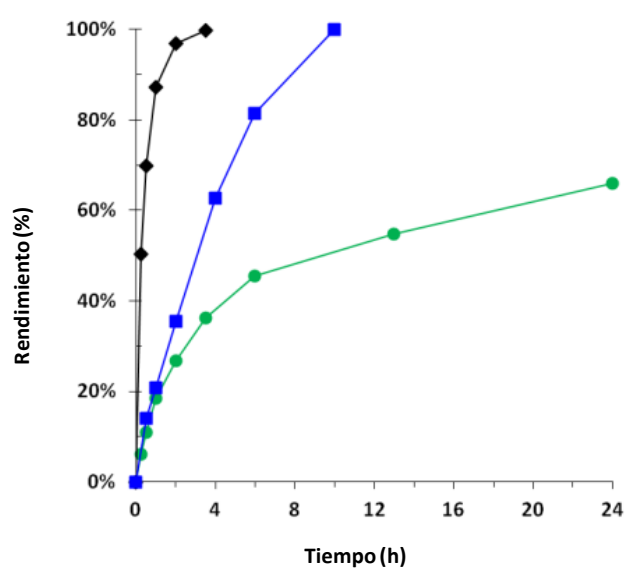

Figura 5.25. Rendimientos de bencilidenmalononitrilo $(\square)$, bencilidencianocinamato de etilo $(\boldsymbol{\nabla})$ y 2 bencilidenacetoacetato de etilo ( $\bullet$ frente al tiempo de reacción para la condensación de Knoevenagel, empleando el material HYB-75P-25B- $\mathrm{NH}_{2}$ como catalizador.

El material HYB-75P-25B- $\mathrm{NH}_{2}$ fue reciclado tres veces para la reacción entre benzaldehído y cianoacetato de etilo. Después de cada ciclo el catalizador fue filtrado, lavado con etanol y finalmente secado a $100^{\circ} \mathrm{C}$ durante 12 horas. A partir de la Figura 5.26., se puede observar que el catalizador puede ser reutilizado durante tres ciclos catalíticos consecutivos sin pérdida de actividad, demostrando la elevada estabilidad como catalizador del material híbrido mesoporoso HYB-75P-25B- $\mathrm{NH}_{2}$.

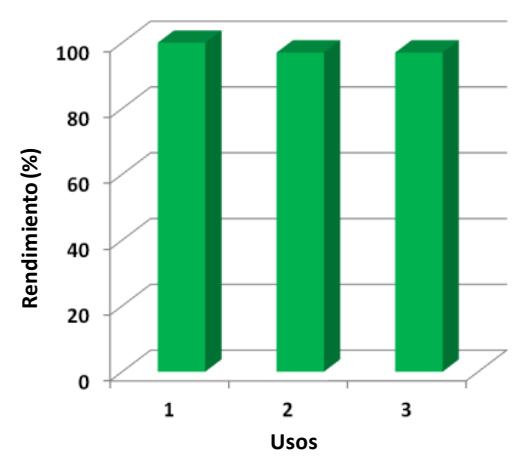

Figura 5.26. Resultados de la actividad catalítica del material híbrido HYB-75P-25B-NH $\mathrm{N}_{2}$ utilizado en la condensación de Knoevenagel entre benzaldehído y cianoacetato de etilo en tres ciclos de reacción consecutivos. Relación molar benzaldehído $(3 \mathrm{mmol}) /$ cianoacetato de etilo $(2.1 \mathrm{mmol})=$ 1.43, $1 \mathrm{~mL}$ de etanol como disolvente, 3.5 horas de reacción. 
Una de las posibles aplicaciones de la reacción de Knoevenagel es la síntesis de cumarinas, las cuales presentan una estructura de benzopirona presente en numerosas fragancias de origen vegetal. Las cumarinas tienen un amplio rango de aplicaciones como aditivos alimentarios y cosméticos, agentes ópticos y tintes y, también, en medicina para la producción de anticoagulantes. En concreto, se ha preparado selectivamente 3cianocumarina a $40^{\circ} \mathrm{C}$ en presencia del material HYB-75P-25B- $\mathrm{NH}_{2}$ a través de la reacción de 2-hidroxibenzaldehído (salicilaldehído) y cianoacetato de etilo (Esquema 5.1.).

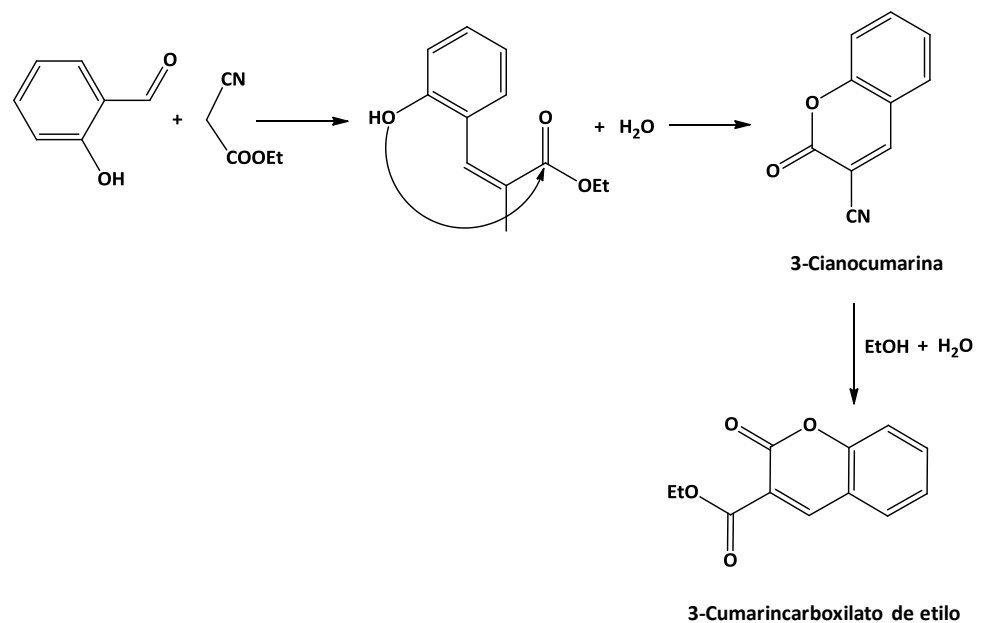

Esquema 5.1. Condensación de Knoevenagel entre 2-hidroxibenzaldehído y cianoacetato de etilo.

Los rendimientos de 3-cianocumarina y cianoacetato de etilo están representados en la Figura 5.27. Específicamente, 3-cianocumarina se obtiene con un rendimiento del 94\%, siendo la conversión completa respecto al cianoacetato de etilo. Además, cuando la reacción se lleva a cabo a $80^{\circ} \mathrm{C}$ en presencia de agua y etanol, es posible convertir la 3cianocumarina en 3-cumarincarboxilato de etilo (Esquema 5.1.). Éste último se obtiene con un rendimiento del $89 \%$ después de 4 horas de reacción, siendo completa la conversión de cianoacetato de etilo junto con otros productos secundarios de cumarina (Figura 5.28.). La posterior conversión de 3-cianocumarina en 3-cumarincarboxilato de etilo constituye una ruta alternativa a su preparación directa a partir de la reacción de condensación de Knoevenagel entre dietilmalonato y salicilaldehído. De hecho, el dietilmalonato es un sustrato con un pKa mayor, cercano a 13, y como se mostró 244 
anteriormente, el material mesoporoso HYB-75P-25B- $\mathrm{NH}_{2}$ presenta centros básicos débiles y no es capaz de llevar a cabo la reacción con sustratos que contengan grupos metilénicos con un pKa superior a 11.

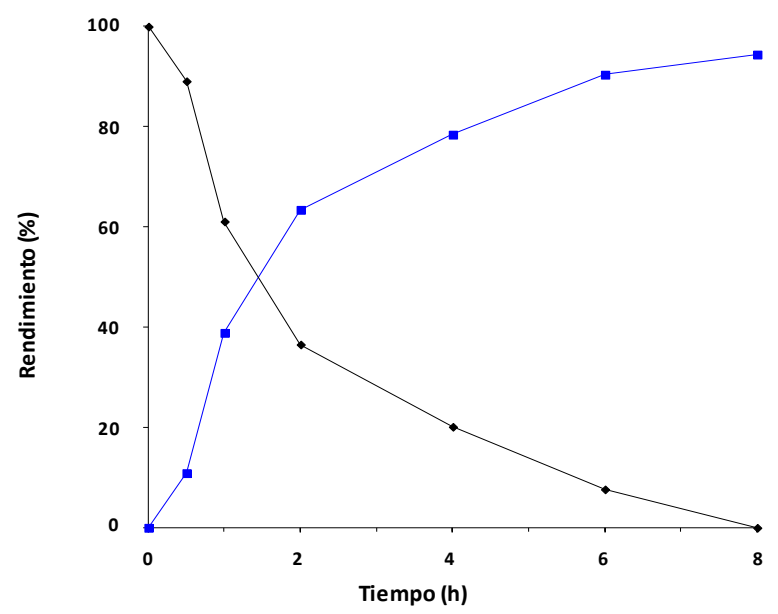

Figura 5.27. Rendimientos de 3-cianocumarina ( $\square$ ) y cianoacetato de etilo $(\diamond)$ frente al tiempo de reacción en presencia del catalizador básico (HYB-75P-25B-NH $_{2}$. Condiciones de reacción: relación molar salicilaldehído $(1.3 \mathrm{mmol}) /$ cianoacetato de etilo $(1.2 \mathrm{mmol})=1.08,1 \mathrm{~mL}$ de etanol como disolvente, $40^{\circ} \mathrm{C}$.

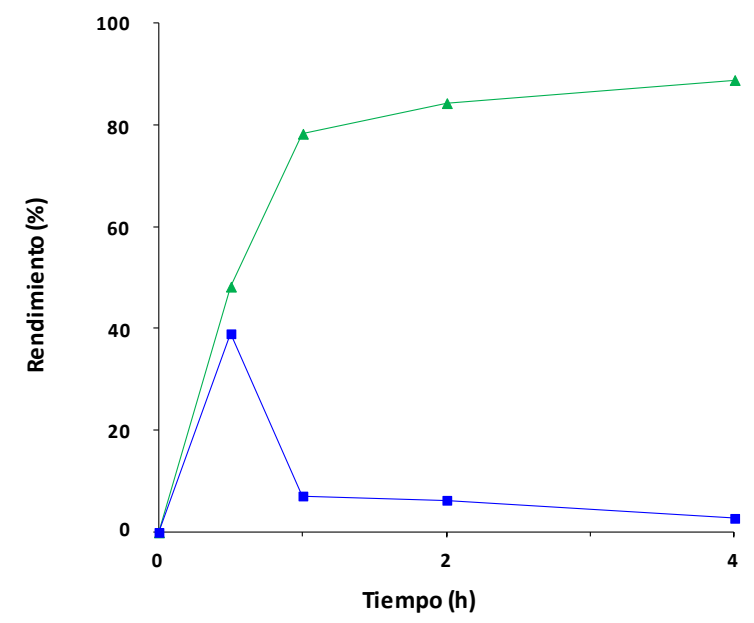

Figura 5.28. Rendimientos de 3-cianocumarina (a) y 3-cumarincarboxilato de etilo $(\boldsymbol{A})$ frente al tiempo de reacción en presencia del catalizador básico (HYB-75P-25B- $\left.\mathrm{NH}_{2}\right)$. Condiciones de reacción: relación molar salicilaldehído $(1.3 \mathrm{mmol}) /$ cianoacetato de etilo $(1.2 \mathrm{mmol})=1.08,1 \mathrm{~mL}$ de etanol y 0.6 $\mathrm{mL}$ de agua, $80^{\circ} \mathrm{C}$. 
La validez como catalizador básico del material híbrido mesoporoso, objeto de estudio en el presente capítulo, puede extenderse a otros procesos más específicos de formación de enlaces $\mathrm{C}-\mathrm{C}$, como es la reacción de Henry (también conocida como reacción nitroaldólica), la cual se basa en la condensación entre un nitroalcano y un aldehído o cetona en presencia de un catalizador básico para formar $\beta$-nitroalcoholes ${ }^{[26]}$. La reacción de Henry es un proceso útil en química orgánica debido a la viabilidad sintética de los productos obtenidos, los cuales pueden convertirse, a su vez, en otros de alto valor añadido. Estas conversiones incluyen la consiguiente deshidratación para generar nitroalquenos, la oxidación de un alcohol secundario para dar lugar a $\alpha$-nitrocetonas o la reducción de un grupo nitro para generar $\beta$-aminoalcoholes. Muchos de estos usos han sido mostrados en la síntesis de varios productos farmacéuticos, incluyendo antibióticos específicos $^{[27]}$. En este trabajo se ha hecho reaccionar benzaldehído con nitrometano (pKa 10.2), empleando el material híbrido HYB-75P-25B- $\mathrm{NH}_{2}$ como catalizador (Esquema 5.2.). Los resultados obtenidos (Figura 5.29.) muestran que, tras 14 horas de reacción, se consigue un rendimiento de nitroestireno del 98\%, siendo importante destacar que, durante la reacción, el producto final obtenido es un nitroalqueno (selectividad del 99\%) formado por la deshidratación consecutiva de nitroalcoholes intermedios.
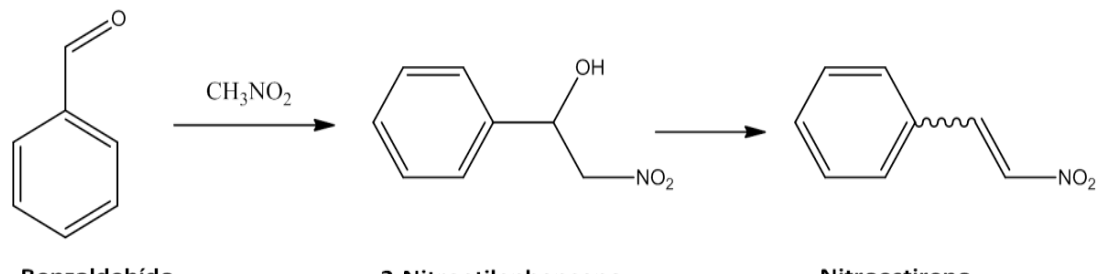

2-Nitroetilenbenceno

Nitroestireno

Esquema 5.2. Reacción de Henry entre benzaldehído y nitrometano. 


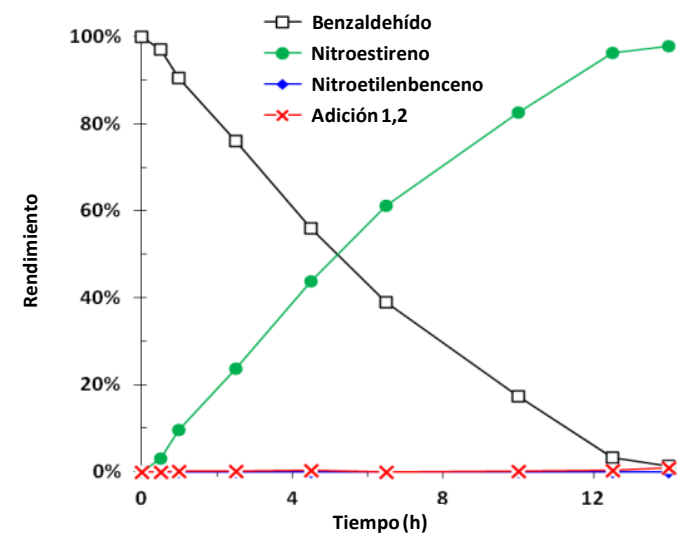

Figura 5.29. Rendimiento a nitroetilenbenceno y nitroestireno frente al tiempo de reacción. Condiciones de reacción: benzaldehído $(1.9 \mathrm{mmol})$ y nitrometano $(14 \mathrm{mmol}), 100^{\circ} \mathrm{C}$, atmósfera inerte $\left(\mathrm{N}_{2}\right)$ y $40 \mathrm{mg}$ de catalizador ( $3.7 \%$ moles de $\left.\mathrm{N}\right)$.

\subsection{Conclusiones}

- Se ha obtenido y caracterizado una nueva familia de materiales mesoporosos híbridos orgánicos-inorgánicos basados en la combinación efectiva de dos tipos diferentes de silsesquioxanos: cúbicos constituidos por dobles anillos de cuatro miembros (D4R), $\mathrm{T}_{8}$ - POSS y tipo puente provenientes de unidades organosilíceas que contienen anillos aromáticos a partir del disilano BTEB ,1,4-bis(trietoxisilil)benceno, siendo utilizado un proceso micelar de ensamblaje molecular en presencia de surfactantes como agentes directores de estructura.

- A través del estudio de caracterización llevado a cabo, se ha confirmado que la estructura de los materiales está conformada por unidades de siloxanos $T_{8}$ - POSS y BTEB enlazados covalentemente, constituyendo una red híbrida estable, robusta y con canales mesoporosos distribuidos homogéneamente, los cuales siguen una simetría hexagonal característica de materiales M41S.

- Se ha confirmado que la mejor estructuración en esta familia de materiales híbridos mesoporosos se consigue empleando una relación adecuada entre los dos tipos de siloxanos utilizados como monómeros estructurales durante el proceso de ensamblaje 
molecular. En concreto, cuando en la síntesis intervienen entre un $5 \%$ y $25 \%$ del total de moles de silicio como BTEB, se han obtenido materiales mesoporosos con una alta homogeneidad y con una distribución del tamaño de poro bien definida, centrada alrededor de $30 \AA$, exhibiendo unas áreas superficiales próximas a los $1000 \mathrm{~m}^{2} \mathrm{~g}^{-1}$. En los casos en que la relación molar utilizada entre ambos tipos de siloxanos está fuera del rango óptimo, los materiales obtenidos muestran una notable disminución en su ordenamiento y regularidad estructural, así como una fuerte reducción en su superficie y volumen poroso, como así se ha confirmado a través de análisis texturales, físico-químicos y espectroscópicos.

- La estructura de este tipo de materiales híbridos mesoporosos conformada, principalmente, por dobles anillos de cuatro miembros (D4R) provenientes de la condensación entre siloxanos $\mathrm{T}_{8}$ - POSS, así como la ausencia de sílice amorfa en su red estructural, ha permitido preparar sólidos mucho más robustos y estables comparado con otros materiales mesoporosos convencionales tipo M41S, siendo este hecho confirmado por su mayor estabilidad hidrotermal al ser sometidos a procesos térmicos $\left(T \geq 100^{\circ} \mathrm{C}\right)$ en presencia de agua.

- La presencia estructural de unidades arílicas insertadas en las paredes de los sólidos mesoporosos puede emplearse como plataforma para la obtención de nuevos materiales funcionales idóneos para ser utilizados en catálisis. Este hecho se ha confirmado por la efectiva incorporación covalente de grupos amino $\left(-\mathrm{NH}_{2}\right)$ en los anillos aromáticos tipo puente presentes en la red organosilícea de los sólidos. Los materiales resultantes se han empleado como catalizadores básicos en diferentes procesos de química fina, mostrando tanto una elevada actividad catalítica como una elevada eficiencia al ser recuperados y reutilizados. 


\subsection{Experimental}

\subsubsection{Síntesis de materiales mesoporosos derivados de POSS}

Los materiales mesoporosos ordenados derivados POSS han sido obtenidos haciendo uso de un surfactante como agente director de estructura, trabajando a $\mathrm{pH}$ ácido y empleando cantidades variables de $\mathrm{T}_{8}$ - POSS y de BTEB como fuentes de silicio, siendo la composición molar en los geles de síntesis:

$$
1 \mathrm{SiO}_{2}\left[x\left(\mathrm{~T}_{8}-\mathrm{POSS}\right)+y(\mathrm{BTEB})\right]: 0.33 \mathrm{C}_{18} \mathrm{TMABr}: 9 \mathrm{HCl}: 133 \mathrm{H}_{2} \mathrm{O}
$$

La preparación de estos materiales consta de dos etapas:

(i) Síntesis

(ii) Calcinación

La etapa de síntesis consiste en la elaboración de un gel, preparando por una parte una disolución ácida que contiene $14.75 \mathrm{~g}$ de $\mathrm{HCl}$ (37\%, Aldrich), $30.51 \mathrm{~g}$ de $\mathrm{H}_{2} \mathrm{O}$ milliQ y 2.15 g de bromuro de octadeciltrimetilamonio ( $\mathrm{C}_{18} \mathrm{TMABr}, 98 \%$, Aldrich). Por otro lado, se prepara una disolución que contiene las cantidades correspondientes de T8silsesquioxano-octakis(tetrametilamonio), (T disueltas en $10 \mathrm{~mL}$ de etanol (extra puro, Scharlau). A continuación, se añade la disolución etanólica a la ácida, gota a gota, y se mantiene en agitación dos horas más a temperatura ambiente. Transcurrido ese tiempo, el gel resultante se envejece a $100^{\circ} \mathrm{C}$ durante 48 horas. Después el gel es filtrado y lavado con abundante agua destilada. El sólido obtenido se seca a $60^{\circ} \mathrm{C}$ durante 12 horas.

Finalmente, el material mesoporoso se somete a un proceso de calcinación en reactor a $400^{\circ} \mathrm{C}$ con flujo de nitrógeno y aire. La programación de temperatura y flujos está representada en la Figura 5.30. 


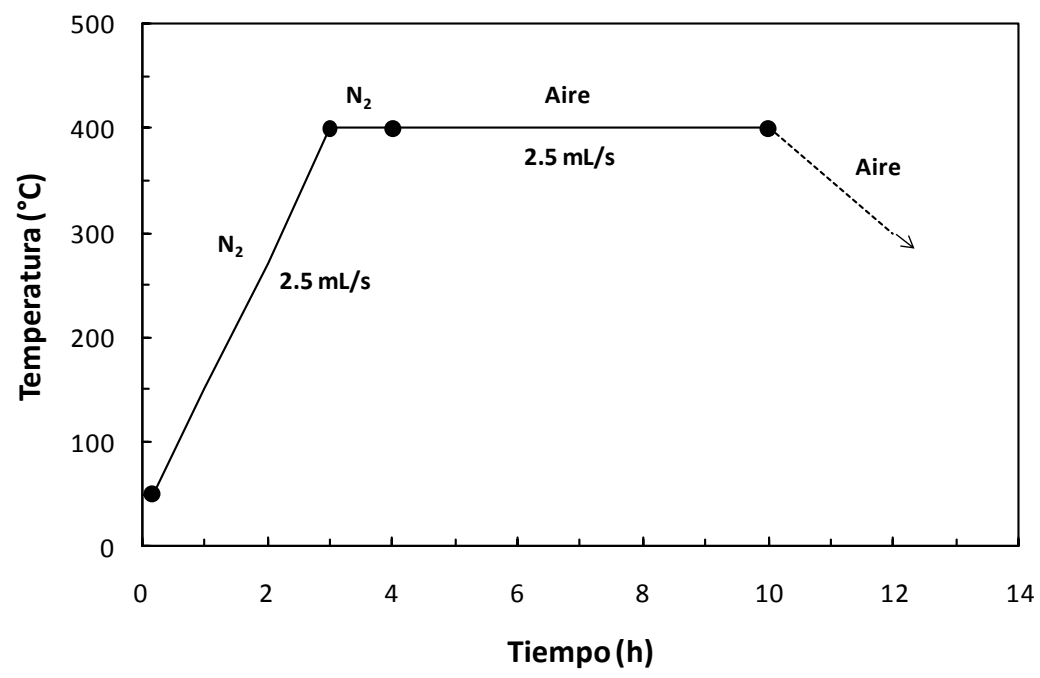

Figura 5.30. Programa de calcinación para la obtención del material HYB-xP-yB.

Tras su calcinación, estos materiales fueron sometidos a diferentes procesos post-síntesis de aminación con el fin de incorporar centros básicos (MWW-BTEB-NH ${ }_{2}$ ). Para estos tratamientos se emplearon los procedimientos descritos anteriormente en otros materiales considerados en esta Tesis (ver apartado 3.3.1.3.).

\subsubsection{Experimentos catalíticos}

Las reacciones de Knoevenagel fueron realizadas en un matraz cónico cerrado bajo atmósfera de nitrógeno y agitación magnética.

- Bencilidenmalononitrilo: se preparó una mezcla de benzaldehído (4.8 mmol) y malononitrilo $(3.3 \mathrm{mmol}$ ) que fue agitada magnéticamente a $303 \mathrm{~K}$ bajo atmósfera inerte $\left(\mathrm{N}_{2}\right)$ a la que se añadió $40 \mathrm{mg}$ de catalizador $(2.1 \% \mathrm{~mol}$ de N). Se empleó acetonitrilo como disolvente (1 mL).

- Cianocinamato de etilo: se preparó una mezcla de benzaldehído (3 mmol) y cianoacetato de etilo $(2.1 \mathrm{mmol})$ que fue agitada magnéticamente a $333 \mathrm{~K}$ bajo atmósfera inerte $\left(\mathrm{N}_{2}\right)$ a la que se añadió $40 \mathrm{mg}$ de catalizador $(3.4 \% \mathrm{~mol}$ de N). Se empleó $1 \mathrm{~mL}$ de etanol como disolvente. 
- 2-bencilidenacetoacetato de etilo: se preparó una mezcla de benzaldehído (3 $\mathrm{mmol}$ ) y acetoacetato de etilo $(2.1 \mathrm{mmol})$ que fue agitada magnéticamente a $353 \mathrm{~K}$ bajo atmósfera inerte $\left(\mathrm{N}_{2}\right)$ a la que se añadió $40 \mathrm{mg}$ de catalizador (3.4 $\%$ mol de N). Se empleó $1 \mathrm{~mL}$ de etanol como disolvente.

La síntesis de cianocumarina se llevó a cabo en un matraz cónico cerrado bajo atmósfera de nitrógeno y agitación magnética.

- Se preparó una mezcla de salicilaldehído $(1.3 \mathrm{mmol})$ y cianoacetato de etilo (1.2 mmol) que fue agitada magnéticamente a $353 \mathrm{~K}$ bajo atmósfera inerte $\left(\mathrm{N}_{2}\right)$ a la que se añadió $40 \mathrm{mg}$ de catalizador (6.2\% mol de $\mathrm{N}$ ).

La reacción de Henry se realizó en matraz cónico cerrado bajo atmósfera de nitrógeno y agitación magnética.

- Nitroestireno: se preparó una mezcla de benzaldehído (1.9 mmol) y nitrometano (14 mmol) que fue agitada magnéticamente a $373 \mathrm{~K}$ bajo atmósfera inerte $\left(\mathrm{N}_{2}\right)$ a la que se añadió $40 \mathrm{mg}$ de catalizador $(3.7 \% \mathrm{~mol}$ de N).

En todos los casos, las muestras se tomaron periódicamente durante el transcurso de la reacción y se analizaron por CG equipado con una columna HP-5 (30 m x $0.25 \times 0.25 \mu \mathrm{m}$ ) y un detector FID. El programa de temperatura empleado fue: $80^{\circ} \mathrm{C}-2$ minutos hasta $300^{\circ} \mathrm{C}$ durante 5 minutos con una rampa de $30^{\circ} \mathrm{C} / \mathrm{min}$. 


\section{Referencias bibliográficas}

[1] P. A. Agaskar, Inorganic Chemistry 1991, 30, 2707.

[2] S. Sulaiman, A. Bhaskar, J. Zhang, R. Guda, T. Goodson, R. M. Laine, Chemistry of Materials 2008, 20, 5563.

[3] J. D. Lichtenhan, Y. A. Otonari, M. J. Carr, Macromolecules 1995, 28, 8435.

[4] X. Zhang, K. J. Haxton, L. Ropartz, D. J. Cole-Hamilton, R. E. Morris, Journal of the Chemical Society, Dalton Transactions 2001, 3261.

[5] F. J. Feher, T. L. Tajima, Journal of the American Chemical Society 1994, 116, 2145.

[6] R. Tamaki, Y. Tanaka, M. Z. Asuncion, J. Choi, R. M. Laine, Journal of the American Chemical Society 2001, 123, 12416.

[7] J. J. Morrison, C. J. Love, B. W. Manson, I. J. Shannon, R. E. Morris, Journal of Materials Chemistry 2002, 12.

[8] K. Naka, M. Fujita, K. Tanaka, Y. Chujo, Langmuir 2007, 23, 9057.

[9] a)R. Laine, M. Roll, M. Asuncion, S. Sulaiman, V. Popova, D. Bartz, D. Krug, P. Mutin, Journal of Sol-Gel Science and Technology 2008, 46, 335; b)M. F. Roll, M. Z. Asuncion, J. Kampf, R. M. Laine, ACS Nano 2008, 2, 320.

[10] a)Y. Hagiwara, A. Shimojima, K. Kuroda, Chemistry of Materials 2007, 20, 1147; b)A. Shimojima, R. Goto, N. Atsumi, K. Kuroda, Chemistry - A European Journal 2008, 14, 8500; c)L. Zhang, H. C. L. Abbenhuis, Q. Yang, Y.-M. Wang, P. C. M. M. Magusin, B. Mezari, R. A. van Santen, C. Li, Angewandte Chemie International Edition 2007, 46, 5003; d)L. Zhang, Q. Yang, H. Yang, J. Liu, H. Xin, B. Mezari, P. C. M. M. Magusin, H. C. L. Abbenhuis, R. A. v. Santen, C. Li, Journal of Materials Chemistry 2008, 18.

[11] C. Kresge, M. Leonowicz, W. Roth, C. Vartuli, S. Beck, Nature 1992, 359, 710.

[12] N. Bion, P. Ferreira, A. Valente, I. S. Goncalves, J. Rocha, Journal of Materials Chemistry 2003, 13, 1910.

[13] S. Fujita, S. Inagaki, Chemistry of Materials 2008, 20, 891.

[14] M. P. Kapoor, S. Inagaki, Bulletin of the Chemical Society of Japan 2006, 79, 1463.

[15] J. Sauer, P. Ugliengo, E. Garrone, V. R. Saunders, Chemical Reviews 1994, 94, 2095.

[16] a)R. A. van Santen, D. L. Vogel, Adv. Solid-State Chem. 1989, 1, 151; b)A. J. M. Man, R. A. van Santen, Zeolites 1992, 12, 269.

[17] a)M. Bärtsch, P. Bornhauser, G. Calzaferri, R. Imhof, J. Phys. Chem. 1994, 98, 2817; b)C. Marcolli, P. Lainé, R. Bühler, G. Calzaferri, J. Tomkinson, The Journal of Physical Chemistry B 1997, 101, 1171.

[18] L. A. Villaescusa, F. M. Márquez, C. M. Zicovich-Wilson, M. A. Camblor, The Journal of Physical Chemistry B 2002, 106, 2796. 
[19] a)Y. Huang, Z. Jiang, Microporous Materials 1997, 12, 341; b)W. Mozgawa, W. Jastrzebski, M. Handke, Journal of Molecular Structure 2005, 744-747, 663.

[20] U. Díaz-Morales, G. Bellussi, A. Carati, R. Millini, W. O. N. Parker Jr, C. Rizzo, Microporous and Mesoporous Materials 2006, 87, 185.

[21] C.-G. Wu, T. Bein, Chemical Communications 1996, 925.

[22] D. A. Loy, J. V. Beach, B. M. Baugher, R. A. Assink, K. J. Shea, J. Tran, J. H. Small, Chemistry of Materials 1999, 11, 3333.

[23] M. Jaroniec, L. A. Solovyov, Langmuir 2006, 22, 6757.

[24] a)I. Rodriguez, S. Iborra, F. Rey, A. Corma, Applied Catalysis A: General 2000, 194-195, 241; b)M. J. Climent, A. Corma, S. Iborra, K. Epping, A. Velty, Journal of Catalysis 2004, 225, 316.

[25] a)F. S. Proust, U. D. Beaucaire, G. R. Dyrkarcz, W. M. Koppes, R. E. Kuznicki, T. A. Marlewski, J. A. Pienkowski, J. M. Puda, J. Org. Chem 1973, 38, 1512; b)G. Jones, Org. React. 1967, 15, 204; c)J. Guyot, A. Kergomard, Tetrahedron 1983, 39, 1167.

[26] a)L. Kurti, B. Czako, Strategic Applications of Named Reactions in Organic Synthesis 2005, Burlington, MA: Elsevier Academic Press, 202; b)O. Noboro, The Nitro Group in Organic Synthesis 2001, New York, NY: WileyVCH., 30.

[27] L. Frederick A, Tetrahedron 2001, 57, 915. 



\section{Capítulo 6}

\section{CONCLUSIONES}

GENERALES 

A lo largo de los capítulos dedicados a la discusión de los resultados experimentales se han ido enumerando las conclusiones extraídas de los mismos de manera detallada.

De forma más general, se enumeran a continuación las conclusiones más importantes de la presente memoria:

- Los resultados obtenidos han confirmado la obtención de nuevos materiales orgánicos-inorgánicos porosos de Clase II con distintos niveles de estructuración y organización, empleando en todos ellos disilanos como precursores durante el proceso de síntesis.

- En concreto, se han sintetizado y caracterizado materiales híbridos de naturaleza laminar, así como materiales mesoporosos ordenados, obtenidos ambos por ensamblaje directo de unidades de estructura previamente formadas, tales como láminas inorgánicas silíceas, siloxanos poliédricos y disilanos. Por otra parte, se han sintetizado y caracterizado materiales orgánicos-inorgánicos mesoporosos no ordenados a través de un proceso sol-gel catalizado por iones fluoruro, empleando disilanos como precursores organosilíceos, en el que las unidades puramente inorgánicas de ensamblaje se forman in situ durante el proceso de síntesis.

- Los materiales híbridos obtenidos presentan unidades orgánicas funcionales insertadas covalentemente en su estructura, mostrando actividad catalítica en diferentes procesos de reacción.

- Se ha confirmado que los materiales híbridos laminares han sido obtenidos a través de un proceso efectivo de pilarización en el que moléculas de disilano se insertan, a modo de pilar, entre las láminas inorgánicas provenientes de silicatos o precursores 
zeolíticos laminares, los cuales son sometidos previamente a una etapa de hinchamiento.

- Los materiales híbridos laminares presentan una mayor accesibilidad debida a la generación de galerías porosas en el espacio interlaminar por las presencia de pilares orgánicos que contienen, a su vez, grupos funcionales activos, ya sea de carácter ácido o básico, los cuales muestran una apreciable actividad catalítica.

- La combinación de grupos funcionales en el espacio interlaminar (básicos) y centros activos (ácidos) en las láminas inorgánicas ha permitido la obtención de materiales híbridos laminares bifuncionales, los cuales exhiben un sistema jerárquico de poros (micro y mesoporosos), siendo empleados con éxito como catalizadores en reacciones consecutivas, tándem o cascada. En estos procesos se llevan a cabo diferentes etapas de reacción, utilizando un único catalizador que es posible recuperar y reutilizar, el cual actua en los diferentes ciclos que componen el proceso sin observar una marcada desactivación del mismo.

- Los resultados obtenidos han confirmado que los procesos sol-gel catalizados por iones fluoruro son una ruta de síntesis viable para preparar materiales mesoporosos híbridos orgánicos-inorgánicos, sin orden estructural a largo alcance, en ausencia de agentes directores de estructura y en condiciones suaves de síntesis, es decir, empleando $\mathrm{pHs}$ cercanos a la neutralidad y temperaturas próximas a la ambiente.

- Siguiendo estos procesos sol-gel en medio fluoruro se han preparado materiales de elevada accesibilidad que presentan insertados en su entramado estructural altos contenidos de fragmentos orgánicos con funcionalidades específicas (ácidas o básicas). 
- A través del estudio de estos materiales híbridos mesoporosos no ordenados, se ha constatado que las propiedades y características de los fragmentos orgánicos incorporados a nivel estructural (rígidos o flexibles), así como las condiciones de síntesis empleadas durante el proceso sol-gel (cantidad de segmentos orgánicos introducidos, concentración de iones fluoruro y tipo de disolvente) influyen decisivamente sobre las propiedades texturales y físico-químicas de los mismos.

- Las diferentes pruebas catalíticas, llevadas a cabo con los materiales mesoporosos híbridos obtenidos a través de procesos sol-gel en medio fluoruro, muestran su validez para ser empleados como catalizadores en procesos de química fina, siendo posible recuperarlos y reutilizarlos nuevamente.

- A través de un proceso micelar por ensamblaje directo de unidades estructurales previamente formadas, tales como siloxanos poliédricos, $\mathrm{T}_{8}-\mathrm{POSS}$, y disilanos (los cuales contienen grupos arílicos a modo de puente), se ha preparado una nueva familia de materiales mesoporosos orgánicos-inorgánicos altamente homogéneos, con una estructura estable y robusta, exhibiendo una simetría hexagonal propia de materiales tipo M41S.

- En estos materiales mesoporosos ordenados obtenidos a partir de siloxanos poliédricos y disilanos, se ha confirmado que es indispensable emplear, durante el proceso de preparación, una relación adecuada entre los dos tipos de unidades estructurales silíceas y organosilíceas para alcanzar un grado de homogeneidad porosa y nivel de organización más elevado.

- Estudios de caracterización pormenorizados han corroborado el efectivo ensamblaje covalente producido entre unidades POSS y disilanos para la generación de materiales híbridos mesoporosos ordenados, confirmándose la integridad de las unidades 
cúbicas formadas por dobles anillos de cuatro miembros (D4R) que conforman su entramado estructural.

- La incorporación post-síntesis de grupos funcionales en las unidades arílicas, las cuales se combinan con los siloxanos poliédricos POSS, ha permitido la generación de materiales híbridos mesoporosos ordenados que poseen centros activos (básicos) altamente accesibles, convirtiéndose de este modo en óptimos catalizadores para llevar a cabo diferentes procesos de reacción con amplio interés en química fina. 
ANEXO I

\section{TÉCNICAS DE}

\section{CARACTERIZACIÓN}



El objetivo de la caracterización físico-química de los catalizadores sintetizados es aportar información estructural, textural así como de las especies presentes y su forma de unión en dichos sólidos. En el presente trabajo se han empleado diversas técnicas de caracterización con el propósito de determinar tanto las propiedades de los nuevos materiales como su composición, estableciendo la influencia de éstas sobre su actividad catalítica.

\section{Difracción de rayos $X$ en polvo (XRD)}

Esta técnica de caracterización está basada en el efecto de la difracción de la radiación X por los planos del retículo cristalino de las muestras siguiendo la ley de Bragg:

$$
n \lambda=2 d_{(h k l)} \operatorname{sen} \vartheta
$$

donde $n$ es un número entero $(n=1,2,3, \ldots), \lambda$ es la longitud de onda de la radiación incidente, $d_{(h k l)}$ es la distancia entre los planos de reflexión que poseen índices de Miller (hkl) y $\vartheta$ es el ángulo de incidencia.

La difracción de rayos $X(D R X)$ es la técnica empleada para la identificación cualitativa de las fases estudiadas, ya que cada material presenta un patrón de difracción característico $^{[1]}$. Además, permite determinar de forma cuantitativa el grado de cristalinidad de una muestra, estableciendo el porcentaje de cada fase presente, y así poder seguir la evolución, durante el periodo de cristalización, de un sistema dado. La determinación de la cristalinidad para cada material se realizó midiendo el área de una o varias bandas de difracción características en una zona del difractograma en el que no existan interferencias debidas a otras fases que pueden competir en las condiciones de síntesis estudiadas, comparándola con la obtenida para una muestra patrón a la que se asigna arbitrariamente el valor de referencia de $100 \%$ de cristalinidad. En el caso de materiales laminares, los difractogramas de rayos $\mathrm{X}$ permiten determinar la distancia interlaminar y su variación debido a la presencia de moléculas de intercambio o intercalación introducidas durante procesos de hinchamiento o pilarización. 
Los difractogramas de las muestras en polvo se adquirieron, de forma general, a temperatura ambiente, en un difractómetro Phillips $X^{\prime}$ Pert empleando radiación monocromática correspondiente a la línea $\mathrm{K} \alpha-\mathrm{Cu}(\lambda=1.54178 \AA$ ̊̊). El difractograma se obtuvo en el rango de ángulos $2 \theta=2-40^{\circ}$ empleando un incremento de $0.02^{\circ}$ por paso durante el barrido. En determinados casos se registraron difractogramas con un barrido más lento (incremento de $0.01^{\circ}$ por paso) entre los ángulos $2 \theta=1-20^{\circ}$, con el objetivo de registrar reflexiones características a ángulos bajos de difracción.

\section{Espectroscopía Infrarroja}

La espectroscopia infrarroja se basa en la medida de la absorción de radiación infrarroja por la muestra. La radiación absorbida corresponde a la frecuencia de vibración de los enlaces que forman parte de los grupos funcionales presentes en los fragmentos o unidades moleculares que componen la muestra, a los cuales va asociada una variación en el momento dipolar. Esta técnica de caracterización proporciona información estructural, superficial y de las propiedades ácido-base de los materiales en función de la región de frecuencias analizada, estando su uso muy generalizado en el estudio de materiales inorgánicos, ya que el número, la posición y la intensidad de las bandas están relacionados con la estructura, fortaleza del enlace y el número de especies activas en el rango infrarrojo.

La espectroscopia con transformada de Fourier (FT-IR) permite una mayor resolución que la espectroscopía infrarroja IR convencional. La técnica se fundamenta en las vibraciones que modulan el momento dipolar en las moléculas, ya que tiene lugar una absorción de radiación IR $(\lambda=750-105 \mathrm{~nm})$ debida a transiciones energéticas en ciertos niveles vibracionales de los enlaces químicos. Un espectro infrarrojo muestra unas bandas específicas, vibraciones características de tensión (streching) o flexión (bending), para cada grupo de átomos, las cuales se caracterizan por la intensidad y rango de frecuencias a las que se producen.

Los espectros de infrarrojo se tomaron a temperatura ambiente en un espectrofotómetro Nicolet 710 FTIR. Para ello se mezclaron 20 mg de muestra seca, 
previamente desgasificada a $100^{\circ} \mathrm{C}$ durante 12 horas, con $100 \mathrm{mg}$ de bromuro pótasico $(\mathrm{KBr})$. Una vez homogeneizada, la mezcla se coloca en un molde y se prensa a vacio durante unos minutos, obteniéndose una pequeña pastilla con un diámetro aproximado de $13 \mathrm{~mm}$.

\section{Espectroscopía laser Raman}

La espectroscopia Raman se fundamenta en la dispersion inelástica que sufren los fotones de una fuente de radiación monocromática, normalmente LASER, al interaccionar con una muestra. Esta técnica permite obtener información acerca de estados vibracionales y rotacionales de los sólidos analizados y de los átomos que los componen, así como acerca de modos de vibración cuantizados de redes cristalinas como los fonones.

Los espectros se adquirieron en un equipo Renishaw Raman In Via equipado con un microscopio Leika DM LM y un diodo laser $785 \mathrm{~nm}$ NIR como fuente de radiación. El laser con una potencia de $30 \mathrm{mV}$ se enfocó sobre regiones de la muestra de 3-5 $\mu \mathrm{m}$ de diámetro, empleando un objetivo 50X y una longitud óptica de $8 \mathrm{~mm}$. Se registraron los espectros en la región de desplazamiento Raman de $100-3000 \mathrm{~cm}^{-1}$, con una resolución <4 $\mathrm{cm}^{-1}$, realizando 10 barridos en un tiempo total de acumulación de $100 \mathrm{~s}$.

\section{Espectroscopía de Resonancia Magnética Nuclear (RMN)}

La espectroscopía de resonancia magnética nuclear (RMN) es una técnica de gran importancia para el análisis de estructuras moleculares, ya que proporciona información sobre el entorno de los átomos que los componen. Se fundamenta en el desdoblamiento de los niveles energéticos de un núcleo de espín distinto de cero por interacción de los momentos magnéticos nucleares con un campo magnético externo muy intenso que debe ser constante y uniforme. La muestra se somete a un campo magnético oscilante adicional que se origina al pasar una corriente de radiofrecuencia. A ciertas frecuencias, los imanes nucleares resuenan con el campo al sufrir transiciones entre niveles de energía. 
Esta técnica permite el análisis de la estructura molecular, debido a que las frecuencias de resonancia de un elemento determinado están influidas por el entorno químico en el que el átomo se encuentra situado. La gran utilidad de esta técnica radica en el hecho de que la variación de la frecuencia de resonancia del núcleo, debida al apantallamiento por los electrones que lo rodean, que se conoce como desplazamiento químico, $\delta$, es característica del entorno químico del núcleo. Por ello, el fenómeno RMN permite identificar el entorno ocupado por los átomos en el interior del sólido. Además de la información directa de las frecuencias de resonancia, los grupos se acoplan unos con otros para producir una estructura fina en el espectro de RMN. La extensión y naturaleza del acoplamiento proporciona información adicional sobre la estructura molecular. La información obtenida de un espectro de resonancia magnética nuclear consiste en desplazamientos químicos (desplazamiento relativo frente a una sustancia de referencia, como TMS para ${ }^{1} \mathrm{H}$ RMN, haciéndose así independiente del campo) y en constantes de acoplamiento, $J$.

Las principales interacciones que se producen son $^{[2]}$ :

- Interacciones dipolares: Debidas a la interacción del núcleo con el campo magnético de los núcleos adyacentes. Pueden ser homonucleares o heteronucleares.

- Interacciones cuadrupolares: Los núcleos con espín I> 1/2 poseen un momento cuadrupolar eléctrico, al tener la carga nuclear distribuida asimétricamente, que interacciona con gradientes de campo eléctrico presentes en el sólido.

- Anisotropía del desplazamiento químico: La magnitud del desplazamiento químico está determinada por las interacciones del núcleo con los electrones de alrededor, pudiendo depender de la orientación de la especie que resuena con respecto al campo. La variación en $\delta$ que depende de la orientación se conoce como anisotropía del desplazamiento químico.

En el caso de líquidos, el rápido movimiento de las moléculas hace que las interacciones nucleares se promedien, con lo que se obtienen espectros de líneas finas. La espectroscopía de $\mathrm{RMN}$ de ${ }^{1} \mathrm{H}$ y ${ }^{13} \mathrm{C}$ de líquidos se ha utilizado en este trabajo para 
caracterizar a las moléculas de los disilanos utilizados. Sin embargo, al analizar las muestras orgánicas-inorgánicas sólidas sintetizadas, las líneas se ensanchan y pierden resolución. El principal problema de esta técnica de caracterización aplicada a sólidos es la anchura de las bandas obtenidas, debido, principalmente, a la interacción dipolar entre distintos núcleos, a interacciones cuadrupolares y anisotropías de desplazamiento químico $^{[3]}$. No obstante, el giro de la muestra en un ángulo de $54^{\circ} 44^{\prime}$, ángulo mágico, respecto de la dirección del campo magnético externo aplicado (MAS-RMN) ${ }^{[4]}$ permite reducir la anchura de las líneas al eliminarse los efectos dipolares entre distintos núcleos y las interacciones cuadrupolares de primer orden, disminuyendo además con esta técnica las anisotropías del desplazamiento químico y las interacciones cuadrupolares de segundo orden.

Para mejorar la relación señal/ruido en los espectros de núcleos con tiempos de relajación largos y poco abundantes, se ha recurrido la polarización cruzada, generalmente de ${ }^{1} \mathrm{H}$, (CP-RMN). La combinación de las técnicas MAS y CP permite obtener una anchura de línea mínima y aumentar la sensibilidad en los espectros de RMN en sólidos. Asimismo, la técnica de polarización cruzada, basada en interacciones dipolares heteronucleares, permite obtener información sobre la proximidad de los núcleos involucrados, de manera que la transferencia de polarización será más efectiva cuanto más próximos estén.

También se emplean otras técnicas como la rotación de ángulo dinámico, la rotación doble, la resonancia magnética nuclear de campo cero o de nutación cuadrupolar. Recientemente, en sólidos se ha empezado a emplear el RMN bidimensional, con el que se puede obtener información de la conectividad entre los distintos átomos. Así, es posible analizar las conectividades Si-O-Si en zeolitas ${ }^{[5]}$, siendo para ello necesario que los materiales estén enriquecidos en ${ }^{29} \mathrm{Si}$.

Los núcleos más estudiados a través de resonancia magnética nuclear en zeolitas son ${ }^{29} \mathrm{Si},{ }^{27} \mathrm{Al},{ }^{13} \mathrm{C},{ }^{1} \mathrm{H},{ }^{19} \mathrm{~F},{ }^{15} \mathrm{~N},{ }^{69,71} \mathrm{Ga},{ }^{11} \mathrm{~B}$ y ${ }^{129} \mathrm{Xe}$, entre otros. En el estudio de materiales zeolíticos esta técnica posee gran variedad de aplicaciones. Así, permite diferenciar varios entornos de $\mathrm{Si}^{[6]}$, diferenciar las distintas posiciones cristalográficas ${ }^{[7]}$, llevar a cabo el seguimiento in situ de reacciones catalíticas ${ }^{[8]}$, determinar la relación Si/Al de la red ${ }^{[6]}$ 
estudiar procesos de desaluminización ${ }^{[9]}$ e isomórficos ${ }^{[10]}$, así como estudiar las especies precursoras de las zeolitas en disolución ${ }^{[11]}$ y determinar la naturaleza de la materia orgánica ocluida en su interior.

Existe una correlación entre el desplazamiento químico del ${ }^{29} \mathrm{Si}$ y el número y tipo de átomos que estén coordinados tetraédricamente a un átomo de silicio a través de átomos de oxígeno puente ${ }^{[12]}$, es decir, depende de la primera esfera de coordinación de un tetraedro de $\mathrm{SiO}_{4}$ determinado. Según esta correlación, es posible distinguir especies $\mathrm{Si}(n \mathrm{Al})^{[12 \mathrm{a}]}$, ya que en zeolitas cada tetraedro de $\mathrm{SiO}_{4}$ está coordinado a $n \mathrm{Al}$ y $(4-n) \mathrm{Si}$, siendo $n=0,1,2,3$ ó 4 . Por lo tanto, existen cinco entornos diferentes para el silicio dependiendo del valor de $n$. Los cinco entornos aparecen en el intervalo -80 a -120 ppm, produciendo cada aluminio una disminución de 5 ppm.

Otro factor que afecta al desplazamiento químico es la geometría del enlace en torno al átomo de Si estudiado, es decir, los ángulos Si-O-T y las longitudes de enlace Si-O. Por lo tanto, se pueden distinguir posiciones cristalográficas no equivalentes, que pueden dar lugar a distintos desplazamientos químicos. Por otra parte, las sustituciones isomórficas de Si ó Al en la red zeolítica por otros elementos produce variaciones del desplazamiento químico de las líneas de ${ }^{29} \mathrm{Si}$ RMN.

A partir del espectro de ${ }^{27} \mathrm{Al}$ es posible determinar la existencia de aluminio coordinado octaédricamente $\left(\mathrm{Al}^{\mathrm{VI}}\right)$ en la zeolita por la presencia de una línea en torno a 0 ppm, que se asigna a aluminio extrarred, bien separada de la señal correspondiente a posiciones $\mathrm{T}$ de la red, ya que el aluminio en coordinación tetraédrica $\left(\mathrm{Al}^{\mathrm{IV}}\right)$ aparece alrededor de 50-60 ppm de desplazamiento químico.

Las medidas de $\mathrm{RMN}$ de ${ }^{29} \mathrm{Si},{ }^{13} \mathrm{C},{ }^{27} \mathrm{Al}$ y ${ }^{19} \mathrm{~F}$ se realizaron en un espectrómetro Bruker AV400 empleando una frecuencia de giro de $5 \mathrm{kHz}$.

Los espectros de RMN de las muestras líquidas se obtuvieron con un espectrómetro Bruker AV300 utilizando diferentes campos $300.13 \mathrm{MHz}$ para el ${ }^{1} \mathrm{H}$ y 75.47 $\mathrm{MHz}$ para el ${ }^{13} \mathrm{C}$. 


\section{Microscopia Electrónica de Transmisión}

Las técnicas de microscopía electrónica proporcionan información local de la forma de las partículas y de la morfología y textura de la superficie de los materiales, así como de su composición química ${ }^{[13]}$. En concreto, en el presente trabajo se ha hecho uso de la microscopia electrónica de transmisión.

La técnica de TEM (Transmission Electron Microscopy) genera una imagen de contraste, de resolución a escala nanométrica, a partir de los electrones transmitidos a través de una muestra ultrafina situada en el camino de un haz de electrones acelerados.

El uso de TEM nos da información sobre la morfología y el tamaño de cristal, igualmente nos permite estudiar al detalle la estructura de los mismos: orientación del cristal, intercrecimientos o defectos cristalinos, e incluso, se puede observar hasta la disposición de los átomos mediante el uso combinado de HRTEM y análisis de imagen por Transformada de Fourier (FT), siempre que se den las condiciones adecuadas.

Las micrografías electrónicas de transmisión que se presentan en este trabajo se obtuvieron en un microscopio Philips CM10 con capacidad para operar a $100 \mathrm{kV}$. Las muestras se prepararon por suspensión del sólido en diclorometano y tratamiento de ultrasonidos durante cinco minutos. Más tarde, se tomó una gota de la parte superior de la suspensión que se depositó sobre una rejilla de cobre (300 mesh) recubierta por una capa agujereada de carbono (honey carbon film).

\section{Análisis Textural}

Una de las propiedades fundamentales de los materiales estudiados en la presente tesis es su porosidad y su superficie específica. La técnica de adsorción de gases se fundamenta en el estudio de los fenómenos de adsorción y desorción gas-sólido para obtener información sobre las propiedades texturales del adsorbente. La interpretación de las isotermas de adsorción-desorción empleando las propiedades geométricas del adsorbato y la modelización matemática de los fenómenos superficiales que determinan la termodinámica de los procesos de adsorción y desorción permiten obtener información 
acerca de la superficie específica, el diámetro de poro y el volumen de poro del sólido estudiado. El adsorbato más comúnmente empleado es el nitrógeno a la temperatura de $196^{\circ} \mathrm{C}$.

La determinación de la superficie específica se realiza utilizando el método BET propuesto por Brunauer, Emmet y $\operatorname{Teller}^{[14]}$ que se basa en dos premisas principales: la superficie del adsorbente es uniforme y no porosa y las moléculas de gas se adsorben sobre capas sucesivas cuando la presión relativa, $p / p_{o}$, tiende al valor 1 , sin considerar las interacciones laterales entre las moléculas del adsorbato, por lo que es aplicable a presiones relativas muy bajas. Dado que en los materiales objeto de estudio la primera premisa no se cumple, los resultados obtenidos sólo son indicativos aunque pueden dar una gran información y permiten que se establezcan comparaciones entre diferentes tipos de materiales porosos. Atendiendo a estas condiciones, la ecuación BET se puede escribir como:

$$
\frac{p}{V\left(p_{0}-p\right)}=\frac{1}{V_{m} c}+\frac{(c-1) p}{V_{m} c p_{0}}
$$

donde: $V$ es el volumen de gas adsorbido por gramo de adsorbente a una presión $p, V_{m}$ es el volumen de gas que se requiere para cubrir la monocapa, $p_{0}$ es la presión de saturación del adsorbato y $c$ es una constante relacionada exponencialmente con el valor de adsorción y condensación del adsorbato. La representación gráfica de los datos de adsorción experimentales $p / V\left(p_{0}-p\right)$ frente a $p / p_{0}$, permite obtener el volumen de gas necesario para completar la monocapa, $V_{m}$, a partir de la pendiente y la ordenada en el origen. Conocido este valor se puede calcular la superficie específica $\mathrm{S}_{\mathrm{BET}}$, expresada en $\mathrm{m}^{2} / \mathrm{g}_{\text {muestra, }}$ a través de la siguiente ecuación:

$$
S_{B E T}=\eta_{m} N_{A} a_{m}
$$

donde $N_{A}$ es el número de Avogadro $\left(6.02 \times 10^{23}\right.$ moléculas $\left./ \mathrm{mol}\right)$ y $a_{m}$ es el área ocupada por una molécula de $\mathrm{N}_{2}\left(16.4 \AA^{2}\right)$.

Se pueden distinguir tres tipos de poros según su diámetro. La clasificación A.S.T.M. (American Section of the International Association for Testing Materials) propone: 
- Microporo: menor de $20 \AA$.

- Mesoporo: entre 20 y $600 \AA ̊$.

- Macroporo: mayor de $600 \AA$.

Para algunos de los materiales estudiados en esta tesis, que combinan microporos con mesoporos y macroporos, en los que se aprecian diferentes tipos de isotermas, es importante determinar la microporosidad escondida en este tipo de sólidos. El área y el volumen de microporo se pueden calcular a partir de los datos de adsorción de nitrógeno, utilizando el procedimiento desarrollado por de Boer ${ }^{[15]}$, denominado “método de la curva $t^{\prime \prime}$, más conocido como t-plot y que consiste en representar el volumen de nitrógeno adsorbido frente al espesor estadístico de una capa adsorbida en una superficie no porosa a una determinada presión relativa $(t)$. El valor de $t$ puede obtenerse a partir de la presión relativa utilizando la ecuación de Harkins y Jura ${ }^{[16]}$ :

$$
t(\AA)=\left(\frac{13.99}{0.034-\log \left(p-p_{0}\right)}\right)^{1 / 2}
$$

Según Greg y Sing ${ }^{[17]}$, la introducción de mesoporos ${ }^{[18]}$ en un sistema microporoso, como ocurre en los materiales pilareados, implica un desvío creciente en la recta $t$-plot para altos valores de $t$. La intersección con el eje $\mathrm{x}$, que mide la cantidad adsorbida, proporciona la contribución del volumen microporoso, mientras que la pendiente en la zona lineal de la curva es proporcional al área debida a mesoporos más el área externa de las partículas. Por otro lado, a partir de la isoterma de adsorción de Ar, realizada a temperatura del argón liquido $\left(-188^{\circ} \mathrm{C}\right)$, es posible obtener el volumen, distribución y tamaño de poro empleando el formalismo de Horvath-Kawazoe ${ }^{[19]}$.

Las isotermas de adsorción-desorción de $\mathrm{N}_{2}$ se registraron a $-196^{\circ} \mathrm{C}$ en un equipo Micrometrics ASAP 2000. La muestra previamente calcinada es pastillada y tamizada para obtener un tamaño de partícula entre 0.59-0.84 mm. Posteriormente, se pre-trata a $100^{\circ} \mathrm{C}$ o $400^{\circ} \mathrm{C}$ y vacío durante toda una noche, dependiendo de si el sólido contiene fragmentos orgánicos en su red estructural, dejándose enfriar finalmente a temperatura ambiente, para determinar exactamente el peso de muestra sobre el que se realizará la adsorción. Para los análisis con $\mathrm{N}_{2}$ se utilizan 250 mg y para los de Ar 150 mg, aproximadamente. 


\section{Análisis Térmico Diferencial y Termogravimétrico}

El análisis térmico (gravimétrico o diferencial) es una técnica que permite determinar y relacionar entre sí las pérdidas de peso (análisis termogravimétrico-ATG) que tiene lugar durante el calentamiento de la muestra a temperatura programada, así como la naturaleza endotérmica y exotérmica de las mismas (análisis termodiferencial-ATD). Así, se puede determinar no solo las pérdidas de peso asociadas al agua y al material orgánico (agentes directores de estructura, ADE, o fragmentos orgánicos estructurales) empleado en la síntesis de materiales, sino también cambios estructurales de una fase cristalina. Estos últimos son procesos exotérmicos, sin pérdida de peso asociada.

Las medidas se han efectuado entre 20 y $800^{\circ} \mathrm{C}$, temperatura a la que generalmente se ha eliminado toda la materia orgánica ocluida en el interior de los materiales, en un equipo Metler Toledo TGA/SDTA 851E, utilizando aproximadamente 10 $\mathrm{mg}$ de muestra. La velocidad de calentamiento es de $10^{\circ} \mathrm{C} / \mathrm{min}$ y los experimentos se realizaron en corriente de aire sintético, con un flujo de $50 \mathrm{~mL} / \mathrm{min}$.

Análisis químico por Plasma de Acoplamiento Inductivo acoplado a un Espectroscopio Óptico de Emisión (ICP-OES)

El análisis químico de una muestra comprende la determinación cualitativa y cuantitativa de los elementos que la constituyen, tanto si se encuentran a nivel mayoritario como minoritario (trazas). La espectroscopía de emisión atómica estudia la emisión de radiación por átomos o iones libres en estado excitado. Esta técnica se basa en la generación y análisis de la radiación emitida por parte de los átomos presentes en un material que es sometido a una serie de procesos consecutivos de disolución, nebulización, ruptura de enlaces para obtener átomos en estado fundamental y, por último, excitación de los mismos ${ }^{[13]}$.

La composición química de los materiales obtenidos se determinó por ICP-OES en un equipo Varian 715-ES. Las muestras sólidas en polvo (aprox. 20-30 mg) se disgregaron en una mezcla de $\mathrm{HNO}_{3} / \mathrm{HF} / \mathrm{HCl}$ de proporciones volumétricas $1 / 1 / 3$. En todos los casos la 
recta de calibrado se adecuó a la concentración aproximada prevista de analito y se determinó utilizando disoluciones estándar (Aldrich).

\section{Análisis Elemental}

La cantidad de materia orgánica presente en los sólidos sintetizados se midió por análisis elemental de C, H, N y S en un analizador Carlo Erba 1106, utilizando sulfanilamida como estándar. 


\section{Referencias bibliográficas}

[1] R. Ballmoos, ED. Butterworth, U.K. 1984.

[2] M. Stöcker, Studies in Surface Science and Catalysis 1994, 85, 429.

[3] a)G. Engelhart, Studies in Surface Science and Catalysis 1991, 58, 285; b)A. D. H. Clague, N. C. M. Alma, Eds. J. Wiley Sons 1989.

[4] a)E. R. Andrew, A. Bradbury, R. G. Eades, Nature 1958; b)I. J. Lowe, Physical Review Letters 1959, 2, 285.

[5] a)C. A. Fyfe, Y. Feng, G. T. Kokotailo, H. Grondey, H. Gies, Bruker Report 1993, 139, 29; b)W. S. Veeman, A. P. M. Kentgens, R. Janssen, Fresenius' Journal of Analytical Chemistry 1987, 327, 63.

[6] J. M. Thomas, J. Klinowski, Adv. In Catal. 1985, 33, 199.

[7] a)M. A. Camblor, A. Corma, S. Valencia, Chemical Communications 1996, 2365; b)C. A. Fyfe, J. H. O'Brien, H. Strobl, Nature 1987, 326, 281.

[8] I. Ivanova, E. G. Derouane, Studies in Surface Science and Catalysis 1994, 85, 357.

[9] J. Datka, W. Kolidziejski, J. Klinowski, B. Sulikowski, Catalysis Letters 1993, 19, 159.

[10] A. Tuel, Y. B. Taarit, Journal of the Chemical Society, Chemical Communications 1992, 1578.

[11] A. V. McCormick, A. T. Bell, Catal. Rev.-Sci. Eng. 1989, 31, 97.

[12] a)E. Lippmaa, M. Maegi, A. Samoson, G. Engelhardt, A. R. Grimmer, Journal of the American Chemical Society 1980, 102, 4889; b)E. Lippmaa, M. Maegi, A. Samoson, M. Tarmak, G. Engelhardt, Journal of the American Chemical Society 1981, 103, 4992.

[13] M. Faraldós, C. Goberna, Consejo Superior de Investigaciones científicas, Madrid, (2002).

[14] S. Brunauer, P. H. Emmett, E. Teller, Journal of the American Chemical Society 1938, 60, 309.

[15] J. H. de Boer, B. C. Lippens, B. G. Linsen, J. C. P. Broekhoff, A. van den Heuvel, T. J. Osinga, Journal of Colloid and Interface Science 1966, 21, 405.

[16] W. D. Harkins, G. Jura, The Journal of Chemical Physics 1943, 11, 430.

[17] B. J. Melde, B. T. Holland, C. F. Blanford, A. Stein, Chemistry of Materials 1999, 11, 3302.

[18] a)M. Kruk, M. Jaroniec, A. Sayari, The Journal of Physical Chemistry $B$ 1997, 101, 583; b)M. Kruk, M. Jaroniec, A. Sayari, Langmuir 1997, 13, 6267.

[19] G. Horvath, K. Kawazoe, J. Chem. Eng. Jpn. 1983, 16, 470. 


\section{ANEXO II}

ÍNDICE DE FIGURAS,

TABLAS Y ESQUEMAS 



\section{ÍNDICE DE FIGURAS}

\section{Capítulo 1: Introducción}

Figura 1.1. Interacciones presentes en materiales híbridos relacionadas con su fuerza relativa. .6

Figura 1.2. Diferentes tipos de materiales híbridos. .7

Figura 1.3. Unidades estructurales inorgánicas: (a) Silanos y derivados, (b) nanopartículas metálicas y (c) precursor laminar. 8

Figura 1.4. Unidades de siloxanos, precursoras de materiales híbridos organosilíceos basados en tetraedros $\mathrm{SiO}_{4}$, obtenidas a través de hidrólisis ácida o básica. 9

Figura 1.5. Esferosilicatos y siloxanos poliédricos derivados como unidades inorgánicas de estructura 9

Figura 1.6. Especies metálicas como unidades estructurales inorgánicas: (a) clusters metálicos (en azul) y (b) nanopartículas metálicas como componentes estructurales de materiales híbridos. .10

Figura 1.7. Ejemplos de láminas inorgánicas de naturaleza zeolítica. .11

Figura 1.8. Ejemplos de moléculas orgánicas de reducidas dimensiones que interaccionan de manera óptima con matrices inorgánicas hidrófilas.

Figura 1.9. Representación artística de macromoléculas y enzimas como ejemplos de unidades estructurales orgánicas que intervienen en la formación de materiales híbridos

Figura 1.10. Unidades discretas de estructura de naturaleza orgánica: Nanotubos de carbono, fullerenos y láminas grafíticas. .14

Figura 1.11. Ejemplos de unidades estructurales orgánicas-inorgánicas: (a) Complejo organometálico y (b) Disilanos .15 
Figura 1.12. Silanos modificados, mono y disilanos, como unidades estructurales que intervienen en procesos de síntesis sol-gel para la obtención de materiales híbridos 16

Figura 1.13. Algunos de los principales disilanos, empleados en la bibliografía, para la preparación de materiales híbridos organosilíceos.

Figura 1.14. Materiales híbridos obtenidos por ensamblaje directo de unidades estructurales. 18

Figura 1.15. Etapas principales de un proceso sol-gel iniciado a partir de tetraalcoxisilanos 20

Figura 1.16. Clasificación de los materiales híbridos orgánicos-inorgánicos de Clase II más representativos en función de las unidades estructurales que los constituyen y del mecanismo de síntesis utilizados para su preparación.

Figura 1.17. (a) Representación esquemática de la estructura básica de una red cristalina metal-orgánica tipo MOF; (b) Ligandos orgánicos bi y multidentados que pueden coordinarse con diferentes especies o clústeres metálicos. 23

Figura 1.18. Proceso de formación de MOFs 24

Figura 1.19. Estructuras metal-orgánicas de la familia del MOF-5 obtenidas por el empleo de diferentes tipos de moléculas bencenodicarboxilato como espaciadores orgánicos.....26 Figura 1.20. Materiales organosilíceos obtenidos a partir de silanos y disilanos funcionalizados. .27

Figura 1.21. Principales tipos de materiales híbridos orgánicos-inorgánicos con organización laminar .30

Figura 1.22. Materiales orgánicos-inorgánicos con diferentes modos de incorporar organocatalizadores. 33

Figura 1.23. Representación esquemática de un catalizador híbrido multifuncional preparado a partir de un precursor tipo disilano que contiene varios centros activos .35 


\section{Capítulo 3: Materiales híbridos laminares}

Figura 3.1. Unidades estructurales de las arcillas. 46

Figura 3.2. Estructura tipo $2: 1$, correspondiente a la montmorillonita, arcilla perteneciente al grupo de las esmectitas.

Figura 3.3. Estructura pilareada de una arcilla tipo $2: 1$ .48

Figura 3.4. Diferentes agentes pilareantes empleados con arcillas como precursores inorgánicos. .49

Figura 3.5. Intercalación de derivados de la prolina en la montmorillonita: (a) intercambio directo por $\mathrm{Na}^{+}$, (b) incorporación adicional de moléculas de alquilamonio en el espacio interlaminar (según referencia [16]). .50

Figura 3.6. Representación esquemática del método de síntesis seguido para la obtención de nanocomposites poliméricos a partir de arcillas (referencias [14] y [17]). .50

Figura 3.7. Estructura de un hidróxido doble laminar. .51

Figura 3.8. Agentes pilareantes más comunes empleados con hidrotalcitas como precursores laminares. .53

Figura 3.9. Ilustración esquemática de materiales híbridos preparados a partir de hidrotalcitas $\mathrm{Mg} / \mathrm{Al}$ con nitratos intercambiables (a), por la intercalación de aniones poli(oxietilensulfato) en forma de monocapa (b) o bicapa (c) en la región interlaminar (siguiendo referencia [31b]). .54

Figura 3.10. Esquema del material híbrido basado en la intercalación de fenilalanina entre láminas ordenadas de hidróxidos dobles laminares (siguiendo referencia [32a]). .54

Figura 3.11. Estructura de diferentes silicatos laminares: (a) Magadiita, (b) Kenyaita e (c) Illerita. .56

Figura 3.12. Esquema del proceso de pilarización empleando TEOS como agente de intercalación y silicatos laminares previamente hinchados. .57 
Figura 3.13. Anclaje de alquilmonosilanos en la magadiita (siguiendo referencia [48]). ....57

Figura 3.14. Generación de nuevas redes estructurales por el anclaje, hidrólisis y polimerización sucesivas de monosilanos partiendo de silicatos laminares como precursores (siguiendo referencia [49]). .58

Figura 3.15. Materiales híbridos pilareados por inserción covalente de disilanos que contienen grupos arílicos a modo de puentes orgánicos utilizando como precursores: (a) Octosilicatos e (b) Ilerita (siguiendo referencias [50a] y [50b]). .58

Figura 3.16. Estructura del titanato laminar JDF-L1 (siguiendo referencia [55a]). 60

Figura 3.17. Hinchamiento y pilareado simultáneo de dodecilamina (DDA) y octilsilano, respectivamente, en el espacio interlaminar del titanato JDF-L1 (siguiendo referencia [60]).

Figura 3.18. Esquema de los precursores zeolíticos laminares tipo (a) MWW, (b) PREFER y (c) Nu6(1)

Figura 3.19. Procesos de hinchamiento, pilarización y deslaminación del precursor zeolítico MWW para la obtención de los materiales MCM-36 e ITQ-2.

Figura 3.20. Esquema del precursor laminar tipo MWW. .65

Figura 3.21. Proceso de síntesis para obtener zeolitas expandidas (IEZ) por tratamiento del precursor laminar MWW con dialquilsilanos (siguiendo referencia [74]). .66

Figura 3.22. Representación de la estructura de la zeolita deslaminada ITQ-2.

Figura 3.23. Zeolita Ti-ITQ-2 obtenida por hibridación de la superficie de las láminas MWW con grupos titanoceno.

Figura 3.24. Representación del material híbrido compuesto por láminas constituidas por oxoaniones de Mo y tetrámeros de Sn (siguiendo referencia [91]). 69

Figura 3.25. Imagen de microscopía electrónica de barrido (SEM) del material híbrido constituido por láminas de grafeno con nanopartículas de Pt soportadas incluidas en una matriz polimérica y porosa de Nafión (siguiendo la referencia [93]). 70 
Figura 3.26. La posible condensación de láminas de makatita para formar láminas de silicato de mayor espesor: (a) Lámina de makatita, proyectada a lo largo del eje $a$, (b) Dos láminas de makatita condensadas para formar una doble lámina constituida por anillos de 4 y 8 miembros (4MR y $8 \mathrm{MR}$ ), (c) Dos láminas de makatita condensadas para dar lugar a una doble lámina formada por anillos de 10 miembros (10MR), (d) Estructura de la magadiita propuesta por Schwieger y col. [37b] y [37d], basada en tres láminas de makatita condensadas según el modelo propuesto en (b) y (e) Estructura propuesta para la magadiita según Nesbitt ${ }^{[95 c]}$, que consiste en 4 láminas de makatita condensadas según el modelo propuesto en (b) y (c) 74

Figura 3.27. Difractograma de rayos $X$ de la Na-magadiita recién sintetizada con la asignación de cada una de sus reflexiones ( $h k l)$. .74

Figura 3.28. Esquema general de preparación de los materiales híbridos pilareados obtenidos a partir de la magadiita como precursor laminar. .76

Figura 3.29. (a) Representación esquemática de los materiales laminares híbridos preparados, utilizando diferentes disilanos como agentes de pilarización. Se incluye la comparación entre las longitudes moleculares de cada uno de los disilanos empleados con el espaciado basal observado por DRX. (b) Disilanos empleados como agentes de pilarización. .78

Figura 3.30. Difractogramas de rayos $X$ de: (a) Na-magadiita, (b) H-magadiita, (c) magadiita hinchada con n-hexilamina y (d) muestra pilareada con BTES antes y (e) después del proceso de extracción ácida (MAG-BTES). .80

Figura 3.31. Difractogramas de rayos $X$ de: (a) Na-magadiita, (b) MAG-BTES, (c) MAGBTMN y (d) MAG-BTEEthy. Los difractogramas de los materiales híbridos pilareados corresponden a los sólidos obtenidos tras el proceso de extracción ácida.

Figura 3.32. Curvas termogravimétricas (ATG) y sus correspondientes derivadas (ATD) de: (a) Na-MAG, (b) MAG-HEX, (c) MAG-HEX-BTES y (d) MAG-BTES. .84 
Figura 3.33. Curvas termogravimétricas (ATG) y sus correspondientes derivadas (ATD) de los materiales extraídos: (a) MAG-BTMN y (b) MAG-BTEEthy. .85

Figura 3.34. Espectros de infrarrojo obtenidos a $300^{\circ} \mathrm{C}$ y vacío de las muestras híbridas laminares derivadas de la magadiita: (a) MAG-BTES, (b) MAG-BTMN, (c) MAG-BTEEthy y (d) Na-MAG

Figura 3.35. Espectros de RMN CP/MAS de ${ }^{13} \mathrm{C}$ de los diferentes materiales híbridos laminares, mostrando la asignación de las bandas a los átomos de carbono contenidos en los sólidos: (a) MAG-BTES, (b) MAG-BTMN y (c) MAG-BTEEthy. .88

Figura 3.36. Espectros de $\mathrm{RMN}$ BD/MAS de ${ }^{29} \mathrm{Si}$ de los diferentes materiales híbridos laminares, mostrando la asignación de átomos de silicio T y Q: (a) Magadiita, (b) MAGBTES, (c) MAG-BTMN y (d) MAG-BTEEthy.

Figura 3.37. Isotermas de adsorción de nitrógeno de los diferentes materiales híbridos laminares derivados de la magadiita. .90

Figura 3.38. Fotografías de microscopía electrónica de transmisión para las muestras: (a) Na-MAG, (b) MAG-BTES, (c) MAG-BTMN y (d) MAG-BTEEthy. Escala de referencia para las fotografías (a), (b) y (c) $100 \mathrm{~nm}$ y (d) $200 \mathrm{~nm}$. .92

Figura 3.39. Transformación de los grupos disulfuro, presentes en el espacio interlaminar de la magadiita pilareada, en fragmentos tiol y sulfónico tras sucesivos procesos de reducción y oxidación. .93

Figura 3.40. Espectros de RMN BD/MAS de ${ }^{13} \mathrm{C}$ de la muestra híbrida MAG-BTES (a), tratada con $\mathrm{P}\left(\mathrm{CH}_{2} \mathrm{CH}_{2} \mathrm{COOH}\right)_{3}$ como agente reductor (b) y, tras un proceso de oxidación con $\mathrm{H}_{2} \mathrm{O}_{2}$ y $_{2} \mathrm{SO}_{4}$ (c). .93

Figura 3.41. Rendimiento a acetato de citronelol frente al tiempo cuando la reacción se llevó a cabo en presencia del catalizador $\mathrm{MAG}-\mathrm{SO}_{3} \mathrm{H}$. Condiciones de reacción: $3.9 \mathrm{mmol}$ citronelol, $2.3 \mathrm{mmol}$ ácido acético, $30 \mathrm{mg}$ de catalizador o $0.56 \% \mathrm{~mol}, 100^{\circ} \mathrm{C}$, sin disolvente. .95 
Figura 3.42. Resultados de actividad catalítica del material híbrido pilareado MAG-BTMN y el sólido basado en sílice mesoporosa HYB-BTMN para llevar a cabo la reacción de condensación de Knoevenagel entre benzaldehído y cianoacetato de etilo. Condiciones de reacción: benzaldehído $(1.9 \mathrm{mmol})$ y cianoacetato de etilo $(1.7 \mathrm{mmol})$, atmósfera inerte $\left(\mathrm{N}_{2}\right), 298 \mathrm{~K}$ y $7 \% \mathrm{~mol}$ de $\mathrm{N}$

Figura 3.43. Esquema de preparación de los materiales híbridos pilareados, MWW-BTEB, obtenidos a partir del precursor zeolítico MWW-P 100

Figura 3.44. Difractogramas de rayos $X$ de: (a) MWW-P, (b) MWW-CTMA, (c) MWWCTMA-BTEB, (d) MWW-BTEB, (e) MWW-BTEB-NH $\mathrm{H}_{2}$ y (f) MWW-BTEB-CAL. 102

Figura 3.45. Moléculas de silsesquioxano y dímeros formados a partir de su condensación: (a) 1,4-bis(trietoxisilil)benceno (BTEB) y (b) agente pilareante arílico derivado del BTEB.102

Figura 3.46. Curvas termogravimétricas (ATG) y sus correspondientes derivadas (ATD) de las muestras: (a) MWW-P, (b) MWW-CTMA, (c) MWW-CTMA-BTEB, (d) MWW-BTEB, (e) MWW-BTEB- $\mathrm{NH}_{2}$ y (f) MWW-BTEB-CAL. 106

Figura 3.47. Espectros de infrarrojo obtenidos a $300^{\circ} \mathrm{C}$ y vacío de las muestras híbridas laminares derivadas del precursor MWW-P: (a) MWW-P-CAL, (b) MWW-BTEB y (c) MWWBTEB- $\mathrm{NH}_{2}$ 108

Figura 3.48. Espectros de RMN CP/MAS de ${ }^{13} \mathrm{C}$ de los diferentes materiales zeolíticos laminares híbridos tipo MWW, mostrando la asignación de las bandas a los átomos de carbono contenidos en los sólidos: (a) MWW-P, (b) MWW-CTMA, (c) MWW-BTEB y (d) MWW-BTEB- $\mathrm{NH}_{2}$ 109

Figura 3.49. Espectros de RMN BD/MAS de ${ }^{29} \mathrm{Si}$ de los diferentes materiales zeolíticos laminares híbridos, mostrando la asignación de átomos de silicio de tipo T y Q: (a) MWW$\mathrm{P}$, (b) MWW-BTEB, (c) MWW-BTEB-NH $\mathrm{N}_{2}$ (d) 1,4-bis(trietoxisilil)benceno puro (BTEB)...111 Figura 3.50. Espectros de RMN BD/MAS de ${ }^{27} \mathrm{Al}$ de los diferentes materiales zeolíticos híbridos: (a) MWW-P, (b) MWW-BTEB y (c) MWW-BTEB- $\mathrm{NH}_{2}$. 112 
Figura 3.51. Isotermas de adsorción de nitrógeno de los diferentes materiales híbridos de tipo MWW. 114

Figura 3.52. Isotermas de adsorción de Argon para materiales con topología MWW......114 Figura 3.53. Distribución de poro BJH de diferentes materiales zeolíticos laminares híbridos con topología MWW. En la gráfica insertada se muestra la distribución de poro, calculada a través del método Horvath-Kawazoe, de los materiales MWW-P-CAL y MWWBTEB.

Figura 3.54. Fotografías de microscopía electrónica de transmisión para las muestras: (a) y (b) MWW-P, (c) y (d) MWW-BTEB. Escala de referencia para las fotografías (a) y (b) 100 $\mathrm{nm},(\mathrm{c}) 500 \mathrm{~nm}$ y (d) $200 \mathrm{~nm}$

Figura 3.55. Modelo teórico del material híbrido MWW-BTEB donde 5/8 de los grupos silanoles han reaccionado con el pilar arílico interlaminar.

Figura 3.56. Clúster representativo del material híbrido pilareado MWW-BTEB. 122

Figura 3.57. Reacción en cascada consistente en dos etapas: Hidrólisis acetal Condensación de Knoevenagel.

Figura 3.58. Resultados de la actividad catalítica del material híbrido bifuncional (MWWBTEB- $\mathrm{NH}_{2}$ ) para la reacción hidrólisis-aldol en cascada. Se representa rendimiento frente a tiempo de reacción del dimetilacetalbenzaldehído (1) (•), benzaldehído (2) (-) y bencilidenmalononitrilo (4) (•). Reacción en cascada en un solo paso: dimetilacetalbenzaldehido (5.45 mmol), malononitrilo (5.24 mmol), $30 \mu \mathrm{L} \mathrm{H}_{2} \mathrm{O}$, acetonitrilo ( $2 \mathrm{~mL}$ ) y $50 \mathrm{mg}$ de catalizador híbrido, durante 7.25 horas a $355 \mathrm{~K}$.

Figura 3.59. Resultados de rendimiento a bencilidenmalononitrilo (4) cuando el catalizador bifuncional MWW-BTEB- $\mathrm{NH}_{2}$ se usa durante cuatro ciclos de reacción consecutivos. 125

Figura 3.60. Molécula de trans-4-aminociclohexanol, empleada para la cristalización del ácido silícico Magadiita. 
Figura 3.61. Molécula de hexametilenimina, empleada para la cristalización del precursor zeolítico laminar MWW-P. 132

\section{Capítulo 4: Materiales híbridos mesoporosos: Procesos sol-gel en medio fluoruro}

Figura 4.1. Ejemplos de catalizadores híbridos obtenidos por el anclaje de monosilanos funcionalizados sobre soportes de alta superficie.

Figura 4.2. Diferentes ejemplos de modos cooperativos establecidos entre centros activos, $A$ y $B$, anclados en la superficie de un soporte que catalizan los reactantes, $R 1$ y $R 2$

Figura 4.3. Esquema de preparación de materiales híbridos no ordenados a través de procesos sol-gel, partiendo de disilanos con fragmentos orgánicos rígidos. 149

Figura 4.4. Auto-ensamblaje molecular de disilanos que poseen cadenas alquílicas a modo de puente debido a las interacciones hidrofóbicas que se establecen entre ellas. 150

Figura 4.5. Material híbrido laminar formado por la interacción electrostática entre grupos ureido-fenilo presentes en las moléculas de silsesquioxano empleadas como precursores: (a) disilano con grupos ureido-fenilo tipo puente, (b) micrografía TEM del material laminar y (c) esquema de la estructura laminar. 151

Figura 4.6. Ensamblaje molecular siguiendo un ordenamiento laminar de disilanos que contienen grupos ureido-quirales a modo de puente. 151

Figura 4.7. Aluminosilicato laminar orgánico-inorgánico denominado ECS-2. 152

Figura 4.8. Métodos para la obtención de materiales híbridos mesoporosos a partir de silanos funcionalizados

Figura 4.9. Proceso de auto-ensamblaje para la obtención de PMOs en presencia de surfactantes (ODTMA) y del disilano bis(trietoxisilil)etano (BTEE) como precursor organosilíceo. 156

Figura 4.10. Modelo artístico de PMO con grupos arílicos formando su red estructural obtenido a partir del disilano BTEB. Los anillos bencénicos están alineados circularmente 
alrededor del canal mesoporoso. Las láminas organosilícicas están dispuestas sucesivamente a lo largo del eje del poro con una separación de $7.6 \AA$ entre las sucesivas láminas formadas por anillos bencénicos. Si naranja; O rojo; C blanco; $\mathrm{H}$ amarillo.

Figura 4.11. Ruta de síntesis seguida para la obtención de PMOs bifuncionales con grupos sulfónicos y amino presentes en su estructura. 158

Figura 4.12. Ruta de síntesis para la obtención de PMOs bifuncionales con grupos arilsulfónicos y amino cohabitando en su estructura.

Figura 4.13. Preparación de materiales zeolíticos con topología Beta que presentan grupos aril-sulfónicos colgando de la superficie de su red cristalina.

Figura 4.14. Esquema de cristalización de los materiales tipo ZOL .161

Figura 4.15. Disilanos (bridged silsesquioxanes) usados como precursores orgánicosinorgánicos para la preparación de materiales híbridos mesoporosos, con sus correspondientes abreviaturas.

Figura 4.16. Procedimiento sol-gel empleado para obtener materiales híbridos no ordenados orgánicos-inorgánicos.

Figura 4.17. Curvas termogravimétricas (ATG) y sus correspondientes derivadas (ATD) de los materiales híbridos.

Figura 4.18. Espectros Raman de los materiales híbridos sintetizados con cada uno de los disilanos. .173

Figura 4.19. Espectros $\mathrm{RMN} C P / \mathrm{MAS}$ de ${ }^{13} \mathrm{C}$ de los diferentes materiales híbridos y la asignación de las bandas a los átomos de carbono que forman parte de los fragmentos orgánicos. 174

Figura 4.20. Espectros de RMN BD/MAS de ${ }^{29} \mathrm{Si}$ de los materiales híbridos y asignación de las bandas $\mathrm{T}$ y $\mathrm{Q}$ de los átomos de $\mathrm{Si}$ que los componen. 176

Figura 4.21. Espectros de $\mathrm{RMN}$ BD/MAS de ${ }^{29} \mathrm{Si}$ de los disilanos de partida usados en la síntesis de los materiales híbridos. 177 
Figura 4.22. Isotermas de adsorción de nitrógeno de los híbridos no ordenados. 180

Figura 4.23. Distribución del diámetro de poro de los materiales híbridos calculado a partir del método $\mathrm{BJH}^{[45]}$ 181

Figura 4.24. Distribución del diámetro de poro del material híbrido HYB-BTES y los materiales mesoporosos convencionales MCM-41, SBA-15 y MSU, calculado a partir del método BJH.

Figura 4.25. Espectros de RMN del material híbrido con una relación $B T E S / T M O S=1$ : $\mathrm{CP} / \mathrm{MAS}$ de ${ }^{13} \mathrm{C}$ (izquierda) y BD/MAS de ${ }^{29} \mathrm{Si}$ (derecha). 184

Figura 4.26. Superficie específica y volumen poroso de muestras híbridas preparadas con diferentes relaciones molares BTEB/TMOS. 186

Figura 4.27. Superficie específica y volumen poroso de muestras híbridas preparadas con diferentes relaciones molares BTES/TMOS. 186

Figura 4.28. Superficie específica y volumen poroso de muestras híbridas preparadas con relaciones molares (BTES/TMOS) $<0.5$. 188

Figura 4.29. Superficie específica y volumen poroso de muestras híbridas preparadas con diferentes relaciones molares $\mathrm{Si} / \mathrm{F}^{-}$, manteniendo la relación $(\mathrm{BTEB} / \mathrm{TMOS})=0.5$. 190

Figura 4.30. Superficie específica y volumen poroso de muestras híbridas preparadas con diferentes relaciones molares $\mathrm{Si} / \mathrm{F}^{-}$, manteniendo la relación $(\mathrm{BTES} / \mathrm{TMOS})=0.5$. 190

Figura 4.31. Superficie específica y volumen poroso de muestras híbridas obtenidas con diferentes disolventes. (Disilano/TMOS) $=0.5$ y $\left(\mathrm{Si}^{-} \mathrm{F}^{-}\right)=319$. 192

Figura 4.32. Superficie específica y volumen poroso de muestras híbridas preparadas con diferentes disolventes. (Disilano/TMOS $)=0.5$ y $\left(\mathrm{Si} / \mathrm{F}^{-}\right)=319$. 192

Figura 4.33. Proceso sol-gel y etapa post-síntesis de oxidación para obtener materiales mesoporosos híbridos con grupos sulfónicos. 193

Figura 4.34. Espectros de $\mathrm{RMN} C P / \mathrm{MAS}$ de ${ }^{13} \mathrm{C}$ del material híbrido con grupos disulfuro antes (HYB-BTES) y después de ser sometido a la etapa de oxidación ( $\left.\mathrm{HYB}-\mathrm{SO}_{3} \mathrm{H}\right)$. 194 
Figura 4.35. Resultados de la actividad catalítica del material híbrido HYB-BTMN en la reacción de Knoevenagel entre benzaldehído y malononitrilo; rendimiento de 2bencilidenmalononitrilo para el primer ciclo $\boldsymbol{\square}, 2^{\underline{0}}$ ciclo $\diamond, 3^{\text {er }}$ ciclo $\boldsymbol{\Delta}, 4^{\underline{0}}$ ciclo $\bullet$ y $5^{\circ}$ ciclo $\square$, Blanco $\bullet$. Condiciones de reacción: benzaldehído $(51.9 \mathrm{mmol})$, malononitrilo (48.5 $\mathrm{mmol}$ ), $6.5 \mathrm{~mL}$ de acetonitrilo, $298 \mathrm{~K}$, atmósfera de nitrógeno y $0.85 \% \mathrm{~mol}$ de $\mathrm{N}$ en el catalizador. 197

\section{Capítulo 5: Materiales híbridos mesoporosos derivados de silanos poliédricos (POSS)}

Figura 5.1. Estructuras de diferentes unidades tipo POSS 210

Figura 5.2. Ejemplo de preparación de unidades POSS funcionalizadas en sus vértices...211

Figura 5.3. Ejemplo de POSS funcionalizado obtenido por un proceso de anclaje postsíntesis a través de los grupos $\mathrm{Si}-\mathrm{OH}$ presentes en los vértices no condensados del poliedro.

Figura 5.4. Diferentes dendrímeros orgánicos-inorgánicos obtenidos a partir de silsesquioxanos poliédricos (POSS). 212

Figura 5.5. Isómeros de unidades Molibdeno-POSS que catalizan la metátesis de olefinas. 212

Figura 5.6. Representación de silsesquioxanos cúbicos $T_{8}$-POSS funcionalizados con grupos fenilamino. 213

Figura 5.7. Incorporación de especies con titanio en redes poliméricas basadas en unidades $T_{8}$-POSS no condensados con grupos silanoles en algunos de sus vértices. .....213 Figura 5.8. Preparación de oligosilsesquioxanos poliédricos (POSS) con grupos carboxílicos. 214

Figura 5.9. Diferentes ejemplos de siloxanos poliédricos funcionalizados soportados sobre sílice de alta superficie. .214 
Figura 5.10. Materiales mesoporosos organizados preparados a partir de unidades vinil- $\mathrm{T}_{8}$ -POSS siguiendo rutas micelares. 215

Figura 5.11. Esquema de la ruta de síntesis empleada para la obtención de los materiales híbridos mesoporosos y representación de la estructura orgánica-inorgánica formada por unidades de tipo $T_{8}$-POSS y arílicas procedentes de sus respectivos silsesquioxanos......218

Figura 5.12. Difractogramas de rayos $X$ de los materiales mesoporosos recién sintetizados: (a) HYB-100P, (b) HYB-50P-50B, (c) HYB-25P-75B, (d) HYB-100B, (e) HYB-95P-5B y (f) HYB75P-25B 220

Figura 5.13. Difractogramas de rayos $X$ de los materiales mesoporosos calcinados: (a) HYB100P, (b) HYB-50P-50B, (c) HYB-25P-75B, (d) HYB-100B, (e) HYB-95P-5B, (f) HYB-75P-25B y (g) HYB-75P-25B- $\mathrm{NH}_{2}$ 221

Figura 5.14. Curvas termogravimétricas (ATG) y sus correspondientes derivadas (ATD) de las muestras: (a) HYB-100P y (b) HYB-100P-CAL 223

Figura 5.15. Curvas termogravimétricas (ATG) y sus correspondientes derivadas (ATD) de las muestras: (a) HYB-75P-25B, (b) HYB-75P-25B-CAL y (c) HYB-75P-25B-NH ${ }_{2}$. .225

Figura 5.16. Espectros de infrarrojo de los materiales calcinados: (a) HYB-100P, (b) HYB75P-25B y (c) HYB-75P-25B- $\mathrm{NH}_{2}$ .226

Figura 5.17. Espectros de infrarrojo en la zona de red para diferentes materiales porosos con un alto contenido silíceo: (a) HYB-75P-25B, (b) HYB-75P-25B-NH ${ }_{2}$, (c) MCM-41 y (d) zeolita A. .228

Figura 5.18. Espectros de $\mathrm{RMN} C P / \mathrm{MAS}$ de ${ }^{13} \mathrm{C}$ de diferentes materiales híbridos mesoporosos estructurados a partir de siloxanos cúbicos $\mathrm{T}_{8}$-POSS unidos a través de fragmentos arílicos, mostrando la asignación de las bandas de los átomos de carbono contenidos en los sólidos: (a) HYB-75P-25B, (b) HYB-75P-25B-CAL y (c) HYB-75P-25B-NH

Figura 5.19. Espectros de RMN BD/MAS de ${ }^{29} \mathrm{Si}$ de diferentes materiales híbridos estructurados a partir de los siloxanos $\mathrm{T}_{8}$ - POSS y BTEB, mostrando la asignación de 


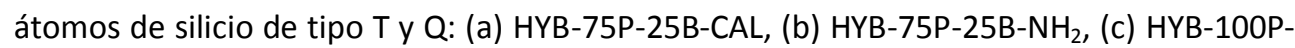
CAL, (d) muestra convencional M41S y (e) 1,4-bis(trietoxisilil)benceno puro (BTEB) ..... 231

Figura 5.20. Isotermas de adsorción de nitrógeno de diferentes materiales híbridos basados en la combinación covalente entre siloxanos cúbicos, $\mathrm{T}_{8}-\mathrm{POSS}$, y arílicos, BTEB

Figura 5.21. Distribución de poro BJH de materiales híbridos mesoporosos basados en interacciones covalentes entre siloxanos cúbicos y arílicos 234

Figura 5.22. Micrografías obtenidas por TEM de las muestras (a) HYB-100P, (b) HYB-95P5B, (c) HYB-75P-25B, (d) HYB-50P-50B y (e) HYB-25P-75B. Escala de referencia para las fotografías (a), (b) y (c) $100 \mathrm{~nm}$ y, (d) y (e) $200 \mathrm{~nm}$ 236

Figura 5.23. Modelo estructural de los materiales híbridos mesoporosos sintetizados a partir del siloxano cúbico $\mathrm{T}_{8}$ - POSS como fuente principal de silicio..... 237

Figura 5.24. Difractogramas de rayos $X$ de los materiales mesoporosos calcinados sometidos a tratamiento térmico $\left(100^{\circ} \mathrm{C}\right.$ y agitación) a diferentes tiempos: (a) HYB-75P25B y (b) MCM-41 240

Figura 5.25. Rendimientos de bencilidenmalononitrilo ( $\boldsymbol{\square})$, bencilidencianocinamato de etilo $(\diamond)$ y 2 -bencilidenacetoacetato de etilo $(\bullet)$ frente al tiempo de reacción para la condensación de Knoevenagel, empleando el material HYB-75P-25B- $\mathrm{NH}_{2}$ como catalizador

Figura 5.26. Resultados de la actividad catalítica del material híbrido HYB-75P-25B-NH utilizado en la condensación de Knoevenagel entre benzaldehído y cianoacetato de etilo en tres ciclos de reacción consecutivos. Relación molar benzaldehído (3 $\mathrm{mmol}) /$ cianoacetato de etilo $(2.1 \mathrm{mmol})=1.43,1 \mathrm{~mL}$ de etanol como disolvente, 3.5 horas de reacción. 243

Figura 5.27. Rendimientos de 3-cianocumarina ( $\mathbf{a}$ ) y cianoacetato de etilo $(\diamond)$ frente al tiempo de reacción en presencia del catalizador básico (HYB-75P-25B- $\mathrm{NH}_{2}$ ). Condiciones 
de reacción: relación molar salicilaldehído (1.3 mmol)/cianoacetato de etilo (1.2 $\mathrm{mmol})=1.08,1 \mathrm{~mL}$ de etanol como disolvente, $40^{\circ} \mathrm{C}$. 245

Figura 5.28. Rendimientos de 3-cianocumarina (a) y 3-cumarincarboxilato de etilo ( $\mathbf{\Delta})$ frente al tiempo de reacción en presencia del catalizador básico (HYB-75P-25B- $\mathrm{NH}_{2}$ ). Condiciones de reacción: relación molar salicilaldehído $(1.3 \mathrm{mmol}) /$ cianoacetato de etilo $(1.2 \mathrm{mmol})=1.08,1 \mathrm{~mL}$ de etanol y $0.6 \mathrm{~mL}$ de agua, $80^{\circ} \mathrm{C}$. 245

Figura 5.29. Rendimiento a nitroetilenbenceno y nitroestireno frente al tiempo de reacción. Condiciones de reacción: benzaldehído (1.9 $\mathrm{mmol})$ y nitrometano (14 $\mathrm{mmol})$, $100^{\circ} \mathrm{C}$, atmosfera inerte $\left(\mathrm{N}_{2}\right)$, y $40 \mathrm{mg}$ de catalizador (3.7\% moles de $\mathrm{N}$ ). 247

Figura 5.30. Programa de calcinación para la obtención del material HYB-xP-yB. 250 


\section{ÍNDICE DE TABLAS}

\section{Capítulo 1: Introducción}

Tabla 1.1. Diferentes tipos de interacciones químicas y sus respectivas fuerzas. 6

\section{Capítulo 3: Materiales híbridos laminares}

Tabla 3.1. Composición de los cinco ácidos silícicos naturales más conocidos en la actualidad .55

Tabla 3.2. Comparación de bandas de difracción de rayos $X$ entre la magadiita descrita en la bibliografía y la sintetizada en este trabajo. .75

Tabla 3.3. Incorporación de grupos orgánicos en el espacio interlaminar de la magadiita estimada por análisis elemental. 82

Tabla 3.4. Propiedades texturales de los materiales híbridos pilareados derivados de la magadiita.

Tabla 3.5. Sólidos de referencia descritos en la bibliografía con centros ácidos presentes en su estructura. Comparación entre la cantidad de centros ácidos accesibles estimados a través de valoraciones ácido-base.

Tabla 3.6. Propiedades texturales y análisis elemental de los catalizadores orgánicosinorgánicos que contienen grupos diamino

Tabla 3.7. Contenido de grupos orgánicos en el espacio interlaminar del precursor de tipo MWW estimado por análisis elemental. Contenido en aluminio estimado por análisis químico. 103

Tabla 3.8. Contenido orgánico en los materiales híbridos de tipo MWW estimado por análisis elemental y termogravimétrico. 107

Tabla 3.9. Propiedades texturales de los materiales híbridos orgánicos-inorgánicos con topología MWW. 
Tabla 3.10. Relación entre el número de moléculas derivadas del disilano BTEB y el contenido orgánico en el material MWW-BTEB.

Tabla 3.11. Resultados catalíticos de la reacción en cascada: Hidrólisis acetal Condensación de Knoevenagel. 124

\section{Capítulo 4: Materiales híbridos mesoporosos: Procesos sol-gel en medio fluoruro}

Tabla 4.1. Análisis elemental y termogravimétrico de las muestras híbridas. 170

Tabla 4.2. Desplazamientos $(\delta)$ de las bandas de los átomos de silicio de tipo $T$ a partir de los espectros de RMN BD/MAS de ${ }^{29} \mathrm{Si}$ de los materiales híbridos porosos y de los disilanos puros utilizados como precursores. 178

Tabla 4.3. Propiedades texturales de los materiales híbridos orgánicos-inorgánicos. 179

Tabla 4.4. Análisis elemental de las muestras obtenidas con los disilanos BTEB y BTES a partir de un gel de síntesis con una composición molar de $1 \mathrm{SiO}_{2}$ [(1-x) TMOS + x Disilano]: $4 \mathrm{MeOH}: 4 \mathrm{H}_{2} \mathrm{O}: 3.13 \times 10^{-3} \mathrm{NH}_{4} \mathrm{~F}$. 184

Tabla 4.5. Contenido en grupos disulfuro y sulfónicos de diferentes materiales mesoporosos obtenidos a partir de BTES. Grado de accesibilidad a los centros ácidos y comparación con su superficie específica. 195

Capítulo 5: Materiales híbridos mesoporosos derivados de silanos poliédricos (POSS)

Tabla 5.1. Contenido orgánico obtenido por análisis elemental y termogravimétrico para las muestras híbridas preparadas a partir de monómeros $\mathrm{T}_{8}$ - POSS y BTEB. 222

Tabla 5.2. Propiedades texturales de los materiales híbridos orgánico-inorgánicos calcinados. 234 
Tabla 5.3. Resultados obtenidos para la reacción de condensación de Knoevenagel entre benzaldehído y diferentes sustratos con grupos metileno activados (con diferente pKa), empleando el material híbrido mesoporoso HYB-75P-25B- $\mathrm{NH}_{2}$ como catalizador...........242 


\section{ÍNDICE DE ESQUEMAS}

\section{Capítulo 3: Materiales híbridos laminares}

Esquema 3.1. Esterificación entre el citronelol y el ácido acético. 95

Esquema 3.2. Condensación de Knoevenagel entre benzaldehído y cianoacetato de etilo 96

\section{Capítulo 4: Materiales híbridos mesoporosos: Procesos sol-gel en medio fluoruro}

Esquema 4.1. (a) Proceso sol-gel: Etapas de hidrólisis y condensación; (b) hidrólisis ácida o básica; (c) sustitución nucleófila de grupos -OR' por iones F. 169

Esquema 4.2. Representación de diferentes materiales obtenidos a través de proceso solgel: (a) elevada relación $\mathrm{Si} / \mathrm{F}^{-}$favorece la formación de un mayor número de partículas pero de menor tamaño, generando cavidades microporosas; (b) baja relación Si/F favorece la generación de un menor número de partículas de mayor diámetro que dan lugar a cavidades mesoporosas. 189

Esquema 4.3. Condensación de Knoevenagel entre benzaldehído y malononitrilo. 196

Capítulo 5: Materiales híbridos mesoporosos derivados de silanos poliédricos (POSS)

Esquema 5.1. Condensación de Knoevenagel entre 2-hidroxibenzaldehído y cianoacetato de etilo. 244

Esquema 5.2. Reacción de Henry entre benzaldehído y nitrometano. 246 



\section{ANEXO III}

\section{LISTA DE ACRÓNIMOS}

Y ABREVIATURAS 



\section{Abreviatura Significado}

\begin{tabular}{|c|c|}
\hline A & Área \\
\hline $\mathrm{ADE}$ & Agente director de estructura \\
\hline $\mathrm{AE}$ & Análisis elemental \\
\hline ATD & Análisis térmico diferencial \\
\hline ATG & Análisis termogravimétrico \\
\hline B.E.T. & Brunnauer-Emmet-Teller \\
\hline B.J.H. & Barret-Joyner-Halenda \\
\hline BTEB & 1,4-Bis(triethoxysilyl)benzene [1,4-bis(trietoxisilil)benceno] \\
\hline BTEE & Bis(triethoxysilyl)ethane [bis(trietoxisilil)etano] \\
\hline BTEEthy & Bis(triethoxysilyl)ethylene [bis(trietoxisilil)etileno] \\
\hline BTES & Bis(triethoxysilylpropyl)disulfide [bis(trietoxisililpropil)disulfuro] \\
\hline BTESM & Bis(triethoxysilyl)methane [bis(trietoxisilil)metano] \\
\hline BTMN & $\begin{array}{l}\text { Bis(trimethoxysilylpropyl)ethylendiamine } \\
\text { [bis(trimetoxisililpropil)etilendiamino] }\end{array}$ \\
\hline CG & Cromatógrafo de gases \\
\hline CG-MS & Cromatógrafo de gases-masas \\
\hline col. & Colaboradores \\
\hline CTMABr & Bromuro de cetiltrimetilamonio \\
\hline СТМАOH & Hidróxido de cetiltrimetilamonio \\
\hline $\mathrm{C}_{18} \mathrm{TMABr}$ & Bromuro de octadeciltrimetilamonio \\
\hline$d$ & Espaciado interplanar cristalino \\
\hline
\end{tabular}




\begin{tabular}{|c|c|}
\hline$d_{\text {BJH }}$ & Diámetro de poro estimado por el método $\mathrm{BJH}$ \\
\hline D4R & Doble four rings (dobles anillos de cuatro miembros) \\
\hline DDA & Dodecilamina \\
\hline DMSO & Dimetilsulfóxido \\
\hline DRX & Difracción de rayos $X$ \\
\hline $\mathrm{EtOH}$ & Etanol \\
\hline FID & Flame Ionization Detector (detector de ionización en llama) \\
\hline FTIR & $\begin{array}{l}\text { Fourier-Transform Infrared spectroscopy (espectroscopia } \\
\text { infrarrojo de transformada de Fourier) }\end{array}$ \\
\hline $\mathrm{HMI}$ & Hexametilenimina \\
\hline HT & Hidrotalcita \\
\hline ICP-OES & $\begin{array}{l}\text { Inductively Coupled Plasma-Optical Emission Spectrometry } \\
\text { (espectrometría de emisión óptica acoplada a plasma de } \\
\text { acoplamiento inductivo) }\end{array}$ \\
\hline IEZ & $\begin{array}{l}\text { Interlayered Expanded Zeolites (materiales zeolíticos } \\
\text { expandidos) }\end{array}$ \\
\hline IZA & International Zeolite Association \\
\hline LDH & Layered double hydroxide (hidróxido doble laminar) \\
\hline $\mathrm{MeOH}$ & Metanol \\
\hline MOF & Metal organic framework (red metal-orgánica) \\
\hline $\mathrm{mp}$ & Microporo \\
\hline MR & Member ring (número de átomos por anillo) \\
\hline $\mathrm{N}_{\mathrm{A}}$ & Número de Avogadro \\
\hline OCTMA & Octadeciltrimetilamonio \\
\hline $\mathrm{OZ}$ & Organozeolita \\
\hline
\end{tabular}




\begin{tabular}{|c|c|}
\hline $\mathrm{p}$ & Presión \\
\hline POSS & $\begin{array}{l}\text { Polyhedral oligomeric silsesquioxanes (silanos oligómericos } \\
\text { poliédricos) }\end{array}$ \\
\hline PMO & $\begin{array}{l}\text { Periodic mesoporous organisilica (organosilica periódica } \\
\text { mesoporosa) }\end{array}$ \\
\hline POM & Polioxometalato \\
\hline Rend. & Rendimiento \\
\hline $\mathrm{RMN}$ & Espectroscopia de resonancia magnética nuclear \\
\hline $\mathrm{S}_{\mathrm{BET}}$ & Superficie BET \\
\hline $\mathrm{S}_{\mathrm{EXT}}$ & Superficie externa \\
\hline $\mathrm{S}_{\mathrm{MIC}}$ & Superficie microporosa \\
\hline Selec. & Selectividad \\
\hline $\mathrm{T}$ & Átomo de silicio o aluminio \\
\hline $\mathrm{T}_{8}-\mathrm{POSS}$ & Silano oligomérico poliédrico formado por 8 átomos T \\
\hline TEM & $\begin{array}{l}\text { Transmission Electron Microscopy (microscopia electrónica de } \\
\text { transmision), }\end{array}$ \\
\hline TEOS & Tetraetilortosilicato \\
\hline $\mathrm{TMA}^{+}$ & Catión tetrametilamonio \\
\hline TMACl & Cloruro de tetrametilamonio \\
\hline TMAOH & Hidróxido de tetrametilamonio \\
\hline TMOS & Tetrametilortosilicato \\
\hline TMS & Tetrametilsilano \\
\hline $\mathrm{TPABr}$ & Bromuro de tetrapropilamonio \\
\hline TPAOH & Hidróxido de tetrapropilamonio \\
\hline
\end{tabular}




\begin{tabular}{cl}
\hline u.a. & Unidades arbitrarias \\
\hline $\mathrm{v}$ & Volumen \\
\hline $\mathrm{V}_{\mathrm{BJH}}$ & Volumen estimado por el método BJH \\
\hline $\mathrm{V}_{\mathrm{MIC}}$ & Volumen microporoso \\
\hline $\mathrm{V}_{\text {Total }}$ & Volumen total \\
\hline ZOL & $\begin{array}{l}\text { Zeolite with Organic group as Lattice (zeolitas con grupos } \\
\text { orgánicos integrando la red estructural) }\end{array}$ \\
\hline
\end{tabular}

\section{Alfabeto}

griego

\begin{tabular}{cl}
\hline$\delta$ & Desplazamiento químico \\
\hline$\theta$ & Ángulo \\
\hline$\lambda$ & Longitud de onda \\
\hline$v$ & Frecuencia de onda \\
\hline
\end{tabular}




\section{RESUMEN}

El campo de los materiales híbridos es una de las temáticas más atractivas y emergentes en nanociencia. La combinación de diferentes precursores con fragmentos orgánicos e inorgánicos por autoensamblaje de sus estructuras originales, durante el proceso de formación de su entramado molecular, permite preparar materiales que exhiben propiedades únicas con múltiples aplicaciones como materiales avanzados.

La presente tesis doctoral se ha centrado en el diseño, síntesis y caracterización de catalizadores funcionales basados en precursores organosiliceos silsesquioxano tipo puente (disilanos), empleando distintas metodologías de síntesis. Como resultado se han obtenido diferentes familias de materiales híbridos porosos con aplicaciones catalíticas.

En primer lugar, a partir de precursores con características laminares, Magadiita y MWW-P, sometidos a procesos de intercambio, hinchamiento, pilarización y extracción de materia orgánica, se incorporaron grupos funcionales activos en su estructura, a modo de pilares intercalados, al mismo tiempo que se mejoraron sus propiedades texturales originales, generándose catalizadores multifuncionales estables y reutilizables para llevar a cabo reacciones consecutivas o en cascada.

Se ha obtenido una segunda familia de materiales mesoporosos orgánicosinorgánicos no ordenados, en ausencia de agentes directores de estructura, a través de un proceso sol-gel en medio fluoruro, lográndose introducir fragmentos orgánicos estructurales, los cuales están formando parte de la red de los materiales. En ellos, se ha estudiado la influencia de las características de los disilanos empleados como precursores en las propiedades finales de los sólidos híbridos obtenidos.

Por último, se prepararon materiales mesoporosos orgánicos-inorgánicos ordenados basados en silanos poliédricos POSS, que actúan como nodos estructurales, unidos entre sí a través de moléculas de disilanos con fragmentos arílicos. Para ello, se ha empleado una ruta micelar de síntesis en condiciones ácidas. Finalmente, los materiales 
obtenidos se sometieron a un proceso de funcionalización, para la introducción de centros activos accesibles en su estructura.

Tanto los materiales híbridos mesoporosos ordenados como no ordenados, con funciones activas integradas en su estructura, han sido utilizados con éxito como catalizadores selectivos para llevar a cabo diferentes procesos en química fina. 


\section{RESUM}

El camp dels materials híbrids és una de les temàtiques més atractives i emergents en nanociència. La combinació de diferents precursors amb fragments orgànics i inorgànics per autoensamblatje de les seues estructures originals, durant el procés de formació del seu entramat molecular, permitix preparar materials que exhibeixen propietats úniques amb múltiples aplicacions com materials avançats.

La present tesi doctoral ha estat centrada en el disseny, síntesi i caracterització de catalitzadors funcionals basats en precursors organosilicis silsesquioxà tipus pont (disilans), fent us de distintes metodologies de síntesi. Com a resultat s'han obtés diferents famílies de materials híbrids porosos amb aplicacions catalítiques.

En primer lloc, a partir de precursors amb característiques laminars, Magadiita i MWW-P, sotmesos a processos d'intercanvi, unflament, pilarització i extracció de matèria orgànica, es varen incorporar grups funcionals actius en la seua estructura, a mode de pilars intercalats, al mateix temps que es milloraren les seues propietats texturals originals, generant-ne catalitzadors multifuncionals estables i reutilitzables per a portar a cap reaccions consecutives o en cascada.

S'ha obtés una segona família de materials mesoporosos orgànics-inorgànics no ordenats, en absència de agents directors d'estructura, a través d'un procés sol-gel en medi fluorur, aconseguint introduir fragments orgànics estructurals, els quals estan formant part de la xarxa dels materials. En ells, ha sigut estudiada l'influencia de les característiques dels disilans emprats com precursors en les propietats finals dels sòlids híbrids obtesos.

Per últim, es prepararen materials mesoporosos orgànics-inorgànics ordenats basats en silans polièdrics POSS, que actuen com nodes estructurals, units entre sí a través de molècules de disilans amb fragments arílics. Per a això, ha sigut emprada una ruta micel·lar de síntesi en condicions àcides. Finalment, els materials obtesos es sotmeteren a 
un procés de funcionalització, per a la introducció de centres actius accessibles en la seua estructura.

Tant els materials híbrids mesoporosos ordenats com no ordenats, amb funcions actives integrades a la seua estructura, han sigut emprats amb éxit com a catalitzadors selectius per a dur a terme diferents processos en química fina. 


\section{ABSTRACT}

The field of hybrid materials is one of the most attractive and emergent matter in nanoscience. The combination of different precursors with organic and inorganic fragments by self-assembling of their original structures, during the molecular framework formation process, allows to prepare materials that show unique properties with multiple applications as advanced materials.

This PhD study has been focused on the design, preparation and characterization of functional catalysts based on bridged silsesquioxanes organosiliceus precursors (disilanes) using different synthesis methods. As a result, we have obtained different families of hybrid porous materials with catalytic applications.

First, from layered precursors, Magadiite and MWW-P, which were subjected to exchange, swelling, pillarization and extraction processes, stable and reusable multifunctional catalysts to carried out cascade reactions were prepared containing active functional groups incorporated in their structure, like intercalated pillars, at the same time that their original textural properties were improve.

A second family of non-ordered organic-inorganic mesoporous materials has been obtained, in absence of structural directing agents, through a fluoride catalized solgel route, achieving to introduce organic structural fragments, which are inside the network of the materials. In all of them, the influence of the disilane precursors nature on the final properties of the obtained hybrid solids has been studied.

Lastly, ordered mesoporous organic-inorganic materials based in polyhedral silsesquioxanes POSS, which act as structural nodes, linked between them through disilane molecules with arilic groups were obtained following an acid micellar route. Finally, the obtained materials were functionalized by post-synthesis treatments, for the introduction of accessible active sites in their structure. 
All mesoporous hybrid materials, ordered and non-ordered, with active functions integrated in their structure, have been successfully used as selective catalysts to perform different process in fine chemistry. 


\section{PUBLICACIONES}

1. U. Díaz, Á. Cantín, T. García, A. Corma, "Layered hybrid materials with nanotechnological applications: use of disilane precursors as pillaring agents". Studies in Surface Science and Catalysis, Vol. Volume 174, Part A (Eds.: P. M. Antoine Gédéon, B. Florence), Elsevier, 2008, pp. 337.

2. U. Diaz, T. Garcia, A. Velty, A. Corma, "Hybrid organic-inorganic catalytic porous materials synthesized at neutral $\mathrm{pH}$ in absence of structural directing agents". Journal of Materials Chemistry 2009, 19, 5970.

3. A. Corma, U. Díaz, T. García, G. Sastre, A. Velty, "Multifunctional Hybrid OrganicInorganic Catalytic Materials with a Hierarchiral System of Well-Defined Micro- and Mesopores". Journal of the American Chemical Society 2010, 132, 15011.

4. J. R. Cabrero-Antonino, T. García, P. Rubio-Marqués, J. A. Vidal-Moya, A. Leiva-Pérez, S. S. Al-Deyab, S. I. Al-Resayes, U. Díaz, A. Corma, "Synthesis of Organic-Inorganic Hybrid Solids with Copper Complex Framework and Their Catalytic Activity for the S-Arylation and the Azide-Alkyne Cycloaddition Reactions". ACS Catalysis 2011, 1, 147.

5. A. Corma, U. Díaz, T. García, A. Velty, “Novel Hybrid Mesoporous Materials Synthesized by Assembling Polyhedral and Bridged Silsesquioxane Monomers". Chemistry A European Journal 2012, 18, 8659. 


\section{OTRAS CONTRIBUCIONES}

1. A. Corma, U. Díaz, T. García, "Nuevos Materiales Laminares Híbridos OrgánicosInorgánicos. Empleo de Disilanos como Agentes de Pilarización." Simposio Iberoamericano de Catálisis, XXI SICAT. Málaga-Benalmádena-Costa. España, 2008, I-571. (ISBN 978-84691-4234-9) 
